\title{
Fracture Behavior of Short Circumferentially Surface-Cracked Pipe
}

Manuscript Completed: October 1995

Date Published: November 1995

Prepared by

P. Krishnaswamy, P. Scott, R. Mohan, S. Rahman,

Y. H. Choi*, F. Brust, T. Kilinski, R. Francini, N. Ghadiali,

C. Marschall, and G. Wilkowski

\section{Battelle}

505 King Avenue

Columbus, OH 43201

M. Mayfield, NRC Project Manager

\section{Prepared for}

Division of Engineering Technology

Office of Nuclear Regulatory Research

U.S. Nuclear Regulatory Commission

Washington, DC 20555-0001

NRC Job Code B5702

\section{*Korea Institute of Nuclear Safety
P.O. Box 114, Yusung \\ *Korea Institute of Nuclear Safety
P.O. Box 114, Yusung \\ Taejeon, Republic of Korea}

\section{DISCLAIMER}

This report was prepared as an account of work sponsored by an agency of the United States Government. Neither the United States Government nor any agency thereof, nor any of their employees, makes any warranty, express or implied, or assumes any legal liability or responsibility for the accuracy, completeness, or usefulness of any information, apparatus, product, or process disclosed, or represents that its use would not infringe privately owned rights. Reference herein to any specific commercial product, process, or service by trade name, trademark, manufacturer, or otherwise does not necessarily constitute or imply its endorsement, recommendation, or favoring by the United States Government or any agency thereof. The views and opinions of authors expressed herein do not necessarily state or reflect those of the United States Government or any agency thereof. 



\section{DISCLAIMER}

Portions of this document may be illegible in electronic image products. Images are produced from the best available original document. 


\section{ABSTRACT}

This topical report summarizes the work performed for the Nuclear Regulatory Commission's (NRC) research program entitled "Short Cracks in Piping and Piping Welds" that specifically focuses on pipes with short, circumferential surface cracks. The following details are provided in this report: (i) material property determinations, (ii) pipe fracture experiments, (iii) development, modification and validation of fracture analysis methods, and (iv) impact of this work on the ASME Section XI Flaw Evaluation Procedures. The material properties developed and used in the analysis of the experiments are included in this report and have been implemented into the NRC's PIFRAC database. Six full-scale pipe experiments were conducted during this program. The analyses methods reported here fall into three categories (i) limit-load approaches, (ii) design criteria, and (iii) elastic-plastic fracture methods. These methods were evaluated by comparing the analytical predictions with experimental data. The results, using 44 pipe experiments from this and other programs, showed that the SC.TNP1 and DPZP analyses were the most accurate in predicting maximum load. New Z-factors were developed using these methods. These are being considered for updating the ASME Section XI criteria. 

EXECUTIVE SUMMARY $\ldots \ldots \ldots \ldots \ldots \ldots \ldots \ldots \ldots \ldots \ldots \ldots \ldots$

ACKNOWLEDGMENTS $\ldots \ldots \ldots \ldots \ldots \ldots \ldots \ldots \ldots \ldots \ldots \ldots \ldots \ldots$

NOMENCLATURE $\ldots \ldots \ldots \ldots \ldots \ldots \ldots \ldots \ldots \ldots \ldots \ldots \ldots \ldots \ldots \ldots \ldots$ xxiii

PREVIOUS REPORTS IN SERIES $\ldots \ldots \ldots \ldots \ldots \ldots \ldots \ldots \ldots \ldots \ldots \ldots \ldots$

1.0 INTRODUCTION $\ldots \ldots \ldots \ldots \ldots \ldots \ldots \ldots \ldots \ldots \ldots \ldots \ldots \ldots \ldots$

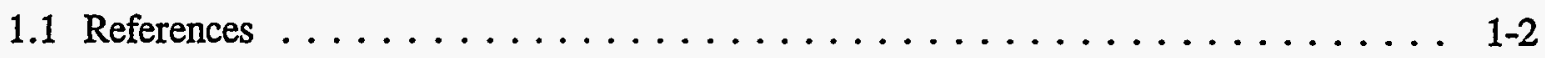

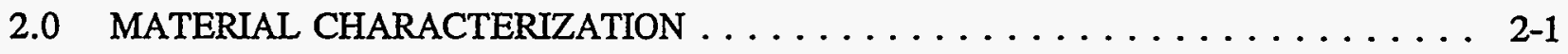

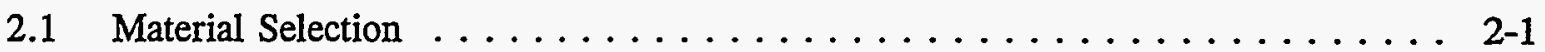

2.2 Tensile Test Results $\ldots \ldots \ldots \ldots \ldots \ldots \ldots \ldots \ldots \ldots \ldots \ldots \ldots$

2.2.1 406-mm (16-inch) Nominal Diameter, Schedule 30, TP304 Stainless Steel (DP2-A52) . . . . . . . . . . . . . . . 2-4

2.2.2 152-mm (6-inch) Nominal Diameter, Schedule XXS, TP304

Stainless Steel (DP2-A35) . . . . . . . . . . . . . . . . . 2-4

2.2.3 152-mm (6-inch) Nominal Diameter, Schedule 40, TP304 Stainless Steel (DP2-A7) . . . . . . . . . . . . . . . . . . 2- 29

2.2.4 SA155-KC60-Class 1.(A515 Grade 60) Carbon Steel (DP2-F26) . . . . . . 2-9

2.2.5 TP316L Stainless Steel (DP2-A51) and Associated Submerged-Arc Weld . . . . . . . . . . . . . . . . . . 2-12

2.2.6 A106 Grade B Carbon Steel and Associated Submerged-Arc Weld . . . . 2-16

2.3 Charpy V-notch Test Results . . . . . . . . . . . . . . . . . . 2-19

2.3.1 SA155-KC60-Class 1 (A515 Grade 60) Carbon Steel (DP2-F26) . . . . . . 2-19

2.3.2 Stainless Steel Submerged-Arc Weld . . . . . . . . . . . . . . . . 2-19

2.3.3 Carbon Steel Submerged-Arc Weld . . . . . . . . . . . . . . . . . 2-19

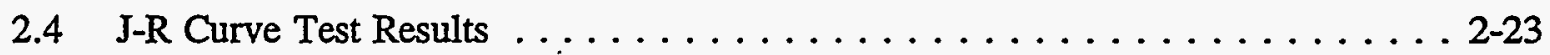

2.4.1 406-mm (16-inch) Nominal Diameter, Schedule 30, TP304

Stainless Steel . . . . . . . . . . . . . . . . . . . . 2-24

2.4.2 152-mm (6-inch) Nominal Diameter, Schedule XXS, TP304

Stainless Steel (DP2-A35) . . . . . . . . . . . . . . . . . . 2-24

2.4.3 152-mm (6-inch) Nominal Diameter, Schedule 40, TP304

Stainless Steel (DP2-A7) . . . . . . . . . . . . . . . . . 2-27

2.4.4 SA155-KC60-Class 1 (A515 Grade 60) Carbon Steel . . . . . . . . . . . . 2-30 
2.4.5 Stainless Steel Submerged-Arc Weld . . . . . . . . . . . . . . 2-30

2.4.6 Carbon Steel Submerged-Arc Weld . . . . . . . . . . . . . . . 2-33

2.5 References .......................... 2-37

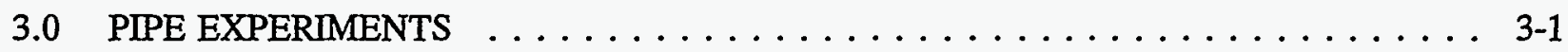

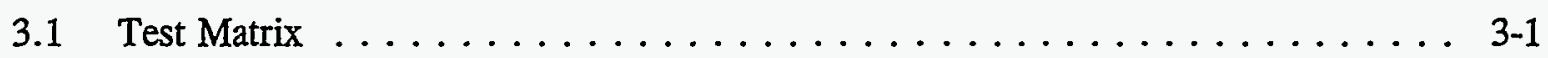

3.1.1 Smaller Diameter Surface-Cracked-Pipe Fracture Experiments Subjected to Pure Bending for Assessing Limit-Load Analyses for Short Cracks . . . 3-1

3.1.2 Large-Diameter Surface-Cracked Pipe Fracture Experiments Under Combined Bending and Tension (Pressure) ............ 3-4

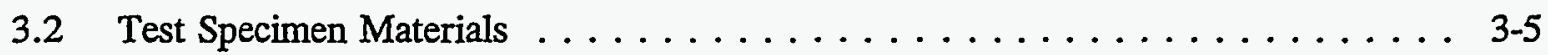

3.2.1 Smaller Diameter Pipe Fracture Experiments in Pure Bending for Assessing Limit-Load Ovalization Corrections . . . . . . . . . . 3-5

3.2.2 Large-Diameter Surface-Cracked Pipe Fracture Experiments Under Combined Bending and Tension (Pressure) . . . . . . . . . . 3-6

3.3 Experimental Facilities $\ldots \ldots \ldots \ldots \ldots \ldots \ldots \ldots \ldots \ldots \ldots \ldots$

3.4 Instrumentation and Data Acquisition $\ldots \ldots \ldots \ldots \ldots \ldots \ldots \ldots$

3.5 Experimental Procedures $\ldots \ldots \ldots \ldots \ldots \ldots \ldots \ldots \ldots \ldots \ldots$

3.6 Experimental Results $\ldots \ldots \ldots \ldots \ldots \ldots \ldots \ldots \ldots \ldots \ldots \ldots \ldots \ldots \ldots$

3.6.1 Smaller Diameter Pipe Fracture Experiments in Pure Bending for Assessing Limit-Load Ovalization Corrections . . . . . . . . . . 3-11

3.6.2 Large-Diameter Surface-Cracked Pipe Fracture Experiments Under Combined Bending and Tension (Pressure) . . . . . . . . . 3-16

3.7 References . . . . . . . . . . . . . . . . . . . . 3-24

4.0 ANALYSIS OF CIRCUMFERENTIALLY SURFACE-CRACKED PIPE $\ldots \ldots \ldots$. . . 4-1

4.1 Background and Scope of Current Work $\ldots \ldots \ldots \ldots \ldots \ldots \ldots$. . . . .

4.1 .1 Analysis Overview $\ldots \ldots \ldots \ldots \ldots \ldots \ldots \ldots \ldots \ldots \ldots$ 4-1

4.1 .2 Objectives and Scope . . . . . . . . . . . . . . 4-10

4.2 Improvements to Existing Methods $\ldots \ldots \ldots \ldots \ldots \ldots \ldots \ldots \ldots$ 4-11

4.2.1 Uncracked Pipe Analysis $\ldots \ldots \ldots \ldots \ldots \ldots \ldots \ldots \ldots \ldots \ldots$ 4-11 


\section{CONTENTS}

$\underline{\text { Page }}$

4.2.2 External and Internal Surface-Crack Analysis Using SC.TNP and SC.TKP Methods - Combined Pressure and Bending Loads . . . . . . . . 4-15

4.2.3 Surface-Crack Mesh-Refinement Study . . . . . . . . . . . 4-22

4.2.4 GE-EPRI Functions for 360-Degree, Deep Surface-Cracked Pipe . . . . . . 4-29

4.2.5 Modification to the Net-Section-Collapse (NSC) Analysis . . . . . . . . . . 4-32

4.2.6 Improvements to SC.TNP and SC.TKP Methods . . . . . . . . . . . 4-33

4.3 The SC.ENG Method . . . . . . . . . . . . . . . . . . . 444

4.3.1 General Background . . . . . . . . . . . . . . . . . . . 4-44

4.3.2 The Elastic Solution . . . . . . . . . . . . . . . . . . 4-48

4.3.3 The Plastic Solution . . . . . . . . . . . . . . . 4-50

4.3.4 The SC.ENG1 and SC.ENG2 Methods . . . . . . . . . . . . 4-54

4.3 .5 Numerical Examples . . . . . . . . . . . . . . . . . . . 4-59

4.4 Analysis of Experiments $\ldots \ldots \ldots \ldots \ldots \ldots \ldots \ldots \ldots \ldots \ldots \ldots$

4.4.1 The NRCPIPES PC Program . . . . . . . . . . . . . . . . 4-65

4.4.2 Analysis of Surface-Cracked-Pipe Experiments - Pure Bending Load Cases . 4-67

4.4.3 Analysis of Surface-Cracked-Pipe Experiments - Combined Bending and Tension Load Cases . . . . . . . . . . . . . . . . 4-77

4.4.4 Discussion of Results . . . . . . . . . . . . . . . 4-70

4.5 Discussion of Results $\ldots \ldots \ldots \ldots \ldots \ldots \ldots \ldots \ldots \ldots$

4.5.1 Limit-Load Approaches . . . . . . . . . . . . . . . . 4-86

4.5.2 Prediction of Moment at Crack Initiation $\ldots \ldots \ldots \ldots \ldots \ldots$. . . . . . . . . . . . . .

4.5.3 Prediction of Maximum Moment . . . . . . . . . . . . . . . 4-87

4.5 .4 Sensitivity Analyses $\ldots \ldots \ldots \ldots \ldots \ldots \ldots \ldots \ldots \ldots$. . . . . . . . . . . . . . . . . . . . . . . . .

4.6 Effect of Anisotropy and Constraint on Toughness . . . . . . . . . . . . 4-103

4.6.1 Anisotropy . . . . . . . . . . . . . . . . . 4 4-104

4.6 .2 Constraint $\ldots \ldots \ldots \ldots \ldots \ldots \ldots \ldots \ldots \ldots \ldots \ldots \ldots \ldots \ldots$

$4.7 \quad$ References $\ldots \ldots \ldots \ldots \ldots \ldots \ldots \ldots \ldots \ldots \ldots \ldots \ldots$

5.0 APPLICATIONS OF RESULTS TO PIPE FLAW EVALUATION CRITERIA _ . . . . 5-1

5.1 ASME Section XI Criteria $\ldots \ldots \ldots \ldots \ldots \ldots \ldots \ldots \ldots \ldots \ldots \ldots$

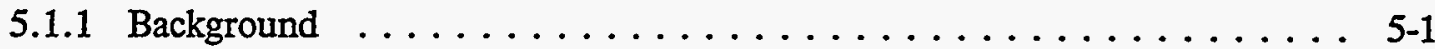

5.1 .2 Validation of Z-factors ................... 5-4

5.1.3 Other Limitations with the Current ASME Pipe Flaw Evaluation Criteria . . 5-15 


\section{CONTENTS}

5.2 Alternative Surface-Cracked Pipe Flaw Evaluation Criteria . . . . . . . . . 5-17

5.2.1 Charpy Energy Based DPZP Criteria . . . . . . . . . . . . 5-17

5.2.2 Z-Factors From Finite-Length Surface-Cracked-Pipe J-Estimation Schemes . 5-24

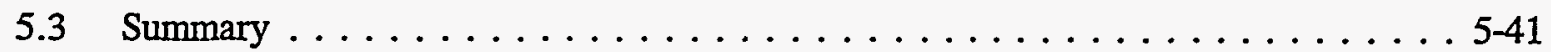

5.4 References . . . . . . . . . . . . . . . . . . 5-44

6.0 SUMMARY AND CONCLUSIONS $\ldots \ldots \ldots \ldots \ldots \ldots \ldots \ldots \ldots$

6.1 Material Characterization $\ldots \ldots \ldots \ldots \ldots \ldots \ldots \ldots \ldots \ldots \ldots \ldots \ldots$

6.2 Pipe Fracture Experiments $\ldots \ldots \ldots \ldots \ldots \ldots \ldots \ldots \ldots \ldots \ldots$

6.3 Analysis of Surface-Cracked Pipe $\ldots \ldots \ldots \ldots \ldots \ldots \ldots \ldots$

6.4 Application to ASME Section XI Flaw Evaluation Criteria . . . . . . . . . 6-6

6.5 References ............................. $6-8$

Appendix A J-Estimation Mẹthod Development for Circumferentially Surface-

Cracked Pipe Under Combined Tension and Bending . . . . . . . . . . A -1

Appendix B Program - EXTCRK7 . . . . . . . . . . . . . . . . B-1

Program - INTCRK7 $\ldots \ldots \ldots \ldots \ldots \ldots \ldots \ldots \ldots \ldots \ldots$

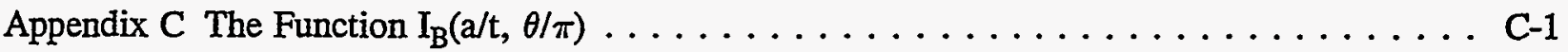

Appendix D Governing Differential Equations with Power-Law Model $\ldots \ldots \ldots \ldots$. . . D-1

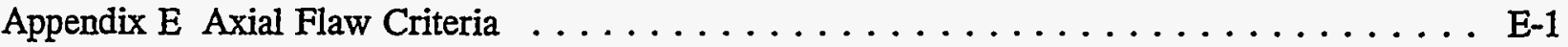




\section{CONTENTS}

$\underline{\text { Page }}$

\section{LIST OF TABLES}

1.1 Summary of surface-cracked pipe experiments conducted in this program $\ldots \ldots \ldots \ldots$

2.1 Test specimen materials $\ldots \ldots \ldots \ldots \ldots \ldots \ldots \ldots \ldots \ldots \ldots \ldots \ldots$

2.2 Chemical composition, percent by weight, of pipe materials and weldments used in surface-cracked pipe experiments $\ldots \ldots \ldots \ldots \ldots \ldots \ldots \ldots$

2.3 Tensile properties of Pipe DP2-A52, 406-mm (16-inch) diameter TP304 stainless steel pipe procured from Westinghouse Savannah River Plant $\ldots \ldots \ldots \ldots$. . . 2-5

2.4 Tensile properties of Pipe DP2-A35, 152-mm (6-inch) nominal diameter, Schedule XXS, TP304 stainless steel pipe (Ref. 2.1) . . . . . . . . . . . . 2-5

2.5 Tensile properties of Pipe DP2-A7, 152-mm (6-inch) nominal diameter, Schedule 40, TP304 stainless steel pipe (Ref. 2.2) $\ldots \ldots \ldots \ldots \ldots \ldots \ldots$. . . . . . . . .

2.6 Tensile properties of Pipe DP2-F26, 711-mm (28-inch) diameter SA155-KC60-Class 1 (A515 Grade 60) carbon steel pipe (Ref. 2.1) . . . . . . . . 2-11

2.7 Tensile properties of Pipe DP2-A51, 711-mm (28-inch) diameter TP316L stainless steel pipe . . . . . . . . . . . . . . . . . 2-13

2.8 Summary table showing the average yield and ultimate strength values for quasi-static testing rates for stainless steel SAW Welds DP2-A45W1, DP2-A45W2, and DP2-A8W4 at $288 \mathrm{C}(550 \mathrm{~F}) \ldots \ldots \ldots \ldots \ldots \ldots$

2.9 Summary of tensile data for Pipe AEC-C5, 610-mm (24-inch) diameter A106 Grade B carbon steel pipe . . . . . . . . . . . . . . . . . 2-17

2.10 Tensile properties of submerged-arc weld metal (DP2-F49W) in 31.8-mm (1.25-inch)-thick A516 Grade 70 plate . . . . . . . . . . . . 2-20

2.11 Charpy $V$-notch impact results for Pipe DP2-F26 (Ref. 2.1) . . . . . . . . . . 2-20

2.12 Charpy V-notch impact results for submerged-arc weld (DP2-A45W2) in TP304 stainless steel plate . . . . . . . . . . . . . . . . . . . 2-23

2.13 Charpy V-notch impact results for submerged-arc weld metal (DP2-F49W) in 31.8-mm (1.25-inch)-thick A516 Grade 70 plate . . . . . . . . . . . . 2-23

2.14 Summary of $J_{i}$ and $d J / d a$ values obtained from compact specimens machined from Pipe DP2-A52 (TP304) (L-C orientation) . . . . . . . . . . . . 2-26 
2.15 Summary of $\mathrm{J}_{\mathrm{i}}$ and $\mathrm{dJ} / \mathrm{da}$ values at $288 \mathrm{C}(550 \mathrm{~F})$ for Pipe DP2-A35 (TP304)

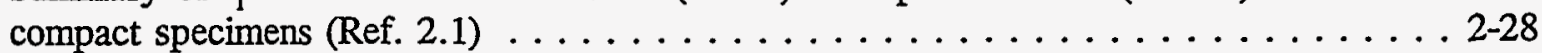

2.16 Summary of $\mathrm{J}_{\mathrm{i}}$ and $\mathrm{dJ} / \mathrm{da}$ values for Pipe DP2-A7 (TP304) compact specimens (Specimens were tested at Materials Engineering Associates at 288 C [550 F]), L-C orientation (Ref. 2.2) . . . . . . . . . . . . . . 2-29

2.17 Summary of $\mathrm{J}_{\mathrm{i}}$ and $\mathrm{dJ} / \mathrm{da}$ values at $288 \mathrm{C}(550 \mathrm{~F})$ for Pipe DP2-F26 (Ref. 2.1) . . . 2-32

2.18 Summary table showing the average $\mathrm{J}_{\mathrm{i}}$ and $\mathrm{dJ} / \mathrm{da}$ values at $288 \mathrm{C}(550 \mathrm{~F})$ for quasi-static testing rates for Welds DP2-A45W1, DP2-A45W2, and DP2-A8W4 . . . . . . 2-35

2.19 Summary of $\mathrm{J}_{\mathrm{i}}$ and $\mathrm{d} \mathrm{J} / \mathrm{da}$ values obtained from compact specimens machined from Weld DP2-F49W

3.1 Matrix of experiments on pipes with circumferential surface cracks conducted as part of the Degraded Piping Program - Phase II (Ref. 3.1) . . . . . . . . . . . . 3-2

3.2 Test matrix for surface-cracked pipe experiments conducted as part of the Short Cracks in Piping and Piping Welds Program . . . . . . . . . . . . .

3.3 Key results from the six surface-cracked pipe experiments conducted as part of the Short Cracks in Piping and Piping Welds program

4.1 Summary of JAERI uncracked experiments analyzed $\ldots \ldots \ldots \ldots \ldots \ldots$. . . . . . . . .

4.2 Matrix of finite element calculations for a deep $(a / t=7 / 8)$ surface-cracked pipe $\ldots \ldots$ 4-30

$4.3 \quad F, V_{1}$ and $V_{2}$ for a circumferentially surface-cracked cylinder in tension $\ldots \ldots . \ldots 4-30$

4.4 $h_{1}, h_{2}$, and $h_{3}$ for a circumferentially surface-cracked cylinder in tension;

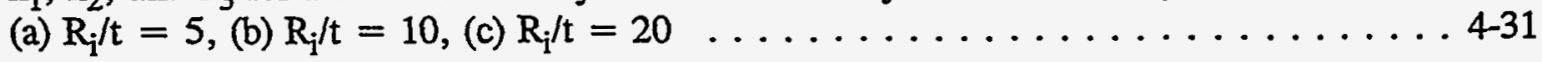

4.5 List of surface-cracked pipe experiments analyzed - pure bending load cases . . . . . 4-68

4.6 Tensile properties for pipe materials listed in Table $4.5 \ldots \ldots \ldots \ldots$. . . . . . . 4-69

4.7 Fracture resistance properties for pipe materials listed in Table $4.5 \ldots \ldots \ldots$. . . . 4-70

4.8 Comparison of NSC predictions with experimental data - pure bending load cases . . . 4-71

4.9 Comparison of experimental crack initiation moments with analytical analyses predictions - pure bending load cases $\ldots \ldots \ldots \ldots \ldots \ldots \ldots \ldots . \ldots \ldots$

4.10 Comparison of experimental maximum moments with analytical predictions -

pure bending load cases 


\section{CONTENTS}

4.11 List of surface-cracked pipe experiments analyzed - combined bending and pressure load cases . . . . . . . . . . . . . . . . . . . . 4 475

4.12 Tensile properties for pipe materials listed in Table $4.11 \ldots \ldots \ldots$. . . . . . . . .

4.13 Fracture resistance properties for pipe experiments listed in Table $4.1 \ldots$. . . . . . 4-79

4.14 Comparison of NSC predictions with experimental data - combined bending

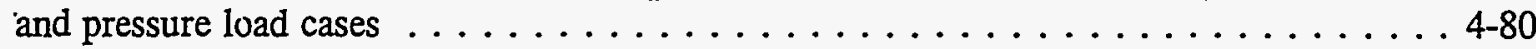

4.15 Comparison of experimental crack initiation moment with analytical predictions - combined bending and pressure load cases . . . . . . . . . 4-81

4.16 Comparison of experimental maximum moment with analytical predictions for combined bending and pressure load cases $\ldots \ldots \ldots \ldots \ldots \ldots \ldots \ldots$

4.17 Mean and coefficient of variation of initiation load ratio predicted by various fracture analyses methods . . . . . . . . . . . . . . . . . . 4-89

4.18 Mean and coefficient of variation of maximum load ratio predicted by various fracture analyses methods . . . . . . . . . . . . . . . . 4-90

4.19 Toughness anisotropy data for an A516 Grade 70 Steel (Battelle Pipe DP2-F40)

(a) Chemistry, (b) Charpy Upper Shelf Energy, Joules (ft-lb), (c) $\mathrm{J}_{\mathrm{i}}$ values at $288 \mathrm{C}(550 \mathrm{~F}),(\mathrm{d})$ Toughness Ratio . . . . . . . . . . . . . . 4-106

4.20 Charpy data for a TP304 stainless steel pipe (Battelle Pipe DP2-A8) . . . . . . . . 4-107

5.1 Code Case $\mathrm{N}-494-2$ FAD curve tabular values $\ldots \ldots \ldots \ldots \ldots \ldots \ldots$

5.2 Material property values used in austenitic pipe technical basis document $\ldots \ldots \ldots$. . 5-9

5.3 Material property data input in Appendix $\mathrm{H}$ technical basis document $\ldots \ldots \ldots . \ldots 5-10$ 


\section{CONTENTS}

$\underline{\text { Page }}$

\section{LIST OF FIGURES}

2.1 Stress-strain curves at $22 \mathrm{C}(72 \mathrm{~F})$ for tensile specimens machined

from Pipe DP2-A52 (TP304) (a) Engineering stress-strain, (b) True stress-strain . . . . . 2-6

2.2 Stress-strain curves at $93 \mathrm{C}(200 \mathrm{~F})$ for tensile specimens machined

from Pipe DP2-A52 (TP304) (a) Engineering stress-strain, (b) True stress-strain . . . . . 2-7

2.3 Stress-strain curves at $288 \mathrm{C}(550 \mathrm{~F})$ for tensile specimens machined

from Pipe DP2-A52 (TP304) (a) Engineering stress-strain,

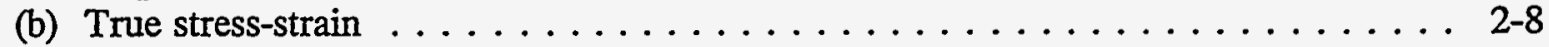

2.4 Engineering stress-strain curves for Pipe DP2-A35 (TP304) at

288 C (550 F) (Ref. 2.1) . . . . . . . . . . . . . . . . . . . . . 2-9

2.5 Engineering stress-strain curves for Pipe DP2-A7 (TP304) at

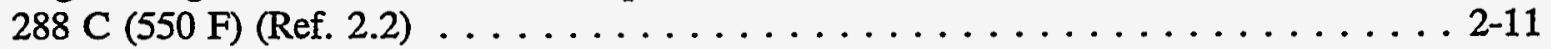

2.6 Stress-strain curves for Pipe DP2-F26 (A515 Grade 60) at

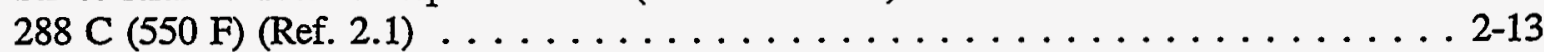

2.7 Engineering stress-strain curves for tensile specimens machined from Pipe DP2-A51 (TP316L) at $20 \mathrm{C}(68 \mathrm{~F})$ and $288 \mathrm{C}(550 \mathrm{~F}) \ldots \ldots \ldots . . \ldots$. . . . . . . .

2.8 Engineering stress-strain curves at $288 \mathrm{C}(550 \mathrm{~F})$ for a submerged-arc

weld (DP2-A45W1) in TP304 stainless steel plate (Ref. 2.1) . . . . . . . . . . . . 2-14

2.9 Engineering stress-strain curves at $288 \mathrm{C}(550 \mathrm{~F})$ for a submerged-arc

weld (DP2-A45W2) in TP304 stainless steel plate (Ref. 2.1) . . . . . . . . . . . 2-15

2.10 Engineering stress-strain curves at $288 \mathrm{C}(550 \mathrm{~F})$ for a submerged-arc

weld (DP2-A8W4) in a TP304 stainless steel pipe, tested at

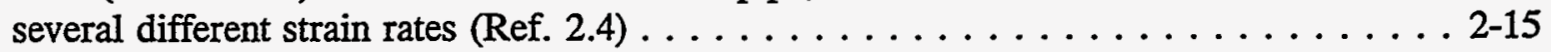

2.11 Stress-strain curves at $288 \mathrm{C}(550 \mathrm{~F})$ for tensile specimens machined in the

longitudinal direction of the pipe from Pipe AEC-C5 (A106 Grade B) . . . . . . . . 2-18

2.12 Tensile properties at $288 \mathrm{C}(550 \mathrm{~F})$ for submerged-arc weld

metal (DP2-F49W) (a) Engineering stress-strain, (b) True

stress-strain

2.13 Charpy impact energy versus test temperature for pipe material

DP2-F26, from Ref. 2.1 


\section{CONTENTS}

2.14 Shear area versus test temperature for pipe material DP2-F26,

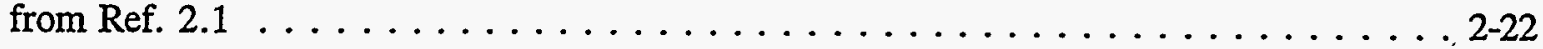

$2.15 \mathrm{~J}$-resistance curves at $22 \mathrm{C}(72 \mathrm{~F})$ for compact specimens machined

from Pipe DP2-A52 (TP304) . . . . . . . . . . . . . . . . . 2-25

$2.16 \mathrm{~J}$-resistance curves at $93 \mathrm{C}(200 \mathrm{~F})$ for compact specimens machined

from Pipe DP2-A52 (TP304) . . . . . . . . . . . . . . . . . . . 2-25

2.17 J-resistance curves at $288 \mathrm{C}(550 \mathrm{~F})$ for compact specimens machined

from Pipe DP2-A52 (TP304) . . . . . . . . . . . . . . . . . 2-26

$2.18 \mathrm{~J}$ versus crack extension at $288 \mathrm{C}$ (550 F) for Pipe DP2-A35 (TP304)

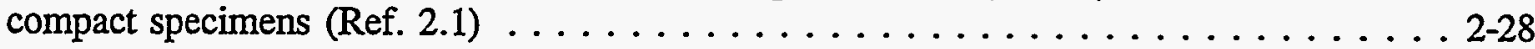

2.19 J-resistance curves at $288 \mathrm{C}(550 \mathrm{~F})$ for DP2-A7 (TP304) fatigue-cracked

compact specimens (Ref. 2.2) . . . . . . . . . . . . . . . . . . . . . . . . 2-29

2.20 Test records for A515 Grade 60 (DP2-F26) steel pre-cracked and side-grooved compact specimens tested at $288 \mathrm{C}(550 \mathrm{~F})(\mathrm{A}, \mathrm{B}$, and $\mathrm{C}$ indicate points at which stable crack growth was interrupted by a crack jump, and displacement shown is at $0.25 \mathrm{~W}$ from

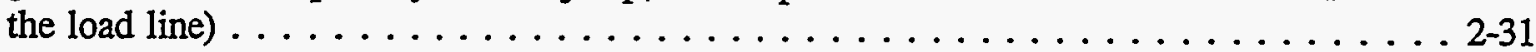

$2.21 \mathrm{~J}_{\mathrm{M}}-\mathrm{R}$ and $\mathrm{J}_{\mathrm{D}}-\mathrm{R}$ curves at $288 \mathrm{C}(550 \mathrm{~F})$ for A515 Grade 70 Pipe DP2-F26 (Ref. 2.1) . . 2-32

2.22 J-resistance curves at $288 \mathrm{C}(550 \mathrm{~F})$ for non-side-grooved, fatigue-cracked $1 T$ compact specimens machined from submerged-arc weld DP2-A45W1 in a TP304 plate $($ Ref. 2.1) . . . . . . . . . . . . . . . . . . . . . . . 2-34

$2.23 \mathrm{~J}$-resistance curves at $288 \mathrm{C}(550 \mathrm{~F})$ for $\mathrm{C}(\mathrm{T})$ specimens having 20-percent side grooves machined from submerged-arc weld DP2-A45W2 in a TP304 plate . . . . . . . 2-34

$2.24 \mathrm{~J}$-resistance curves at $288 \mathrm{C}(550 \mathrm{~F})$ for compact specimens from submerged-arc weld DP2-A8W4 in a TP304 stainless steel pipe (Ref. 2.4) . . . . . . . . . . 2-35

2.25 Composite plot of J-resistance curves for SAW DP2-F49W tests . . . . . . . . . 2-36

3.1 Empirical ovalization correction factor for circumferentially surface-cracked pipe in bending $(\mathrm{a} / \mathrm{t}=0.66$ and $\theta / \pi=0.5)$, (Ref. 3.1) $\ldots \ldots \ldots \ldots \ldots \ldots \ldots$

3.2 Schematic of test apparatus used in Experiments 1.2.1.21 and 1.2.1.22 . . . . . . . 3-8

3.3 Schematic of pipe in load frame used in Experiments 1.2.1.20, 1.2.3.15, 1.2.3.16,

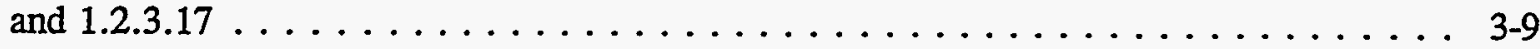




\section{CONTENTS}

Page

3.4 Post-test photograph of the pipe specimen in the loading frame for Experiment 1.2.3.16

3.5 Moment versus rotation (measured with inclinometers) for Experiment 1.2.1.20 . . . . . 3-13

3.6 Calculated moment versus calculated half rotation angle $(\phi)$ using data on pipe displacement at the load points from Experiment 1.2.1.21 . . . . . . . . . 3-13

3.7 Moment versus calculated half rotation angle $(\phi)$ from data on pipe displacement at the load points from Experiment 1.2.1.22

3.8 Post-test photograph of Experiment 1.2.1.20 showing the buckle at the girth weld

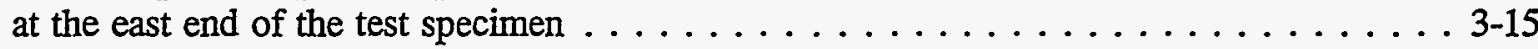

3.9 Rotation measured with string potentiometers and inclinometers versus pipe displacement at the load points for Experiment 1.2.1.20 . . . . . . . . . . 3-15

3.10 A post-test photograph of the specimen for Experiment 1.2.1.22 positioned in the loading fixtures and for which a buckle occurred at the weld away from the crack plane . . . . . . . . . . . . . . . . . . 3-17

3.11 Crack centerline crack-mouth-opening displacements versus pipe displacement at the load points for Experiment 1.2.1.22 . . . . . . . . . . . . . 3-17

3.12 Ovalization (percent change in diameter) versus pipe displacement at the load points for Experiment 1.2.1.20 . . . . . . . . . . . . . . 3-18

3.13 Surface-crack growth versus pipe displacement at the load points for Experiment 1.2.1.20

3.14 Surface-crack growth at the center of the surface crack versus pipe displacement at the load points for Experiment 1.2.1.21

3.15 Moment versus half rotation angle $(\phi)$ based on the inclinometers for Experiment 1.2.3.15 . . . . . . . . . . . . . . . . . . . . . . . 3-19

3.16 Moment versus half rotation angle $(\phi)$ based on the inclinometers for Experiment 1.2.3.16 ......................... . 3-20

3.17 Crack section moment versus half rotation angle $(\phi)$ based on the inclinometers for Experiment 1.2.3.17 . . . . . . . . . . . . . . . 3-20

3.18 Ovalization (percent change in top-to-bottom pipe diameter) versus pipe displacement at the load points for Experiment 1.2.3.15 


\section{CONTENTS}

3.19 Ovalization (percent change in top-to-bottom pipe diameter) versus load-point

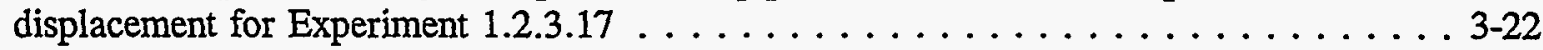

3.20 Surface-crack growth versus pipe displacement at the load points for

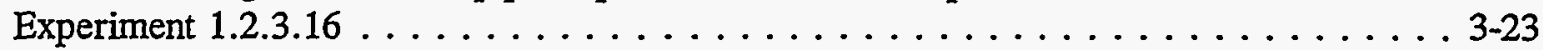

3.21 Surface-crack growth versus pipe displacement at the load points for

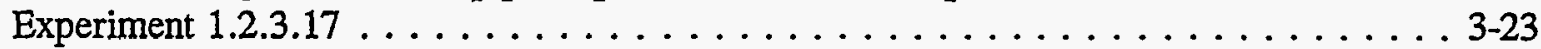

4.1 Schematic of idealized surface-cracked pipe geometry and loading $\ldots \ldots \ldots$. . . . 4 -2

4.2 Nomenclature and loading for the application of the Net-Section-Collapse and

IWB-3640 analyses to a pipe with a circumferential surface crack subjected to

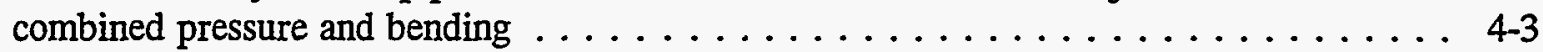

4.3 The $\mathrm{R}-6$ failure assessment diagram $\ldots \ldots \ldots \ldots \ldots \ldots \ldots \ldots$

4.4 Fit of DPZP equation through pipe data $\ldots \ldots \ldots \ldots \ldots \ldots \ldots \ldots$

4.5 Comparison of predicted with experimental maximum moments from JAERI uncracked

stainless steel unpressurized pipe bending experiments . . . . . . . . . . . 4-14

4.6 Finite-element mesh of JAERI uncracked pipe Experiment S-17 using 3-D solid

elements (a) One element through thickness, (b) Four elements through thickness . . . . 4-16

4.7 Uncracked pipe FE analysis; comparison between FE results and JAERI pipe

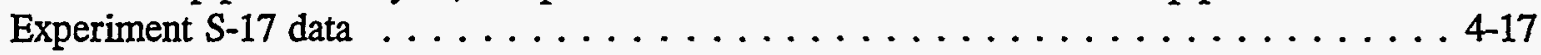

4.8 Elliptical geometry and loading configuration for surface-cracked pipe;

(a) External surface flaw geometry, (b) Internal surface flaw geometry,

(c) Surface-cracked pipe under bending and pressure loads $\ldots \ldots \ldots \ldots \ldots \ldots$ 4-18

4.9 Comparison between J-estimation scheme (INTCRK7) and FE results for internal-

surface-cracked pipe Experiment $4131-4$, neglecting effects of internal pressure . . . . 4-21

4.10 Comparison of J-estimation scheme (INTCRK7) and FE results for Experiment

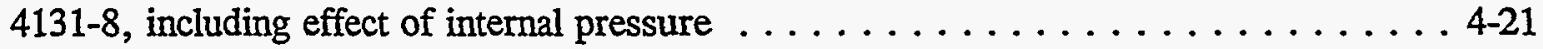

4.11 Finite element model (Mesh 1) of surface-cracked pipe (intermediate mesh size)

(a) Total mesh, (b) Magnified view of the cracked region, (c) Crack tip region

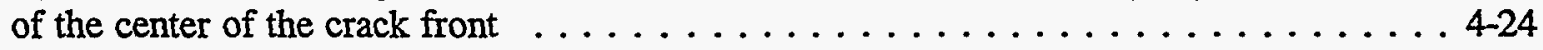

4.12 Detail of the crack-tip region at the center of the crack front for Mesh $2 \ldots \ldots$. . . $\ldots 45$

4.13 Detail of the crack-tip region at the center of the crack front for Mesh $3 \ldots \ldots$. . . 25 


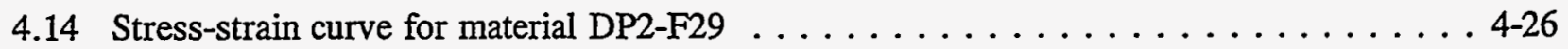

4.15 Predicted and experimentally measured load versus pipe displacement of the load points . . . . . . . . . . . . . . . . . . . . 4-26

4.16 Calculated J-integral values versus pipe displacement at the load point relationship for the various models studied . . . . . . . . . . . . 4-28

4.17 Predicted variation of CMOD with applied pipe displacement at the load point $\ldots \ldots$. . 4-28

4.18 Crack opening configuration at the center of the crack front corresponding to an applied load-line displacement at the load point of $114.3 \mathrm{~mm}(4.500 \mathrm{inch})$

4.19 Plot of the ratio of experimental stress to predicted stress as a function of

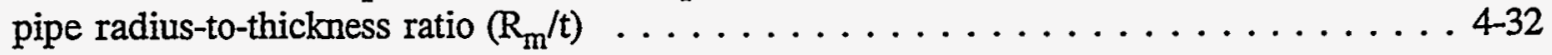

4.20 The predicted variation of J-integral values from the line-spring model and 3D FEM as a function of applied load (the material behavior assumed is shown in Figure 4.21$) \ldots \ldots \ldots \ldots \ldots \ldots \ldots \ldots \ldots \ldots \ldots \ldots \ldots \ldots$. . . . . . . . . . . . . . . .

4.21 Stress-strain relation for a Ramberg-Osgood material with $n=5.0$ and $\alpha=1.0 \ldots \ldots$-34

4.22 The predicted variation of J-integral values with applied load (the material behavior assumed is shown in Figure 4.21$) \ldots \ldots \ldots \ldots \ldots \ldots \ldots \ldots \ldots$

4.23 Comparison of the moment versus half rotation predicted by the finite element model

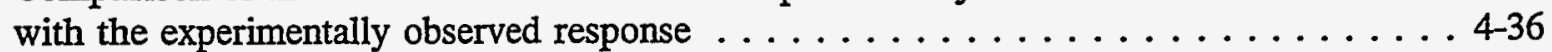

4.24 Variation of J-integral values with applied end moment for a flaw $1 / 4$ of the pipe circumference in length, $\theta / \pi=1 / 4$

4.25 Variation of J-integral values with applied end moment for a flaw $1 / 16$ the pipe

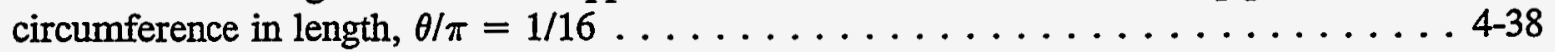

4.26 Variation of J-integral values with tensile load for a flaw $1 / 4$ of the pipe circumference in length, $\theta / \pi=1 / 4$

4.27 Variation of J-integral values with tensile load for a flaw $1 / 16$ of the pipe circumference in length, $\theta / \pi=1 / 16$

4.28 Comparison of FEM results and SC.TNP and SC.TKP prediction for an internal flaw $\theta / \pi=1 / 4$ and $n=3$

4.29 Comparison of FEM results and SC.TNP and SC.TKP prediction for an external flaw $\theta / \pi=1 / 16$ and $n=3$ 


\section{CONTENTS}

4.30 Comparison of FEM results and SC.TNP and SC.TKP prediction for an internal flaw $\theta / \pi=1 / 4$ and $n=10$

4.31 Comparison of FEM results and SC.TNP and SC.TKP prediction for an external flaw

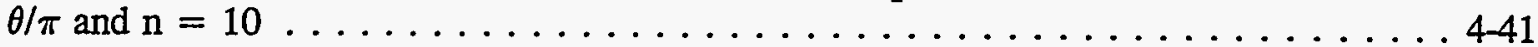

4.32 Comparison of FEM results and SC.TNP and SC.TKP prediction for an internal flaw $\theta / \pi$ and $\mathrm{n}=3$

4.33 Comparison of FEM results and SC.TNP prediction with different values of $L$ for an internal flaw with $\theta / \pi$ and $\mathrm{n}=3$

4.34 Comparison of FEM results and SC.TNP prediction with different values of $L$ for an internal flaw with $\theta / \pi$ and $n=10$

4.35 Variation of $\mathrm{J}$ from the SC.TNP analysis with applied moment for $\theta / \pi=1 / 4$, $\mathrm{a} / \mathrm{t}=0.5$, and $\mathrm{n}=3$

4.36 Variation of $\mathrm{J}$ from the SC.TNP analysis with applied moment for $\theta / \pi=1 / 4$, $a / t=0.5$, and $n=10$

4.37 Variation of $J$ from the SC.TNP analysis with applied moment for $\theta / \pi=1 / 16$, $\mathrm{a} / \mathrm{t}=0.5$, and $\mathrm{n}=3$

4.38 Variation of $J$ from the SC.TNP analysis with applied moment for $\theta / \pi=1 / 16$, $\mathrm{a} / \mathrm{t}=0.5$, and $\mathrm{n}=10$

4.39 Variation of J from the SC.TNP analysis with applied moment for $\theta / \pi=1 / 4$, $\mathrm{a} / \mathrm{t}=0.5$, and $\mathrm{n}=3$

4.40 Variation of $\mathrm{J}$ from the SC.TNP analysis with applied moment for $\theta / \pi=1 / 4$, $\mathrm{a} / \mathrm{t}=0.5$, and $\mathrm{n}=10$

4.41 Reduced section analogy by the SC.ENG methods $\ldots \ldots \ldots \ldots \ldots \ldots$. . . . . . . 4-51

4.42 Comparisons of J-integral by various estimation methods with the finite-element results for surface-cracked pipes under pure bending when $\theta / \pi=1 / 4$ and $n=3$

4.43 Comparisons of J-integral by various estimation methods with the finite-element results for surface-cracked pipes under pure bending when $\theta / \pi=1 / 4$ and $n=10 \ldots 4-60$

4.44 Comparisons of J-integral by various estimation methods with the finite-element results for surface-cracked pipes under pure bending when $\theta / \pi=1 / 16$ and $n=3 \ldots 4-61$

4.45 Comparisons of J-integral by various estimation methods with the finite-element results for surface-cracked pipes under pure bending when $\theta / \pi=1 / 16$ and $n=10 \ldots 4-61$ 


\section{CONTENTS}

Page

4.46 Comparisons of J-integral by the SC.ENG methods with the finite-element results of Kumar and German (Ref. 4.35) for a surface-cracked pipe under pure bending . . . . . 4-64

4.47 Comparisons of J-integral by the SC.ENG methods with the finite-element results of Brickstad (Ref. 4.36) and Kumar and German (Ref. 4.35) for a surface-cracked pipe under pure bending . . . . . . . . . . . . . . . . . . . . 4-64

4.48 Load versus pipe displacement at the load point (excludes displacements from test machine compliance) for Experiment 1.2.1.21 - analytical predictions and experimental data . . . . . . . . . . . . . . . . . . . . 4-76

4.49 Load versus pipe displacement at the load point (excludes displacements from test-machine compliance) for Experiment 1.2.1.22 - analytical predictions and experimental data ........................... . . . . . . . . .

4.50 Comparison of experimental data with analytical prediction of load versus pipe displacement at the load points for Experiment 1.2.1.20 . . . . . . . . . . . 4-84

4.51 Comparison of experimental data with analytical prediction of load versus pipe displacement at the load points for Experiment 1.2.3.15 . . . . . . . . . . . 4-84

4.52 Comparison of experimental data with analytical prediction of load versus pipe displacement at the load points for Experiment 1.2.3.16 . . . . . . . . . . 4-85

4.53 Comparison of experimental data with analytical prediction of load versus pipe displacement at the load points for Experiment 1.2.3.17 . . . . . . . . . 4-85

4.54 Plot of the maximum moment ratio (maximum experimental moment/maximum predicted moment) for the SC.TNP1 and SC.TNP2 analyses as a function of outside pipe diameter for the pure bending experiments

4.55 Plot of the maximum stress ratio (maximum experimental stress/maximum predicted stress) for the SC.TKP1 and SC.TKP2 analyses as a function of outside pipe diameter for the combined pressure and bend experiments

4.56 Plot of the maximum stress ratio (maximum experimental stress/maximum predicted stress) for the SC.ENG1 and SC.ENG2 analyses as a function of outside pipe diameter for the combined pressure and bend experiments

4.57 Plot of the maximum moment ratio (maximum experimental moment/maximum predicted moment) for the SC.TNP1 and SC.TNP2 analyses as a function of the mean pipe radius-to-pipe wall thickness ratio $\left(\mathrm{R}_{\mathrm{m}} / \mathrm{t}\right)$ for the pure bending $\ldots \ldots \ldots \ldots$ 4-93 


\section{CONTENTS}

Page

4.58 Plot of the maximum moment ratio (maximum experimental moment/maximum predicted moment) for the ASME Appendix $C$ and ASME Appendix $H$ analyses as a function of the mean pipe radius-to-pipe wall thickness ratio $\left(R_{m} / t\right)$ for the pure bending experiments . . . . . . . . . . . . . . . . . 4-94

4.59 Plot of the maximum moment ratio (maximum experimental moment/maximum predicted moment) for the R6, Code Case N-494-2, and DPZP analyses as a function of the mean pipe radius-to-pipe wall thickness ratio $\left(R_{m} / t\right)$ for the pure bending experiments . . . . 4-94

4.60 Plot of the maximum stress ratio (maximum experimental stress/maximum predicted stress) for the SC.ENG1 and SC.ENG2 analyses as a function of the mean pipe radius-to-pipe wall thickness ratio $\left(R_{m} / t\right)$ for the combined pressure and bend experiments . . . . . . . . . . . . . . . . . . . . . 4-95

4.61 Plot of the maximum moment ratio (maximum experimental moment/maximum predicted moment) for the SC.TKP1 and SC.TKP2 analyses as a function of the mean pipe radius-to-pipe wall thickness ratio $\left(R_{m} / t\right)$ for the pure bending experiments $\ldots \ldots \ldots$. . .96

4.62 Plot of the ratio of the Net-Section-Collapse predicted moment to the SC.TKP1 predicted moment as a function of the inside pipe radius-to-pipe wall thickness ratio for the case of a 6-inch nominal diameter, stainless steel pipe with a crack 50 percent of the pipe wall thickness in depth and 50 percent of the pipe

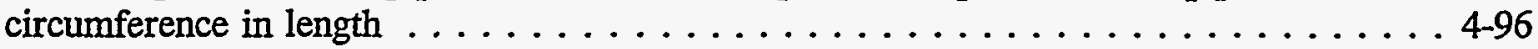

4.63 Plot of the maximum moment ratio (maximum experimental moment/maximum predicted moment) for the SC.TNP1 and SC. TNP2 analyses as a function of the crack lengthto-pipe circumference ratio $(\theta / \pi$ for the pure bending experiments $\ldots \ldots \ldots \ldots \ldots$ 4-98

4.64 Plot of the maximum stress ratio (maximum experimental stress/maximum predicted stress) for the SC.TNP1 and SC.TNP2 analyses as a function of the crack lengthto-pipe circumference ratio $(\theta / \pi)$ for the combined pressure and bend experiments . . . 4-98

4.65 Plot of the maximum stress ratio (maximum experimental stress/maximum predicted stress) for the SC.ENG1 and SC.ENG2 analyses as a function of the crack lengthto-pipe circumference ratio $(\theta / \pi)$ for the combined pressure and bend experiments

4.66 Plot of the maximum moment ratio (maximum experimental moment/maximum predicted moment) for the SC.ENG1 and SC.ENG2 analyses as a function of the crack depthto-pipe wall thickness ratio $(a / t)$ for the pure bending experiments $\ldots \ldots \ldots \ldots \ldots$ 4-99

4.67 Plot of the maximum stress ratio (maximum experimental stress/maximum predicted stress) for the SC.ENG1 and SC.ENG2 analyses as a function of the crack depthto-pipe wall thickness ratio (a/t) for the combined pressure and bend experiments . . . . 4-100 


\section{CONTENTS}

Page

4.68 Plot of the ratio of the Net-Section-Collapse predicted stress to the SC.ENG1 predicted stress as a function of the crack depth-to-pipe wall thickness ratio $(\mathrm{a} / \mathrm{t})$ for the case of a 6 -inch nominal diameter, Schedule 40 stainless steel pipe with a crack 50 percent of the pipe circumference in length . . . . . . . . . 4-101

4.69 Plot of the maximum stress ratio (maximum experimental stress/maximum predicted stress) for the SC.ENG1 and SC.ENG2 analyses as a function of the strainhardening exponent $(\mathrm{n})$ for the combined pressure and bend experiments

4.70 Plot of the maximum stress ratio (maximum experimental stress/maximum predicted stress) for the SC.ENG1 and SC.ENG2 analyses as a function of the internal pipe pressure for the combined pressure and bend experiments . . . . . . . 4 4-103

4.71 Toughness anisotropy of ASTM A 106B pipe (Note: Reprinted with permission) . . . 4-104

5.1 Ferritic pipe FAD curve from ASME Code Case $N-494-2 \ldots \ldots \ldots \ldots \ldots$

5.2 Power-law extrapolated stainless steel weld $\mathrm{J}_{\mathrm{D}}-\mathrm{R}$ curve from Reference 5.8,

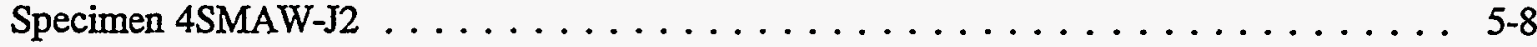

5.3 Comparison of Appendix C SMAW Z-factor with newly calculated values using technical basis document and power-law extrapolated $\mathrm{J}_{\mathrm{D}}-\mathrm{R}$ curve, ASME Code

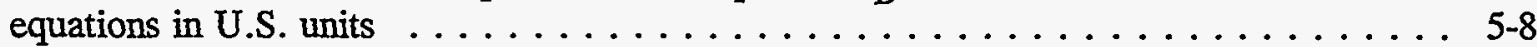

5.4 Material Category 2, carbon steel SAW toughness data (Specimen F40W2-54 from Battelle) (a) J-R curve, (b) $\mathrm{J} / \mathrm{T}$ curve $\ldots \ldots \ldots \ldots \ldots \ldots \ldots \ldots \ldots \ldots$

5.5 Reconstructed J-R curve from linear tangent extrapolation of $\mathrm{J} / \mathrm{T}$ curve in Figure $5.4 \ldots$. $5-12$

5.6 1T, 3T, and 9.5T C(T) specimen J-R curves for ferritic submerged-arc weld compact specimens (DP2-F40W2), from Reference 5.5 (a) $\mathrm{J}_{\mathrm{D}}-\mathrm{R}$ curves, (b) $\mathrm{J}_{\mathrm{M}}-\mathrm{R}$ curves) $\ldots$. 5-13

5.7 Comparison of various J-R curves for carbon steel SAW (ASME Section XI Appendix $\mathrm{H}$ Material Category 2$) \quad \ldots \ldots \ldots \ldots \ldots \ldots \ldots \ldots \ldots \ldots \ldots \ldots \ldots$

5.8 Comparison of ASME Section XI Appendix H SAW Z-factor equation with Z-factors using various J-R curves in Figure 5.7, Zahoor modified GE/EPRI analysis, and technical basis document material property input . . . . . . . . . . . 5-14

5.9 Comparison of Appendix H ferritic SAW Z-factor equation with Z-factors calculated with various TWC estimation schemes using technical basis properties and $\mathrm{J} / \mathrm{T}$ extrapolated J-R curve . . . . . . . . . . . . . . . . . . 5-16

5.10 Redefining $\mathrm{C}$ factors in the DPZP analysis using all current surface-cracked pipe data 
5.11 Redefining $\mathrm{C}$ factors in the DPZP analysis using all current surface-cracked-pipe data (expanded scale of Figure 5.11) . . . . . . . . . . . . . 5-20

5.12 Fit of surface-cracked ferritic steel pipe data to define $\mathrm{J}_{\mathfrak{i}}$ versus $\mathrm{CVP}$

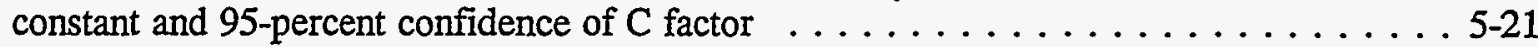

5.13 Comparison of Z-factors from DPZP analysis with ASME IWB-3650 analysis for ferritic steels . . . . . . . . . . . . . . . . . . . . . . . 5-22

5.14 Comparison of Z-factors from DPZP analysis with ASME IWB-3640 analysis

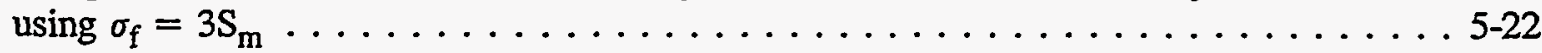

5.15 Comparison of Z-factors from DPZP analysis with ASME IWB-3640 analysis using

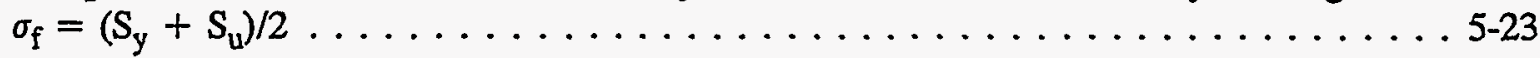

5.16 DPZP Z-factors as a function of Charpy energy for 406-mm (16-inch) diameter pipe and comparison with ASME IWB-3650 values . . . . . . . . . . . . . 5-24

5:17 Code Case Z-factor analysis steps for 114.3-mm (4.5-inch) outside diameter pipe using $\mathrm{J} / \mathrm{T}$ extrapolated ferritic pipe SAW J-R curve (a) Limit-load analysis maximum bending stress, (b) Code-Case-calculated maximum bending stress, (c) Comparison of Z-factors from the Code Case analysis with the ASME Section XI

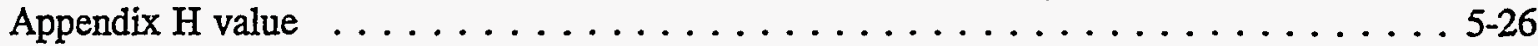

5.18 Code Case Z-factor analysis steps for 406.4-mm (16-inch) outside diameter pipe using J/T extrapolated ferritic pipe SAW J-R curve (a) Limit-load analysis maximum bending stress, (b) Code Case calculated maximum bending stress, (b) Comparison of Z-factors from the Code Case analysis with the ASME Section XI

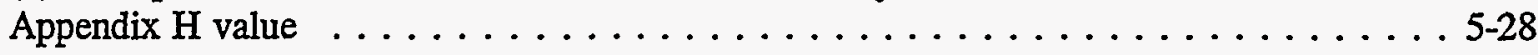

5.19 Code Case Z-factor analysis steps for 1067-mm (42-inch) outside diameter pipe using J/T extrapolated ferritic pipe SAW J-R curve (a) Limit-load analysis maximum bending stress, (b) Code Case calculated maximum bending stress, (b) Comparison of Z-factors from the Code Case analysis with the ASME Section XI

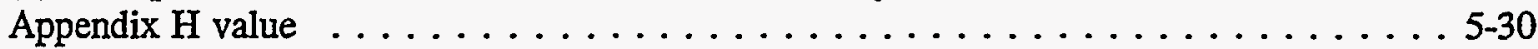

5.20 SC.TNP1 Z-factor analysis steps for 114.3-mm (4.5-inch) outside diameter pipe using J/T extrapolated ferritic pipe SAW J-R curve (a) Net-Section-Collapse analysis predicted moment, (b) SC.TNP1 calculated maximum moments with the $\mathrm{J} / \mathrm{T}$ extrapolated $\mathrm{J}_{\mathrm{D}}-\mathrm{R}$ curve, (c) Comparison of $\mathrm{Z}$-factors from the SC.TNP1 analysis with the ASME Section XI Appendix $\mathrm{H}$ value $\ldots \ldots \ldots \ldots \ldots \ldots \ldots \ldots$ 


\section{CONTENTS}

$\underline{\text { Page }}$

5.21 SC.TNP1 Z-factor analysis steps for 406.4-mm (16-inch) outside diameter pipe using $\mathrm{J} / \mathrm{T}$ extrapolated ferritic pipe SAW J-R curve (a) Net-Section-Collapse analysis predicted moment, (b) SC.TNP1 calculated maximum moments with the $\mathrm{J} / \mathrm{T}$ extrapolated $\mathrm{J}_{\mathrm{D}}-\mathrm{R}$ curve, (c) Comparison of Z-factors from the SC.TNP1 analysis with the ASME Section XI Appendix $\mathrm{H}$ value $\ldots \ldots \ldots \ldots \ldots$. . . . . . . .

5.22 SC.TNP1 Z-factor analysis steps for 1.067-m (42-inch) outside diameter pipe using J/T extrapolated ferritic pipe SAW J-R curve (a) Net-Section-Collapse analysis predicted moment, (b) SC.TNP1 calculated maximum moments with the $\mathrm{J} / \mathrm{T}$ extrapolated $\mathrm{J}_{\mathrm{D}}-\mathrm{R}$ curve, (c) Comparison of Z-factors from the SC.TNP1 analysis with the ASME Section XI Appendix $\mathrm{H}$ value $\ldots \ldots \ldots \ldots \ldots \ldots \ldots$. . . . . . . .

5.23 Comparison of the SC.TNP1 Z-factors with the ASME Appendix H equation Z-factor values versus pipe diameter using the $\mathrm{J} / \mathrm{T}$ extrapolated $\mathrm{J}_{\mathrm{D}}-\mathrm{R}$ curve $\ldots \ldots \ldots \ldots \ldots \ldots$

5.24 SC.TNP1 Z-factor analysis steps for 1.067-m (42-inch) outside diameter pipe (Using 1T C(T) $\mathrm{J}_{\mathrm{M}}-\mathrm{R}$ curve from Figure 5.7) (a) SC.TNP1 calculated maximum moments, (b) Comparison of Z-factors from the SC. TNP1 analysis with the ASME Section XI Appendix H value, (c) Ratio of SC.TNP1 Z-factors using $\mathrm{J} / \mathrm{T}$ extrapolated $\mathrm{J}_{\mathrm{D}^{-}}-\mathrm{R}$ curve to $\mathrm{Z}$-factors using $\mathrm{J}_{M^{-}} \mathrm{R}$ curve versus $\theta / \pi \ldots \ldots$. $\ldots$.40

5.25 Ratio of SC.TNP1 Z-factors using J/T extrapolated $J_{D}-R$ curve to

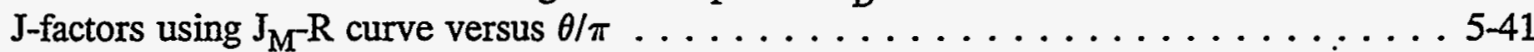

A.1 Geometry and loading of a pipe with an internal circumferential surface crack (a) Surface-cracked pipe under bending and tensile loading, (b) Cross-section containing internal surface crack,

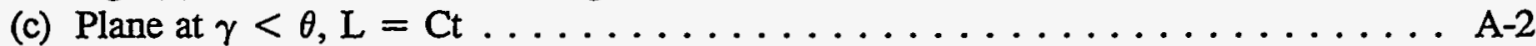

E.1 Comparison of axial-cracked pipe burst data to Maxey analysis with $\sigma_{\mathrm{f}}=2.4 \mathrm{~S}_{\mathrm{m}}$ and ASME Table $\mathrm{H}-6410$ values 


\section{EXECUTIVE SUMMARY}

This topical report summarizes the work performed within the Nuclear Regulatory Commission's (NRC) research program entitled "Short Cracks in Piping and Piping Welds". The overall research program objective was to verify and improve fracture analyses for circumferentially cracked largediameter nuclear piping with crack sizes typically used in leak-before-break (LBB) analysis or inservice flaw evaluations. The program was based on synergistic interactions of material characterization, full-scale pipe fracture experiments, and analysis. Only quasi-static loading rates were considered here since the NRC's International Piping Integrity Research Group (IPIRG) program focused on seismic loading rates on cracked piping systems.

The specific objective of the effort described in this topical report was to investigate the failure behavior of small and large diameter pipes with short, internal, circumferential surface cracks subjected to both pure bending and combined bending and pressure-induced tensile loads. Typically, the crack sizes for the experiments were selected to be as short as possible, and yet long enough to avoid failure due to buckling.

The major accomplishments in this task are summarized below along with the impact of this work on the ASME Section XI - Flaw Evaluation Procedures.

\section{Material Characterization}

Six piping materials and two weld materials were characterized. The characterization procedures included chemical analysis, tensile tests, Charpy tests for the ferritic steels and the weld metals, and toughness tests to determine the J-resistance curves.

The major accomplishments in this effort are summarized below:

- $\quad$ Two types of welds are typically used for power plant carbon steel piping by Babcock and Wilcox. Fracture resistance data on the Mn-Mo-Ni submerged-arc weld used in 10 percent of their piping and some pressure vessels were developed in the Degraded Piping Program. Similar data on the high Mn-Mo submerged-arc weld used in 90 percent of their piping was developed in this effort. The C(T) specimen tests at $22 \mathrm{C}(72 \mathrm{~F})$ on the high Mn-Mo weld exhibited only small amounts of crack growth before undergoing unstable, cleavage fracture. At $288 \mathrm{C}(550 \mathrm{~F})$, however, both types of submerged-arc welds had virtually identical J-R curves.

- The stainless steel submerged-arc weld evaluated in this program was created using the same General Electric weld procedure as that used in the Degraded Piping Program and the IPIRG-1 Program. There were significant differences in the weld metal yield strengths between the three welds evaluated in this program, the Degraded Piping Program, and the IPIRG-1 Program. Although there were large differences in $\mathrm{J}_{\text {Ic }}$ values, the J-R curves for the three different welds were not significantly different. The stainless steel welds had a similar initiation toughness but higher J-R curve than the Babcock and Wilcox carbon steel welds. 
- Data from these material characterization efforts were incorporated into the NRC's PIFRAC database, and subsequently used in NUREG/CR-6004, "Probabilistic Pipe Fracture Evaluations for Leak-Rate-Detection Applications."

\section{Pipe Fracture Experiments}

Prior to this program, there were very few experimental data on short circumferential surface-cracked pipes under combined pressure and bending, especially for large diameter pipes where elastic-plastic fracture is more likely to occur. Therefore, six surface-cracked-pipe experiments were conducted with identical dimensionless crack sizes (length of 25 percent of circumference and depth 50 percent of thickness). This crack size was selected as it was the smallest flaw size that would ensure that the pipe with even the largest value of pipe radius-to-thickness ratio would not buckle under the given loading configuration. The six pipe experiments are summarized as follows:

- Three pipe experiments were conducted to investigate radius-to-thickness effects on the Net-Section-Collapse analysis method. These included two tests with a 152-mm (6-inch) diameter pipe and one using a 406-mm (16-inch) diameter short surface-cracked, stainless steel pipe. The two 152-mm (6-inch) diameter pipe experiments were conducted at $288 \mathrm{C}(550 \mathrm{~F})$. The $406-\mathrm{mm}$ (16-inch) diameter pipe experiment was conducted at $99 \mathrm{C}(210 \mathrm{~F})$.

- Three more experiments were conducted to investigate the effect of large diameter pipe on the in-service flaw acceptance criteria embodied in Section XI of the ASME Code. The first was a 711-mm (28-inch) nominal diameter carbon steel pipe with a short surface crack in the base metal. The second was also on a 711-mm (28-inch) nominal diameter stainless steel pipe with a short surface crack in a submerged-arc weld, and the third involved a 610 -mm (24-inch) nominal diameter carbon steel pipe with a short surface crack in the submerged-arc weld. These tests were also conducted at $288 \mathrm{C}$ $(550 \mathrm{~F})$ and under combined pressure and bending loads.

Data from these experiments were included in the CIRCUMCK.WK1 database that was developed in this program. For each experiment, the applied loads, pipe displacements, crack growth history, crack-mouth-opening displacements, pipe rotations, internal pressure, and pipe temperatures were recorded. These data were used to compare the experimental observations with analytical predictions.

\section{Analysis of Surface-Cracked Pipe}

Analysis efforts in this task had four thrust areas. These were to (i) improve existing analysis methods, (ii) develop new analysis procedures, (iii) validate analysis methods using experimental data and/or finite element results, and (iv) address some unresolved issues involving finite element analysis of surface-cracked pipes. Significant advances were made in all four areas, especially since there had been very limited work done in developing J-estimation based schemes for finite-length circumferential surface cracks in the past. The key accomplishments in the four areas are summarized below:

- Using the full-scale-pipe experimental data, a simple empirical correction factor was developed for the Net-Section-Collapse Criterion to account for pipe ovalization under 
bending loads. This correction factor was found to be dependant on the pipe radius-to-thickness ratio and independent of the surface-crack length within the range of the data available.

- Two improvements were made to the existing finite-length circumferential surfacecracked pipe J-estimation schemes SC.TNP and SC.TKP. These methods were developed during the Degraded Piping Program and were based on the GE/EPRI 360degree surface-crack h-functions. First, the GE-EPRI influence functions for deep surface cracks were developed. Second, a finite-element-based correction was made to the ' $L$ ' parameter used in these schemes to improve the predictions of $J$. The original methods are called SC.TNP1 and SC.TKP1, whereas the modified ' $L$ ' parameter methods are called SC.TNP2 and SC.TKP2.

- A new J-estimation scheme (SC.ENG), independent of all the other methods, was developed. Two versions of this method (SC.ENG1 and SC.ENG2) were derived based on either the original Net-Section-Collapse analysis limit-load equations or the Kurihara modification to the Net-Section-Collapse analysis equations. The predictions were verified against finite element results from this effort as well as those available in the literature. The predictions of $\mathrm{J}$, the crack-driving force, using the SC.ENG methods were found to be much better than those using the SC.TNP1 and SC.TKP1 methods.

- Three previously unresolved issues were addressed. First, the discrepancy between finite element predictions and experimental data on stainless steel uncracked pipes under bending loads was resolved. It was found that full three-dimensional brick elements were necessary to model the load-deflection behavior of uncracked pipe beyond yielding. Second, the level of mesh refinement at the crack tip of a surface-cracked pipe that is needed to yield satisfactory finite element results was established. Also, a comparison between three-dimensional brick elements and the line-spring models indicated that the applied $\mathrm{J}$ can be calculated by the simpler line-spring approach with sufficient accuracy. Third, new J-estimation schemes to handle external surface cracks under combined bending and internal pressure were developed. These analyses were based on the original SC.TNP1 and SC.TKP1 methods.

- A new personal computer program, NRCPIPES Version 2.0a, to analyze the behavior of surface-cracked piping under pure bending or combined bending and tension loads was developed and released. This is the only computer code available of its kind. The ASME Section XI procedures, the new and improved J-estimation scheme analyses methods, the R6 Option 1, and the Battelle Dimensionless Plastic-Zone Screening (DPZP) method were incorporated into this program.

- NRCPIPES was used to analyze past experiments as well as those from this program. Statistical comparisons between the various analyses to predict the maximum momentcarrying capacity of 28 pure bending and 16 combined pressure and bending pipe experiments from this and other programs showed the following: 
For pure bending of surface-cracked pipes:

- The most accurate predictions of the maximum loads were made using the SC.TNP1 method. The mean experiment-to-predicted maximum load ratio was 1.02. The standard deviation was also the lowest at 0.14 .

- The next most accurate analysis methods were the Battelle DPZP method and the ASME austenitic pipe Appendix-C method (with safety factor of 1.0). The mean experiment-to-predicted maximum load ratios were 1.18 and 1.19 , respectively.

- The method that underpredicted the maximum loads by the greatest margin was the ASME Section XI ferritic pipe Appendix-H Z-factor approach. For this approach the mean experiment-to-predicted maximum load ratio was 1.87 . The ASME Code Case N-494-2 analysis method for ferritic pipe was more accurate than the Appendix-H Z-factor method and had a mean experiment-to-predicted maximum load ratio of 1.44 .

For surface-cracked pipes under combined pressure and bending loads:

- The most accurate predictions of the maximum loads were obtained using the DPZP method. The mean experiment-to-predicted maximum load ratio was 1.05. The standard deviation was also the lowest at 0.13 . This method was found to be more accurate for combined loading than for pure bending cases.

- $\quad$ The second-most-accurate methods were the SC.TNP1 method and the ASME austenitic pipe Appendix-C method (with safety factor of 1.0). The mean experiment-to-predicted maximum load ratios were 1.10 and 1.16 , respectively. The SC.TNP1 method was slightly less accurate for combined loading than it was for pure bending cases, and the ASME Section XI Appendix-C mean value was better for combined loading cases than it was for pure bending.

- The method that underpredicted the maximum loads by the greatest margin was the ASME Section XI ferritic pipe Appendix-H Z-factor approach with a mean experiment-to-predicted maximum load ratio of 2.14. This value was higher than that for pure bending cases. The ASME Code Case N-494-2 analysis method for ferritic pipe was more accurate than the ASME Appendix-H Z-factor analysis with a mean experiment-to-predicted maximum load ratio of 1.42 and a standard deviation of 0.18 . These values were similar to those for pure bending experiments.

As stated above, the SC.TNP2, SC.TKP2 and SC.ENG1 and SC.ENG2 analyses had the best comparisons with $\mathrm{J}$ values from the finite element results. However, the mean experiment-to-predicted maximum load ratios for these methods ranged from 1.32 to 1.44 for pure bending and 1.21 to 1.61 for combined loading. The reason for this discrepancy between the accuracy of the prediction of $\mathrm{J}$ values and maximum loads is suspected to be associated with the effects of constraint and toughness anisotropy. These effects are especially pronounced for ferritic base metal pipe experiments. The toughness data used in the analyses methods involved typical J-R curves from $C(T)$ specimens that were machined in an L-C orientation, whereas the crack growth in a surface-cracked pipe is in the L-R direction. The L-R orientation toughness can be 
much higher in ferritic base metals. Also, these methods should yield better predictions for low cycle fatigue crack growth than obtained with the SC.TNP1 analysis.

\section{ASME Section XI Flaw Evaluation Criteria}

These efforts included (i) reviewing and validating the ASME Section XI pipe flaw evaluation criteria, (ii) noting some of the current limitations, (iii) examining alternative approaches to evaluate Z-factors, and (iv) improving the accuracy of Z-factors and simplifying the existing procedures to compute them. The results showed that the ASME Section XI pipe flaw evaluation criteria could not be reproduced using the input provided in the technical basis documents. For austenitic pipe, there were questions on the applicability of the material property data that were used to calculate the current code Z-factors. This raised concern about the technical basis of the past Z-factors.

Due to this problem and the large underprediction of maximum loads by the ferritic pipe Appendix $H$ approach, Z-factors were recalculated using several different methods during this effort. These methods are summarized below.

\section{Z-factors from Through-Wall-Cracked Pipe Analyses}

- $\quad$ For ferritic pipe submerged-arc welds, the $Z$-factors calculated using $J_{D}-R$ and $J_{M}-R$ curves using the Zahoor-modified GE/EPRI solution (used to compute Z-factors for ferritic pipe in the technical basis document) were significantly different. This difference was found to be inherent for cases where a through-wall-cracked pipe solution procedure is used to analyze a surface-cracked pipe problem.

- Contrary to expectations, for the various circumferential through-wall-cracked pipe J-estimation schemes, the Z-factors did not approach the value of 1.0 with decreasing diameter.

\section{Z-factors from Surface-Cracked Pipe Analyses}

- A Charpy energy-based criterion using the DPZP analysis was developed to compute $\mathrm{Z}$-factors for surface-cracked pipe. This method allows for a smooth transition from limit-load solution to the elastic-plastic fracture mechanics solution and inherently accounts for anisotropy and constraint effects. However, as with the ASME Section XI Z-factor approaches, this method does not account for flaw size effects on the Z-factors. The Z-factors predicted using mean values from the DPZP analysis are well below those from the ASME code for ferritic welds but close to those for austenitic welds.

- The Code Case N-494-2 analysis procedure was used to develop Z-factors for ferritic pipe submerged-arc weld flaws. This procedure showed that in general the Appendix-H Z-factors were higher than the Z-factors from the Code Case, but for flaws with depths of 75 percent of the pipe wall thickness, the Code Case Z-factors were higher than the Appendix- $\mathrm{H}$ values. Also, the Code Case $\mathrm{Z}$-factors tend to increase with decreasing circumferential crack length, which is contrary to what was expected. 
Executive Summary

- The SC.TNP1 J-estimation scheme from this report was also used to develop Z-factors for ferritic pipe submerged-arc weld flaws. These Z-factors were constant for circumferential crack lengths between 10 and 100 percent of the pipe circumference and for crack depths between 30 and 75 percent of the pipe wall thickness.

An additional calculation using two significantly different $J-R$ curves from the same material with the SC.TNP1 analysis showed little difference between Z-factors for the largest diameter pipe (most sensitive) case. These $J-R$ curves were a $J_{M}-R$ curve and $J / T$ extrapolated $J_{D}-R$ curve, which were especially different for larger amounts of crack growth. This contrasts with the findings for the through-wall-cracked pipe Z-factors, which showed significant effects depending on the type of J-R curve used. This lower sensitivity of the SC.TNP1 analysis to these J-R curves is due to the fact that for the surface-cracked pipes there is only a small amount of crack growth to reach maximum load. Over this small amount of crack growth, there was little difference between these two J-R curves.

New Z-factors were calculated for pipes with finite-length surface cracks using the SC.TNP1 procedure. These results can be extended to carbon steel base metal and stainless steel weld cases and can also be combined with the Charpy Energy/DPZP criterion to take advantage of the desirable features of the two approaches. The effect of $\mathrm{R} / \mathrm{t}$ ratio on the $\mathrm{Z}$-factors using the SC.TNP1 analysis needs to be evaluated in the future.

The principle of extrapolating Z-factors for crack depths less than 30 percent of the wall thickness and crack lengths less than 10 percent of the pipe circumference using the SC.TNP1 Z-factor analysis could be applied to the Charpy Energy/DPZP approach. The Charpy Energy/DPZP criterion showed very little difference in the value of the $Z$-factor for surface flaws with depths of 50 percent of the wall thickness and crack lengths of 25 percent of the pipe circumference from this program and flaws with depths of 66 percent of the wall thickness and crack lengths of 50 percent of the pipe circumference from the Degraded Piping program. This result is consistent with those obtained using the SC.TNP1 method. The SC.TNP1 and Charpy Energy/DPZP Z-factors agreed closely. This is not unexpected as the two analysis methods were found to be the most accurate of the methods investigated in this effort.

A number of other considerations for improvements to the ASME pipe flaw evaluation criteria were also discussed. The more significant ones are summarized below:

- By redefining the flow stress as the average of the yield and ultimate strengths, rather than as a function of $S_{m}$, the austenitic and ferritic pipe criteria could be combined and also extended to include Class 2 and 3 piping.

- When the total stress in the piping is below the actual yield stress for the material, the contribution of thermal expansion and seismic anchor motion stresses to fracture is equal to that of primary stresses, even for the case of TP304 stainless steel base metal. Hence, at these stress levels, the secondary stresses should be incorporated with a full safety factor. 
If the calculated stresses assuming elastic behavior are above the yield strength, then a nonlinear correction will greatly increase the allowable flaw size and also account for thermal expansion and the seismic anchor motion stresses, which are displacementcontrolled. The methodology to do this still needs to be developed. Also, it will be necessary to consider whether the inertial stresses are above the yield strength for the material. This aspect is especially important in light of the proposed design stress limits in ASME Section III.

- Seismic loading can:

(i) cause low-cycle fatigue crack growth,

(ii) reduce the J-R curve due to the cyclic loadings, and

(iii) increase the toughness of austenitic steels, but may lower the toughness and strength of ferritic steels because of the higher loading rates.

These effects are not considered in the flaw evaluation criteria for Service Level B, C, or D stresses. The development of the analyses for these stresses is based on data from quasi-static, monotonic loading of the specimens. Hence, perhaps there should be different $Z$-factors (or toughness corrections) for Service Level A conditions than for Service Level B, C, and D conditions.

- The flaw evaluation criteria consider constant depth (rectangular shaped) surface flaws. Real cracks seldom have a constant depth. The development of an equivalent flaw length, as is done in ANSI Standard B31G for the oil and gas industry, would be useful. 



\section{ACKNOWLEDGMENTS}

This work was supported by the U.S. Nuclear Regulatory Commission through the Electrical; Materials and Mechanical Engineering Branch, Division of Engineering Technology, of the Office of Nuclear Regulatory Research under Contract No. NRC-04-90-069. Mr. A. Hiser and Mr. M. Mayfield were the program monitors.

Dr. Young Hwan Choi of KINS performed analysis efforts while he was a visiting scientist at Battelle during this program. We thank him for his diligent efforts.

Dr. Masanori Kikuchi of the Science University of Tokyo stayed at Battelle as a visiting scientist for a short time during this program, and provided us with finite element results that were used in comparisons with experimental results and J-estimation scheme analyses. We thank him for his contribution.

The 16-inch nominal diameter stainless steel pipe used in this program was donated by Westinghouse Savannah River Corporation. We wish to thank Mr. R. Sindelar and Mr. N. G. Awadalla for their assistance with this pipe donation.

We would also like to thank others at Battelle who helped in these efforts. Technicians who contributed to these efforts were: Mr. R. Gertler, Mr. P. Held, Mr. P. Mincer, Mr. D. Rider, Mr. J. Ryan, Mr. D. Shoemaker, and Mr. J. Woods. We thank Mrs. D. Clegg and Mrs. V. Kreachbaum for typing this report and Dr. A. Hopper and Mr. K. Dufrane for editing the final draft of this document. We also would like to acknowledge the work done by Dr. Jalees Ahmad on the EXTCRK7 and INTCRK7 computer codes during early stages of this program. Dr. Ahmad was at Battelle at the time and is currently at Research Applications Incorporated. 


\section{NOMENCLATURE}

\section{SYMBOLS}

A

a

$a_{c}$

$a_{0}$

â

b

C

$\mathrm{C}_{\mathrm{e}}$

$\hat{\mathrm{C}}$

C

$\mathrm{C}_{1}$

$\mathrm{C}_{1}^{\prime}, \mathrm{C}_{2}^{\prime}$,

$\mathrm{C}_{3}^{\prime}, \mathrm{C}_{4}^{\prime}$

c

CVN

D

$\mathrm{D}_{\mathrm{o}}$

E

$\mathrm{E}_{\mathrm{n}}$

$E^{\prime}$
Crack area, function used in ASME Section XI Appendix-H Z-factor equation

Flaw depth

Area of Charpy specimens

Initial crack length

Reduced thickness length in SC.ENG analyses

Remaining ligament length

Empirical constant used in DPZP analysis

Empirical correction factor to NSC extension

Proportionality constant in SC.ENG method

Constant used in SC.TNP analyses

Coefficient used to fit J-resistance curve

Constants of integration for the SC.ENG methods

Half the mean circumferential crack length

Charpy V-notch energy

Nominal outside pipe diameter

Outside diameter

Young's modulus

Function defined in the SC.TNP methods

Equivalent Young's modulus for plane stress or plane strain conditions 
F

$F_{B}$

$F_{1}$

$\mathrm{F}_{\mathrm{n}}$

$\mathrm{F}(\theta)$

$\mathrm{F}^{\prime}$

$\mathrm{G}(\mathrm{a} / \mathrm{t})$

$\bar{G}_{N}$

$\mathrm{H}(\mathrm{a} / \mathrm{t})$

$\mathrm{h}_{1}, \mathrm{~h}_{2}, \mathrm{~h}_{3}, \mathrm{~h}_{4}$

I

$I_{B}, I_{B 1}, I_{B 2}$

J

$\mathrm{J}_{\mathrm{D}}$

$\mathrm{J}_{\mathrm{e}}$

$\mathrm{J}_{\mathrm{i}}$

$J_{\text {Ic }}$

$\mathrm{J}_{\mathrm{M}}$

$\mathrm{J}_{\mathbf{p}}$

$K(a / t)$

$\mathrm{K}_{\mathrm{I}}$

$\mathrm{K}_{\mathrm{Ic}}$

Function used in elastic stress intensity factor definition in GE/EPRI Method

Geometric factor for $K_{\mathrm{I}}$ due to bending loads

Function defined in developing axial flaw criteria

Elastic function of pipe geometry, $\lambda$ and $n$

Function of crack angle, $\theta$, used in NSC approach

Constant used in original Ramberg-Osgood equation

Function used in deriving the SC.ENG method

Function used in the SC.TKP methods

Function used in the SC.ENG methods

Functions tabulated in GE/EPRI method

Moment of inertia

Functions of pipe and crack geometry defined in the SC.ENG methods

J-integral fracture parameter

Deformation J

Elastic component of J-integral

$\mathrm{J}$-integral at crack initiation but not necessarily a valid $\mathrm{J}_{\mathrm{IC}_{\mathrm{c}}}$ by ASTM E813-81

$\mathrm{J}$ at crack initiation under Mode I loading

Modified value of $\mathrm{J}$ integral

Plastic component of J-integral

Function used in the SC.ENG methods

Mode I stress intensity factor

Plane strain linear elastic fracture toughness 


\begin{tabular}{|c|c|}
\hline $\mathrm{K}_{\mathrm{r}}$ & Toughness ratio in the FAD curve \\
\hline k & Constant used to relate axial load to axial stress \\
\hline$\hat{\mathbf{K}}$ & Function in the SC.ENG methods \\
\hline $\mathrm{L}$ & Length parameter used in SC.TNP and SC.TKP \\
\hline $\mathrm{L}_{\mathrm{r}}$ & Strength ratio in R6 Analysis \\
\hline$\ell$ & Axial flaw length \\
\hline$\ell_{\text {crit }}$ & Critical axial flaw length \\
\hline $\mathbf{M}$ & Moment \\
\hline$M_{L}^{c}$ & Limit moment due to the crack \\
\hline$M_{L}^{d}$ & Limit moment at reduced cross section in SC.ENG method \\
\hline $\mathrm{M}_{\mathrm{k}}$ & Moment defined in SC.ENG methods \\
\hline$M_{1}$ & $\begin{array}{l}\text { Function defined in developing the axial flaw criteria } \\
\text { - }\end{array}$ \\
\hline $\mathrm{M}_{\mathrm{MES}}$ & Buckling moment predicted by Mesloh's method \\
\hline $\mathrm{M}_{\mathrm{nsc}}$ & Net-Section-Collapse Moment \\
\hline $\mathrm{M}_{\mathrm{o}}$ & Limit moment base on $\sigma_{0}$ \\
\hline $\mathrm{M}_{2}$ & Function used in axial flaw criteria \\
\hline $\mathrm{m}$ & Kurihara correction factor to NSC solutions \\
\hline $\mathrm{m}(\mathrm{a} / \mathrm{t}, \theta / \pi)$ & Function used in SC.ENG2 method \\
\hline$N$ & Number of cycles for fatigue loading \\
\hline $\mathbf{n}$ & Ramberg-Osgood strain-hardening exponent \\
\hline $\mathbf{P}$ & Tension load \\
\hline$P_{e}$ & Thermal expansion stress \\
\hline
\end{tabular}


$P_{i}$

$\mathrm{P}_{\mathrm{m}}$

$P_{0}$

$\mathrm{p}$

Q

$\mathrm{Q}_{1}, \mathrm{Q}_{2}$

$R_{c}$

$\mathbf{R}_{\mathbf{i}}$

$\mathrm{R}_{\ell}$

$\mathrm{R}_{\mathrm{m}}$

$\mathrm{R}_{\mathrm{o}}$

$\mathrm{S}_{\mathrm{F}}$

$\mathrm{S}_{\mathrm{r}}$

$S_{u}$

$\mathrm{S}_{\mathrm{y}}$

$\mathrm{T}$

$\mathrm{T}^{\prime}$

t

$t_{e}$

U

$\mathrm{Uc}^{\mathrm{c}}$

$\mathrm{U}^{\mathrm{nc}}$

$\mathrm{U}_{\mathrm{o}}$
Crack initiation load

Axial tension stress from pressure

Limit load based on $\sigma_{\mathrm{o}}$

Pressure

Function of $\mathrm{n}$ and pipe geometry in the SC.TNP methods

Functions used to define $\mathrm{K}(\mathrm{a} / \mathrm{t})$ in the SC.ENG methods

Pipe radius at crack tip

Inside radius

Lower limit of integration for radius

Mean pipe radius

Outside radius

Safety factor

Stress ratio used in FAD curve

ASME ultimate stress

ASME yield strength

Tearing modulus

Axial force definition in the SC.TNP methods

Thickness of pipe wall

Effective thickness of pipe

d-c electric potential

Internal strain energy due to crack

Internal strain energy without crack

Value of $U$ at crack initiation 


\begin{tabular}{|c|c|}
\hline $\mathrm{U}^{\mathrm{T}}$ & Total internal strain energy $\left(U^{c}+U^{n c}\right)$ \\
\hline$V_{1}, V_{2}, V_{3}$ & Displacement functions in GE/EPRI analysis \\
\hline W & Compact tension specimen width \\
\hline Z & A stress multiplier in the ASME IWB- 3640 and -3650 analyses \\
\hline$Z^{\prime}$ & Function used in the SC.TNP methods \\
\hline$Y^{\prime}$ & Function used in the SC.TNP methods \\
\hline $\mathbf{y}$ & Half the spacing between d-c electric potential probes \\
\hline$\alpha$ & Ramberg-Osgood parameter \\
\hline$\alpha^{\prime}$ & Angle from center of crack in EXTCRK7 \\
\hline $\bar{\alpha}$ & Function used to define $\delta$ in the SC.TNP methods \\
\hline$\beta$ & Fully plastic neutral axis angle \\
\hline$\Gamma$ & Gamma function \\
\hline$\gamma$ & Half-angle along the cracked section \\
\hline$\Delta$ & Pipe displacement at the load point \\
\hline$\Delta \mathrm{a}$ & Increment of crack growth \\
\hline$\Delta \mathrm{a}_{0}$ & Normalizing parameter \\
\hline$\Delta^{c}$ & Pipe displacement due to the crack \\
\hline$\Delta_{\mathrm{e}}^{\mathrm{c}}$ & Elastic component of the pipe displacement due to the crack \\
\hline$\Delta_{\mathrm{p}}^{\mathrm{c}}$ & Plastic component of the pipe displacement due to the crack \\
\hline$\Delta \mathrm{J}$ & Incremental value of $\mathrm{J}$ \\
\hline$\Delta^{\mathrm{nc}}$ & Pipe displacement without the crack \\
\hline$\Delta_{\mathrm{e}}^{\mathrm{nc}}$ & Elastic component of the pipe displacement without the crack \\
\hline
\end{tabular}




\begin{tabular}{|c|c|}
\hline$\Delta_{\mathrm{p}}^{\mathrm{nc}}$ & Plastic component of the pipe displacement without the crack \\
\hline$\delta$ & Remote displacement due to tension stress in the SC.TNP methods \\
\hline $\boldsymbol{\epsilon}$ & Strain \\
\hline$\epsilon_{\mathrm{o}}$ & Reference strain $\left(\sigma_{0} / E\right)$ \\
\hline$\epsilon_{\infty}$ & Remote strain away from the crack section \\
\hline$\eta$ & Geometric factor used in J-integral analysis \\
\hline$\eta_{\mathrm{p}}$ & Plastic component of $\eta$ \\
\hline$\theta$ & Half-crack angle \\
\hline$\nu$ & Poisson's ratio \\
\hline$\rho_{\mathrm{n}}$ & Half the neutral axis angle in SC.TNP2 method \\
\hline$\phi$ & Half rotation of pipe \\
\hline$\phi^{\mathrm{c}}$ & Half rotation of pipe due to crack \\
\hline$\phi_{\mathrm{e}}^{\mathrm{c}}$ & Elastic pipe rotation due to crack \\
\hline$\phi_{\mathrm{p}}^{\mathrm{c}}$ & Plastic pipe rotation due to crack \\
\hline$\phi_{\mathrm{p}}^{\mathrm{nc}}$ & Half plastic rotation of uncracked pipe \\
\hline $\boldsymbol{\sigma}$ & Stress \\
\hline$\sigma_{\mathrm{B}_{\mathrm{EXPT}}}$ & Experimental value of the bending stress \\
\hline$\sigma_{\mathrm{B}_{\mathrm{NSC}}}$ & Net-section-collapse analysis predicted failure stress \\
\hline$\sigma_{\mathrm{f}}$ & Flow stress \\
\hline$\sigma_{\mathrm{h}}$ & Allowable hoop stress \\
\hline$\sigma_{\infty}$ & Remote stress away from the crack section \\
\hline$\sigma_{M_{E X P T}}$ & Experimental value of the membrane stress \\
\hline
\end{tabular}




$\begin{array}{ll}\sigma_{\text {nsc }} & \text { Net-Section-Collapse analysis predicted failure stress } \\ \sigma_{\mathrm{o}} & \text { Reference stress } \\ \sigma_{\mathrm{u}} & \text { Ultimate stress } \\ \sigma_{\mathrm{y}} & \text { Yield stress } \\ \sigma_{0.005} & \text { Stress at } 0.5 \text { percent strain } \\ \mathrm{x}^{\prime} & \text { Angle along circumferential crack }\end{array}$

2.

ABAQUS

A/D

AEC

ASME

ASTM

$\mathrm{B} \& W$

CEGB

CIRCUMCK.WK1

CMOD

COD

COLAPS

$\mathrm{C}(\mathrm{T})$

CVP

DAS

d-c EP

DP2

\section{ACRONYMS AND INITIALISMS}

Finite element computer code

Analogue to digital

Atomic Energy Commission (U.S.)

American Society of Mechanical Engineers

American Society for Testing and Materials

Babcock and Wilcox

Central Electricity Generating Board

Lotus $^{\circledR}$ database of circumferentially cracked pipe fracture experiments

Crack-mouth-opening displacement

Crack-opening displacement

Computer code to analyze buckling of pipe

Compact (tension) specimen

Charpy V-notch upper-shelf (plateau) energy

Data acquisition systems

Direct-current electric potential

Degraded Piping Program - Phase II 
DPFAD

DPZP

Dyn

EPFM

EPRI

EXTCRK7

FAD

FAC

FE

FC

FEM

GE

GTAW

HSLA

IBM

IPIRG

INTCRK7

JAERI

$\mathrm{J}-\mathrm{R}, \mathrm{J}_{\mathrm{R}}$

$\mathbf{J}_{\mathrm{D}}-\mathbf{R}$

$\mathrm{J}_{\mathrm{M}}-\mathrm{R}$

J-Q

KINS
Deformation plasticity failure assessment diagram

Dimensionless Plastic-Zone Parameter

Dynamic

Elastic-plastic fracture mechanics

Electric Power Research Institute (U.S.)

Computer code to analyze external surface-cracked pipe

Failure assessment diagram

Failure assessment curve

Finite element

Fatigue crack

Finite element method

General Electric

Gas tungsten arc weld

High strength low alloy

International Business Machine (computer)

International Piping Integrity Research Group

Computer code to analyze internal surface-cracked pipe

Japanese Atomic Energy Research Institute

J-resistance curve

Deformation theory J-resistance curve

Modified J-resistance curve

Parameters used to describe constraint effects

Korea Institute of Nuclear Safety 
LBB

LBB.ENG,

LBB.ENG3

L-C

LEFM

LLD

L-R

LVDT

LWR

MEA

MTS

NPS

NRC

NRCPIPE

NRCPIPES

NSC

NUREG/CR

PC

PIFRAC

QS

SA

SAM

SAW
Leak-before-break

Circumferential TWC analysis methods developed at Battelle

Longitudinal-circumferential orientation (direction of through-wall crack growth around pipe circumference)

Linear elastic fracture mechanics

Load-line displacement

Longitudinal-radial orientation (direction of surface crack growth)

Linear variable displacement transducer

Light water reactor

Materials Engineering Associates

Materials testing machine manufacturer

Nominal pipe size (diameter)

Nuclear Regulatory Commission (U.S.)

PC computer program for circumferential TWC analyses

PC computer program for circumferential SC analyses

Net-Section Collapse

Nuclear Regulatory Commission Contractor Report

Personal computer

Pipe material property database

Quasi-satic

Shear area percent

Seismic anchor motion

Submerged-arc weld 
Nomenclature

SC.ENG, SC.ENG1,

SC.ENG2

Surface-crack analysis methods developed during this program

SC.TKP, SC.TKP1

Surface crack analysis using thick pipe approximations developed during the Degraded Piping Program and now called SC.TKP1

SC.TKP2

A modification to SC.TKP1

SC.TNP, SC.TNP1

Surface crack analysis using thin pipe approximations developed during the Degraded Piping Program and now called SC.TNP1

SC.TNP2

A modification to SC.TNP1

$\operatorname{SEN}(\mathrm{T})$

Single-edge notch tension specimen

$\mathrm{S}_{\mathrm{m}}$

Design value of the stress intensity

SMAW

Shielded-metal-arc weld

SMN

Sharp machine notch

TIG

Tungsten inert gas (weld)

T-stress

Parameter used to quantify constraint effects

TWC

Through-wall crack, through-wall-cracked

USNRC

United States Nuclear Regulatory Commission 


\section{PREVIOUS REPORTS IN SERIES}

\section{Reports from this Program}

"Short Cracks in Piping and Piping Welds," First Semiannual Report, NUREG/CR-4599, Vol. 1, No. 1, March 1991.

"Short Cracks in Piping and Piping Welds," Second Semiannual Report, NUREG/CR-4599, Vol. 1, No. 2, April 1992.

"Short Cracks in Piping and Piping Welds," Third Semiannual Report, NUREG/CR-4599, Vol. 2, No. 1, September 1992.

"Short Cracks in Piping and Piping Welds," Fourth Semiannual Report, NUREG/CR-4599, Vol. 2, No. 2, February 1993.

"Short Cracks in Piping and Piping Welds," Fifth Semiannual Report, NUREG/CR-4599, Vol. 3, No. 1, October 1993.

"Short Cracks in Piping and Piping Welds," Sixth Semiannual Report, NUREG/CR-4599, Vol. 3, No. 2, March 1994.

"Short Cracks in Piping and Piping Welds," Seventh Program Report, NUREG/CR-4599, BMI-2173, Vol. 4, No. 1, April 1995.

Assessment of Short Through-Wall Circumferential Cracks in Pipes--Experiments and Analysis," NUREG/CR-6235, April 1995.

"Fracture Evaluations of Fusion-Line Cracks in Nuclear Pipe Bimetallic Welds," NUREG/CR-6297, April 1995.

"Effect of Dynamic Strain Aging on the Strength and Toughness of Nuclear Ferritic Piping at LWR Temperatures," NUREG/CR-6226, October 1994.

"Effects of Toughness Anisotropy and Combined Tension, Torsion, and Bending Loads on Fracture Behavior of Ferritic Nuclear Pipe," NUREG/CR-6299, April 1995.

"Refinement and Evaluation of Crack-Opening Analyses for Short Circumferential Through-Wall Cracks in Pipes," NUREG/CR-6300, April 1995.

"Probabilistic Pipe Fracture Evaluations for Leak-Rate Detection Applications," NUREG/CR-6004, April 1995.

"Validity Limits in J-Resistance Curve Determination-Volume 1: An Assessment of the $J_{M}$ Parameter," NUREG/CR-6264, Volume 1, February 1995. 
"Validity Limits in J-Resistance Curve Determinations--Volume 2: A Computational Approach to Ductile Crack Growth Under Large-Scale Yielding Condition," NUREG/CR-6264, Volume 2, February 1995.

"Stainless Steel Submerged Arc Weld Fusion Line Toughness," NUREG/CR-6251, April 1995.

\section{Previous Related Documents from NRC's Degraded Piping Program}

"Degraded Piping Program - Phase II," Semiannual Report, NUREG/CR-4082, Vol. 1, Oct. 1984.

"Degraded Piping Program - Phase II," Semiannual Report, NUREG/CR-4082, Vol. 2, June 1985.

"Degraded Piping Program - Phase II," Semiannual Report, NUREG/CR-4082, Vol. 3, March 1986.

"Degraded Piping Program - Phase II," Semiannual Report, NUREG/CR-4082, Vol. 4, July 1986.

"Degraded Piping Program - Phase II," Semiannual Report, NUREG/CR-4082, Vol. 5, Dec. 1986.

"Degraded Piping Program - Phase II," Semiannual Report, NUREG/CR-4082, Vol. 6, April 1988.

"Degraded Piping Program - Phase II," Semiannual Report, NUREG/CR-4082, Vol. 7, March 1989.

"Degraded Piping Program - Phase II," Semiannual Report, NUREG/CR-4082, Vol. 8, March 1989.

"NRC Leak-Before-Break (LBB.NRC) Analysis Method for Circumferentially Through-Wall Cracked Pipes Under Axial Plus Bending Loads," Topical Report, NUREG/CR-4572, March 1986.

"Elastic-Plastic Finite Element Analysis of Crack Growth in Large Compact Tension and Circumferentially Through-Wall-Cracked Pipe Specimen--Results of the First Battelle/NRC Analysis Round Robin," Topical Report, NUREG/CR-4573, September 1986.

"An Experimental and Analytical Assessment of Circumferential Through-Wall Cracked Pipes Under Pure Bending," Topical Report, NUREG/CR-4574, June 1986.

"Predictions of J-R Curves With Large Crack Growth From Small Specimen Data," Topical Report, NUREG/CR-4687, September 1986.

"An Assessment of Circumferentially Complex-Cracked Pipe Subjected to Bending," Topical Report, NUREG/CR-4687, September 1986.

"Analysis of Cracks in Stainless Steel TIG Welds," Topical Report, NUREG/CR-4806, November 1986.

"Approximate Methods for Fracture Analyses of Through-Wall Cracked Pipes," Topical Report, NUREG/CR-4853, January 1987. 
"Assessment of Design Basis for Load-Carrying Capacity of Weld-Overlay Repair," Topical Report, NUREG/CR-4877, February 1987.

"Analysis of Experiments on Stainless Steel Flux Welds," Topical Report, NUREG/CR-4878, February 1987.

"Experimental and Analytical Assessment of Circumferentially Surface-Cracked Pipes Under Bending," Topical Report, NUREG/CR-4872, April 1987.

\section{Previous Related Documents from NRC's International Piping Integrity Research Group (IPIRG) Program}

"Evaluation and Refinement of Leak-Rate Estimation Models," NUREG/CR-5128, Revision 1, June 1994.

"Loading Rate Effects on Strength and Fracture Toughness of Pipe Steels Used in Task 1 of the IPIRG Program," Topical Report, NUREG/CR-6098, October 1993.

"Stability of Cracked Pipe Under Inertial Stresses," NUREG/CR-6233, Volume 1, August 1994.

\section{Other Related Program Reports}

"Validation of Analysis Methods for Assessing Flawed Piping Subjected to Dynamic Loading," NUREG/CR-6234, August 1994. 


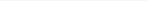




\subsection{INTRODUCTION}

The United States Nuclear Regulatory Commission (USNRC) frequently has to evaluate the structural integrity of circumferential part-through surface-cracked pipes in nuclear power plant piping systems. Codified approaches have been developed for ferritic and austenitic piping within ASME Section XI Articles IWB-3640, IWB-3650, Appendices C and H, and Code Case N-494-2. The overall objective of the work reported here was to validate these methods.

As part of the overall research effort needed to validate the ASME Section XI pipe flaw evaluation criteria, the USNRC sponsored the Degraded Piping Program - Phase II at Battelle. During that program, 29 experiments were conducted on pipes with circumferential surface cracks. These experiments were analyzed using the ASME Section XI austenitic and ferritic pipe flaw evaluation criteria, which are based on the Net-Section-Collapse analyses of the pipe and simplified modifications for elastic-plastic fracture. The Dimensionless Plastic-Zone Screening Criterion was also developed and used to analyze the experiments in that program. In addition, a new J-estimation scheme for finite length internal surface-cracked pipe was developed. This scheme, with two versions, SC.TNP and SC.TKP, was used to predict the loads at crack initiation, the maximum load, and the moment-rotation response of surface-cracked pipe. The results of the surface-cracked pipe experiments and analyses from the Degraded Piping Program efforts are presented in NUREG/CR4872 (Ref. 1.1).

Most of the data and analyses developed on surface-cracked pipes in past programs (Refs. 1.1 and 1.2) have involved relatively long crack lengths. These crack lengths have typically been about half of the pipe circumference. For shorter crack lengths, the previously mentioned methodologies were not verified. Therefore, as part of the USNRC's Short Cracks in Piping and Piping Welds Program, one task was devoted to investigating the failure behavior of small- and large-diameter pipes with short internal surface cracks subjected to bending and tensile loads. Typically, the crack sizes were selected to be as short as possible, and yet long enough to avoid failure due to buckling under combined pressure and bending loads.

The experimental program consisted of characterizing the material properties (tensile and J-R curves) of the steels used in the full-scale pipe experiments. Six pipe experiments were conducted on surfacecracked pipes. The matrix of these experiments is given in Table 1.1. As seen, three of these experiments involved small-diameter stainless steel pipes, and three experiments involved larger diameter pipes with cracks in the welds of two of them.

The analysis efforts on surface-cracked pipe involved three major activities: (i) improving the existing J-estimation schemes, SC.TNP and SC. TKP, (ii) verifying the estimation schemes using 3D finite element (FE) analysis of surface-cracked pipe along with a study on the effects of mesh refinement on the FE results, and (iii) developing a new J-estimation scheme (SC.ENG) along the lines of the LBB.ENG2 Method (Ref. 1.3), which is a J-estimation scheme applicable to through-wallcracked pipes under bending loads. 
Table 1.1 Summary of surface-cracked pipe experiments conducted in this program

\begin{tabular}{|c|c|c|c|c|c|c|c|c|c|c|c|}
\hline \multirow{2}{*}{$\begin{array}{c}\begin{array}{c}\text { Experiment } \\
\text { No. }\end{array} \\
1.2 .1 .20\end{array}$} & \multicolumn{2}{|c|}{$\begin{array}{l}\text { Diameter, } \\
\text { mm (inch) }\end{array}$} & \multicolumn{2}{|c|}{$\begin{array}{l}\text { Thickness, } \\
\text { mm (inch) }\end{array}$} & \multirow{2}{*}{$\frac{\text { Material }}{\text { TP304 }}$} & \multirow{2}{*}{$\begin{array}{c}\begin{array}{c}\text { Crack } \\
\text { Length, } \\
\text { Percent } \\
\text { Circ. }\end{array} \\
25.0\end{array}$} & \multirow{2}{*}{$\begin{array}{c}\text { Crack Depth, } \\
\text { Percent Wall } \\
\text { Thickness }\end{array}$} & \multicolumn{2}{|c|}{$\begin{array}{l}\text { Temperature, } \\
\mathbf{C} \quad \text { (F) } \\
\end{array}$} & \multicolumn{2}{|c|}{$\begin{array}{l}\text { Pressure, } \\
\text { MPa (psi) }\end{array}$} \\
\hline & 406.7 & $(16.01)$ & 9.50 & $(0.374)$ & & & & 99 & (210) & 1.55 & (225) \\
\hline 1.2.1.21 & 166.6 & (6.56) & 20.9 & $(0.822)$ & TP304 & 21.8 & 50.0 & 288 & $(550)$ & -0 - & $-0-$ \\
\hline 1.2.1.22 & 168.3 & $(6.627)$ & 7.10 & $(0.278)$ & TP304 & 25.0 & 50.0 & 288 & $(550)$ & -0 & -0 \\
\hline 1.2 .3 .15 & 711.0 & (28.0) & 22.7 & $(0.893)$ & A515 Gr. 60 & 25.0 & 50.0 & 288 & $(550)$ & 9.56 & $(1,387)$ \\
\hline 1.2 .3 .16 & 711.0 & $(28.0)$ & 30.2 & (1.19) & TP316L SAW & 25.0 & 50.0 & 288 & (550) & 10.1 & $(1,470)$ \\
\hline 1.2.3.17 & 610.0 & $(24.0)$ & 42.7 & (1.68) & A106B SAW & 25.0 & 60.5 & 288 & (550) & 15.5 & $(2,250)$ \\
\hline
\end{tabular}

Data for 44 full-scale pipe experiments conducted at Battelle in the past (Refs. 1.1 and 1.2), including the six from this program, were used in validating the various analyses.

This report is divided into 6 sections. Section 2.0 deals with the material characterization efforts for this program. Section 3.0 details the six pipe experiments. Section 4.0 describes the analysis improvements as well as the development of the new SC.ENG method. Comparisons between experimental results and analytical predictions are also presented in Section 4.0. Application of the results towards assessing and improving the ASME Section XI pipe flaw evaluation criteria are given in Section 5.0. Discussion of results and concluding remarks are made in Section 6.0.

\subsection{References}

1.1 Scott, P. M., and Ahmad, J. A., "Experimental and Analytical Assessment of Circumferentially Surface-Cracked Pipes Under Bending," NUREG/CR-4872, April 1972.

1.2 Kanninen, M. F., and others, "Instability Predictions for Circumferentially Cracked Type 304 Stainless Steel Pipes Under Dynamic Loadings," Final Report on EPRI Project T118-2, by Battelle Columbus Laboratories, EPRI Report Number NP-2347, April 1982.

1.3 Brust, F. W., "Approximate Methods for Fracture Analyses of Through-Wall Cracked Pipes," NRC Topical Report by Battelle Columbus Division, NUREG/CR-4853, February 1987. 


\subsection{MATERIAL CHARACTERIZATION}

In this section, the results of the material characterization efforts for the surface-cracked pipe fracture experiments conducted in this program are discussed. The discussion begins with a description of the materials selected for use as test specimens. Next the results of the chemical composition analyses, tensile tests, Charpy tests, and fracture toughness tests for the test specimen materials are presented. All tensile and fracture toughness testing was done at quasi-static rates under monotonic displacement control.

\subsection{Material Selection}

Six different materials were evaluated for the six pipe experiments conducted as part of this effort, see Table 2.1. The first three pipe materials listed in Table 2.1 are relatively small diameter, TP304 stainiess steel pipes, which where chosen because they had a wide range of pipe radius-to-thickness $\left(R_{m} / t\right)$ ratios and it was felt that they would fail under limit-load conditions. Selecting relatively small diameter high toughness pipe materials for this effort facilitated the analysis in that any lowering of the failure moments with respect to the Net-Section-Collapse (NSC) predicted moments could be attributed to ovalization effects (i.e., those values predicted by $R_{m} / t$ effects) and not containedplasticity (i.e., elastic-plastic) effects.

The 406-mm (16-inch) diameter pipe material (DP2-A52) was obtained from the excess pipe inventory of the Savannah River Facility. The mean pipe radius-to-wall thickness ratio $\left(R_{m} / t\right)$ for this pipe was 20.9. The 152-mm (6-inch) nominal diameter, Schedule XXS, stainless steel pipe (DP2-A35) was purchased from a pipe warehouse specifically for the Degraded Piping Program. The $R_{m} / t$ ratio for this pipe was 3.5. This pipe had been used in a previous Degraded Piping Program Experiment (4112-4) with a much larger surface crack, i.e., a/t $=0.653$ and $\theta / \pi=0.442$. The 152-mm (6-inch) nominal diameter, Schedule 40, stainless steel pipe (DP2-A7) was obtained from the excess pipe inventory from a nuclear power plant. The $R_{m} / t$ ratio for this pipe was 11.4 . This pipe had also been tested previously in the Degraded Piping Program (Experiment 4112-2), during which a much larger surface crack, i.e., $a / t=0.634$ and $\theta / \pi=0.502$, was used.

The three remaining pipe materials listed in Table 2.1 were relatively large diameter, 610-mm (24inch) and larger, lower toughness pipe materials, which were expected to fail under elastic-plastic conditions. The pipe material for Experiment 1.2.3.15 (DP2-F26) was obtained from the excess pipe inventory of a nuclear power plant as part of the Degraded Piping Program. Pipe DP2-F26 was a seam-welded 711 -mm (28-inch) diameter by 22.2 -mm $(0.875$-inch) nominal wall thickness SA155KC60-Class 1 carbon steel pipe. This pipe was fabricated from A515 Grade 60 plate. 
Table 2.1 Test specimen materials

\begin{tabular}{|c|c|c|c|c|c|c|}
\hline \multirow[b]{2}{*}{ Experiment } & \multirow{2}{*}{$\begin{array}{l}\text { Base Metal } \\
\text { Designation }\end{array}$} & \multirow[b]{2}{*}{ Material } & \multicolumn{2}{|c|}{$\begin{array}{c}\text { Nominal Pipe } \\
\text { Diameter, }\end{array}$} & \multicolumn{2}{|c|}{$\begin{array}{c}\text { Actual } \\
\text { Wall Thickness, }\end{array}$} \\
\hline & & & $\mathbf{m m}$ & (inch) & $\mathbf{m m}$ & (inch) \\
\hline 1.2.1.20 & DP2-A52 & TP304 & 406 & (16) & 9.5 & $(0.374)$ \\
\hline 1.2.1.21 & DP2-A35 & TP304 & 152 & (6) & 20.9 & $(0.822)$ \\
\hline 1.2.1.22 & DP2-A7 & TP304 & 152 & (6) & 7.1 & $(0.278)$ \\
\hline 1.2.3.15 & DP2-F26 & A515 Gr. 60 & 711 & $(28)$ & 22.7 & $(0.893)$ \\
\hline 1.2.3.16 & DP2-A51 & TP316L SAW & 711 & (28) & 30.2 & (1.19) \\
\hline 1.2.3.17 & AEC-C5 & A106B SAW & 610 & (24) & 42.7 & (1.68) \\
\hline
\end{tabular}

The pipe material for Experiment 1.2.3.16 (DP2-A51) was a section of TP316L stainless steel pipe obtained from the excess pipe inventory of the Nine Mile Point plant. The crack for this experiment was in the center of a low-toughness submerged-arc weld (SAW). The weld was prepared by United McGill Corporation of Columbus, Ohio, using procedures recommended by the General Electric Company. The weld was a single-vee weld having a $1.6 \mathrm{~mm}(0.063 \mathrm{inch})$ land and a $2.4 \mathrm{~mm}(0.094$ inch) gap. The first two root passes employed the gas tungsten arc process (GTAW), the next two passes used the shielded-metal-arc process (SMAW), and the remaining passes used the submergedarc process (SAW). The filler metal met Specification SFA-5.9 (Class ER-308) for GTAW and SAW, and SFA-5.4 (Class ER-308) for SMAW. The flux was ER-308/ST-100 (Lincoln weld).

The pipe material for Experiment 1.2.3.17 (AEC-C5) was a section of A106 Grade B pipe left over from a previous Battelle program conducted for the United States Atomic Energy Commission (AEC) during the 1960's. The crack for this experiment was in the center of a low-toughness submerged-arc weld. This weld was also prepared by the United McGill Corporation following the procedures specified by Babcock and Wilcox (B\&W), which were supposedly typical of the carbon steel weld procedures used in the Midland plant. The weld procedure was automatic submerged-arc, using a high manganese, high molybdenum wire carrying the designations EA3 and SFA 5.23. The flux was Linde 80. The chemical compositions of each of the pipes and weldments is given in Table 2.2. 
Table 2.2 Chemical composition, percent by weight, of pipe materials and weldments used in surface-cracked pipe experiments

\begin{tabular}{|c|c|c|c|c|c|c|c|c|}
\hline $\begin{array}{l}\text { Experiment Number } \\
\text { Material } \\
\text { Material } \\
\text { Identification }\end{array}$ & $\begin{array}{l}\text { 1.2.1.20 } \\
\text { TP304 } \\
\text { A52 }\end{array}$ & $\begin{array}{l}\text { 1.2.1.21 } \\
\text { TP304 } \\
\text { A35 }\end{array}$ & $\begin{array}{l}\text { 1.2.1.22 } \\
\text { TP304 } \\
\text { A7 }\end{array}$ & $\begin{array}{l}1.2 .3 .15 \\
\text { A515 Gr. } 60 \\
\text { F26 }\end{array}$ & $\begin{array}{l}1.2 .3 .16 \\
\text { TP316L } \\
\text { A51 }\end{array}$ & $\begin{array}{l}\text { SAW } \\
\text { A45W2 }\end{array}$ & $\begin{array}{l}\text { 1.2.3.17 } \\
\text { A106B } \\
\text { AEC-C5 }\end{array}$ & $\begin{array}{l}\text { SAW } \\
\text { F49W }\end{array}$ \\
\hline $\begin{array}{l}\mathrm{C} \\
\mathrm{Mn} \\
\mathrm{P} \\
\mathrm{S} \\
\mathrm{Si} \\
\end{array}$ & $\begin{array}{l}0.02 \\
1.9 \\
0.02 \\
0.03 \\
0.41 \\
\end{array}$ & $\begin{array}{l}0.054 \\
1.72 \\
0.023 \\
0.010 \\
0.45 \\
\end{array}$ & $\begin{array}{l}0.043 \\
1.87 \\
0.021 \\
0.011 \\
0.39 \\
\end{array}$ & $\begin{array}{l}0.13 \\
0.80 \\
0.009 \\
0.027 \\
0.25 \\
\end{array}$ & $\begin{array}{l}0.021 \\
1.8 \\
0.031 \\
0.018 \\
0.55 \\
\end{array}$ & $\begin{array}{l}0.03 \\
2.26 \\
0.032 \\
0.010 \\
0.89 \\
\end{array}$ & $\begin{array}{l}0.25 \\
0.75 \\
0.017 \\
0.016 \\
0.26 \\
\end{array}$ & $\begin{array}{l}0.084 \\
1.55 \\
0.016 \\
0.013 \\
0.44 \\
\end{array}$ \\
\hline $\begin{array}{l}\mathrm{Ni} \\
\mathrm{Cr} \\
\mathrm{Mo} \\
\mathrm{Cu} \\
\mathrm{Sn}\end{array}$ & $\begin{array}{l}8.8 \\
18.4 \\
0.29 \\
0.17 \\
0.01\end{array}$ & $\begin{array}{l}9.2 \\
18.2 \\
0.26 \\
0.13 \\
0.006\end{array}$ & $\begin{array}{l}10.2 \\
18.3 \\
0.18 \\
0.16 \\
0.007\end{array}$ & $\begin{array}{l}0.13 \\
0.13 \\
0.40 \\
0.12 \\
0.007\end{array}$ & $\begin{array}{l}9.8 \\
17.3 \\
2.1 \\
0.2 \\
0.008\end{array}$ & $\begin{array}{l}9.6 \\
19.7 \\
0.10 \\
0.26 \\
0.010\end{array}$ & $\begin{array}{l}\text { N.D. (a) } \\
\text { N.D. } \\
\text { N.D. } \\
\text { N.D. } \\
\text { N.D. }\end{array}$ & $\begin{array}{l}0.013 \\
0.024 \\
0.47 \\
0.055 \\
0.003\end{array}$ \\
\hline $\begin{array}{l}\mathrm{Al} \\
\mathrm{V} \\
\mathrm{Nb} \\
\mathrm{Zr} \\
\mathrm{Ti}\end{array}$ & $\begin{array}{l}0.01 \\
0.09 \\
0.00 \\
0.00 \\
0.01\end{array}$ & $\begin{array}{l}0.002 \\
0.08 \\
\text { N.D. } \\
0.001 \\
0.000\end{array}$ & $\begin{array}{l}0.004 \\
0.07 \\
\text { N.D. } \\
0.001 \\
0.001\end{array}$ & $\begin{array}{l}0.003 \\
0.000 \\
\text { N.D. } \\
0.000 \\
0.000\end{array}$ & $\begin{array}{l}0.01 \\
0.08 \\
0.013 \\
0.001 \\
0.004\end{array}$ & $\begin{array}{l}0.015 \\
0.070 \\
0.012 \\
0.015 \\
0.006\end{array}$ & $\begin{array}{l}\text { N.D. } \\
\text { N.D. } \\
\text { N.D. } \\
\text { N.D. } \\
\text { N.D. }\end{array}$ & $\begin{array}{l}0.005 \\
0.001 \\
0.000 \\
0.001 \\
0.001\end{array}$ \\
\hline $\begin{array}{l}\mathrm{B} \\
\mathrm{Ca} \\
\mathrm{Co} \\
\mathrm{Cb} \\
\mathrm{W} \\
\mathrm{Pb} \\
\mathrm{Se} \\
\mathrm{N}\end{array}$ & $\begin{array}{l}0.0007 \\
0.001 \\
0.19 \\
\text { N.D. } \\
\text { N.D. } \\
\text { N.D. } \\
\text { N.D. } \\
\text { N.D. }\end{array}$ & $\begin{array}{l}0.0006 \\
\text { N.D. } \\
0.06 \\
0.033 \\
0.00 \\
\text { N.D. } \\
\text { N.D. } \\
\text { N.D. }\end{array}$ & $\begin{array}{l}0.0005 \\
\text { N.D. } \\
0.09 \\
0.018 \\
0.01 \\
\text { N.D. } \\
\text { N.D. } \\
\text { N.D. }\end{array}$ & $\begin{array}{l}0.001 \\
\text { N.D. } \\
0.006 \\
0.000 \\
0.00 \\
0.00 \\
\text { N.D. } \\
\text { N.D. }\end{array}$ & $\begin{array}{l}0.0002 \\
0.0024 \\
0.12 \\
\text { N.D. } \\
0.0 \\
\text { N.D. } \\
0.00 \\
0.076\end{array}$ & $\begin{array}{l}0.0008 \\
0.0008 \\
0.013 \\
\text { N.D. } \\
0.0 \\
\text { N.D. } \\
0.00 \\
\text { N.D. }\end{array}$ & $\begin{array}{l}\text { N.D. } \\
\text { N.D. } \\
\text { N.D. } \\
\text { N.D. } \\
\text { N.D. } \\
\text { N.D. } \\
\text { N.D. } \\
\text { N.D. }\end{array}$ & $\begin{array}{l}0.0003 \\
0.0006 \\
0.002 \\
\text { N.D. } \\
\text { N.D. } \\
\text { 0.00 } \\
\text { N.D. } \\
\text { N.D. }\end{array}$ \\
\hline
\end{tabular}

(a) N.D. = Not Determined 


\subsection{Tensile Test Results}

Summary graphs and tables of the tensile test results are presented in this section. All specimens were machined parallel to the pipe axis. The exception was material AEC-C5 for which circumferential tensile test results were also available from the previous Battelle/AEC program. All tests were conducted at quasi-static loading rates. For the weld metal experiments (1.2.3.16 and 1.2.3.17) both the base metal and weld metal tensile properties are shown.

\subsubsection{6-mm (16-inch) Nominal Diameter, Schedule 30, TP304 Stainless Steel (DP2-A52)}

Threaded-end, round-bar tensile specimens, having a gage diameter of $6.35 \mathrm{~mm}(0.25 \mathrm{inch})$ and a reduced section 31.8-mm (1.25-inches) long, were machined such that the specimen axis was parallel to the axis of the pipe.

Quasi-static tensile tests were conducted at $22 \mathrm{C}, 93 \mathrm{C}$, and $288 \mathrm{C}(72,200$, and $550 \mathrm{~F})$ in a servohydraulic machine at a nominal strain rate of $3 \times 10^{-4} \mathrm{~s}^{-1}$. Strain was monitored using a 25.4 $\mathrm{mm}$ (1.0 inch) extensometer having spring-loaded ceramic arms that contacted the specimen at each end of the gage length.

Table 2.3 is a summary of the tensile properties of this 406-mm (16-inch) diameter stainless steel pipe material. Engineering and true stress-strain curves at the three test temperatures are shown in Figures 2.1 through 2.3. As can be seen in both Table 2.3 and Figures 2.1 through 2.3, there was a definite drop in both yield and ultimate strength as the test temperature was increased from $22 \mathrm{C}(72 \mathrm{~F})$ to $288 \mathrm{C}(550 \mathrm{~F})$, which is to be expected. There was also a definite decrease in fracture elongation as the test temperature was increased.

\subsubsection{2-mm (6-inch) Nominal Diameter, Schedule XXS, TP304 Stainless Steel (DP2-A35)}

As part of a previous program (Ref. 2.1), threaded-end round-bar tensile specimens were machined from Pipe DP2-A35. Each had a 6.35-mm $(0.25$-inch) diameter reduced section and was oriented such that the tensile axis was parallel to the pipe axis. An extensometer of $25.4 \mathrm{~mm}$ (1.0 inch) gage length was used to measure axial strain. Tests were conducted using a Baldwin hydraulic testing machine at a head speed that was selected to produce fracture within 10 to 20 minutes, corresponding to the approximate time to achieve crack initiation in the pipe fracture experiments. Tensile properties at 22,149 , and $288 \mathrm{C}(72,300$, and $550 \mathrm{~F})$ are given in Table 2.4 . Figure 2.4 shows the engineering stress-strain curves at $288 \mathrm{C}(550 \mathrm{~F})$ for this material. The stress-strain curves at the lower temperatures are not shown.

As with the other stainless steel materials, there was a significant reduction in the yield strength, ultimate strength, and elongation as the test temperature was increased from $22 \mathrm{C}(72 \mathrm{~F})$ to $288 \mathrm{C}$ $(550 \mathrm{~F})$. However, the reduction in elongation was not as extensive for this material as it was for the other stainless steel materials evaluated. 
Table 2.3 Tensile properties of Pipe DP2-A52, 406-mm (16-inch) diameter TP304 stainless steel pipe procured from Westinghouse Savannah River Plant

\begin{tabular}{|c|c|c|c|c|c|c|}
\hline $\begin{array}{l}\text { Specimen } \\
\text { Number }\end{array}$ & $\begin{array}{c}\text { Test } \\
\text { Temperature, } \\
\text { C (F) }\end{array}$ & & $\begin{array}{l}\text { 0.2-Percent } \\
\text { Offset Yield } \\
\text { Strength, } \\
\text { MPa (ksi) }\end{array}$ & $\begin{array}{l}\text { Ultimate } \\
\text { Tensile } \\
\text { Strength, } \\
\text { MPa (ksi) }\end{array}$ & $\begin{array}{l}\text { Elongation, } \\
\text { percent in } \\
25.4 \mathrm{~mm} \\
(1 \text { inch })\end{array}$ & $\begin{array}{c}\text { Area } \\
\text { Reduction, } \\
\text { percent }\end{array}$ \\
\hline A52-3T & $22(72)$ & & $263(38.1)$ & $644(93.4)$ & 76.0 & 78.0 \\
\hline \multirow[t]{2}{*}{ A52-4T } & $22(72)$ & & $272(39.4)$ & $646(93.7)$ & 77.0 & 77.0 \\
\hline & & Average & $268(38.8)$ & $645(93.6)$ & 76.5 & 77.5 \\
\hline A52-1T & $93(200)$ & & $223(32.3)$ & $505(73.3)$ & 64.0 & 83.0 \\
\hline \multirow[t]{2}{*}{ A52-2T } & $93(200)$ & & $225(32.6)$ & $512(74.3)$ & 61.0 & 78.0 \\
\hline & & Average & 224 (32.5) & $509(73.8)$ & 62.5 & 80.5 \\
\hline $\mathrm{A} 52-5 \mathrm{~T}$ & $288(550)$ & & $171(24.8)$ & $432(62.6)$ & 40.0 & 71.0 \\
\hline \multirow[t]{2}{*}{ A52-6T } & $288(550)$ & & $155(22.5)$ & $431(62.5)$ & 41.0 & 72.0 \\
\hline & & Average & $163(23.7)$ & $432(62.6)$ & 40.5 & 71.5 \\
\hline
\end{tabular}

Table 2.4 Tensile properties of Pipe DP2-A35, 152-mm (6-inch) nominal diameter, Schedule XXS, TP304 stainless steel pipe (Ref. 2.1)

\begin{tabular}{ccccccc}
\hline $\begin{array}{c}\text { Specimen } \\
\text { Number }\end{array}$ & $\begin{array}{c}\text { Test } \\
\text { Temperature } \\
\text { C (F) }\end{array}$ & & $\begin{array}{c}\text { 0.2-Percent } \\
\text { Offset Yield } \\
\text { Strength, } \\
\text { MPa (ksi) }\end{array}$ & $\begin{array}{c}\text { Ultimate } \\
\text { Tensile } \\
\text { Strength, } \\
\text { MPa (ksi) }\end{array}$ & $\begin{array}{c}\text { Elongation, } \\
\text { percent in } \\
\text { 25.4 mm } \\
\text { (1 inch) }\end{array}$ & $\begin{array}{c}\text { Area } \\
\text { Reduction, } \\
\text { percent }\end{array}$ \\
\hline A35-1 & $24(75)$ & & $259(37.5)$ & $634(92.0)$ & 79.9 & 81.7 \\
A35-2 & $24(75)$ & & $245(35.5)$ & $629(91.2)$ & 77.9 & 79.5 \\
& & Average & $252(36.5)$ & $632(91.6)$ & 78.9 & 80.6 \\
A35-3 & & & & & & \\
A34-4 & $149(300)$ & & $181(26.2)$ & $487(70.6)$ & 54.8 & 80.3 \\
& $149(300)$ & & $183(26.6)$ & $492(71.3)$ & 55.8 & 81.7 \\
& & Average & $182(26.4)$ & $490(71.0)$ & 55.3 & 81.0 \\
A35-5 & & & & & & \\
A35-6 & $288(550)$ & & $150(21.8)$ & $485(70.3)$ & 47.5 & 73.0 \\
& $288(550)$ & & $151(21.9)$ & $470(68.1)$ & 49.5 & 77.0 \\
& & Average & $151(21.9)$ & $478(69.2)$ & 48.5 & 75.0 \\
\hline
\end{tabular}




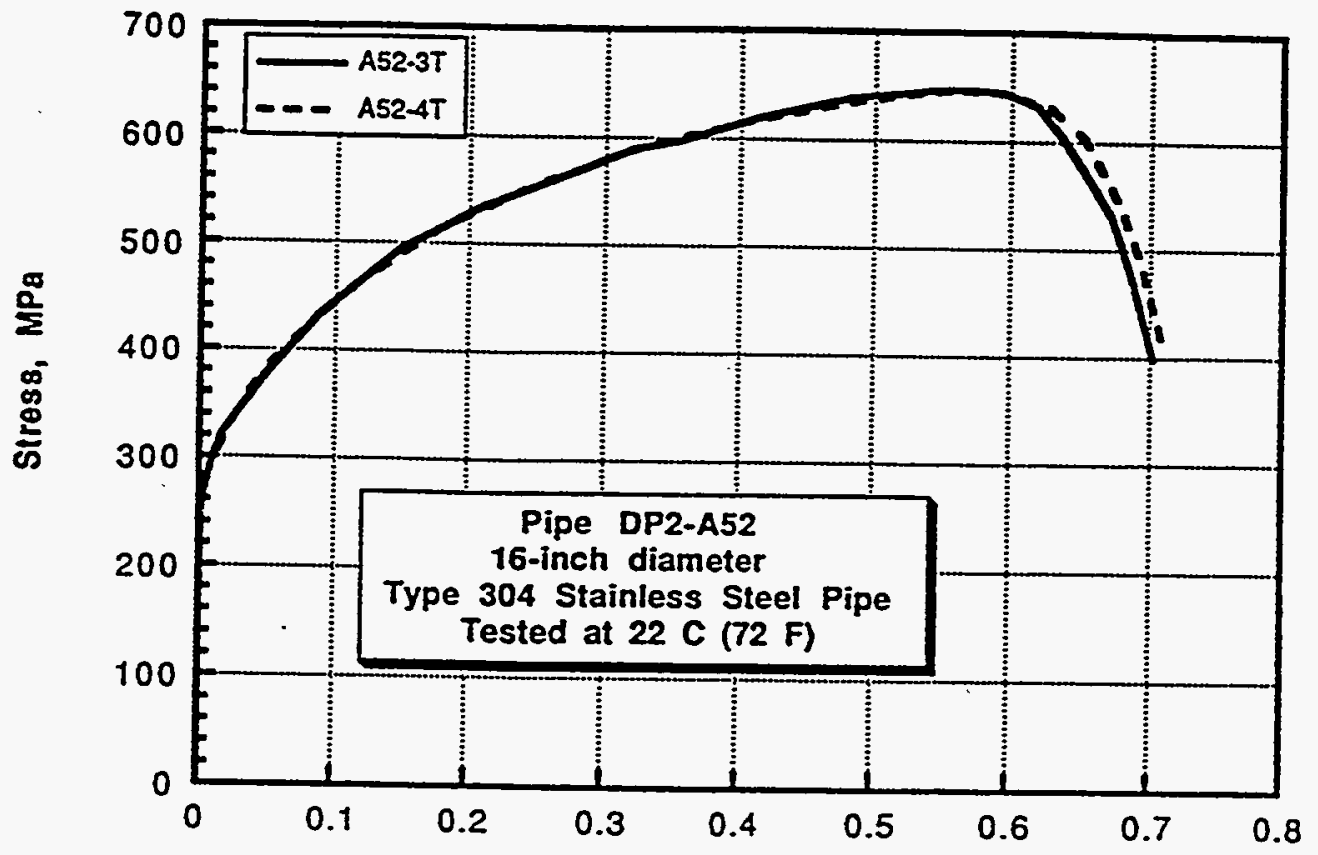

(a) Engineering stress-strain

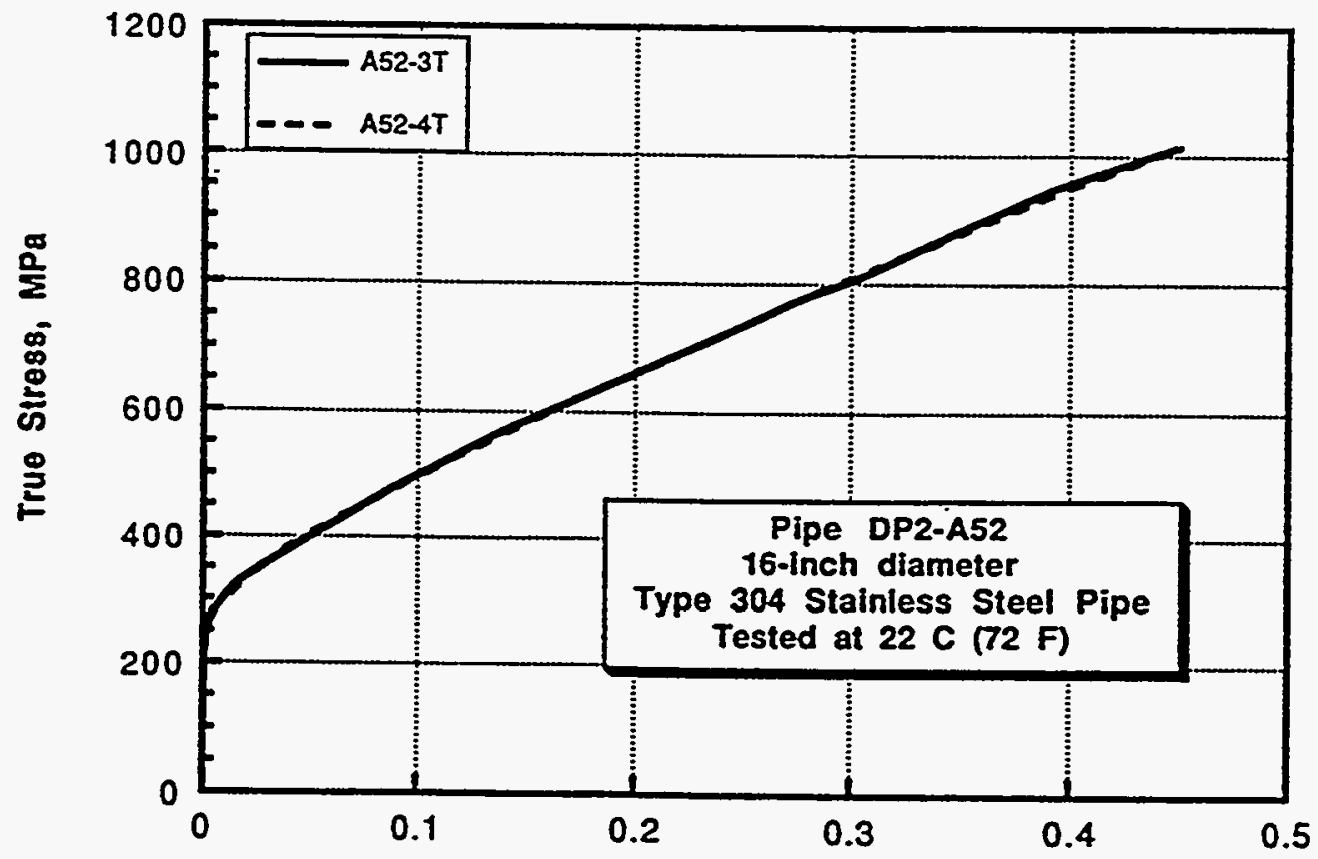

(b) True stress-strain

Figure 2.1 Stress-strain curves at $22 \mathrm{C}(72 \mathrm{~F})$ for tensile specimens machined from Pipe DP2-A52 (TP304) 


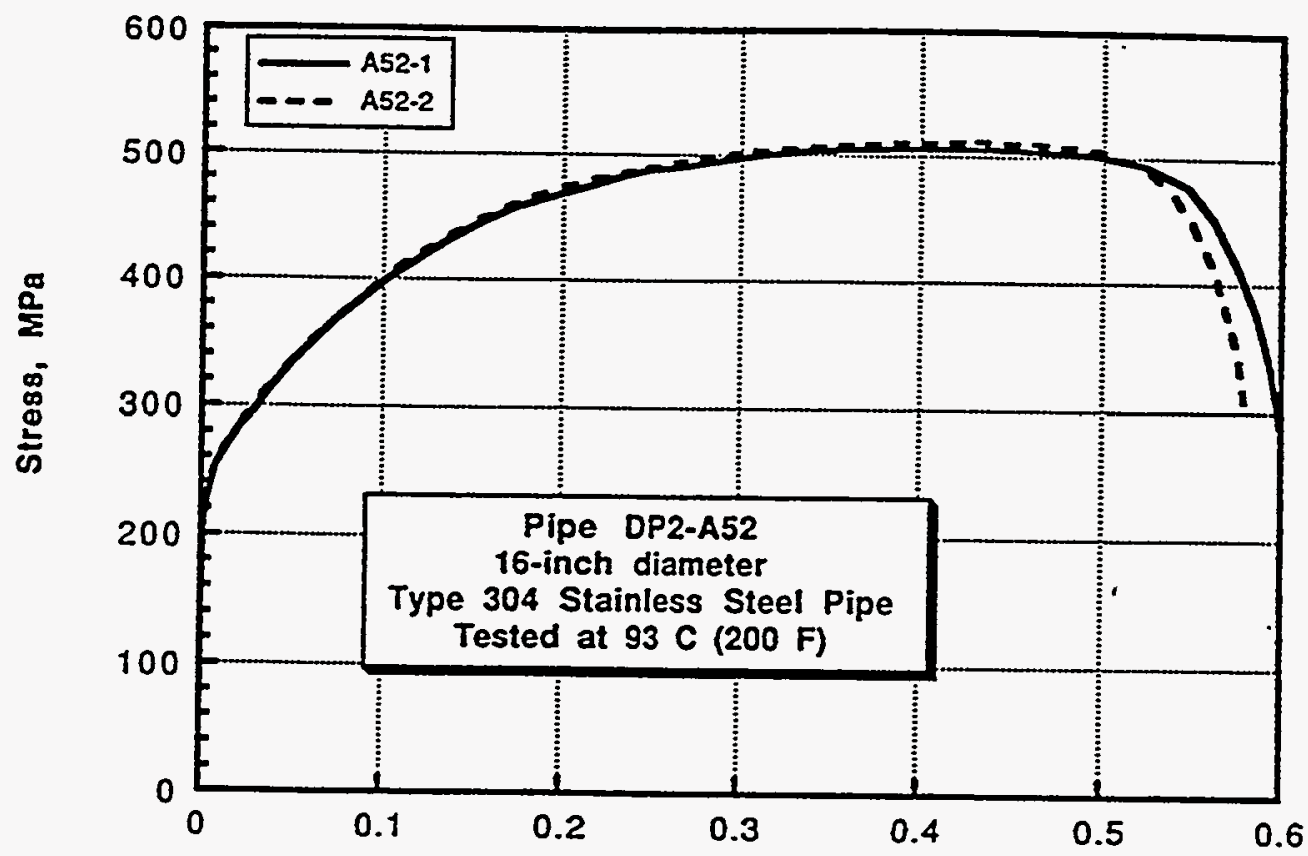

(a) Engineering stress-strain

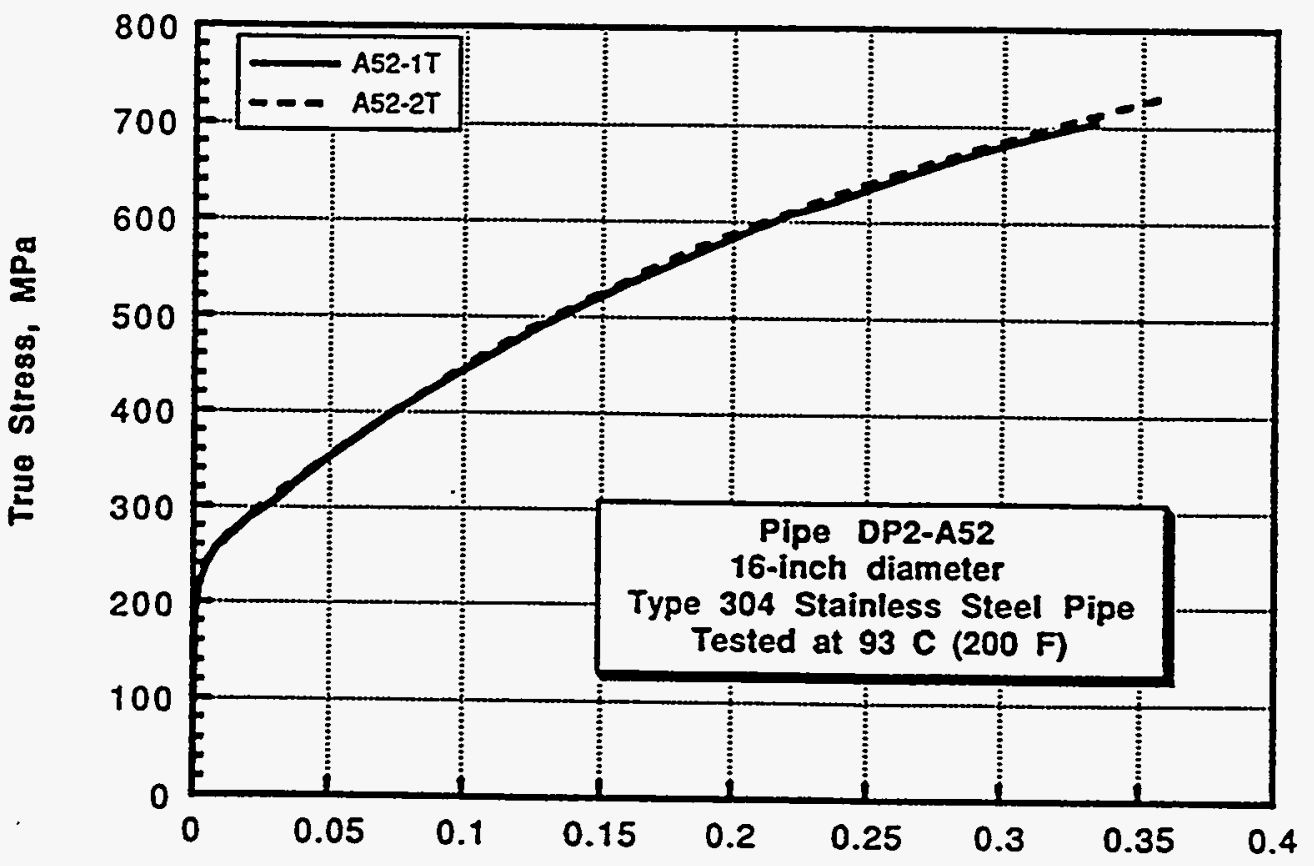

(b) True stress-strain

Figure 2.2 Stress-strain curves at $93 \mathrm{C}(200 \mathrm{~F})$ for tensile specimens machined from Pipe DP2-A52 (TP304) 


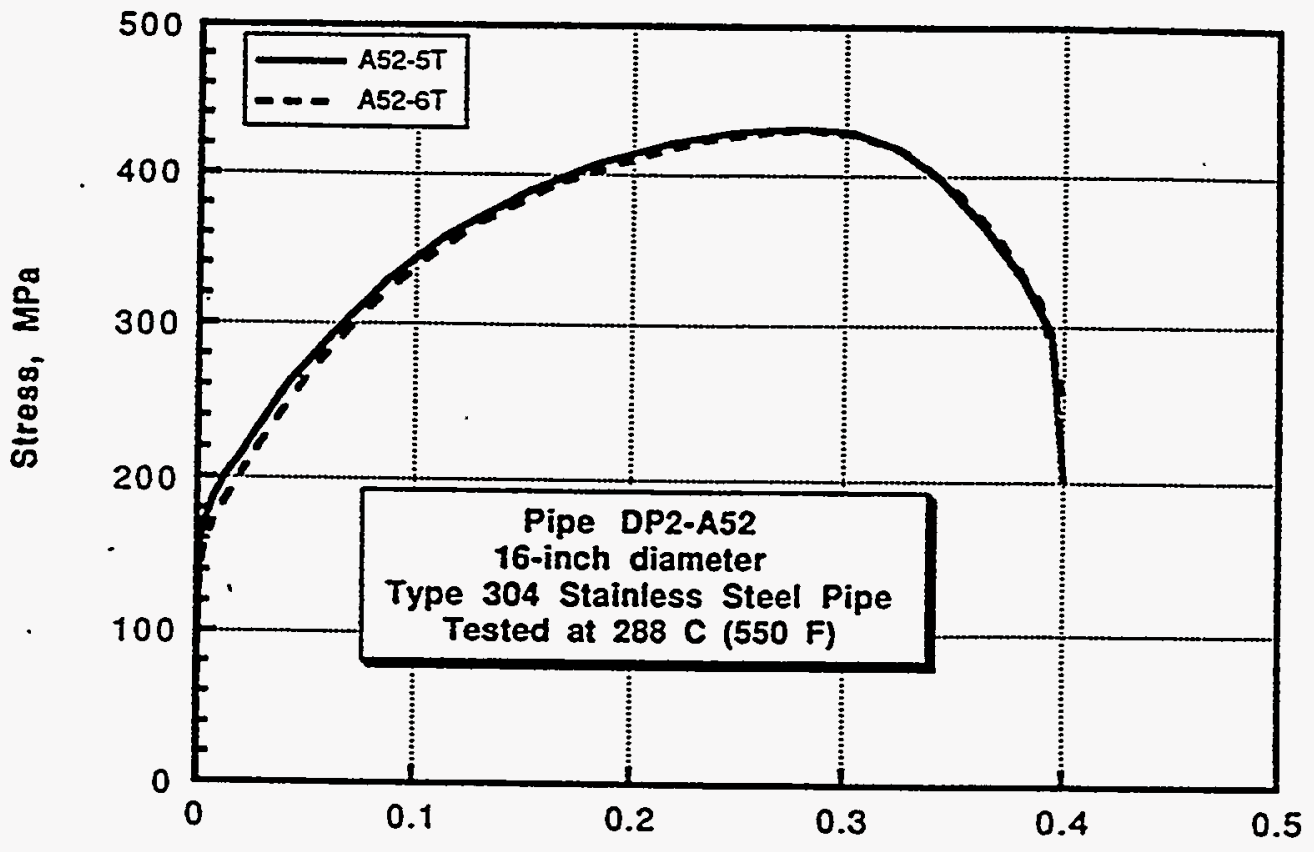

(a) Engineering stress-strain

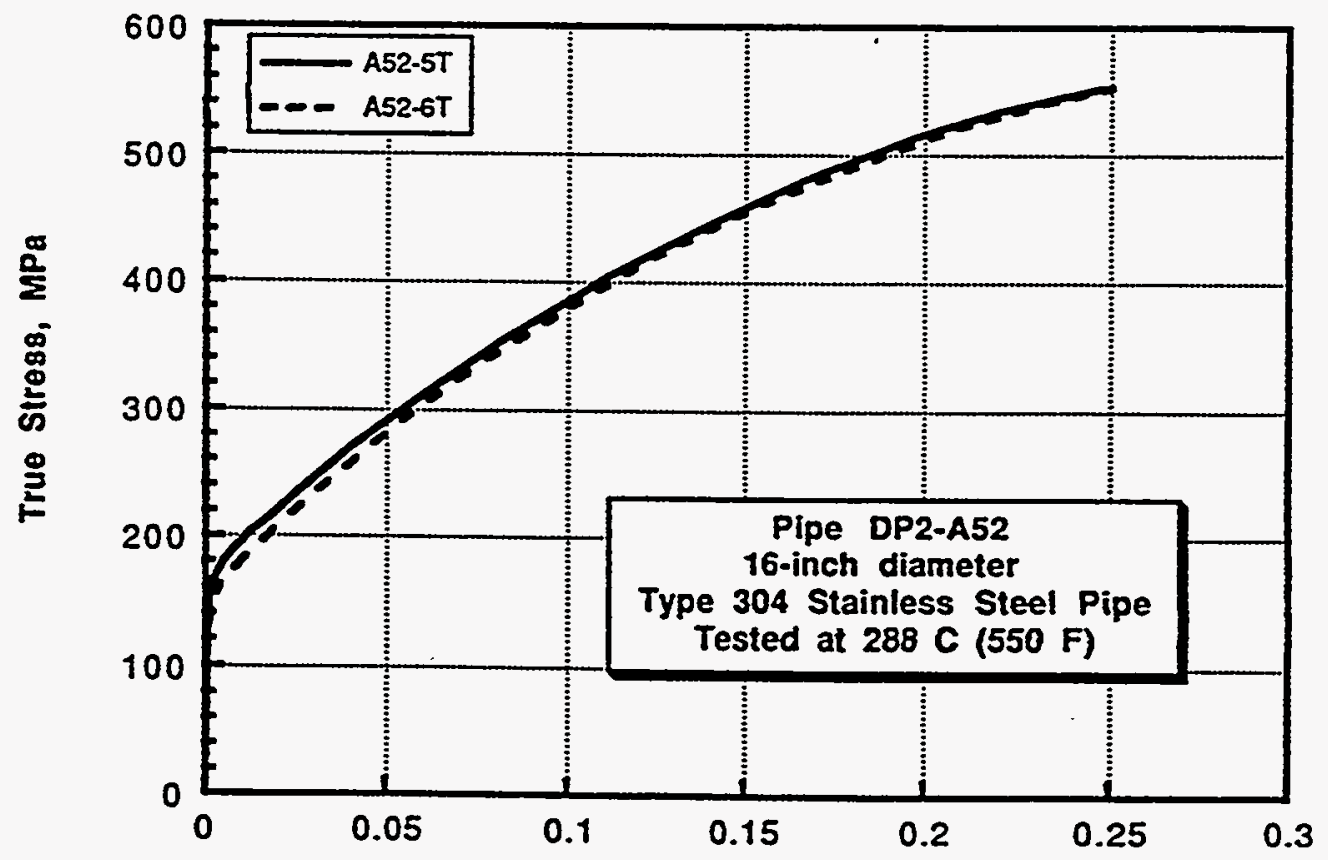

(b) True stress-strain

Figure 2.3 Stress-strain curves at $288 \mathrm{C}(550 \mathrm{~F})$ for tensile specimens machined from Pipe DP2-A52 (TP304) 


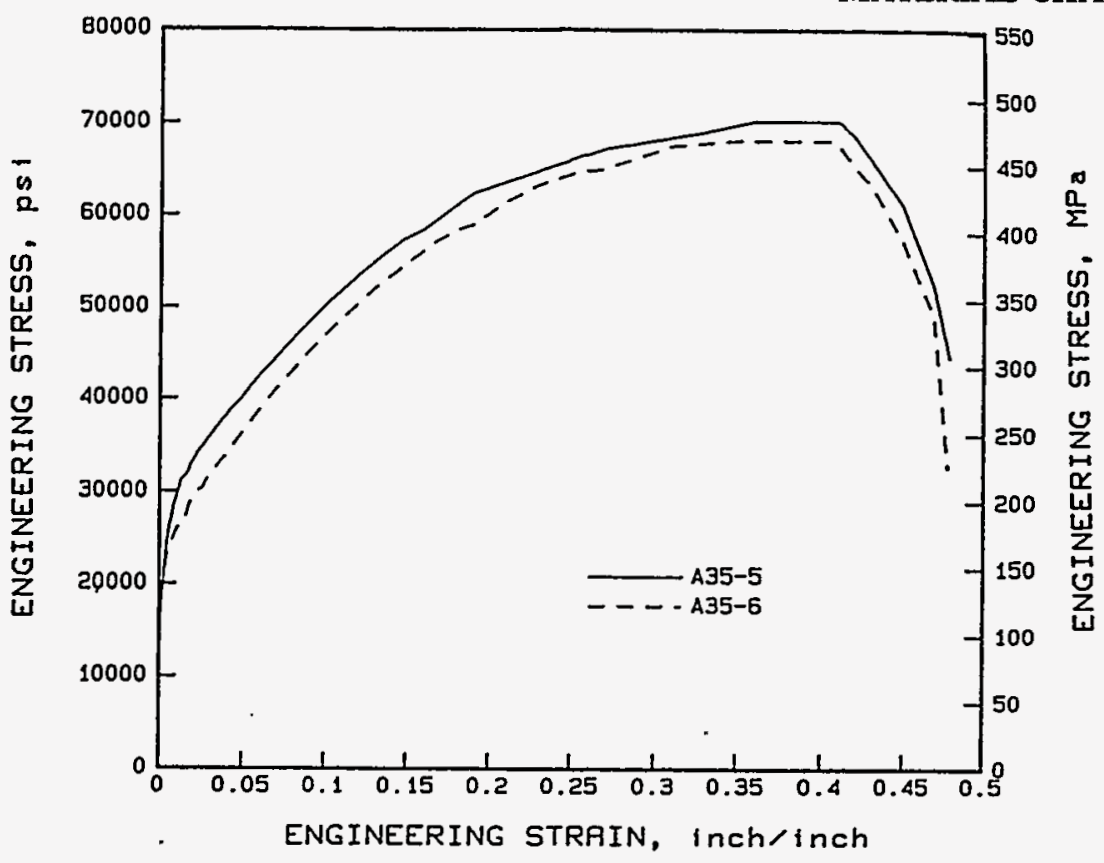

Figure 2.4 Engineering stress-strain curves for Pipe DP2-A35 (TP304) at $288 \mathrm{C}$ (550 F) (Ref. 2.1)

\subsubsection{2-mm (6-inch) Nominal Diameter, Schedule 40, TP304 Stainless Steel (DP2-A7)}

Tensile tests on this steel were conducted at Materials Engineering Associates (MEA) as part of a previous program (Ref. 2.2), using threaded-end round-bar specimens. Each bar had a 2.87-mm (0.113-inch) diameter reduced section and was oriented such that the tensile axis was parallel to the pipe axis. An extensometer of $12.7-\mathrm{mm}$ (0.5-inch) gage length was used to measure axial strain. Tensile properties at 22,149 , and $288 \mathrm{C}(72,300$, and $550 \mathrm{~F})$ are given in Table 2.5 .

Figure 2.5 shows the engineering stress-strain curves up to the onset of necking at $288 \mathrm{C}$ (550 F) for this material. For strains beyond necking, and possibly for strains prior to neck formation, problems were experienced with extensometer slippage because of the large amounts of diametral contraction. As with the other stainless steel materials, there was a significant reduction in the yield strength, ultimate strength, and elongation as the test temperature was increased from $22 \mathrm{C}(72 \mathrm{~F})$ to $288 \mathrm{C}$ (550 F).

\subsubsection{SA155-KC60-Class 1 (A515 Grade 60) Carbon Steel (DP2-F26)}

As part of a previous program (Ref. 2.1), round-bar tensile specimens were machined from a section of the A515 Grade 60 carbon steel pipe material (DP2-F26) and used to conduct quasi-static tensile tests at room temperature, $149 \mathrm{C}(300 \mathrm{~F})$, and $288 \mathrm{C}(550 \mathrm{~F})$. The tensile tests were conducted using a Baldwin hydraulic testing machine at a cross head speed selected to produce fracture within 10 to 20 minutes, corresponding to the approximate times to achieve crack initiation in the pipe fracture experiments. The results of those tests are summarized in Table 2.6. 
Table 2.5 Tensile properties of Pipe DP2-A7, 152-mm (6-inch) nominal diameter, Schedule 40, TP304 stainless steel pipe (Ref. 2.2)

(Specimens were fabricated and tested by Materials Engineering Associates)

\begin{tabular}{|c|c|c|c|c|c|c|c|}
\hline $\begin{array}{c}\text { Specimen } \\
\text { Number }\end{array}$ & $\begin{array}{r}\mathrm{T} \\
\text { Tempe } \\
\mathbf{C}\end{array}$ & $\begin{array}{l}\text { est } \\
\text { rrature, } \\
\text { (F) }\end{array}$ & & $\begin{array}{c}\text { 0.2-Percent } \\
\text { Offset Yield } \\
\text { Strength, } \\
\text { MPa (ksi) }\end{array}$ & $\begin{array}{c}\text { Ultimate } \\
\text { Tensile } \\
\text { Strength, } \\
\text { MPa (ksi) }\end{array}$ & $\begin{array}{l}\text { Elongation, } \\
\text { percent in } \\
25.4 \mathrm{~mm} \\
(1 \text { inch })\end{array}$ & $\begin{array}{c}\text { Area } \\
\text { Reduction, } \\
\text { percent }\end{array}$ \\
\hline ZP12-9L & 26.7 & (80) & & $194(28.2)$ & $595(86.3)$ & 75.4 & 79.7 \\
\hline \multirow[t]{2}{*}{ ZP12-14L } & 26.1 & (79) & & $238(34.5)$ & $594(86.1)$ & 84.8 & 79.7 \\
\hline & & & Average & $216(31.4)$ & $594(86.2)$ & 80.1 & 79.7 \\
\hline ZP12-10L & 149 & $(300)$ & & $177(25.6)$ & $464(67.3)$ & 54.0 & 77.2 \\
\hline \multirow[t]{2}{*}{ ZP12-15L } & 149 & $(300)$ & & $174(25.3)$ & $467(67.8)$ & 56.4 & 78.9 \\
\hline & & & Average & $176(25.5)$ & $466(67.6)$ & 55.2 & 78.1 \\
\hline ZP12-12L & 288 & (550) & & $148(21.4)$ & $445(64.6)$ & 40.8 & 60.5 \\
\hline ZP12-16L & 288 & $(550)$ & & - & $447(64.9)$ & 41.4 & 60.5 \\
\hline \multirow[t]{2}{*}{ ZP12-11L } & 288 & (550) & & $146(21.2)$ & $454(65.8)$ & 48.0 & 69.9 \\
\hline & & & Average & $147(21.3)$ & $449(65.1)$ & 43.3 & 63.6 \\
\hline
\end{tabular}




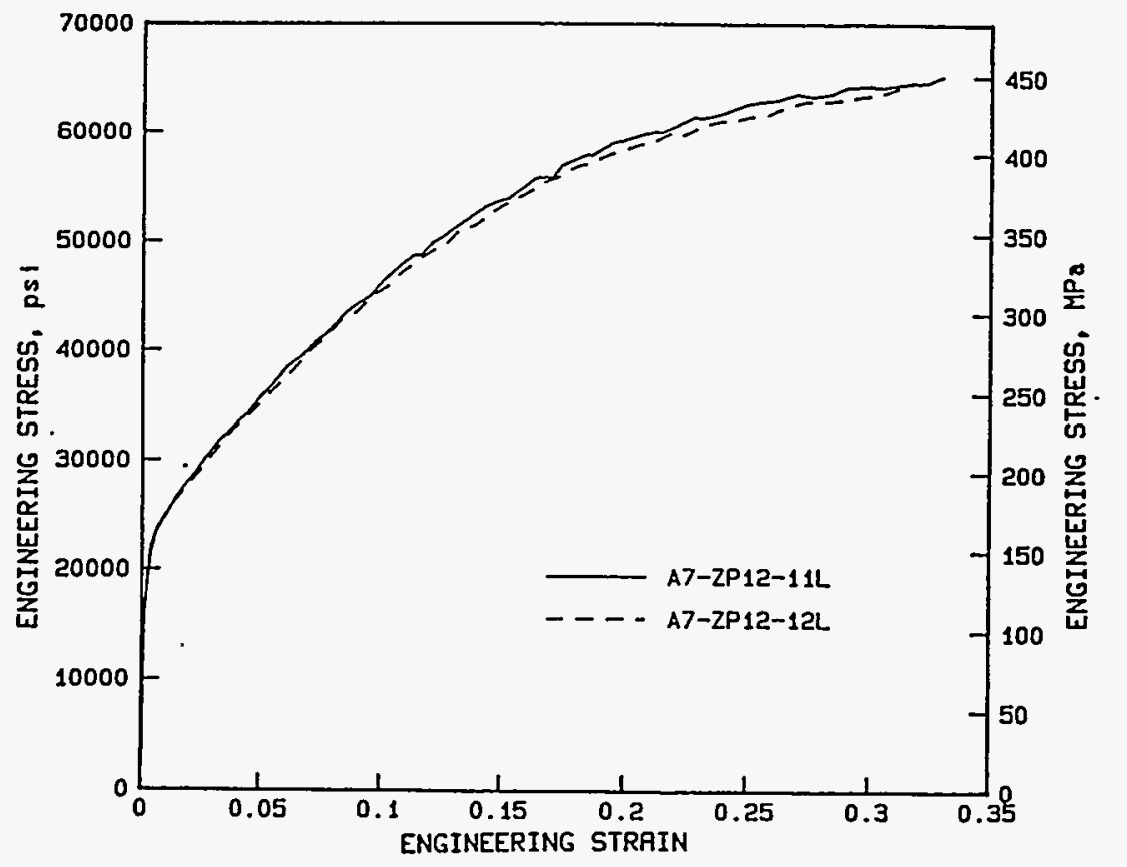

Figure 2.5 Engineering stress-strain curves for Pipe DP2-A7 (TP304) at 288 C (550 F) (Ref. 2.2)

Table 2.6 Tensile properties of Pipe DP2-F26, 711-mm (28-inch) diameter SA155-KC60-Class 1 (A515 Grade 60) carbon steel pipe (Ref. 2.1)

\begin{tabular}{|c|c|c|c|c|c|c|}
\hline $\begin{array}{c}\text { Specimen } \\
\text { Number }\end{array}$ & $\begin{array}{c}\text { Test } \\
\text { Temperature, } \\
\text { C (F) } \\
\end{array}$ & . & $\begin{array}{c}\text { 0.2-Percent } \\
\text { Offset Yield } \\
\text { Strength, } \\
\text { MPa (ksi) } \\
\end{array}$ & $\begin{array}{c}\text { Ultimate Tensile } \\
\text { Strength, } \\
\text { MPa (ksi) }\end{array}$ & $\begin{array}{c}\text { Elongation, } \\
\text { percent in } \\
25.4 \mathrm{~mm} \\
(1 \mathrm{inch})\end{array}$ & $\begin{array}{c}\text { Area } \\
\text { Reduction, } \\
\text { percent }\end{array}$ \\
\hline F26-1 & $22(72)$ & & $276(40.1)$ & $440(63.9)$ & 31.2 & 69.0 \\
\hline \multirow[t]{2}{*}{ F26-2 } & $22(72)$ & & $262(38.0)$ & $436(63.3)$ & 37.2 & 70.0 \\
\hline & & Average & $269(39.1)$ & $438(63.6)$ & 34.3 & 69.5 \\
\hline F26-3 & $149(300)$ & & $270(39.2)$ & $524(76.1)$ & 22.5 & 53.1 \\
\hline \multirow[t]{2}{*}{$F 26-4$} & $149(300)$ & & 266 (38.6) & $527(76.5)$ & 23.0 & 50.1 \\
\hline & & Average & $268(38.9)$ & $526(76.3)$ & 22.8 & 51.6 \\
\hline F26-5 & $288 \quad(550)$ & & $231(33.5)$ & $541(78.6)$ & 30.5 & 54.1 \\
\hline \multirow[t]{2}{*}{ F26-6 } & $288(550)$ & & $230(33.4)$ & $545(79.1)$ & 29.0 & 53.1 \\
\hline & & Average & $231(33.5)$ & $543(78.9)$ & 29.8 & 53.6 \\
\hline
\end{tabular}


Figure 2.6 shows engineering stress-strain curves from tensile tests for this carbon steel at $288 \mathrm{C}$ $(550 \mathrm{~F})$. This steel did not exhibit the pronounced serrations on the stress-strain curves at this temperature/strain rate condition that have been observed for other carbon steel materials. These serrations are typically attributed to dynamic strain aging effects (Ref. 2.3). The absence of serrations in Figure 2.6 indicates that this material may not be susceptible to dynamic strain aging at these temperatures and strain-rate conditions. However, as will be discussed later, the $288 \mathrm{C}$ $(550 \mathrm{~F})$, quasi-static fracture toughness tests for this material did exhibit distinct periods of unstable crack growth, which were attributed to dynamic strain aging effects. One possible explanation for this apparent discrepancy is that the strain rate at the crack tip for the nominal quasi-static fracture toughness tests may have been sufficiently higher than the nominal strain rate for the quasi-static tensile tests that the material was transistioning into a temperature/strain-rate regime for which it was more susceptible to dynamic strain aging effects.

\subsubsection{TP31ட Stainless Steel (DP2-A51) and Associated Submerged-Arc Weld}

As part of this program, round-bar tensile specimens were machined from a section of the TP316L stainless steel pipe material (DP2-A51) and subjected to quasi-static tensile tests at room temperature and $288 \mathrm{C}(550 \mathrm{~F})$.

Tensile properties for this stainless steel base metal material (DP2-A51) are summarized in Table 2.7. Figure 2.7 shows the engineering stress-strain curves for this stainless steel base metal material. As evident in Table 2.7 and Figure 2.7, the higher test temperature caused a dramatic decrease in both the strength (yield and ultimate) and ductility (fracture elongation and reduction in area) for this stainless steel material. Strength decreases are the expected result of increased test temperature. However, the reason for the decrease in fracture elongation and reduction in area as temperature was raised is unknown. The reduction in both was too large to be attributed to experimental scatter.

As part of this and two previous programs (Refs. 2.1 and 2.4), round-bar tensile specimens were machined from sections of stainless steel submerged-arc welds and subjected to quasi-static tensile tests at room temperature and $288 \mathrm{C}(550 \mathrm{~F})$. Tensile specimens were machined and tested from three different welds, made at three different times. The weld procedures for each weld were nominally the same as used in the pipe experiments. Two of the welds were fabricated in flat plates (DP2-A45W1 and DP2-A45W2) and one was fabricated in a section of 16-inch nominal diameter Schedule 100 stainless steel pipe (DP2-A8W4).

Tensile properties for these stainless steel welds are summarized in Table 2.7. Figures 2.8 through 2.10 show the engineering stress-strain curves for these three welds. (Note, only $288 \mathrm{C}$ [550 F] tensile data were generated for Welds DP2-A45W1 and DP2-A8W4.) As can be seen in Table 2.7 and Figure 2.9 there was a decrease in strength (especially ultimate strength) and elongation with increasing test temperature. Of further note from Table 2.8 is the fact that there was significant scatter in the $288 \mathrm{C}(550 \mathrm{~F})$ tensile data from one weld to another. Additionally, the yield strength of Weld DP2-A8W4 was 42 percent less than the yield strength for Weld DP2-A45W2. 


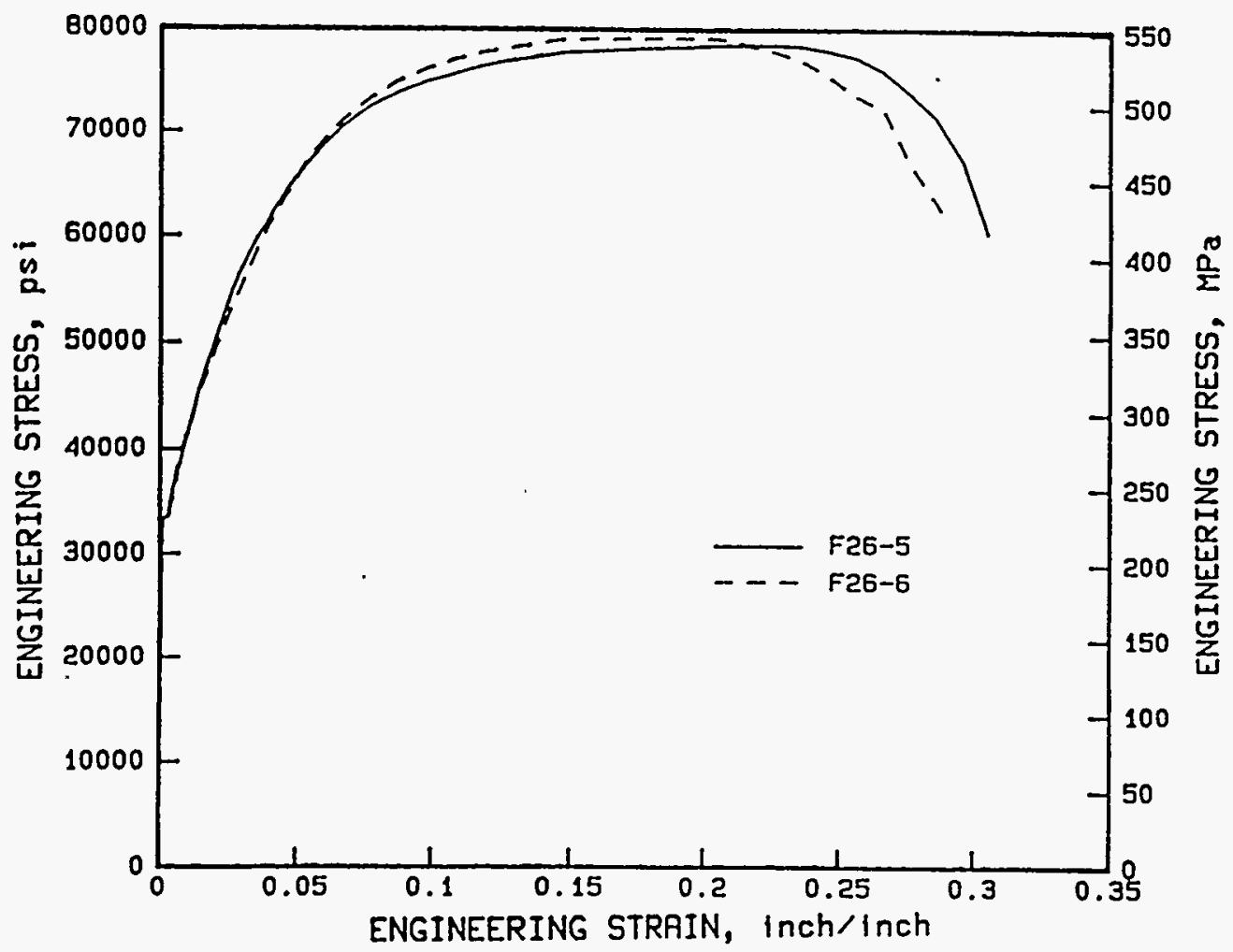

Figure 2.6 Stress-strain curves for Pipe DP2-F26 (A515 Grade 60) at 288 C (550 F) (Ref. 2.1)

Table 2.7 Tensile properties of Pipe DP2-A51, 711-mm (28-inch) diameter TP316L stainless steel pipe

\begin{tabular}{cccccc}
\hline Specimen & $\begin{array}{c}\text { Test } \\
\text { Temperature, } \\
\text { C (F) }\end{array}$ & $\begin{array}{c}\text { 0.2-Percent } \\
\text { Offset Yield } \\
\text { Strength, } \\
\text { MPa (ksi) }\end{array}$ & $\begin{array}{c}\text { Utimate Tensile } \\
\text { Strength, } \\
\text { MPa (ksi) }\end{array}$ & $\begin{array}{c}\text { Elongation, } \\
\text { percent in } \\
\text { 25.4 mm } \\
\text { (1 inch) }\end{array}$ & $\begin{array}{c}\text { Area } \\
\text { Reduction, } \\
\text { percent }\end{array}$ \\
\hline A51-1 & $20(68)$ & $254(36.9)$ & N.D. ${ }^{(a)}$ (N.D.) & 79.0 & 82.8 \\
A51-2 & $20(68)$ & $263(38.1)$ & $597(86.6)$ & 79.0 & 83.9 \\
A51-4 & $288(550)$ & $143(20.8)$ & $427(62.0)$ & 38.4 & 70.8 \\
\hline
\end{tabular}

(a) N.D. $=$ Not Determined 


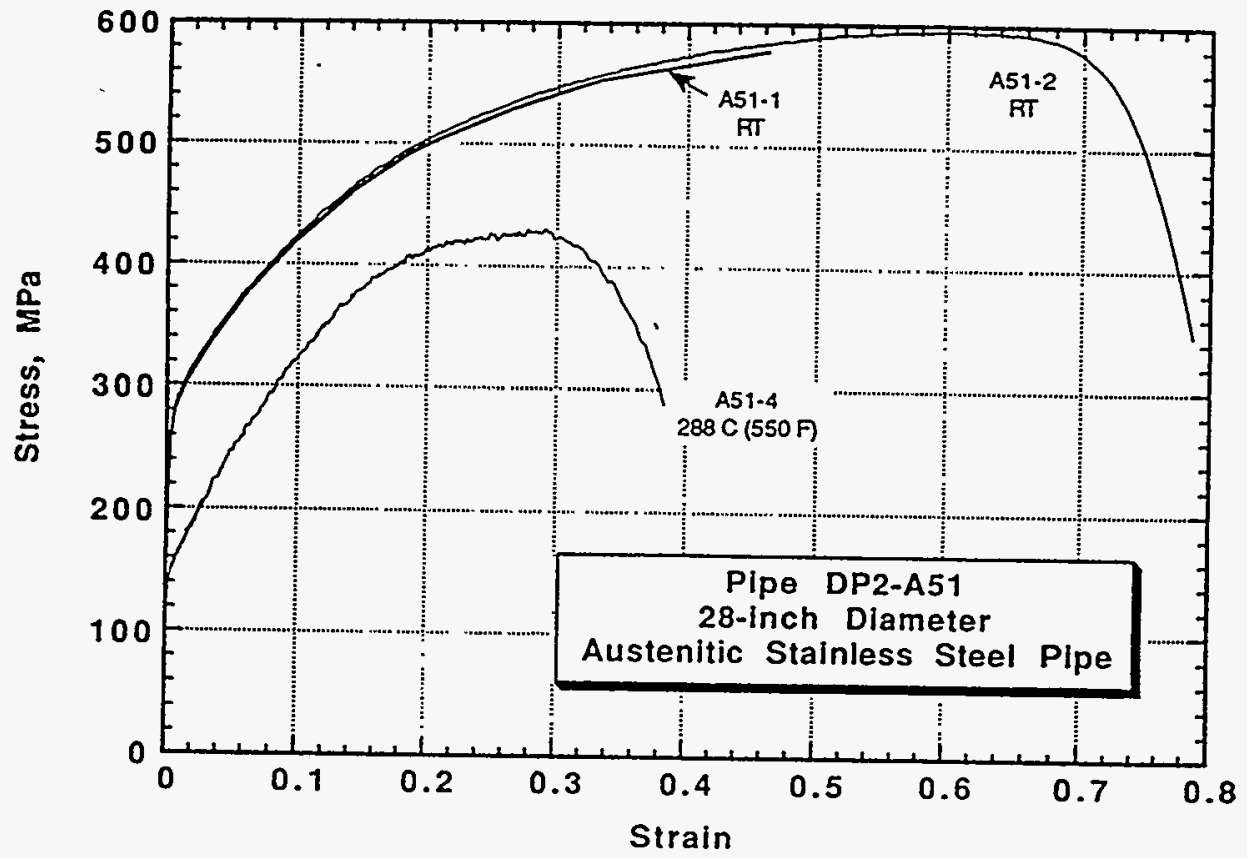

Figure 2.7 Engineering stress-strain curves for tensile specimens machined from Pipe DP2-A51 (TP316L) at $20 \mathrm{C} \mathrm{(68} \mathrm{F)} \mathrm{and} 288 \mathrm{C}$ (550 F)

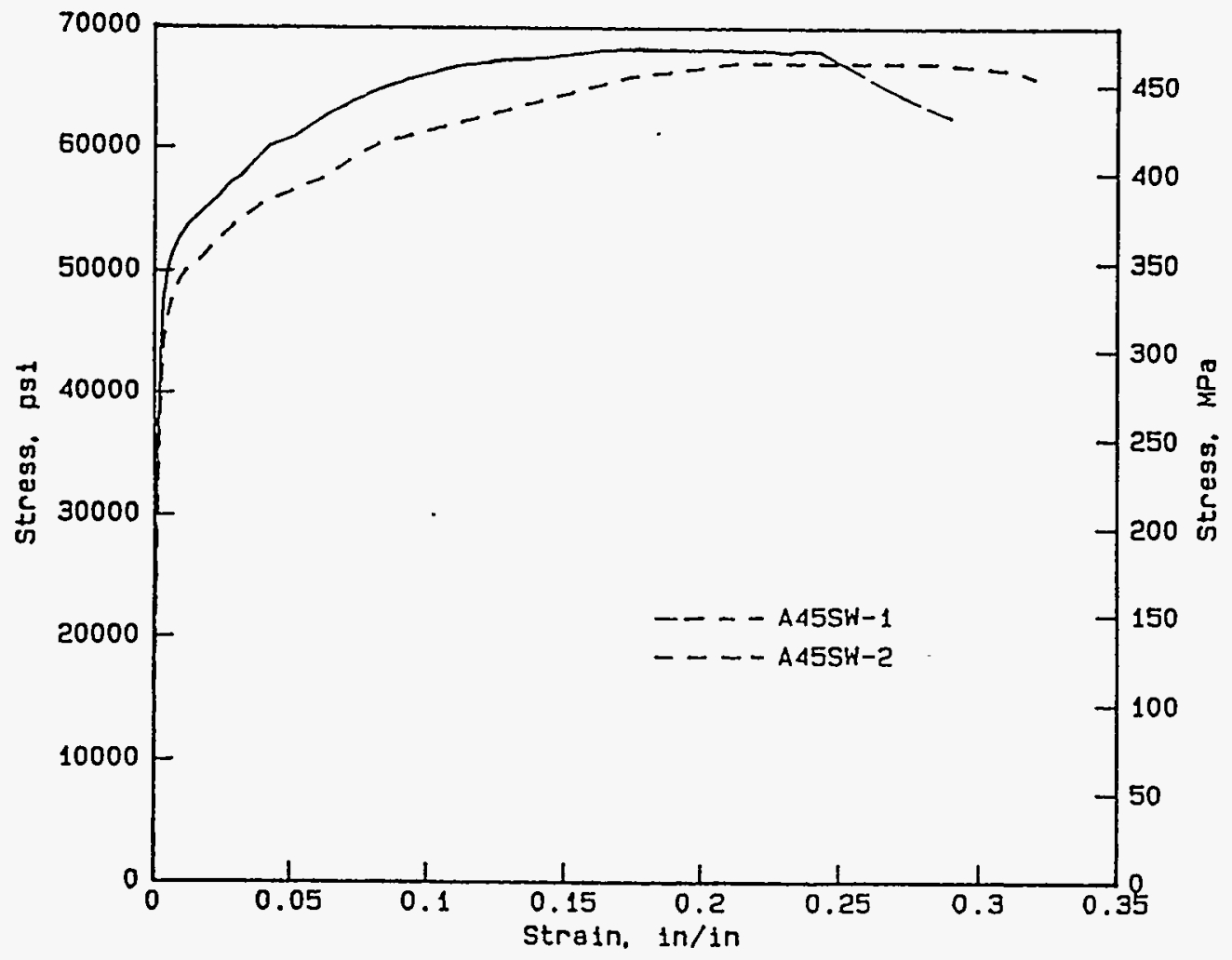

Figure 2.8 Engineering stress-strain curves at $288 \mathrm{C}(550 \mathrm{~F})$ for a submerged-arc weld (DP2-A45W1) in TP304 stainless steel plate (Ref. 2.1) 


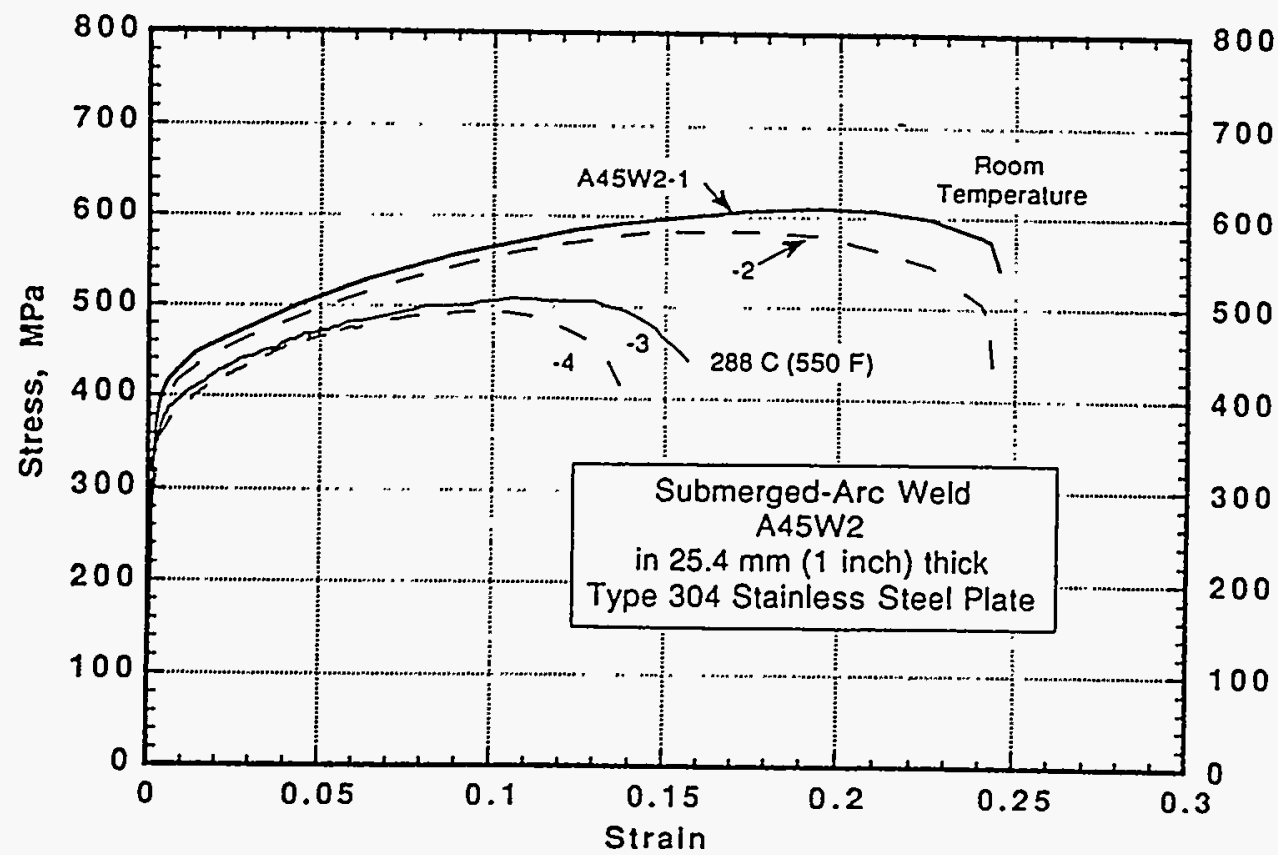

Figure 2.9 Engineering stress-strain curves at $288 \mathrm{C}$ (550 F) for a submerged-arc weld (DP2-A45W2) in TP304 stainless steel plate (Ref. 2.1)

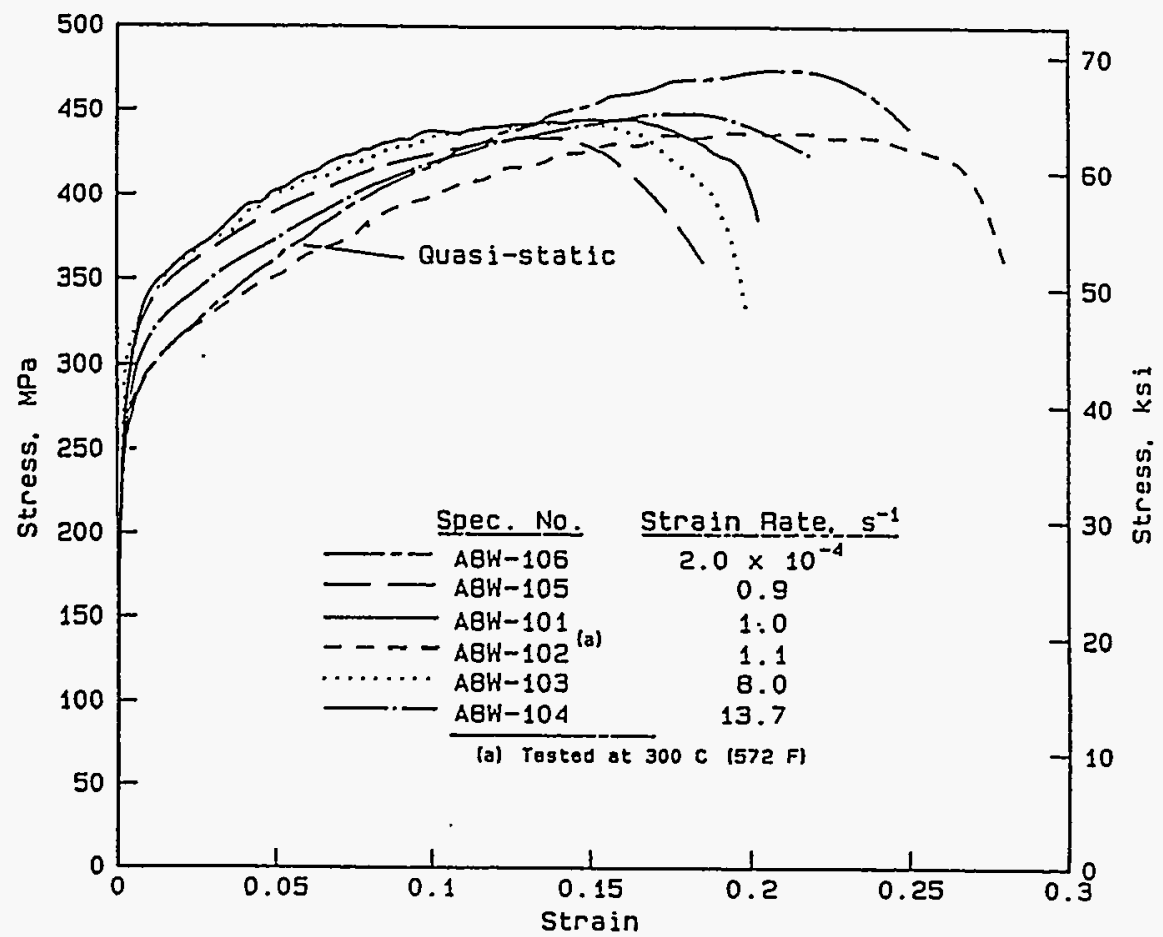

Figure 2.10 Engineering stress-strain curves at $288 \mathrm{C}$ (550 $\mathrm{F}$ ) for a submerged-arc weld (DP2-A8W4) in a TP304 stainless steel pipe, tested at several different strain rates (Ref. 2.4) 
Table 2.8 Summary table showing the average yield and ultimate strength values for quasi-static testing rates for stainless steel SAW Welds DP2-A45W1, DP2-A45W2, and DP2-A8W4 at $288 \mathrm{C}(550 \mathrm{~F})$

\begin{tabular}{lllcc}
\hline $\begin{array}{l}\text { Weld } \\
\text { Identification }\end{array}$ & $\begin{array}{l}\text { Plate or } \\
\text { Pipe Weld }\end{array}$ & $\begin{array}{l}\text { Program Which } \\
\text { Developed Data }\end{array}$ & $\begin{array}{c}\text { 0.2-Percent Offset } \\
\text { Yield Strength, } \\
\text { MPa (ksi) }\end{array}$ & $\begin{array}{c}\text { Ultimate Tensile } \\
\text { Strength, } \\
\text { MPa (ksi) }\end{array}$ \\
\hline DP2-A45W1 & Plate & Degraded Piping & $325(47.1)^{(a)}$ & $466(67.6)^{(a)}$ \\
DP2-A45W2 & Plate & Short Cracks & $366(53.1)^{(a)}$ & $503\left(72.9\left(^{(a)}\right.\right.$ \\
DP2-A8W4 & Pipe & IPIRG-1 & $258(37.4)^{(b)}$ & $469(68.0)^{(b)}$ \\
& & Average & $316(45.9)$ & $479(69.5)$ \\
\hline
\end{tabular}

(a) Round bar tensile specimen with 19-mm (0.75-inch) gage section made up of entirely weld metal.

(b) Flat, pin-loaded tensile specimens with a 20.3-mm (0.8-inch) gage section made up of entirely weld metal.

\subsubsection{A106 Grade B Carbon Steel and Associated Submerged-Arc Weld}

Longitudinal tensile properties were measured as part of this program using a $133 \mathrm{kN}$ (30 kip) electromechanical test machine. (Circumferential tensile tests had been conducted in a previous Battelle/AEC program.) The longitudinal tensile tests were performed in air at $288 \mathrm{C}(550 \mathrm{~F})$ at a crosshead speed of $0.13 \mathrm{~mm} / \mathrm{sec}(0.03 \mathrm{in} / \mathrm{min})$.

Tensile properties for this carbon steel base metal material (AEC-C5) are summarized in Table 2.9. Figure 2.11 shows the engineering and true stress-strain curves up to the onset of necking at $288 \mathrm{C}$ $(550 \mathrm{~F})$ for this carbon steel base metal material. For strains beyond necking and possibly for strains prior to neck formation, problems were experienced with extensometer slippage because of large amounts of diametral contraction. As was the case for the A515 Grade 60 carbon steel material evaluated in Experiment 1.2.3.15 (DP2-F26), this material did not exhibit the pronounced serrations on the stress-strain curves at this temperature/strain rate condition that are typical of materials sensitive to dynamic strain aging effects (Ref. 2.1).

Round-bar tensile specimens were machined from a section of a carbon steel submerged-arc weld and subjected to quasi-static tensile tests at room temperature and $288 \mathrm{C}(550 \mathrm{~F})$. The weld for the flat plate (DP2-F49W) and the pipe experiment were fabricated at the same time. 
Table 2.9 Summary of tensile data for Pipe AEC-C5, 610-mm (24-inch) diameter A106 Grade B carbon steel pipe

\begin{tabular}{lcccc}
\hline Specimen & $\begin{array}{c}\text { Temperature, } \\
\text { C (F) }\end{array}$ & $\begin{array}{c}\text { Yield Strength, } \\
\text { MPa (ksi) }\end{array}$ & $\begin{array}{c}\text { Ultimate Strength, } \\
\text { MPa (ksi) }\end{array}$ & $\begin{array}{c}\text { Elongation, } \\
\text { percent }\end{array}$ \\
\hline L-5T1 & $288(550)$ & $220(31.9)$ & $545(79.0)$ & 27.0 \\
C-5T2 & $288(550)$ & $248(36.0)$ & $539(78.1)$ & 28.0 \\
& & Circumferential & \\
End A & $21(70)$ & $309(44.9)$ & $506(73.4)$ & $35.0(\mathrm{a})$ \\
End A & $149(300)$ & $240(34.8)$ & $528(76.7)$ & 22.5 \\
End A & $316(600)$ & $230(33.4)$ & $528(76.6)$ & 29.5 \\
End D & $21(70)$ & $302(43.8)$ & $505(73.3)$ & 37.8 \\
End D & $149(300)$ & $268(38.9)$ & $562(81.5)$ & 18.9 \\
End D & $316(600)$ & $218(31.7)$ & $546(79.3)$ & 24.5 \\
\hline
\end{tabular}

(a) 50.8-mm (2-inch) gage section. 


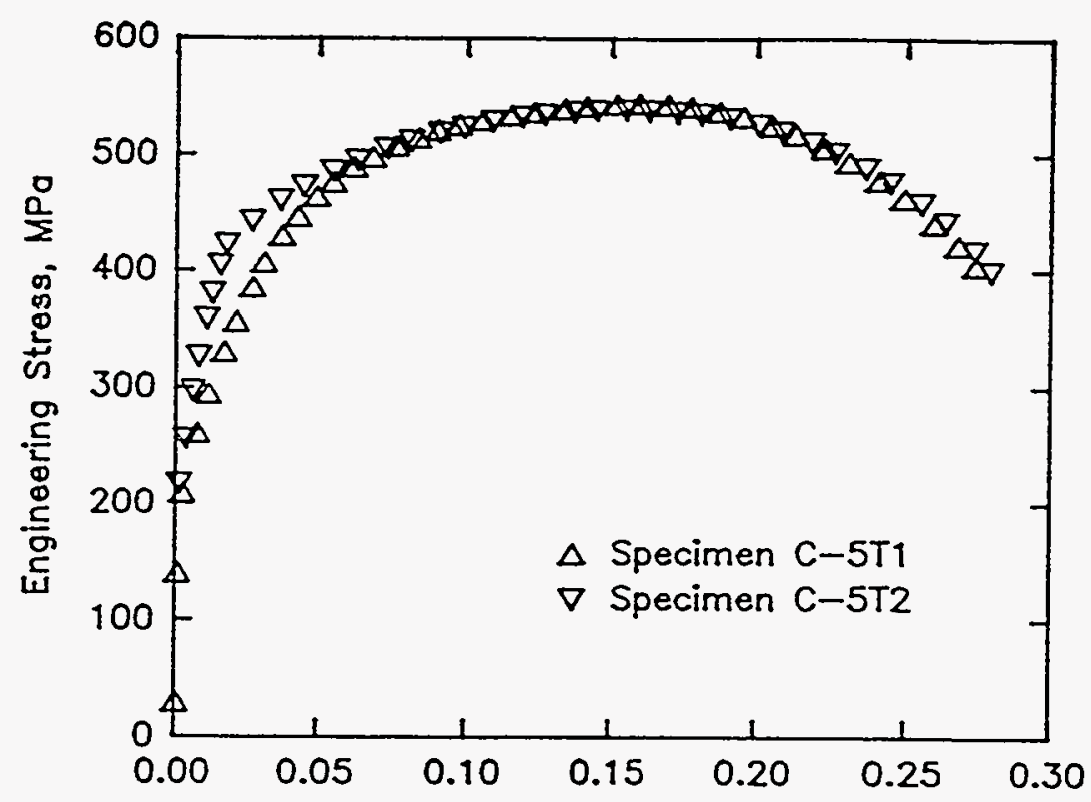

Engineering Stress, MPa

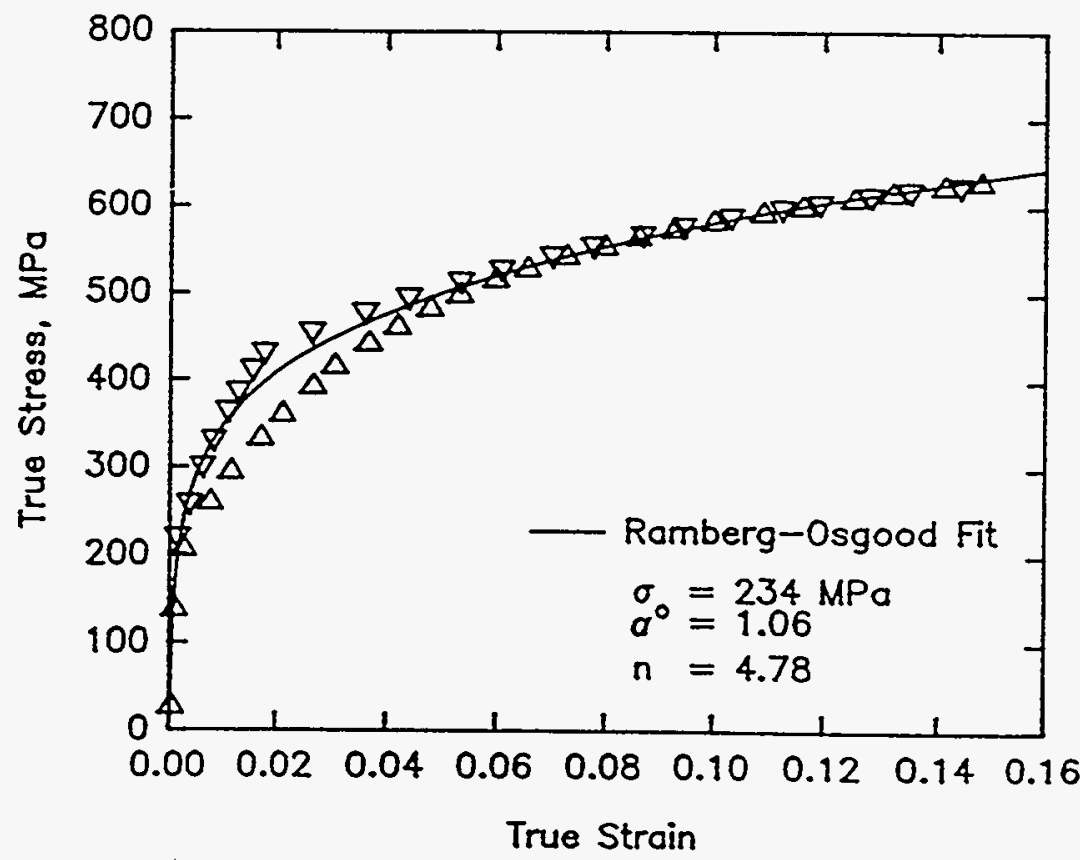

Figure 2.11 Stress-strain curves at $288 \mathrm{C}(550 \mathrm{~F})$ for tensile specimens machined in the longitudinal direction of the pipe from Pipe AEC-C5 (A106 Grade B) 
Tensile properties for this carbon steel weld are summarized in Table 2.10. Figure 2.12 shows the engineering and true stress-strain curves for this weld metal at room temperature and $288 \mathrm{C}$ (550 F). Note from Table 2.10 and Figure 2.12 that the yield strength and fracture elongation decreased slightly as the test temperature increased while the ultimate strength increased slightly.

\subsection{Charpy V-notch Test Results}

In this section of the report, the results from a series of Charpy impact tests for the carbon steel pipe material for Experiment 1.2.3.15, the stainless steel weld for Experiment 1.2.3.16, and the carbon steel weld for Experiment 1.2.3.17 are presented.

\subsubsection{SA155-KC60-Class 1 (A515 Grade 60) Carbon Steel (DP2-F20)}

As part of a previous program (Ref. 2.1), full-size Charpy V-notch specimens were machined from Pipe DP2-F26 such that the fracture extended in the circumferential direction normal to the pipe axis (L-C orientation). Test temperatures were selected to encompass the ductile/brittle transition region. Test results are summarized in Table 2.11. Figures 2.13 and 2.14 are plots of the absorbed energy and shear area, respectively, as a function of temperature.

\subsubsection{Stainless Steel Submerged-Arc Weld}

As part of this program, standard Charpy V-notch impact specimens were machined from the weldment such that the crack would grow in the middle of the weld along the welding direction. Tests were conducted in duplicate at room temperature and at $288 \mathrm{C}(550 \mathrm{~F})$.

The results, shown in Table 2.12 , indicated that the toughness was similar at the two temperatures but, on average, was slightly greater at $288 \mathrm{C}(550 \mathrm{~F})$ than at room temperature. This finding, for an impact-loaded notched bend specimen, differed from that for a quasi-statically loaded precracked compact specimen (see the next section of this report). In the latter case, toughness values at $288 \mathrm{C}$ $(550 \mathrm{~F})$ were significantly below those at room temperature.

\subsubsection{Carbon Steel Submerged-Arc Weld}

As part of this program, six full-size Charpy V-notch impact specimens were machined from the weldment such that the notch was located in the center of the weld and the crack grew in the direction of the weld, i.e., the L-C orientation of the pipe. Three specimens were tested at room temperature and three at $288 \mathrm{C}(550 \mathrm{~F})$ to determine energy absorption values and the percentage of the fracture surface that exhibited shear. The results are presented in Table 2.13. On average, the specimens were tougher at $288 \mathrm{C}(550 \mathrm{~F})$ than at $22 \mathrm{C}(72 \mathrm{~F})-106$ Joules $(77.8 \mathrm{ft}-\mathrm{lb})$ versus 77 Joules $(56.8$ $\mathrm{ft-ib)}$ and 100 percent shear versus 77 percent shear, respectively. 
Table 2.10 Tensile properties of submerged-arc weld metal (DP2-F49W) in 31.8-mm (1.25-inch)-thick A516 Grade 70 plate

\begin{tabular}{cccccc}
\hline Specimen & $\begin{array}{c}\text { Test } \\
\text { Temperature, } \\
\text { Identification }\end{array}$ & $\begin{array}{c}\text { 0.2-Percent } \\
\text { Offset Yield } \\
\text { Strength, } \\
\text { MPa (ksi) }\end{array}$ & $\begin{array}{c}\text { Ultimate } \\
\text { Tensile } \\
\text { Strength, } \\
\text { MPa (ksi) }\end{array}$ & $\begin{array}{c}\text { Elongation, } \\
\text { percent in } \\
\text { 25.4 mm } \\
\text { (1 inch) }\end{array}$ & $\begin{array}{c}\text { Area } \\
\text { Reduction, } \\
\text { percent }\end{array}$ \\
\hline F49W-1 & $22(72)$ & $447(64.8)$ & $554(80.4)$ & 20.8 & 62.1 \\
F49W-2 & $22(72)$ & $445(64.5)$ & $554(80.3)$ & 21.2 & 62.8 \\
& Average & $446(64.7)$ & $554(80.4)$ & 21.0 & 62.5 \\
F49W-3 & $288(550)$ & $412(59.8)$ & $574(83.3)$ & 19.9 & 54.1 \\
F49W-4 & $288(550)$ & $417(60.5)$ & $576(83.5)$ & 17.1 & 48.8 \\
& Average & $415(60.2)$ & $575(83.4)$ & 18.5 & 51.5 \\
\hline
\end{tabular}

Table 2.11 Charpy V-notch impact results for Pipe DP2-F26 (Ref. 2.1)

\begin{tabular}{|c|c|c|c|c|c|c|}
\hline \multicolumn{2}{|c|}{$\begin{array}{c}\text { Temperature, } \\
\text { C } \quad \text { (F) }\end{array}$} & \multicolumn{2}{|c|}{$\begin{array}{l}\text { Absorbed } \\
\text { Energy, } \\
\text { J (ft-lb) }\end{array}$} & \multicolumn{2}{|c|}{ Lateral Expansion, } & $\begin{array}{c}\text { Shear Area, } \\
\text { Percent }\end{array}$ \\
\hline-26 & $(-15)$ & 6.8 & (5) & 0.183 & $(0.0072)$ & 2 \\
\hline-9 & (15) & 11 & (8) & 0.310 & $(0.0122)$ & 10 \\
\hline 0 & (32) & 43 & (32) & 0.533 & $(0.0210)$ & 20 \\
\hline 0 & (32) & 95 & $(70)$ & 1.75 & $(0.0688)$ & 40 \\
\hline 12 & (54) & 103 & (76) & 1.93 & $(0.0758)$ & 40 \\
\hline 13 & (55) & 122 & (90) & 2.13 & $(0.0838)$ & 55 \\
\hline 24 & (75) & 136 & $(100)$ & 2.27 & $(0.0892)$ & 60 \\
\hline 46 & (115) & 157 & (116) & 2.38 & $(0.0936)$ & 85 \\
\hline 66 & $(150)$ & 172 & $(127)$ & 2.34 & $(0.0920)$ & 100 \\
\hline 100 & (212) & 171 & (126) & 2.35 & $(0.0926)$ & 100 \\
\hline
\end{tabular}




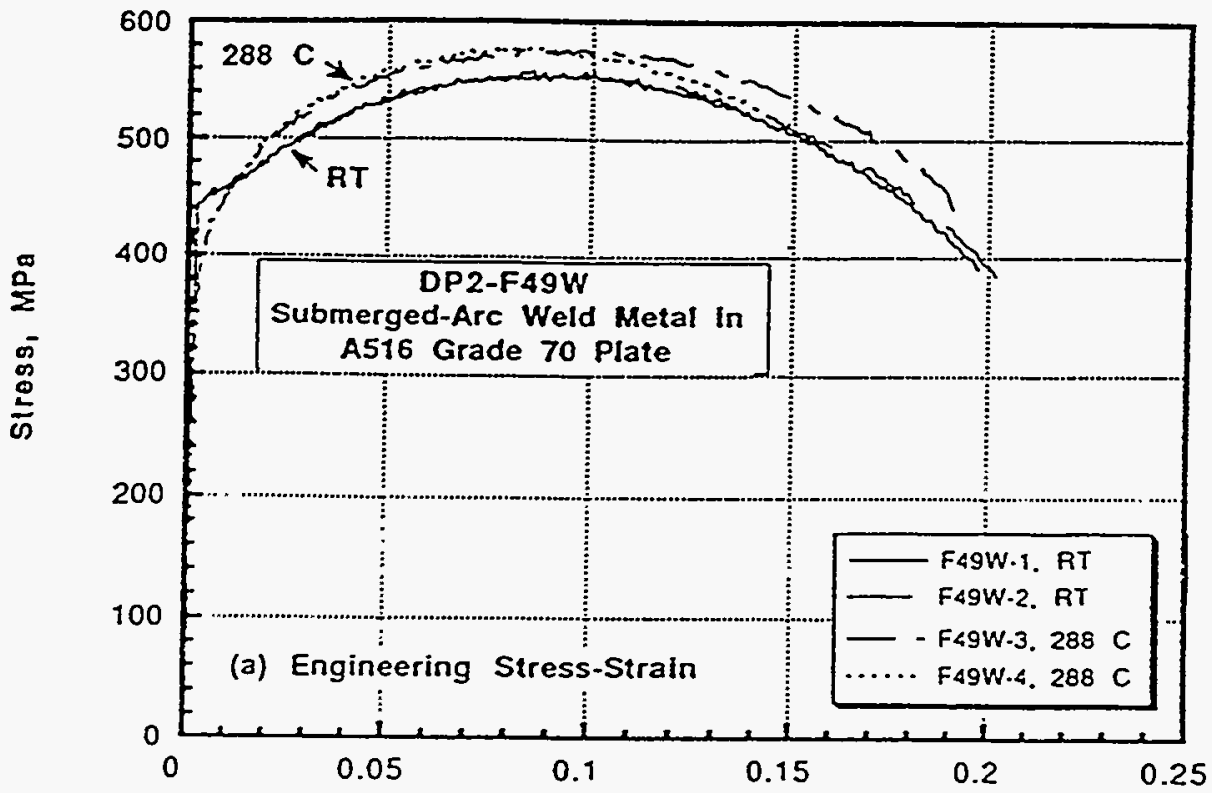

(a) Engineering stress-strain

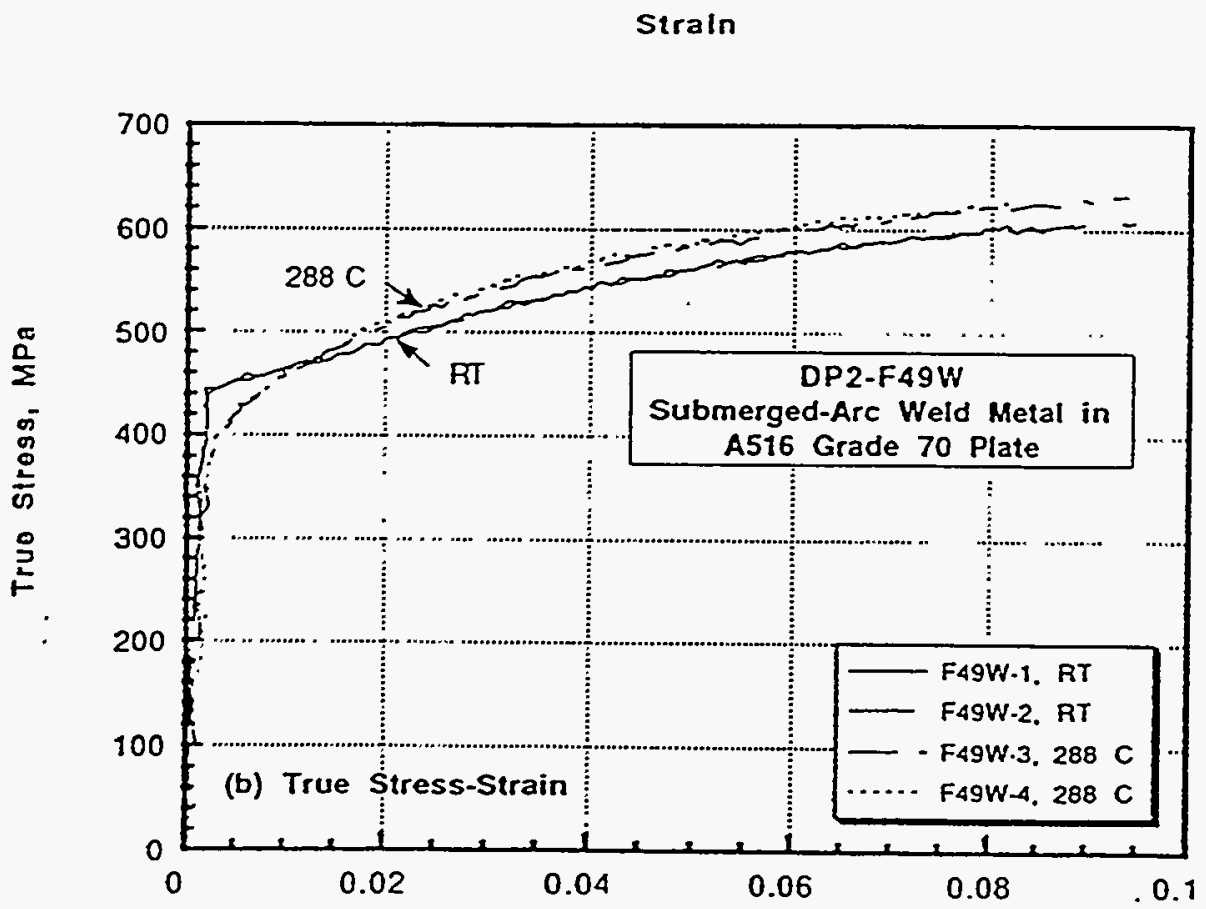

(b) True stress-strain

Figure 2.12 Tensile properties at $288 \mathrm{C}$ (550 F) for submerged-arc weld metal (DP2-F49W) 


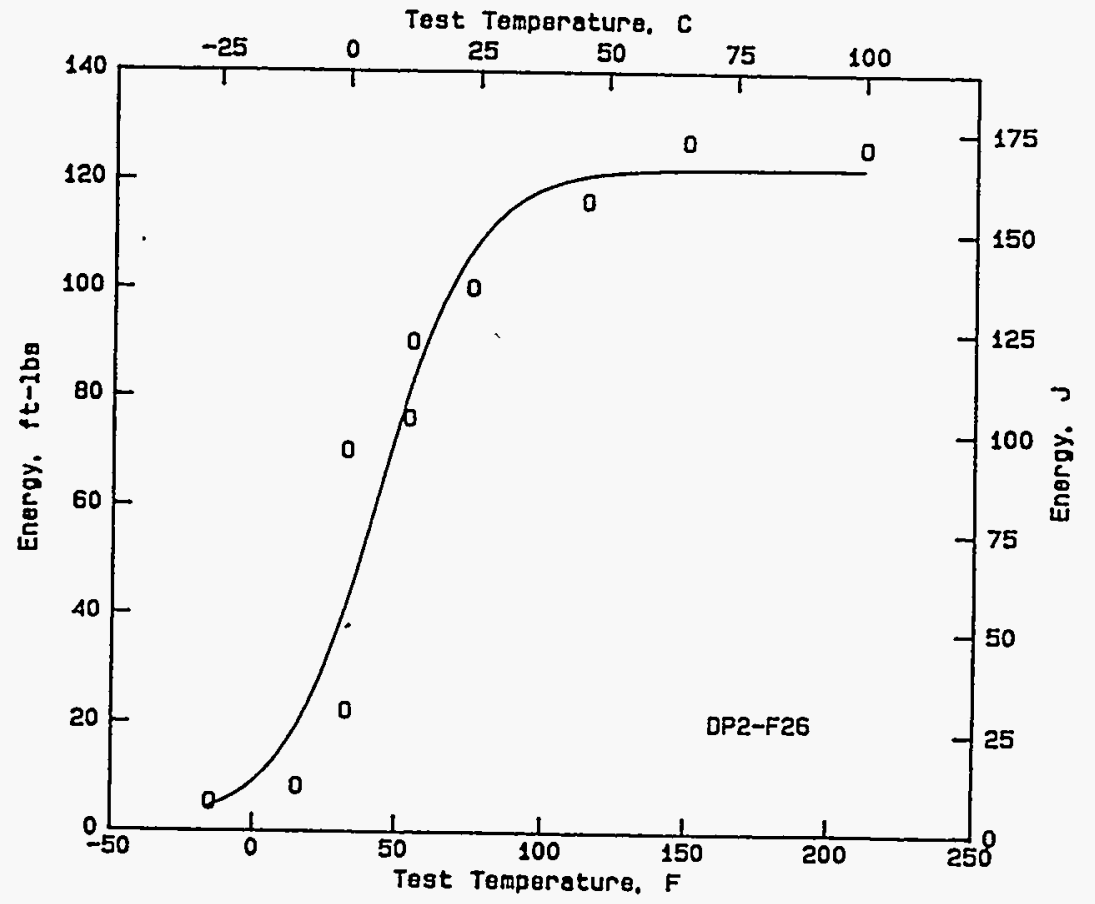

Figure 2.13 Charpy impact energy versus test temperature for pipe material DP2-F26, from Ref. 2.1

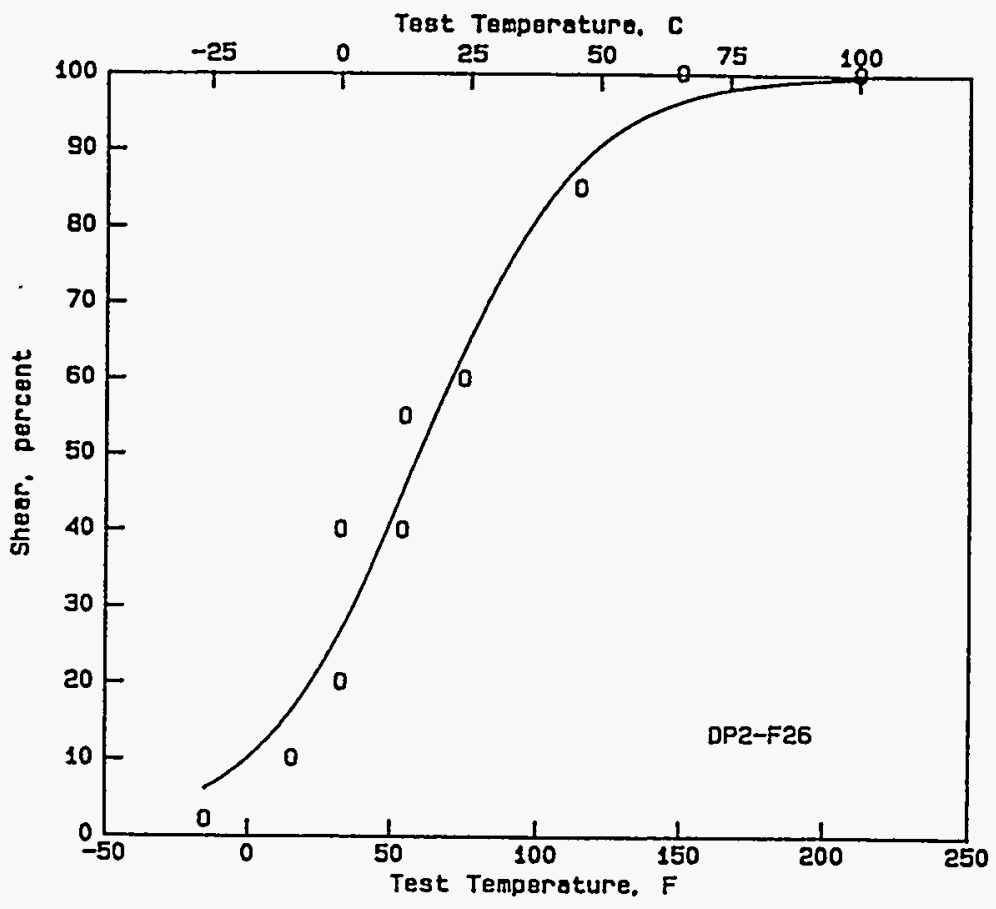

Figure 2.14 Shear area versus test temperature for pipe material DP2-F26, from Ref. 2.1 
Table 2.12 Charpy V-notch impact results for submerged-arc weld (DP2-A45W2) in TP304 stainless steel plate

\begin{tabular}{rllc}
\hline Test Temperature, & \multicolumn{2}{c}{ Absorbed Energy, } \\
C & (F) & J & (ft-lb) \\
\hline 22 & $(72)$ & 56 & $(41)$ \\
22 & $(72)$ & 62 & $(46)$ \\
288 & $(550)$ & 64 & $(47)$ \\
288 & $(550)$ & 67 & $(49.5)$ \\
\hline
\end{tabular}

Table 2.13 Charpy V-notch impact results for submerged-arc weld metal (DP2-F49W) in 31.8-mm (1.25-inch)-thick A516 Grade 70 plate

\begin{tabular}{|c|c|c|c|c|c|}
\hline \multicolumn{2}{|c|}{$\begin{array}{l}\text { Test Temperature, } \\
\text { C (F) }\end{array}$} & \multicolumn{2}{|c|}{$\begin{array}{c}\text { Absorbed Energy, } \\
\mathbf{J} \quad \text { (ft-lb) }\end{array}$} & \multicolumn{2}{|r|}{$\begin{array}{c}\text { Shear Area, } \\
\text { Percent }\end{array}$} \\
\hline 21 & $(70)$ & 76.6 & $(56.5)$ & & 75 \\
\hline 21 & (70) & 84.1 & $(62.0)$ & & 80 \\
\hline \multirow[t]{2}{*}{21} & (70) & 70.5 & $(52.0)$ & & 75 \\
\hline & & Average 77.1 & $(56.8)$ & Average & 77 \\
\hline 288 & $(550)$ & 104 & $(76.5)$ & & 100 \\
\hline 288 & $(550)$ & 119 & $(81.0)$ & & 100 \\
\hline \multirow[t]{2}{*}{288} & $(550)$ & 103 & $(76.0)$ & & 100 \\
\hline & & Average 106 & $(77.8)$ & Average & 100 \\
\hline
\end{tabular}

\subsection{J-R Curve Test Results}

Summary graphs and tables of quasi-static J-R curve tests are presented in this section. All specimens were machined in the L-C orientation, which simulates growth of a circumferential through-wall crack.

Data obtained during the fracture toughness tests conducted at Battelle were load $(\mathrm{P})$, load-line displacement (LLD), and d-c electric potential (U). The unloading compliance method was used to infer crack growth data for the fracture toughness tests conducted at MEA (Ref. 2.2). For the Battelle tests, the point of crack initiation was estimated from the electric potential data. To achieve this estimate, graphs of $U$ versus LLD and $P$ versus $U$ were examined for points of slope change prior to maximum load. Engineering judgement was then applied to estimate $U_{0}$, the value of $U$ at crack initiation. Crack growth beyond crack initiation was then calculated from the ratio $U / U_{0}$ using 
the Johnson expression described in Reference 2.5. Note that the term for the spacing (2y) of the voltage probes in the Johnson expression was allowed to increase in proportion to the LLD as the test progressed, because experience has shown that this procedure provides a more accurate estimate of the crack growth in highly ductile materials (Ref. 2.6).

\subsubsection{6-mm (16-inch) Nominal Diameter, Schedule 30, TP304 Stainless Steel}

As part of this program, six 0.5T-planform-size compact type specimens [8.4-mm (0.33-inch) thick] were machined from Pipe DP2-A52 for the purpose of conducting J-resistance tests at 22, 93, and $288 \mathrm{C}(72,200$, and $550 \mathrm{~F})$. Specimen thicknesses were the maximum achievable from the wall thickness of the pipe. The specimens were side grooved to a depth of 10 percent of the thickness per side.

The specimens were tested in displacement control in a screw-driven Instron machine having a capacity of $90 \mathrm{kN}(20,000 \mathrm{lbs})$. The crosshead speed was $0.5 \mathrm{~mm} /$ minute $(0.02 \mathrm{inch} /$ minute $)$, which caused crack initiation in approximately 5 to 10 minutes. The tests were terminated when the crack had extended 45 to 50 percent of the original ligament. The total elapsed time for each test was approximately 20 to 25 minutes.

The procedures used to calculate $J$ values from each test were those specified in ASTM E1152-87, Standard Test Method for Determining J-R Curves. In addition, values of Modified $J\left(J_{M}\right)$ were calculated following procedures outlined by Ernst (Refs. 2.7 and 2.8).

J-resistance curves are shown in Figures 2.15, 2.16, and 2.17 for tests conducted at 22, 93, and $288 \mathrm{C}(72,200$, and $550 \mathrm{~F})$, respectively. Values of $\mathrm{J}_{\mathrm{i}}$ and $\mathrm{dJ} / \mathrm{da}$ are summarized in Table 2.14. The values of $\mathrm{dJ} / \mathrm{da}$ are for crack extension in the range of approximately 0.15 to $1.5 \mathrm{~mm}(0.006$ to 0.060 inch).

Table 2.14 shows the significant effect of test temperature on the fracture resistance of this stainless steel. At $288 \mathrm{C}$ (550 F), the value of $\mathrm{J}_{\mathrm{i}}$ was approximately only half of the room temperature value, while $\mathrm{dJ} / \mathrm{da}$ values were reduced by approximately 40 percent for the same temperature increase.

\subsubsection{2-mm (6-inch) Nominal Diameter, Schedule XXS, TP304 Stainless Steel (DP2-A35)}

As part of a previous program (Ref. 2.1), 1T-planform-size compact specimens (16.3-mm [0.64-inch] thick) were machined from Pipe DP2-A35. Specimen thicknesses were the maximum achievable from the 21.9-mm (0.864-inch) nominal wall thickness of pipe. Two different types of starting notches were employed: (a) a fatigue precrack and (b) a sharp machined notch having a radius of about 0.13 $\mathrm{mm}(0.005$ inch). 


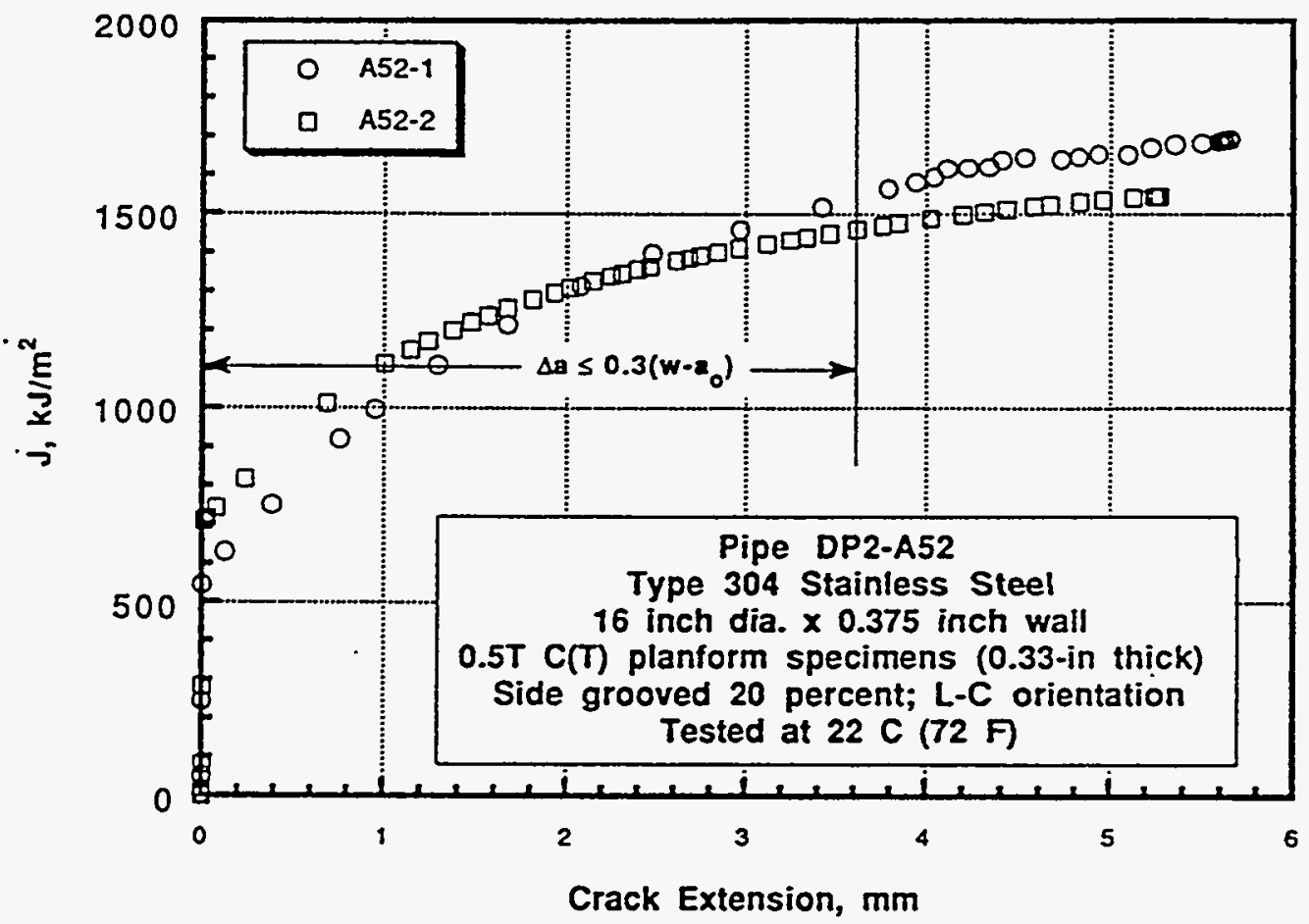

Figure 2.15 J-resistance curves at $22 \mathrm{C}(72 \mathrm{~F})$ for compact specimens machined from Pipe DP2-A52 (TP304)

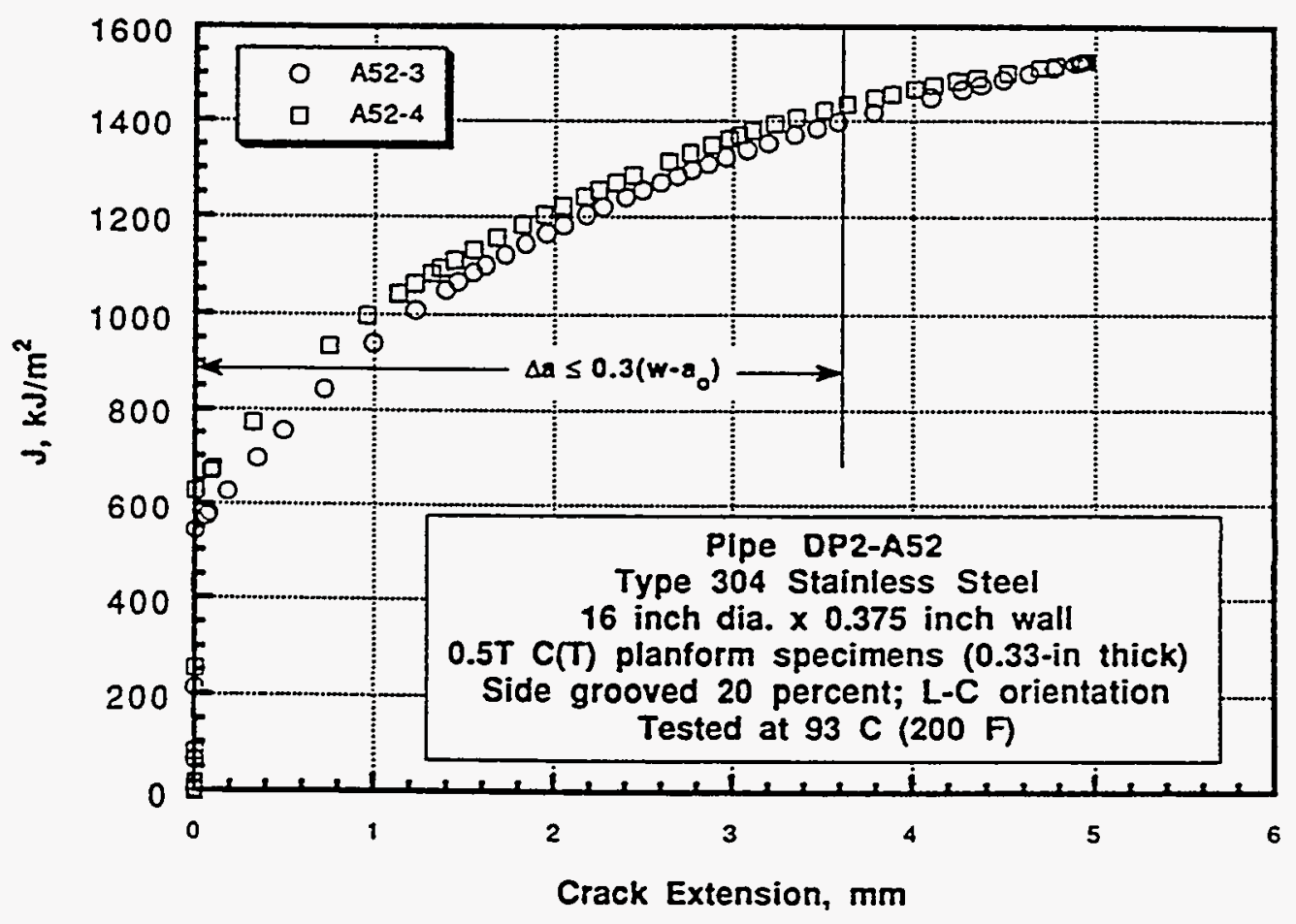

Figure 2.16 J-resistance curves at $93 \mathrm{C}(200 \mathrm{~F})$ for compact specimens machined from Pipe DP2-A52 (TP304) 


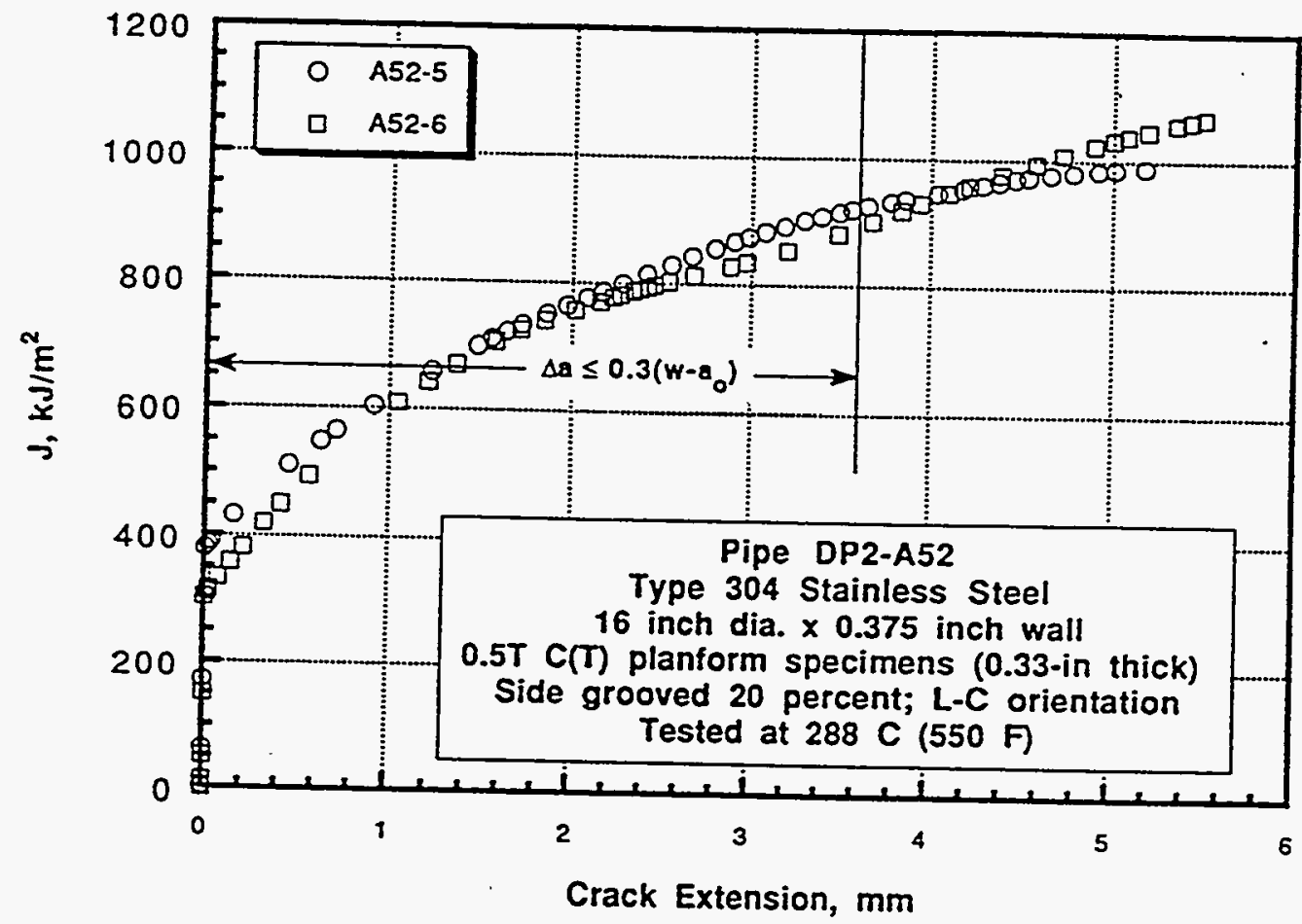

Figure 2.17 J-resistance curves at $288 \mathrm{C}$ (550 F) for compact specimens machined from Pipe DP2-A52 (TP304)

Table 2.14 Summary of $J_{i}$ and $\mathbf{d J} /$ da values obtained from compact specimens machined from Pipe DP2-A52 (TP304) (L-C orientation)

\begin{tabular}{|c|c|c|c|c|c|c|c|}
\hline \multirow{2}{*}{$\begin{array}{c}\begin{array}{c}\text { Specimen } \\
\text { Identification No. }\end{array} \\
\text { A52-1 }\end{array}$} & \multicolumn{2}{|c|}{$\begin{array}{l}\text { Test Temperature, } \\
\begin{array}{ll}\text { C } & \text { (F) }\end{array}\end{array}$} & & \multicolumn{2}{|c|}{$\begin{array}{c}\mathrm{J} \text { at Initiation, } \\
\mathrm{kJ} / \mathrm{m}^{2} \\
\left(\mathbf{i n}-\mathrm{lb} / \mathrm{in}^{2}\right)\end{array}$} & \multicolumn{2}{|c|}{$\begin{array}{c}\mathrm{dJ}^{\mathrm{d} / \mathrm{da}^{(\mathrm{a})}}, \\
\left.\mathrm{MJ} / \mathrm{m}^{3} \quad \text { (in- } \mathrm{lb} / \mathrm{in}^{3}\right)\end{array}$} \\
\hline & 22 & $(72)$ & & 544 & $(3,105)$ & 398 & $(57,720)$ \\
\hline \multirow[t]{2}{*}{ A52-1 } & 22 & (72) & & 705 & $(4,024)$ & 325 & $(47,140)$ \\
\hline & & & Average & 625 & $(3,565)$ & 362 & $(52,430)$ \\
\hline A52-3 & 93 & (200) & & 541 & $(3,088)$ & 345 & $(50,040)$ \\
\hline \multirow[t]{2}{*}{ A52-4 } & 93 & $(200)$ & & 627 & $(3,579)$ & 299 & $(43,360)$ \\
\hline & & & Average & 584 & $(3,334)$ & 322 & $(46,700)$ \\
\hline A $52-5$ & 288 & (550) & & 377 & $(2,152)$ & 200. & $(29,010)$ \\
\hline \multirow[t]{2}{*}{ A52-6 } & 288 & $(550)$ & & 303 & $(1,729)$ & 249 & $(36,110)$ \\
\hline & & & Average & 340 & $(1,941)$ & 225 & $(32,560)$ \\
\hline
\end{tabular}

(a) Linear fit of J-R curve for crack growth of $0.15 \mathrm{~mm}(0.006 \mathrm{inch})$ to $1.5 \mathrm{~mm}(0.060 \mathrm{inch})$. 
Specimens were tested at $288 \mathrm{C}(550 \mathrm{~F})$ at a displacement rate designed to cause crack initiation in about 5 to 20 minutes, similar to that required for crack initiation in the pipe fracture tests. The tests were terminated when the crack had extended by an amount equal to 60 to 70 percent of the original ligament. Crack growth was accompanied by appreciable thickness reduction at the crack plane (necking), on the order of 40 percent for the non-side-grooved specimens and 25 percent for the sidegrooved specimens.

Deformation $\mathrm{J}\left(\mathrm{J}_{\mathrm{D}}\right)$ and Modified $\mathrm{J}\left(\mathrm{J}_{\mathrm{M}}\right)$ were calculated for each specimen. $\mathrm{J}_{\mathrm{D}}$ was calculated in the manner specified in ASTM E813-81 following the method developed by Ernst and Paris, which takes into account crack growth (Ref. 2.8). $\mathrm{J}_{\mathrm{M}}$ was calculated in the manner developed by Ernst, Paris, and Landes as specified in Reference 2.7. In calculating both $J_{D}$ and $J_{M}$, no account was taken of the thinning of the specimen ahead of the crack or of the thickening at the back edge.

A graph of $\mathrm{J}_{\mathrm{D}}$ versus crack extension is shown in Figure 2.18. Values of $\mathrm{J}$ at crack initiation $\left(\mathrm{J}_{\mathrm{i}}\right)$ and $\mathrm{dJ} / \mathrm{da}$ for the initial portion of the J-R curve are shown in Table 2.15. The values of $\mathrm{dJ} / \mathrm{da}$ were obtained for crack growth values in the range of approximately 0.15 to $1.5 \mathrm{~mm}(0.006$ to $0.060 \mathrm{inch})$.

\subsubsection{2-mm (6-inch) Nominal Diameter, Schedule 40, TP304 Stainless Steel (DP2-A7)}

As part of a previous program (Ref. 2.2), 0.4T-planform-size compact specimens (5.79-mm [0.228-inch] thick) were machined from Pipe DP2-A7. Both machining and testing were conducted at Materials Engineering Associates (MEA). Specimen thicknesses were the maximum achievable from the nominal 7.11-mm (0.280-inch) thick pipe.

Tests were conducted at $288 \mathrm{C}(550 \mathrm{~F})$ and employed the unloading compliance method to determine crack extension. From the measured loads, load-line displacements, and calculated crack lengths, values of $J$ were calculated for each crack length. As for pipe material DP2-A35, Deformation $J\left(J_{D}\right)$ and Modified $\mathrm{J}\left(\mathrm{J}_{\mathrm{M}}\right)$ were calculated for each specimen.

A graph of $\mathrm{J}_{\mathrm{D}}$ versus crack extension is shown in Figure 2.19. $\mathrm{J}$ values at crack initiation $\left(\mathrm{J}_{\mathrm{i}}\right)$ for the MEA tests were obtained by constructing a blunting line on the J-R curves, namely

$$
\mathrm{J}=2 \sigma_{\mathrm{f}} \Delta \mathrm{a}
$$

where $\sigma_{\mathrm{f}}$ is the flow stress (the average of yield and ultimate strengths). A straight line was fit to the data points between the two exclusion lines that were drawn parallel to the blunting line. This straight line was extrapolated to the blunting line to provide $J$ at crack initiation values. As is frequently the case for austenitic materials, the experimental data exhibited by specimens machined from Pipe DP2-A7 had a steeper initial slope than did the calculated blunting line. Had a steeper blunting line been used, for example $J=4 \sigma_{f} \Delta a$, values of $J$ at crack initiation would have been markedly lower, on the order of 50 percent lower than those obtained when the usual blunting line was used.

Values of $J$ at crack initiation and values of $d J / d a$ for the initial portion of the $J-R$ curve are shown in Table 2.16. The values of $\mathrm{dJ} / \mathrm{da}$ were obtained for $\Delta$ a values within the exclusion lines. 


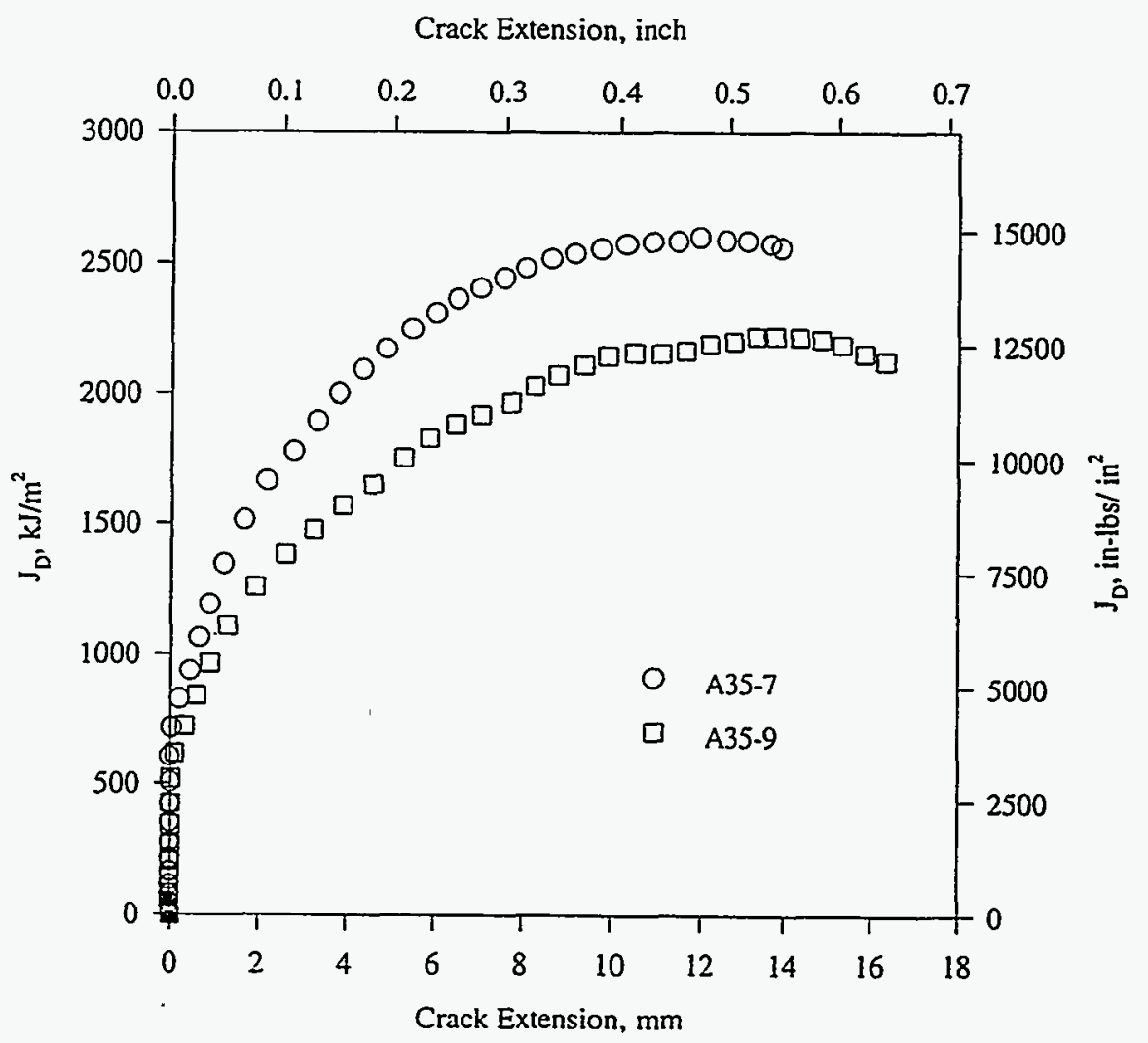

Figure 2.18 J versus crack extension at $288 \mathrm{C}$ (550 F) for Pipe DP2-A35 (TP304) compact specimens (Ref. 2.1)

Table 2.15 Summary of $J_{i}$ and $d J / d a$ values at $288 \mathrm{C}$ (550 F) for Pipe DP2-A35 (TP304) compact specimens (Ref. 2.1)

\begin{tabular}{|c|c|c|c|c|c|c|}
\hline $\begin{array}{c}\text { Specimen } \\
\text { Identification } \\
\text { No. }\end{array}$ & $\begin{array}{l}\text { Notch } \\
\text { Type }^{(a)}\end{array}$ & $\begin{array}{c}\text { Percent } \\
\text { Side-grooves }\end{array}$ & $\begin{array}{r}\mathbf{J} \text { at I } \\
\mathbf{M J} / \mathbf{m}^{2}\end{array}$ & $\begin{array}{l}\text { nitiation, } \\
\left(\text { in-lb/in }{ }^{2}\right)\end{array}$ & $\mathrm{MJ} / \mathrm{m}^{3}$ & $\begin{array}{l}\text { J/da, } \\
\left(\mathrm{in}-\mathrm{lb} / \mathrm{in}^{3}\right)\end{array}$ \\
\hline A35-7 & $\mathrm{FC}$ & 0 & 690 & $(3,965)$ & 564 & $(81,780)$ \\
\hline A35-9 & $\mathrm{FC}$ & 20 & 570 & $(3,270)$ & 439 & $(63,640)$ \\
\hline
\end{tabular}

(a) FC = fatigue crack. 


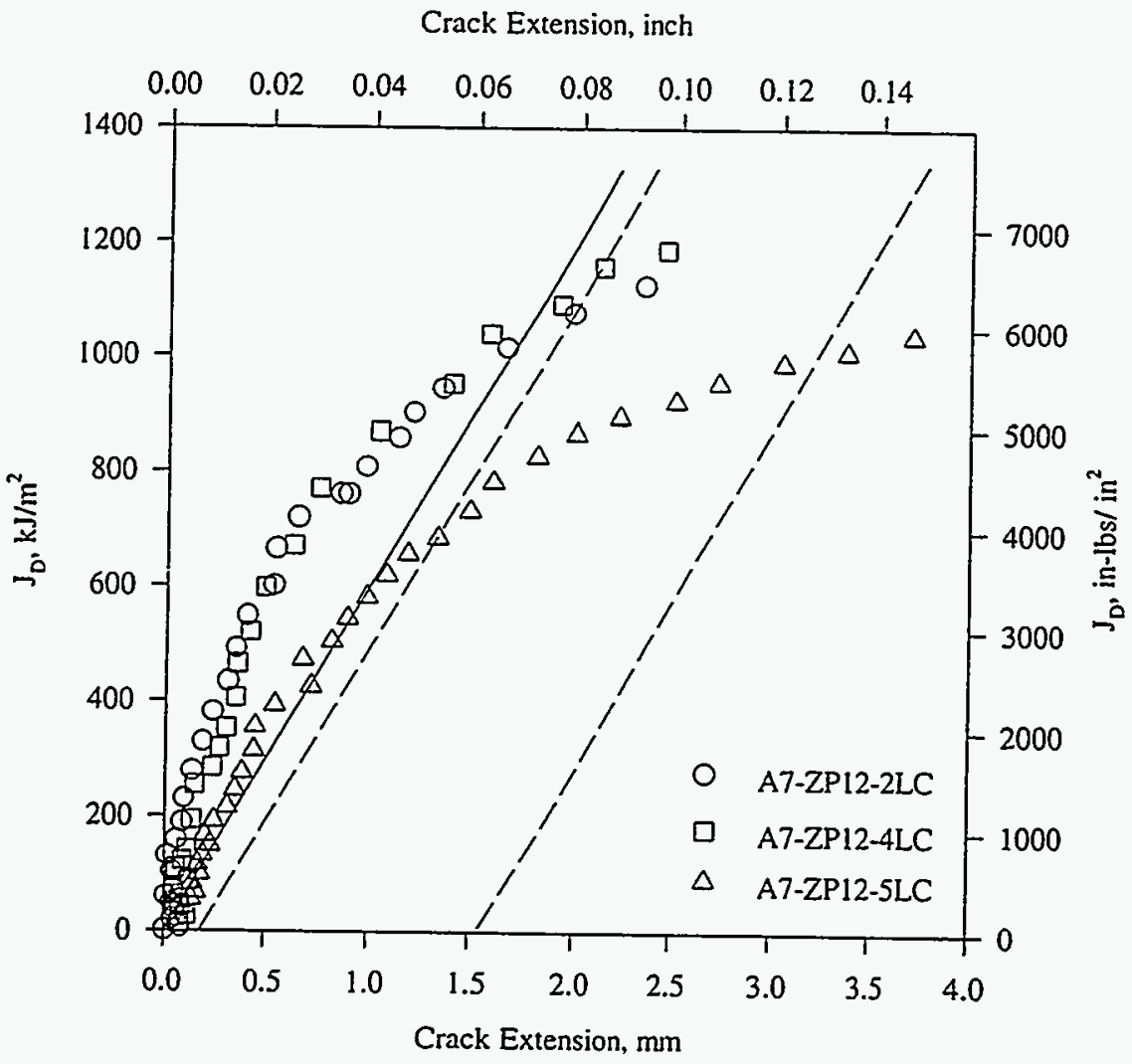

Figure 2.19 J-resistance curves at $288 \mathrm{C}$ (550 F) for DP2-A7 (TP304) fatigue-cracked compact specimens (Ref. 2.2)

Table 2.16 Summary of $J_{i}$ and dJ/da values for Pipe DP2-A7 (TP304) compact specimens (Specimens were tested at Materials Engineering Associates at $288 \mathrm{C}$ [550 F]), L-C orientation (Ref. 2.2)

\begin{tabular}{|c|c|c|c|c|c|c|c|}
\hline $\begin{array}{c}\text { Specimen } \\
\text { Identification } \\
\text { No. }\end{array}$ & $\begin{array}{c}\text { Notch } \\
\text { Type }^{(\mathrm{a})}\end{array}$ & $\begin{array}{c}\text { Percent } \\
\text { Side- } \\
\text { grooves }\end{array}$ & & $\begin{array}{c}\mathrm{J} \text { at } \mathrm{In} \\
\mathrm{MJ} / \mathrm{m}^{2}\end{array}$ & $\begin{array}{l}\text { itiation, } \\
\left(\mathbf{i n}-\mathrm{lb} / \mathbf{i n}^{2}\right)\end{array}$ & $\mathrm{MJ} / \mathbf{m}^{\mathbf{d}}$ & $\begin{array}{l}\mathbf{J} / \mathrm{da}, \\
\left(\mathrm{in}-\mathrm{lb} / \mathrm{in}^{3}\right)\end{array}$ \\
\hline ZP12-2LC & $\mathrm{FC}$ & 0 & & $1.5^{(b)}$ & $(8,560)$ & & (c) \\
\hline \multirow[t]{2}{*}{ ZP12-4LC } & $\mathrm{FC}$ & 0 & & $1.6^{(\mathrm{b})}$ & $(9,132)$ & & (c) \\
\hline & & & Avg. & 1.55 & $(8,846)$ & & \\
\hline ZP12-5LC & FC & 20 & & 0.873 & $(4,985)$ & 289 & $(41,940)$ \\
\hline
\end{tabular}

(a) $\mathrm{FC}=$ fatigue crack.

(b) Test was terminated before the $\mathrm{J}-\Delta$ a curve crossed the calculated blunting line. The value shown is an estimate of the intersection point.

(c) $\mathrm{dJ} / \mathrm{da}$ was not calculated because the test was terminated before the $\mathrm{J}-\Delta$ a curve crossed the calculated blunting line. 


\subsubsection{SA155-KC60-Class 1 (A515 Grade 60) Carbon Steel}

As part of a previous program (Ref. 2.1), 1T-planform-size compact (tension) fracture toughness specimens were machined from this carbon steel pipe material and tested at $288 \mathrm{C}(550 \mathrm{~F})$. Specimen thicknesses were the maximum aclievable from the nominal 22.2-mm (0.875-inch) thickness of the pipe and ranged from 19.1 to $21.1 \mathrm{~mm}(0.75$ to $0.83 \mathrm{inch})$. Two different types of starting notches were employed: a fatigue precrack and a machined notch having a radius of about $0.13 \mathrm{~mm}(0.005$ inch), introduced with a 0.20 -mm (0.008-inch)-thick saw blade. The latter notch type is the same as that used in the corresponding pipe fracture experiments. The initial crack (or notch) depth was such that $\mathrm{a} / \mathrm{W}$ was about 0.5 .

Because the initial tests at $288 \mathrm{C}(550 \mathrm{~F})$ on the fatigue-cracked and machined-notch specimens produced crack growth at an angle to the intended fracture plane, duplicate specimens were side grooved 10-percent per side prior to testing to achieve crack growth in the intended plane.

The specimens were tested at $288 \mathrm{C}(550 \mathrm{~F})$ at a displacement rate designed to cause crack initiation in about 5 to 15 minutes, similar to that required for the pipe fracture tests. The tests were terminated once the crack had extended 40 to 60 percent of the original ligament.

In the two specimens that contained side grooves, stable crack growth was interrupted several times by small bursts of rapid fracture. These were indicated by distinct steps in the load versus displacement and electric-potential versus displacement records, see Figure 2.20. The compact specimens without side grooves, on the other hand, displayed only stable crack growth. In those compact specimens that displayed bursts of rapid fracture, the fracture surface provided no obvious indications of a change in fracture mechanism when stable fracture changed to unstable fracture and back again.

Deformation $\mathrm{J}\left(\mathrm{J}_{\mathrm{D}}\right)$ and Modified $\mathrm{J}\left(\mathrm{J}_{\mathrm{M}}\right)$ were calculated for each specimen using procedures noted earlier. J-resistance curves for this material are shown in Figure 2.21 and values of $\mathrm{J}_{\mathrm{i}}$ and $\mathrm{dJ} / \mathrm{da}$ are summarized in Table 2.17. The J-R curves were terminated at the point of the first significant crack jump because there is no agreed-upon method for calculating $J$ during and after a crack instability.

\subsubsection{Stainless Steel Submerged-Arc Weld}

Compact (tension) fracture toughness specimens were machined from sections of stainless steel submerged-arc welds and tested at room temperature and $288 \mathrm{C}$ (550 F). Specimens were machined and tested from three different welds, made at three different times. The weld procedures for each weld were nominally the same as used in the pipe experiment, Experiment 1.2.3.16. Two of the welds were fabricated in flat plates (DP2-A45W1 and DP2-A45W2) and one was fabricated in a section of 16-inch nominal diameter, Schedule 100, stainless steel pipe (DP2-A8W4).

Compact specimens of 1T, 3T, and 9.5T-planform size, 25.4-mm (1-inch) thick, were machined from the submerged-arc weld DP2-A45W1. Specimens having 1T-planform-size specimens were machined from the other two welds. In each case, the specimens were oriented such that crack growth would 

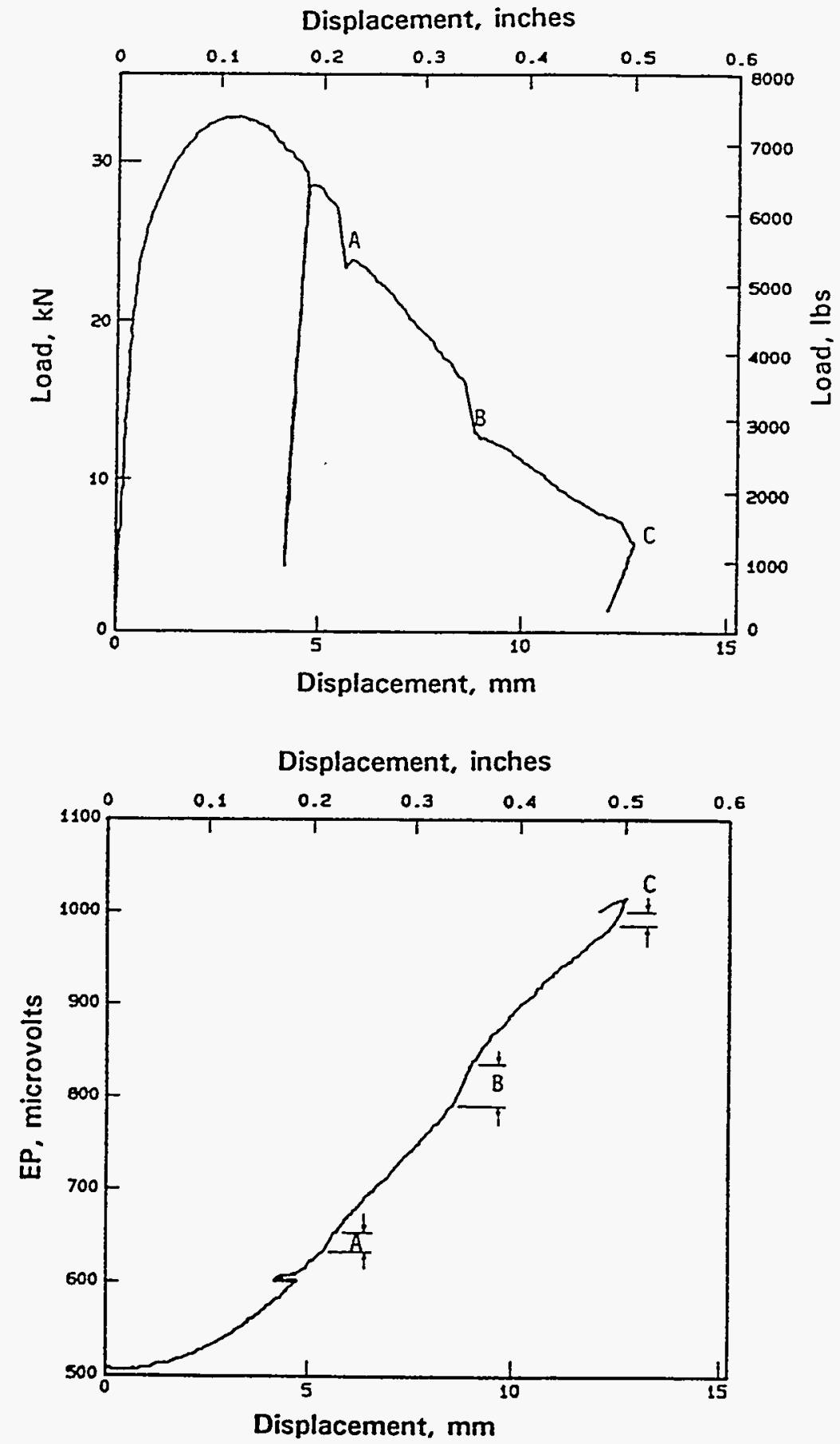

Figure 2.20 Test records for A515 Grade 60 (DP2-F26) steel pre-cracked and side-grooved compact specimens tested at $288 \mathrm{C}(550 \mathrm{~F})$ (A, B, and C indicate points at which stable crack growth was interrupted by a crack jump, and displacement shown is at $0.25 \mathrm{~W}$ from the load line) 
Table 2.17 Summary of $J_{i}$ and $d J / d a$ values at $288 \mathrm{C}$ (550 F) for Pipe DP2-F26 (Ref. 2.1)

\begin{tabular}{|c|c|c|c|c|}
\hline Specimen No. & $\begin{array}{l}\text { Notch }^{(a)} \\
\text { Type }\end{array}$ & $\begin{array}{l}\text { Percent } \\
\text { Side- } \\
\text { Grooves }\end{array}$ & $\begin{array}{l}J \text { at Initiation, } \\
\mathrm{kJ} / \mathrm{m}^{2}\left(\mathrm{in}-\mathrm{lb} / \mathrm{in}^{2}\right)\end{array}$ & $\begin{array}{c}\mathrm{dJ} / \mathrm{da}^{(\mathrm{b})} \\
\mathrm{MJ} / \mathrm{m}^{3}\left(\mathrm{in}-\mathrm{lb} / \mathrm{in}^{3}\right)\end{array}$ \\
\hline F26-17 & $\mathrm{FC}$ & 0 & $180.4(1,030)$ & - \\
\hline F26-19 & FC & 20 & $217.2(1,240)$ & $135(19,500)$ \\
\hline F26-21 & SMN & 0 & $259.7(1,483)$ & - \\
\hline \multirow[t]{2}{*}{ F26-22 } & SMN & 20 & $206.5(1,180)$ & $126(18,200)$ \\
\hline & & Average & $216.0(1,233)$ & $130(18,850)$ \\
\hline
\end{tabular}

(a) $\mathrm{FC}=$ Fatigue crack; SMN = Sharp machined notch.

(b) Using data from the initial portion of the J-R curve; $0.15 \mathrm{~mm}$ (0.006 inch) $<\Delta \mathrm{a}<1.5 \mathrm{~mm}(0.060 \mathrm{inch})$.

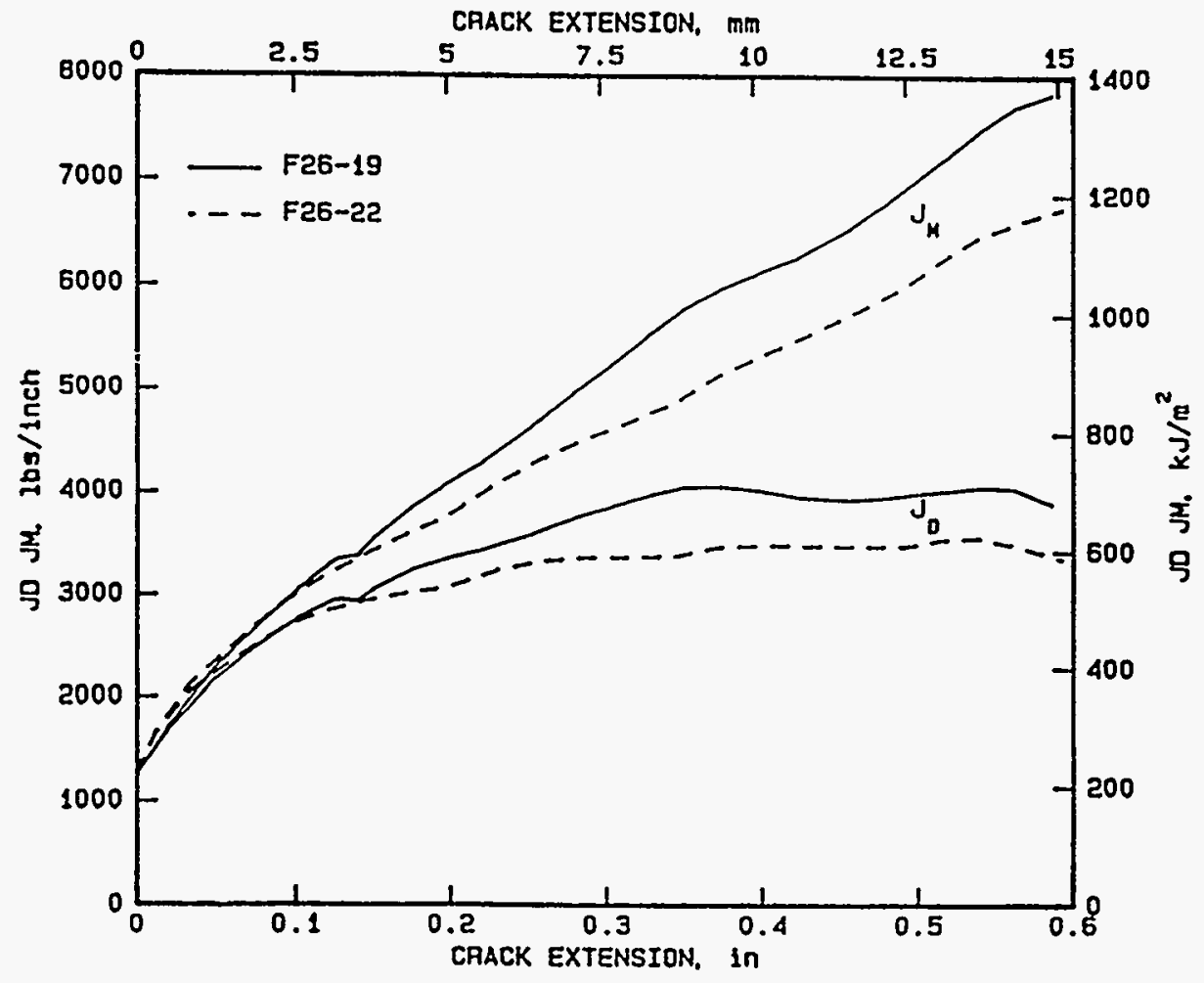

Figure 2.21 $J_{M}-R$ and $J_{D}-R$ curves at $288 \mathrm{C}$ (550 F) for A515 Grade 70 Pipe DP2-F26 (Ref. 2.1) 
be along the weld centerline. Specimen thicknesses were the full thickness of the plates, or the maximum achievable from the $26.1-\mathrm{mm}$ (1.031-inch) nominal wall thickness of the pipe. The weld crown was left intact for the $3 \mathrm{~T}$ and $9.5 \mathrm{~T}$ specimens, but was removed for the $1 \mathrm{~T}$ specimens. Data for the $3 \mathrm{~T}$ and $9.5 \mathrm{~T}$ specimens are given in Reference 2.5 .

Two different types of starting notches were employed, a fatigue precrack and a sharp machined notch having a radius of approximately $0.13 \mathrm{~mm}(0.005 \mathrm{inch})$. The specimens were tested at a displacement rate designed to cause crack initiation in about 5 to 20 minutes, similar to that required for crack initiation in the quasi-static pipe fracture tests. The crack path in the $1 \mathrm{~T}$ compact specimens was typically along the weld centerline and was accompanied by a modest amount of thickness reduction at the crack plane. The crack front on the root side (TIG weld-region) lagged behind that on the crown side (SAW).

Deformation $\mathrm{J}\left(\mathrm{J}_{\mathrm{D}}\right)$ and Modified $\mathrm{J}\left(\mathrm{J}_{\mathrm{M}}\right)$ were calculated for each specimen as previously noted. $\mathrm{J}$-resistance curves for each of the three stainless steel submerged-arc welds tested are shown in Figures 2.22 through 2.24. Values of $\mathrm{J}_{\mathrm{i}}$ and $\mathrm{dJ} / \mathrm{da}$ for each weld are summarized in Table 2.18. Both Figure 2.21 (Weld DP2-A45W2) and Table 2.18 show the marked effect of test temperature on the fracture resistance of the weld metal, with or without side grooves present. At $288 \mathrm{C}$ (550 F), both $\mathrm{J}_{\mathrm{i}}$ and $\mathrm{dJ} / \mathrm{da}$ were approximately only half of their values at room temperature. Differences between side-grooved and non-side-grooved specimens were relatively small.

\subsubsection{Carbon Steel Submerged-Arc Weld}

The weld from which these compact (tension) specimens were machined was fabricated in a flat plate welded at the same time as the weld used in the pipe experiment was fabricated. As part of this program, six 1.25T-planform-size compact (tension) fracture toughness specimens were machined from this carbon steel submerged-arc weld (DP2-F49W). Four were side grooved to a depth of 10 percent per side, two of which were tested at $22 \mathrm{C}(72 \mathrm{~F})$ and two at $288 \mathrm{C}(550 \mathrm{~F})$. The remaining two specimens were tested without side grooves at $288 \mathrm{C}(550 \mathrm{~F})$. Specimens were oriented such that crack growth would be along the weld centerline in the direction of the weld.

The specimens were tested in displacement control. The crosshead speed was $0.635 \mathrm{~mm} / \mathrm{min}(0.025$ inch/min) to cause crack initiation in approximately 4 to 7 minutes. Each high temperature test was terminated when the crack had extended 40 to 55 percent of the original ligament. In the tests conducted at room temperature, the $C(T)$ specimens showed only a small amount of stable crack growth before undergoing rapid, unstable cleavage fracture. Fracture in these room temperature tests occurred prior to the attainment of maximum load.

The procedures used to calculate values of $\mathrm{J}$ from each compact-specimen test were those specified in ASTM E1152-87, Standard Test Method for Determining J-R Curves. In addition, values of Modified $\mathrm{J}\left(\mathrm{J}_{\mathrm{M}}\right)$ were calculated, following the procedures outlined by Ernst, Paris, and Landes (Ref. 2.7). J-resistance curves from these six compact-specimen tests are shown in Figure 2.25 and values of $\mathrm{J}_{\mathrm{i}}$ and $\mathrm{dJ} / \mathrm{da}$ are summarized in Table 2.19 . 


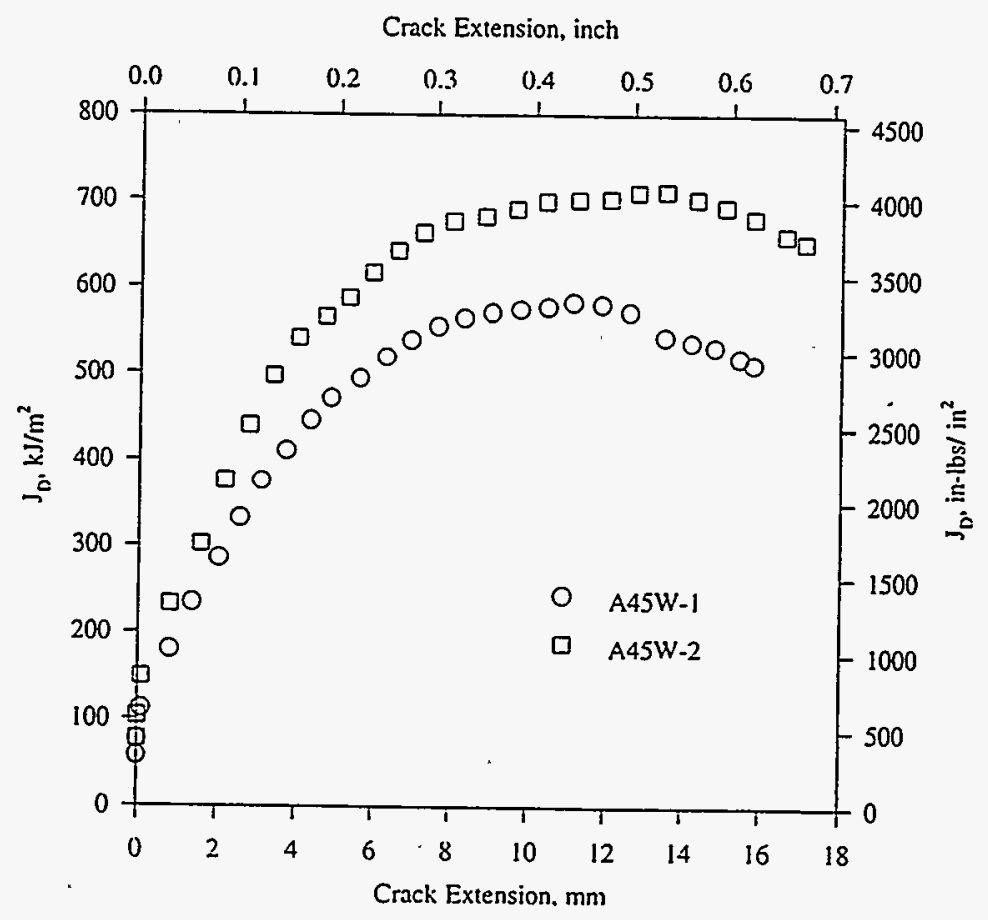

Figure 2.22 J-resistance curves at $288 \mathrm{C}(550 \mathrm{~F})$ for non-side-grooved, fatigue-cracked 1T compact specimens machined from submerged-arc weld DP2-A45W1 in a TP304 plate (Ref. 2.1)

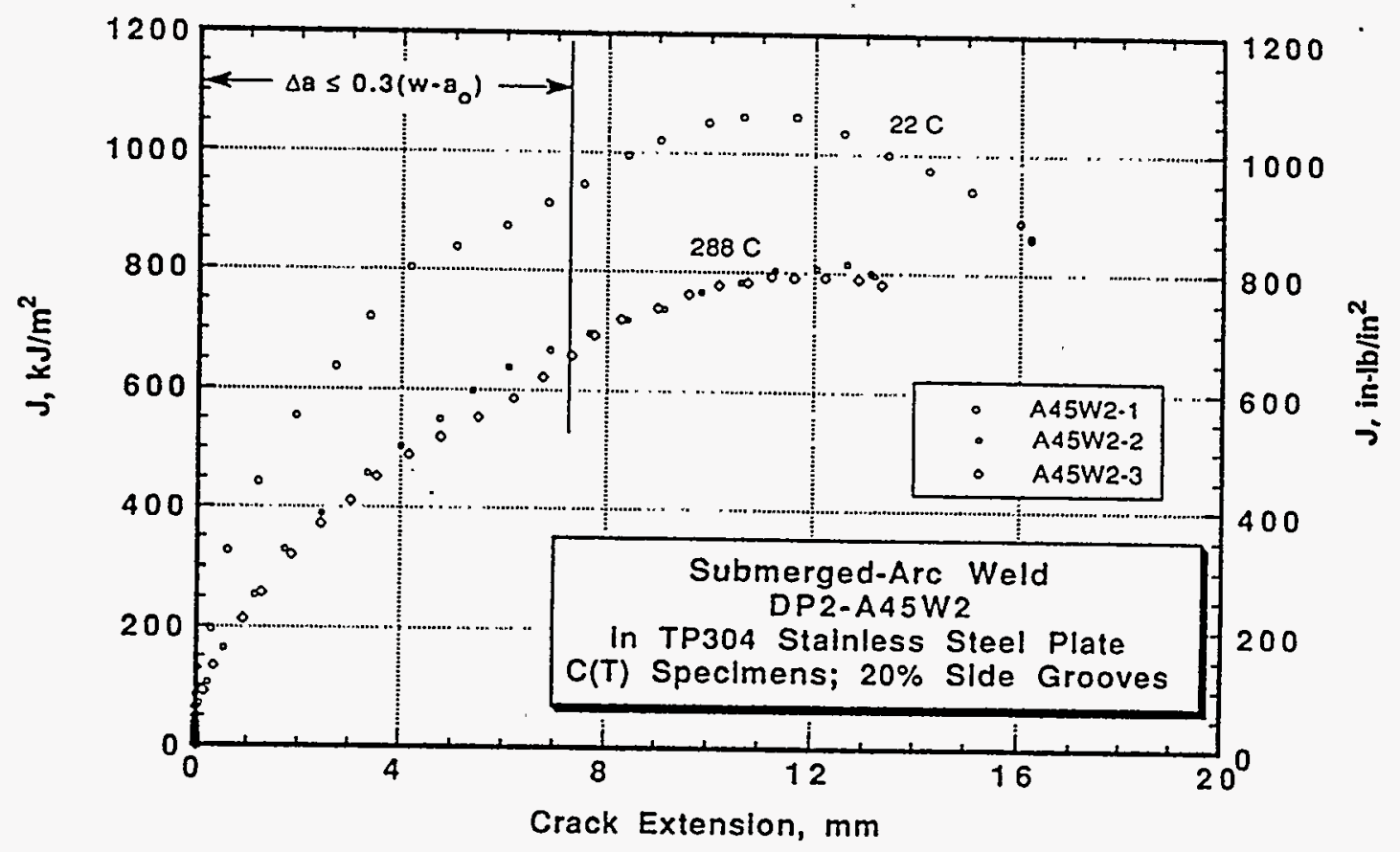

Figure 2.23 J-resistance curves at $288 \mathrm{C}(550$ F) for $\mathrm{C}(\mathrm{T})$ specimens having 20-percent side grooves machined from submerged-arc weld DP2-A45W2 in a TP304 plate 


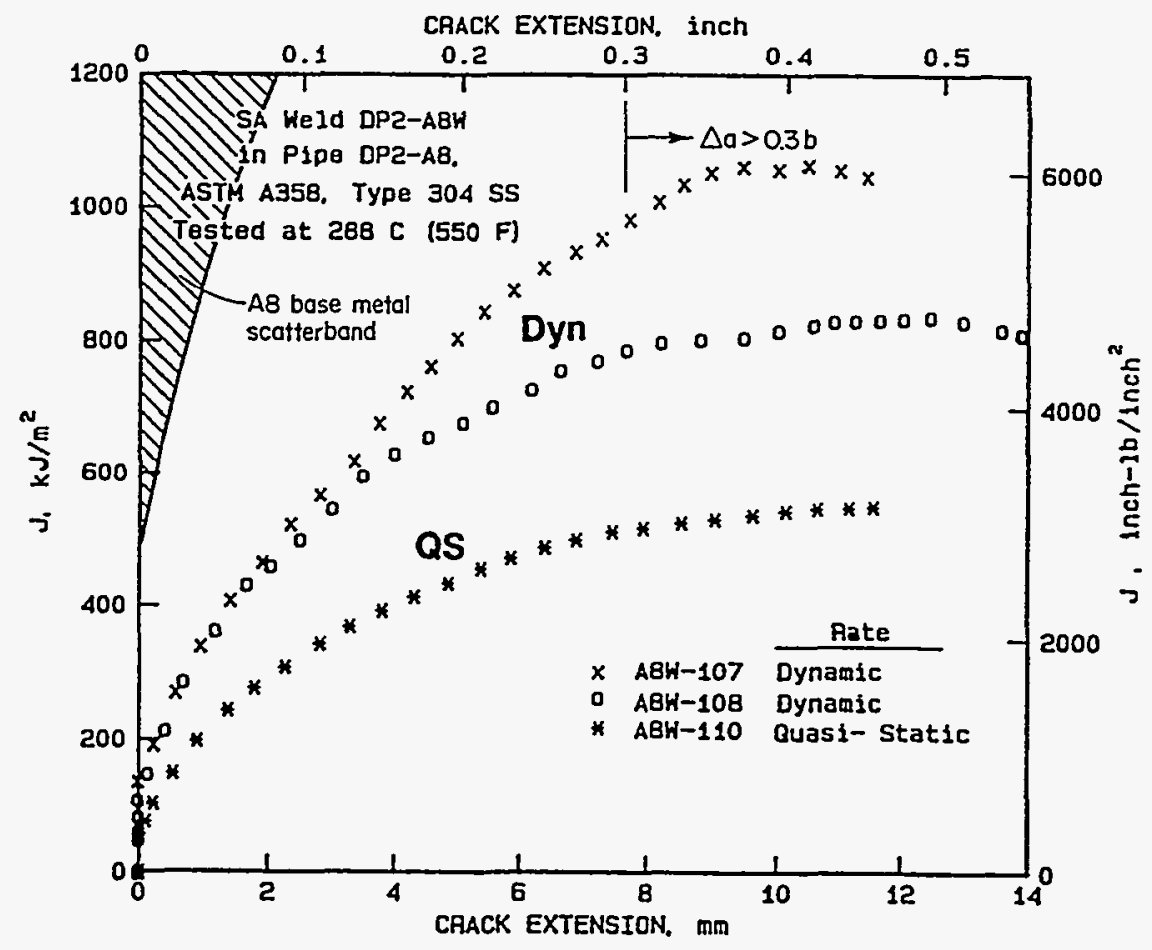

Figure 2.24 J-resistance curves at $288 \mathrm{C}(550 \mathrm{~F})$ for compact specimens from submerged-arc weld DP2-A8W4 in a TP304 stainless steel pipe (Ref. 2.4)

Table 2.18 Summary table showing the average $J_{i}$ and $d J / d a$ values at $288 \mathrm{C}(550 \mathrm{~F})$ for quasi-static testing rates for Welds DP2-A45W1, DP2-A45W2, and DP2-A8W4

\begin{tabular}{|c|c|c|c|c|}
\hline $\begin{array}{c}\text { Weld } \\
\text { Identification }\end{array}$ & $\begin{array}{c}\text { Plate or } \\
\text { Pipe Weld }\end{array}$ & $\begin{array}{l}\text { Program Which } \\
\text { Developed Data }\end{array}$ & $\begin{array}{l}\mathrm{J} \text { at Initiation, } \\
\mathrm{kJ} / \mathrm{m}^{2} \text { (in-lb/in }\end{array}$ & $\begin{array}{c}\mathrm{dJ} / \mathrm{da}^{(\mathrm{a})} \\
\mathrm{MJ} / \mathrm{m}^{3}\left(\mathrm{in}-\mathrm{lb} / \mathrm{in}^{3}\right)\end{array}$ \\
\hline DP2-A45W1 & Plate & Degraded Piping & $108^{(\mathrm{b})}\left(616^{(\mathrm{b})}\right)$ & $109(15,800)$ \\
\hline DP2-A45W2 & Plate & Short Cracks & $\begin{array}{l}59.7^{(\mathrm{c})}\left(341^{(\mathrm{c})}\right) \\
47.3^{(\mathrm{d})}\left(270^{(\mathrm{d})}\right)\end{array}$ & $\begin{array}{l}160(23,250) \\
147(21,350)\end{array}$ \\
\hline \multirow[t]{2}{*}{ DP2-A8W4 } & Pipe & IPIRG-1 & $55.2^{(\mathrm{c})}\left(315^{(\mathrm{c})}\right)$ & $135(19,550)$ \\
\hline & & Average & $(385)$ & $138(19,990)$ \\
\hline
\end{tabular}

(a) Using data from initial portion of J-R curve; $0.15 \mathrm{~mm}$ (0.006 inch) $<\Delta \mathrm{a}<1.5 \mathrm{~mm}$ (0.060 inch).

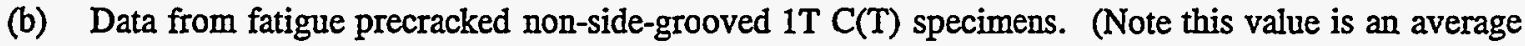
value of two specimens. There were also $3 \mathrm{~T}$ and $9.5 \mathrm{~T}$ specimens tested with the same thickness. See NUREG/CR-4575, Table 3.1 (Ref. 2.9).

(c) Data from fatigue precracked 20-percent side-grooved specimens.

(d) Data from fatigue precracked non-side-grooved specimens. 


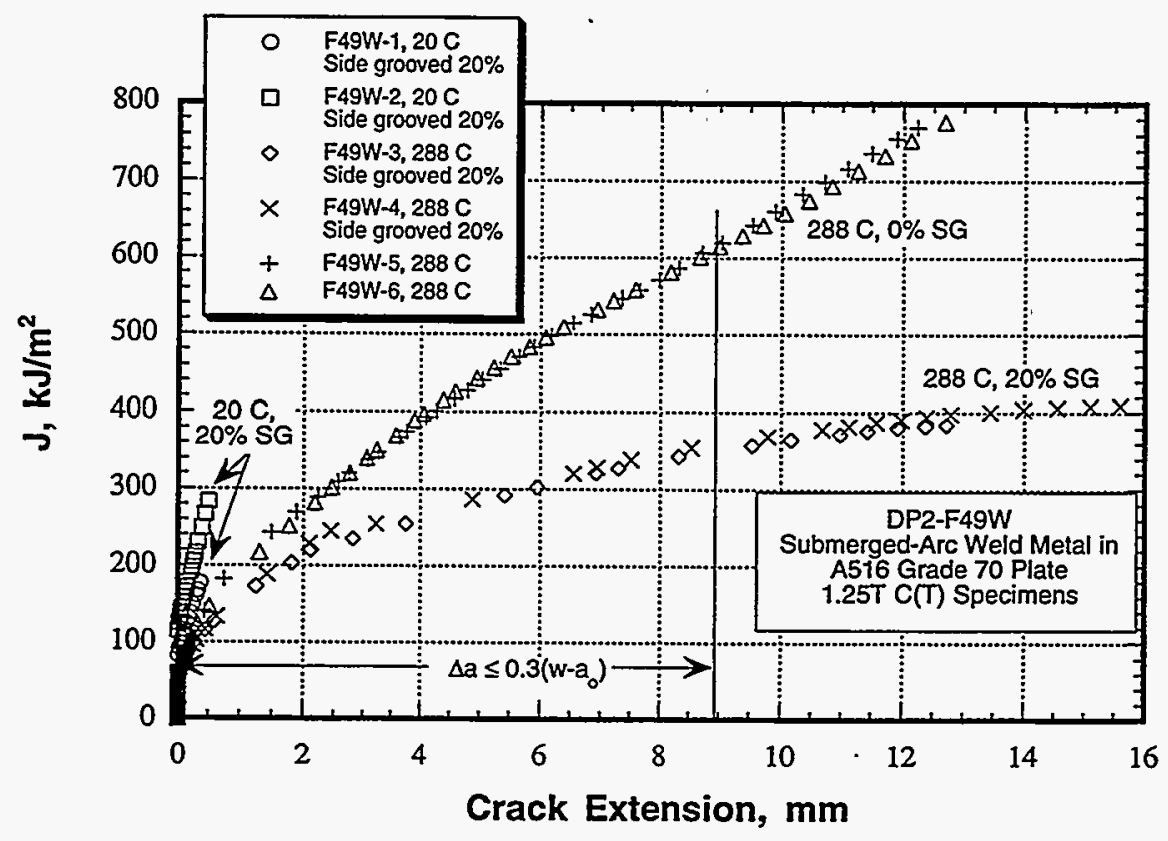

Figure 2.25 Composite plot of J-resistance curves for SAW DP2-F49W tests

Table 2.19 Summary of $J_{i}$ and $d J / d a$ values obtained from compact specimens machined from Weld DP2-F49W

\begin{tabular}{|c|c|c|c|c|c|c|c|}
\hline \multirow{2}{*}{$\begin{array}{l}\text { Specimen } \\
\text { Identification } \\
\text { No. } \\
\text { F49W-1 }\end{array}$} & \multicolumn{2}{|c|}{$\begin{array}{c}\text { Test } \\
\text { Temperature, } \\
\text { C (F) }\end{array}$} & & \multicolumn{2}{|c|}{$\begin{array}{l}\mathrm{J} \text { at Initiation, } \\
\mathbf{k J} / \mathbf{m}^{2}\left(\mathrm{in}-\mathrm{lb} / \mathbf{i n}^{2}\right)\end{array}$} & \multicolumn{2}{|c|}{$\mathbf{d J} / \mathbf{d a}^{(\mathrm{a})}$} \\
\hline & 22 & $(72)$ & & 84 & $(479)$ & $256^{(\mathrm{b})}$ & $(37,125)$ \\
\hline \multirow[t]{2}{*}{ F49W-2 } & 22 & $(72)$ & & 117 & $(665)$ & $316^{(b)}$ & $(45,830)$ \\
\hline & & & Average & 101 & $(572)$ & 286 & $(41,480)$ \\
\hline F49W-3 & 288 & $(550)^{\circ}$ & & 53 & (303) & 65.0 & $(9,430)$ \\
\hline \multirow[t]{2}{*}{ F49W-4 } & 288 & $(550)$ & & 59 & (336) & 65.0 & $(9,430)$ \\
\hline & & & Average & 56 & $(320)$ & 65.0 & $(9,430)$ \\
\hline F49W-5 ${ }^{(c)}$ & 288 & $(550)$ & & 55 & (315) & 93.0 & $(13,490)$ \\
\hline \multirow[t]{2}{*}{ F49W-6 (d) $^{(\mathrm{d})}$} & 288 & $(550)$ & & 62 & (356) & 93.0 & $(13,490)$ \\
\hline & & & Average & 59 & (336) & 93.0 & $(13,490)$ \\
\hline
\end{tabular}

(a) Linear fit of J-R curve for crack growth of $0.15 \mathrm{~mm}(0.006 \mathrm{inch})$ to $1.5 \mathrm{~mm}(0.060 \mathrm{inch})$.

(b) Stable crack growth less than $1.5 \mathrm{~mm}$ (0.06 inch).

(c) Non-side grooved; other specimens were side grooved 20 percent. 


\subsection{References}

2.1 Wilkowski, G. M., and others, "Degraded Piping Program -Phase II," Summary of Technical Results and Their Significance to Leak-Before-Break and In-Service Flaw Acceptance Criteria, March 1984-January 1989, by Battelle Columbus Division, NUREG/CR-4082, Vol. 8, March 1989.

2.2 Hiser, A. L. and Callahan, G. M., "A User's Guide to the NRC's Piping Fracture Mechanics Database (PIFRAC)," NUREG/CR-4894, May 1987.

2.3 Marschall, C. W., Mohan, R., Krishnaswamy, P., and Wilkowski, G. M., "Effect of Dynamic Strain Aging on the Strength and Toughness of Nuclear Ferritic Piping at LWR Temperatures," NUREG/CR-6226, October 1994.

2.4 Marschall, C. W., Landow, M., and Wilkowski, G. M., "Loading Rate Effects on Strength and Fracture Toughness of Pipe Steels Used in Task 1 of the IPIRG Program," NUREG/CR-6098, October 1993.

2.5 Schwalbe, K. and Hellmann, D., "Application of the Electric Potential Method to Crack Length Measurements Using Johnson's Formula," Journal of Testing and Evaluation, Vol. 9., No. 3, pp. 218-221, May 1981 .

2.6 Marschall, C. W., Held, P. R., Landow, M. P., and Mincer, P. N., "Use of the Direct-Current Electric Potential Method to Monitor Large Amounts of Crack Growth in Highly Ductile Metals," Fracture Mechanics: Twenty-First Symposium. ASTM STP 1074, J. P. Gudas, J. A. Joyce, and E. M. Hackett, Eds., American Society for Testing and Materials, Philadelphia, pp. 581-593, 1990.

2.7 Enst, H. A., Paris, P. C., and Landes, J. D., "Estimation of the J-Integral and Tearing Modulus T from Single Specimen Test Record," Fracture Mechanics - 13th Conference, ASTM STP 743, R. Roberts, ed., American Society for Testing and Materials, pp. 476-502, 1981.

2.8 Ernst, H. A. and Paris, P. C., "Techniques of Analysis of Load-Displacement Records by J-Integral Method," NUREG/CR-122, January 1980.

2.9 Papaspyropoulos, V., Marschall, C., and Landow, M., "Predictions of J-R Curves with Large Crack Growth From Small Specimen Data," NUREG/CR-4575, September 1986. 


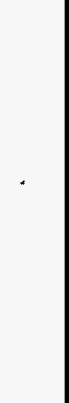




\subsection{PIPE EXPERIMENTS}

During the Degraded Piping Program - Phase II (Ref. 3.1) a number of experiments were conducted on relatively small diameter pipes (406-mm [16-inch] diameter and smaller) with circumferential surface cracks, see Table 3.1. The loading conditions were four-point bending with no internal pipe pressure, internal pipe pressure with no bending, and combined pressure and four-point bending. A number of materials (ferritic and austenitic base metals and welds) and a variety of pipe radius-tothickness ratios $\left(R_{m} / t\right)$ were evaluated. In each case the size of the internal circumferential surface crack was relatively large. The typical crack size evaluated in the Degraded Piping Program was 50 percent of the pipe circumference in length and 66 percent of the pipe wall thickness in depth. In addition to this Degraded Piping Program data, there were eight surface-crack pipe experiments conducted as part of a program conducted at Battelle for EPRI (Ref. 3.2). Test conditions, experimental results, and material property data for each of these surface-crack experiments are included in the circumferentially cracked pipe fracture database, CIRCUMCK.WK1, compiled as part of this program (Ref. 3.3.). Two elements lacking in this database were surface-cracked pipe fracture data for larger diameter pipe and data for shorter crack lengths. The test matrix for this program was designed to address these needs.

\subsection{Test Matrix}

The test matrix of experiments on pipes with short circumferential surface cracks conducted for this program is shown in Table 3.2. The test matrix contains six experiments. Two sets of experiments are shown in Table 3.2, one group of relatively small diameter pipes for which limit-load conditions should prevail, and one group of relatively large diameter pipes for which elastic-plastic conditions should prevail.

\subsubsection{Smaller Diameter Surface-Cracked-Pipe Fracture Experiments Subjected to Pure Bending for Assessing Limit-Load Analyses for Short Cracks}

The first three experiments listed in Table 3.2 (Experiments 1.2.1.20, 1.2.1.21, and 1.2.1.22) are experiments using high toughness stainless steel pipe for which limit-load conditions should prevail. Data from these experiments will be used to assess if a correction is needed for the surface-cracked pipe Net-Section-Collapse analysis. As part of the Degraded Piping Program (Ref. 3.1), it was found that the larger diameter, thinner-wall pipe specimens (i.e., larger $\mathrm{R}_{\mathrm{m}} / \mathrm{t}$ ratios) were failing at stress levels below what would be expected based on the Net-Section-Collapse analysis, even though the materials evaluated were tough enough that limit-load conditions should have been satisfied based on the Dimensionless-Plastic-Zone Parameter (DPZP) screening criterion (Ref. 3.4). As part of the Degraded Piping Program, an empirical correction factor for the Net-Section-Collapse analysis for circumferentially surface-cracked pipe in pure bending was developed (Ref. 3.5), see Figure 3.1. The data represented in Figure 3.1 are for experiments with relatively large surface cracks, typically 50 percent of the pipe circumference in length and 66 percent of the pipe wall thickness in depth. As a 
Table 3.1 Matrix of experiments on pipes with circumferential surface cracks conducted as part of the Degraded Piping Program - Phase II (Ref. 3.1)

\begin{tabular}{|c|c|c|c|c|c|c|c|}
\hline $\begin{array}{c}\text { Experiment } \\
\text { No. } \\
\end{array}$ & $\begin{array}{l}\text { Nominal Pipe } \\
\text { Diameter, } \\
\text { mm (inch) }\end{array}$ & Material & Schedule & $\mathbf{R}_{\mathrm{m}} / \mathbf{t}$ & $\begin{array}{c}\text { a/t, } \\
\text { percent }\end{array}$ & $\begin{array}{c}\theta / \pi, \\
\text { percent }\end{array}$ & $\begin{array}{c}\text { Internal Pipe } \\
\text { Pressure, } \\
\text { MPa (psi) }\end{array}$ \\
\hline \multicolumn{8}{|c|}{ Surface-Cracked Pipe Subjected to Pure Bending Loads } \\
\hline $4112-1$ & $406(16)$ & TP316L & $40 \mathrm{~S}$ & 20.2 & 65.8 & 51.1 & - \\
\hline $4112-2$ & $152(6)$ & TP304 & 40 & 11.4 & 63.4 & 50.2 & - \\
\hline $4112-3$ & $152(6)$ & TP304 & 120 & 5.7 & 65.9 & 51.8 & - \\
\hline $4112-4$ & $152(6)$ & TP304 & $\mathrm{XXS}$ & 3.2 & 65.3 & 63.1 & - \\
\hline $4112-5$ & $152(6)^{\circ}$ & A106B & 40 & 10.9 & 63.1 & 50.8 & - \\
\hline $4112-6$ & $152(6)$ & $\mathrm{A} 106 \mathrm{~B}$ & 120 & 5.2 & 68.0 & 50.3 & - \\
\hline $4112-7$ & $152(6)$ & A106B & $\mathrm{XXS}$ & 3.4 & 63.3 & 52.6 & - \\
\hline $4112-8$ & $406(16)$ & $\mathrm{A} 106 \mathrm{~B}$ & 100 & 7.1 & 66.2 & 53.2 & - \\
\hline $4112-9$ & $406(16)$ & A106B & 40 & 15.4 & 66.2 & 53.5 & - \\
\hline $4115-1$ & $254(10)$ & A333 Gr. 6 & 100 & 7.2 & 70.0 & 42.0 & - \\
\hline $4115-2$ & $254(10)$ & A333 Gr. 6 & 100 & 7.4 & 71.0 & 43.0 & - \\
\hline $4115-4$ & $152(6)$ & TP304 & 120 & 5.1 & 49.0 & 52.0 & - \\
\hline $4115-5$ & $152(6)$ & TP304 & 120 & 5.1 & 60.0 & 41.5 & - \\
\hline $4115-7$ & $152(6)$ & TP304 & 120 & 5.5 & 64.7 & 100.0 & - \\
\hline $4115-8$ & 152 (6) & TP304 & 120 & 5.5 & 62.6 & 100.0 & - \\
\hline $4115-9$ & 152 (6) & TP304 & 120 & 5.5 & 65.5 & 100.0 & - \\
\hline $4131-6$ & $152(6)$ & TP304 & 120 & 5.1 & 69.0 & 53.5 & - \\
\hline $4131-8$ & $254(10)$ & A333 Gr. 6 & 100 & 8.5 & 67.8 & 48.0 & - \\
\hline \multicolumn{8}{|c|}{ Surface-Cracked Pipe Subjected to Pure Pressure Loads } \\
\hline $4121-3$ & $152(6)$ & TP304 & 120 & 5.7 & 70.0 & 50.0 & $41.9(6,075)$ \\
\hline $4121-6$ & $254(10)$ & A333 Gr. 6 & 100 & 5.5 & 68.0 & 50.0 & $43.4(6,300)$ \\
\hline \multicolumn{8}{|c|}{ Surface-Cracked Pipe Subjected to Combined Pressure and Bending } \\
\hline $4131-2$ & $152(6)$ & TP304 & 120 & 5.8 & 70.9 & 52.1 & $24.5(3,550)$ \\
\hline $4131-4$ & $254(10)$ & A333 Gr. 6 & 100 & 7.7 & 65.9 & 52.5 & $18.3(2,650)$ \\
\hline $4141-2$ & $152(6)$ & TP304 SAW & 120 & 5.1 & 64.2 & 50.0 & $15.2(2,200)$ \\
\hline $4141-4$ & $406(16)$ & TP304 SAW & 100 & 7.4 & 67.0 & 50.0 & $11.0(1,600)$ \\
\hline $4141-6$ & $406(10)$ & TP304 SAW & 100 & 7.4 & 68.6 & 50.0 & $11.0(1,600)$ \\
\hline $4141-8$ & $406(16)$ & A106B SAW & 100 & 7.4 & 67.0 & 50.0 & $15.5(2,250)$ \\
\hline $4143-1$ & $406(16)$ & Aged CF8M & 100 & 7.1 & 55.0 & 50.0 & $15.5(2,250)$ \\
\hline $4143-2$ & $305(12)$ & Aged CF8M & 160 & 4.7 & 65.3 & 50.0 & $15.5(2,250)$ \\
\hline $4143-3$ & 305 (12) & Aged CF8M & 160 & 4.9 & 66.0 & 58.0 & $15.5(2,500)$ \\
\hline
\end{tabular}


Table 3.2 Test matrix for surface-cracked pipe experiments conducted as part of the Short Cracks in Piping and Piping Welds Program

\begin{tabular}{|c|c|c|c|c|c|c|c|c|c|}
\hline $\begin{array}{c}\text { Experiment } \\
\text { No. }\end{array}$ & $\begin{array}{l}\text { Nominal } \\
\text { Pipe } \\
\text { Diameter, } \\
\text { mm (inch) }\end{array}$ & Schedule & $R_{m} / t$ & Material & $\begin{array}{c}\text { Battelle } \\
\text { Material } \\
\text { Identification } \\
\text { No. }\end{array}$ & $\begin{array}{c}\text { Test } \\
\text { Temperature, } \\
\text { C (F) }\end{array}$ & $\begin{array}{c}\text { Test } \\
\text { Pressure, } \\
\text { MPa (psi) }\end{array}$ & $a / t$ & $\theta / \pi$ \\
\hline \multicolumn{10}{|c|}{ Small Diameter Short Surface-Crack Experiments } \\
\hline 1.2.1.20 & $406(16)$ & 30 & 20.9 & TP304 & DP2-AS2 & $99(210)$ & $1.55(225)$ & 0.476 & 0.25 \\
\hline 1.2 .1 .21 & $152(6)$ & $\mathrm{XXS}$ & 3.5 & TP304 & DP2-A35 & $288(550)$ & - & 0.50 & 0.218 \\
\hline 1.2 .1 .22 & $152(6)$ & 40 & 11.4 & TP304 & DP2-A7 & $288(550)$ & - & 0.50 & 0.25 \\
\hline \multicolumn{10}{|c|}{ Large Diameter Short Surface-Crack Experiments } \\
\hline 1.2.3.15 & $711(28)$ & - & 15.2 & A515 Gr. 60 & DP2-F26 & $288(550)$ & $9.56(1,387)$ & 0.50 & 0.25 \\
\hline 1.2.3.16 & $711(28)$ & - & 11.3 & TP316L SAW & DP2-A51 & $288(550)$ & $10.1(1,470)$ & 0.50 & 0.25 \\
\hline 1.2 .3 .17 & $610(24)$ & 120 & 6.6 & A106B SAW & AEC-C5 & $288(550)$ & $15.5(2,250)$ & 0.605 & 0.25 \\
\hline
\end{tabular}

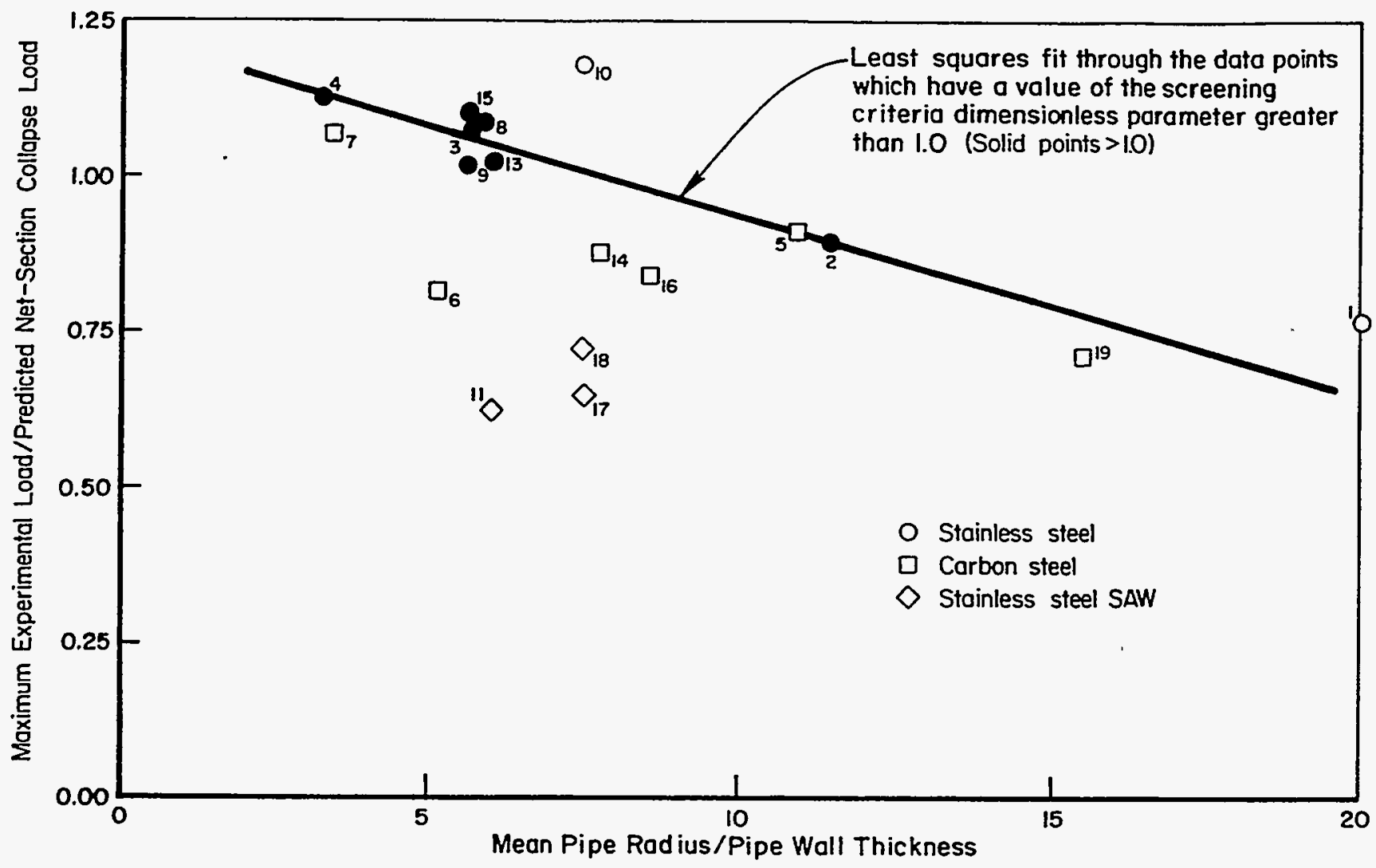

Figure 3.1 Empirical ovalization correction factor for circumferentially surface-cracked pipe in bending $(a / t=0.66$ and $\theta / \pi=0.5$ ), Ref. 3.1 $\left(\sigma_{\mathrm{a}}=\right.$ axial stress, $\sigma_{\mathrm{b}}=$ bending stress, $\sigma_{\mathrm{NSC}}=$ Net-Section-Collapse predicted bending stress) 
result, data on smaller crack sizes are needed to generalize such a correction factor. This $R_{m} / t$ correction for the Net-Section-Collapse analysis is necessary since many of the elastic-plastic fracture analyses and code flaw assessment criteria (i.e., IWB-3640 and IWB-3650 from Section XI of the ASME Code) have the Net-Section-Collapse analysis as their technical basis limit-load solution.

The initial surface-crack size for each of the experiments conducted as part of this effort was 25 percent of the pipe circumference in length and 50 percent of the pipe wall thickness in depth. This initial flaw size was based on pretest analysis, which showed that these dimensions were the smallest flaw size that would allow fracture prior to the onset of pipe buckling of the largest $R_{m} / t$ pipe. In addition to these data, there were two experiments on small-diameter, stainless steel pipes with relatively short surface cracks conducted as part of the Battelle/EPRI program (Ref. 3.2), which were also used for this assessment of the $R_{m} / t$ correction. The mean pipe radius-to-thickness ratios $\left(R_{m} / t\right)$ for these five smaller diameter pipe experiments ranged from 3.5 to 21 .

The pipe material for each experiment was a high toughness stainless steel. Therefore, for the pipe diameters under consideration in this subtask, limit-load conditions should have occurred. This will facilitate the analysis of the data in that any lowering of the failure moments with respect to the NetSection-Collapse predicted moments can be attributed to ovalization effects and not contained plasticity, i.e., elastic-plastic conditions.

The two 152-mm (6-inch) nominal-diameter pipe experiments conducted as part of this effort were unpressurized. Initially it was planned that all three pipe experiments would be unpressurized. However, it was determined during the course of the program that the test specimen for the 406-mm (16-inch) diameter Schedule 30 specimen (Experiment 1.2.1.20) had to be pressurized to minimize the risk of the test specimen buckling during the course of the loading. The fact that the pipe in this experiment was pressurized is not ideal since the internal pipe pressure stiffens the pipe and influences the amount of ovalization and, thus, the empirical correction factor associated with this experiment. However, it was deemed necessary to pressurize this pipe specimen because the 152-mm (6-inch) nominal diameter Schedule 40 pipe sample (Experiment 1.2.1.22) buckled prior to attaining maximum load. Consequently, this 406-mm (16-inch) diameter pipe, with a larger $\mathrm{R}_{\mathrm{m}} / \mathrm{t}$ ratio (21 versus 12 for the $152-\mathrm{mm}$ (6-inch) diameter, Schedule 40 pipe specimen) would also probably have buckled prior to attaining maximum load if it had not been pressurized. The pipe pressure chosen for this experiment (1.55 MPa [225 psi]) was the typical operating pressure of the Westinghouse Savannah River plant (donors of the pipe material) and sufficient to prevent buckling based on pretest design calculations. The test temperature for all three experiments conducted as part of this program was $288 \mathrm{C}(550 \mathrm{~F})$. The test temperature for the two EPRI short-surface-crack experiments was ambient. The pipes in both of these EPRI experiments were unpressurized.

\subsubsection{Large-Diameter Surface-Cracked Pipe Fracture Experiments Under Combined Bending and Tension (Pressure)}

The remaining three specimens listed in Table 3.2 are large diameter pipes (610-mm [24-inch] diameter and larger) having circumferential internal surface cracks for fracture experiments. The objective of these three experiments was to develop experimental data on large diameter pipes with short surface cracks under more typical combined pressure and bend loading conditions for the 
purpose of assessing the pipe flaw evaluation procedures embodied in Section XI of the ASME Code (Refs. 3.6 and 3.7) and J-estimation scheme analyses being developed, modified, and validated in Section 4 of this report.

Note, prior to this project, the database included only one large diameter, short-surface-cracked-pipe experiment, a 762-mm (30-inch) diameter carbon steel pipe experiment conducted as part of the IPIRG-1 program (Ref. 3.8.) The crack size for this experiment was relatively small, 16.6 percent of the pipe circumference in length and 50 percent of the pipe wall thickness in depth. However, the toughness of the material for this experiment was such that limit-load conditions prevailed. The test specimen was fabricated from a section of carbon steel pipe manufactured in Japan. The material specification was STS49, which is similar to A333 Grade 6. Consequently, a need existed in the pipe fracture experimental database for data on additional experiments on larger diameter pipes with short surface cracks for which elastic-plastic conditions exist.

\subsection{Test Specimen Materials}

Each of the six pipe experiments had cracks in different materials. The Battelle material identification numbers for each of these materials is included in the pipe test matrix in Table 3.2.

\subsubsection{Smaller Diameter Pipe Fracture Experiments in Pure Bending for Assessing Limit-Load Ovalization Corrections}

\subsubsection{DP2-A52}

DP2-A52 was a longitudinally seam-welded, 406-mm (16-inch) diameter, Schedule 30 (9.5-mm [0.374-inch] wall thickness), TP304 stainless steel pipe donated to this program by the operators of the Savannah River Nuclear facility. The chemical analyses, tensile properties, and fracture toughness values for this pipe material were reported in Section 2 of this report.

\subsubsection{DP2-A35}

DP2-A35 was a seamless, 152-mm (6-inch) nominal diameter, Schedule XXS (20.9-mm [0.822-inch] wall thickness), TP304 stainless steel pipe purchased from a pipe vendor by Battelle as part of the Degraded Piping Program. A pipe experiment with a long surface crack (Experiment 4112-4) was conducted using this same pipe material as part of the Degraded Piping Program. The chemical analyses, tensile properties, and fracture toughness values for this pipe material were reported in Section 2 of this report.

\subsubsection{DP2-A7}

DP2-A7 is a seamless, 152-mm (6-inch) nominal diameter, Schedule 40 (7.1-mm [0.278-inch] wall thickness), TP304 stainless steel pipe obtained from the excess pipe inventory of a nuclear power plant. A pipe experiment with a long surface crack (Experiment 4112-2) was conducted using this same pipe material as part of the Degraded Piping Program. The chemical analyses, tensile properties, and fracture toughness values for this pipe material were reported in Section 2 of this report. 


\subsubsection{Large-Diameter Surface-Cracked Pipe Fracture Experiments Under Combined Bending and Tension (Pressure)}

\subsubsection{DP2-F26}

DP2-F26 is a seam-welded, $711-\mathrm{mm}$ (28-inch) diameter by $22.2-\mathrm{mm}(0.875$-inch) nominal wall thickness, SA155-KC60-CL1 carbon steel pipe. The pipe was fabricated from A515 Grade 60 plate. The pipe was obtained from the excess pipe inventory from a nuclear power plant. The pipe would have been used as part of the steam-line piping system in the plant. A pipe experiment with a short through-wall crack (Experiment 1.1.1.21) was conducted using this same pipe material as part of Task 1 of this program (Ref. 3.3). A pipe experiment with a long through-wall crack (Experiment 4111-2) was conducted using a spool of pipe from this same pipe length as part of the Degraded Piping Program. The chemical composition, Charpy V-notch data, tensile properties, and fracture toughness values for this pipe material were reported in Section 2 of this report.

\subsubsection{DP2-A51}

DP2-A51 is a longitudinally seam welded, $711-\mathrm{mm}$ (28-inch) diameter by $30.2-\mathrm{mm}$ (1.19-inch) wall thickness, SA-240 TP316L stainless steel pipe. The pipe was obtained from the excess pipe inventory from the Nine Mile Point nuclear power plant. The pipe would have been used as part of the recirculation line piping system in that plant. The crack was located in a shop-fabricated submergedarc weld (SAW) fabricated in this program. This same weld procedure was used to fabricate a number of similar stainless steel submerged-arc welds tested in the Degraded Piping and IPIRG programs. This weld procedure was obtained from the General Electric Corporation. The chemical composition, tensile properties, and fracture toughness values for both the pipe material and weld are reported in Section 2 of this report. Charpy data for the weld metal is also given in Section 2.

\subsubsection{AEC-C5}

AEC-C5 is a $610-\mathrm{mm}$ (24-inch) diameter by 43.2-mm (1.7-inch) wall thickness A106 Grade B pipe. Originally this pipe sample was used in an Atomic Energy Commission (AEC) pipe fracture program conducted at Battelle in the 1960's (Ref. 3.9). Data already exist from this AEC program for three elevated temperature, axially flawed base metal, pipe burst tests using this pipe material. In addition, there were some material property data available, i.e., circumferential tensile, transverse Charpy, and chemical analyses, from the prior AEC program.

The circumferential surface crack for this experiment was located in a shop fabricated submerged-arc weld (SAW). This same weld procedure was used previously in Experiment 1.1.1.24, i.e., the 610$\mathrm{mm}$ (24-inch) diameter carbon steel weld through-wall-crack experiment conducted in Task 1 of this program (Ref. 3.3). The weld procedure was obtained from Babcock and Wilcox (B\&W) as being typical of the procedures used by B\&W in the construction of the Midland nuclear power plant and 90 percent of the welds in other plants. The weld wire was a high-manganese, high-molybdenum wire carrying the designations EA3 and SFA 5.23. The flux was Linde 80. The chemical composition, Charpy V-notch impact, tensile properties, and fracture toughness values for this pipe material and weld were reported in Section 2 of this report. 


\subsection{Experimental Facilities}

The $580 \mathrm{kN}$ (130 kip) MTS servo-hydraulic load frame in Battelle's Fatigue and Fracture Laboratory was the test frame used for the two 152-mm (6-inch) nominal diameter, stainless steel, surfacecracked-pipe experiments (Experiments 1.2.1.21 and 1.2.1.22), see Figure 3.2. The roller assemblies shown in Figure 3.2 allowed the pipe to rotate and translate as it was being loaded in bending. The inner and outer spans for this facility were $610 \mathrm{~mm}$ ( 24 inches) and 1,524 mm (60 inches), respectively.

Battelle's large pipe bend facility at West Jefferson, Ohio, was used for the 406-mm (16-inch) diameter Schedule 30 Savannah River pipe experiment (Experiment 1.2.1.20) and the three largediameter short-surface-crack pipe experiments (Experiments 1.2.3.15, 1.2.3.16, and 1.2.3.17), see Figure 3.3. The strongback for this facility is a large welded H-beam, $15.25-\mathrm{m}$ (50-feet) long, 2.75 meters (9-feet) wide, and 2.0-meters (6.5-feet) high. The strongback is equipped with two hydraulic rams, each with a load capacity of $2.0 \mathrm{MN}(450,000 \mathrm{lbs})$ at $20.7 \mathrm{MPa}(3,000 \mathrm{psi})$ pressure and a stroke capacity of 1.22 meters (48 inches). The spacing between the hydraulic rams (i.e., the inner span) is 3.35 meters ( 11 feet). The test pipes were held down at the ends by a series of wire ropes. The spacing between the wire ropes (i.e., outer span) was 11.6 meters (38 feet). A series of rollers on top of the rams allowed the test pipes to rotate and translate as they were being loaded in bending.

\subsection{Instrumentation and Data Acquisition}

The instrumentation scheme for the four short-crack experiments conducted at West Jefferson was very similar for each experiment. For each experiment, the following data were collected:

- $\quad$ The applied load at each actuator was measured using Lebeau ${ }^{\circledR} 1,335 \mathrm{kN}$ (300 kip) compression-only load cells in series with each load train.

- The load-line displacement of each actuator was measured using Temposonics ${ }^{\circledR}$ displacement transducers.

- The direct-current electric potential (d-c EP) was measured at multiple locations along the internal surface crack and a reference (base metal) potential reading was made remote from the crack.

- The crack-mouth-opening displacement (CMOD) at the crack centerline was measured.

- The rotation of the pipe on either side of the crack plane was measured using inclinometers. 


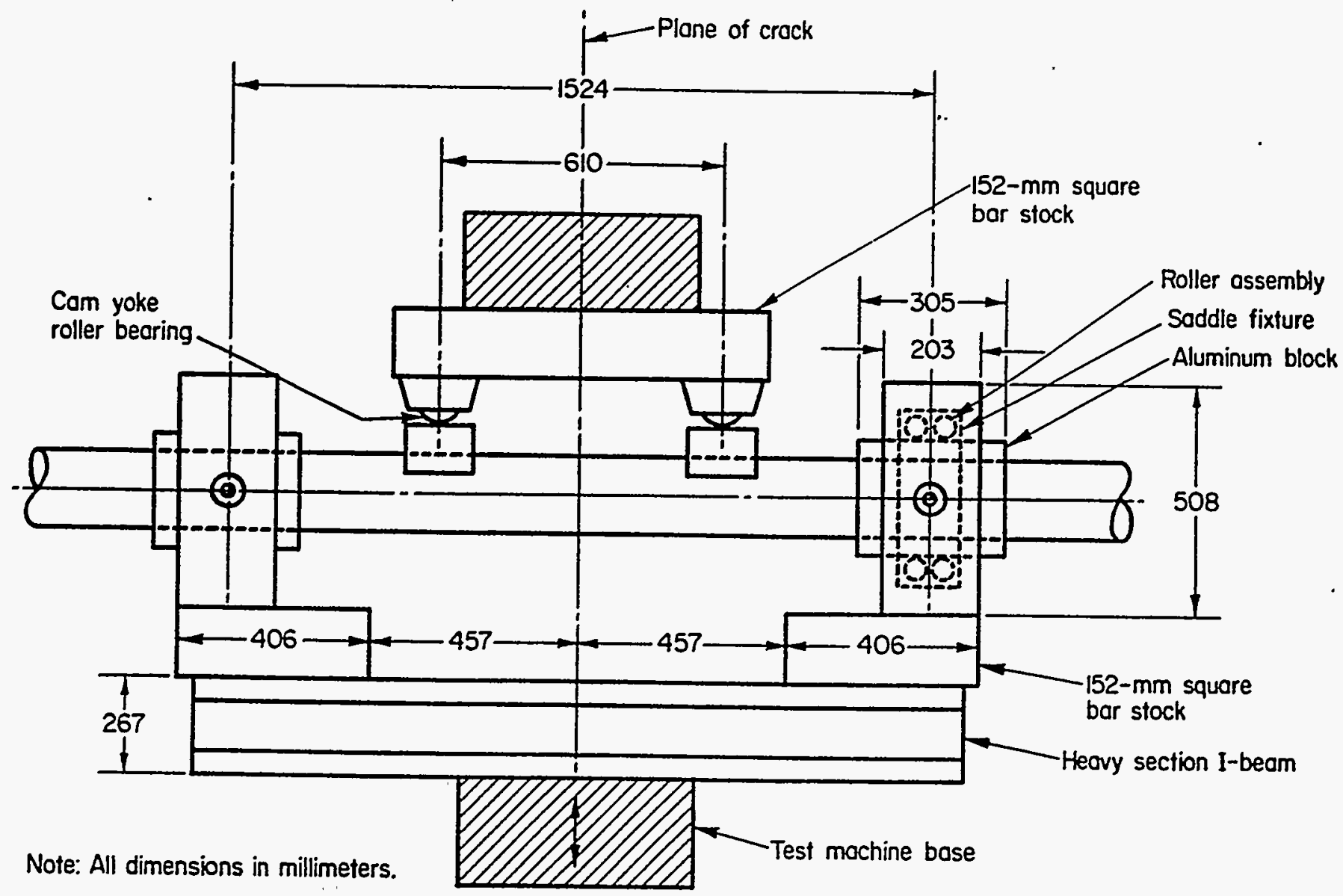

Figure 3.2 Schematic of test apparatus used in Experiments 1.2.1.21 and 1.2.1.22 


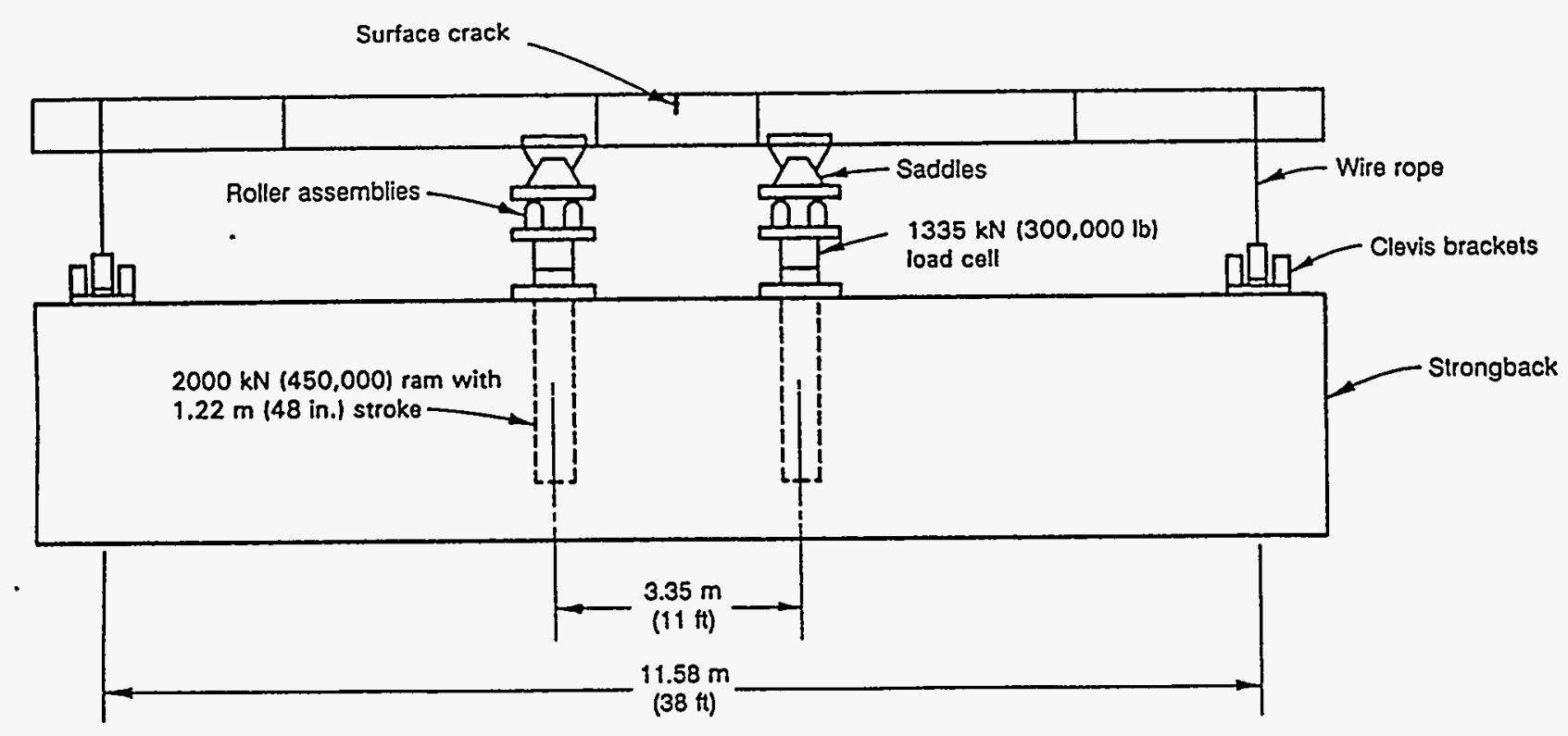

Figure 3.3 Schematic of pipe in load frame used in Experiments 1.2.1.20, 1.2.3.15, 1.2.3.16, and 1.2.3.17 
- The displacements of the pipe, relative to the outer load points, at the crack plane, 0.61 meters (24 inches) on either side of the crack plane, and 1.68 meters (66 inches) on either side of the crack plane were measured. These displacement measurements were made using a series of string potentiometers. From these displacements, the rotation of the pipe can also be determined along the length of the pipe.

- The ovalization of the pipe in the vicinity of the crack plane was measured. (Note, no ovalization data were obtained for Experiment 1.2.3.16.)

- The internal pipe pressure was measured.

- The pipe temperature was measured at several locations on the pipe surface.

In addition, for the 406-mm (16-inch) diameter, Schedule 30, TP304 stainless steel, short-surfacecracked-pipe experiment (Experiment 1.2.1.20), longitudinal and circumferential strains were measured on the internal and external surfaces of the pipe wall, directly opposite from the center of the surface crack.

For the two 152-mm (6-inch) nominal diameter stainless steel short-surface-cracked-pipe experiments, the data collected were very similar to those collected for the four larger-diameter, short-surfacecracked-pipe experiments. The major differences were that ovalization data were not obtained in these experiments, and in some cases different instrumentation schemes were used to collect the data. For example, the rotation data were acquired using an LVDT-based device instead of inclinometers.

For all six experiments, the data were acquired with a PC with Metrabyte ${ }^{\circledR}$ DAS-8, 8-channel, high speed A/D converters and Metrabyte ${ }^{\circledR}$ EXP-16 expansion multiplexer/conditioners. The computer collected data at 12-bit resolution using LabTech Notebook data acquisition and control software.

\subsection{Experimental Procedures}

Once the test pipe was placed in the loading fixture, and the final instrumentation calibration checks completed, it was heated to $288 \mathrm{C}(550 \mathrm{~F})$. The pipe was brought to temperature using a series of flexible heater tapes wound helically along the length of the pipe. The pipe was covered in fiberglass insulation prior to the test to reduce heat loss. Figure 3.4 shows a post-test photograph of Experiment 1.2.3.16 in the load frame.

After the pipe temperature had stabilized for at least 60 minutes, bending loads were applied to the pipe at quasi-static loading rates. The loading rates for the experiments conducted in the large pipe bend facility at West Jefferson were in the range of 0.71 to $10.24 \mathrm{~mm} /$ minute $(0.028$ to 0.403 inches/minute). The loading rate for the $152-\mathrm{mm}$ (6-inch) diameter experiments conducted in the 580 $\mathrm{kN}$ (130 kip) machine was $0.025 \mathrm{~mm} / \mathrm{second}$ ( $0.001 \mathrm{inch} / \mathrm{second})$. 


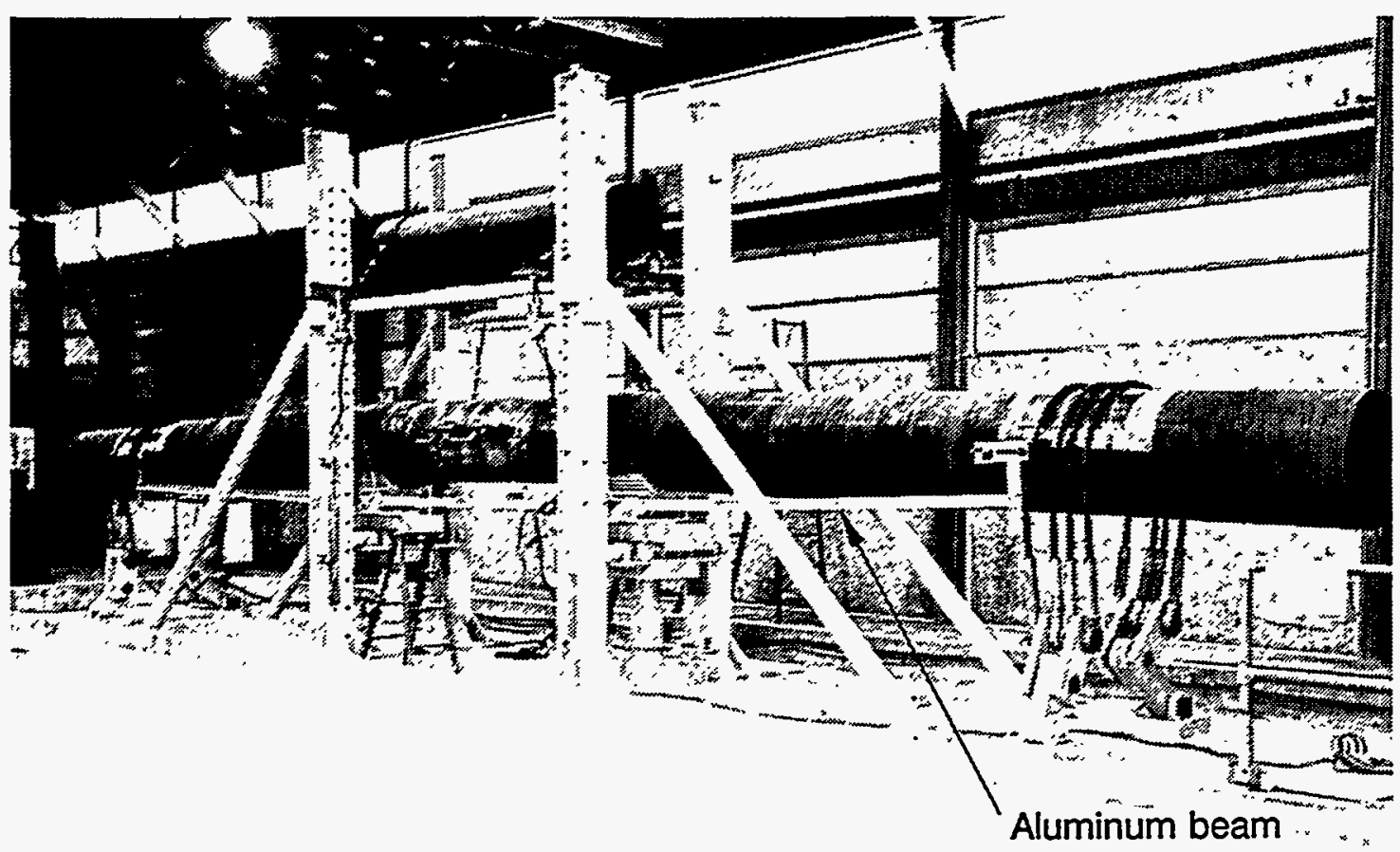

Figure 3.4 Post-test photograph of the pipe specimen in the loading frame for Experiment 1.2.3.16

\subsection{Experimental Results}

Table 3.3 presents the key results from the six pipe experiments conducted as part of this effort. Included are the material, pertinent pipe and crack dimensions, internal pipe pressure, material property data, and applied moments at crack initiation and maximum load. (Note, the moment values reported in Table 3.3 and throughout this report for the two 152-mm (6-inch) diameter, short-surfacecracked pipe experiments conducted in Battelle's Fatigue and Fracture Laboratory have been kinematically corrected to account for the large applied displacements and relatively short moment arms for these experiments.)

\subsubsection{Smaller Diameter Pipe Fracture Experiments in Pure Bending for Assessing Limit-Load Ovalization Corrections}

\subsubsection{Moment-Rotation Response}

Figures 3.5 through 3.7 are plots of the applied crack section moment as a function of crack rotation for the three smaller-diameter surface-cracked-pipe experiments, i.e., Experiments 1.2.1.20, 1.2.1.21, and 1.2.1.22, respectively.

For each figure, the half rotation angle $(\phi)$ is plotted, i.e., the angle of one moment arm of the pipe relative to its initial horizontal position. 


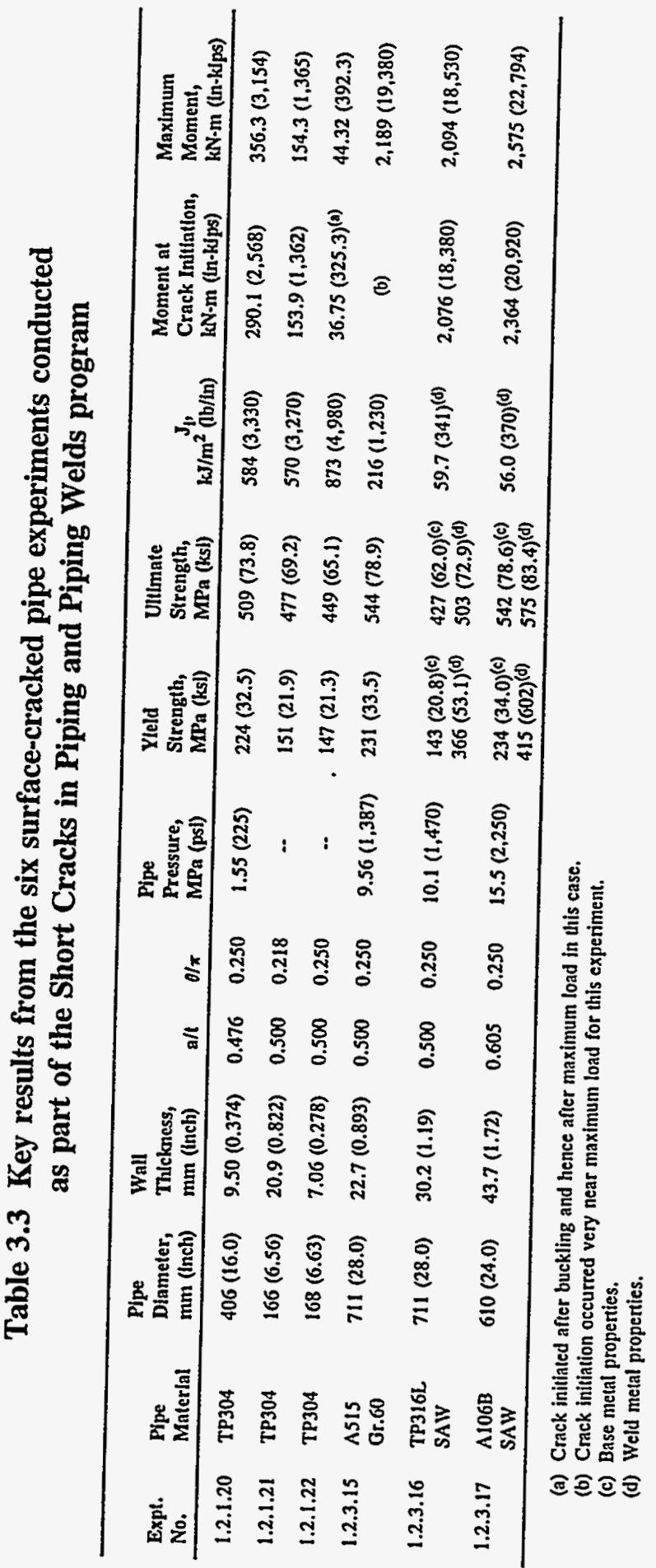




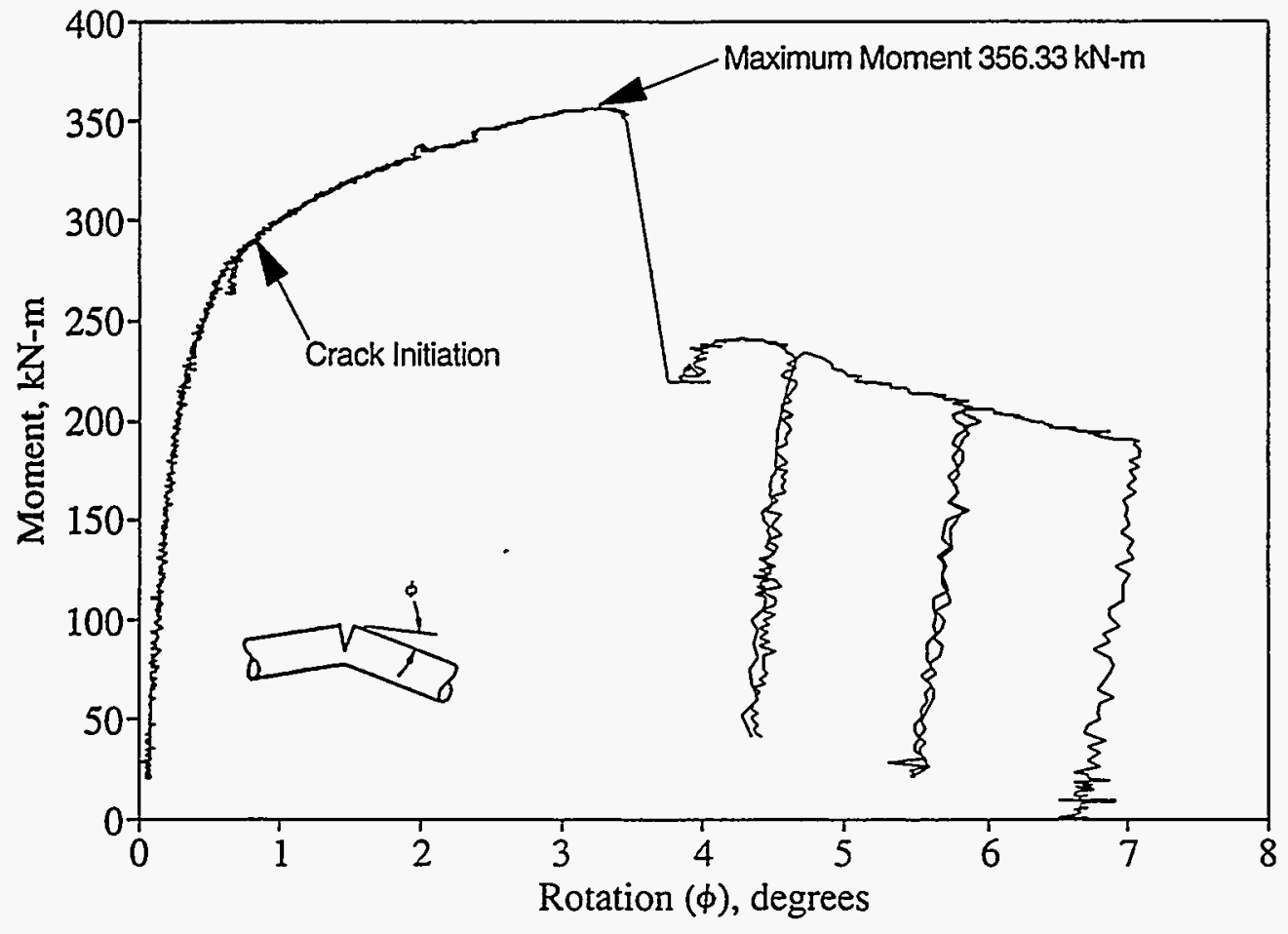

Figure 3.5 Moment versus rotation (measured with inclinometers) for Experiment 1.2.1.20

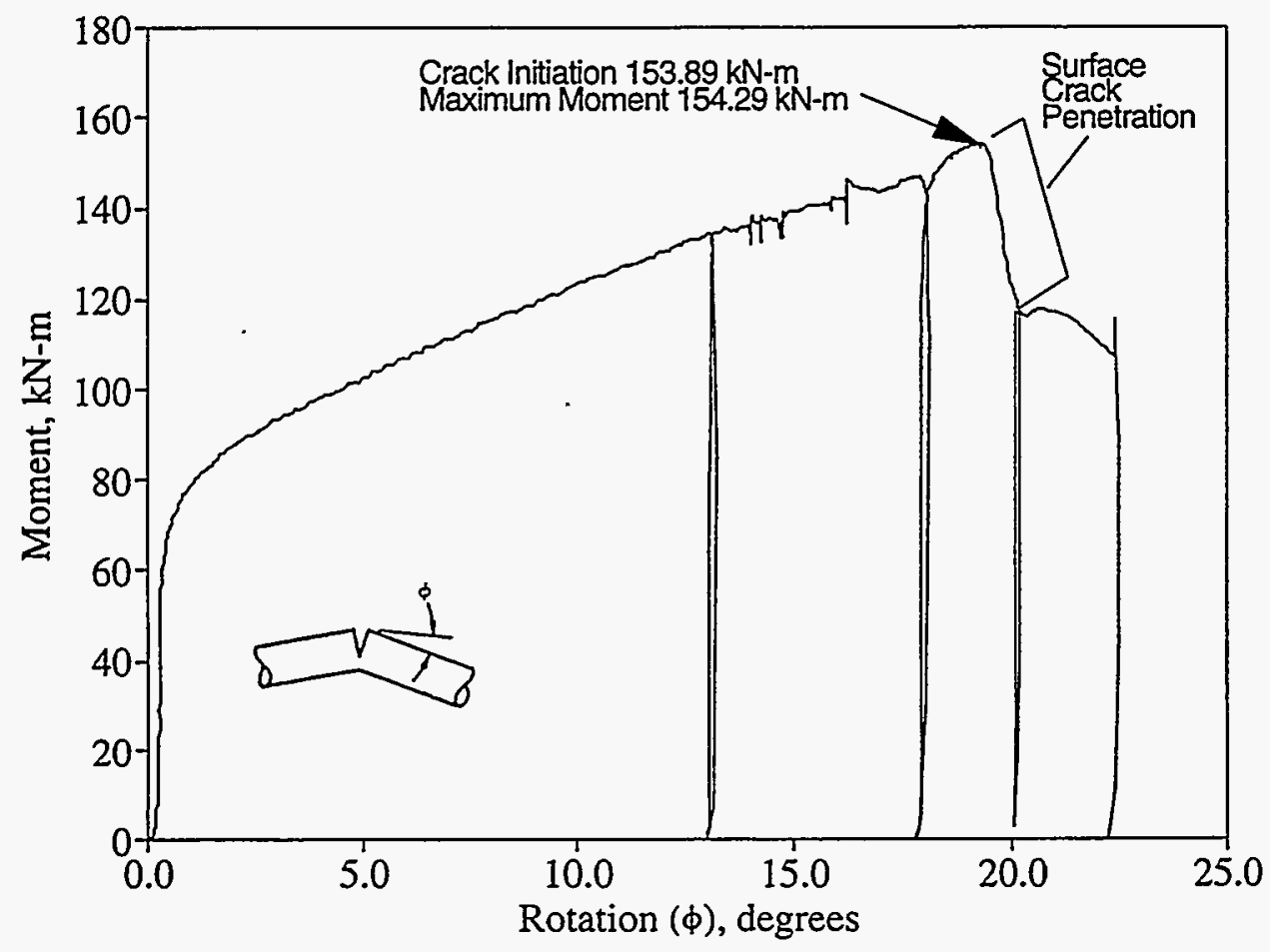

Figure 3.6 Calculated moment versus calculated half rotation angle $(\phi)$ using data on pipe displacement at the load points from Experiment 1.2.1.21 


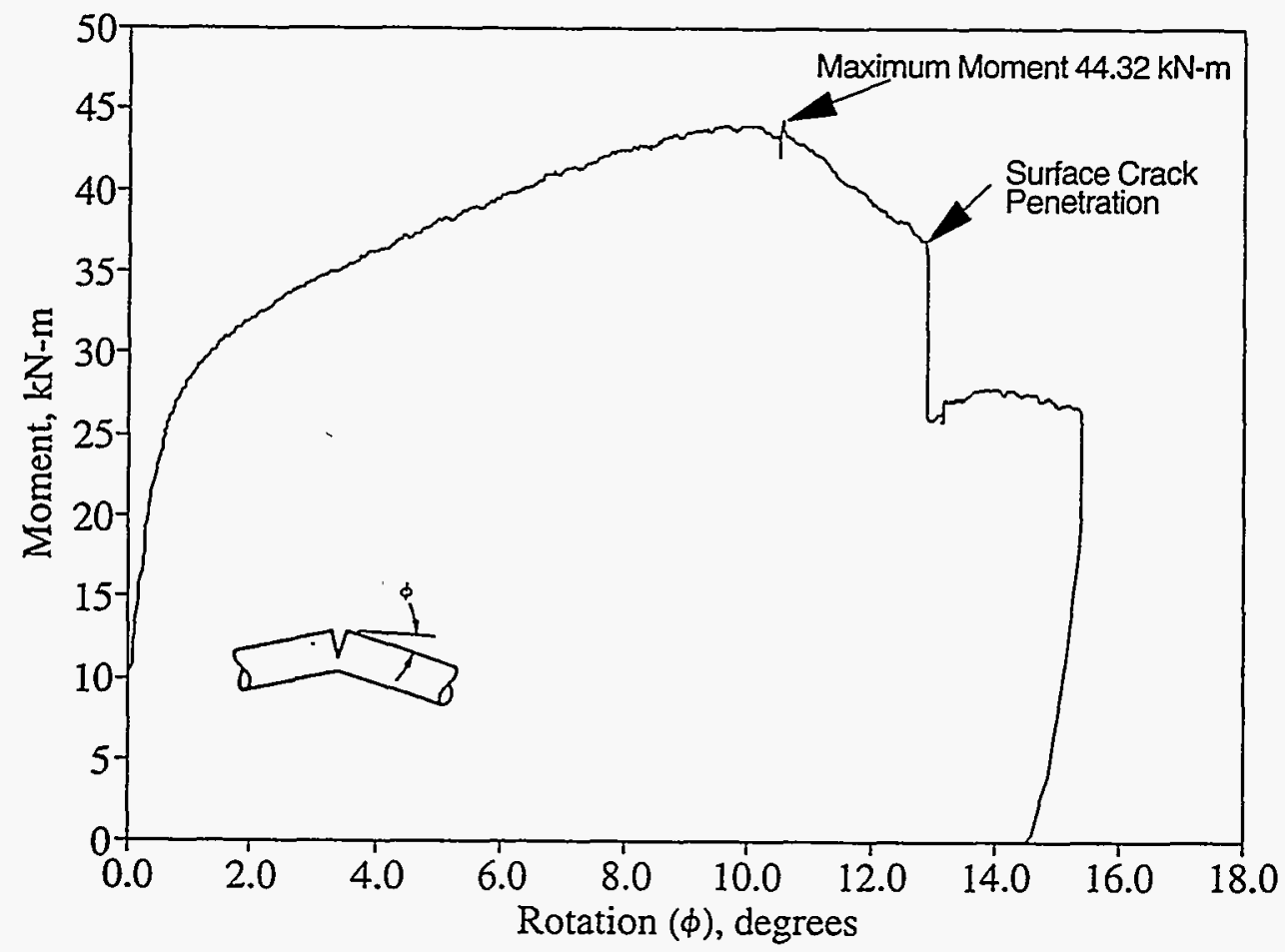

Figure 3.7 Moment versus calculated half rotation angle $(\phi)$ from data on pipe displacement at the load points from Experiment 1.2.1.22

Figure 3.5 is the moment-rotation plot for Experiment 1.2.1.20. The test specimen in this experiment buckled slightly prior to the attainment of maximum load. Figure 3.8 is a post-test photograph of the buckle at the girth weld at the east end of the test specimen. Figure 3.9 presents the rotation data from this experiment as a function of the displacement of the pipe at the load points. The rotation data in this figure are based on two different measuring systems, inclinometers and relative pipe displacement measurements. As seen in Figure 3.9, the agreement in the data for the two methods is good for displacements up to $200 \mathrm{~mm}$ (7.9 inches). After that point, the rotations based on the relative pipe displacement were less than those based on the inclinometer. This deviation between the two sets of rotation data may be an indication of when the buckle started to form. The rotation data shown in Figures 3.5 and 3.9 include the rotations due to the buckle as well as the rotations due to the crack and the pipe. The large drop in moment in Figure 3.5 immediately after the attainment of maximum load is when the surface crack penetrated the pipe wall thickness. The maximum moment for this experiment was $356.3 \mathrm{kN}-\mathrm{m}$ (3,154 in-kips). The moment at crack initiation was $290.1 \mathrm{kN}-\mathrm{m}$ (2,568 in-kips), i.e., 81.4 percent of the maximum moment for the experiment.

Figure 3.6 is the moment-rotation response for the experiment on the 152-mm (6-inch) diameter, Schedule XXS, TP304 stainless steel pipe with a short surface crack (Experiment 1.2.1.21). The second major unloading shown in Figure 3.6 occurred because the loads were so high that alignment pins in the fixturing were breaking. The specimen was unloaded and the test frame was reinforced. The reloading of the second cycle occurred several days later. Crack initiation occurred just before the maximum moment of $154.3 \mathrm{kN}-\mathrm{m}$ [1,365 in-kips], hence, limit-load conditions were met. 


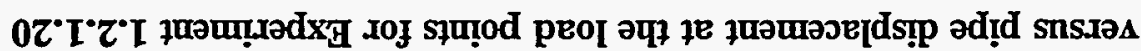

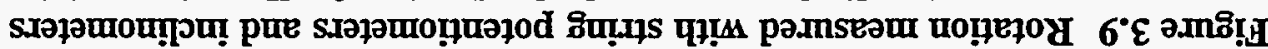

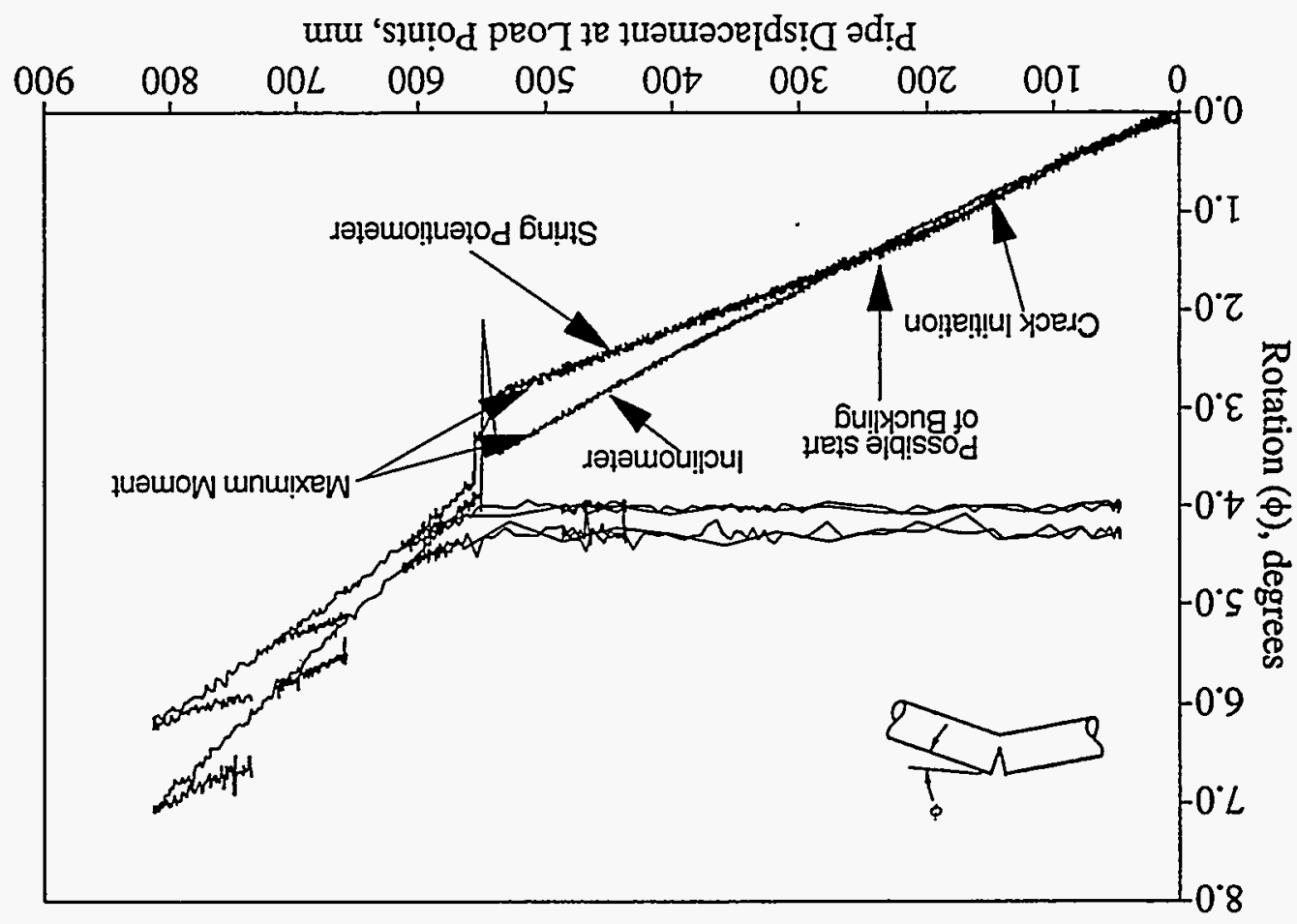

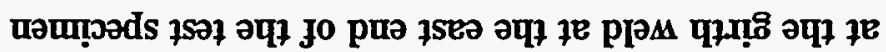

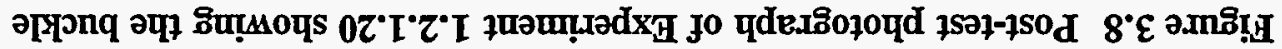

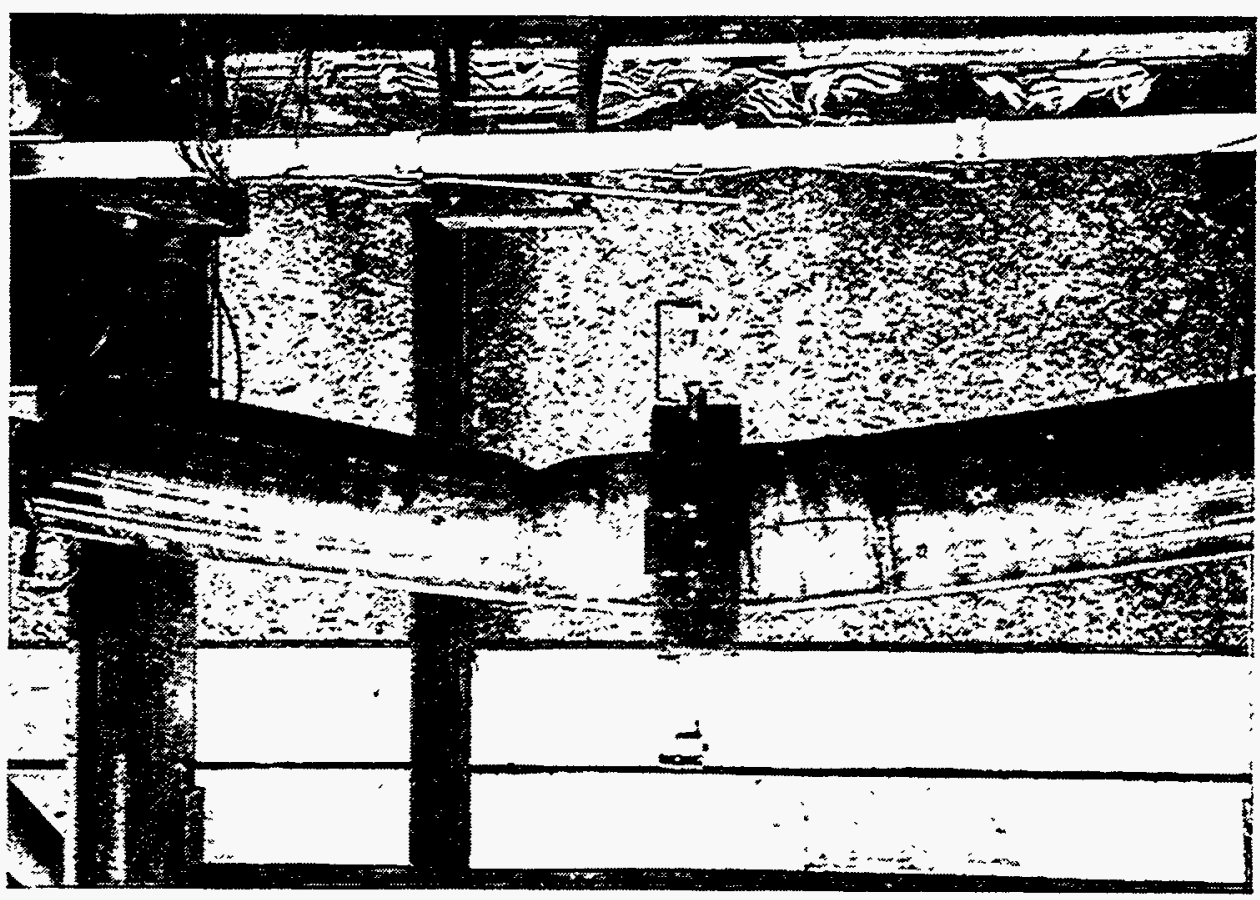


Figure 3.7 is the moment-rotation response for Experiment 1.2.1.22 conducted on the 152-mm (6-inch) diameter, Schedule 40, TP304 stainless steel pipe with a short surface crack. The maximum moment for Experiment 1.2.1.22 (44.32 kN-m [392.3 in-kips]) corresponded to the start of a buckle at a girth weld $100 \mathrm{~mm}$ ( 4 inches) from the crack plane, see Figure 3.10. The surface crack initiated well after the buckle started, and a small instability occurred as the surface crack propagated through the pipe wall and completely around the machined notch ligament. For fracture analysis purposes, the experimental maximum load should be considered a lower bound to the crack initiation and maximum loads. The crack then grew stably as a through-wall crack. The load at which buckling occurred agreed well with the predicted loads from the pretest buckling analysis. Interestingly, fracture still occurred even though the crack initiated well after the buckle formed. Previously it was believed that once buckling started, a fracture would not start because the energy would be going toward extending the buckle and not toward extending the crack. It should be noted though that the crack-mouth-opening displacement (CMOD) data showed that the surface crack was continually loaded during the buckling process, see Figure 3.11.

\subsubsection{Pipe Ovalization Data}

Figure 3.12 is a plot of the pipe ovalization at the crack section as a function of the pipe displacement at the load points for Experiment 1.2.1.20, the 406-mm (16-inch) diameter, Schedule 30, stainless steel pipe with a short surface crack. (Note, no ovalization data were obtained for the two 152-mm (6-inch) diameter short-surface-crack pipe experiments.) For this 406-mm (16-inch) diameter pipe experiment, the pipe diameter decreased in the vertical plane and increased in the horizontal plane due to the applied loads. This ovalization behavior was consistent with trends that have been observed in the past where through-wall-cracked pipe increased in diameter in the vertical plane and surfacecracked pipe decreased in diameter in the vertical plane with increasing applied bending loads. This decrease in pipe diameter in the vertical plane for surface-cracked pipe was perhaps the reason why there was a decrease in load-carrying capacity for the larger $\mathrm{R}_{\mathrm{m}} / \mathrm{t}$ ratio pipes relative to the NetSection-Collapse analysis, which assumes a circular pipe cross section. The decrease in pipe diameter in the top-to-bottom direction reduces the effective section modulus, which in turn lowers the bending resistance of the cracked pipe. The larger the $R_{m} / t$ ratio, the greater the reduction in top-to-bottom diameter, and thus, the lower the bending moment that can be attained.

\subsubsection{Crack Growth Data}

Figures 3.13 and 3.14 are plots of surface-crack growth as a function of load-point displacements for Experiments 1.2 .1 .20 and 1.2.1.21. Since the surface crack grew rapidly through the pipe wall immediately after crack initiation in Experiment 1.2.1.22, there were not enough data to perform stable crack growth calculations for that experiment.

\subsubsection{Large-Diameter Surface-Cracked Pipe Fracture Experiments Under Combined Bending and Tension (Pressure)}

\subsubsection{Moment-Rotation Response}

Figures 3.15 through 3.17 are plots of the applied crack section moment as a function of crack rotation for the three large-diameter, surface-crack pipe experiments, i.e., Experiments 1.2.3.15, 


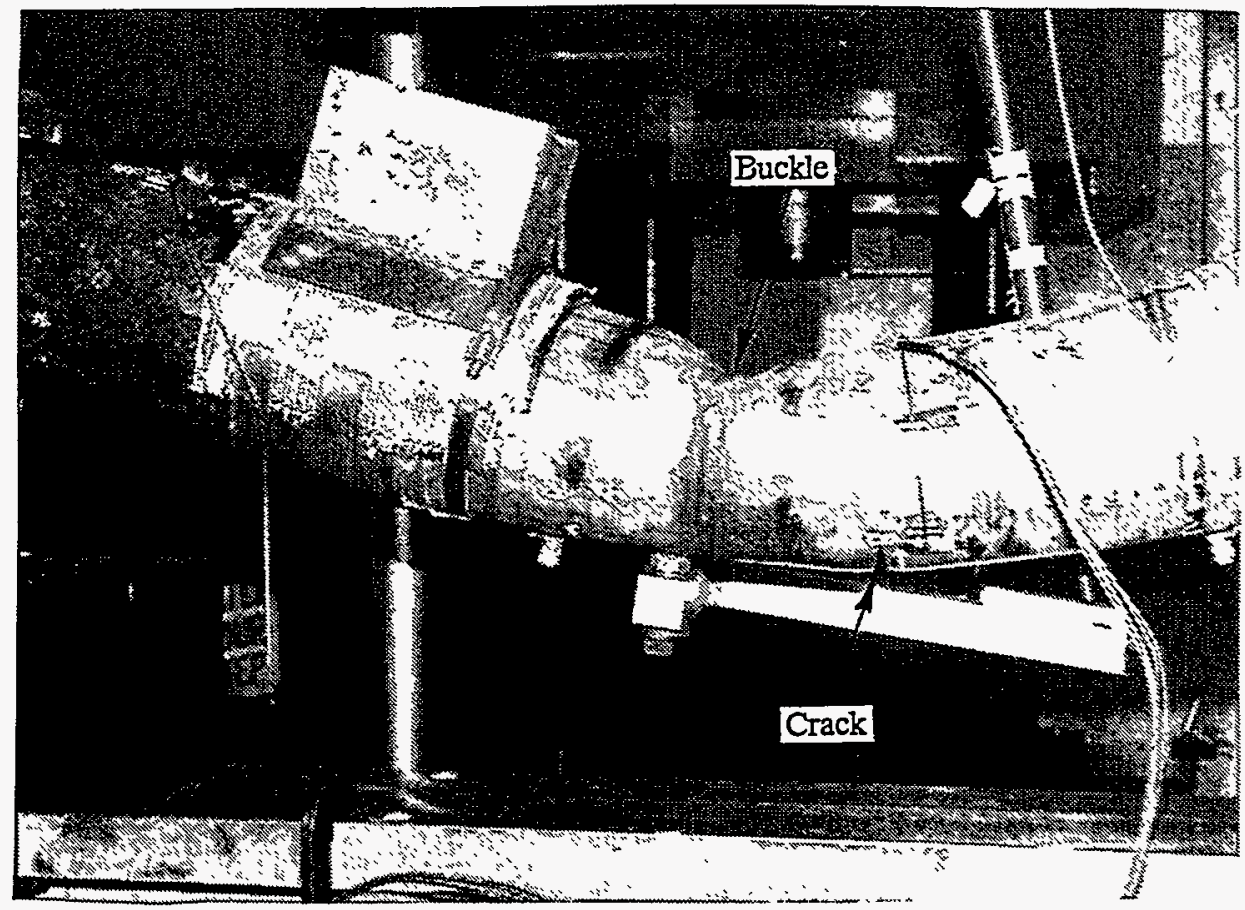

Figure 3.10 A post-test photograph of the specimen for Experiment 1.2.1.22 positioned in the loading fixtures and for which a buckle occurred at the weld away from the crack plane

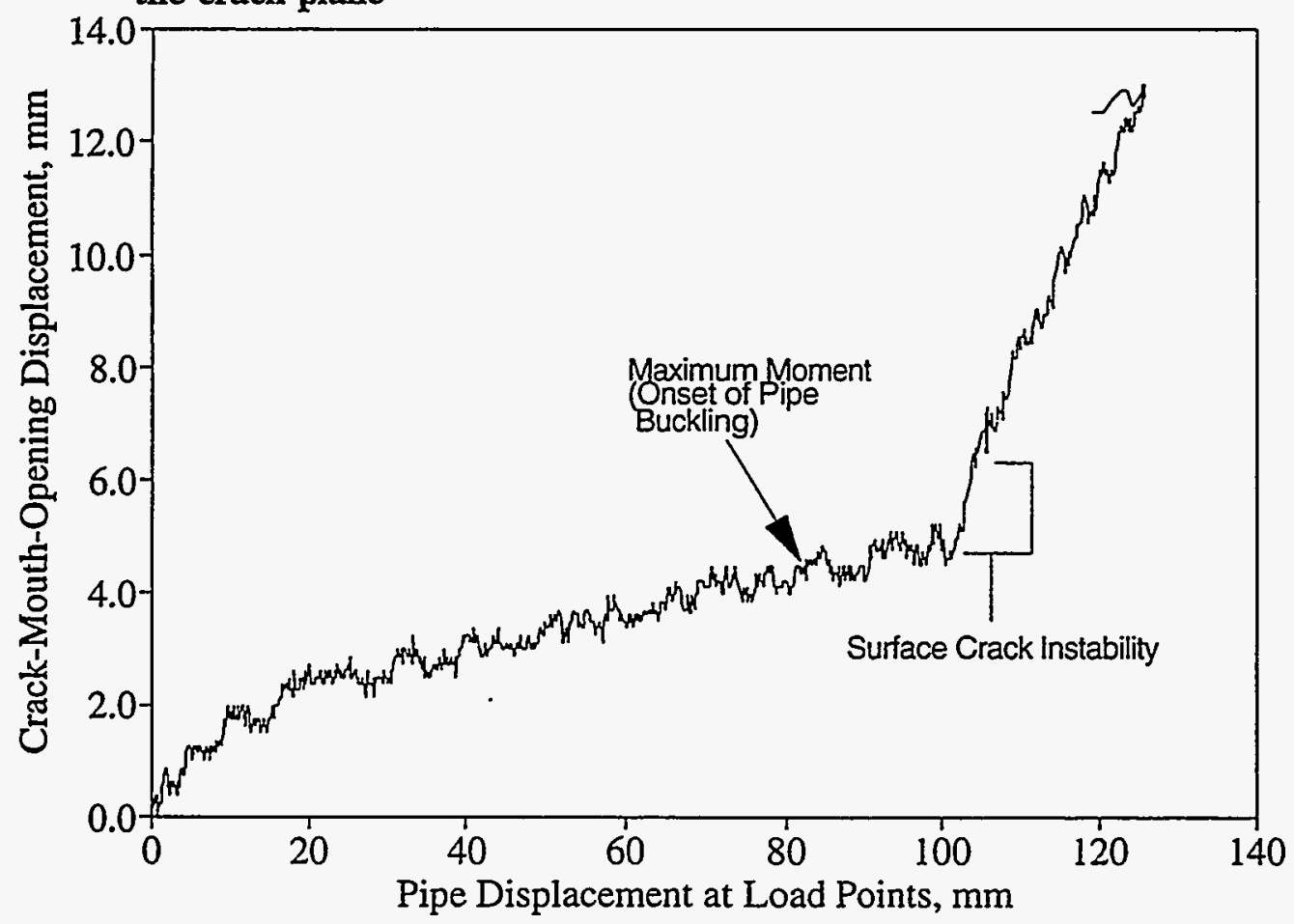

Figure 3.11 Crack centerline crack-mouth-opening displacements versus pipe displacement at the load points for Experiment 1.2.1.22 


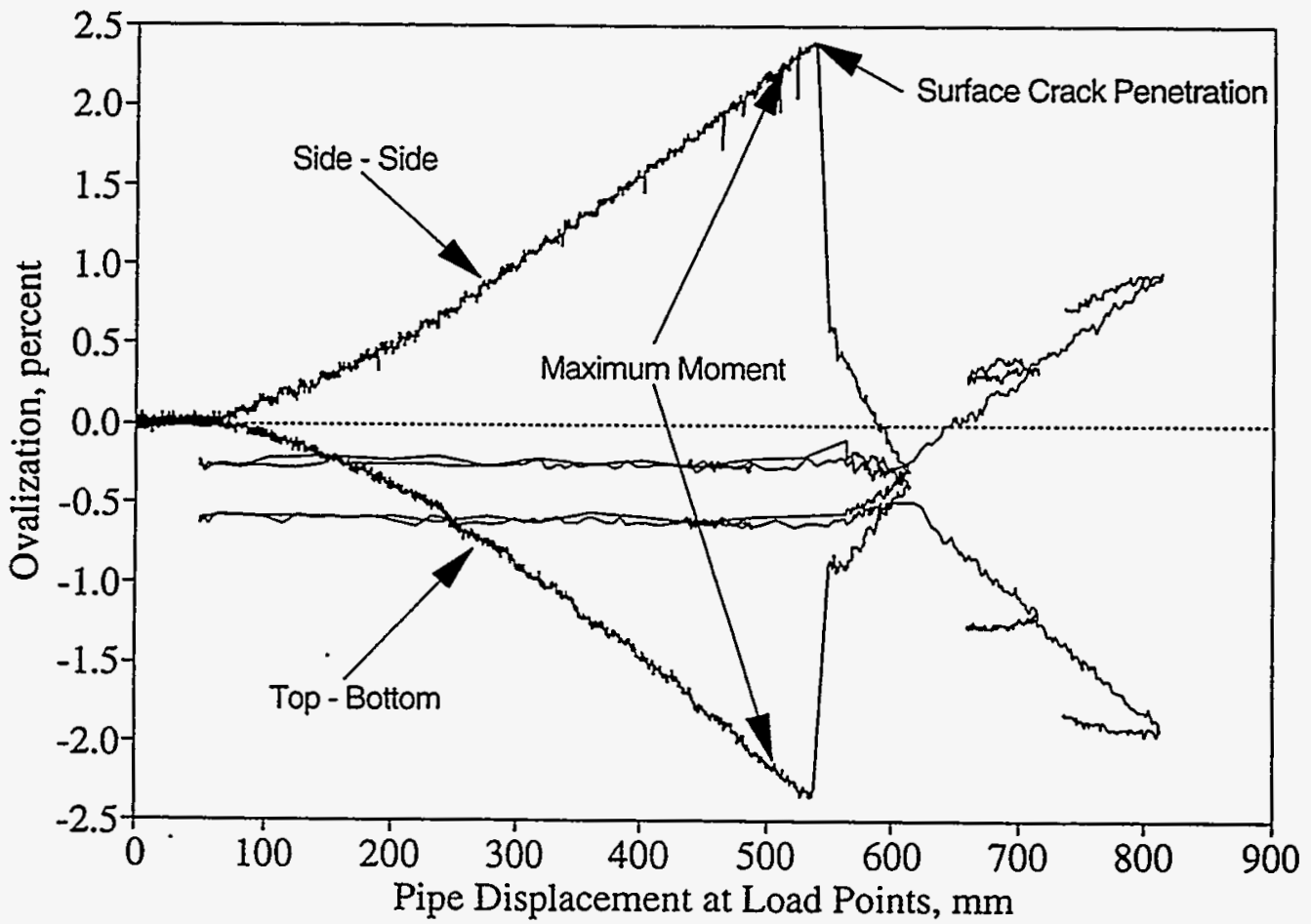

Figure 3.12 Ovalization (percent change in diameter) versus pipe displacement at the load points for Experiment 1.2.1.20

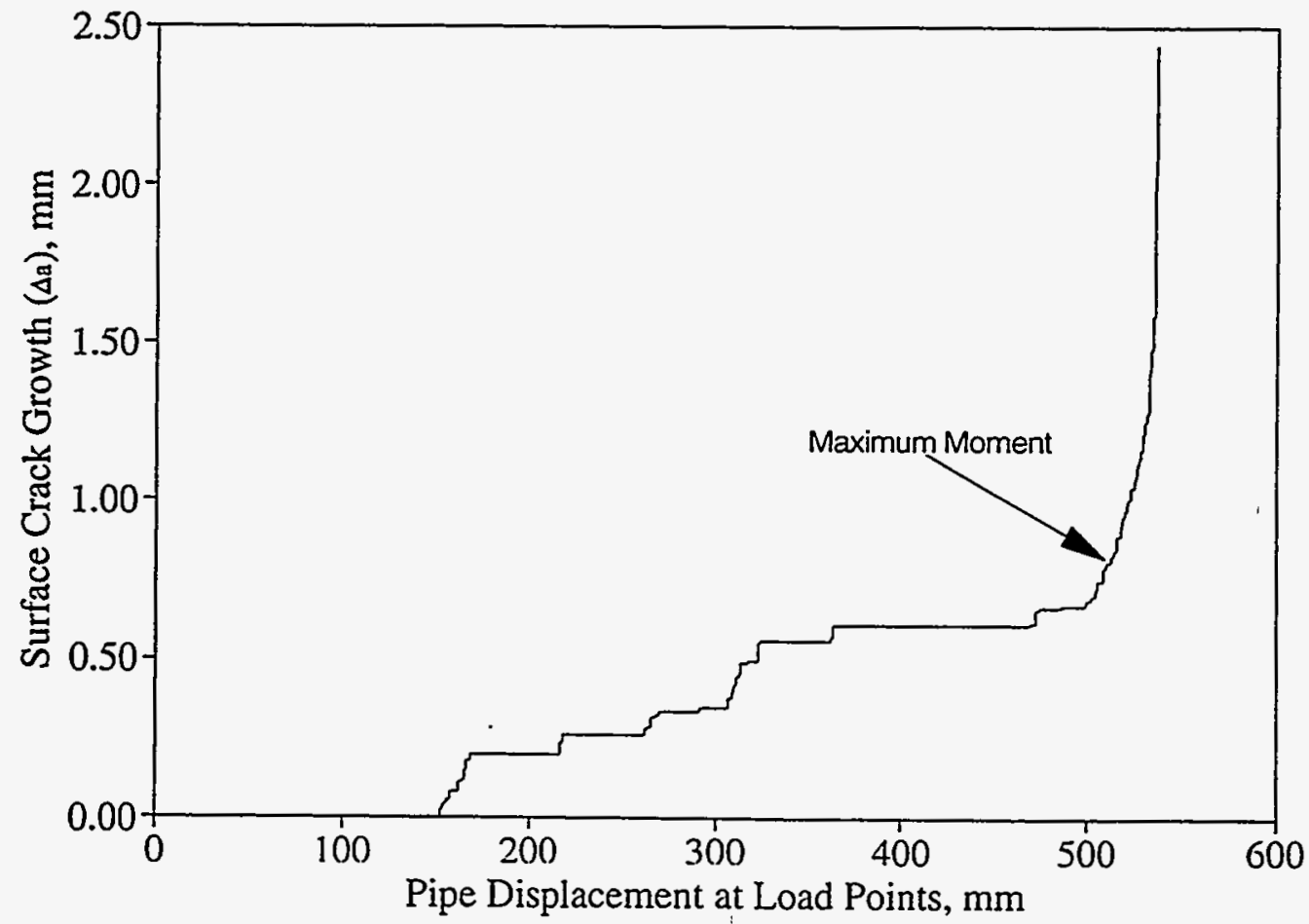

Figure 3.13 Surface-crack growth versus pipe displacement at the load points for Experiment 1.2.1.20 


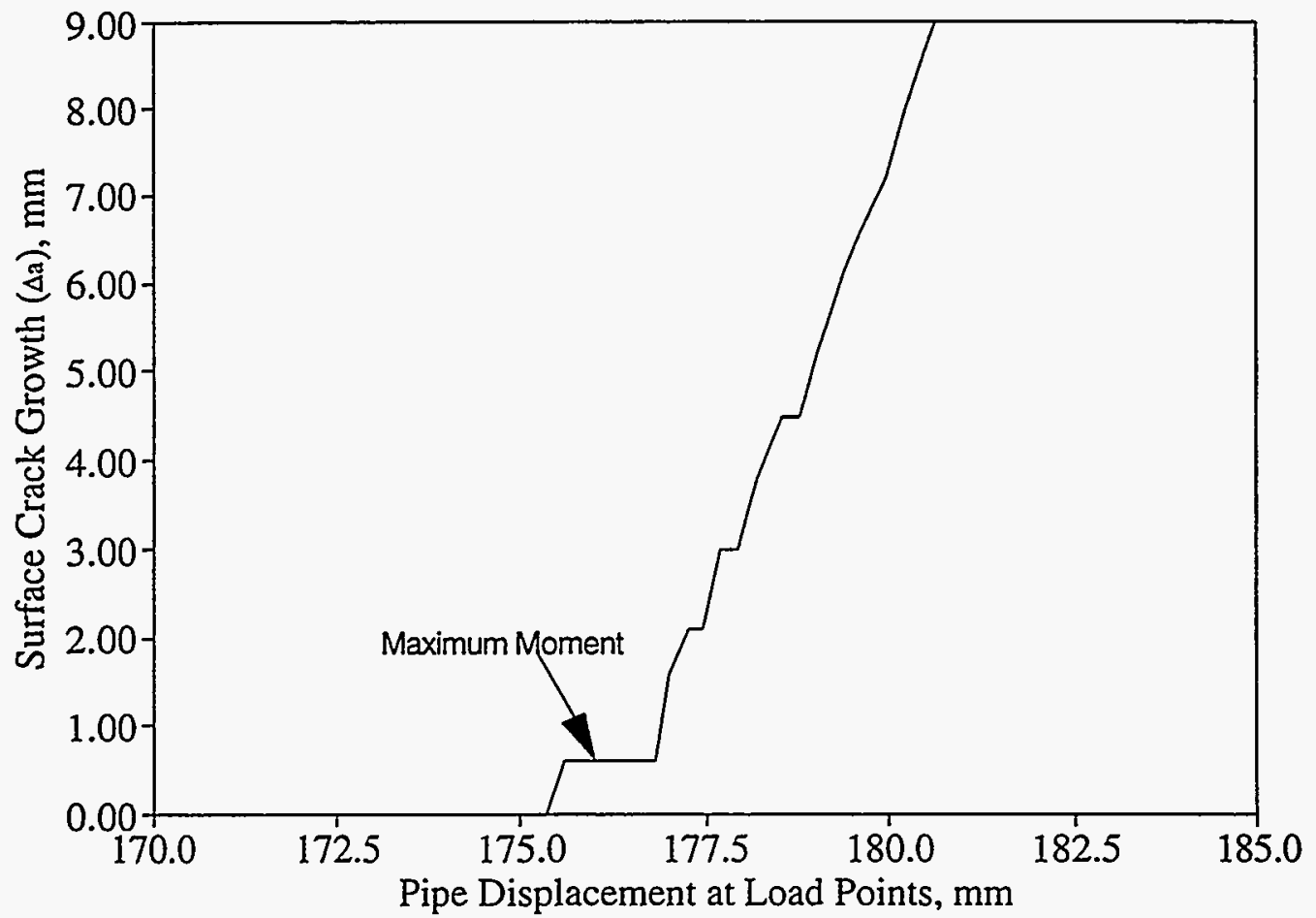

Figure 3.14 Surface-crack growth at the center of the surface crack versus pipe displacement at the load points for Experiment 1.2.1.21

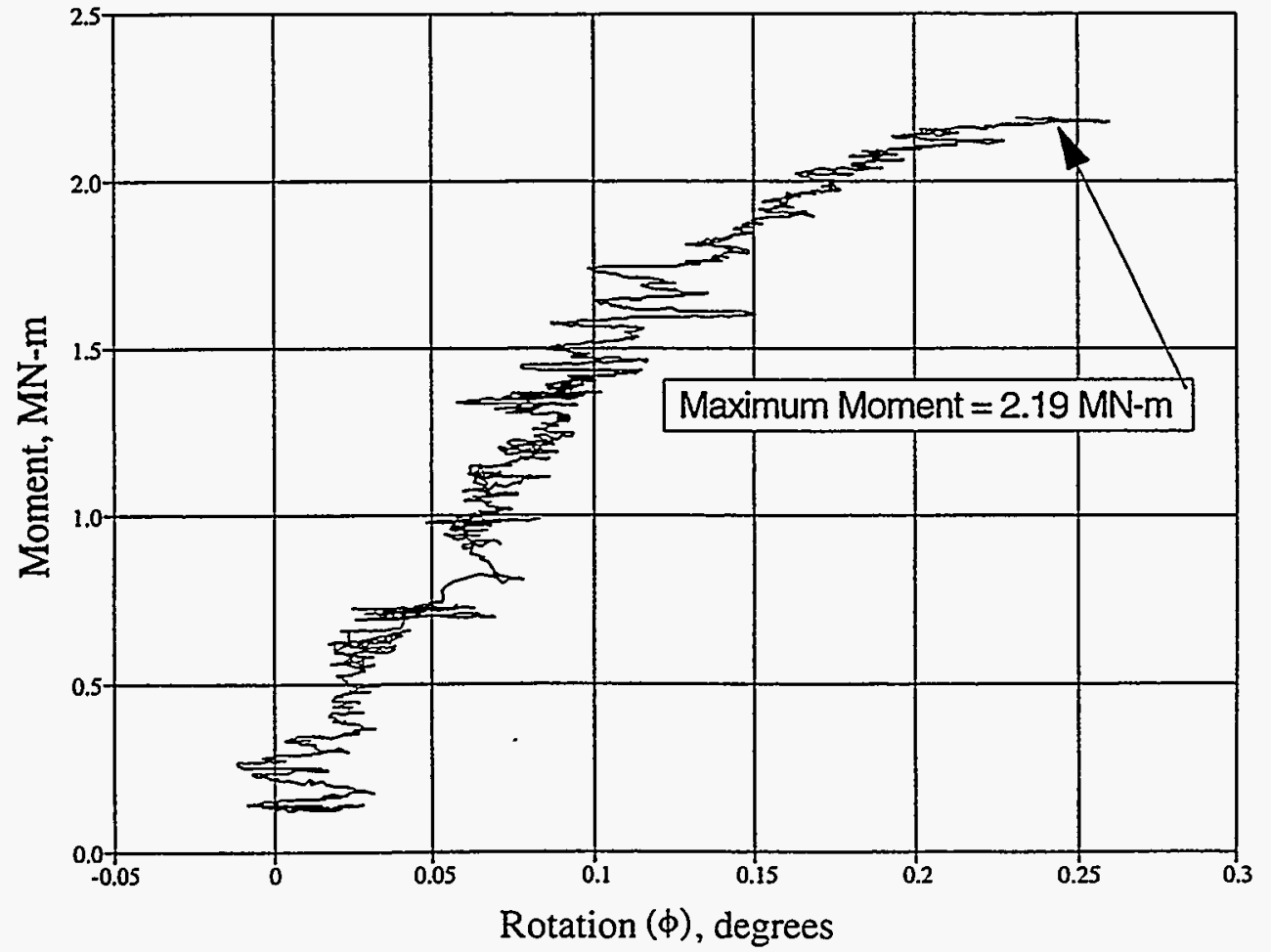

Figure 3.15 Moment versus half rotation angle $(\phi)$ based on the inclinometers for Experiment 1.2.3.15 


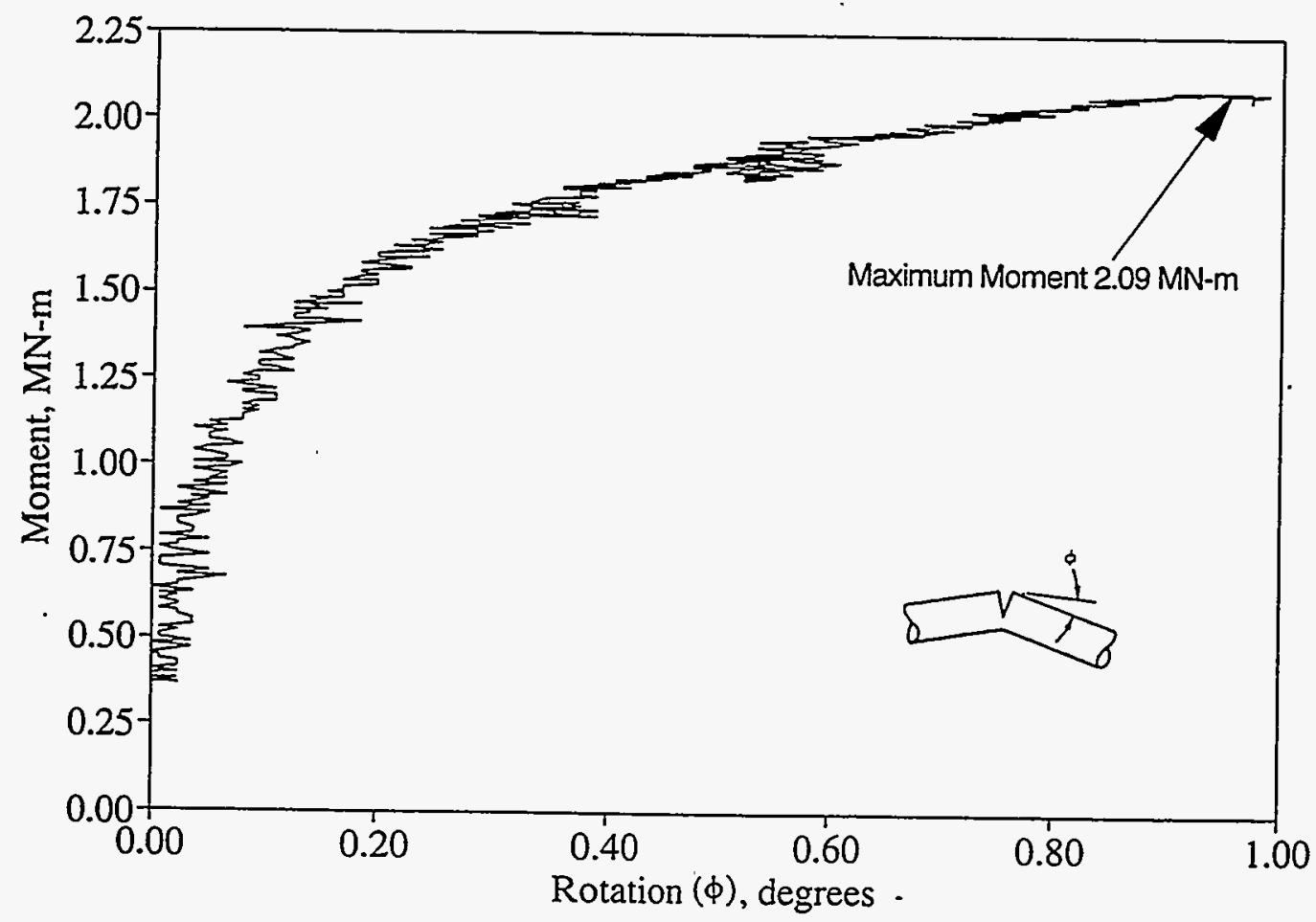

Figure 3.16 Moment versus half rotation angle $(\phi)$ based on the inclinometers for Experiment 1.2.3.16

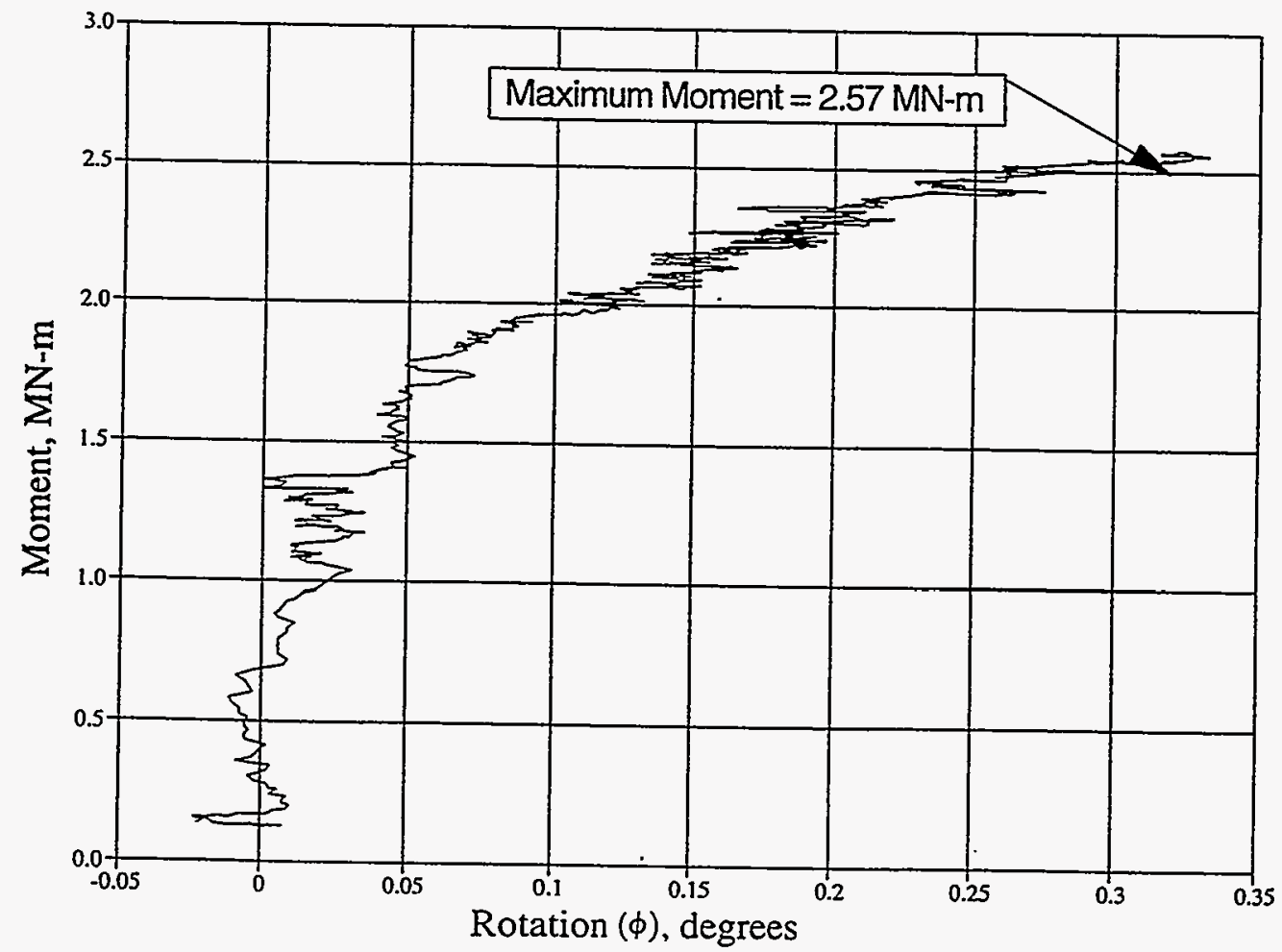

Figure 3.17 Crack section moment versus half rotation angle $(\phi)$ based on the inclinometers for Experiment 1.2.3.17 
1.2.3.16, and 1.2.3.17. In each figure, the half rotation angle $(\phi)$ is plotted, i.e., the angle between one moment arm of the pipe and its initial horizontal position. For each experiment, the rotation and pipe displacements were small enough, and the moment arms long enough, to preclude the need for a kinematic correction to the moment or rotation data. The noise in Figures 3.15 and 3.17 is due to noise on the inclinometers for these two experiments.

Figure 3.15 is a plot of the moment-rotation response for Experiment 1.2.3.15. The maximum moment for this experiment was 2,189 $\mathrm{kN}$-m (19,380 in-kips). Due to the lack of a change in the electric potential versus CMOD curve for this experiment, it was assumed that the crack in this experiment initiated very near maximum load and then grew rapidly through the remaining ligament of the pipe wall. As a result of this lack of data, a crack growth analysis could not be performed for this experiment.

Figure 3.16 is a plot of the moment-rotation response for Experiment 1.2.3.16. The maximum moment for this experiment was $2,094 \mathrm{kN}$-m (18,530 in-kips). The moment at crack initiation was $2,076 \mathrm{kN}-\mathrm{m}(18,380$ in-kips), i.e., 99 percent of the maximum moment for the experiment.

Figure 3.17 shows the moment-rotation response for Experiment 1.2.3.17. The maximum moment for this experiment was $2,575 \mathrm{kN}$-m (22,794 in-kips). The moment at crack initiation was 2,364 $\mathrm{kN}-\mathrm{m}(20,920$ in-kips), i.e., 91.8 percent of the maximum moment for the experiment.

\subsubsection{Pipe Ovalization Data}

Figures 3.18 and 3.19 are plots of the pipe ovalization at the crack section as a function of pipe displacement at the load points for Experiments 1.2.3.15 and 1.2.3.17, respectively. (Note, no ovalization data were obtained for Experiment 1.2.3.16, the experiment on the 711-mm (28-inch) diameter stainless steel SAW pipe with a short surface crack.) For Experiments 1.2.3.15 and 1.2.3.17, the extent of pipe ovalization was significantly less than what had been observed previously for Experiment 1.2.1.20, see Figure 3.9. However, the test specimens for these two experiments had much lower $R_{m} / t$ ratios than the test specimen for Experiment 1.2.1.20 (15 and 6.5 versus 21 ) and were pressurized to a much higher pipe pressure than Experiment 1.2.1.20 (9.56 and 15.5 $\mathrm{MPa}$ [1,387 and $2,250 \mathrm{psi}]$ versus $1.55 \mathrm{MPa}$ [225 psi]). Both of these factors (lower $\mathrm{R}_{\mathrm{m}} / \mathrm{t}$ ratios and higher internal pipe pressure) will tend to restrict the amount of pipe ovalization that takes place.

\subsubsection{Crack Growth Data}

Figures 3.20 and 3.21 are plots of surface-crack growth as a function of the pipe displacement at the load points for Experiments 1.2.3.16 and 1.2.3.17, respectively. As stated earlier no crack growth data are available for Experiment 1.2.3.15. 


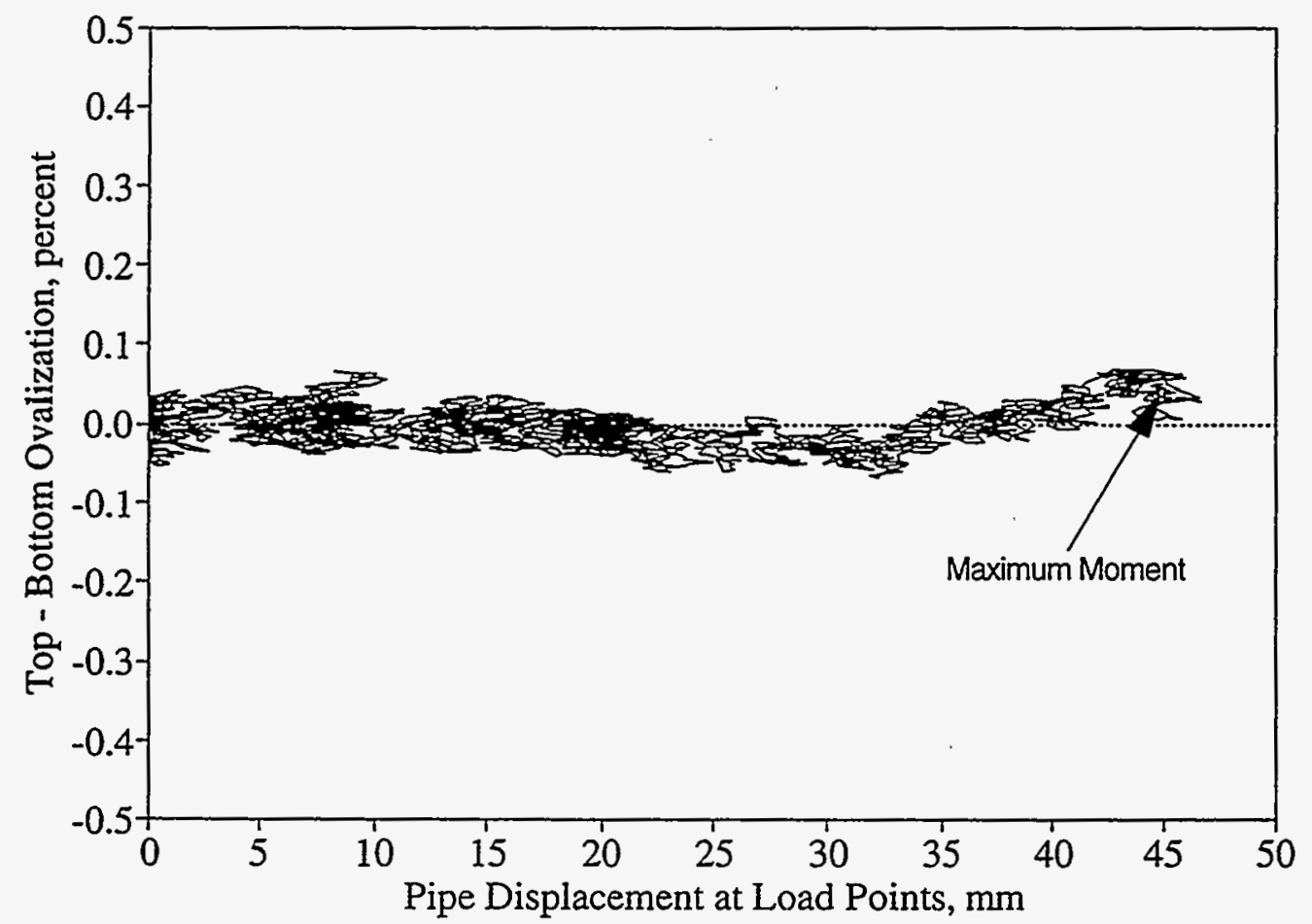

Figure 3.18 Ovalization (percent change in top-to-bottom pipe diameter) versus pipe displacement at the load points for Experiment 1.2.3.15

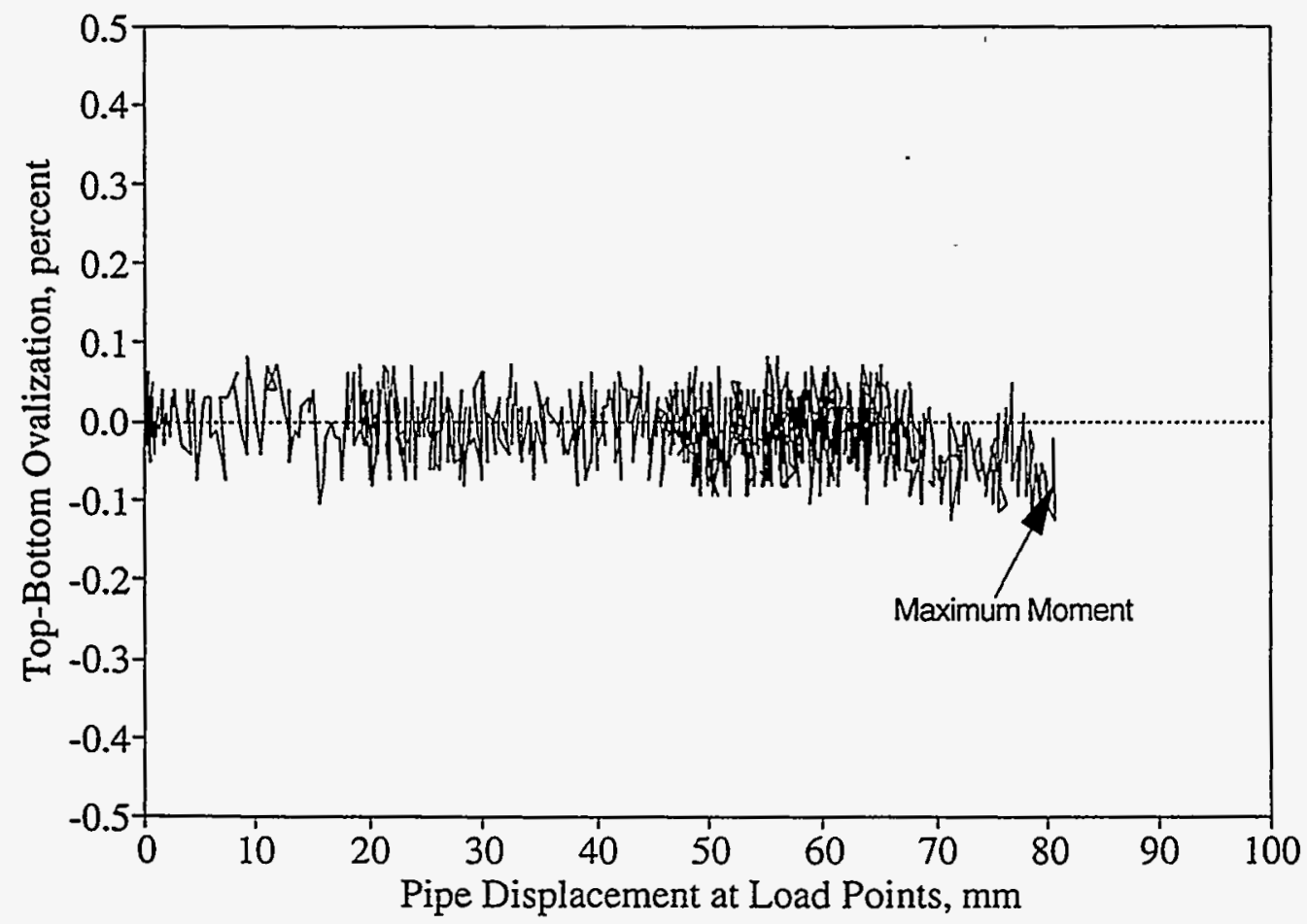

Figure 3.19 Ovalization (percent change in top-to-bottom pipe diameter) versus load-point displacement for Experiment 1.2.3.17 


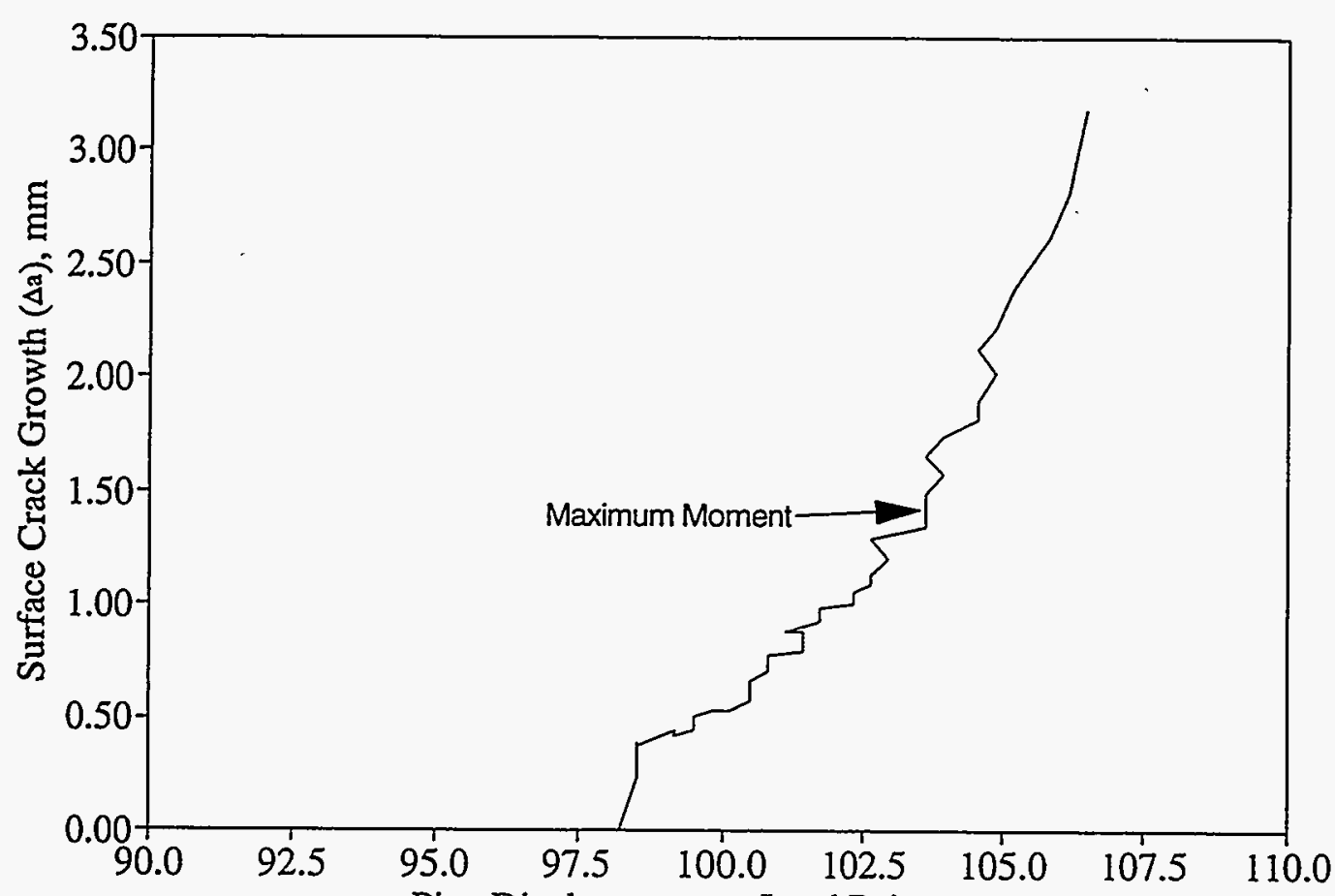

Pipe Displacement at Load Points, $\mathrm{mm}$

Figure 3.20 Surface-crack growth versus pipe displacement at the load points for Experiment 1.2.3.16

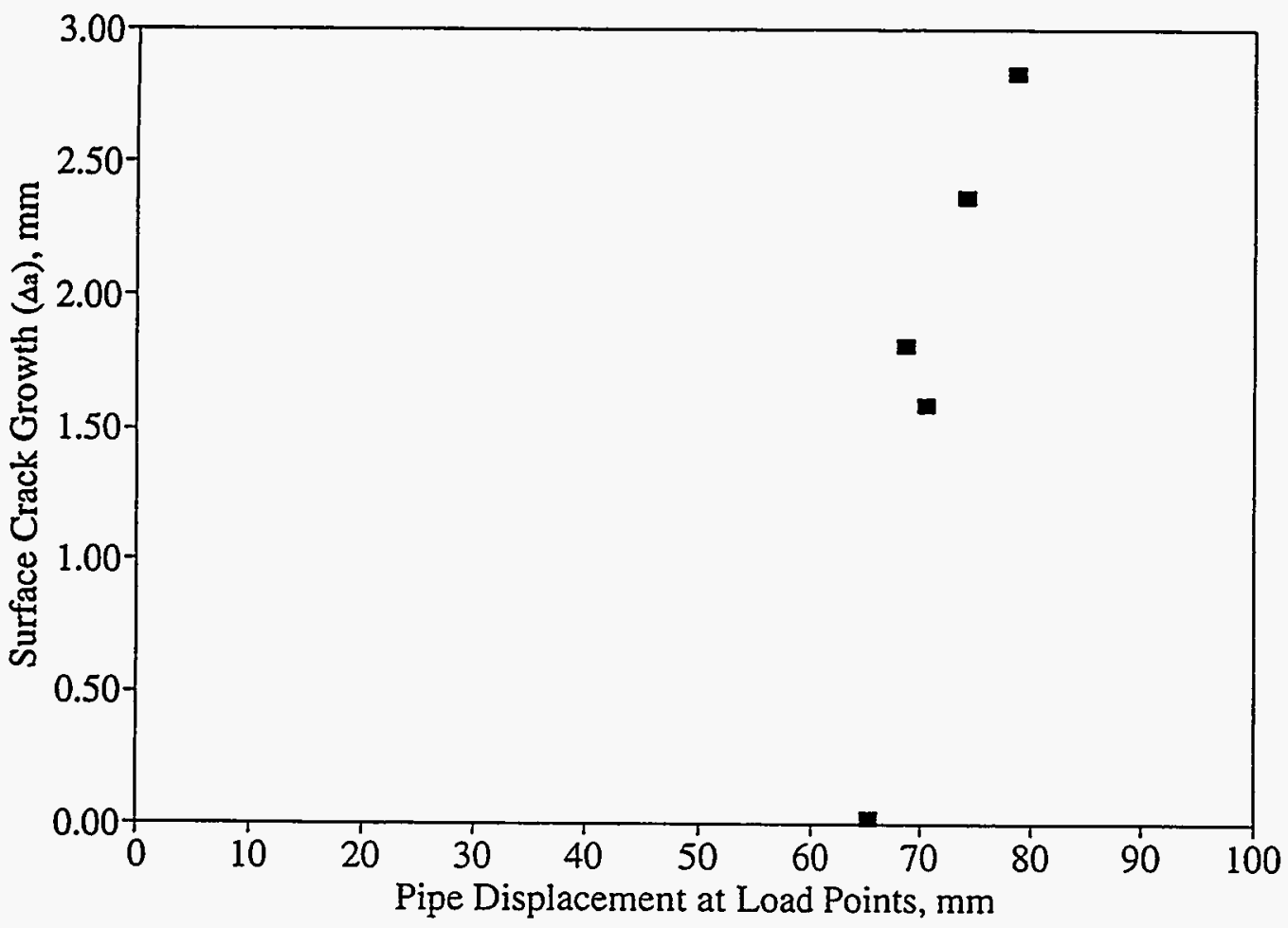

Figure 3.21 Surface-crack growth versus pipe displacement at the load points for Experiment 1.2.3.17 


\subsection{References}

3.1 Wilkowski, G. M., and others, "Degraded Piping Program -Phase II," Summary of Technical Results and Their Significance to Leak-Before-Break and In-Service Flaw Acceptance Criteria, March 1984-January 1989, by Battelle Columbus Division, NUREG/CR-4082, Vol. 8, March 1989.

3.2 Kanninen, M. F., and others, "Instability Predictions for Circumferentially Cracked Type 304 Stainless Steel Pipes Under Dynamic Loadings," Final Report on EPRI Project T118-2, by Battelle Columbus Laboratories, EPRI Report Number NP-2347, April 1982.

3.3 Wilkowski, G. M., and others, "Short Cracks in Piping and Piping Welds," Semiannual Report, April 1992 - September 1992, NUREG/CR-4599, Vol. 3, No. 1, September 1993.

3.4 G. M. Wilkowski, and P. M. Scott, "A Statistical Based Circumferentially Cracked Pipe Fracture Mechanics Analysis for Design on Code Implementation," Nuclear Engineering and Design, Vol. III, pp. 173-187, 1989.

3.5 Wilkowski, G. M., and others, "Degraded Piping Program - Phase II," Seventh Progress Report: October 1987 - January 1989, by Battelle Columbus Division, NUREG/CR-4082, Vol. 7, March 1989.

3.6 "Evaluation of Flaws in Austenitic Steel Piping," (Technical basis document for ASME IWB3640 analysis procedure), prepared by Section XI Task Group for Piping Flaw Evaluation, EPRI Report NP-4690-SR, April 1986.

3.7 American Society of Mechanical Engineers Boiler and Pressure Vessel Code, Section XI, Article IWB-3650, 1992 Edition, July 1, 1992. Published by American Society of Mechanical Engineers, New York, N.Y. 10017.

3.8 Schmidt, R. A., Wilkowski, G. M., and Mayfield, M. E., “The International Piping Integrity Research Group (IPIRG) Program - An Overview," SMiRT-11, Paper G23/1, August 1991.

3.9 Eiber, R. J., Maxey, W. A., and Duffey, A. R., "Investigation of the Initiation and Extent of Ductile Pipe Rupture,” Battelle Memorial Institute Report, BMI-1908, 1971. 


\subsection{ANALYSIS OF CIRCUMFERENTIALLY SURFACE-CRACKED PIPE}

The experimental work in this report was described in Sections 2 and 3. In Section 2, the results from a series of material characterization tests were discussed. In Section 3, the results for the fullscale surface-cracked-pipe experiments conducted as part of this program were discussed in detail. Before analyzing the results of the pipe experiments and discussing the implications of those experiments to the flaw evaluation procedures, improvements to existing analysis procedures, as well as new methods developed, are presented.

This section describes the theoretical analysis and predictive methods for evaluating the structural integrity of circumferentially surface-cracked pipe. Section 4.1 provides an overview of the background and scope of activities. Section 4.2 deals with improvements made to existing analysis methods. Section 4.3 describes the SC.ENG method, a new J-estimation scheme developed to predict the crack-driving force and the moment-rotation behavior of a surface-cracked pipe, including the prediction of crack initiation and maximum moments under combined bending and pressure loads. In Section 4.4, the predictions from the various analysis methods are compared with experimental data from this program as well as other data in the literature. Section 4.5 presents a discussion of the results from these analysis efforts, including statistical evaluation of the data. The effects of anisotropy and constraint are summarized in Section 4.6.

The implications of the current work on the ASME Section XI flaw evaluation procedures are detailed in Section 5 of this report, and are therefore, not discussed in this section.

\subsection{Background and Scope of Current Work}

\subsubsection{Analysis Overview}

Prior to this program there were only a few methods available for analyzing the failure behavior of circumferentially surface-cracked pipe. These can be broadly categorized into (i) limit-load solutions, (ii) design criteria, and (iii) J-estimation schemes. Each of these methods involve certain idealizations of the crack geometry, material stress-strain behavior, and material resistance to crack growth. A previous NUREG report (Ref. 4.1) discussed some of these analysis procedures.

Figure 4.1 shows a schematic of the idealized geometry of a surface-cracked pipe under combined bending and tension loads. As seen, a constant-depth internal surface crack is assumed to be located symmetrically with the center of the crack subjected to the maximum (tensile) bending stresses. For this idealized crack geometry, the objective of the various analysis procedures is to predict one or more of the following:

- the load at which the crack initiates,

- the maximum load-carrying capacity of the cracked pipe, 

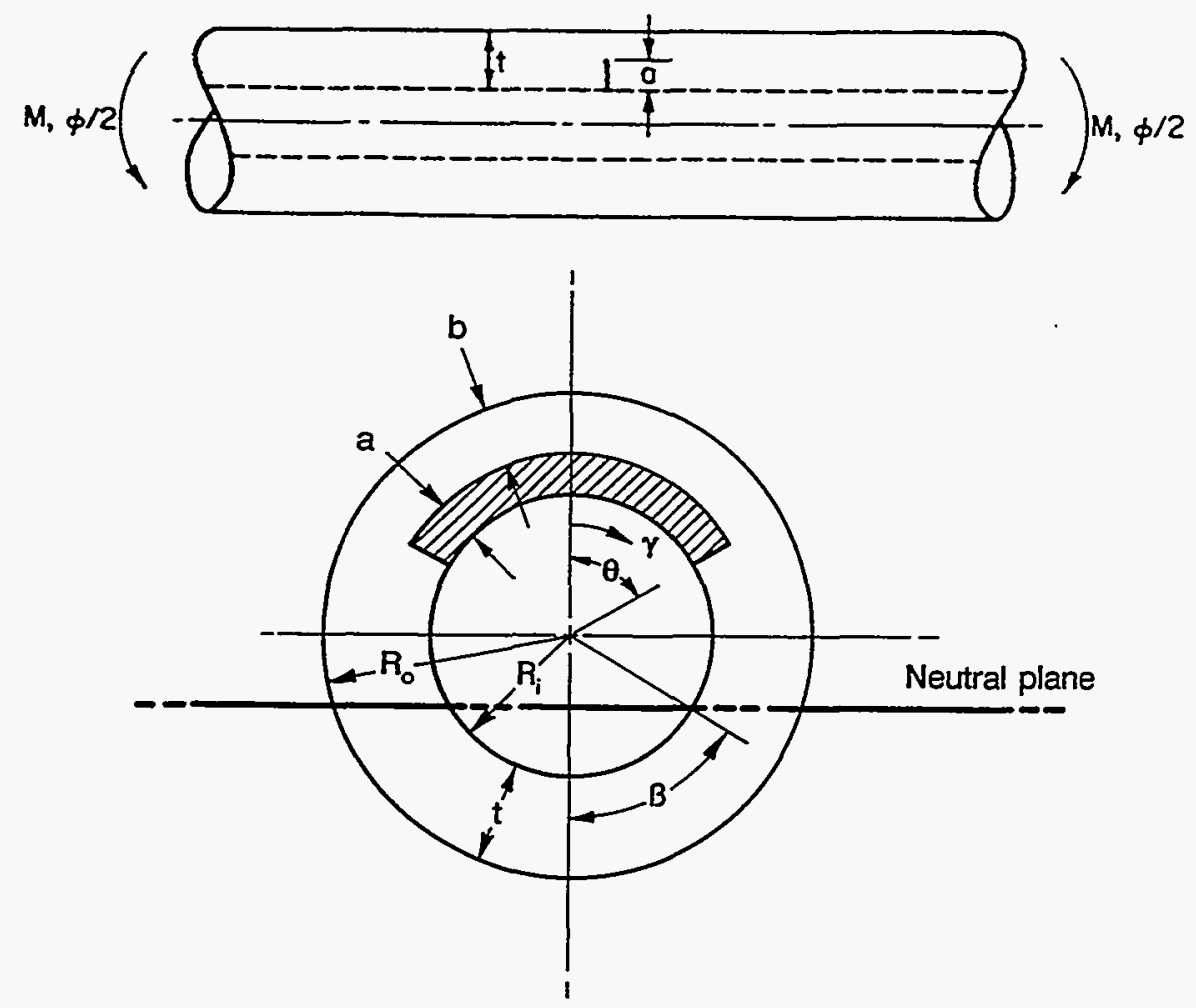

Figure 4.1 Schematic of idealized surface-cracked pipe geometry and loading

- the moment-rotation behavior of the cracked pipe, or

- $\quad$ the margin of safety for a given service load.

Each of the three categories of analysis procedure, i.e., limit-load solutions, design criteria, and J-estimation schemes, are summarized below along with their limitations.

\subsubsection{Limit-Load Solutions}

Limit-load approaches assume that the material follows elastic-perfectly-plastic stress-strain behavior. Therefore, the maximum load-carrying capacity predictions are based on the condition that the remaining ligament in the cracked section reaches the flow stress for the material. The influence of toughness is ignored, as the assumption is that the resistance to crack initiation is high enough that crack initiation is reached at or very close to maximum load. The Net-Section-Collapse (NSC) criterion and its modifications fall under this category of analysis. Such analyses are used only to determine the maximum load-carrying capacity of surface-cracked pipe. 

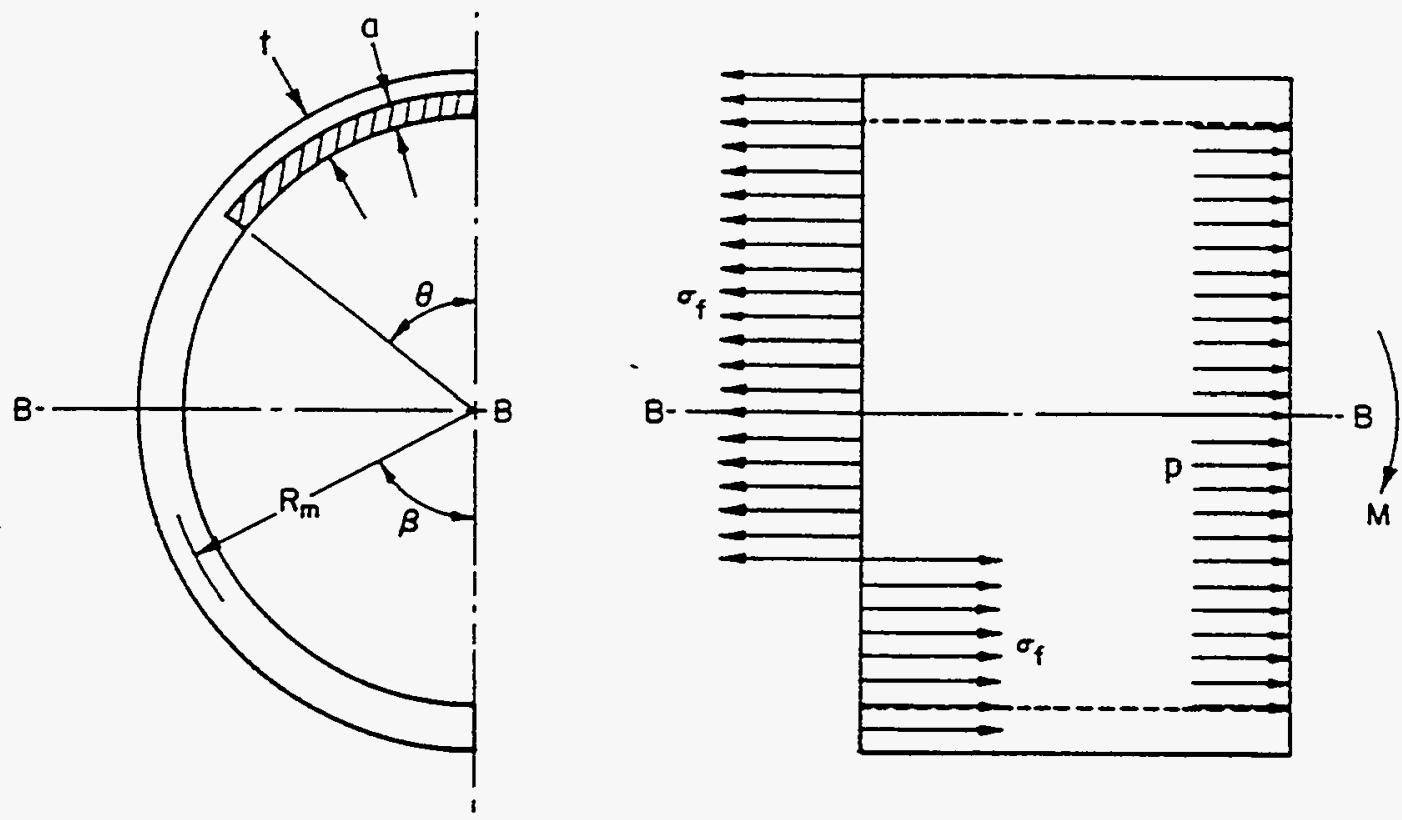

Figure 4.2 Nomenclature and loading for the application of the Net-Section-Collapse and IWB-3640 analyses to a pipe with a circumferential surface crack subjected to combined pressure and bending

The NSC Criterion: In this procedure the remaining ligament in the cracked section is assumed to reach fully plastic conditions at failure with the stresses in the entire cross section equalling the flow stress for the material as shown in Figure 4.2. A simple beam theory analysis developed in Reference 4.2 wherein static equilibrium conditions are enforced shows that the maximum momentcarrying capacity is given by Equation 4-1.

$$
M_{n s c}=2 \sigma_{f} R_{m}^{2} t\left[2 \sin \beta-\frac{a}{t} \sin \theta\right]
$$

where the stress inversion angle $\beta$ is given by

$$
\beta=\frac{\pi-\theta(\mathrm{a} / \mathrm{t})}{2}-\frac{\pi \mathrm{R}_{\mathrm{i}}^{2} \mathrm{p}}{4 \mathrm{R}_{\mathrm{m}} \sigma_{\mathrm{f}}^{t}}
$$

where

$$
\begin{array}{lll}
\theta & =\text { half crack angle } \\
\mathrm{M}_{\mathrm{nsc}} & = & \text { NSC limit moment }
\end{array}
$$




$\begin{array}{lll}\mathrm{R}_{\mathrm{i}} & = & \text { inner radius of pipe } \\ \mathrm{R}_{\mathrm{m}} & = & \text { mean radius of the pipe } \\ \mathrm{p} & = & \text { internal pressure } \\ \mathrm{t} & = & \text { pipe wall thickness } \\ \mathrm{a} & = & \text { surface crack depth, and } \\ \sigma_{\mathrm{f}} & = & \text { flow stress. }\end{array}$

Figure 4.2 shows the pipe geometry and the stress distribution. The above analysis assumes that the ratio $R_{m} / t$ is large $(>10)$ and, therefore, thin-wall pipe approximations are valid.

Modification to the NSC Criterion: Based on experimental results, Kurihara (Ref. 4.3) modified the NSC equation for pipes with short, but deep, surface flaws. An empirical factor " $m$ " with the proposed form

$$
\mathrm{m}=1-(\mathrm{a} / \mathrm{t})^{2}(\theta / \pi)^{0.2}
$$

was used as a scaling factor to multiply the right-hand side of the NSC criterion, Equation 4-1.

There are two major limitations to the NSC analysis. First, fully plastic conditions in the remaining ligament do not necessarily exist in surface-cracked pipes in all cases, and therefore, contained plasticity sometimes needs to be accounted for in the analysis. Secondly, the moments at crack initiation and the moment-rotation behavior of the cracked pipe are not predicted by this method.

\subsubsection{Design Criteria}

Analysis methods aimed at developing design criteria are based on a combination of simple limit-load solutions, linear-elastic fracture mechanics analyses, and semi-empirical corrections based on experimental data. In some cases, design safety factors are incorporated into the procedure implicitly, while in others they are specified explicitly. Such design procedures, discussed in this section, include the R-6 method (Refs. 4.4 and 4.5) developed in the United Kingdom and the ASME Section XI flaw evaluation criteria in the U.S. (Refs. 4.6 and 4.7). The two methods are summarized next.

The R-6 Revision 3 Method: This approach for evaluating the integrity of flawed structures made of strain-hardening materials was originally developed by the Central Electric Generating Board (CEGB) in the United Kingdom (Refs. 4.4 and 4.5). The basic method involves a diagram of the toughness ratio $\mathrm{K}_{\mathrm{r}}$ versus the load ratio $\mathrm{L}_{\mathrm{r}}$ as shown in Figure 4.3. The value of $\mathrm{K}_{\mathrm{r}}$ for a flawed structure is the ratio of the linear-elastic stress intensity factors $\left(\mathrm{K}_{\mathrm{I}}\right)$ to the material toughness $\left(\mathrm{K}_{\mathrm{IC}}\right)$. The value of $\mathrm{L}_{\mathrm{r}}$ is the ratio of the nominal stress in the component $(\sigma)$ to the yield stress $\left(\sigma_{\mathrm{y}}\right)$ of the material. If the point $\left(\mathrm{L}_{\mathrm{r}}, \mathrm{K}_{\mathrm{r}}\right)$ falls within the failure assessment curve, shown in Figure 4.3, then the structure is determined to be safe. Otherwise the structure is deemed unsafe.

This method has some inherent safety factors incorporated into the Failure Assessment Curve (FAC), $\mathrm{K}_{\mathrm{T}}=\mathrm{f}\left(\mathrm{L}_{\mathrm{r}}\right)$, and hence the predicted failure loads should be lower than the experimental values. The ratio of the distance from the origin to the $\mathrm{FAC}$ through the point $\left(\mathrm{L}_{\mathrm{r}}, \mathrm{K}_{\mathrm{r}}\right)$ to the distance from the 
origin to the point $\left(\mathrm{L}_{\mathrm{r}}, \mathrm{K}_{\mathrm{r}}\right)$ in Figure 4.3 is the margin of safety for the structure. Three analyses options are available depending on the material property information available for the structure. Further details are provided in References 4.4 and 4.5. The moment-rotation behavior of the cracked pipe cannot be predicted by this method.

The ASME Section XI Flaw Evaluation Criteria: The ASME Section XI IWB-3640 criteria (Ref. 4.6) and IWB-3650 (Ref. 4.7) are applicable to austenitic and ferritic piping, respectively. The technical basis for the limit-load solutions embodied in these methods is the NSC criterion (Eq. 4-1). However, there are three differences between the Section XI and the NSC criteria:

- the flow-stress definition in the ASME criteria is.related to $S_{m}$, the design value of the stress intensity in the pipe,

- for some classes of piping the exact thick-wall solution is used to calculate the bending stresses for the uncracked pipe, and

- a correction factor $\mathrm{Z}$ is introduced to account for the lower toughness of flux welds in predicting the maximum allowable stress.

There are additional differences for analyzing ferritic pipes. Since the overall objective of this report is to evaluate the ASME Section XI Criteria, an entire section, Section 5, is devoted to these flaw evaluation procedures. Therefore, we will not discuss these methods further in this section.

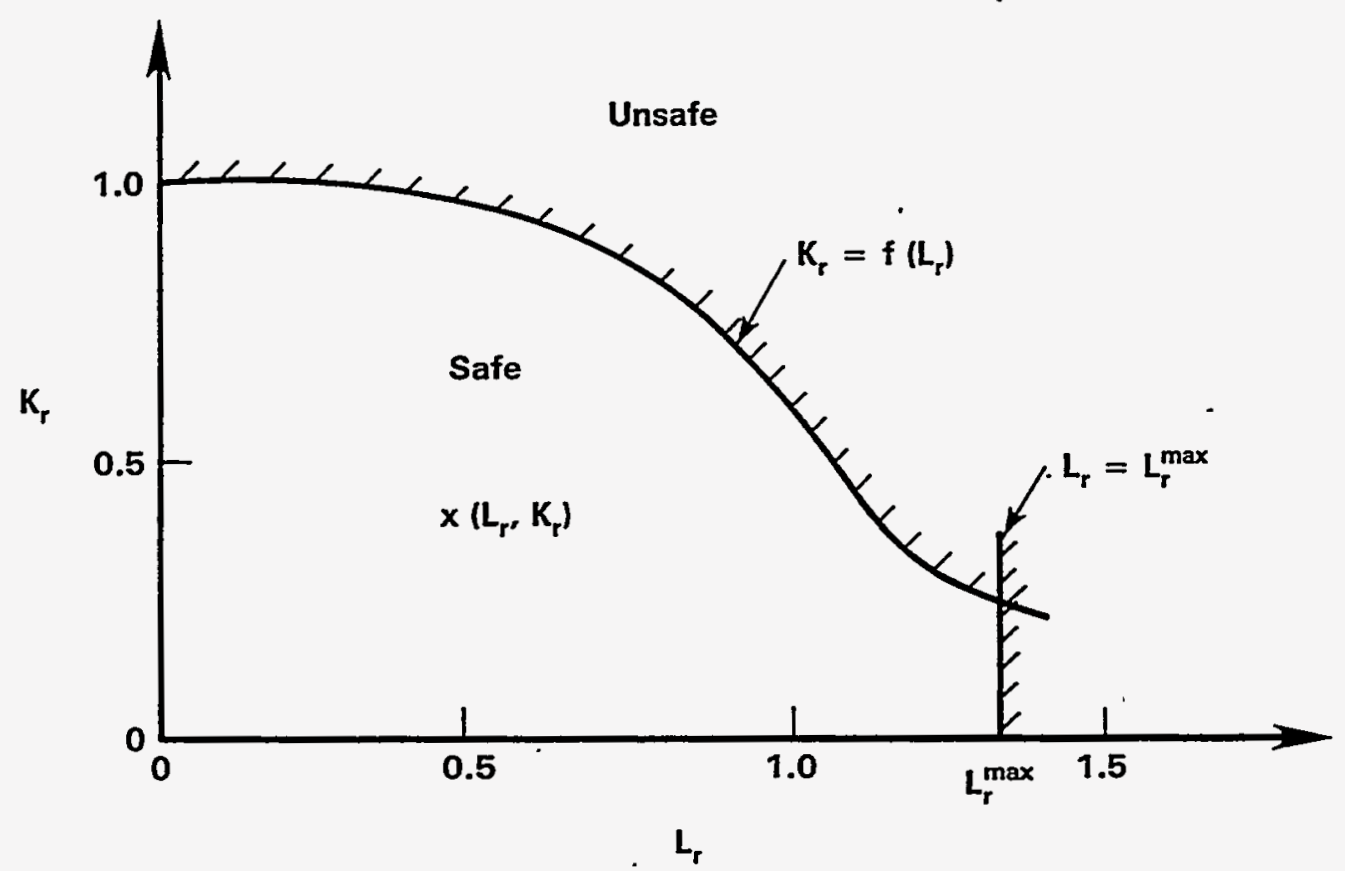

Figure 4.3 The R-6 failure assessment diagram 


\subsubsection{J-Estimation Schemes}

The most sophisticated method of analysis involves elastic-plastic fracture mechanics (EPFM) and the associated J-estimation schemes (Ref. 4.8). The material stress-strain behavior for these methods is idealized by the Ramberg-Osgood model given by

$$
\frac{\epsilon}{\epsilon_{\mathrm{o}}}=\frac{\sigma}{\sigma_{\mathrm{o}}}+\alpha\left[\frac{\sigma}{\sigma_{\mathrm{o}}}\right]^{\mathrm{n}}
$$

where $\sigma_{0}$ is the reference stress, usually assumed to be the yield stress; $\epsilon_{0}$ is the reference strain, defined as being equal to $\sigma_{0} / E$ where $E$ is the modulus of elasticity; and $\alpha$ and $n$ are strain-hardening parameters determined from a best fit of the stress-strain curve data. The fracture toughness of the material is described by the J-R curve developed using a standard $C(T)$ specimen as discussed in Section 2. The J-R curve is frequently characterized by a power-law equation of the form

$$
J_{R}(\Delta a)=J_{I c}+C_{1}\left[\frac{\Delta a}{\Delta a_{o}}\right]^{m}
$$

where $\Delta \mathrm{a}$ is the crack extension, $\mathrm{J}_{\mathrm{Ic}}$ is the fracture toughness at initiation, and $\mathrm{C}_{1}$ and $\mathrm{m}$ are powerlaw curve fit parameters for the experimental data. In Equation 4-5, $\Delta \mathrm{a}_{\mathrm{o}}$ is a normalizing parameter equal to unity in the same units as that for $\Delta$ a so that $C_{1}$ has the units of $\mathrm{J}_{\mathrm{Ic}}$, that is $\mathrm{kJ} / \mathrm{m}^{2}$ (in-lbs/in ${ }^{2}$ ).

Once the material stress-strain behavior and crack resistance are idealized, the next step in the estimation scheme involves decomposition of the crack-driving force $(J)$ and the rotation due to the crack $\left(\phi^{c}\right)$, or displacement due to the presence of a crack, into their elastic and plastic components as

$$
\begin{gathered}
\mathrm{J}=\mathrm{J}_{\mathrm{e}}+\mathrm{J}_{\mathrm{p}} \\
\phi^{\mathrm{c}}=\phi_{\mathrm{e}}^{\mathrm{c}}+\phi_{\mathrm{p}}^{\mathrm{c}}
\end{gathered}
$$

With appropriate assumptions, a unique relation between the applied moment, $M$, and the rotation components, $\phi_{\mathrm{e}}^{\mathrm{c}}$ and $\phi_{\mathrm{p}}^{\mathrm{c}}$, is then established. The components $\mathrm{J}_{\mathrm{e}}$ and $\mathrm{J}_{\mathrm{p}}$ are then estimated quite readily as explained in Reference 4.8 . 
The difference between various J-estimation schemes is the manner in which the $M-\phi_{\mathrm{p}}^{\mathrm{c}}$ relation is obtained. Once this is available, J-estimation schemes can be used to predict the initiation load and the maximum load, as well as the moment-rotation behavior of a cracked pipe.

This methodology has been developed very successfully for through-wall-cracked piping as discussed in the NUREG/CR-6235 report from this program. The GE/EPRI method (Refs. 4.9 and 4.10), as well as SC.TNP and SC.TKP (Ref. 4.1) methods, which were the only J-estimation schemes available for analyzing circumferential surface-cracked pipes before this program, are discussed next.

The GE-EPRI Estimation Scheme: The GE-EPRI method (Refs. 4.9 and 4.10) was one of the first Jestimation schemes developed. The $\phi_{\mathrm{p}}^{\mathrm{c}}$ and $\mathrm{J}_{\mathrm{p}}-\mathrm{M}$ relation in this method are determined through finite element $(\mathrm{FE})$ analyses on various crack geometries and strain hardening parameters.

Dimensionless influence functions are developed using the FE results for predicting the applied J, the crack-opening displacement (COD), and the pipe rotations for several geometries and material strainhardening properties. For surface-cracked pipe, the only functions developed initially were those for 360-degree circumferential cracks under pure tensile loading. Functions for finite length cracks were subsequently determined for certain limited cases.

The primary limitation of this method involves the errors introduced in extrapolating the existing influence functions, which were developed originally for tension loads, to bending loads as well as the errors introduced in using the functions for finite length surface cracks. Some GE-EPRI functions were also found to be in error as discussed in NUREG/CR-6235. In addition, prior to this program, these functions were not available for deep surface-cracked pipes.

The SC.TNP and SC.TKP J-Estimation Schemes. Realizing the limitations of the GE-EPRI method, efforts were undertaken in the Degraded Piping Program - Phase II (Ref. 4.1) to develop a J-estimation scheme for surface-cracked pipe similar to what existed for through-wall-cracked pipes (Ref. 4.10). Using existing GE-EPRI functions (Ref. 4.10) for a 360-degree surface-cracked pipe under tension loading, a complete scheme was developed to predict the applied $\mathrm{J}$, and the momentrotation behavior of a pipe under pure bending. Tables of the dimensionless functions required for the numerical computations were developed in Reference 4.1 and incorporated into two computer programs SC.TNP and SC.TKP. SC.TNP involved thin-walled approximations in the analysis while SC.TKP used the thick-wall analysis. Predictions using SC.TNP analysis agreed better with experimental data than those using the SC.TKP method (Ref. 4.1).

There were three limitations in this analysis. First, this method (Ref. 4.1) involves a "disposable" length parameter "L", the distance from the plane of the crack to that cross section where the stresses are assumed to become uniform. This parameter was not well defined and the results varied with the choice of "L". Also, the GE-EPRI functions for deeply cracked specimens were not available. Another limitation was that the method was applicable only for pure bending loads. Combined loads could not be handled by this method. However, it must be noted though that this was the only $\mathrm{J}$-estimation scheme available for finite-length surface-cracked pipes under bending loads. 


\subsubsection{Other Predictive Methods for Surface-Cracked Pipes}

Other methods which account for plasticity at the crack tip, but cannot be classified strictly as estimation schemes or design criteria, are the Code Case N-494-2 approach (Ref. 4.11) and the Dimensionless Plastic-Zone Parameter (DPZP) Criteria (Ref. 4.12). The DPZP method is based on a semi-empirical analysis of experimental data. These two methods are discussed next.

Code Case N-494-2 Approach: The Code Case N-494-2 approach (Ref. 4.11) is similar to the R6 method in that it involves a failure assessment diagram (FAD). It is based on deformation plasticity and uses some of the GE-EPRI functions (Ref. 4.10) to specify the bounding failure assessment curve for surface-cracked pipe. This method is essentially the same as the EPFM approach used in the GEEPRI J-estimation scheme. While safety factors may be specified externally in this method, it suffers from the same limitations as those for the R-6 approach, namely that rotations and/or displacements are not predicted. The shape of the FAD curve is material and geometry dependant. This method is currently being incorporated into the ASME Section XI Flaw Evaluation Procedures by using a lower bounding FAD curve shape (Ref. 4.13). Currently, this Code Case is applicable only to ferritic materials.

The Dimensionless Plastic-Zone Parameter (DPZP) Analysis: The DPZP analysis is a semi-empirical procedure developed at Battelle (Refs. 4.1 and 4.12) and is used to analyze surface-cracked pipe under bending and tension loads. In this analysis, a fully plastic condition is assumed to occur when the Irwin plastic-zone size (Ref. 4.14) equals the remaining tensile ligament length. The ratio of the maximum predicted stress to the calculated NSC stress is expressed as a function of the DPZP as

$$
\frac{\sigma}{\sigma_{\text {nsc }}}=\left[\frac{2}{\pi}\right] \arccos \{\exp [-\mathrm{C}(\mathrm{DPZP})]\}
$$

where

$$
\mathrm{DPZP}=2 \mathrm{EJ}_{\mathrm{i}} /\left(\pi^{2} \sigma_{\mathrm{f}}^{2} \mathrm{D}\right)
$$

$$
\begin{array}{lll}
\sigma & = & \text { total failure stress } \\
\sigma_{\text {nSc }} & = & \text { NSC predicted tension and bending stress } \\
\mathrm{E} & = & \text { elastic modulus } \\
\mathrm{J}_{\mathbf{i}} & = & \left.\mathrm{J} \text { at crack initiation (may be } \mathrm{J}_{\mathrm{IC}}\right) \\
\sigma_{\mathrm{f}} & =\text { flow stress }=\left(\sigma_{\mathrm{y}}+\sigma_{\mathrm{u}}\right) / 2 \\
\mathrm{D} & =\text { nominal pipe diameter, and } \\
\mathrm{C} & = & \text { statistically based curve-fit parameter. }
\end{array}
$$

For surface-cracked pipe fracture data the parameter $C$ for a best fit through the data is 32 . For a 95percent-confidence-level fit of the data, the parameter $\mathrm{C}$ is 8.9. A plot of $\sigma / \sigma_{\text {nsc }}$ versus DPZP, Figure 4.4, shows both surface-cracked and through-wall-cracked pipe data. 


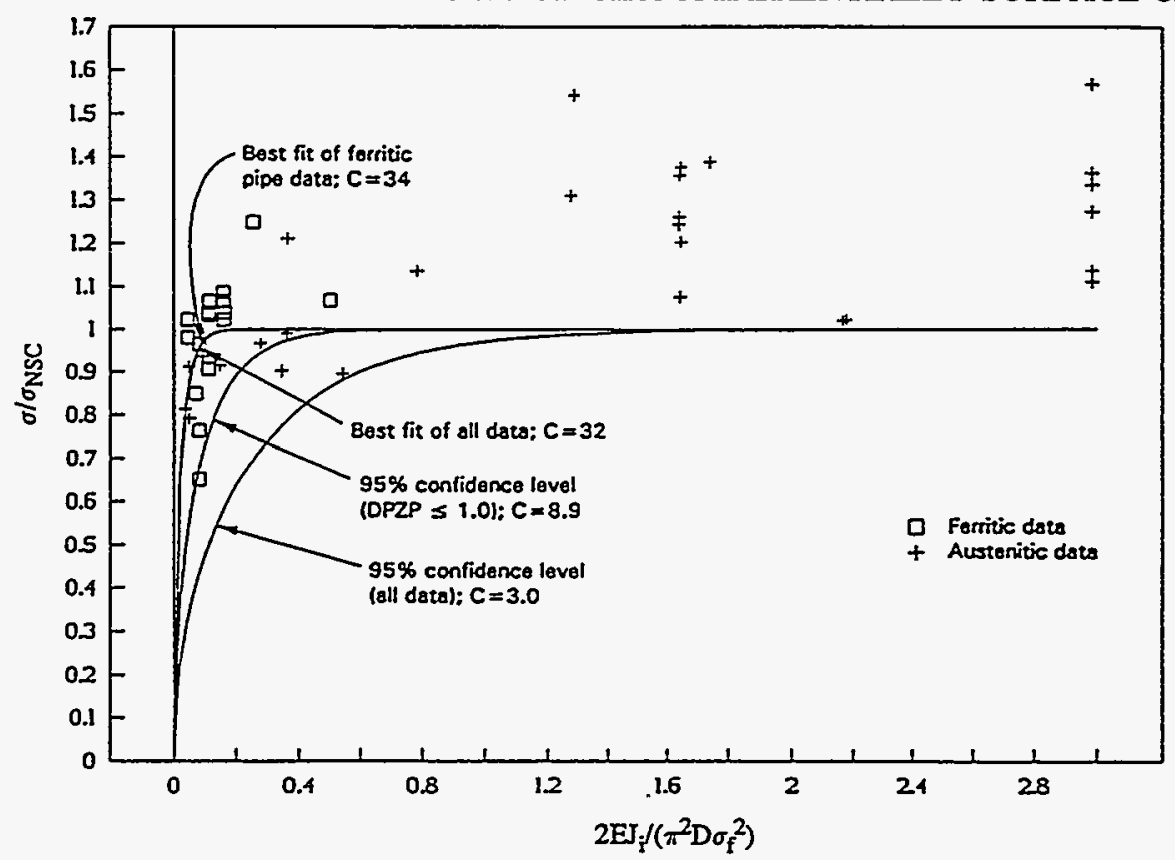

Figure 4.4 Fit of DPZP equation through pipe test data

The primary limitation of this method includes the empiricism involved in determining $C$, the statistically based parameter. This parameter is based on pipe tests with large surface cracks, and hence may not accurately predict short surface-crack behavior. Also, moment-rotation behavior of the pipe is not predicted. Major advantages are that it is relatively simple to use and inherently accounts for through-thickness toughness anisotropy, constraint effects on toughness, and pipe ovalization effects.

\subsubsection{The $\eta$-Factor Approach}

The previously described approaches are predictive methods that can be used to assess the structural integrity of circumferentially surface-cracked pipe with some idealized material properties and/or crack-resistance behavior. In addition to these methods, there are what can be classified as "generative J-estimation schemes". These methods, known as the $\eta$-factor approaches, require a priori knowledge of the moment rotation behavior of the cracked pipe, which is used to compute the J-R curve. Such methods are useful mainly for comparing the crack resistance of a laboratory C(T) specimen with the that of a pipe, but by themselves cannot be used as a scheme to predict failure loads of cracked pipes. Some predictive analysis methods incorporate an $\eta$-factor calculation, such as the SC.ENG method to be discussed later. For completeness, the $\eta$-factor approach is also reviewed briefly below.

This approach outlines an approximate method to estimate the energy release rate "J" for surfacecracked pipe. Assuming fully plastic conditions exist in the cracked plane, this method is used to evaluate the plastic component of the crack driving force, $\mathrm{J}_{\mathrm{p}}$, from the experimental load-displacement (or moment-rotation) curve for surface-cracked pipe. Essentially, $\mathrm{J}_{\mathrm{p}}$ is given by . 


$$
\mathrm{J}_{\mathrm{p}}=\eta_{\mathrm{p}} \int_{0}^{\phi_{\mathrm{p}}^{\mathrm{c}}} \mathrm{Md} \phi_{\mathrm{p}}^{\mathrm{c}}
$$

where

$$
\begin{aligned}
\mathrm{M} & =\text { the moment } \\
\phi_{\mathrm{p}}^{\mathrm{c}} & =\text { the plastic component of the pipe rotation due to the crack, and } \\
\eta_{\mathrm{p}} & =\text { a factor depending solely on the flaw and pipe size. }
\end{aligned}
$$

Several papers (Refs. 4.15 and 4.16) are available to compute the $\eta$-factor for circumferentially cracked pipe under bending or combined bending and tension loads. The propensity for crack growth, either in the radial or the circumferential direction, is considered in determining J. For crack growth calculations, $\eta_{\mathrm{p}}$ should be inside the integral.

The limitation of this approach is that it is not truly a predictive method as the moment-rotation curve for the surface-cracked pipe is needed as an input to evaluate $J$.

\subsubsection{Objectives and Scope}

As seen above, each of the aforementioned analysis methods has certain limitations. Therefore, the analysis work in the Short Cracks in Piping and Piping Welds program was aimed at improving existing analysis methods, developing new J-estimation schemes, and comparing analytical predictions with experimental results for various pipe materials, flaw geometries, and loading configurations.

The improvements in the analysis methods will help in assessing and modifying the ASME Section XI flaw evaluation criteria (Refs. 4.6, 4.7 and 4.13) discussed in Section 5 of this report.

Specifically, the scope of the current effort is to:

- $\quad$ modify the NSC method empirically to account for ovalization effects (Section 4.2.5),

- improve the existing J-estimation schemes SC.TNP and SC.TKP (Section 4.2.6),

- develop a new J-estimation scheme (SC.ENG) along the same lines as the LBB.ENG method for TWC pipes (Ref. 4.17) (Section 4.3),

- verify the predictions of the J-estimation schemes using finite element (FE) analyses (Section 4.3),

- develop a PC Program NRCPIPES similar to NRCPIPE (Ref. 4.18) for through-wallcracked pipes based on the analysis methods that already exist (Section 4.4), and

- compare experimental data with analytical predictions from the various methods (Section 4.4). 


\subsection{Improvements to Existing Methods}

The primary objective here was to improve the existing analysis methods. However, during the course of this program several "gaps" in technology, or other unresolved problems, relating to the analysis of surface-cracked pipe were encountered. These efforts, though not directly aimed at improving existing methods, were also addressed in this task and are discussed in this section.

Four such studies were: (i) the analysis of an uncracked pipe under bending loads including plasticity effects, (ii) the analysis of external surface cracks in pipes under combined bending and tension loads using the SC.TNP and SC.TKP methods, (iii) the determination of the effect of crack tip mesh refinement on the finite element results for surface-cracked pipe, and (iv) the development of influence functions for the GE/EPRI J-estimation scheme for deep surface-cracked pipe.

These four stand-alone efforts are presented first. The improvements to the existing limit-load approach (NSC method) as well as modifications to the SC.TNP/SC.TKP estimation schemes are presented after this. The impact of the analysis work on the ASME Section XI flaw evaluation procedures is detailed in Section 5.

\subsubsection{Uncracked Pipe Analysis}

\subsubsection{Objective}

The objective of this activity was to analyze and predict the moment-carrying capacity of an uncracked pipe under bending loads beyond the yield stress. This was done (i) to determine the buckling loads and compare them with the failure loads for short surface-cracked pipes, and (ii) incorporate uncracked pipe plasticity in load or displacement predictions for short surface-cracked pipe.

\subsubsection{Approach}

Existing methods available in the literature to predict the behavior of uncracked pipe were first reviewed. The five methods available are discussed below:

(1) The Nonlinear Beam Theory Approach: For strain-hardening materials with a strain-hardening exponent " $n$ ", the nonlinear beam theory solution relates the applied moment to the total rotation for an uncracked pipe. This relation is given in Reference 4.9 by Equation 4-11.

$$
\phi_{\mathrm{p}}^{\mathrm{nc}}=\frac{2 \mathrm{~L} \alpha \epsilon_{\mathrm{o}}}{\mathrm{R}_{\mathrm{m}}}\left[\frac{\mathrm{M}}{4 \sigma_{\mathrm{o}} \mathrm{R}_{\mathrm{m}}^{2} \mathrm{t} \beta^{\prime}}\right]^{\mathrm{n}}
$$


where

$$
\beta^{\prime}=\frac{\sqrt{\pi}}{2} \frac{\Gamma\left(1+\frac{1}{2 \mathrm{n}}\right)}{\Gamma\left(\frac{3}{2}+\frac{1}{2 \mathrm{n}}\right]}
$$

and

$$
\begin{array}{lll}
\phi_{\mathrm{p}}^{\mathrm{nc}} & = & \text { plastic rotation of uncracked pipe, } \\
\mathrm{L} & = & \text { pipe length, } \\
\alpha, \mathrm{n} & = & \text { Ramberg-Osgood constants, } \\
\sigma_{\mathrm{o}}, \epsilon_{\mathrm{o}} & = & \text { reference stress and strain, respectively, } \\
\mathrm{R}_{\mathrm{m}} & =\text { mean pipe radius, } \\
\mathrm{t} & =\text { pipe wall thickness, and } \\
\Gamma & =\text { Gamma function. }
\end{array}
$$

Since the Ramberg-Osgood stress-strain relation used in this method is a monotonically increasing function, the moment, as predicted by Equation 4-11, continuously increases with rotation. Hence, this approach is not useful for predicting the maximum moment-carrying capacity or buckling loads for pipes.

(2) The Net-Section-Collapse Approach: The maximum moment from the NSC approach, assuming that the entire section under consideration has reached limit load, was developed in Reference 4.2.

$$
M_{n s c}=4 \sigma_{f} R_{m}^{2} F(\theta)
$$

where

$$
\begin{array}{ll}
\mathrm{M}_{\mathrm{nsc}}= & \text { NSC moment } \\
\sigma_{\mathrm{f}} & =\text { flow stress }=\left(\sigma_{\mathrm{y}}+\sigma_{\mathrm{u}}\right) / 2, \\
\mathrm{R}_{\mathrm{m}}= & \text { mean pipe radius, } \\
\mathrm{t} & =\text { pipe thickness, and } \\
\mathrm{F}(\theta) & =1 \text { (for an uncracked pipe) }
\end{array}
$$

Again, the NSC approach does not predict the moment-rotation behavior for the uncracked pipe, but only the maximum load-carrying capacity. 
(3) The Mesloh Method: This method was originally derived (Ref. 4.19) empirically at Battelle using experimental data to predict the buckling strength of offshore pipelines. The maximum moment is predicted by

$$
\mathrm{M}_{\mathrm{MES}}=\mathrm{D}^{2} \mathrm{t} \sigma_{0.005}[500 /(445+\mathrm{D} / \mathrm{t})]
$$

where

$$
\begin{aligned}
& \mathrm{D}=\text { nominal outside pipe diameter, } \\
& \mathrm{t}=\text { pipe wall thickness, and } \\
& \sigma_{0.005}=\text { stress at } 0.5 \text { percent strain, } \approx \sigma_{\mathrm{y}}
\end{aligned}
$$

While the buckling strength can be estimated using Equation 4-14, the moment-rotation behavior is not predicted by this method.

(4) The "COLAPS" Code: This computer program "COLAPS" was also written at Battelle to study buckling of pipes under bending loads (Ref. 4.20). The method incorporates the strainhardening characteristics of the pipe material into the analysis. This code was originally developed at Battelle for the offshore pipeline industry, and also does not address the momentrotation behavior of the pipe.

(5) Finite Element Approach: A finite element code such as ABAQUS (Ref. 4.21) has four possible options for modelling uncracked pipe behavior. These involve (i) a straight pipe element, (ii) an "elbow" element (with a zero-degree bend) to simulate straight piping, (iii) the shell element, which is more accurate than the straight pipe or elbow elements, and (iv) the full 3-D brick elements for the highest accuracy in predictions. Straight pipe beam elements, even with plasticity options, are generally recognized not to work well for bucking predictions, and hence were not used. Strain-hardening characteristics can be included easily in the material models used and the elements accommodate ovalization effects due to bending. Thus, both maximum buckling load and moment rotation behavior can be obtained from the FE analyses.

\subsubsection{Results}

There are two major results from this activity. The first compares the buckling moments from five uncracked pipe experiments with the maximum predicted moments from four of the methods described above-the NSC criterion, the Mesloh approach, the COLAPS code, and the FE analysis using "elbow" elements. The finite element results using shell elements were almost identical to those using "elbow" elements. These predictions are compared with experimental data on uncracked pipe experiments conducted by JAERI (Refs. 4.22 and 4.23). Table 4.1 shows the details of the JAERI stainless steel pipe experiments analyzed as well as the material properties used. A plot of the ratio of the predicted-to-experimental maximum moment versus the $R_{m} / t$ ratio for the pipes analyzed in Table 4.1 is shown in Figure 4.5. As seen, a comparison of the experiments with the calculated 
Table 4.1 Summary of JAERI uncracked experiments analyzed

\begin{tabular}{|c|c|c|c|c|c|c|}
\hline \multirow[b]{2}{*}{ Experiment No. } & \multirow{2}{*}{$\begin{array}{c}\text { Outer } \\
\text { Diameter, } \\
\text { mm (inch) }\end{array}$} & \multirow[b]{2}{*}{ Schedule } & \multirow{2}{*}{$\begin{array}{c}\text { Yield } \\
\text { Strength, } \\
\text { MPa (ksi) }\end{array}$} & \multirow{2}{*}{$\begin{array}{l}\text { Ultimate } \\
\text { Strength, } \\
\text { MPa (ksi) }\end{array}$} & \multicolumn{2}{|c|}{$\begin{array}{c}\text { Ramberg- } \\
\text { Osgood } \\
\text { Constants }^{(a)}\end{array}$} \\
\hline & & & & & $\alpha$ & $\mathbf{n}$ \\
\hline$S-1^{(b)}$ & $86.1(3.39)$ & 40 & $270(39.0)$ & $617(89.4)$ & 3.19 & 5.63 \\
\hline$S-21^{(b)}$ & $87.4(3.44)$ & 160 & $267(38.6)$ & $612(88.6)$ & 2.74 & 6.02 \\
\hline$S-17^{(b)}$ & $85.1(3.35)$ & 80 & $333(48.3)$ & $632(91.5)$ & 2.07 & 8.39 \\
\hline $\mathrm{TT}-00^{(\mathrm{c})}$ & $168(6.50)$ & 80 & $239(34.7)$ & $622(90.2)$ & 3.23 & 6.43 \\
\hline $\mathrm{TT}-100^{(c)}$ & $324(12.60)$ & 80 & $258(37.4)$ & $52(84.4)$ & 0 & ) \\
\hline
\end{tabular}

(a) With $\sigma_{0}=\sigma_{\mathrm{y}}$ and $\mathrm{E}=26.5 \times 10^{6} \mathrm{psi}$.

(b) Data from Reference 4.22 .

(c) Data from Reference 4.23.

(d) Stress-strain curve not available.

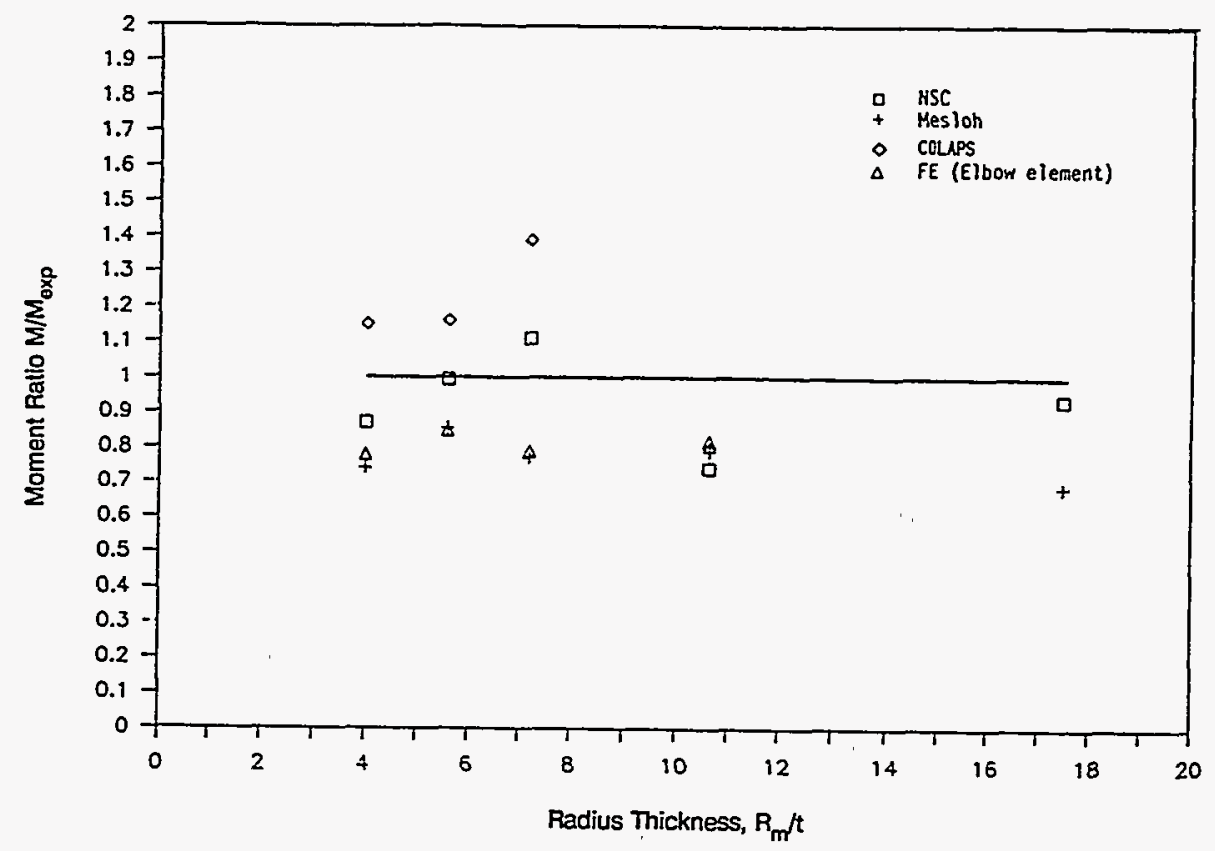

Figure 4.5 Comparison of predicted with experimental maximum moments from JAERI uncracked stainless steel unpressurized pipe bending experiments 
values shows that the Mesloh Method and the ABAQUS "elbow" element gave virtually identical predictions and were consistently lower than the experimental values.

The predictions of the buckling moments by the Mesloh method had an average of 77.2 percent of the experimental results with a standard deviation of 0.065 . The FE method had an average value of 81.2 percent of the experimental data with a standard deviation of 0.028 . Compared with these, the COLAPS code and the NSC analysis had much larger scatter with average values of 1.11 and 0.93 , respectively, and with standard deviations of 0.29 and 0.18 , respectively. The effect of $R_{m} / t$ on the accuracy of the predictions was negligible for these experiments. These results indicate that for stainless steel pipes, the buckling load can be calculated very simply using the Mesloh Method (Ref. $4.19)$ with an empirical correction of $1.295(=1 / 0.772)$. The Mesloh method was developed as a design criterion and had some inherent margin built into it.

The results using the ABAQUS "elbow" element underpredicted the maximum load by almost 20 percent. This was quite surprising as both ovalization effects and elastic-plastic material behavior are included in the FE model. A considerable effort was spent in resolving this discrepancy, including FE modelling of a simple stainless steel four-point bend bar for which exact data were available in the literature. Also, a detailed 3D FE study was conducted to investigate the effect of mesh refinement on the numerical predictions. Sample meshes for this mesh-refinement study are shown in Figures 4.6a and 4.6b for JAERI Pipe Experiment S-17 (Ref. 4.22).

At the end of this effort it was determined that a full 3-D FE analysis, with an incremental plasticity material model, was needed to predict both the moment rotation as well as the maximum moment for an uncracked stainless steel pipe satisfactorily. Figure 4.7 shows a comparison of the 3-D FE results with experimental data for JAERI stainless steel pipe Experiment S-17. Elbow elements as well as shell elements do not capture the stiffness changes and ovalization of the stainless steel pipe accurately enough and lead to gross underestimation of the maximum load in the plastic range, sometimes as much as 25 percent. This result, trivial as it seems, is quite important as it can lead to gross errors in predictions in the plastic range, especially because the elbow and shell elements are used frequently to model piping behavior.

\subsubsection{External and Internal Surface-Crack Analysis Using SC.TNP and SC.TKP Methods - Combined Pressure and Bending Loads}

\subsubsection{Background and Objective}

The incentive for this work was to provide Brookhaven National Laboratory staff with a methodology to analyze low cycle fatigue growth of external surface cracks in piping under combined pressure and bending loads for analysis of a high-level vibration pipe test conducted in Japan (Ref. 4.24). Even though J-estimation schemes are not rigorously applicable to fatigue problems, an engineering approach could be formulated if such an analysis procedure were available. With this background, a stand-alone task to address external surface-cracks in piping under combined bending and tension loads was initiated within the Short Cracks in Piping and Piping Welds Program. The results were summarized in the second semiannual report from this program (Ref. 4.25). Since this work was initiated as part of the Surface-Crack Analysis Task in the Short Cracks in Piping and Piping Welds program, the results are included in this report along with the derivation of the J-estimation scheme. 


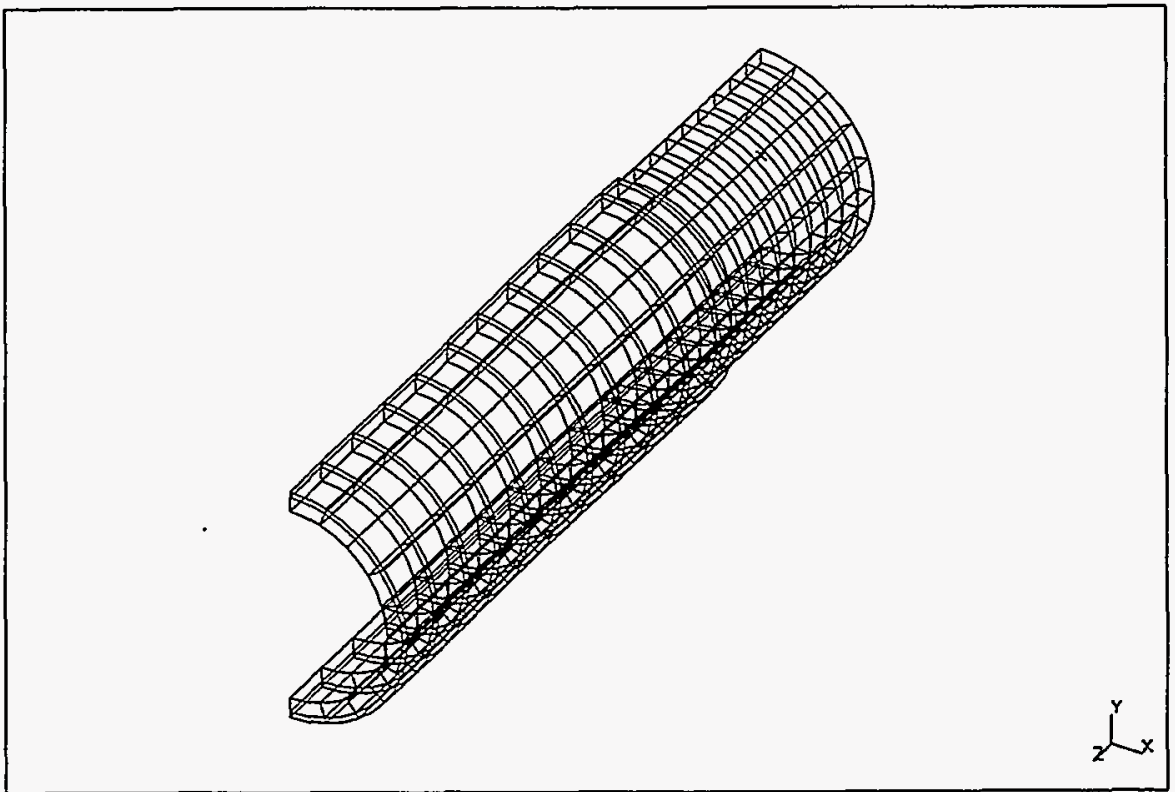

(a) One element through thickness at mid-span location

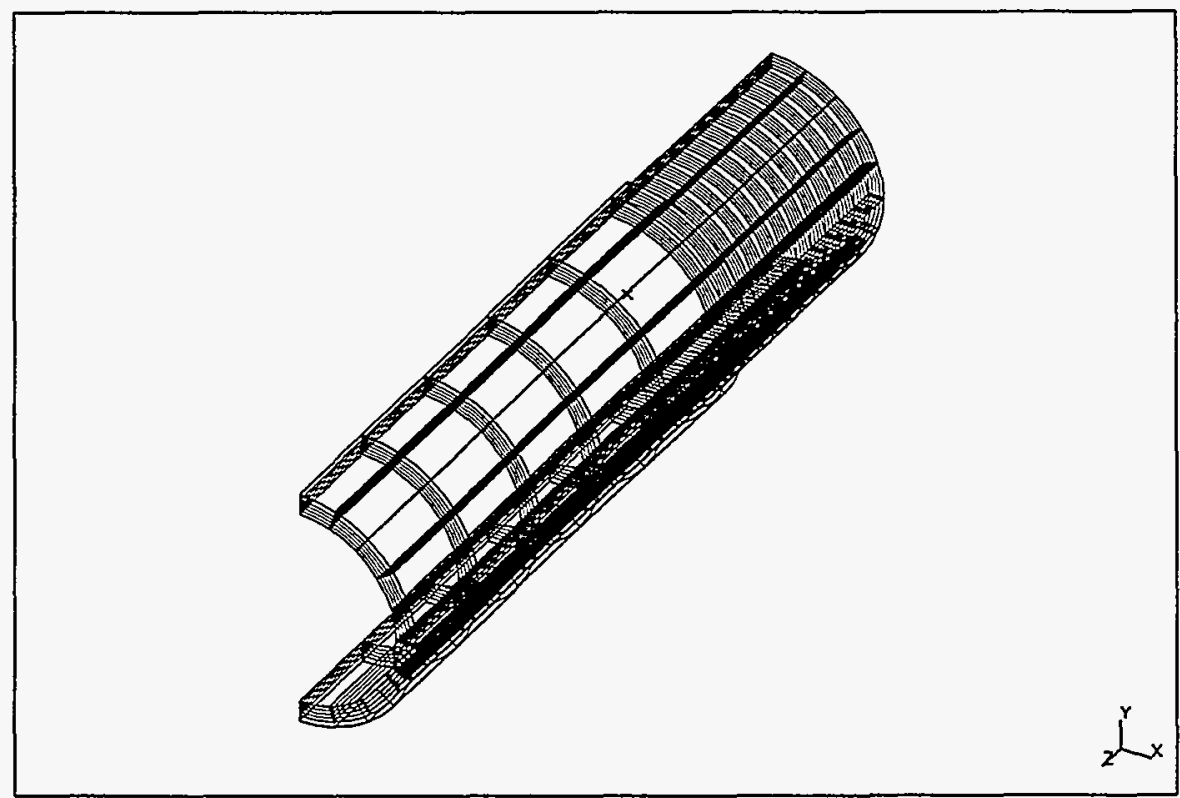

(b) Four elements through thickness at mid-span location

Figure 4.6 Finite-element mesh of JAERI uncracked pipe Experiment S-17 using 3-D solid elements 


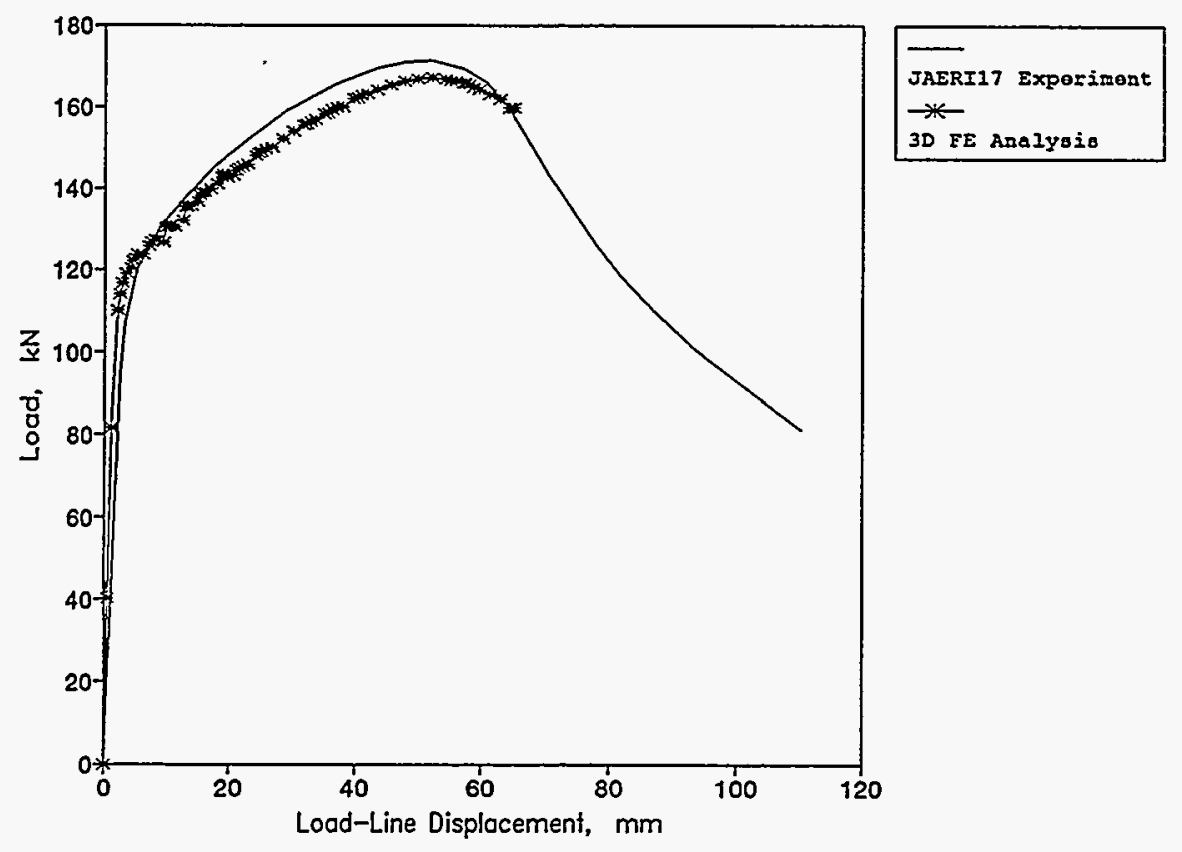

Figure 4.7 Uncracked pipe FE analysis; comparison between FE results and JAERI Pipe Experiment S-17 data

As stated above, the objective of this effort was to extend the SC.TNP and SC.TKP methods described in Reference 4.1 to enable the analysis of external surface-cracked pipe under combined bending and tension cyclic loads. Once developed, such an estimation scheme requires only minor modifications for the case of internal cracks under similar load situations. Hence, both internal and external cracks were analyzed simultaneously in this effort.

\subsubsection{Approach}

The two methods, SC.TNP and SC.TKP, developed during the Degraded Piping Program (Ref. 4.1) were developed for internal surface-cracked pipe under pure bending loads. To extend these methods for the external surface crack case involved: (i) minor changes to the original J-estimation derivation to account for the crack on the external surface, (ii) major modifications to the estimation scheme to account for combined bending and tension (due to internal pressure) loads, and (iii) development of a computer code based on the new schemes. A summary of these changes is discussed below. The detailed equations for the J-estimation schemes are given in Appendix A.

Geometry of Surface Cracks: Two types of flaw geometries were analyzed-the conventional constant depth flaw shown in Figure 4.1 and an elliptical flaw as shown in Figure 4.8. The elliptical approximation to a surface flaw is sometimes more appropriate than a constant depth flaw when compared with those detected in service piping. For the elliptical flaw, the external surface flaw depth " $a$ " varies as a function of the angle " $x^{\prime \prime}$ from the center of the flaw as shown in Figure 4.8(a). The general equation used to describe " $a$ " is given by: 


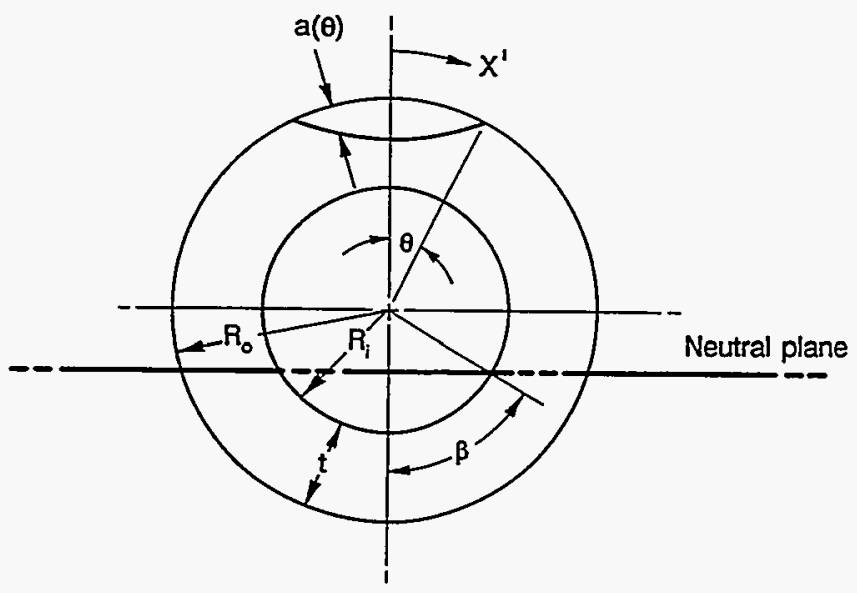

(a) External surface flaw geometry

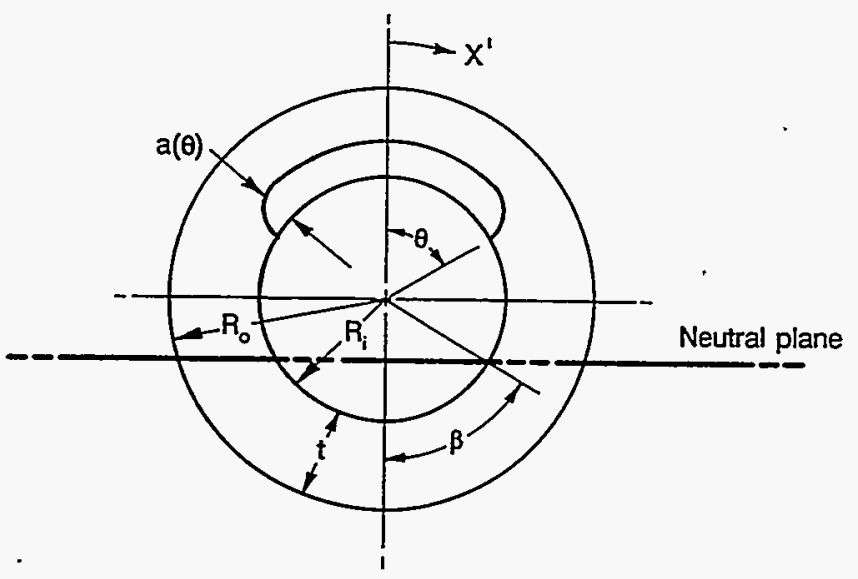

(b) Internal surface flaw geometry

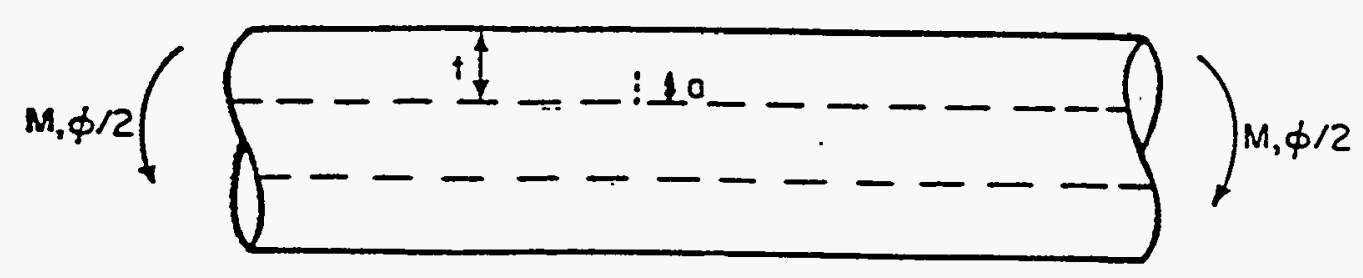

(c) Surface-cracked pipe under bending and pressure loads

Figure 4.8. Elliptical geometry and loading configuration for surface-cracked pipe 


$$
a\left(x^{\prime}\right)=R_{0}-r_{1} x^{\prime}
$$

where

$$
\begin{aligned}
& r_{1}=\left[R_{0}^{2}+r_{0}^{2}-2 R_{0} r_{0} \cos \alpha^{\prime}\right]^{1 / 2} \\
& r_{0}=\left[\frac{a_{0}^{2} a^{2}}{a_{0}^{2} \sin ^{2} \alpha^{\prime}+a^{2} \cos ^{2} \alpha^{\prime}}\right]^{1 / 2} \\
& a=\left[\frac{2 a_{0}^{2} R_{0}^{2} \cos ^{2}(\theta / 2)(1-\cos \theta)}{a_{0}^{2}-2 R_{0}^{2} \sin ^{2}(\theta / 2)(1-\cos \theta)}\right]^{1 / 2}
\end{aligned}
$$

and

$$
\alpha^{\prime}=\sin ^{-1}\left[\frac{\mathrm{r}_{1} \sin \left(\mathrm{x}^{\prime}\right)}{\mathrm{r}_{\mathrm{o}}}\right]
$$

where $\quad R_{0}=$ outer radius of pipe

$\mathrm{a}_{\mathrm{o}}=$ maximum crack depth

$\theta=$ half crack angle

$\mathrm{r}_{1}=$ function of the angle $\gamma$, and

$\mathrm{x}^{\prime}=$ angle from the maximum crack depth, see Figure 4.8

For given $\mathrm{R}_{0}, \theta$, and " $\mathrm{a}_{\mathrm{o}}$ ", Equations 4-15 through 4-19 have to be solved numerically to obtain the crack depth function $a\left(x^{\prime}\right)$. A similar approach was used to define the elliptical internal surface-crack $a\left(x^{\prime}\right)$, Figure 4.8(b).

Combined Bending and Tension Loads: All J-estimation schemes are based on Ilyushin's theorem as described in Reference 4.8. This theorem states that if the stress-strain behavior for a material is described by a homogenous function, linear or nonlinear, then the load-deflection behavior for a structure also assumes a simple homogenous form, provided proportional loading is satisfied. The restriction to proportional monotonic loading is automatically satisfied in the pure bending case as only a single load is involved.

For the combined bending and tension case, an assumption needs to be made that the ratio of bending to tension loads can be described by a single parameter that is monotonically increasing during the 
loading process. Although this assumption is violated for the case of constant internal pressure with increasing bending loads, the results from such analyses have been shown to be valid for other specimen configurations (Ref. 4.26). With this assumption of the simultaneous application of pressure and bending loads, the development of the J-estimation scheme follows the same procedure as that for SC.TNP described in Reference 4.1. Details of the derivation of this estimation scheme are given in Appendix A.

Development of EXTCRK7 and INTCRK7: Once the estimation scheme, derived in Appendix A, was completed, the equations were coded into a FORTRAN program. Two versions of this program were prepared, EXTCRK7 for external surface-cracked pipe and INTCRK7 for internal surfacecracked pipes under combined loads. Each version provides the option of using either thin-wall-pipe approximations (SC.TNP), or thick-wall-pipe equations (SC.TKP).

Given the pipe size, material properties, and the flaw geometry, the programs can be used to predict the value of $J$ for any given value of the applied moment and internal pressure. These codes cannot predict the moment-rotation behavior of the cracked pipe as this was not needed for the analysis cases at Brookhaven. Complete program listings of EXTCRK7 and INTCRK7 are given in Appendix B.

\subsubsection{Verification of Predictions Using EXTCRK7 and INTCRK7}

Once the estimation scheme presented in Appendix A was coded into EXTCRK7 and INTCRK7, it had to be verified against existing solutions. This was done by comparing the predicted value of $\mathrm{J}$ for the internal surface-crack case with finite element results obtained by Professor Kikuchi at the Science University of Tokyo. These FE results were for Experiment Number 4131-4 from the Degraded Piping Program (Ref. 4.27). This experiment involved a pipe with an outside diameter $\left(\mathrm{D}_{0}\right)$ of 272 $\mathrm{mm}$ (10.7 inches), wall thickness ( $\mathrm{t})$ of $16.6 \mathrm{~mm}(0.654 \mathrm{inch}), \mathrm{R} / \mathrm{m}$ of 8.2 , and an internal flaw of uniform depth (a) of $10.9 \mathrm{~mm}$ ( $0.43 \mathrm{inch}$ ). The pipe material stress-strain curve is represented by the Ramberg-Osgood equation with $\sigma_{\mathrm{o}}=241 \mathrm{MPa}, \epsilon_{\mathrm{o}}=0.001167, \alpha=3.46$ and $\mathrm{n}=4$. The pipe was subjected to four-point bending and had an internal pressure (p) of $18.3 \mathrm{MPa}(2,650 \mathrm{psi})$. First, neglecting the effects of pressure loading, Figure 4.9 shows a plot of the predicted value of $\mathrm{J}$ at various values of half the applied bending load $\mathrm{P}$. Up to load values of $66.7 \mathrm{kN}$ (15,000 pounds), the values of $\mathrm{J}$ predicted by the estimation schemes are in agreement with the $\mathrm{FE}$ results. At higher loads, the predictions for $J$ using the thick-wall analysis are higher than those from the FE results. The predictions from the thin-wall analysis are lower than those from the FE calculations. This is consistent with past comparisons made during the Degraded Piping Program (Ref. 4.1).

Results for the case of combined bending and pressure loading are shown in Figure 4.10. In this case Professor Kikuchi modeled Degraded Piping Program Experiment 4131-4. For this case, the deviation between the FE results and the estimation schemes occurs at a lower load of about $35.6 \mathrm{kN}$ ( 8,000 pounds). As for the case of pure bending, the predictions for $J$ from the thick-wall analysis are significantly higher than those from $\mathrm{FE}$ results at the higher loads and the predictions for $\mathrm{J}$ from the thin-wall analysis are lower than the FE results at the higher loads.

It should be recognized that even with the current method, the error in predicting the load at a given J value would not be as large as the error in predicting $J$ for a given load. For example, at the $J_{i}$ value of $0.155 \mathrm{MJ} / \mathrm{m}^{2}\left(885 \mathrm{in}-\mathrm{lb} / \mathrm{in}^{2}\right)$ for the material, Figure 4.10 gives an initiation load $\left(\mathrm{P}_{\mathrm{i}}\right)$ to be 


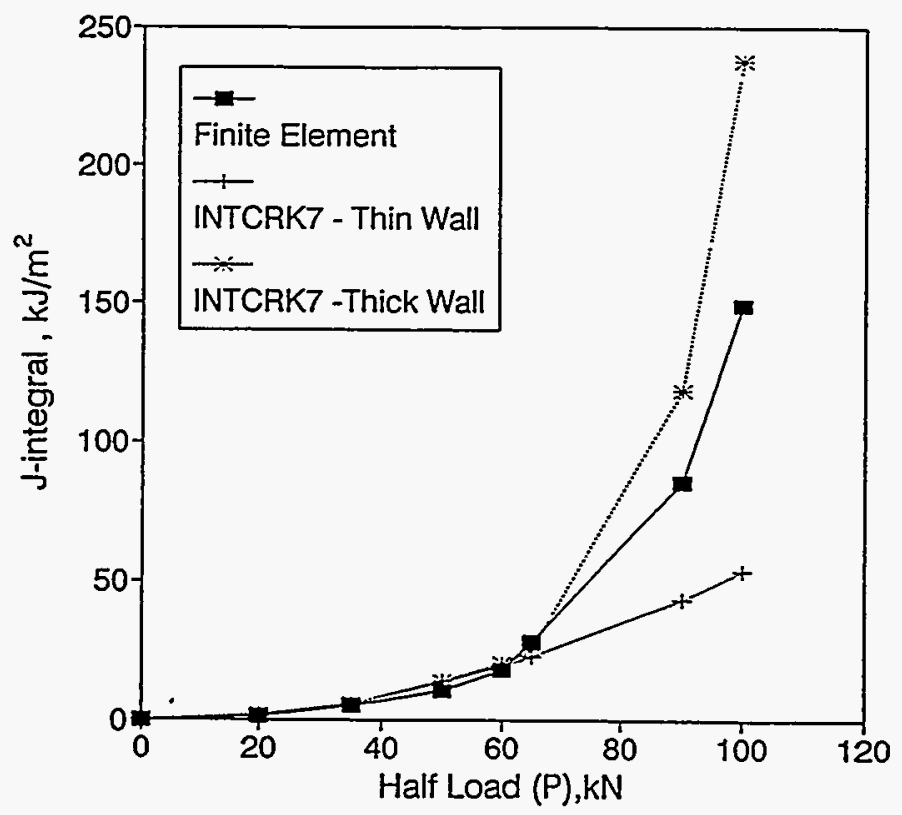

Figure 4.9 Comparison between J-estimation scheme (INTCRK7) and FE results for internal-surface-cracked pipe Experiment 4131-4, neglecting effects of internal pressure

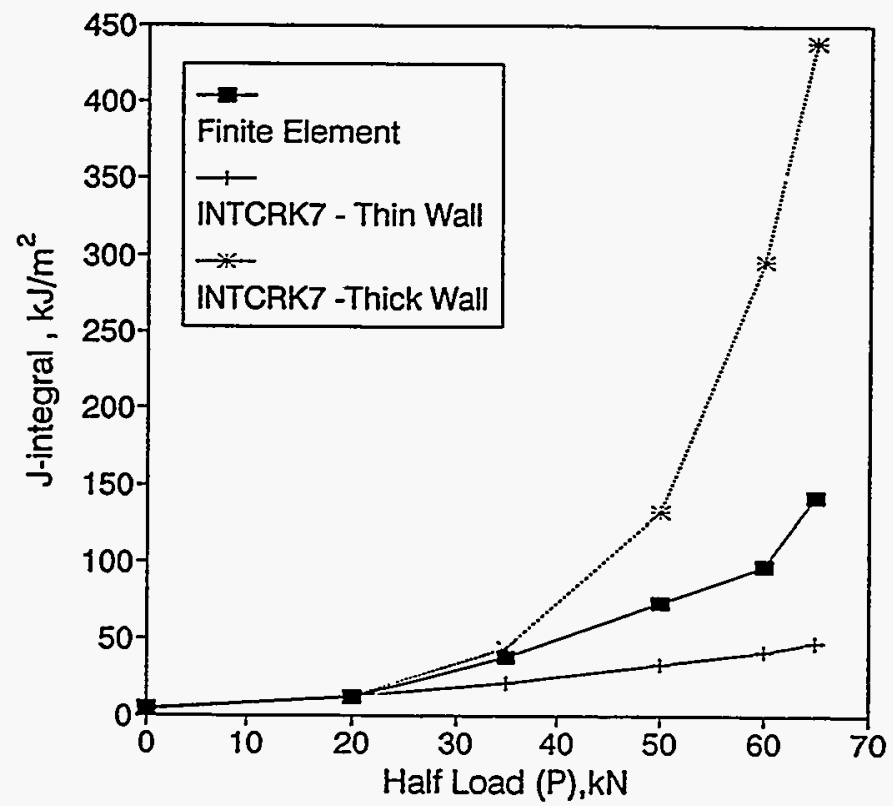

Figure 4.10 Comparison of J-estimation scheme (INTCRK7) and FE results for Experiment 4131-8, including effects of internal pressure 
$51.2 \mathrm{kN}(11,520$ pounds) by the thick-wall estimation formula and $66.0 \mathrm{kN}$ (14,830 pounds) by the finite element results. The experimental value for $P_{i}$ was $73.4 \mathrm{kN}(16,510$ pounds).

As stated before, one of the incentives for this work was to provide an analysis for Brookhaven National Laboratory staff to analyze the low cycle fatigue crack growth in a pipe system experiment conducted in Japan (Ref. 4.24). A note of caution is necessary for this application. Typically low cycle fatigue crack growth data are generated using the Dowling approach where da/dN $=C(\Delta \mathrm{J})^{\mathrm{m}}$ (Ref. 4.28). Such data are developed from laboratory specimen tests (i.e., C(T) specimens) where J is calculated by integrating the cyclic load-displacement record. For negative load ratios (lowest/highest load in the test), the compressive load-displacement area is used only down to a point where crack closure is suspected to occur (Ref. 4.28). As an example, the compressive load at which crack closure occurs for fully reversed loading can typically be at 30 percent of the maximum tensile load. Hence, the Dowling $J$ value is an "operational $J "$. This is not the same $J$ as calculated by finite element analysis or pipe J-estimation schemes. "Adjustments" to the pipe J applied values are needed to give an operational J consistent with the Dowling values. Reference 4.29 is an example of a lowcycle fatigue analysis using through-wall-cracked pipe J-estimation schemes modified to be consistent with the Dowling J parameter for reverse loading.

\subsubsection{Discussion}

As discussed above, this work was done in 1991 during the first year of the program. One of the objectives at that time was to incorporate this methodology into the PC program NRCPIPES for analyzing surface-cracked piping. The two codes developed during this effort, INTCRK7 and EXTCRK7, were delivered to the USNRC and to Brookhaven in 1991, but not included as optional analysis methods in the NRCPIPES code, especially since EXTCRK7 was not verified against FE solutions and there were program size limitations for the NRCPIPES code.

\subsubsection{Surface-Crack Mesh-Refinement Study}

\subsubsection{Background and Objective}

In order to accurately compute the crack tip fields and J-integral values for surface-cracked pipes using finite element analyses, sufficient care has to be taken to ensure adequate refinement of the mesh. Earlier work during the Degraded Piping Program (Ref. 4.30) and by Shimakawa and Yagawa (Ref. 4.31) has shown that mesh refinement, load increments, and material modelling can strongly influence the finite element solutions. In the following, a critical examination of the effect of mesh refinement on finite element solutions for circumferentially surface-cracked pipe loaded under 4-point bending was made using the commercially available software program ABAQUS (Ref. 4.21). A fanlike mesh focused at the crack-tip was employed in all cases, since this yields more accurate solutions for quasi-static crack problems. There were three levels of mesh refinement that could be examined, namely, refinement along the thickness direction of the cracked and uncracked ligaments, refinement along the crack front direction, and refinement along the circumferential direction of the fan-like mesh focussed at the crack tip. Since the most critical location in circumferentially 
surface-cracked pipes is at the center of the flaw, the mesh refinement examined in this task was confined to the thickness direction of the crack and the remaining ligament of the pipe."

\subsubsection{Approach}

Mesh refinement in circumferentially surface-cracked pipes loaded under 4-point bending was examined using three 3D finite element meshes with 8-noded brick elements. There were 13 elements used along the circumferential crack front in all cases. Mesh 1 consists of eight elements radially along the crack and seven elements radially along the ligament. Figure 4.11(a) shows Mesh 1 and Figure 4.11(b) shows a magnified view of the cracked region. The detail of the crack-tip region at the center of the crack front is shown in Figure 4.11(c). The size of the smallest element at the crack tip in Mesh 1 is $0.0508 \mathrm{~mm}$ ( 0.002 inch). Mesh 1 may be considered as a moderately refined model. Mesh 2 was a coarser model than Mesh 1, consisting of only five elements along the crack and four along the ligament. Details of the crack tip region at the center of the crack front for Mesh 2 are shown in Figure 4.12. Mesh 3 was a more refined model than Mesh 1, consisting of 14 elements along the crack and 13 elements along the ligament. Detailed view of the crack tip for Mesh 3 is shown in Figure 4.13.

Elasto-plastic simulations of a surface-cracked pipe experiment from the Degraded Piping Program (Experiment 4112-8), References 4.1 and 4.27, have been carried out using the aforementioned three 3-D finite-element models and a shell finite-element model with the crack being modelled with linespring elements. The stress-strain behavior of the material is shown in Figure-4.14.

\subsubsection{Results}

The predicted load versus pipe displacement at the load-point relationship using all the models was compared with the experimentally measured data in Figure 4.15. There were negligible differences between the predictions for the various models. This was not surprising since the load point, being sufficiently far away from the crack, was relatively unaffected by details of crack-tip refinement. The difference between the predicted and measured values increased beyond a pipe displacement of $95.25 \mathrm{~mm}$ (3.75 inch). The predicted load at crack initiation was more than 9 percent higher than the measured load.

* In all cases, the crack was modelled with a fan-like mesh with uniform grading in the circumferential direction (giving an angular resolution of 22.5 degrees and with geometrically increasing radial grading with varying number of rings for each mesh). 

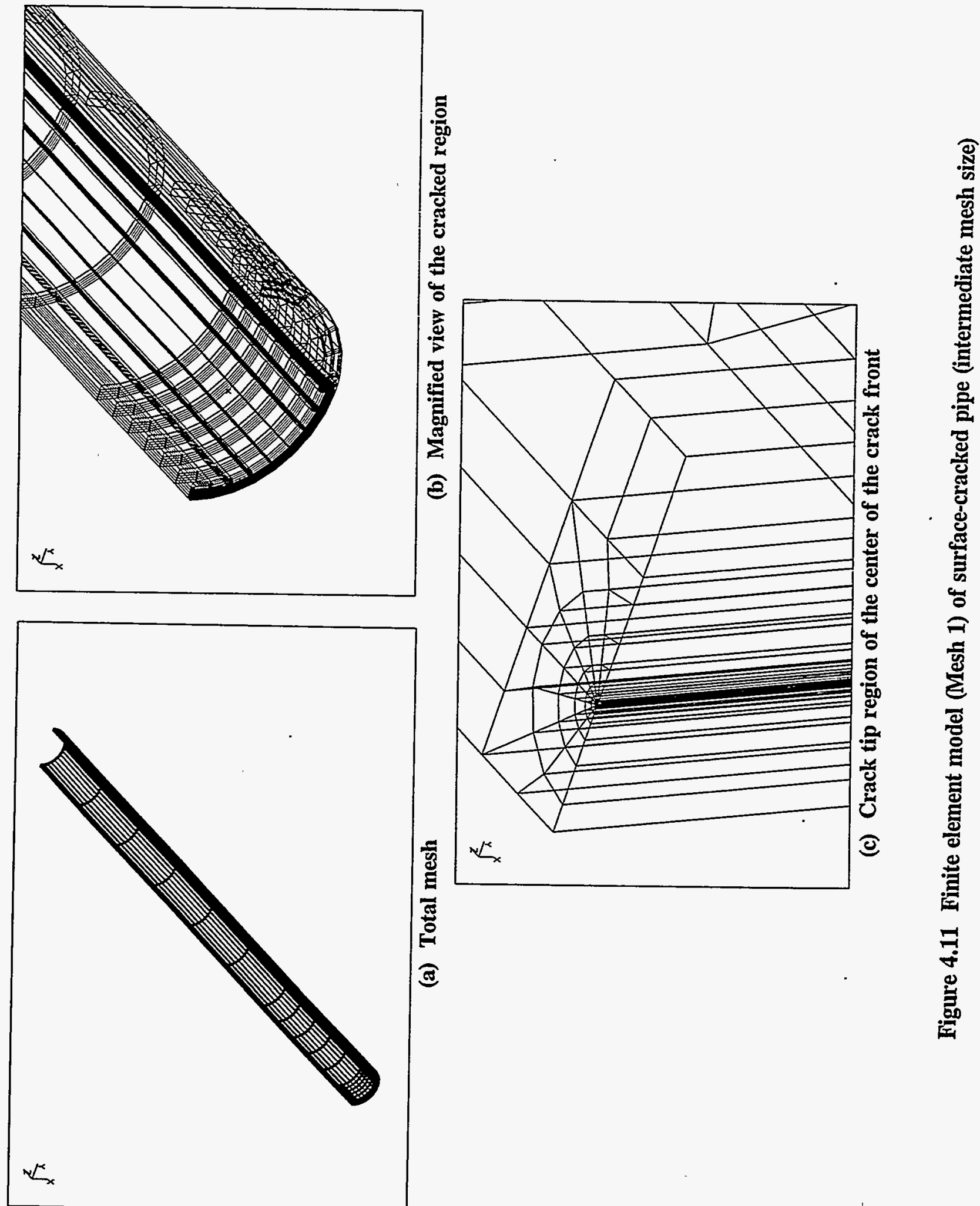


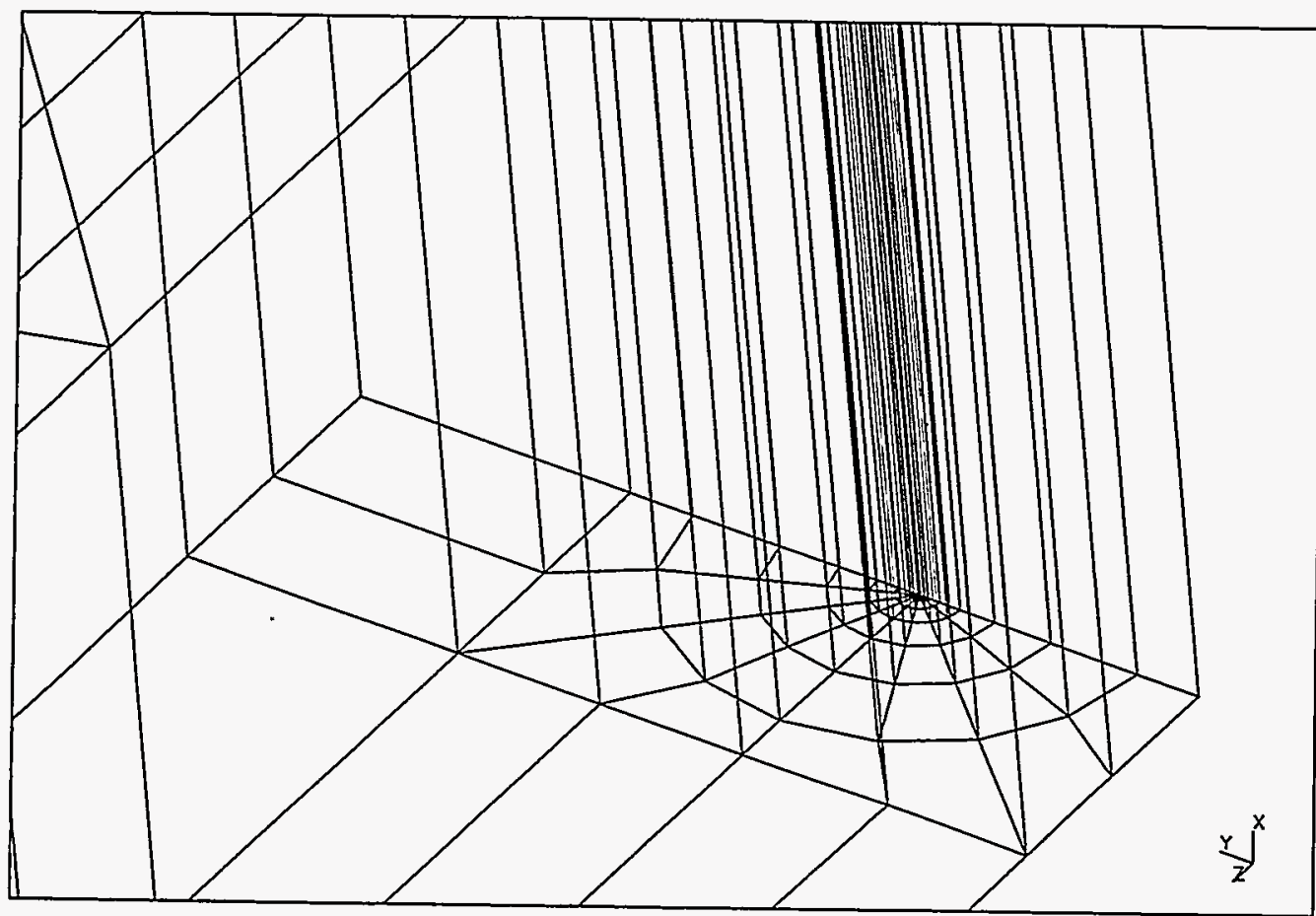

Figure 4.12 Detail of the crack-tip region at the center of the crack front for Mesh 2

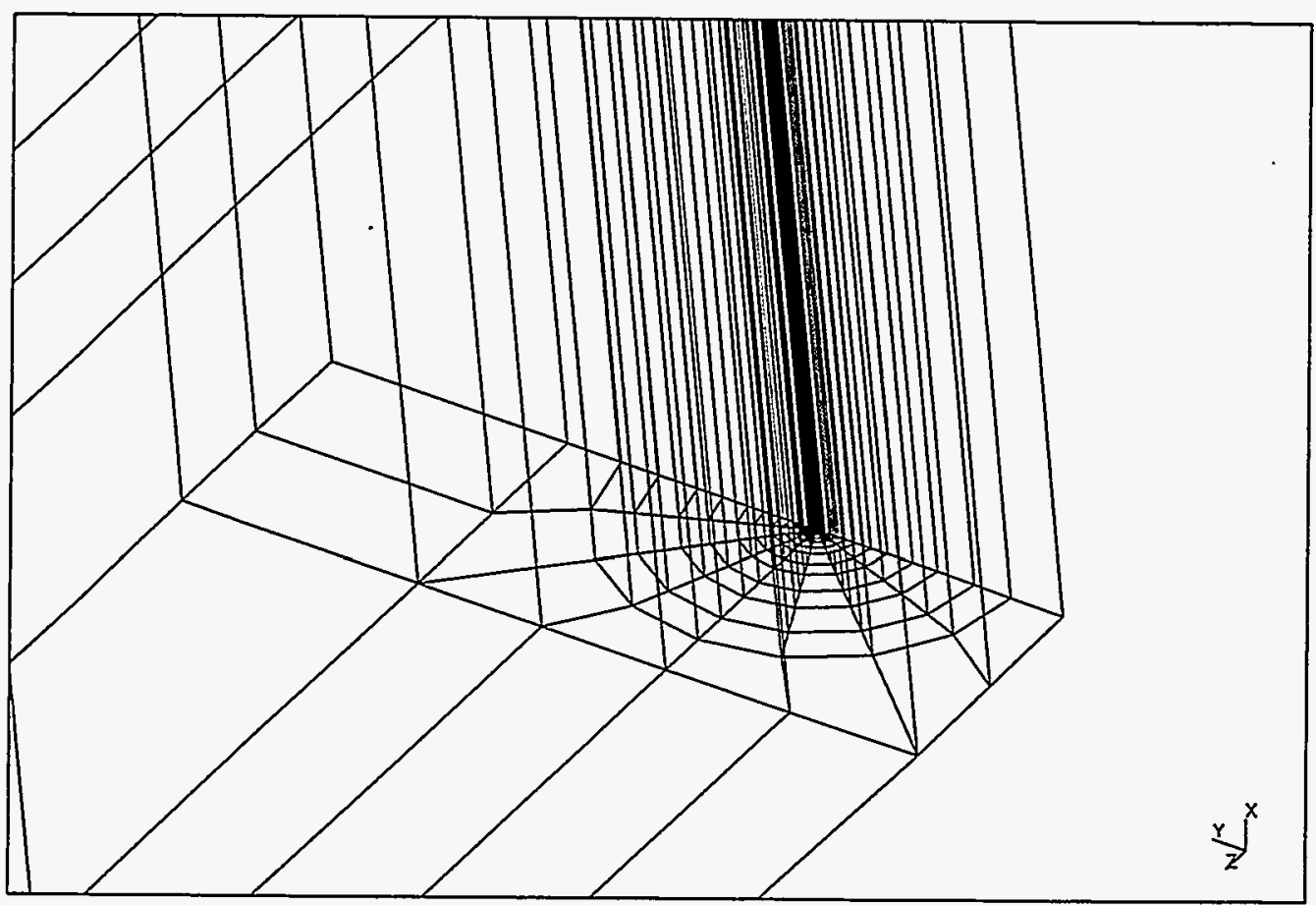

Figure 4.13 Detail of the crack-tip region at the center of the crack front for Mesh 3 


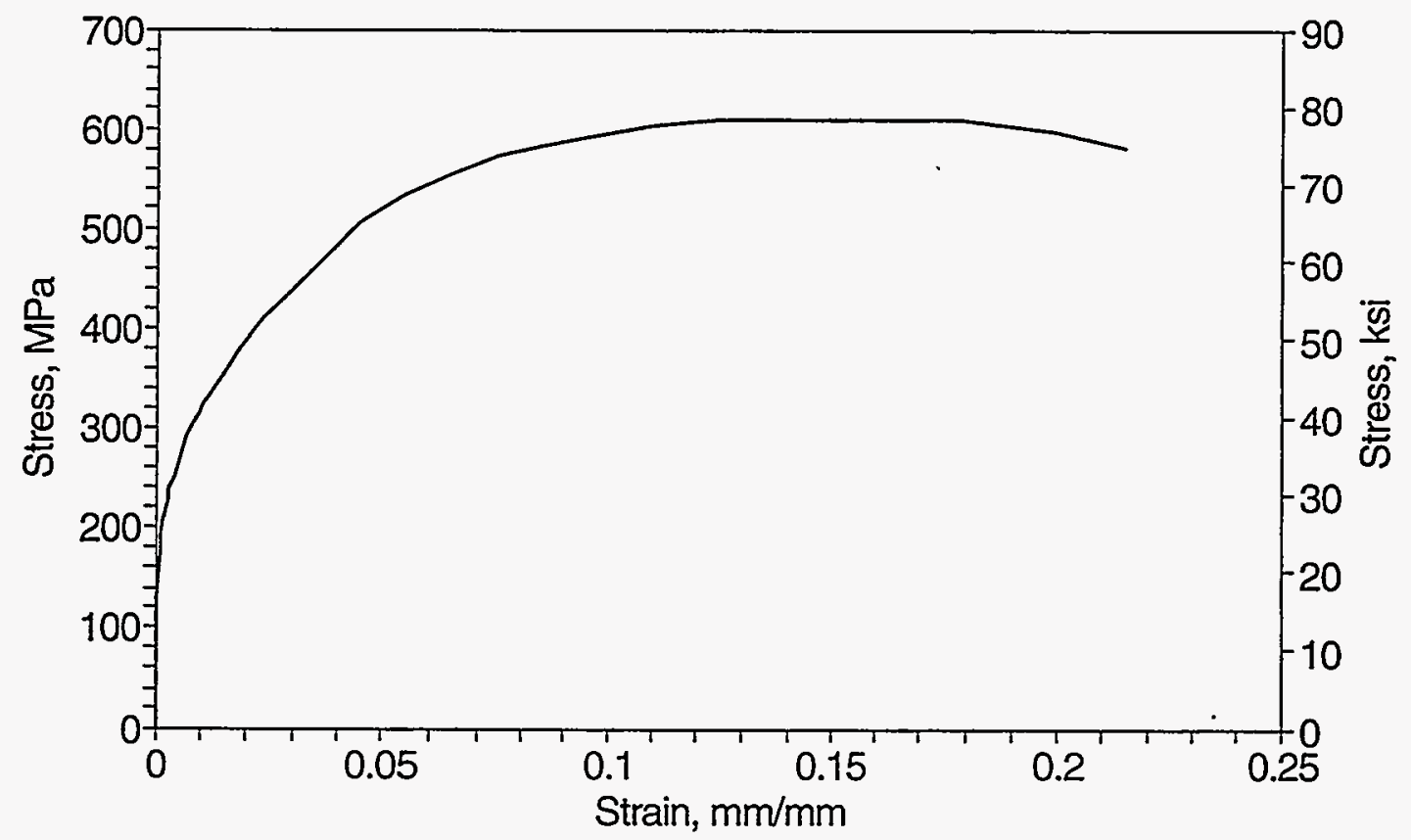

Figure 4.14 Stress-strain curve for material DP2-F29

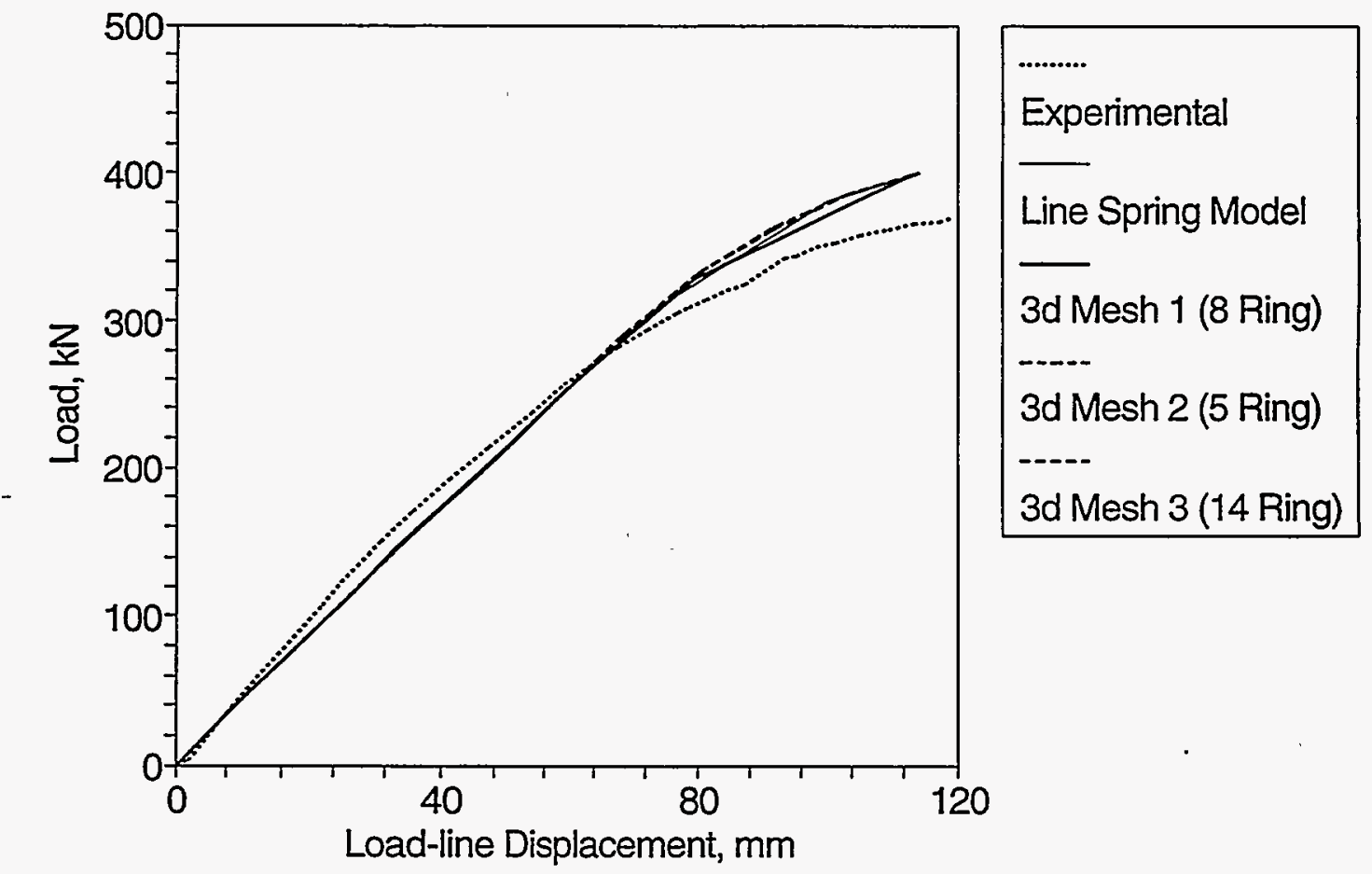

Figure 4.15 Predicted and experimentally measured load versus pipe displacement of the load points 
The calculated J-integral versus pipe displacement values at the load point is shown in Figure 4.16. Although the various models showed little difference in the load versus pipe displacement at the load point relationship (see Figure 4.15), they exhibited a notable difference in the $J$ integral values with load-point displacement relationship. The calculated values of the J-integral for the three 3D finite element meshes were almost path independent. However, a \pm 10 percent variation of $\mathrm{J}$-integral values between the various contours was observed in the case of Mesh 2 (coarser mesh), while a \pm 5 percent variation of J-integral values between the various contours was observed for Meshes 1 and 3. This was expected in light of more refinement of the crack tip region in Meshes 1 and 3. The applied load-line displacement was achieved in 8 time steps (moderate increments) for Meshes 1 through 3. The analysis was repeated with more time steps (finer increments) for Meshes 2 and 3. The reason for this will be discussed later.

Several conclusions may be inferred from Figure 4.16. Below a pipe displacement (at the load point) value of $95.25 \mathrm{~mm}$ ( $3.75 \mathrm{inch}$ ), the differences between predicted values of J-integral were less than 6 percent between the various models. However, the differences became more noticeable beyond this value of pipe displacement. The line-spring model predicted the highest values of J-integral. The coarse mesh (Mesh 2) with moderate time increments predicts lower values of J-integral compared with Meshes 1 and 3. Interestingly enough, Meshes 1 and 3 predicted similar J-integral values, implying that Mesh 1 was optimum for this analyses. To further investigate this, finer displacement increments were used for Meshes 2 and 3. The reason for using finer increments for Mesh 2 was to explore whether the predicted J-integral values would be closer to the predictions of Mesh 1 . If this were true, then a coarser mesh such as Mesh 2 with fine increments would be adequate for the analysis. However, the predicted values of $\mathrm{J}$ with finer increments using Mesh 2 still diverged from the solution obtained from Mesh 1 . Thus, using only five elements along the crack is not adequate for analysis of surface-cracked pipe.

To further reinforce that the solution obtained with Meshes 1 and 3 was indeed a convergent solution, Mesh 3 was used to analyze this problem with finer displacement increments. The predicted variation of the J-Integral values with pipe displacement using finer increments with Mesh 3 yielded similar results as Mesh 1. Thus, using at least eight elements along the crack and at least seven elements along the ligament was necessary for analyzing circumferentially surface-cracked pipe subjected to 4-point bending.

This conclusion was further supported by the effect of mesh refinement on crack-opening displacement (CMOD). Figure 4.17 shows the variation of CMOD versus applied pipe displacement at the load point relationship. As is evident from this figure, nearly identical variations were obtained for Meshes 1 and 3. As expected, the variation obtained using the coarser mesh (Mesh 2) deviates from those obtained by the other two meshes, especially so at higher values of applied pipe displacement.

The crack-opening configuration at the center of the crack front corresponding to a pipe displacement at the load point of $114.3 \mathrm{~mm}$ (4.5 inches) obtained using the various finite element meshes is shown in Figure 4.18. The prediction of the coarser mesh was lower than those of the other two meshes. 


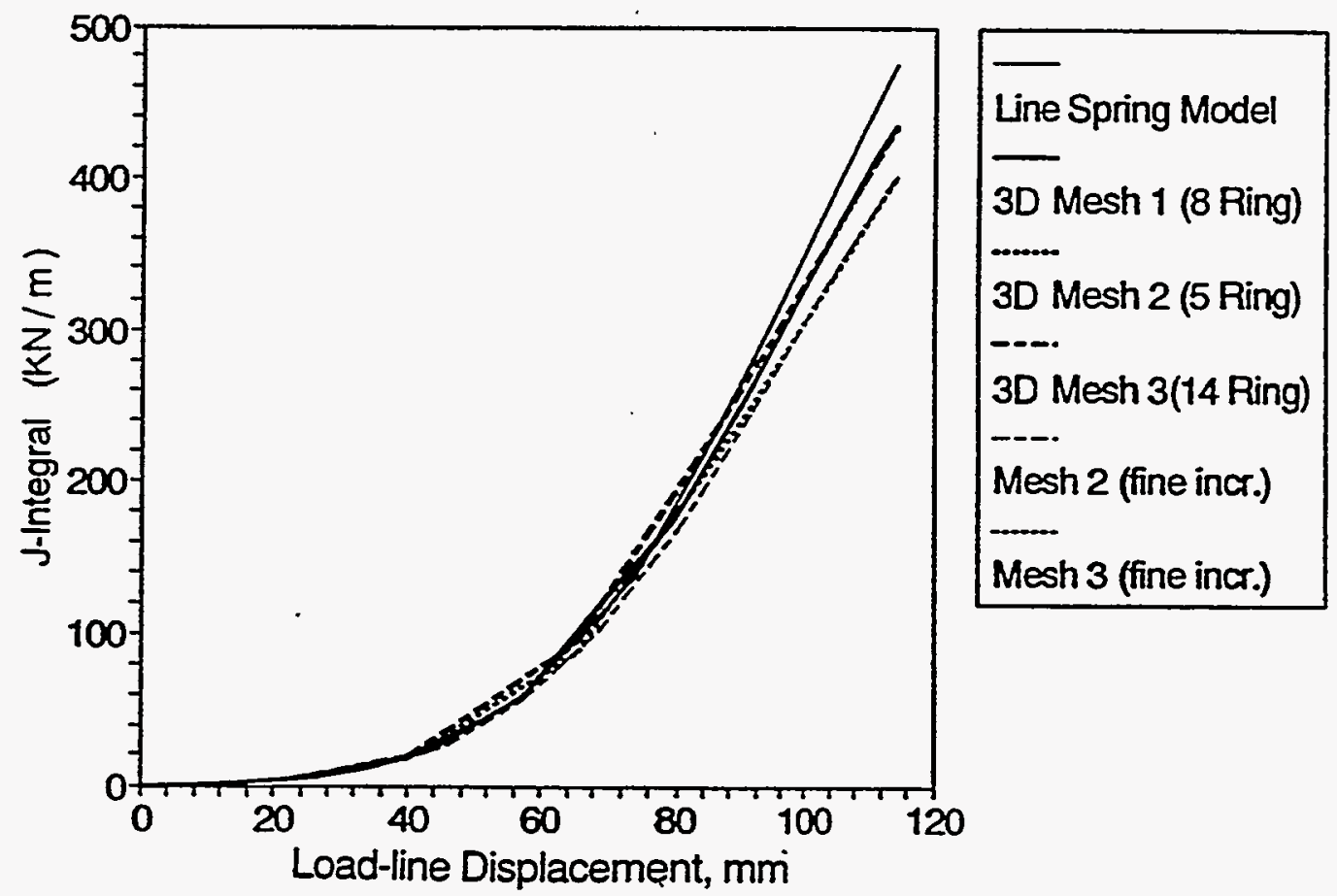

Figure 4.16 Calculated J-integral values versus pipe displacement at the load point relationship for the various models studied

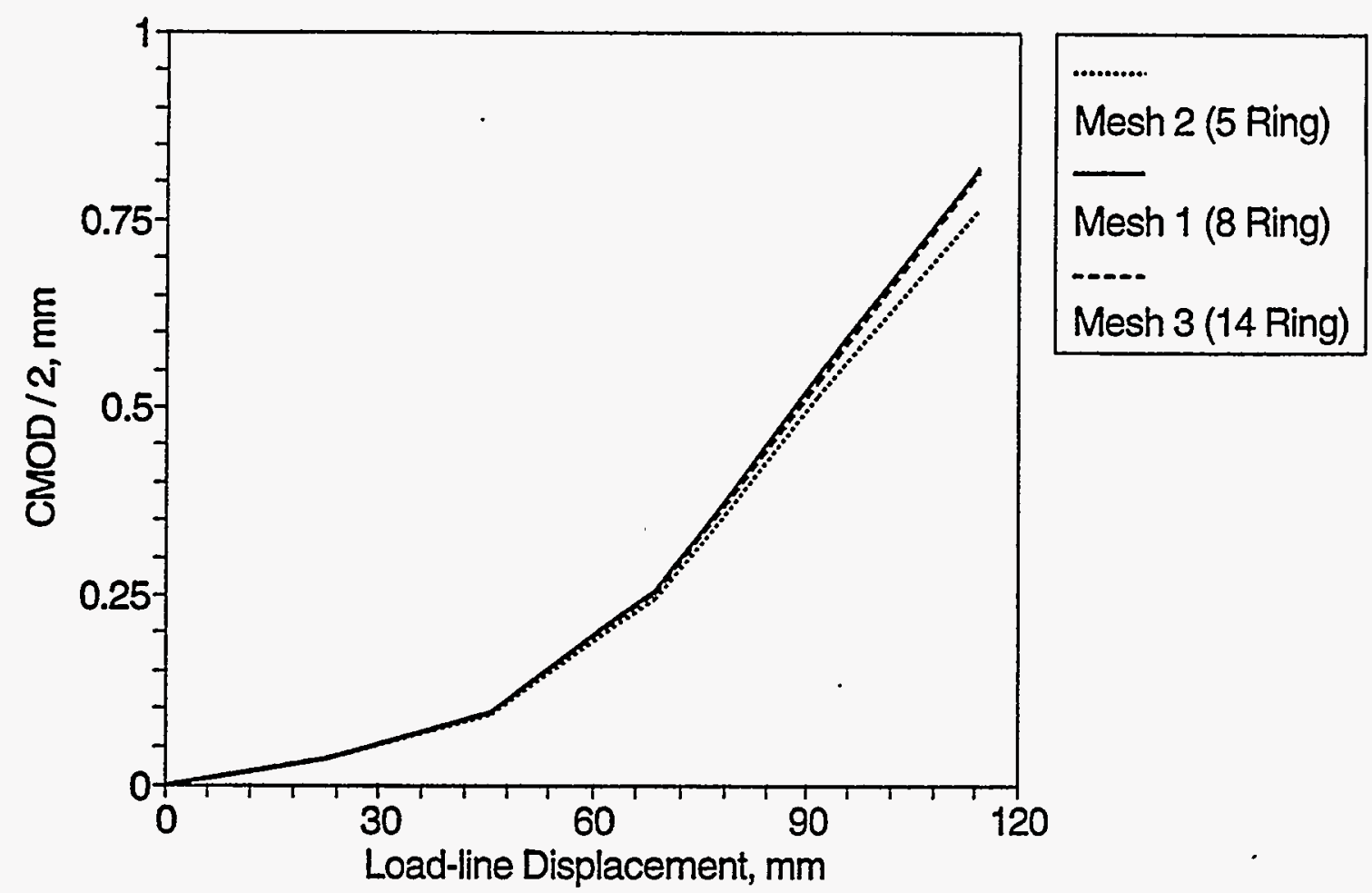

Figure 4.17 Predicted variation of CMOD with applied pipe displacement at the load point 


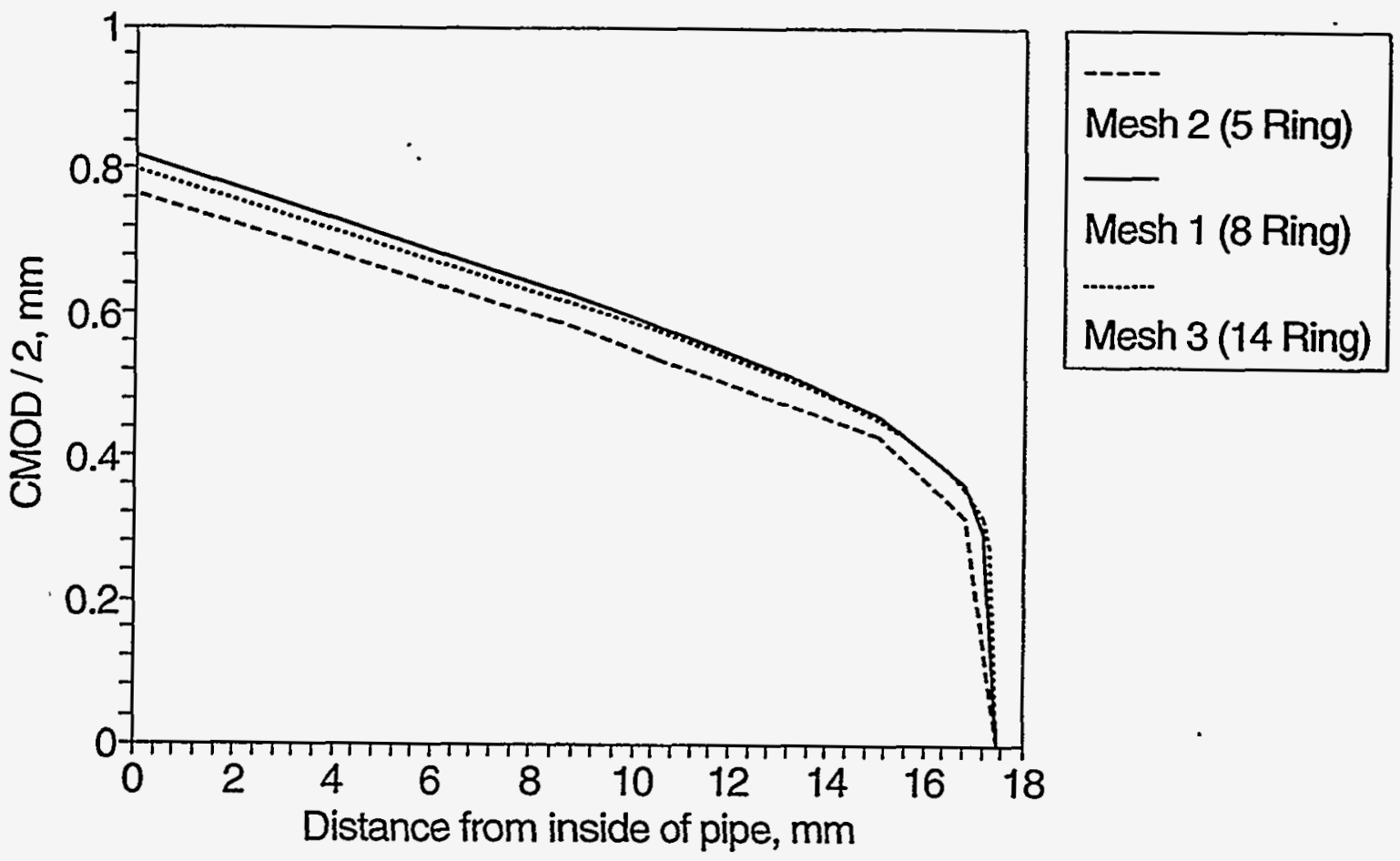

Figure 4.18 Crack-opening configuration at the center of the crack front corresponding to an applied pipe displacement at the load point of $114.3 \mathrm{~mm}$ ( $4.500 \mathrm{inch}$ )

\subsubsection{GE-EPRI Functions for 360-Degree, Deep Surface-Cracked Pipe}

As discussed in the topical report from this program on through-wall-cracked piping, NUREG/CR6235, several functions originally developed in the GE/EPRI J-estimation scheme (Ref. 4.10) were found to be in error. Also, for 360-degree, deep surface-cracked pipes under tension loads, the dimensionless GE-EPRI functions have never been evaluated. These functions are necessary since they are used in the SC.TNP and SC.TKP methods, which are frequently used to analyze deeply cracked pipes, especially during stable crack growth.

Two-dimensional axisymmetric finite element analyses were performed to model deeply cracked pipe $(\mathrm{a} / \mathrm{t}=7 / 8)$. Table 4.2 shows the matrix of FE calculations performed. The FE results were used to evaluate the influence functions for various pipe geometries $\left(R_{m} / t\right.$ ratios) and material hardening exponents. These functions and the physical quantities they estimate are listed below.

- $\quad$ Elastic Behavior

- F Stress intensity factor

- $\mathrm{V}_{1}$ CMOD

- $V_{2}$ Pipe displacement due to the crack 
- $\quad$ Fully Plastic Behavior

- $h_{1}$ Crack-driving force $J$

- $\mathrm{h}_{2}$ CMOD

- $h_{3}$ Pipe displacement due to the crack

Table 4.2 Matrix of finite element calculations for a deep $(a / t=7 / 8)$ surface-cracked pipe

\begin{tabular}{ccccc}
\hline Model No. & Model Name & $\mathbf{R}_{\mathbf{i}} / \mathbf{t}$ & $\mathbf{n}^{(\mathbf{a})}$ & Remarks \\
\hline 1 & Cylcrack5875 & 5 & $1,2,3,5,7,10$ & 6 runs \\
2 & Cylcrack10875 & 10 & $1,2,3,5,7,10$ & 6 runs \\
3 & Cylcrack20875 & 20 & $1,2,3,5,7,10$ & 6 runs \\
\hline
\end{tabular}

(a) $\mathrm{n}$ is the power-law hardening exponent; $\mathrm{n}=1$ is the elastic case.

Table 4.3 shows the matrix of results from the elastic runs used to compute $F, V_{1}$, and $V_{2}$. Table $4.4 \mathrm{a}, 4.4 \mathrm{~b}$, and $4.4 \mathrm{c}$ show the results from the fully plastic analyses used to evaluate $h_{1}, h_{2}$, and $h_{3}$ for $R_{i} / t$ values of 5,10 , and 20 , respectively.

Table 4.3 F, $V_{1}$ and $V_{2}$ for a circumferentially surface-cracked cylinder in tension

\begin{tabular}{rr|c}
\hline & & a/t $=7 / 8$ \\
\hline \multirow{2}{*}{$\mathrm{R}_{\mathrm{i}} / \mathrm{t}=5$} & $\mathrm{~F}$ & 2.641 \\
& $\mathrm{~V}_{1}$ & 4.673 \\
& $\mathrm{~V}_{2}$ & 2.450 \\
\hline & $\cdot$ & \\
\hline & $\mathrm{F}$ & 3.067 \\
$\mathrm{R}_{\mathrm{i}} / \mathrm{t}=10$ & $\mathrm{~V}_{1}$ & 6.571 \\
& $\mathrm{~V}_{2}$ & 3.291 \\
\hline & & \\
\hline & $\mathrm{F}$ & 3.594 \\
$\mathrm{R}_{\mathrm{i}} / \mathrm{t}=20$ & $\mathrm{~V}_{1}$ & 8.708 \\
& $\mathrm{~V}_{2}$ & 4.401 \\
\hline
\end{tabular}


Table $4.4 h_{1}, h_{2}$, and $h_{3}$ for a circumferentially surface-cracked cylinder in tension

(a) $\mathbf{R}_{\mathrm{i}} / \mathbf{t}=\mathbf{5}$

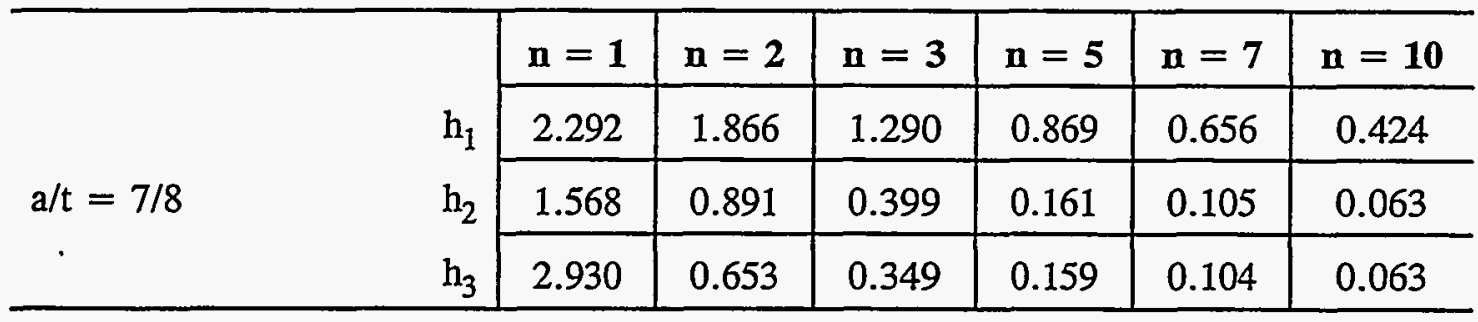

(b) $\mathbf{R}_{\mathrm{i}} / \mathrm{t}=\mathbf{1 0}$

\begin{tabular}{ll|c|c|c|c|c|c}
\hline & & $\mathbf{n}=\mathbf{1}$ & $\mathbf{n}=\mathbf{2}$ & $\mathbf{n}=\mathbf{3}$ & $\mathbf{n}=\mathbf{5}$ & $\mathbf{n}=\mathbf{7}$ & $\mathbf{n}=\mathbf{1 0}$ \\
\cline { 3 - 8 } $\mathrm{a} / \mathrm{t}=7 / 8$ & $\mathrm{~h}_{1}$ & 2.877 & 2.092 & 1.350 & 0.898 & 0.599 & 0.198 \\
\cline { 3 - 8 } & $\mathrm{h}_{2}$ & 2.128 & 1.119 & 0.461 & 0.171 & 0.096 & 0.023 \\
\cline { 3 - 8 } & $\mathrm{h}_{3}$ & 3.099 & 0.798 & 0.393 & 0.161 & 0.096 & 0.023 \\
\hline
\end{tabular}

(c) $\mathrm{R}_{\mathrm{i}} / \mathrm{t}=\mathbf{2 0}$

\begin{tabular}{|c|c|c|c|c|c|c|c|}
\hline \multirow{4}{*}{$a / t=7 / 8$} & \multirow[b]{2}{*}{$\mathrm{h}_{1}$} & $\mathbf{n}=\mathbf{1}$ & $n=2$ & $\mathbf{n}=3$ & $\mathrm{n}=5$ & $\mathrm{n}=7$ & $\mathrm{n}=10$ \\
\hline & & 3.799 & 2.412 & 1.371 & 0.825 & 0.517 & 0.150 \\
\hline & $\mathrm{h}_{2}$ & 2.765 & 1.448 & 0.545 & 0.167 & 0.085 & 0.021 \\
\hline & $\mathrm{h}_{3}$ & 3.391 & 0.996 & 0.447 & 0.161 & 0.084 & 0.021 \\
\hline
\end{tabular}


These functions were incorporated into the PC program NRCPIPES discussed below and are used in the SC.TNP and SC.TKP analysis methods.

\subsubsection{Modification to the Net-Section-Collapse (NSC) Analysis}

One of the objectives for conducting the small-diameter, short surface-cracked pipe experiments discussed in Section 3.0 was to obtain a simple correction to the NSC criterion to account for ovalization effects. Pipe ovalization can reduce the moment-carrying capacity. Figure 4.19 shows a plot of the ratio of the maximum experimental stress (bending plus axial membrane stress due to internal pressure) to the sum of the NSC stress (Eq. 4-1) and the axial membrane stress as a function of the pipe radius-to-thickness ratio, $R_{m} / t$. A point to note here is that for all the data shown, the DPZP parameter is greater than 0.2, see Figure 4.19. Thus, in each case, limit-load failure is expected to prevail. As seen in Figure 4.19, all data from a previous Battelle/EPRI program (Ref. 4.32), the Degraded Piping Program (Ref. 4.1), and this program, including both long and short surface-crack lengths, followed very well-defined behavior. Based on this figure, it was concluded that an empirical correction factor, independent of the crack length, can be used as an ovalization correction factor for the NSC analysis (Eq. 4-1). The results were validated using the values of $h_{1}$, $h_{2}$, and $h_{3}$ for $a / t=3 / 4$ in the GE/EPRI Handbook (Ref. 4.10). Also, the $h_{1}, h_{2}$, and $h_{3}$ functions showed the same variation with $\mathrm{n}$ and $\mathrm{a} / \mathrm{t}$ as presented in Reference 4.10.

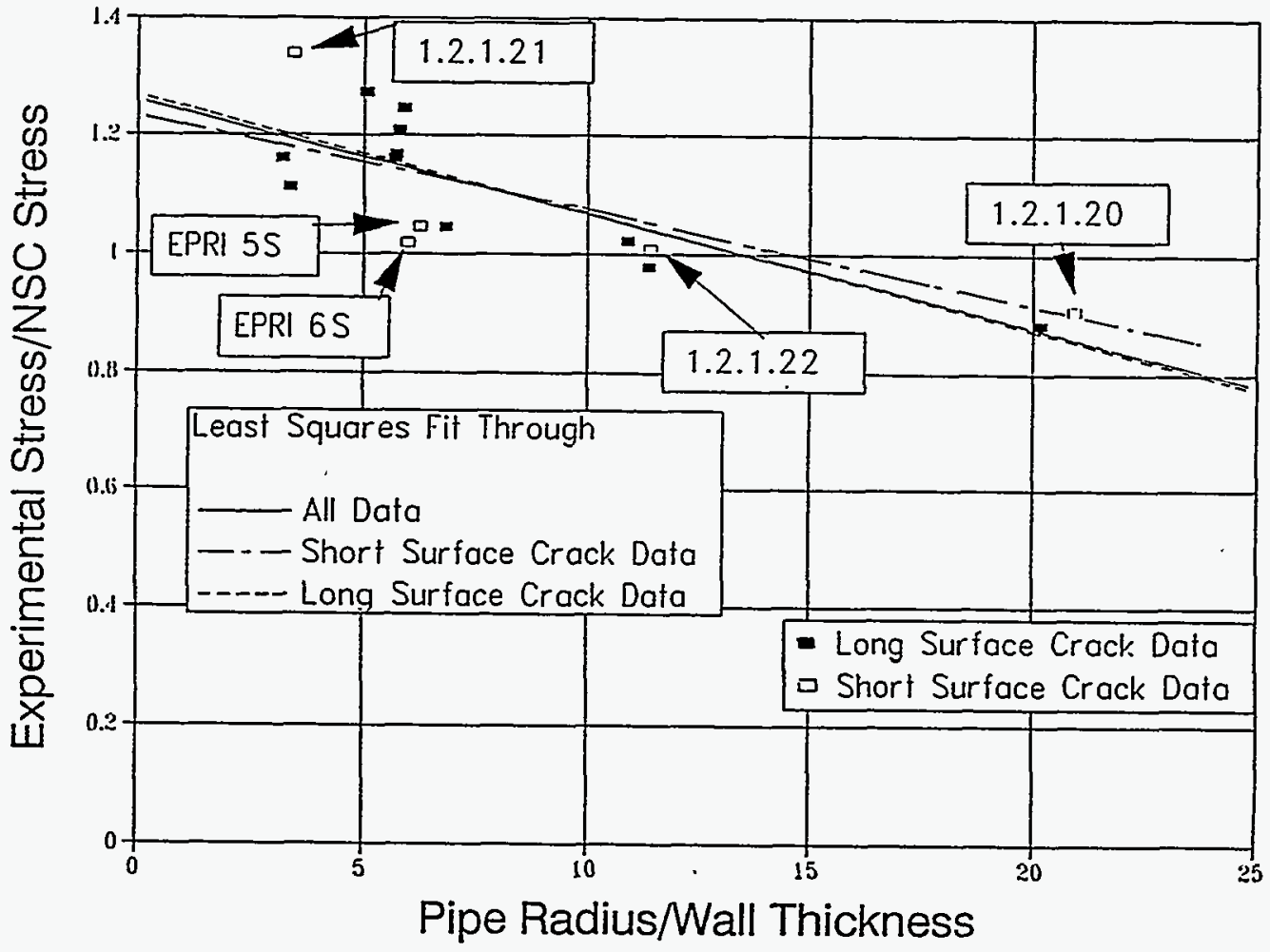

Figure 4.19 Plot of the ratio of experimental stress to predicted stress as a function of pipe radius-to-thickmess ratio $\left(R_{m} / t\right)$ 
This correction factor, $C_{e}$, is obtained by a linear fit through all the data in Figure 4.19 and is given by

$$
C_{e}=1.257-0.01919\left(R_{m} / t\right)
$$

The predictions using the NSC criterion with the above correction factor, $\mathrm{C}_{\mathrm{e}}$, are compared with experimental data in Section 4.4 .

\subsubsection{Improvements to SC.TNP and SC.TKP Methods}

\subsubsection{Introduction}

Based on the surface-crack mesh-refinement analyses reported in Section 4.2.3, results obtained using the line-spring model for surface-cracked pipes appeared accurate and adequate enough for comparing with the various J-estimation schemes. The analyses using line-spring and 3-D models of the surfacecracked pipe reported in the Section 4.2.4 were extended to higher applied load levels. The 3-D analysis used was the very fine mesh (Mesh 3). The calculated variation of J-integral versus load is shown in Figure 4.20. For higher loads, the line-spring model predicts $J$-integral values much higher than the corresponding values obtained from the 3-D model. The stress-strain behavior used in the analyses, shown in Figure 4.21, exhibits an initial steep hardening followed by a non-hardening regime. Since the line-spring model is not ideally suited for materials whose hardening behavior changes substantially with strain, the calculated variation shown in Figure 4.20 is not surprising. Before determining which of these two models is suitable for use in the verification of J-estimation schemes, it is important to understand the philosophy behind them.

The J-estimation schemes rely on the fact that the behavior of the material can be approximated by a Ramberg-Osgood relation (or deformation plasticity) with power-law hardening. Thus, it is important to examine the predictions of the line-spring and 3-D models for materials whose behavior can be approximated by a Ramberg-Osgood relation. Figure 4.21 shows the stress-strain response for a Ramberg-Osgood material (with $\mathrm{n}=5$ and $\alpha=1.0$ ). Analyses were conducted assuming the stressstrain behavior shown in Figure 4.21 using line-spring and 3-D models. In addition, an analysis of the 3-D model was conducted using the deformation plasticity option in ABAQUS. The variation of J-integral values with applied load as predicted by the various models is shown in Figure 4.22. It can be observed that the line-spring and 3-D models predict nearly identical variations. Thus for a uniformly hardening material, the line-spring model would be accurate and hence is adequate for comparison with J-estimation schemes.

Further credence to the line-spring/shell analysis was established by the simulation of a surfacecracked-pipe experiment conducted at Battelle (Experiment Number 1.2.1.20). The outer diameter and thickness of the pipe were $407.0 \mathrm{~mm}$ (16.01 inch) and $9.60 \mathrm{~mm}(0.376$ inch), respectively. The ratios of crack depth-to-pipe thickness and crack length angle-to-circumference were 0.476 and 0.25 , respectively. The stress-strain response used in the analysis was obtained from a Ramberg-Osgood fit of the actual stress-strain response of the material. The Ramberg-Osgood parameters were: $\sigma_{0}=$ $224 \mathrm{MPa}(32.5 \mathrm{ksi}), \mathrm{n}=4.94$, and $\alpha=4.21$. The cracked pipe was loaded under internal pressure 


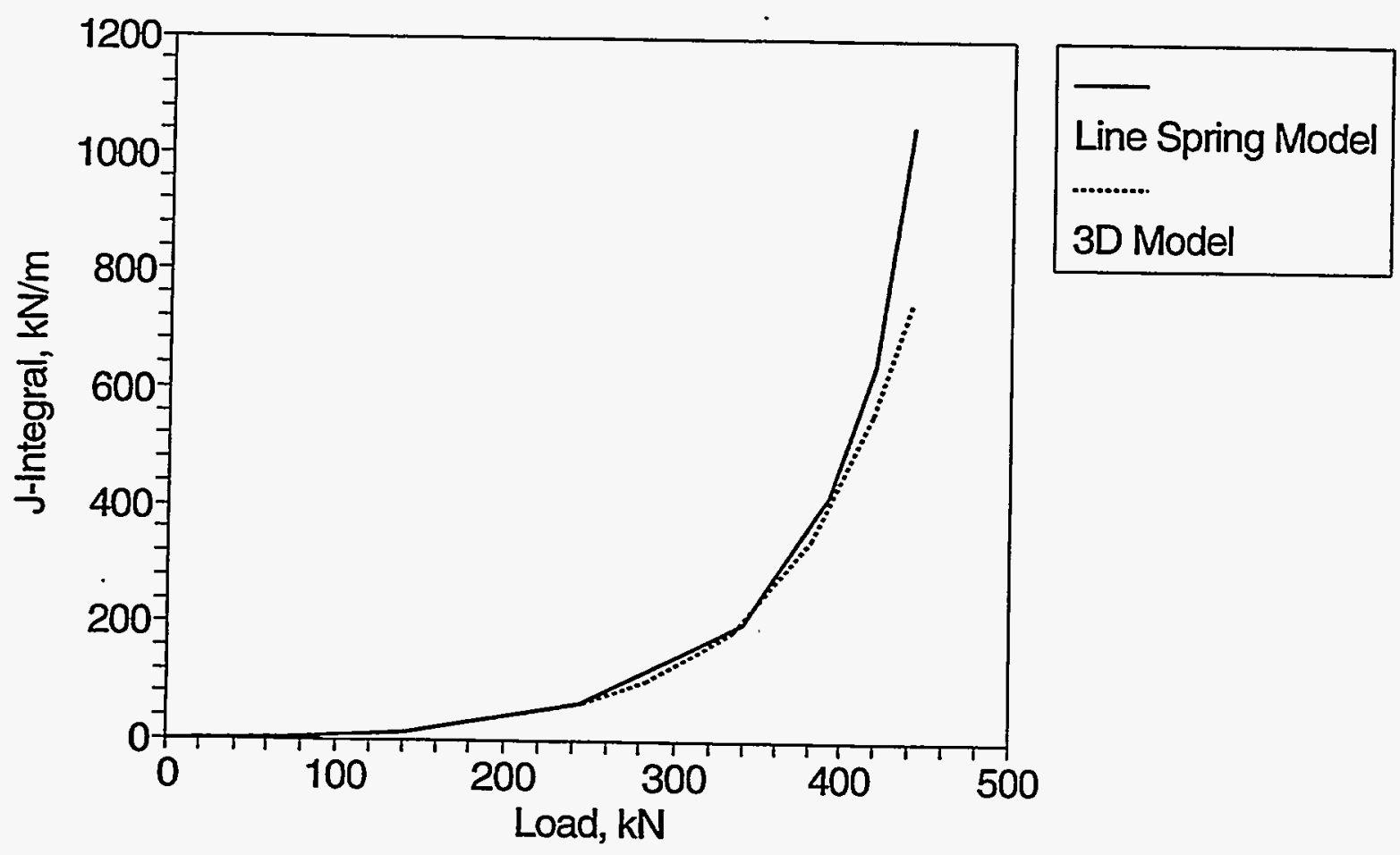

Figure 4.20 The predicted variation of J-integral values from the line-spring model and 3D FEM as a function of applied load (the material behavior assumed is shown in Figure 4.14)

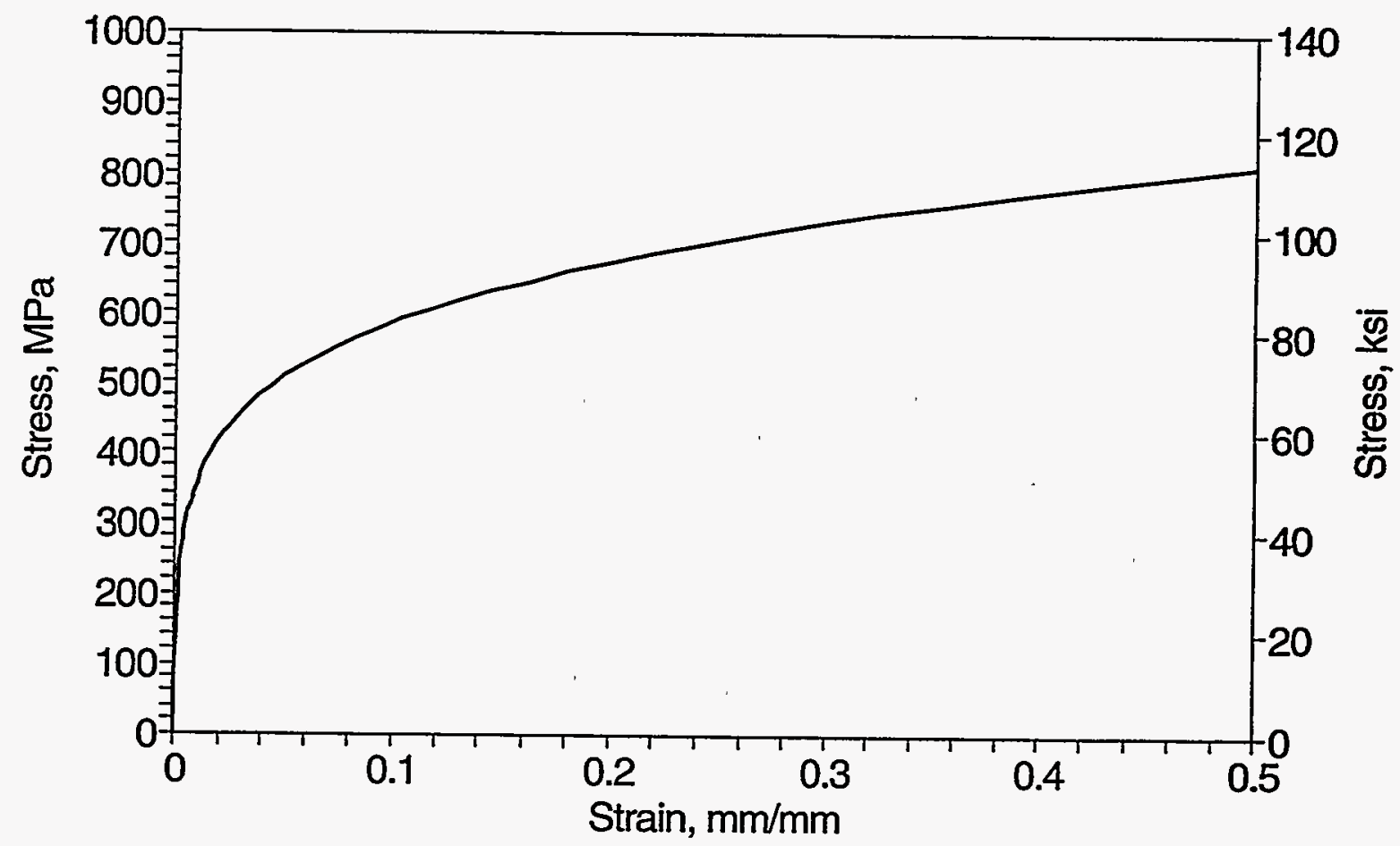

Figure 4.21 Stress-strain relation for a Ramberg-Osgood material with $\mathrm{n}=\mathbf{5 . 0}$ and $\alpha=\mathbf{1 . 0}$ 


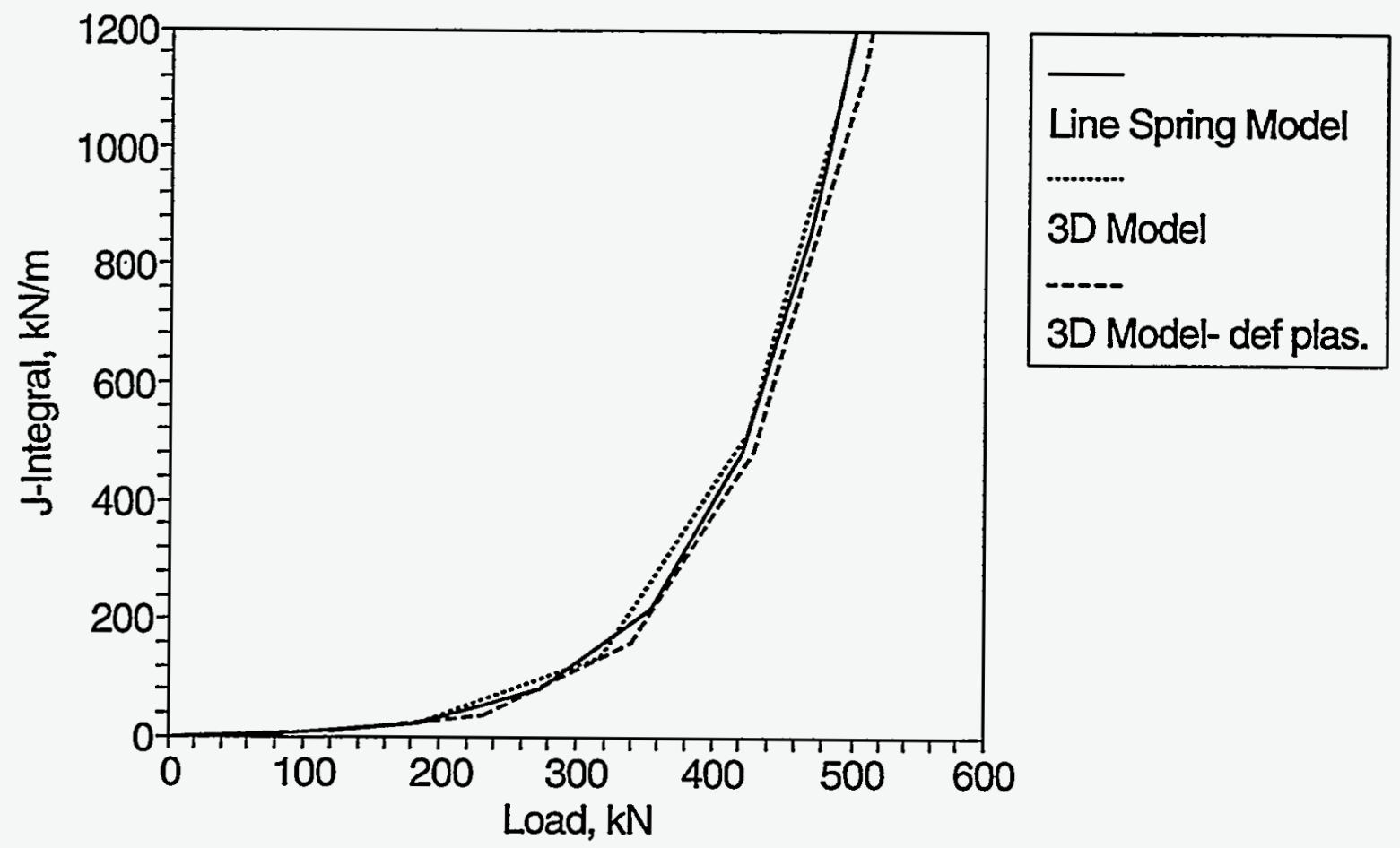

Figure 4.22 The predicted variation of J-integral values with applied load (the material behavior assumed is shown in Figure 4.21)

of $1.57 \mathrm{MPa}(225 \mathrm{psi})$ prior to applying a bending moment. The rotation was measured at a distance of $559 \mathrm{~mm}$ (22 inches) away from the crack. The good agreement between the experimental momentrotation response and the FE predictions, see Figure 4.23 , enhances the applicability of the linespring/shell model in the analyses of surface-cracked pipes.

Having established the validity of the line-spring analysis, the objective then became making improvements to the SC.TNP and SC.TKP estimation schemes (Ref. 4.1) by comparing the results from these analyses with FE computations. The FE computations are discussed in Section 4.2.6.2 below. After this, the predictions of SC.TNP and SC.TKP are compared with FE results to make some semi-empirical corrections to the estimation schemes. 


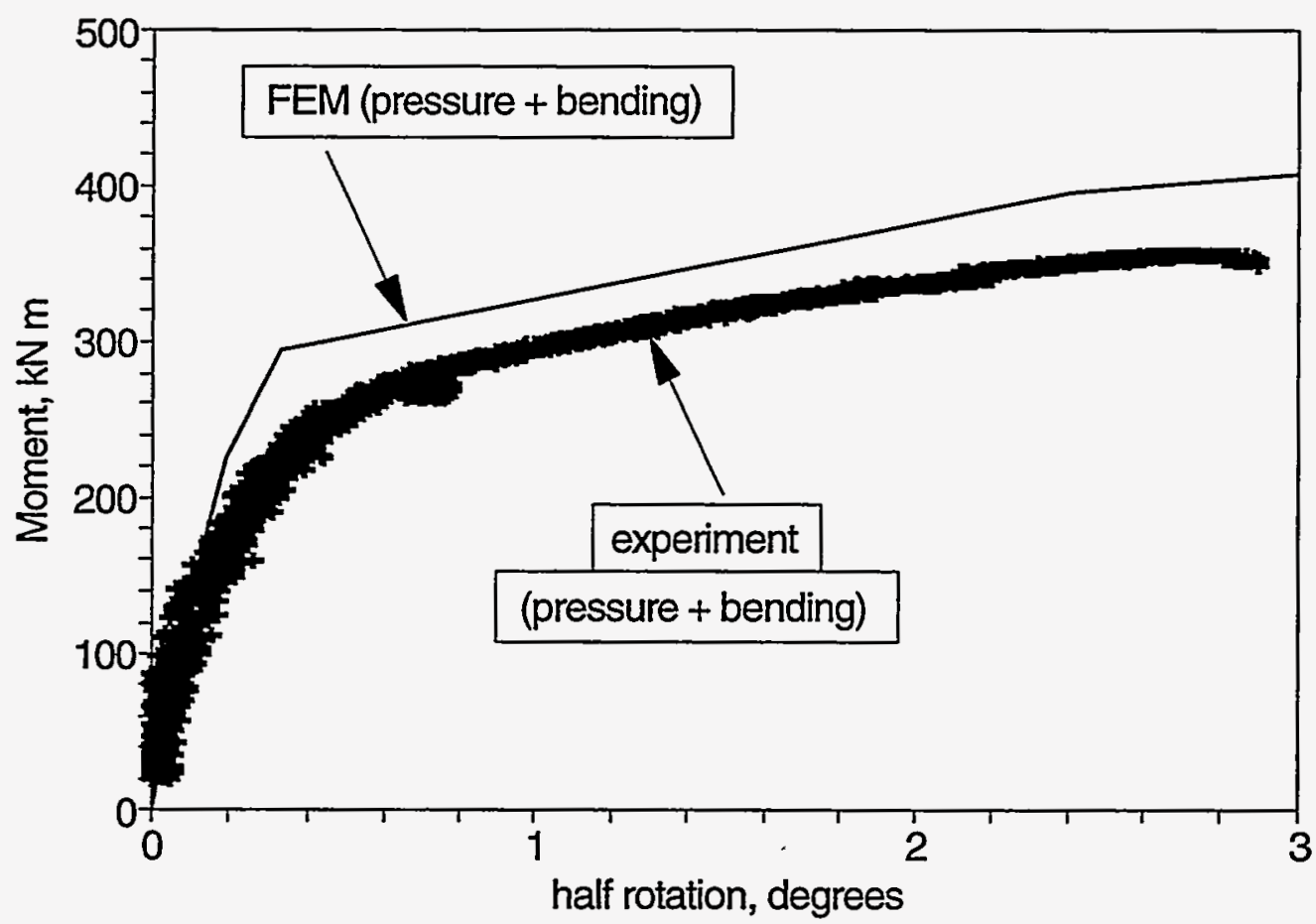

Figure 4.23 Comparison of the moment versus half rotation predicted by the finite element model with the experimentally observed response

\subsubsection{Finite Element Analyses of Surface-Cracked Pipes}

In order to verify the J predictions using the SC.TNP and SC.TKP methods, finite element analyses of surface-cracked pipes were conducted using the line-spring/shell model. The following flaw geometries were examined:

- Internal Surface Flaws

- $\quad$ length/circumference, $\theta / \pi: \quad 1 / 16$ and $1 / 4$

- depth/thickness, a/t: $\quad 0.5$

- External Surface Flaws

- length/circumference, $\theta / \pi: \quad 1 / 4$

- depth/thickness, a/t: $\quad 0.5$

For all the above cases the Ramberg-Osgood coefficient, $\alpha$, was taken to be 1.0 . The outer radius and thickness of the pipe were $404 \mathrm{~mm}$ (15.9 inch) and $26.42 \mathrm{~mm}$ (1.04 inch), respectively. After a careful study, an optimum length of the pipe, such that end effects due to load application are minimal along the crack, was chosen to be $1.98 \mathrm{~m}$ (78 inch). The pipe was modelled with 8-noded isoparametric shell elements and the crack was modelled with 3-noded line-spring elements using ABAQUS. Though the finite element analysis uses incremental theory of plasticity, the material stress-strain behavior was modelled using Ramberg-Osgood relation. The Ramberg-Osgood parameters used were $\mathrm{n}=3$ and 10 , and $\alpha=1$. For all the cases, the load was imposed via rigid 
beam elements connected to the ends of the pipe. All of the analyses were conducted to fully plastic loads as defined in ABAQUS.

The variation of J-integral values at the center of the crack front, for the case of pure bending, is shown in Figures 4.24 and 4.25 for $\theta / \pi=1 / 4$ and $1 / 16$, respectively. As anticipated, the external flaw gives rise to higher $\mathrm{J}$-integral values for a given load than the corresponding internal flaw. In addition, Figures 4.24 and 4.25 reveal that increasing values of $n$ (decreasing hardening) sharply elevate the J-integral values for a given load. Note, however, that for the case of $\theta / \pi=1 / 16$, little difference is observed in the J-integral predictions between the internal and external cracked pipes for $\mathrm{n}=10$.

For the case of the cracked pipe subjected to pure tension, displacement boundary conditions were applied at the ends of the pipe. These boundary conditions may restrict induced bending in the vicinity of the flaw. Conversely, prescribing loads at the ends of the pipe may involve induced bending effects (the induced bending is expected to be larger for larger crack lengths). The difference between applied loads or displacements at the pipe ends becomes negligible as the length of the pipe modeled becomes much larger than its radius.

Figures 4.26 and 4.27 show the variation of J-integral values with load for the cases of crack length/circumference ratios of $1 / 4$ and $1 / 16$ respectively, for $n=3$. Similar results were obtained for $\mathbf{n}=10$. As anticipated, the external flaw gives rise to higher J-integral values for a given load than the corresponding internal flaw when the crack length/circumference is $1 / 4$. It is noted that for this crack geometry the induced bending is higher than that for the other geometry. Figure 4.27 reveals that the internal flaw gives rise to higher J-integral values than the external flaw for the case of crack length/circumference ratio of $1 / 16$. This is attributed to the fact that induced bending, which results in elevating J-integral values for external flaws compared with the internal flaws, is less significant for this geometry.

\subsubsection{Comparison of FE Results With SC.TNP and SC.TKP Predictions}

The comparisons of the predictions using the SC.TNP and SC.TKP analyses with finite element results using the line-spring model are shown in Figures 4.28 through 4.32 for the case of pure bending. Figures 4.28 and 4.29 compare the variation of $J$ with applied bending moment for an internal and external circumferential flaw with $\theta / \pi=1 / 4$, respectively, with a Ramberg-Osgood exponent of 3 , i.e., $n=3$. While the FEM results are bounded by the SC.TNP and SC.TKP results, as anticipated for the internal flaw, the predictions for the SC.TNP and SC.TKP analyses are almost identical for an external flaw, and moreover, these predictions are significantly less than those for the FEM analyses. Similar results were obtained for the case of $n=10$ for the same flaw geometries, Figures 4.30 and 4.31. For an internal flaw with $\theta / \pi=1 / 16$, however, the predictions of SC.TNP and SC.TKP are not as low, in a relative sense, when compared with the corresponding FEM predictions, Figure 4.32.

It appears that the predictions of SC.TNP and SC.TKP analyses are reasonable, considering the approximations involved in these analyses, for the case of internal flaws. They appear to be in error 


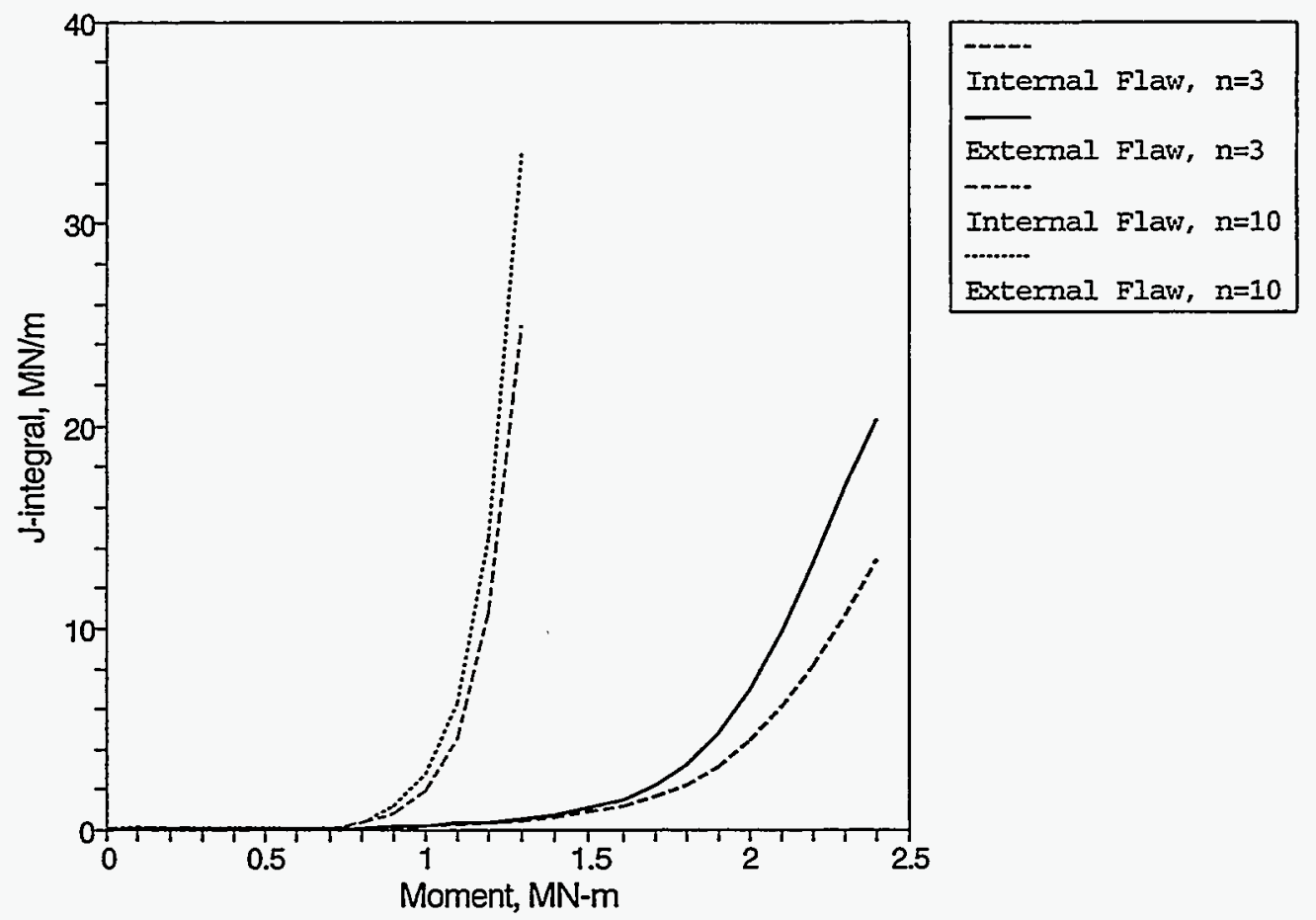

Figure 4.24 Variation of J-integral values with applied end moment for a flaw $1 / 4$ of the pipe circumference in length, $\theta / \pi=1 / 4$

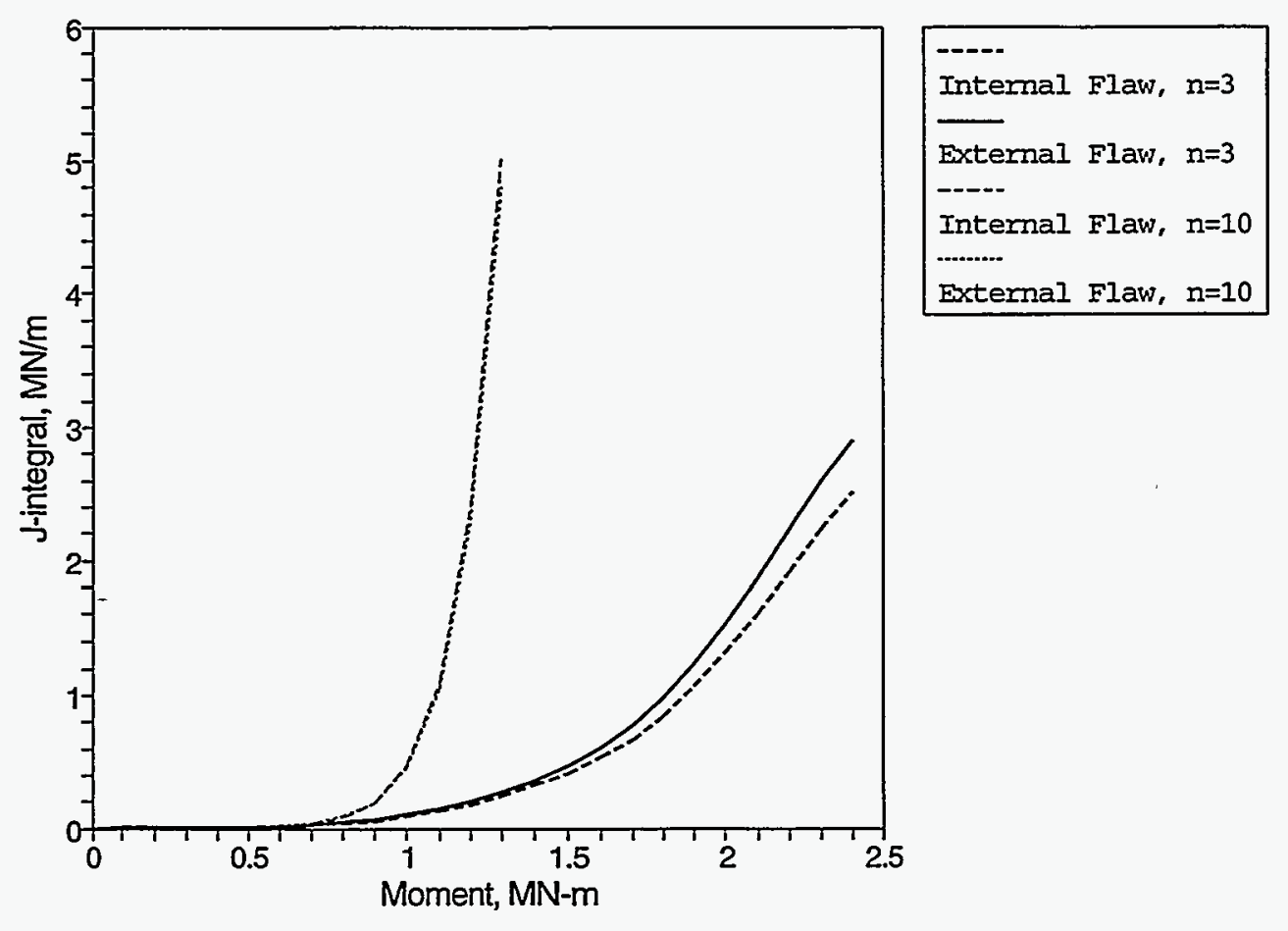

Figure 4.25 Variation of $J$-integral values with applied end moment for a flaw $1 / 16$ the pipe circumference in length, $\theta / \pi=1 / 16$ 


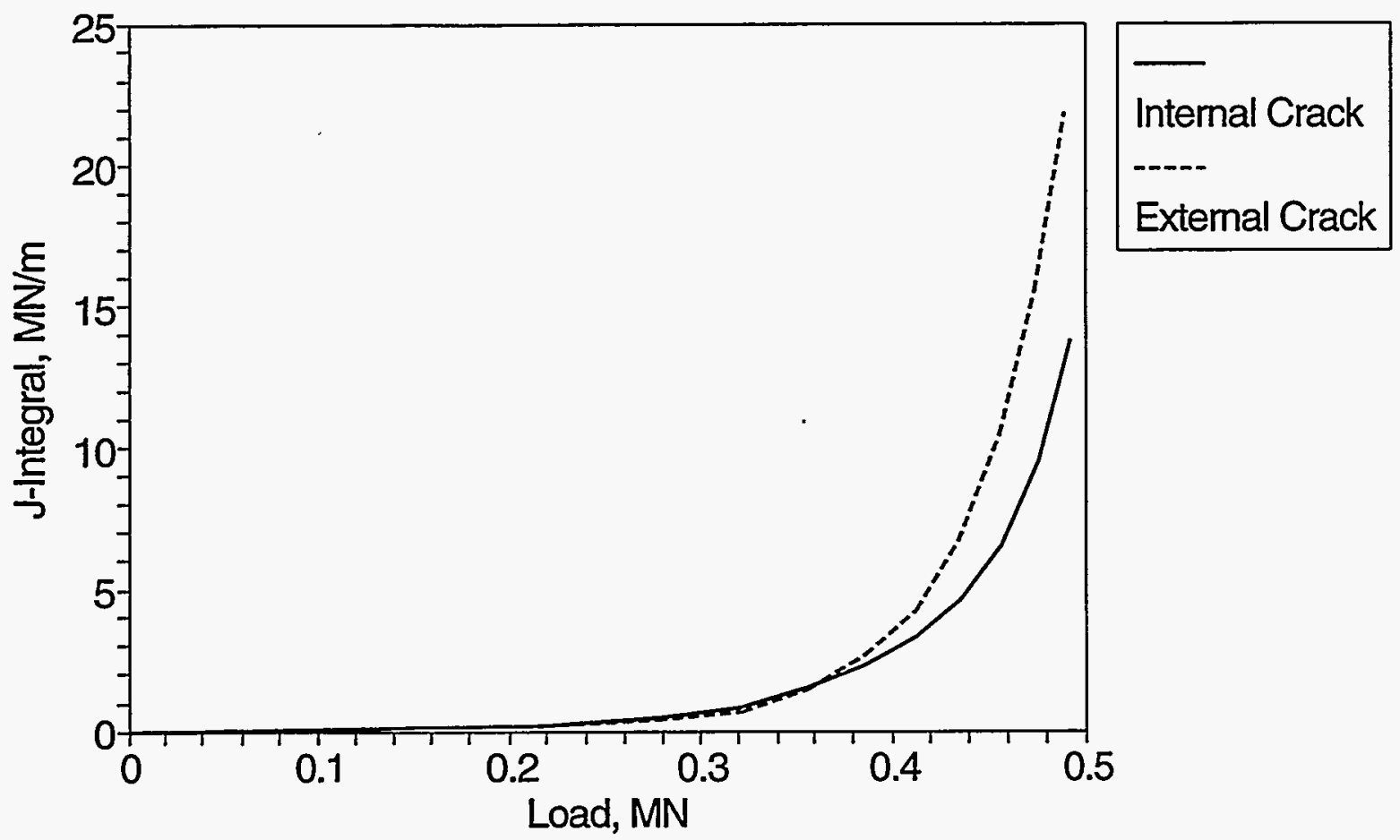

Figure 4.26 Variation of J-integral values with tensile load for a flaw $1 / 4$ of the pipe circumference in length, $\theta / \pi=1 / 4$

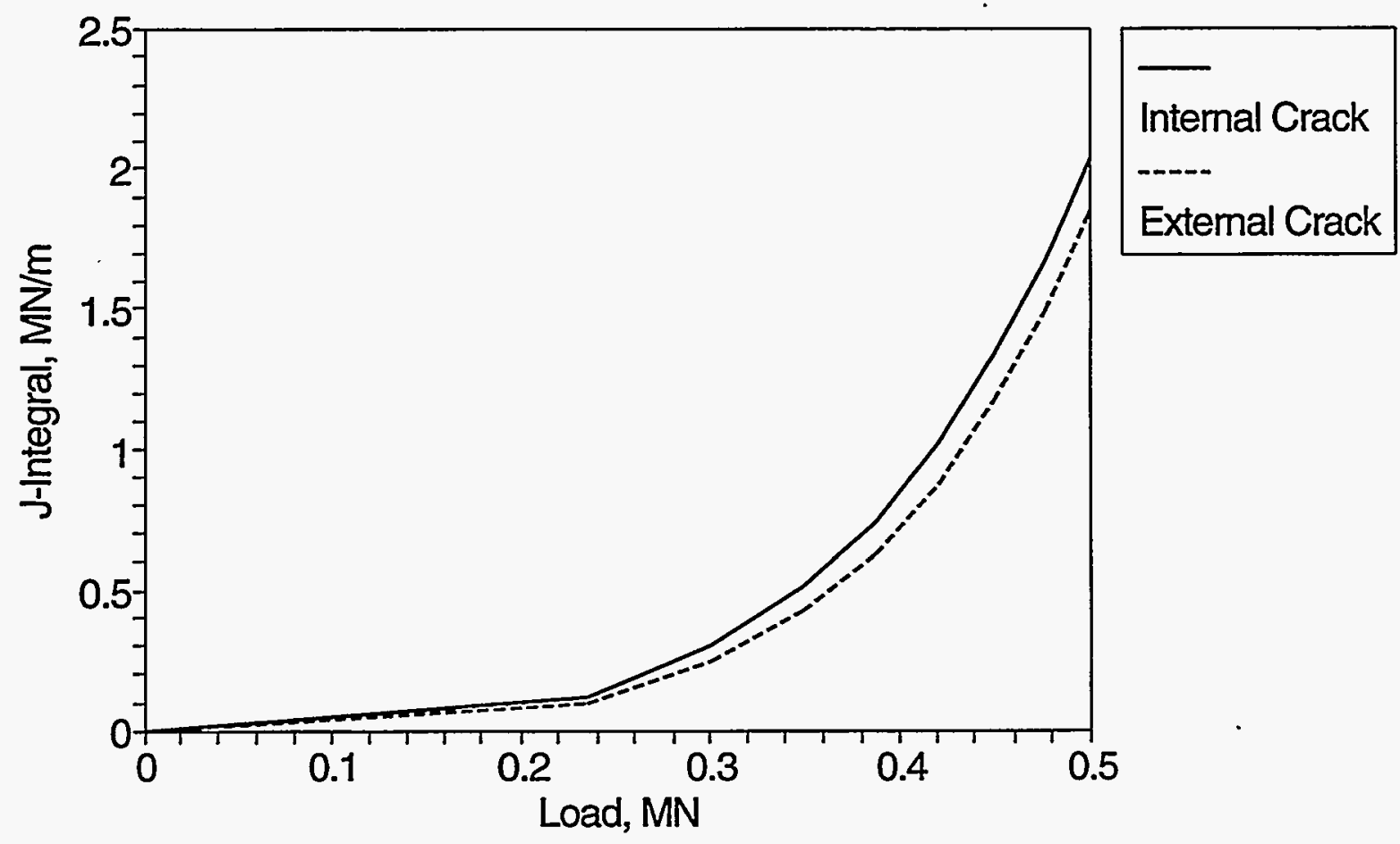

Figure 4.27 Variation of J-integral values with tensile load for a flaw $1 / 16$ of the pipe circumference in length, $\theta / \pi=1 / 16$ 


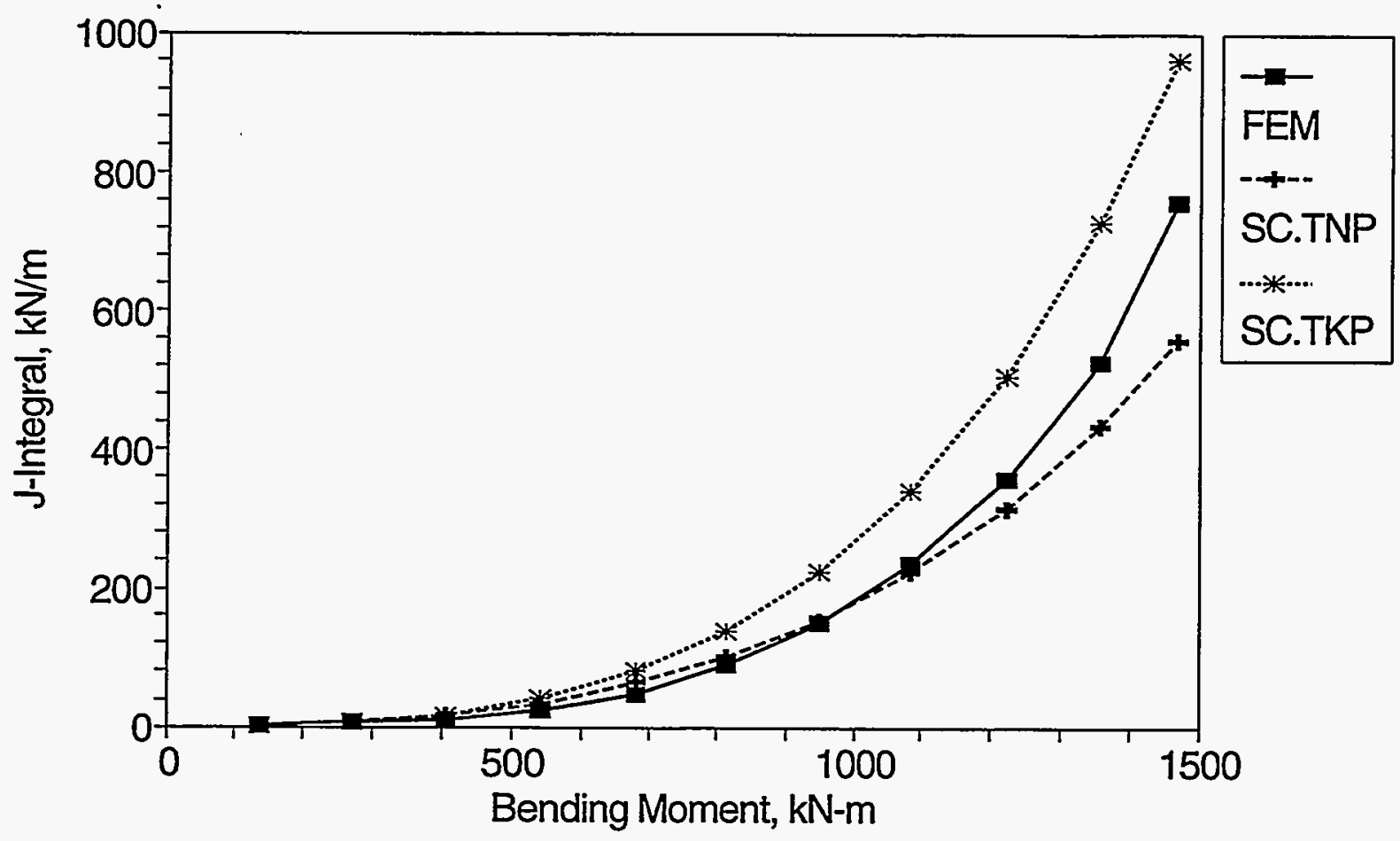

Figure 4.28 Comparison of FEM results and SC.TNP and SC.TKP prediction for an internal flaw $\theta / \pi=1 / 4$ and $n=3$

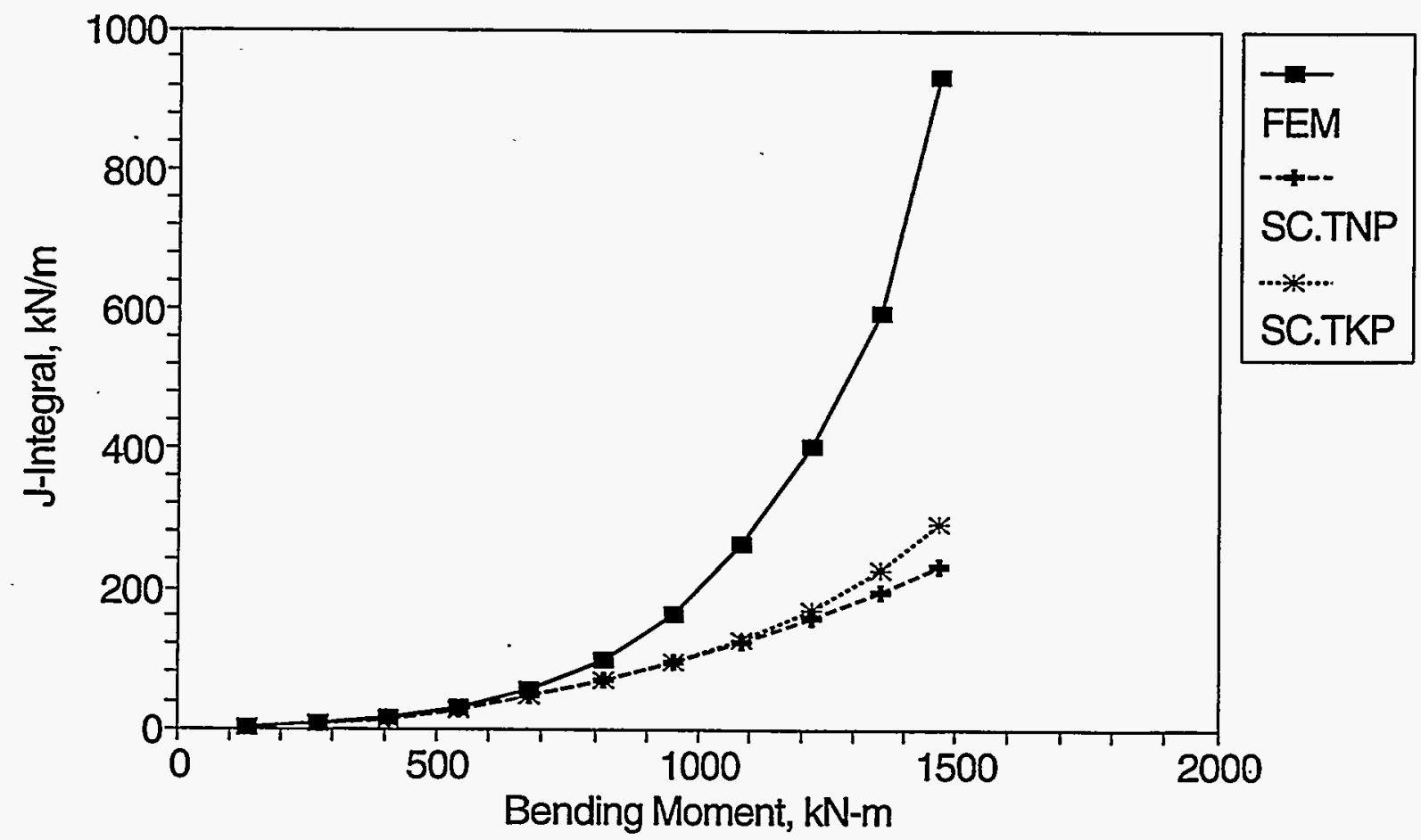

Figure 4.29 Comparison of FEM results and SC.TNP and SC.TKP prediction for an external flaw $\theta / \pi=1 / 4$ and $n=3$ 


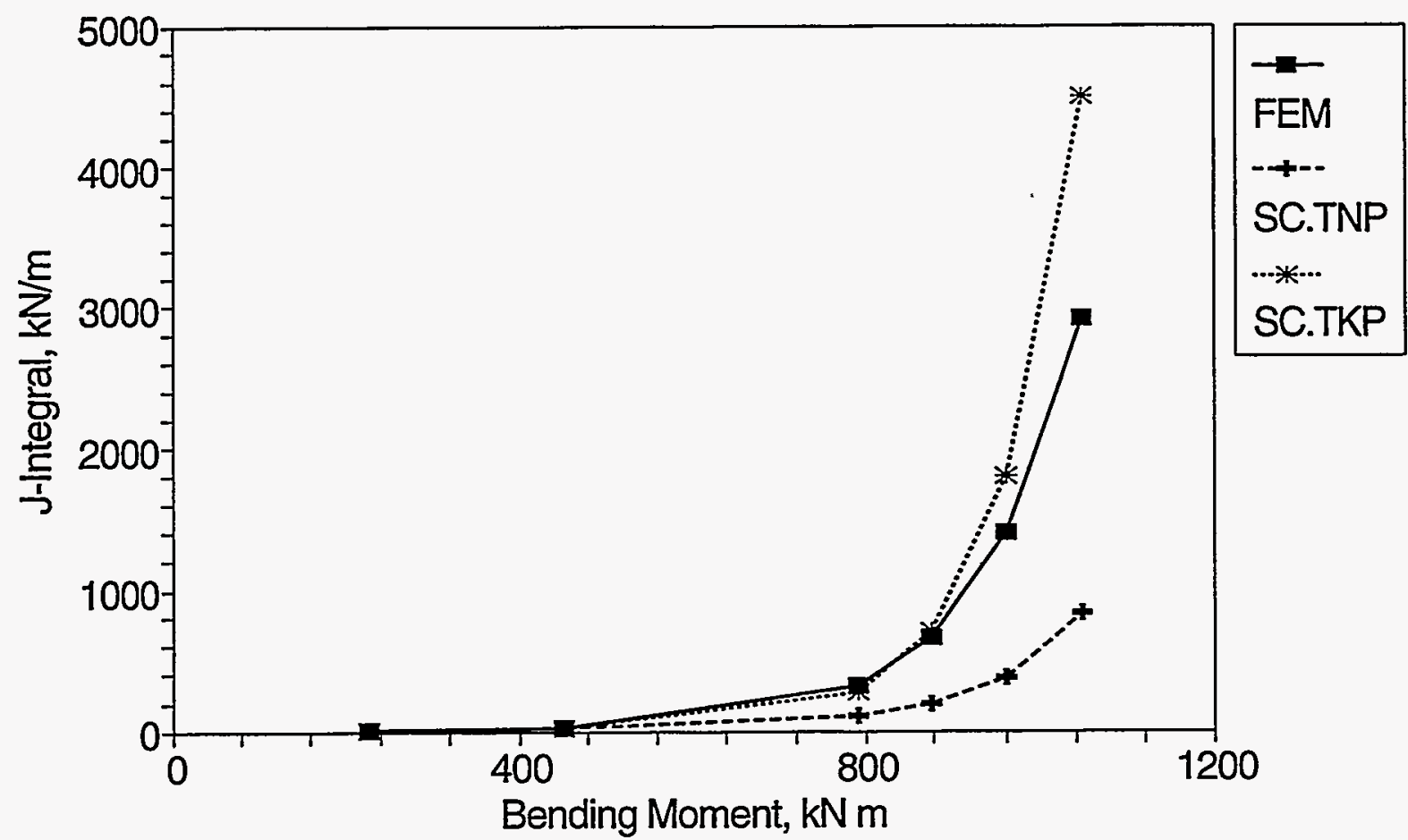

Figure 4.30 Comparison of FEM results and SC.TNP and SC.TKP prediction for an internal flaw $\theta / \pi=1 / 4$ and $n=10$

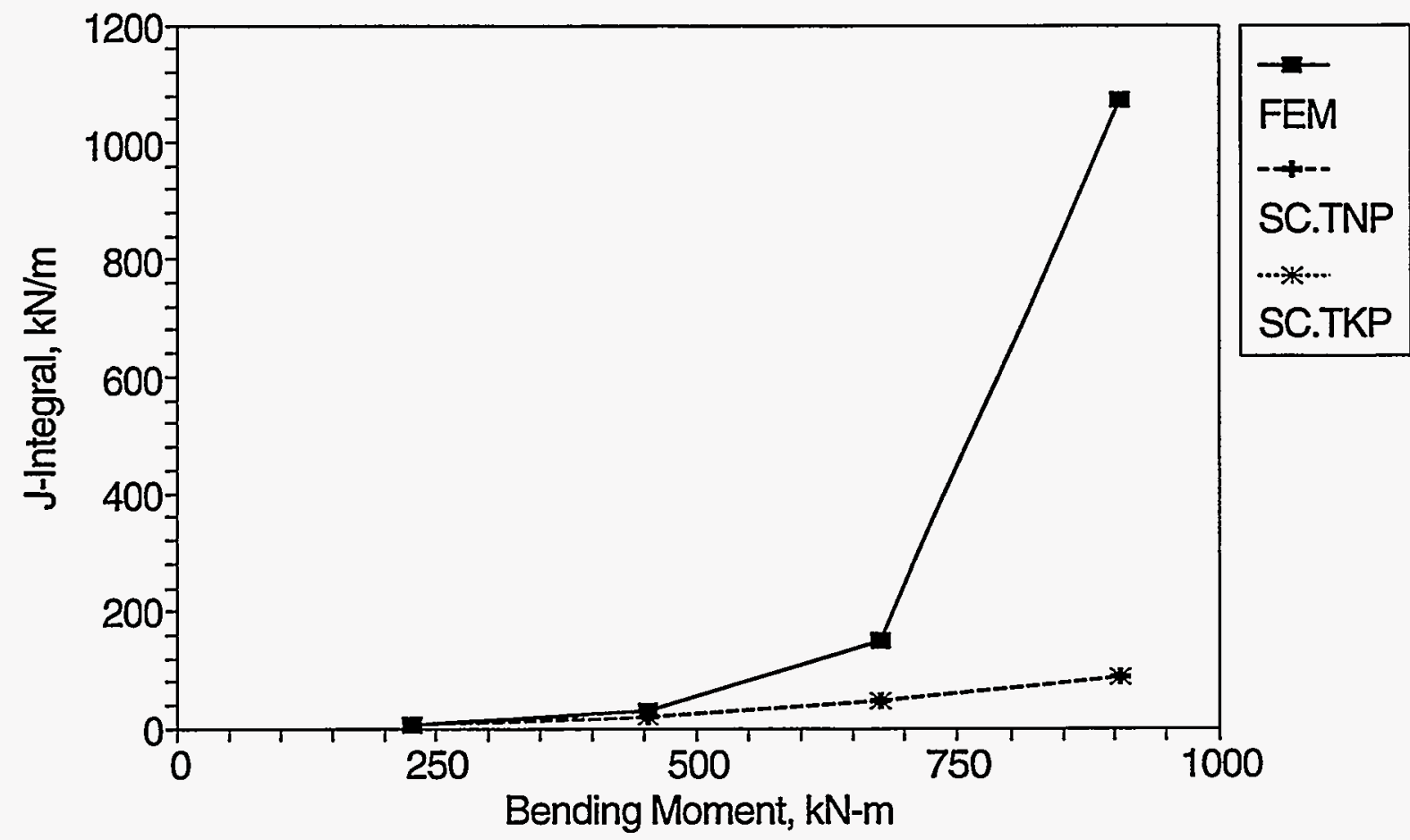

Figure-4.31 Comparison of FEM results and SC.TNP and SC.TKP prediction for an external flaw $\theta / \pi=1 / 4$ and $n=10$ 


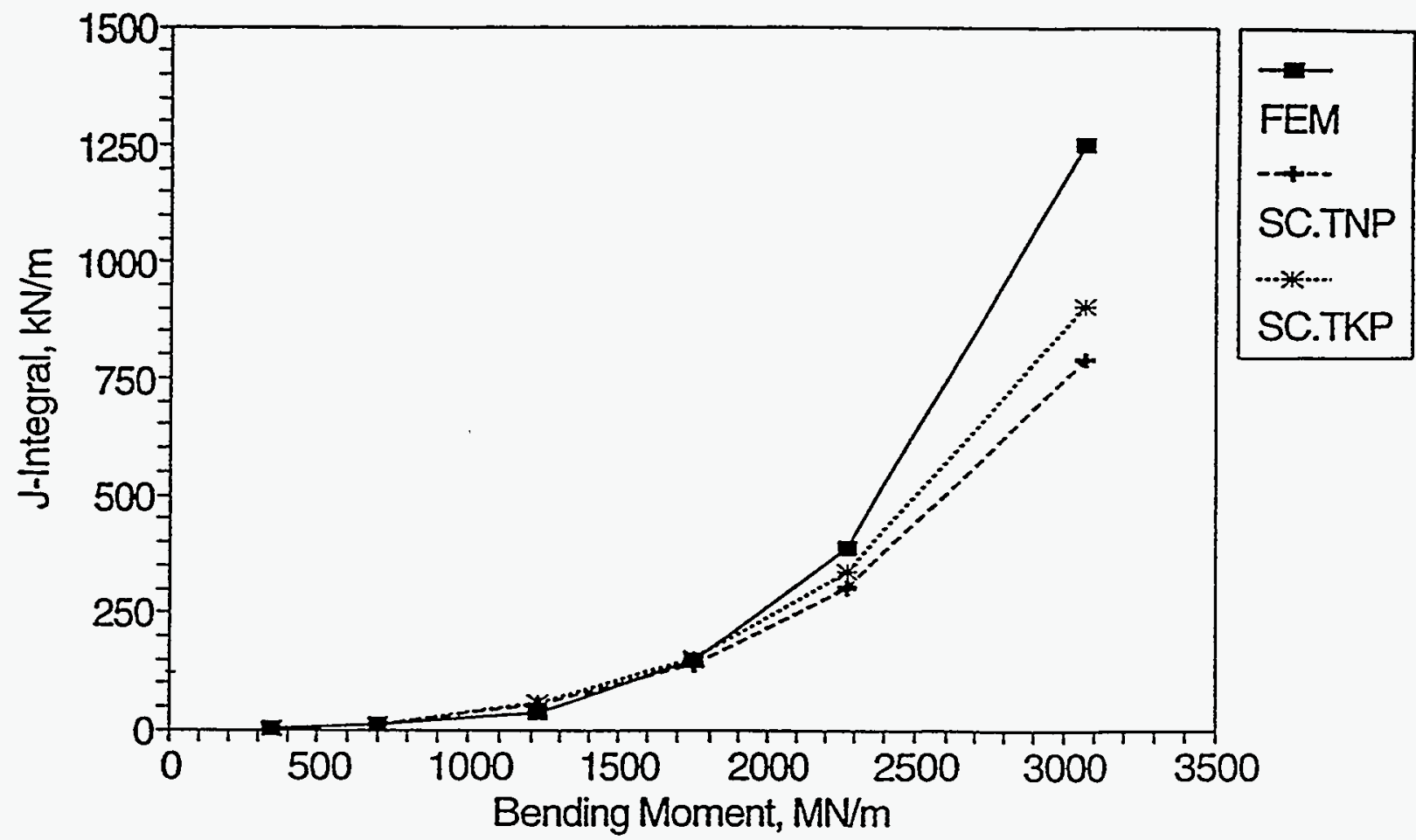

Figure 4.32 Comparison of FEM results and SC.TNP and SC.TKP prediction for an internal flaw with $\theta / \pi=1 / 16$ and $n=3$

for the case of external flaws. Apart from the significant underprediction of J-Integral values for a given applied moment when compared with FEM predictions, both the SC.TNP and SC.TKP analyses render similar values of J-Integral for the case of external flaws. In addition, the J-integral values obtained for external flaws using these analyses are less than the corresponding values for internal flaws. These two observations indicate that the analyses of external flaws are not well treated in the SC.TNP and SC.TKP methodologies.

The SC.TNP methodology uses a length parameter, $L$, which is the distance from the crack plane to the plane for which the stresses in the pipe wall can be assumed to be equal to that in the uncracked pipe. Since a clear definition of this parameter is elusive, this parameter was initially chosen to be approximately equal to the thickness of the pipe wall (Ref. 4.1) in the predictions shown in Figures 4.28 through 4.32. The effect of changing this parameter, $\mathrm{L}$, was examined for the crack geometries considered. The variation of J-integral versus bending moment for several values of $L$ is shown in Figures 4.33 and 4.34 for an internal crack in a material with a strain-hardening exponent equal to 3 and 10 , respectively. The total crack angle $(2 \theta)$ for these cases was 90 degrees, $\theta / \pi=1 / 4$. For purposes of comparison, the FEM results are also shown in these figures. It can be seen that predictions of SC.TNP agreed well with FEM results when $L$ is chosen to be between $2 t$ and $3 t$ for $\mathrm{n}=3$, whereas $\mathrm{L}$ needs to be closer to $10 \mathrm{t}$ for the case of $\mathrm{n}=10$. These two figures demonstrate the influence of the strain-hardening level of the material on the choice of $\mathrm{L}$. 


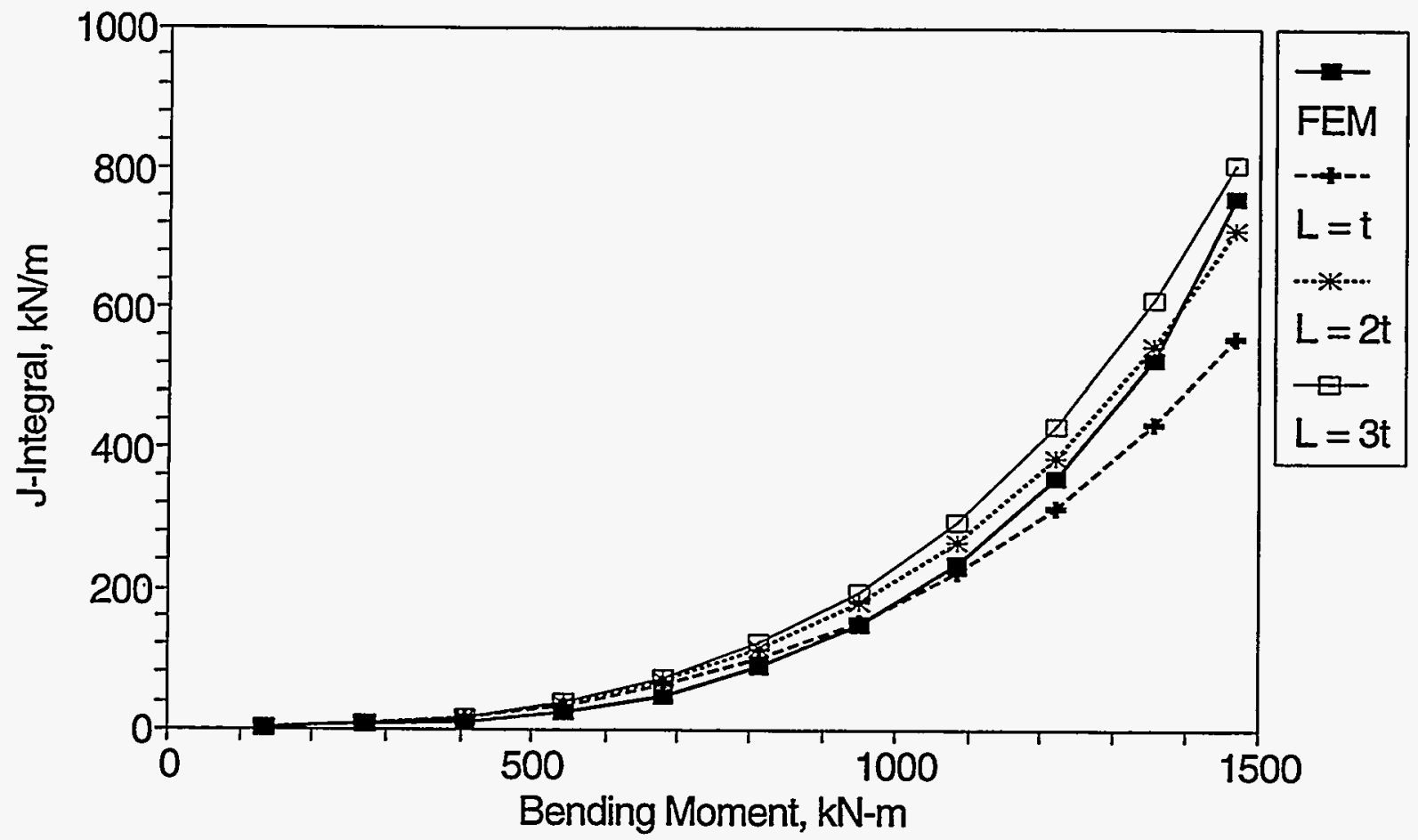

Figure 4.33 Comparison of FEM results and SC.TNP prediction with different values of $L$ for an internal flaw with $\theta / \pi=1 / 4$ and $n=3$

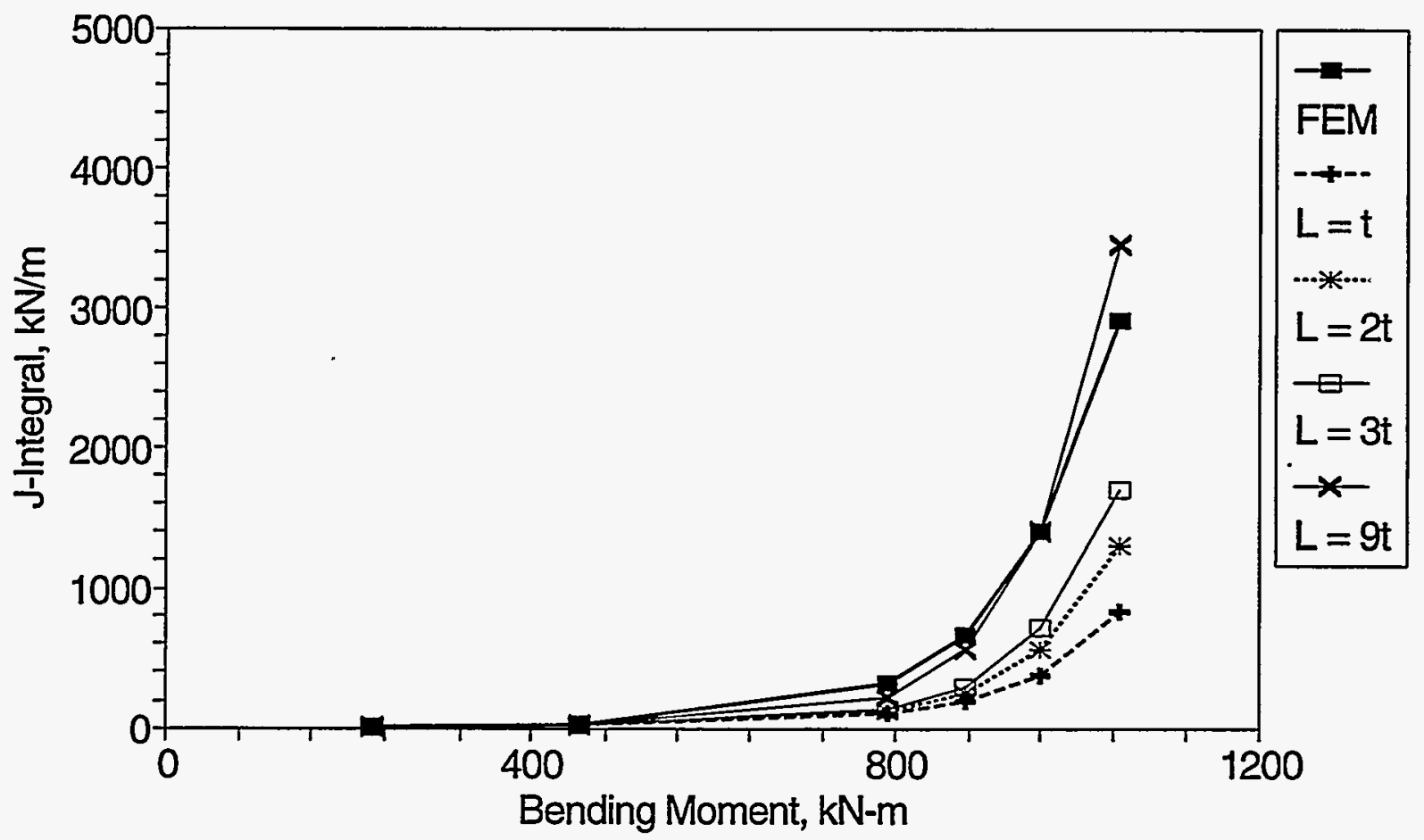

Figure 4.34 Comparison of FEM results and SC.TNP prediction with different values of $L$ for an internal flaw with $\theta / \pi=1 / 4$ and $n=10$ 


\subsubsection{Modified SC.TNP and SC.TKP Schemes}

Based on the dependence of the SC.TNP predictions on the length parameter, $L$, it appeared that the SC.TNP scheme could be modified by incorporating the dependence of the length parameter on the hardening exponent. For the SC.TNP scheme, this length parameter is taken to be $(n-1) t$, where $t$ is the thickness of the pipe. The variations of J-integral versus applied bending moment for two different crack geometries and for two different $n$ values are shown in Figures 4.35 through 4.38 . It can be seen that for the case of the larger flaw, $\theta / \pi=1 / 4$, the predictions of SC.TNP with $\mathrm{L}=$ ( $\mathrm{n}$ 1)t compare well with the predictions of FEM (Figures 4.35 and 4.36). For the case of a smaller flaw $(\theta / \pi=1 / 16)$, the predictions of the modified SC.TNP with $L=(n-1) t$, agree well with the predictions of FEM for $n=3$, see Figure 4.37. However, the modified SC.TNP scheme overpredicts $J$ for a given moment for this smaller flaw when $n=10$, see Figure 4.38. This is not surprising since the SC.TNP scheme assumes that the plane normal to the crack front may be viewed as representing a plane from an axisymmetrically surface-cracked pipe. This assumption is strictly valid only for long cracks. Thus, the SC.TNP predictions compare better with the predictions of FEM for longer flaws.

In the case of SC.TKP, the length parameter is taken to be $L=(n+1) /(2 n+1) t$. The variations of $J-$ integral versus applied bending moment for one crack geometry and for two different $n$ values are shown in Figures 4.39 and 4.40. It can be seen that for the case of the larger flaw $(\theta / \pi=1 / 4)$ the predictions of the modified SC.TKP analysis with the new length parameter compare well with the predictions of FEM (Figures 4.39 and 4.40). The original SC.TKP scheme for this geometry overpredicts $\mathrm{J}$ for a given moment compared with the FEM results. In the case of a smaller flaw $(\theta / \pi=1 / 16)$, it was reported earlier that the predictions of the original SC.TKP underpredicted $I$ for a given moment compared with the FEM results. Since the suggested modification to the SC.TKP scheme reduces the $\mathrm{J}$ value for a given moment, this modification is not appropriate for smaller flaws. Similar to the SC.TNP scheme, the SC.TKP scheme assumes that the plane normal to the crack front may be viewed as representing a plane from an axisymmetrically surface-cracked pipe. This assumption is strictly valid only for long cracks. Thus, the modified SC.TKP scheme may be more appropriate for longer flaws.

The original SC.TNP and SC.TKP methods are designated as SC.TNP1 and SC.TKP1, respectively, in the remainder of this report. The modified versions are denoted as SC.TNP2 and SC.TKP2.

\subsection{The SC.ENG Method}

\subsubsection{General Background}

In this program, a new method was developed to predict the energy release rates for surface-cracked pipes subjected to remote bending loads. This method of analysis involves determining the momentrotation behavior based on (1) classical deformation theory of plasticity, (2) a constitutive law characterized by the Ramberg-Osgood model, and (3) an equivalence criterion incorporating a reduced thickness analogy for simulating system compliance due to the presence of a crack in a pipe. The method is general in the sense that it may be applied in the complete range between elastic and fully 
Internal crack angle $=90, n=3$

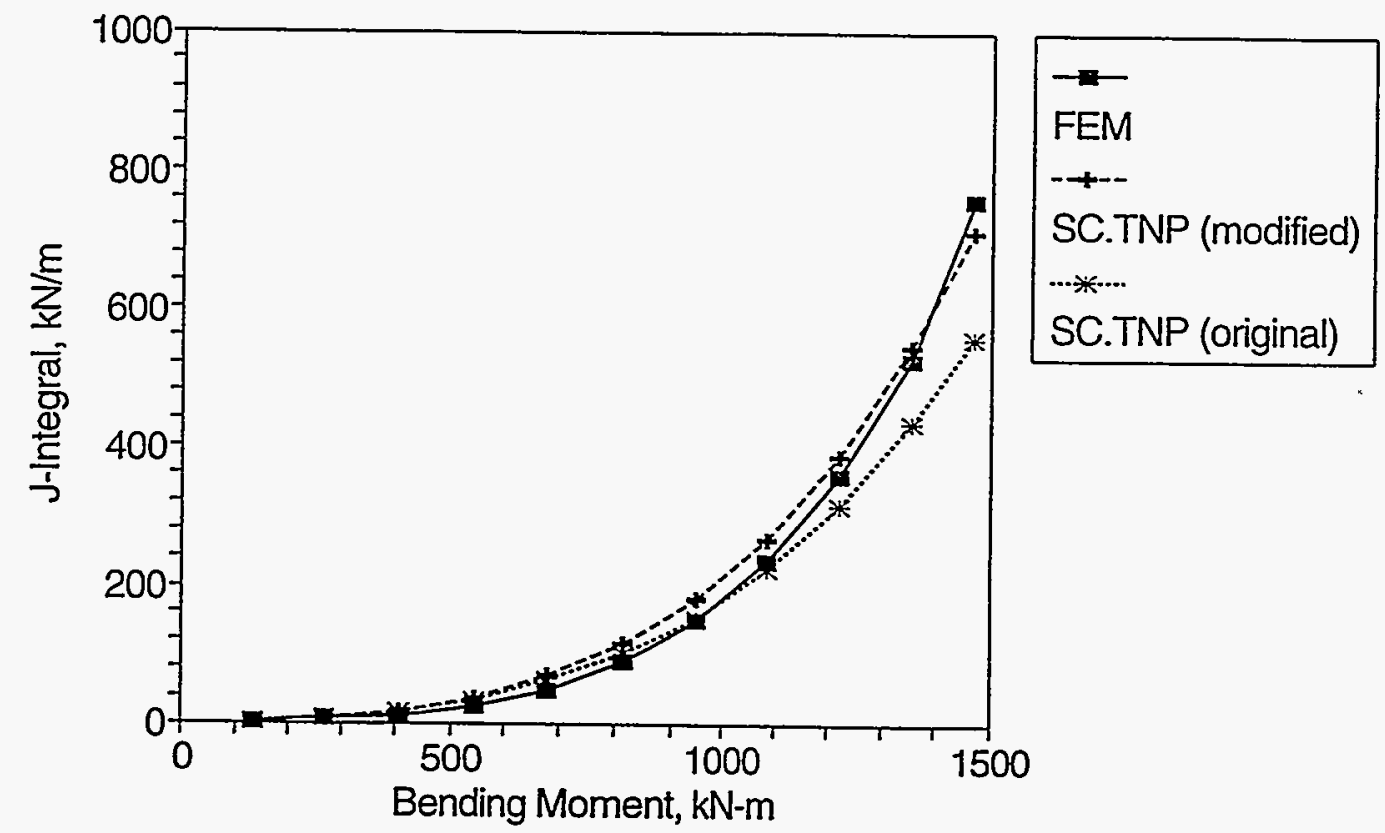

Figure 4.35 Variation of $\mathrm{J}$ from the SC.TNP analysis with applied moment for $\theta / \pi=1 / 4, a / t=0.5$, and $n=3$

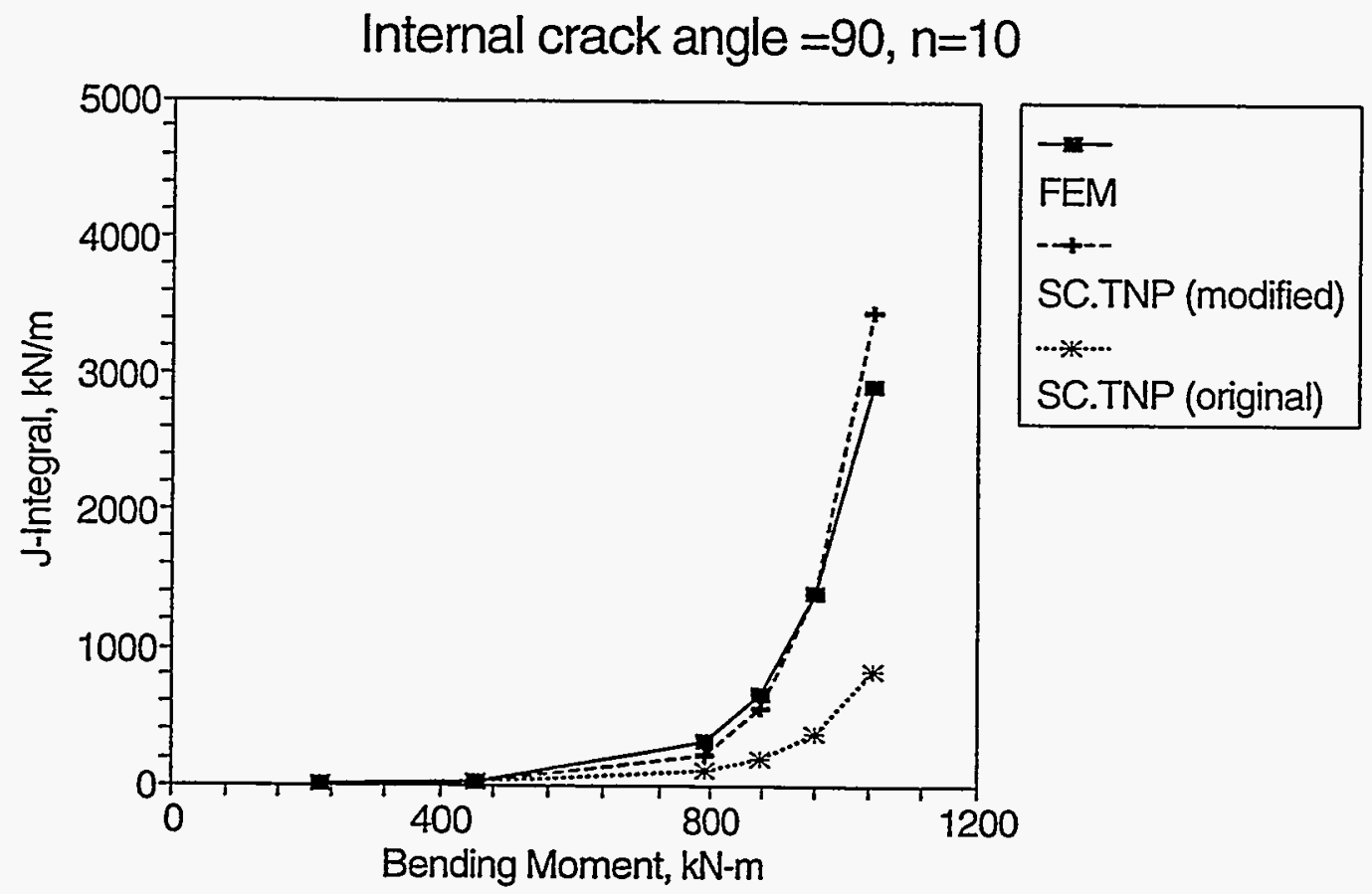

Figure 4.36 Variation of $J$ from the SC.TNP analysis with applied moment for $\theta / \pi=1 / 4, a / t=0.5$, and $n=10$ 


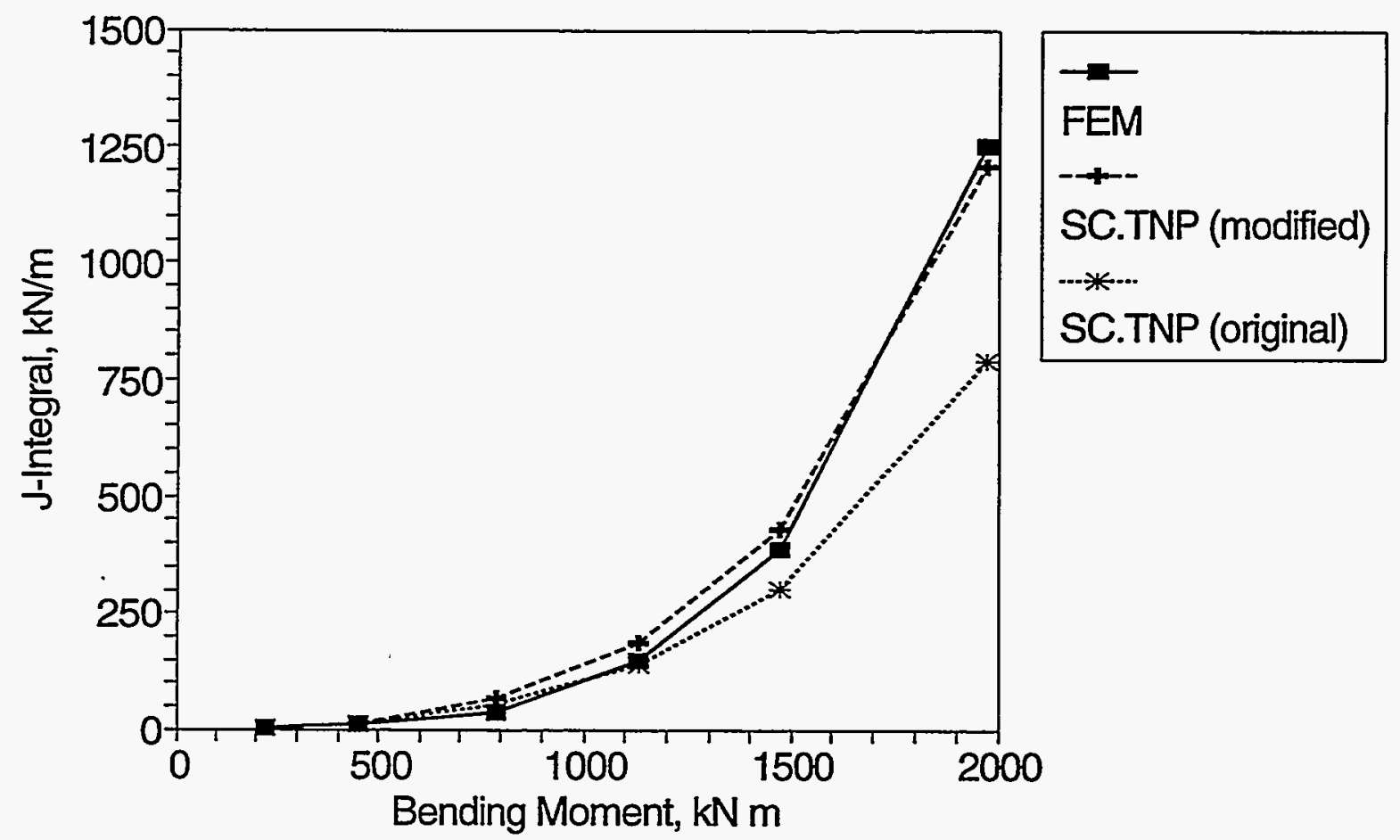

Figure 4.37 Variation of $\mathrm{J}$ from the SC.TNP analysis with applied moment for $\theta / \pi=1 / 16, a / t=0.5$, and $n=3$

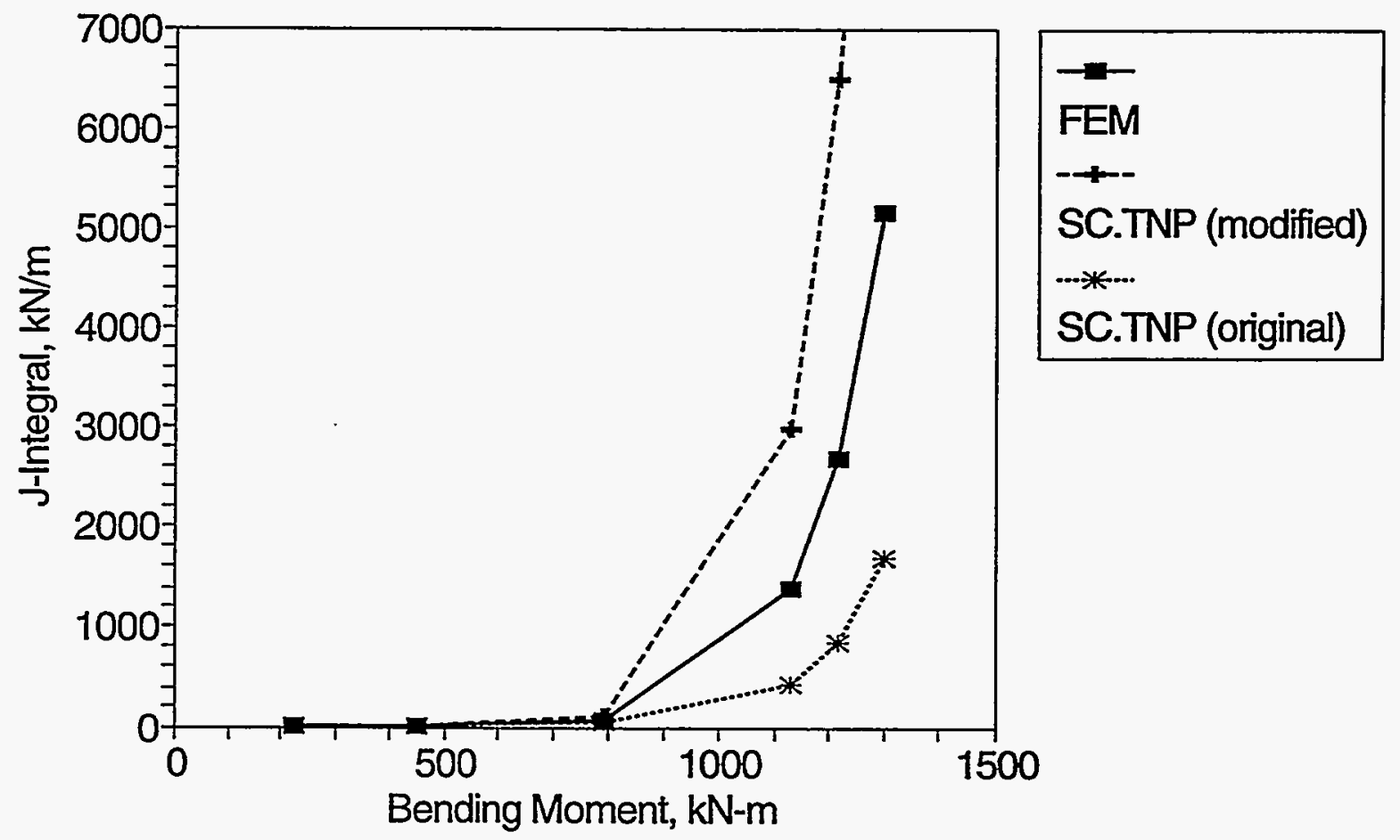

Figure 4.38 Variation of $\mathrm{J}$ from the SC.TNP with applied moment for $\theta / \pi=1 / 16, a / t=0.5$, and $n=10$ 


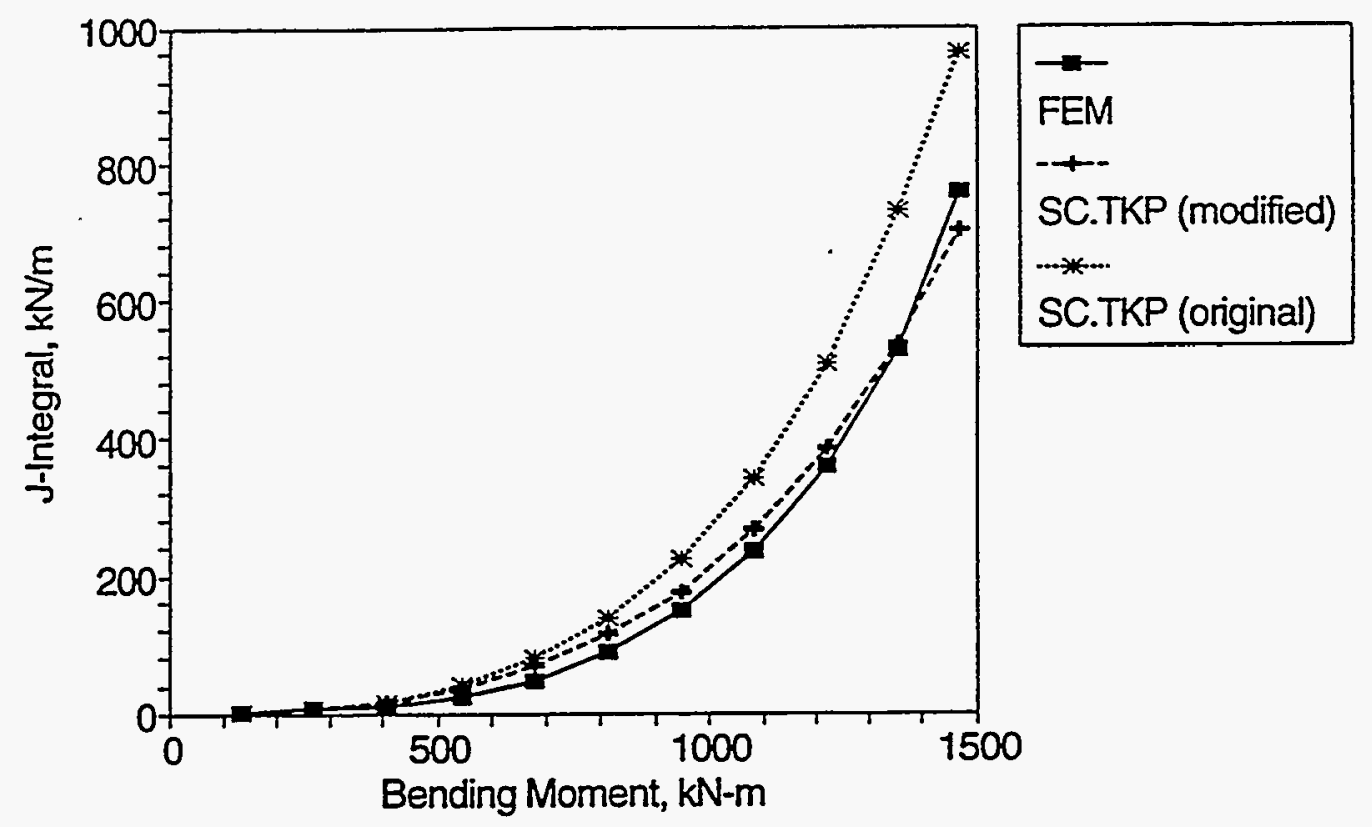

Figure 4.39 Variation of $J$ from the SC.TKP analysis with applied moment for $\theta / \pi=1 / 4, a / t=0.5$, and $n=3$

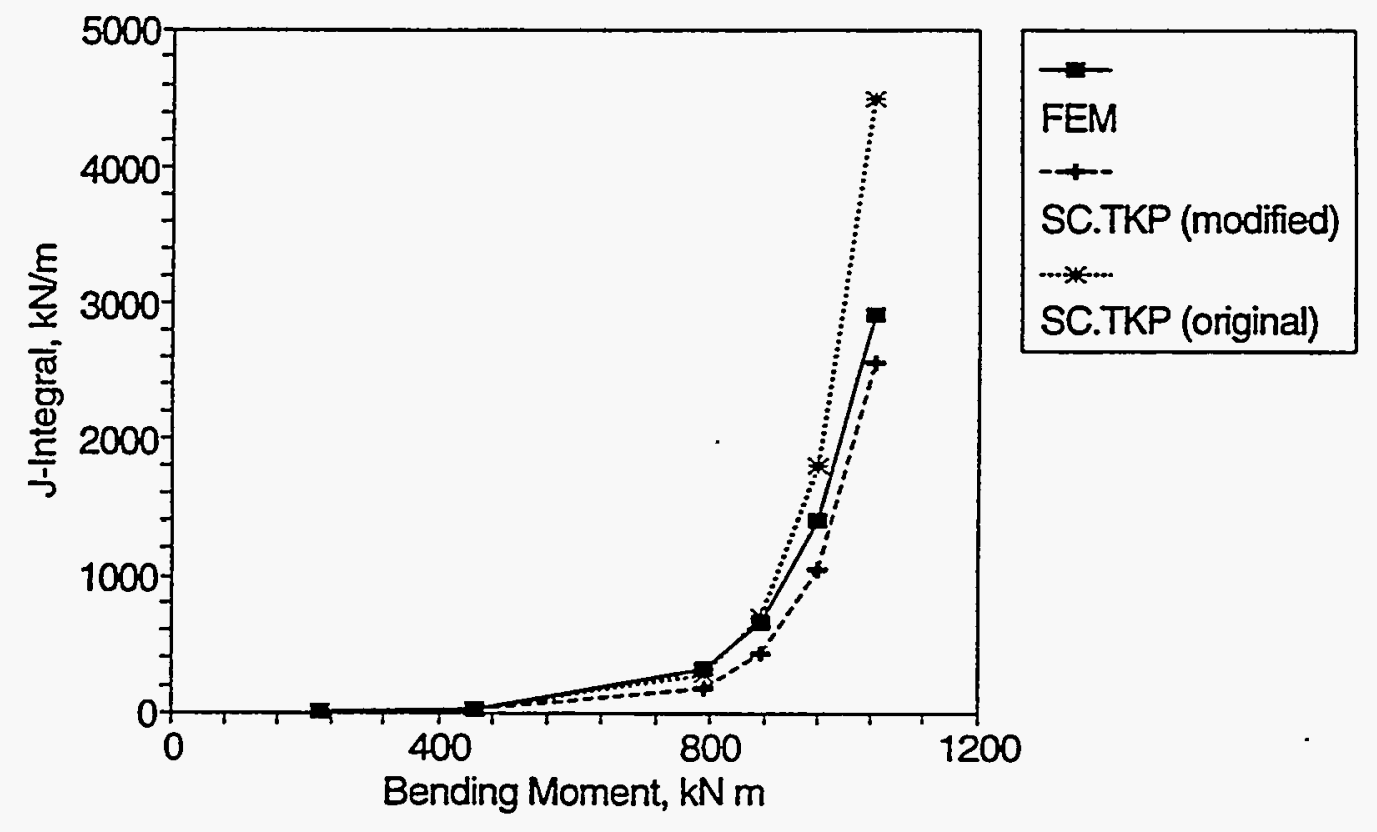

Figure 4.40 Variation of $J$ from the SC.TKP analysis with applied moment for $\theta / \pi=1 / 4, a / t=0.5$, and $n=10$ 
plastic conditions. Since it is based on J-tearing theory, it is subject to the usual limitations imposed upon this theory, e.g., proportional loading, etc. As explained earlier, this has the implication that the crack growth must be small, although in practice, J-tearing methodology is used far beyond the limits of its theoretical validity with acceptable results (Ref. 4.8). Several numerical examples are presented to illustrate the proposed technique, which is verified with the reference solutions from FEM.

This method was originally developed for analyzing through-wall cracks as described in NUREG/CR4853. In this work, it was first extended to analyze surface-cracked pipe under pure bending loads. It was then further extended to the case of tension and bending loads with a simple correction when it was incorporated into NRCPIPES, Section 4.4

Consider Figure 4.1, which illustrates a pipe with a constant-depth, internal, surface crack symmetrically placed in its bending plane. The pipe has mean radius, $R_{\mathrm{m}}$, wall thickness, $t$, and is subjected to a pure bending moment, $\mathrm{M}$, applied at remote ends. The depth and total angle of the surface crack are denoted by a and $2 \theta$, respectively. In the development of a J-estimation scheme, it is generally assumed that the rotation at the load point due to the presence of crack $\left(\phi^{c}\right)$ and the crack driving force $(J)$ admit additive decomposition into elastic and plastic components

$$
\begin{gathered}
\phi^{\mathrm{c}}=\phi_{\mathrm{e}}^{\mathrm{c}}+\phi_{\mathrm{p}}^{\mathrm{c}} \\
J=J_{\mathrm{e}}+\mathrm{J}_{\mathrm{p}}
\end{gathered}
$$

where the subscripts " $\mathrm{e}$ " and " $\mathrm{p}$ " refer to elastic and plastic contributions. In the elastic range, $\phi_{\mathrm{e}}^{\mathrm{c}}$ and $\mathrm{M}$ are uniquely related. In addition, if the deformation theory of plasticity holds, a unique relationship also exists between $\phi_{\mathrm{p}}^{\mathrm{c}}$ and $\mathrm{M}$. Once these relationships are determined, the elastic component, $\mathrm{J}_{\mathrm{e}}$, and the plastic component, $\mathrm{J}_{\mathrm{p}}$, of the total energy release rate, $\mathrm{J}$, can be obtained readily.

\subsubsection{The Elastic Solution}

The elastic energy release rate, $\mathrm{J}_{\mathrm{e}}$, at the point of maximum depth can be defined as

$$
\mathrm{J}_{\mathrm{e}}=\frac{\partial \mathrm{U}^{\mathrm{T}}}{\partial \mathrm{A}}=\frac{\partial}{\partial \mathrm{A}}\left(\mathrm{U}^{\mathrm{c}}+\mathrm{U}^{\mathrm{nc}}\right)=\frac{\partial \mathrm{U}^{\mathrm{c}}}{\partial \mathrm{A}}
$$

where $U^{T}$ is the total internal strain energy, $U^{n c}$ is the strain energy that would exist if there were no crack present, $U^{c}$, which is the difference between $U^{T}$ and $U^{n c}$, is the additional strain energy in the pipe due to the presence of crack, and $A$ is the cracked area $2 a \theta\left(R_{m}-t / 2+a / 2\right)$. For thin-walled pipe with Mode-I crack growth, $\mathrm{J}_{\mathrm{e}}$ at maximum depth can be obtained as 


$$
\mathrm{J}_{\mathrm{e}}=\frac{\mathrm{K}_{\mathrm{I}}^{2}}{\mathrm{E}^{\prime}}
$$

where $\mathrm{E}^{\prime}=\mathrm{E} /\left(1-\nu^{2}\right)$ for plane strain conditions, with $\mathrm{E}$ and $\nu$ representing the elastic modulus and Poisson's ratio of the material, respectively, and $\mathrm{K}_{\mathrm{I}}$ is the Mode-I stress intensity factor. From linear-elastic fracture mechanics theory (LEFM), $\mathrm{K}_{\mathrm{I}}$ at the deepest point of the crack is given by

$$
\mathrm{K}_{\mathrm{I}}=\frac{\mathrm{M}}{\pi \mathrm{R}_{\mathrm{m}}^{2} \mathrm{t}} \mathrm{F}_{\mathrm{B}}(\mathrm{a} / \mathrm{t}, \theta / \pi) \sqrt{\pi \mathrm{a}}
$$

where $\mathrm{F}_{\mathrm{B}}(\mathrm{a} / \mathrm{t}, \theta / \pi)$ is a geometry function relating $\mathrm{K}_{\mathrm{I}}$ of a cracked shell to that for the same size of crack in an infinite plate. According to Article IWB-3650 in ASME Section XI of the ASME Code (Ref. 4.7), the $\mathrm{F}_{\mathrm{B}}$-function is

$$
\mathrm{F}_{\mathrm{B}}(\mathrm{a} / \mathrm{t}, \theta / \pi)=1.1+\frac{\mathrm{a}}{\mathrm{t}}\left[-0.09967+5.0057\left[\frac{\mathrm{a}}{\mathrm{t}} \frac{\theta}{\pi}\right]^{0.565}-2.8329\left[\frac{\mathrm{a}}{\mathrm{t}} \frac{\theta}{\pi}\right]\right]
$$

From Equations 4-24 to $4-25, \mathrm{U}^{c}$ can be integrated to yield

$$
U^{c}=\frac{M^{2}}{\pi R_{m}^{4} t^{2} E^{\prime}} I_{B}(a / t, \theta / \pi)
$$

where

$$
\mathrm{I}_{\mathrm{B}}(\mathrm{a} / \mathrm{t}, \theta / \pi)=2 \theta\left[\mathrm{R}_{\mathrm{m}}-\frac{\mathrm{t}}{2}\right] \int \mathrm{aF_{B } ^ { 2 }}(\mathrm{a} / \mathrm{t}, \theta / \pi) \mathrm{da}+2 \theta \int \mathrm{a}^{2} \mathrm{~F}_{\mathrm{B}}^{2}(\mathrm{a} / \mathrm{t}, \theta / \pi) d a
$$

Using Castigliano's theorem,

$$
\phi_{\mathrm{e}}^{\mathrm{c}}=\frac{\partial \mathrm{U}^{\mathrm{c}}}{\partial \mathrm{M}}
$$

which when combined with Equation 4-28 gives 


$$
\phi_{\mathrm{e}}^{\mathrm{c}}=\frac{2 \mathrm{M}}{\pi \mathrm{R}_{\mathrm{m}}^{4} \mathrm{t}^{2} \mathrm{E}^{\prime}} \mathrm{I}_{\mathrm{B}}(\mathrm{a} / \mathrm{t}, \theta / \pi)
$$

representing the relation between moment and elastic rotation. Equations 4-25 to 4-27 completely specify $J_{e}$, and hence the elastic solution is complete in closed form. Equation 4-31 provides the relation between $M$ and $\phi_{e}^{c}$, which will be required for the calculation of $J_{p}$ explained in the next section. The integral in Equation 4-29 can be evaluated using the expression of $F_{B}(a / t, \theta / \pi)$ given by Equation 4-27. Explicit functional form of $I_{B}(a / t, \theta / \pi)$ is given in Appendix $C$.

\subsubsection{The Plastic Solution}

The plastic energy release rate, $\mathrm{J}_{\mathrm{p}}$, at the point of maximum depth, can be defined as

$$
\mathrm{J}_{\mathrm{p}}=\int_{0}^{\mathrm{M}} \partial \frac{\phi_{\mathrm{p}}^{\mathrm{c}}}{\partial \mathrm{A}} \mathrm{dM}=\frac{\partial}{\partial \mathrm{A}} \int_{0}^{\mathrm{M}} \phi_{\mathrm{p}}^{\mathrm{c}} \mathrm{dM}
$$

The evaluation of $\mathrm{J}_{\mathrm{p}}$ requires determination of the $\mathrm{M}-\phi_{p}^{c}$ relation. When this relation is obtained, Equation 4-32 can be used to find $\mathrm{J}_{\mathrm{p}}$ and can then be added to $\mathrm{J}_{\mathrm{e}}$ to determine the total $\mathrm{J}$.

The constitutive law used to describe the material's stress-strain $(\sigma-\epsilon)$ relation is again the RambergOsgood model given by

$$
\frac{\epsilon}{\epsilon_{\mathrm{o}}}=\frac{\sigma}{\sigma_{\mathrm{o}}}+\alpha\left[\frac{\sigma}{\sigma_{\mathrm{o}}}\right]^{\mathrm{n}}
$$

where $\sigma_{0}$ is the reference stress, usually assumed to be the yield stress, $\epsilon_{0}=\sigma_{0} / E$ is the associated reference strain, and $\alpha$ and $n$ are parameters usually chosen from a best fit of experimental tensile data. In applying the Ramberg-Osgood relation to the cracked-pipe problem, it is necessary to relate the stresses (or moments) to rotations. Ilyushin showed that the field solutions to the boundary value problem involving a monotonically increasing load or displacement type parameter is "proportional" (Ref. 4.8). Consequently, Equation 4-33 applies (minus the elastic term) and deformation theory plasticity is assumed to be valid. Thus,

$$
\phi_{\mathrm{c}}^{\mathrm{p}} \propto \mathrm{M}^{\mathrm{n}}
$$


giving

$$
\phi_{c}^{\mathrm{p}}=\hat{C} M^{\mathrm{n}}
$$

where $\hat{C}$ is the proportionality constant, which can be determined via the finite element method. In this study, an alternative analytical formulation is proposed to evaluate $\hat{C}$ and hence, estimate $J_{p}$. This is explained below.

\subsubsection{Evaluation of $\hat{\mathbf{C}}$}

Suppose that the actual pipe can be replaced by a pipe with reduced thickness, $t_{e}$, which extends for a distance, $\hat{a}$, at the center, see Figure 4.41. Far from the crack plane, the rotation of the pipe is not greatly influenced by whether a crack exists or some other discontinuity is present as long as the discontinuity can approximate the effects of the crack. The reduced thickness section, which actually results in a material discontinuity, is an attempt to simulate the reduced system compliance due to the presence of the crack. This equivalence approach was originally suggested by Brust (Ref. 4.17) for analyzing through-wall-cracked (TWC) pipes with base metal cracks under pure bending. Later Rahman and Brust successfully implemented a similar approach to evaluate the J-integral for TWC pipes with weld metals cracks that can account for both base and weld metal tensile properties (Refs. 4.33 and 4.34). It is assumed here that the deformation theory of plasticity controls the stress-strain response and that beam-theory assumptions hold.

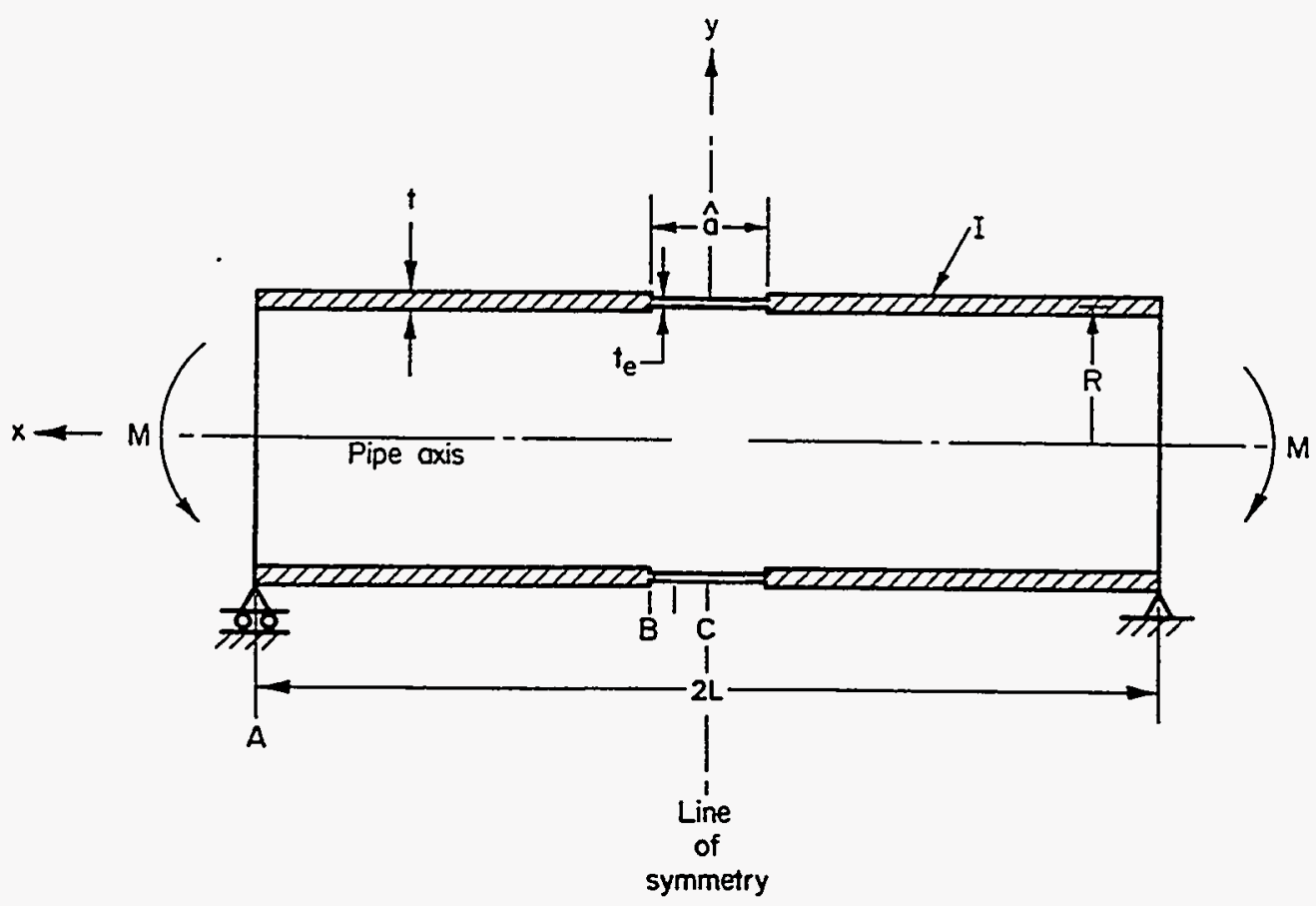

Figure 4.41 Reduced section analogy by the SC.ENG methods 
Consider the equivalent pipe with the material discontinuity in Figure 4.41 and subjected to a bending moment, $\mathrm{M}$, at both ends. Using classical beam theory, the ordinary differential equations governing the displacement of beams with a Ramberg-Osgood constitutive law can be easily derived. These equations, when supplemented by the appropriate boundary and compatibility conditions, can be solved following elementary operations of calculus. Details of the algebra associated with these solutions are provided in Appendix D. The rotations (dy/dx in Equations D-2 and D-5 in Appendix D) provide a relationship between the far-field plastic rotation due to material discontinuity and the corresponding elastic rotations. According to the equivalence method, the same relationship is assumed to hold between $\phi_{\mathrm{p}}^{\mathrm{c}}$ and $\phi_{\mathrm{e}}^{\mathrm{c}}$. In general, such a relation would depend on geometry, material properties of the pipe, equivalent thickness, $t_{e}$, and also the spatial coordinate, $x$ (see Figure 4.41). In particular, when the spatial location is selected to be the Point $B$ (i.e., at $x=\hat{a} / 2$ ), the explicit relation between $\phi_{\mathrm{p}}^{\mathrm{c}}$ and $\phi_{\mathrm{e}}^{\mathrm{c}}$ becomes

$$
\phi_{p}^{c}=\left[\frac{t}{t_{e}}\right]^{n-1}\left[\frac{\pi}{4 \hat{K}}\right]^{n} \alpha\left[\frac{M}{M_{0}}\right]^{n-1} \phi_{e}^{c}
$$

in which

$$
\begin{gathered}
\mathrm{M}_{\mathrm{o}}=\pi \mathrm{R}_{\mathrm{m}}^{2} \mathrm{t \sigma _{ \textrm {o } }} \\
\hat{\mathrm{K}}=\frac{\sqrt{\pi}}{2} \frac{\Gamma\left[1+\frac{1}{2 \mathrm{n}}\right]}{\Gamma\left[\frac{3}{2}+\frac{1}{2 \mathrm{n}}\right]}
\end{gathered}
$$

Following the substitution of $\phi_{\mathrm{e}}^{\mathrm{c}}$ from Equation 4-31 into Equation 4-36, $\phi_{\mathrm{p}}^{\mathrm{c}}$ becomes

$$
\phi_{p}^{c}=\left[\frac{t}{t_{e}}\right]^{n-1}\left[\frac{\pi}{4 \hat{K}}\right]^{n}\left[\frac{M}{M_{0}}\right]^{n-1} \frac{2 \alpha M}{\pi R_{m}^{4} t^{2} E^{\prime}} I_{B}(a / t, \theta / \pi)
$$


which, when compared with Equation 4-35, yields

$$
\hat{C}=\frac{\alpha}{M_{0}^{n-1}}\left[\frac{\pi}{4 \hat{K}}\right]^{n} H(a / t)^{n-1} G(a / t)
$$

where

$$
\begin{gathered}
H(a / t)=\frac{t}{t_{e}} \\
G(a / t)=\frac{2}{\pi R_{m}^{4} t^{2} E^{\prime}} I_{B}(a / t, \theta / \pi)
\end{gathered}
$$

Following differentiation with respect to crack depth, a, the partial derivative of $\hat{C}$ is

$$
\frac{\partial \hat{C}}{\partial a}=\frac{\alpha}{t M_{0}^{n-1}}\left[\frac{\pi}{4 \hat{K}}\right]^{n}\left[H(a / t)^{n-1} \frac{d G(a / t)}{d(a / t)}+(n-1) G(a / t) H(a / t)^{n-2} \frac{d H(a / t)}{d(a / t)}\right]
$$

where

$$
\frac{d G(a / t)}{d(a / t)}=\frac{2}{\pi R_{m}^{4} t^{2} E^{\prime}} \frac{d_{B}(a / t, \theta / \pi)}{d(a / t)}
$$

and

$$
\frac{\mathrm{dI}_{\mathrm{B}}(\mathrm{a} / \mathrm{t}, \theta / \pi)}{\mathrm{d}(\mathrm{a} / \mathrm{t})}=\mathrm{t}^{2}(\mathrm{a} / \mathrm{t})\left[2 \theta\left(\mathrm{R}_{\mathrm{m}}-\mathrm{t} / 2\right)+2 \theta \mathrm{t}(\mathrm{a} / \mathrm{t})\right] \mathrm{F}_{\mathrm{B}}^{2}(\mathrm{a} / \mathrm{t}, \theta / \pi)
$$

The explicit expressions for the functions $\mathrm{H}(\mathrm{a} / \mathrm{t})$ and $\mathrm{dH}(\mathrm{a} / \mathrm{t}) / \mathrm{d}(\mathrm{a} / \mathrm{t})$ depend on the type of limit-load solutions used for surface-cracked pipes. These are discussed in the forthcoming sections. 


\subsubsection{Estimation of $\mathrm{J}_{\mathrm{p}}$}

Having determined $\hat{C}$ and $\partial \hat{C} / \partial a$, Equation 4-32 can be simplified further to evaluate $\mathrm{J}_{\mathrm{p}}$. Following simple algebra, it can be shown that

$$
\begin{aligned}
J_{p}= & {\left[\frac{\alpha M^{n+1}}{2 t \theta M_{0}^{n+1}\left(R_{m}-t / 2+a\right)(n+1)}\right] \cdot\left[\frac{\pi}{4 \hat{K}}\right]^{n} \cdot } \\
& \cdot\left[H(a / t)^{n-1} \frac{d G(a / t)}{d(a / t)}+(n-1) G(a / t)[H(a / t)]^{n-2} \frac{d H(a / t)}{d(a / t)}\right]
\end{aligned}
$$

Equations 4-25 and 4-46 provide closed form expressions of $J_{e}$ and $J_{p}$, respectively.

\subsubsection{The SC.ENG1 and SC.ENG2 Methods}

The evaluation of $J_{p}$ in Equation $4-46$ requires determination of $\mathrm{H}(\mathrm{a} / \mathrm{t})$ and $\mathrm{dH}(\mathrm{a} / \mathrm{t}) / \mathrm{d}(\mathrm{a} / \mathrm{t})$. According to the definition of $\mathrm{H}(\mathrm{a} / \mathrm{t})$ (see Equation 4-41), this also requires estimating the equivalent thickness, $t_{e}$, for the uncracked pipe. In the equivalence method proposed here, $t_{e}$ can be determined by forcing the Net-Section-Collapse moment of the equivalent uncracked pipe to be equal to the Net-SectionCollapse moment of the actual cracked pipe. For an uncracked pipe with reduced thickness, $t_{e}$, the Net-Section-Collapse moment, $\mathrm{M}_{\mathrm{L}}^{\mathrm{d}}$, is

$$
\mathrm{M}_{\mathrm{L}}^{\mathrm{d}}=4 \sigma_{\mathrm{f}} \mathrm{R}_{\mathrm{m}}^{2} t_{\mathrm{e}}
$$

where $\sigma_{\mathrm{f}}$ is the flow or collapse stress of the material. However, in determining the Net-Section Collapse moment, $\mathrm{M}_{\mathrm{L}}^{\mathrm{c}}$, for circumferential surface-cracked pipe, there are several solutions available in the literature. In this study, two such equations, based on the original Net-Section-Collapse equation (Ref. 4.2) and the Kurihara modification (Ref. 4.3), are used to determine $\mathrm{H}(\mathrm{a} / \mathrm{t})$ and its derivative for evaluation of $J_{p}$. Accordingly, the expression of $J_{p}$ based on $H(a / t)$ and $d H(a / t) / d(a / t)$ obtained from the original Net-Section-Collapse equations and Kurihara modification to the NetSection-Collapse equations are defined as the SC.ENG1 and the SC.ENG2 methods, respectively. The explicit details for the evaluations of $\mathrm{H}(\mathrm{a} / \mathrm{t})$ and $\mathrm{dH}(\mathrm{a} / \mathrm{t}) / \mathrm{d}(\mathrm{a} / \mathrm{t})$ by these two methods are given below. 


\subsubsection{The SC.ENG1 Method}

The following are the original equations for the Net-Section-Collapse moment, $M_{L}^{c}$ (Ref. 4.2), and the resulting expressions for $\mathrm{H}(\mathrm{a} / \mathrm{t})$ and $\mathrm{dH}(\mathrm{a} / \mathrm{t}) / \mathrm{d}(\mathrm{a} / \mathrm{t})$ used by the SC.ENG1 method:

For $\beta<\pi-\theta$

$$
\begin{aligned}
M_{L}^{c} & =2 R_{m}^{2} t \sigma_{f}\left[2 \sin \beta-\frac{a}{t} \sin \theta\right] \\
\beta & =\frac{\pi-\theta(a / t)}{2}
\end{aligned}
$$

When the limit moments from Equations 4-47 and 4-48 are made equal,

$$
\begin{aligned}
H(a / t) & =\frac{2}{2 \sin \frac{\pi-\theta(a / t)}{2}-\frac{a}{t} \sin \theta} \\
\frac{d H(a / t)}{d(a / t)} & =\frac{2\left[\theta \cos \frac{\pi-\theta(a / t)}{2}+\sin \theta\right]}{\left[2 \sin \frac{\pi-\theta(a / t)}{2}-\frac{a}{t} \sin \theta\right]^{2}}
\end{aligned}
$$

For $\beta \geq \pi-\theta$

$$
M_{L}^{c}=2 R_{m}^{2} t \sigma_{f}\left[2-\frac{a}{t}\right] \sin \beta
$$

where

$$
\beta=\frac{\pi(1-a / t)}{(2-a / t)}
$$

When the limit loads from Equations 4-47 and 4-51 are made equal, 


$$
\begin{gathered}
H(a / t)=\frac{2}{(2-a / t) \sin \left[\frac{\pi(1-a / t)}{(2-a / t)}\right]} \\
\frac{d H(a / t)}{d(a / t)}=\frac{\frac{2 \pi \cos \left[\frac{\pi(1-a / t)}{(2-a / t)}\right]}{(2-a / t)}+\sin \left[\frac{\pi(1-a / t)}{(2-a / t)}\right]}{\left[(2-a / t) \sin \left[\frac{\pi(1-a / t)}{(2-a / t)}\right]\right]^{2}}
\end{gathered}
$$

\subsubsection{The SC.ENG2 Method}

The following are the Kurihara modifications to the equations for the Net-Section-Collapse moment, $M_{L}^{c}$ and the resulting expressions for $H(a / t)$ and $d H(a / t) / d(a / t)$ used by the SC.ENG2 method:

For $\beta<\pi-\theta$

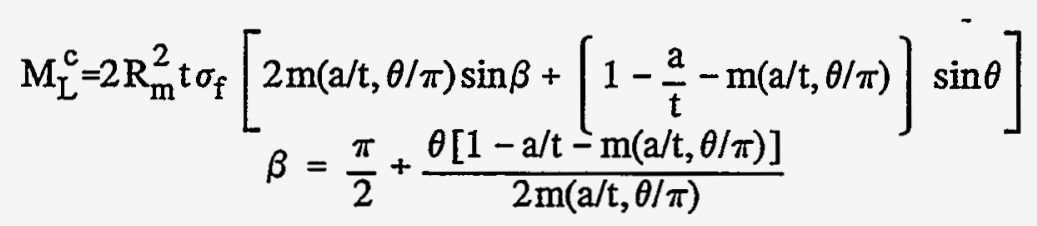

When the limit moments from Equations 4-47 and 4-54 are made equal,

$$
\begin{gathered}
H(a / t)=\frac{2}{K(a / t)} \\
\frac{d H(a / t)}{d(a / t)}=-\frac{2}{K(a / t)^{2}} \frac{d K(a / t)}{d(a / t)}
\end{gathered}
$$


where

$$
\mathrm{K}(\mathrm{a} / \mathrm{t})=2 \mathrm{~m}(\mathrm{a} / \mathrm{t}, \theta / \pi) \sin \left[\frac{\pi}{2}+\frac{\theta[1-\mathrm{a} / \mathrm{t}-\mathrm{m}(\mathrm{a} / \mathrm{t}, \theta / \pi)]}{2 \mathrm{~m}(\mathrm{a} / \mathrm{t}, \theta / \pi)}\right]+[1-\mathrm{a} / \mathrm{t}-\mathrm{m}(\mathrm{a} / \mathrm{t}, \theta / \pi)] \sin \theta(4-57)
$$

and

$$
\begin{gathered}
\frac{\mathrm{dK}(\mathrm{a} / \mathrm{t})}{\mathrm{d}(\mathrm{a} / \mathrm{t})}=\frac{1}{\mathrm{~m}(\mathrm{a} / \mathrm{t}, \theta / \pi)} \cos \left[\frac{\pi}{2}+\frac{\theta[1-\mathrm{a} / \mathrm{t}-\mathrm{m}(\mathrm{a} / \mathrm{t}, \theta / \pi)]}{2 \mathrm{~m}(\mathrm{a} / \mathrm{t}, \theta / \pi)}\right] \cdot\left[-\mathrm{m}(\mathrm{a} / \mathrm{t}, \theta / \pi) \theta-\theta(1-\mathrm{a} / \mathrm{t}) \frac{\partial \mathrm{m}(\mathrm{a} / \mathrm{t}, \theta / \pi)}{\partial(\mathrm{a} / \mathrm{t})}\right] \\
+2 \frac{\partial \mathrm{m}(\mathrm{a} / \mathrm{t}, \theta / \pi)}{\partial(\mathrm{a} / \mathrm{t})} \sin \left[\frac{\pi}{2}+\frac{\theta[1-\mathrm{a} / \mathrm{t}-\mathrm{m}(\mathrm{a} / \mathrm{t}, \theta / \pi)]}{2 \mathrm{~m}}\right]-\left[1+\frac{\partial \mathrm{m}(\mathrm{a} / \mathrm{t}, \theta / \pi)}{\partial(\mathrm{a} / \mathrm{t})}\right] \sin \theta \\
\mathrm{m}(\mathrm{a} / \mathrm{t}, \theta / \pi)=1-\left[\frac{\mathrm{a}}{\mathrm{t}}\right]^{2}\left[\frac{\theta}{\pi}\right]^{0.2} \\
\frac{\partial \mathrm{m}(\mathrm{a} / \mathrm{t}, \theta / \pi)}{\partial(\mathrm{a} / \mathrm{t})}=-2\left[\frac{\mathrm{a}}{\mathrm{t}}\right]\left[\frac{\theta}{\pi}\right]^{0.2}
\end{gathered}
$$

For $\beta \geq \pi-\theta$

$$
\begin{aligned}
M_{L}^{c} & =2 R_{m}^{2} t \sigma_{f}\left[1-\frac{a}{t}+m(a / t, \theta / \pi)\right] \sin \beta \\
\beta & =\frac{\pi(1-a / t)}{[1-a / t+m(a / t, \theta / \pi)]}
\end{aligned}
$$

When the limit loads from Equations 4-47 and 4-61 are made equal,

$$
H(a / t)=\frac{2}{K(a / t)}
$$

and

$$
\frac{d H(a / t)}{d(a / t)}=-\frac{2}{K(a / t)^{2}} \frac{d K(a / t)}{d(a / t)}
$$


where

$$
\begin{aligned}
& K(a / t)=Q_{1}(a / t) \sin Q_{2}(a / t) \\
& \frac{d K(a / t)}{d(a / t)}=Q_{1}(a / t) \cos Q_{2}(a / t) \frac{d Q_{2}(a / t)}{d(a / t)}+\sin Q_{2}(a / t) \frac{d Q_{1}(a / t)}{d(a / t)} \\
& \mathrm{Q}_{1}(\mathrm{a} / \mathrm{t})=1-\frac{\mathrm{a}}{\mathrm{t}}+\mathrm{m}(\mathrm{a} / \mathrm{t}, \theta / \pi) \\
& \mathrm{Q}_{2}(\mathrm{a} / \mathrm{t})=\frac{\pi(1-\mathrm{a} / \mathrm{t})}{\mathrm{Q}_{1}(\mathrm{a} / \mathrm{t})} \\
& \frac{\mathrm{dQ}_{1}(\mathrm{a} / \mathrm{t})}{\mathrm{d}(\mathrm{a} / \mathrm{t})}=-1+\frac{\partial \mathrm{m}(\mathrm{a} / \mathrm{t}, \theta / \pi)}{\partial(\mathrm{a} / \mathrm{t})} \\
& \frac{d Q_{2}(a / t)}{d(a / t)}=-\frac{\pi Q_{1}(a / t)+\pi(1-a / t) \frac{d Q_{1}(a / t)}{d(a / t)}}{Q_{1}(a / t)^{2}} \\
& \mathrm{~m}(\mathrm{a} / \mathrm{t}, \theta / \pi)=1-\left[\frac{\mathrm{a}}{\mathrm{t}}\right]^{2}\left[\frac{\theta}{\pi}\right]^{0.2} \\
& \frac{\partial \mathrm{m}(\mathrm{a} / \mathrm{t}, \theta / \pi)}{\partial(\mathrm{a} / \mathrm{t})}=-2\left[\frac{\mathrm{a}}{\mathrm{t}}\right]\left[\frac{\theta}{\pi}\right]^{0.2}
\end{aligned}
$$

The function $\mathrm{m}(\mathrm{a} / \mathrm{t}, \theta / \pi)$, defined by Equation 4-59 or 4-70, is an empirical function developed by Kurihara. The constants in the equation for $\mathrm{m}(\mathrm{a} / \mathrm{t}, \theta / \pi)$ (e.g., 2 and 0.2$)$ were developed from a best fit of experimental data on maximum loads for small diameter TP304 pipes with short and deep circumferential surface cracks. When these constants are assigned large positive values, $\mathrm{m}$ approaches 1 and the resulting Kurihara modifications to the Net-Section-Collapse equations degenerate to the original equations. In that case, the difference between the SC.ENG1 and SC.ENG2 methods also vanishes. In this study, however, the constants suggested by Kurihara (i.e., 2 and 0.2 ) were used throughout the numerical examples presented in the next section of this report. 


\subsubsection{Numerical Examples}

In this section, several numerical examples are presented to illustrate the SC.ENG1 and the SC.ENG2 methods for predicting J-integral under pure bending loads. In all cases, elastic-plastic finite-element results were. used to evaluate the accuracy of the proposed methods. Two example sets were considered. In Example Set 1, all finite-element results were produced from this program, see Section 4.2.3. In Example Set 2, finite-element solutions from sources outside of Battelle were used to verify the J-estimation results.

\subsubsection{Example Set 1}

In order to evaluate the accuracy of the SC.ENG1 and SC.ENG2 methods, the J-integral solutions for several surface-cracked pipes under pure bending loads were compared with finite-element results given in Section 4.2.3. Four cases were considered. The following input parameters were used:

$\begin{array}{ll}\text { Geometry: } & \mathrm{D}_{\mathrm{o}}=404.2 \mathrm{~mm}(15.91 \text { inches }) \\ \mathrm{t} & =26.4 \mathrm{~mm}(1.04 \text { inches }) \\ \theta / \pi & =0.0625,0.25 \\ \mathrm{a} / \mathrm{t} & =0.5 \\ & \\ \text { Material Properties: } & \sigma_{0}=241 \mathrm{MPa}(35.0 \mathrm{ksi}) \\ \mathrm{E} & =206 \mathrm{GPa}(30,000 \mathrm{ksi}) \\ \nu & =0.29 \\ \alpha & =1 \\ & \mathrm{n}=3,10\end{array}$

Figures 4.42 to 4.45 show the plots of J versus M obtained by the SC.ENG1 and SC.ENG2 methods and the finite element method (FEM). The FEM solutions were obtained by using ABAQUS (Ref. 4.21) with the line-spring elements. Finite-element results from the line-spring model were previously validated against those from the full-scale 3D models. Due to symmetries with respect to loading and crack geometry, only a quarter of the cracked pipe needed to be modeled. Comparisons with FEM results suggest that the SC.ENG2 method provides very accurate estimates of the J-integral for various applied loads and for various combinations of $\theta / \pi$ and strain-hardening exponents. The agreement between the SC.ENG2 and FEM solutions is exceptionally good when $\theta / \pi$ or $\mathrm{n}$ are larger. Figures 4.42 to 4.45 also show the corresponding results from the SC.ENG1 method which predicted lower values of $J$ than either the SC.ENG2 method or the finite-element solution for any given moment. Since, the Kurihara modification in the SC.ENG2 method lowers the Net-Section-Collapse load from the original equations, the equivalent thickness, $t_{e}$, is larger in the SC.ENG1 method than that in the SC.ENG2 method. Therefore, in the SC.ENG1 method, the values of the $\mathrm{H}(\mathrm{a} / \mathrm{t})$ and $d H(a / t) / d(a / t)$ functions (note: $\left.H(a / t)=t / t_{e}\right)$ would be smaller, resulting in lower values of $J_{p}$ by the SC.ENG1 method as compared with that by the SC.ENG2 method (see Equation 4-46). Hence, the trend shown in these figures is expected.

Figures 4.42 to 4.45 also show the results from the existing J-estimation methods, i.e., SC.TNP1 and SC.TKP1, for the same pipe cases. These results are also shown here to facilitate comparisons with the SC.ENG1 and SC.ENG2 methods and hence, to determine the level of improvements by the 


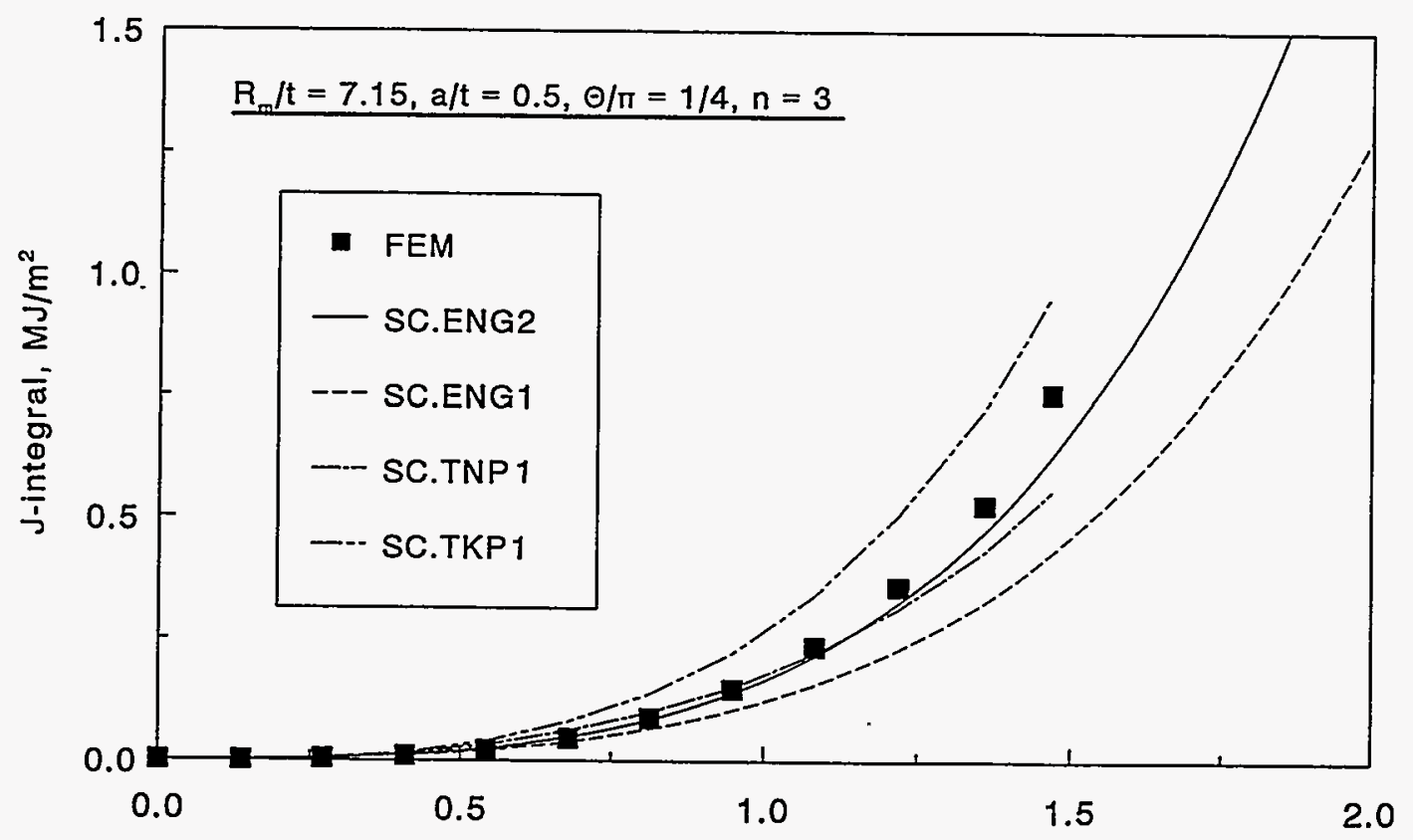

Applied Moment, MN-m

Figure 4.42 Comparisons of J-integral by various estimation methods with the finite-element results for surface-cracked pipes under pure bending when $\theta / \pi=1 / 4$ and $n=3$

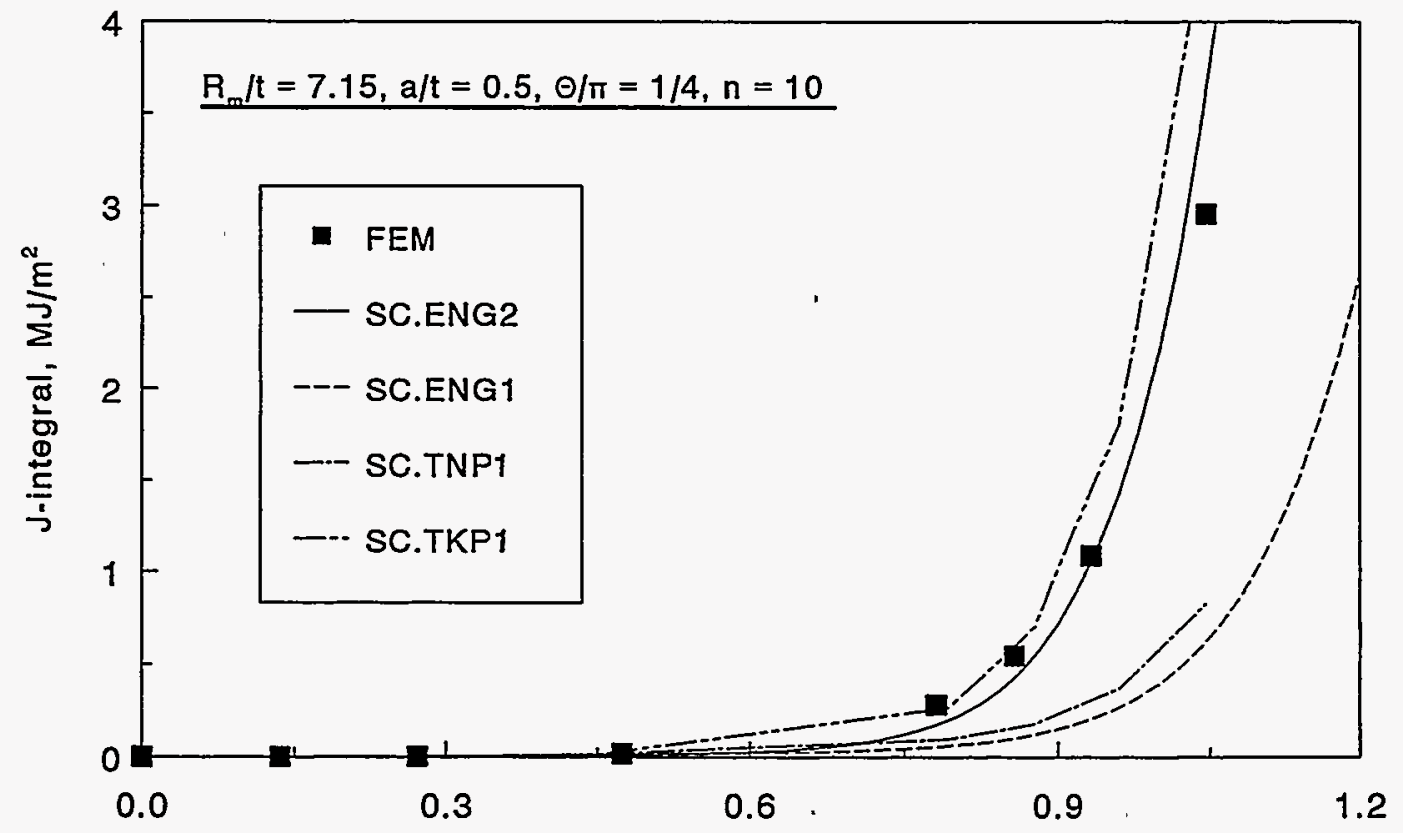

Applied Moment, MN-m

Figure 4.43 Comparisons of J-integral by various estimation methods with the finite-element results for surface-cracked pipes under pure bending when $\theta / \pi=1 / 4$ and $n=10$ 


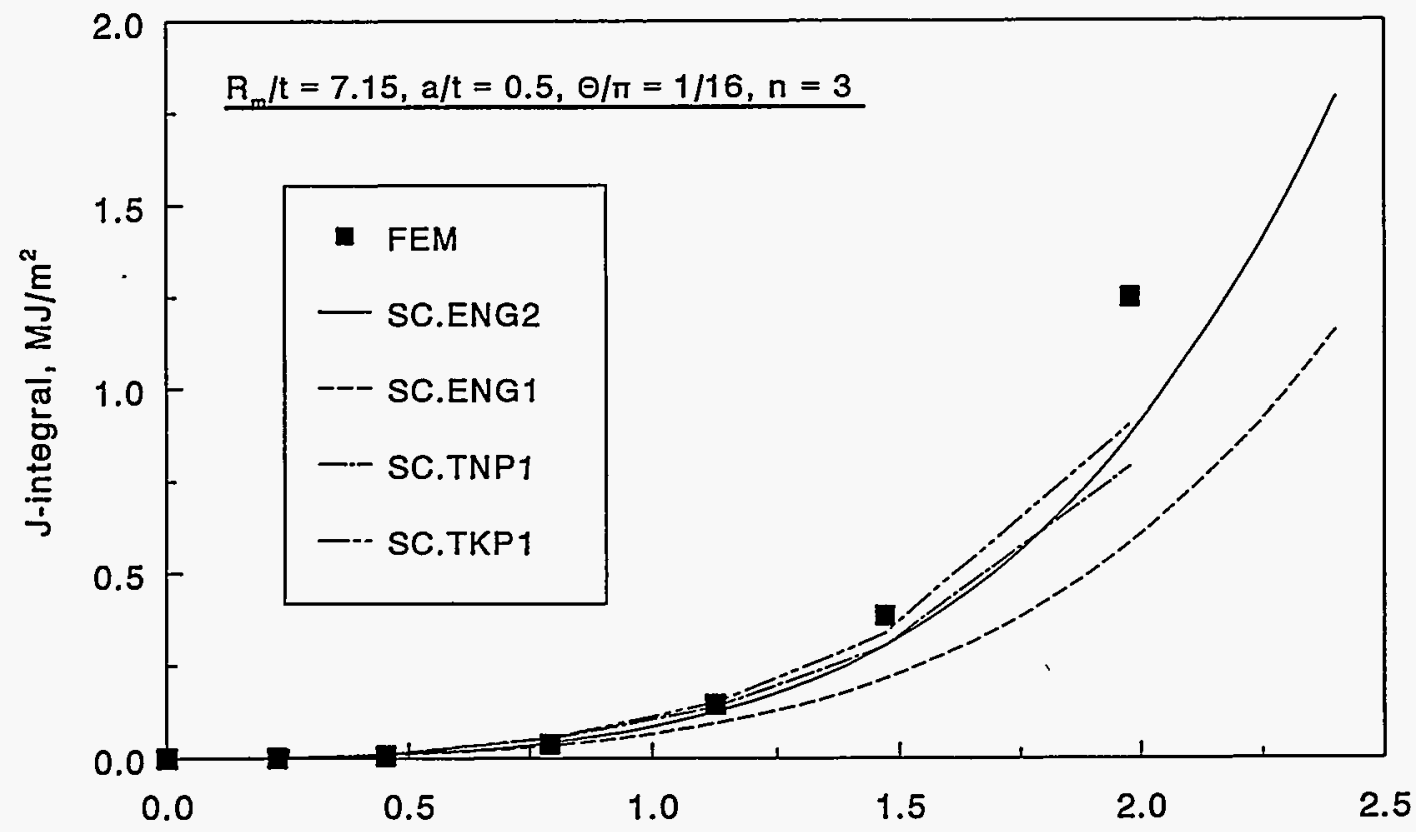

Applied Moment, MN-m

Figure 4.44 Comparisons of J-integral by various estimation methods with the finite-element results for surface-cracked pipes under pure bending when $\theta / \pi=1 / 16$ and $n=3$

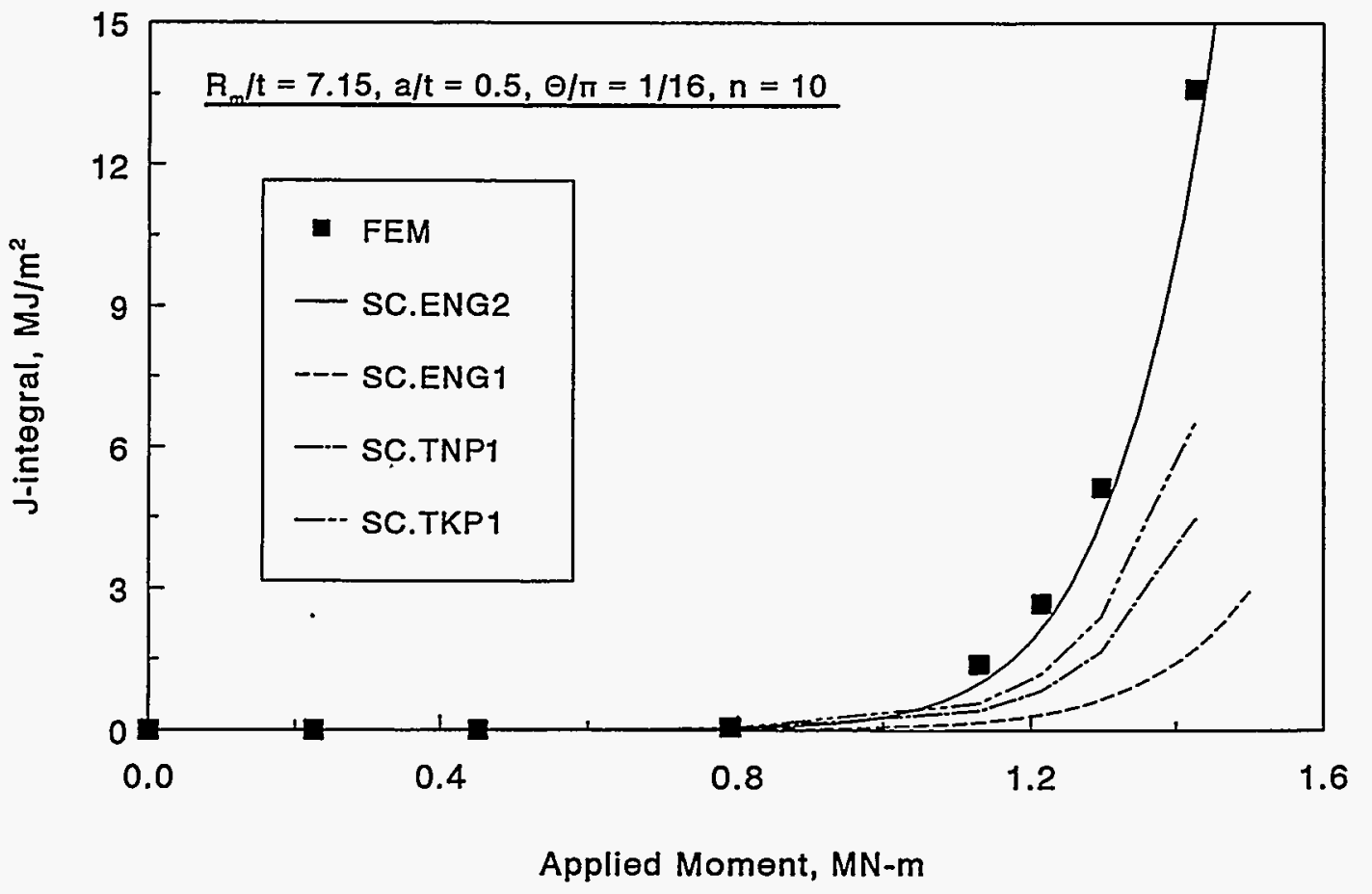

Figure 4.45 Comparisons of $J$-integral by various estimation methods with the finite-element results for surface-cracked pipes under pure bending when $\theta / \pi=1 / 16$ and $\mathrm{n}=10$ 
newly developed estimation methods. From the above figures, it appears that the SC.ENG2 method provides more accurate estimates of the J-integral than either the SC.TNP1 or SC.TKP1 methods for all the pipe cases under study. However, more numerical studies with various pipe geometries $\left(\mathrm{R}_{\mathrm{m}} / \mathrm{t}\right.$ ratio) and crack sizes (e.g., a/t and $\theta / \pi$ ratios) need to be undertaken to make a generic conclusion.

\subsubsection{Example Set 2}

During this study, additional efforts were undertaken to verify the SC.ENG methods. They involved comparisons of J-integral values obtained by the SC.ENG methods with nonlinear finite-element results from sources other than Battelle. From our literature survey, we identified several surfacecracked pipes (under pure bending) for which detailed finite-element results of J-integral were available. Comparisons of predicted $\mathrm{J}$ from the SC.ENG methods with these reported calculations are given below.

\section{Finite-Element J-integral Calculations by Kumar and German}

The analysis of Kumar and German (Ref. 4.34) had the following input parameters (in the usual notation):

$\begin{array}{ll}\text { Geometry: } & \mathrm{D}_{\mathrm{o}}=554.7 \mathrm{~mm}(21.84 \mathrm{inch}) \\ \mathrm{t} & =26.42 \mathrm{~mm}(1.04 \mathrm{inch}) \\ \theta / \pi & =0.25 \\ \mathrm{a} / \mathrm{t} & =0.5 \\ & \\ \text { Material Properties: } & \sigma_{\mathrm{o}}=241 \mathrm{MPa}(35.0 \mathrm{ksi}) \\ & \mathrm{E}=206 \mathrm{GPa}(29,900 \mathrm{ksi}) \\ v & =0.29 \\ \alpha & =1 \\ \mathrm{n} & =2,5, \text { and } 10\end{array}$

Figure 4.46 shows the plots of $J$ versus moment values obtained by the SC.ENG2 method and the finite-element method from the EPRI NP-5596 report (Ref. 4.34). Comparisons with FEM results suggest that the SC.ENG2 method provides accurate estimates of the J-integral for the various applied loads for several values of the material constant, $n$. The agreement between SC.ENG2 and FEM solutions is excellent when the hardening constant, $n$, is larger. Similar observations were also made in the comparisons of results presented using FEM solutions from this program.

\section{Finite Element J-integral Calculations by Brickstad}

A pipe with a circumferential, constant-depth, surface crack was analyzed by B. Brickstad at AB Svensk Anläggningsprovning of Swedish Plant Inspection, Ltd (Ref. 4.35). In this work, numerical comparisons were made for the J-integral using ABAQUS and GE/EPRI solutions as a function of applied bending moment. For this case, the input parameters in the usual notation were: 


$\begin{array}{ll}\text { Geometry: } & \mathrm{D}_{\mathrm{o}}=170.5 \mathrm{~mm}(6.71 \mathrm{inch}) \\ \mathrm{t} & =7.75 \mathrm{~mm}(0.305 \mathrm{inch}) \\ \theta / \pi & =0.25 \\ & \mathrm{a} / \mathrm{t}=0.5 \\ & \\ \text { Material Properties: } & \sigma_{\mathrm{o}}=345 \mathrm{MPa}(50.0 \mathrm{ksi}) \\ & \mathrm{E}=207 \mathrm{GPa}(30,000 \mathrm{ksi}) \\ & v=0.3 \\ & \alpha=2\end{array}$

J was evaluated at the center of the surface crack (Ref. 4.36).

The results of the J-integral from the above report are shown in Figure 4.47 as a function of applied moment. In this figure, the horizontal coordinate represents the applied bending moment normalized with respect to the limit-moment of the uncracked pipe. Two sets of finite-element results are presented and they correspond to the solutions from the ABAQUS and GE/EPRI finite-element calculations. The ABAQUS solutions involved 8-noded shell elements and 3-noded nonlinear linespring elements. The GE/EPRI solutions involved influence functions which were also developed using shell and line-spring elements. The J-integral by the GE/EPRI FEM results are slightly higher than those by ABAQUS FEM. Also, plotted in the same figure are the results of the SC.ENG2 method. Comparisons with FEM results suggest that the SC.ENG2 method can provide very accurate estimates of J-integral for various applied loads. The SC.ENG2 results appear to be closer to Brickstad's ABAQUS solutions. 


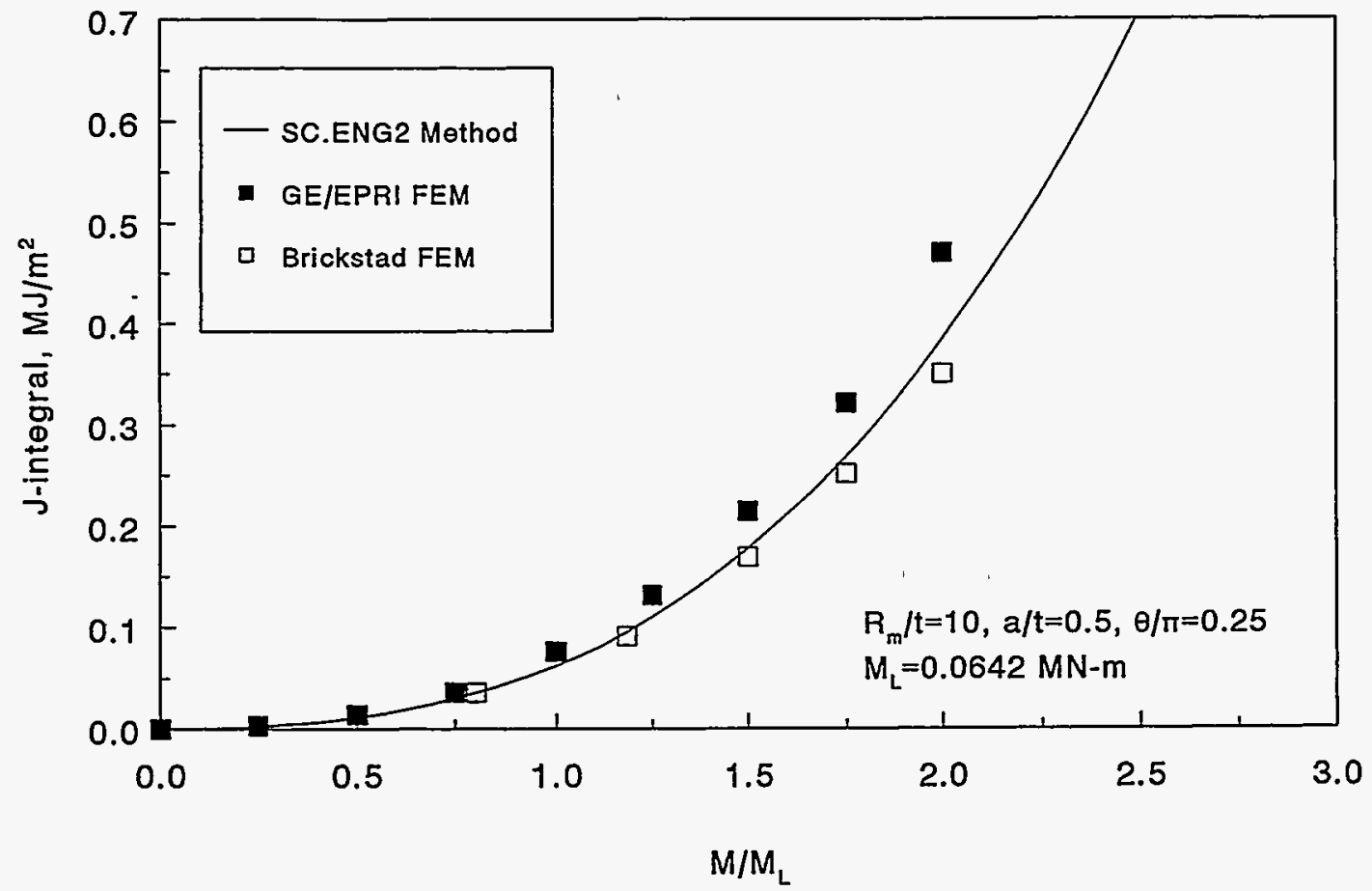

Figure 4.46 Comparisons of J-integral by the SC.ENG methods with the finite-element results of Kumar and German (Ref. 4.35) for a surface-cracked pipe under pure bending

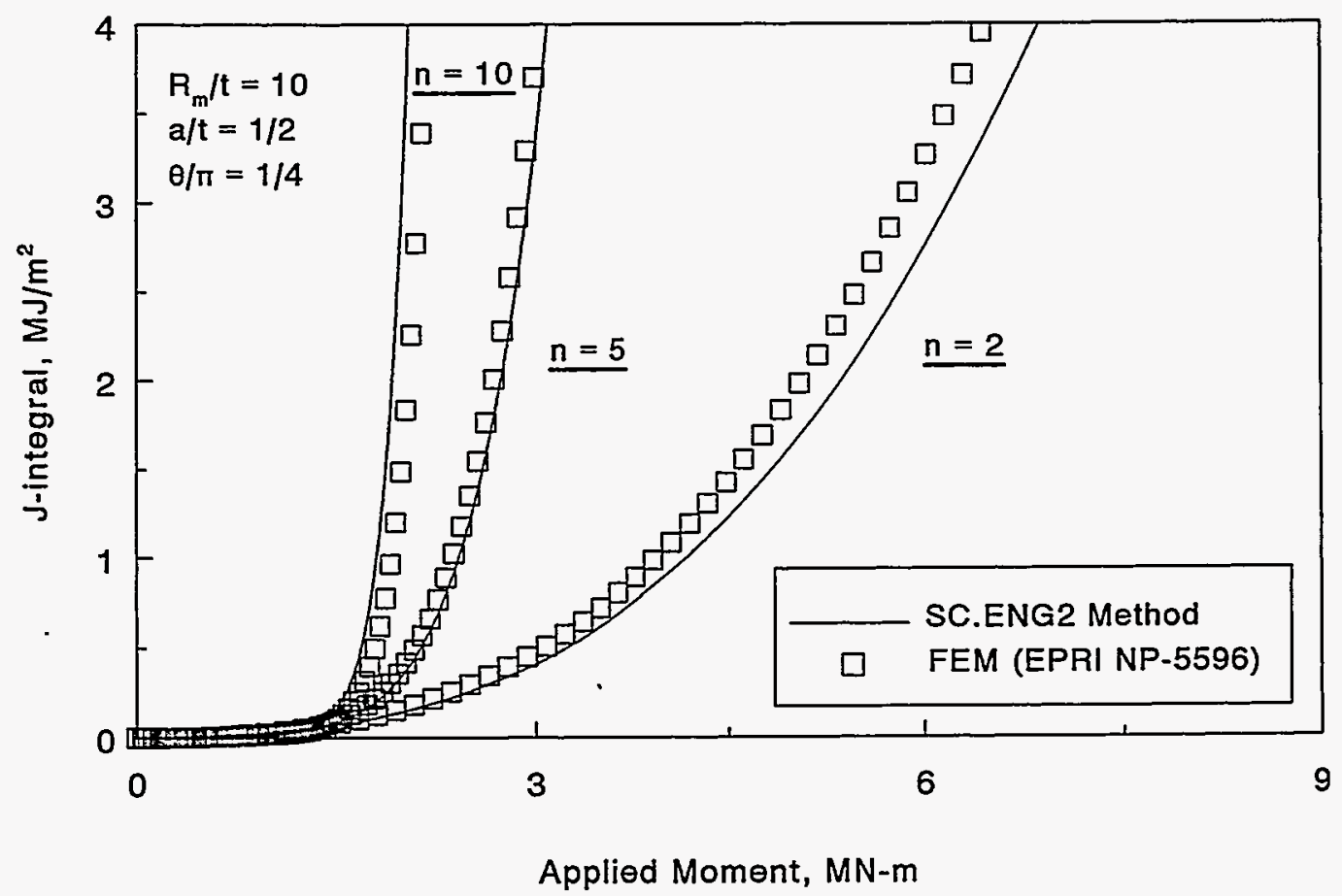

Figure 4.47 Comparisons of $J$-integral by the SC.ENG methods with the finite-element results of Brickstad (Ref. 4.36) and Kumar and German (Ref. 4.35) for a surface-cracked pipe under pure bending 


\subsection{Analysis of Experiments}

\subsubsection{The NRCPIPES PC Program}

\subsubsection{Objective}

As part of the Degraded Piping Program - Phase II, a PC computer program, NRCPIPE, was written to analyze through-wall-cracked pipes under pure bending and combined bending and pressure loads (Ref. 4.18). One of the objectives of the Short Cracks in Piping and Piping Welds program was to develop a similar code, NRCPIPES, to analyze surface-cracked pipe under bending and tension loads. Although a separate task addressed the development of NRCPIPES and its users manuals, an overview of this code is provided here since it was used to analyze the experiments reported in this section.

\subsubsection{Approach}

The first step in creating NRCPIPES involved converting the SC.TNP1 and SC.TKP1 codes based on the methods developed in the Degraded Piping Program (Ref. 4.1) to a PC program. This was accomplished early during the Short Cracks in Piping and Piping Welds program and NRCPIPES, Version 1.0 was created. Subsequently, the improvements to surface-cracked pipes J-estimation schemes, the new methods developed during the program, and some of the other methods available in the literature have been incorporated into NRCPIPES (Version 2.0). Version 2.0 of this code was one of the final deliverables from the Short Cracks in Piping and Piping Welds program.

A list of the analysis procedures and a brief summary of the methods incorporated into NRCPIPES Version 2.0, is given below:

- SC.TNP1 Method: This is the original SC.TNP J-estimation scheme as described in Reference 4.1. The code from the mainframe computer was converted to a Quick Basic $\mathrm{PC}$ version. Crack initiation moment, maximum moment, crack-tip-opening displacement, as well as the moment-rotation behavior are predicted by this method using thin-wall approximations. This was originally developed for pure bending of pipes, but has now been modified to account for tension loads also.

- $\quad$ SC.TKP1 Method: This is also the original SC.TKP method as described in Reference 4.1. The code from the mainframe computer was converted to a Quick Basic PC version. Crack initiation moment, maximum moment, crack-tip-opening displacement, as well as the moment-rotation behavior under combined bending and tension loads are predicted by this method using the thick-wall solutions. This was originally developed for pure bending of pipes, but has now been modified to account for tension loads also.

- $\quad$ SC.TNP2 Method: A correction factor based on correlation with finite element results was used to estimate ' $L$ ' as described in Section 4.2.6. This improved predictions for J as compared with the SC.TNP1 method. As for SC.TNP1, the crack initiation moment, 
maximum moment, crack-tip-opening displacement, as well as the moment-rotation behavior under combined bending and tension loads are predicted by this method.

- SC.TKP2 Method: A correction factor based on finite element results was used to estimate ' $\mathrm{L}$ ' as described in Section 4.2.6. This improved the predictions for $\mathrm{J}$ as compared with the SC.TKP1 method. The crack initiation moment, maximum moment, crack-tip-opening displacement, and the moment-rotation behavior under combined bending and tension loads are predicted by this method.

- The Original NSC Analysis: This evaluation procedure is based on Equation 4.1 presented in Section 4.2. Only the maximum limit moment is predicted by this method for surface-cracked pipe under combined bending and tension loads.

- SC.ENG1 Method: This procedure, as described in Section 4.3, is based on the original NSC method, and can be used to predict crack initiation and maximum moment as well as the moment-rotation behavior of a surface-cracked pipe under bending and combined bending and tension loads.

- SC.ENG2 Method: This procedure, as described in Section 4.3, is based on the Kurihara modification to the NSC method and can be used to predict crack initiation and maximum moment as well as the moment-rotation behavior of a surface-cracked pipe under bending and combined bending and tension loads.

- The R6, Option 1, Revision 3 Procedure: This procedure, developed by the CEGB (Refs. 4.4 and 4.5), is used quite extensively in Europe and is therefore included as one of the options in the analysis methods in NRCPIPES. This procedure underpredicts the experimental loads since it was developed as a failure avoidance criteria. It can be used to estimate both initiation and maximum loads for surface-cracked pipe under combined bending and tension loading. The numerical algorithm used in this analysis method is identical to the one used for through-wall-cracked pipes described in NUREG/CR-6235 (Ref. 4.37).

- ASME Section XI, Appendix C, Flaw Evaluation Procedure: This is the flaw evaluation criterion for stainless steel pipe used in the U.S. and elsewhere and has been incorporated into the NRCPIPES code as an optional analysis.

- $\quad$ ASME Section XI, Appendix H, Flaw Evaluation Procedure: Appendix H of Section XI is analogous to Appendix $C$, but it deals with carbon steel piping.

- The Dimensionless Plastic-Zone Parameter (DPZP) Criterion: This semi-empirical analysis model developed at Battelle is based on a dimensionless plastic-zone parameter, DPZP, discussed in Section 4.2, and is also included as an option in the PC code.

- The Code Case N-494-2 Approach: The Code Case N-494-2 approach described in Section 4.2 and in detail in References 4.11 is incorporated into NRCPIPES and can be used to predict the failure loads of surface-cracked pipes. (In Version 2.0 of 
NRCPIPES, an earlier proposed austenitic pipe FAD curve was implemented. This austenitic pipe FAD curve has since been found to be in error and was not published in a revision of Code Case $\mathrm{N}-494$. Hence, this austenitic curve in Version 2.0 of NRCPIPES should not be used and a revision to NRCPIPES is needed in the future.)

NRCPIPES Version 2.0 with all of the above analysis methods was used to predict the behavior of surface-cracked pipe for which experimental data are available. These analytical predictions are compared with experimental data in the two sections that follow. Section 4.4.2 deals with the analysis of pipe experiments conducted under pure bending loads. These include experiments from this program as well as past programs for which data are available. Analysis of pipe experiments conducted under bending and tension (due to internal pressure) loads are presented in Section 4.4.3. After presenting these results, a discussion and explanation of some of the observations in Sections 4.4.2 and 4.4.3 are given in Section 4.5.

\subsubsection{Analysis of Surface-Cracked-Pipe Experiments - Pure Bending Load Cases}

\subsubsection{List of Experiments Analyzed}

Table 4.5 lists the details of the 28 pipe experiments analyzed. In addition to the experiment number another reference number is also defined for convenience. The pipe material, diameter, wall thickness, test temperature, and flaw dimensions are also given in Table 4.5. Only two of these experiments, Reference Numbers 27 and 28, were conducted during this program. The tensile properties of the pipe materials listed in Table 4.5 are given in Table 4.6. These include the yield and ultimate strengths, as well as the constants used to fit the engineering stress-strain curve to a Ramberg-Osgood model, which are used in the $J$ estimation schemes. The fracture resistance properties for the pipe materials in Table 4.5 are given in Table 4.7 and include the crack initiation value of $J$, the slope of the $J-R$ curve, $d J / d a$, as well as the curve-fit parameters used to fit the experimental data to a power-law function. The data provided in Tables 4.5 through 4.7 were obtained from Version 2.1b of the CIRCUMCK.WK1 database (Ref. 4.38).

\subsubsection{Predictions Using Limit-Load Approaches}

The bending moments at which the cracks initiated during the pipe experiments and the maximum moments carried by the cracked pipes are given in Table 4.8. The maximum moment predictions using the original NSC criterion, Equation 4-1, are also listed for the various experiments in Table 4.8. The ratios of the maximum moments from the experiments to the predictions from the original NSC criteria and its two modifications are also presented in Table 4.8. An average value for these ratios for the 28 experiments for each of the three methods as well as the standard deviations for each method were also calculated. On average, both the original Net-Section-Collapse analysis and Kurihara modification to the Net-Section-Collapse analysis underpredicted the maximum experimental moments. As seen, the simple modification for ovalization developed at Battelle, discussed in Section 4.3 , results in a slight overprediction (i.e., 2 percent) of the maximum experimental moments. 
Table 4.5 List of surface-cracked pipe experiments analyzed - pure bending load cases

\begin{tabular}{|c|c|c|c|c|c|c|c|c|c|c|}
\hline \multirow{2}{*}{$\begin{array}{l}\text { Ref. } \\
\text { No. }\end{array}$} & \multirow{2}{*}{$\begin{array}{l}\text { Expt. } \\
\text { No. }\end{array}$} & \multirow{2}{*}{ Material } & \multicolumn{2}{|c|}{$\begin{array}{l}\text { Outer Pipe } \\
\text { Diameter, }\end{array}$} & \multicolumn{2}{|c|}{$\begin{array}{l}\text { Pipe Wall } \\
\text { Thickness, }\end{array}$} & \multicolumn{2}{|c|}{$\begin{array}{c}\text { Test } \\
\text { Temperature, }\end{array}$} & \multirow{2}{*}{\multicolumn{2}{|c|}{$\begin{array}{l}\text { Surface Flaw } \\
\text { Dimensions, }\end{array}$}} \\
\hline & & & & & $\mathbf{m m}$ & (inch) & C & & & \\
\hline 1 & $4112-1$ & TP316L & 405 & (15.95) & 9.80 & $(0.386)$ & 288 & $(550)$ & 0.511 & 0.658 \\
\hline 2 & $4112-2$ & TP304 & 167 & $(6.590)$ & 7.01 & $(0.276)$ & 288 & $(550)$ & 0.502 & 0.634 \\
\hline 3 & $4112-3$ & TP304 & 169 & $(6.636)$ & 13.6 & $(0.536)$ & 288 & $(550)$ & 0.518 & 0.659 \\
\hline 4 & $4112-4$ & TP304 & 168 & (6.627) & 22.5 & $(0.885)$ & 288 & $(550)$ & 0.442 & 0.653 \\
\hline 5 & $4112-5$ & A106 Gr. B & 169 & $(6.666)$ & 7.44 & $(0.293)$ & 288 & (550) & 0.508 & 0.631 \\
\hline 6 & $4112-6$ & A106 Gr. B & 167 & (6.594) & 14.8 & $(0.582)$ & 288 & (550) & 0.503 & 0.680 \\
\hline 7 & $4112-7$ & A106 Gr. B & 168 & $(6.621)$ & 21.5 & (0.845) & 288 & $(550)$ & 0.526 & 0.633 \\
\hline 8 & $4112-8$ & A106 Gr. B & 403 & $(15.85)$ & 26.4 & (1.04) & 288 & $(550)$ & 0.532 & 0.662 \\
\hline 9 & $4112-9$ & A106 Gr. B & 405 & $(15.95)$ & 12.7 & $(0.500)$ & 288 & (550) & 0.535 & 0.662 \\
\hline 10 & $4115-1$ & A333 Gr. 6 & 265 & $(10.44)$ & 17.3 & $(0.680)$ & 288 & (550) & 0.420 & 0.700 \\
\hline 11 & $4115-2$ & A333 Gr. 6 & 272 & $(10.71)$ & 17.1 & $(0.674)$ & 288 & (550) & 0.430 & 0.710 \\
\hline 12 & $4115-4$ & TP304 & 168 & $(6.627)$ & 14.9 & $(0.587)$ & 288 & $(550)$ & 0.520 & 0.490 \\
\hline 13 & $4115-5$ & TP304 & 168 & $(6.620)$ & 15.0 & $(0.590)$ & 288 & (550) & 0.415 & 0.600 \\
\hline 14 & $4115-7$ & TP304 & 168 & (6.614) & 13.9 & $(0.549)$ & 288 & (550) & 1.00 & 0.647 \\
\hline 15 & $4115-8$ & TP304 & 168 & $(6.612)$ & 14.0 & $(0.553)$ & 288 & $(550)$ & 1.00 & 0.626 \\
\hline 16 & $4115-9$ & TP304 & 168 & $(6.630)$ & 14.0 & $(0.551)$ & 288 & (550) & 1.00 & 0.655 \\
\hline 17 & $4131-6$ & TP304 & 159 & $(6.254)$ & 14.3 & $(0.563)$ & 288 & (550) & 0.535 & 0.690 \\
\hline 18 & $4131-8$ & A333 Gr. 6 & 271 & $(10.65)$ & 15.1 & $(0.593)$ & 288 & $(550)$ & 0.480 & 0.678 \\
\hline 19 & EPRI-13S & TP304 & 414 & (16.28) & 28.3 & (1.115) & 20 & (68) & 0.475 & 0.660 \\
\hline 20 & EPRI-2S & TP304 & 114 & (4.5) & 8.89 & $(0.350)$ & 20 & (68) & 0.500 & 0.380 \\
\hline 21 & EPRI-3S & TP304 & 114 & $(4.5)$ & 9.02 & $(0.355)$ & 20 & (68) & 0.500 & 0.594 \\
\hline 22 & EPRI-SS & TP304 & 114 & (4.5) & 8.53 & $(0.336)$ & 20 & (68) & 0.250 & 0.387 \\
\hline 23 & EPRI-6S & TP304 & 114 & (4.5) & 8.81 & $(0.347)$ & 20 & (68) & 0.250 & 0.608 \\
\hline 24 & EPRI-8S & TP304 & 114 & $(4.5)$ & 8.79 & $(0.346)$ & 20 & (68) & 0.750 & 0.413 \\
\hline 25 & EPRI-9S & TP304 & 114 & $(4.5)$ & 8.51 & $(0.335)$ & 20 & (68) & 0.750 & 0.645 \\
\hline 26 & EPRI-10S & TP304 & 114 & $(4.5)$ & 9.27 & $(0.365)$ & 20 & (68) & 0.500 & 0.575 \\
\hline $27^{(\mathrm{a})}$ & 1.2.1.21 & TP304 & 167 & $(6.560)$ & 20.9 & $(0.822)$ & 288 & $(550)$ & 0.218 & 0.500 \\
\hline $28^{(a)}$ & 1.2.1.22 & TP304 & 168 & $(6.627)$ & 7.06 & $(0.278)$ & 288 & (550) & 0.250 & 0.500 \\
\hline
\end{tabular}

(a) Experiments conducted during this program. 
Table 4.6 Tensile properties for pipe materials listed in Table 4.5

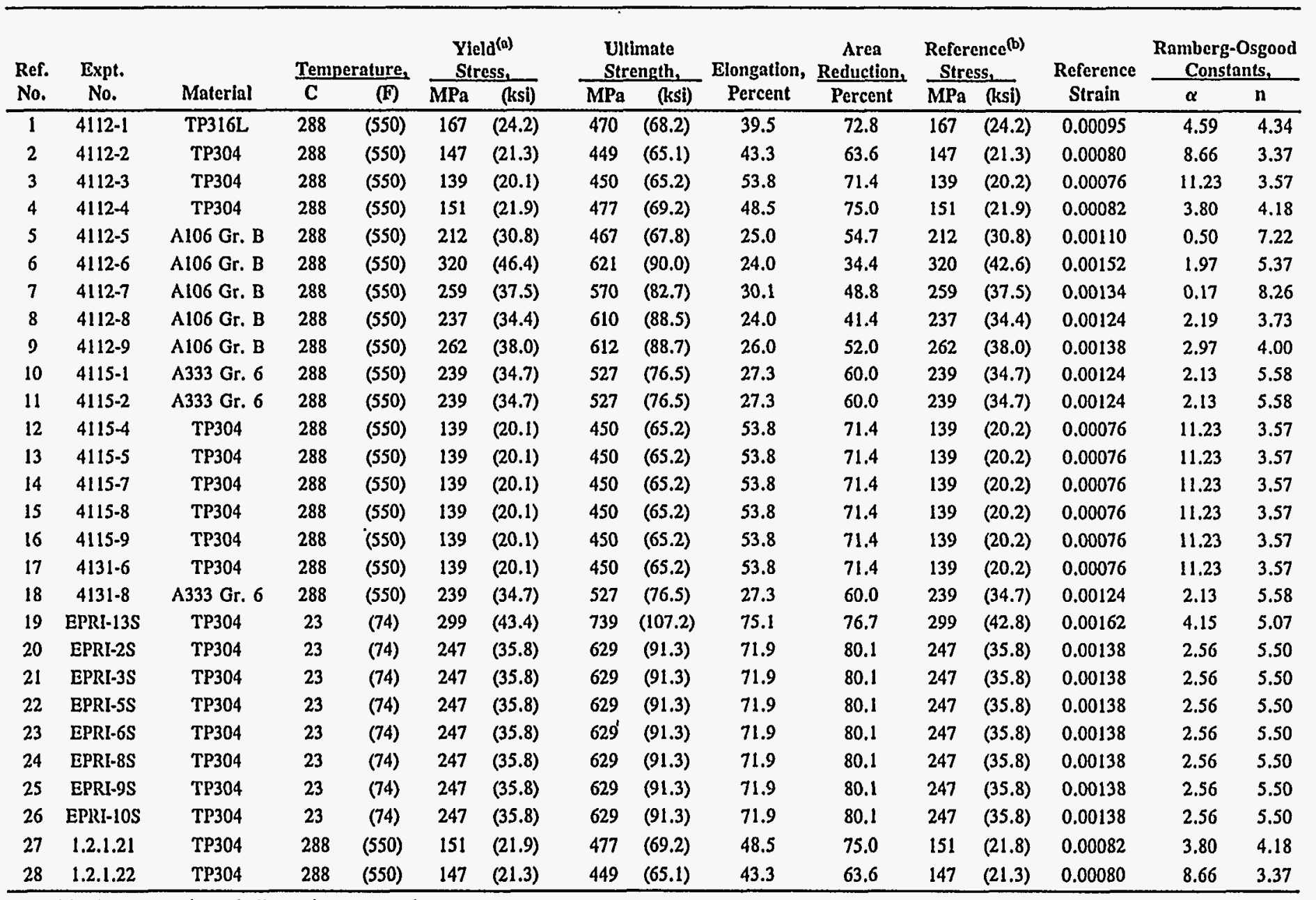

(a) Average value of all specimens tested.

(b) Values obtained by one specimen selected to represent the tensile behavior. 
Table 4.7 Fracture resistance properties for pipe materials listed in Table 4.5

\begin{tabular}{|c|c|c|c|c|c|c|c|c|c|c|c|}
\hline \multirow{3}{*}{$\begin{array}{l}\text { Ref. } \\
\text { No. }\end{array}$} & \multirow{3}{*}{$\begin{array}{l}\text { Expt. } \\
\text { No. }\end{array}$} & \multirow[b]{3}{*}{ Material } & \multirow{2}{*}{\multicolumn{2}{|c|}{ Temperature, }} & \multirow{2}{*}{\multicolumn{2}{|c|}{$\mathbf{J}_{\text {at }}$ Initiation, }} & \multirow{2}{*}{\multicolumn{2}{|c|}{ Slope of J-R Curve, }} & \multicolumn{3}{|c|}{$\begin{array}{c}\text { - Curve Fit Constants for J-R } \\
\text { Curve, }{ }^{(a)}\end{array}$} \\
\hline & & & & & & & & & \multicolumn{2}{|c|}{$\mathrm{C}_{12}$} & \multirow[t]{2}{*}{$\mathbf{m}$} \\
\hline & & & $\mathbf{C}$ & (F) & $\mathrm{MJ} / \mathrm{m}^{2}$ & (in-lbs/in') & $\mathrm{MJ} / \mathrm{m}^{3}$ & (in-lbs/in & $\mathrm{MJ} / \mathrm{m}^{2}$ & (in-lbs/in $\left.{ }^{2}\right)$ & \\
\hline 1 & $4112-1$ & TP316L & 288 & $(550)$ & 0.382 & $(2,180)$ & 236 & $(34,200)$ & 2.15 & $(12,280)$ & 0.717 \\
\hline 2 & $4112-2$ & TP304 & 288 & (550) & 0.873 & $(4,985)$ & 289 & $(41,940)$ & 5.25 & $(29,990)$ & 0.854 \\
\hline 3 & $4112-3$ & TP304 & 288 & (550) & 0.646 & $(3,687)$ & 242 & $(35,100)$ & 6.26 & $(35,730)$ & 0.982 \\
\hline 4 & $4112-4$ & TP304 & 288 & $(550)$ & 0.573 & $(3,270)$ & 439 & $(63,640)$ & 6.02 & $(34,353)$ & 0.809 \\
\hline 5 & $4112-5$ & A106 Gr. B & 288 & $(550)$ & 0.243 & $(1,388)$ & 161 & $(23,350)$ & 3.36 & $(19,202)$ & 0.988 \\
\hline 6 & $4112-6$ & A106 Gr. B & 288 & $(550)$ & 0.103 & $(588)$ & 107 & $(15,550)$ & 1.63 & $(9,308)$ & 0.814 \\
\hline 7 & $4112-7$ & A106 Gr. B & 288 & (550) & 0.180 & $(1,030)$ & 142 & $(20,600)$ & 1.05 & $(5,998)$ & 0.788 \\
\hline 8 & $4112-8$ & A106 Gr. B & 288 & (550) & 0.149 & $(850)$ & 89 & $(12,910)$ & 0.42 & $(2,417)$ & 0.470 \\
\hline 9 & $4112-9$ & A106 Gr. B & 288 & $(550)$ & 0.138 & (786) & 83 & $(12,100)$ & 0.77 & $(4,393)$ & 0.602 \\
\hline 10 & $4115-1$ & A333 Gr. 6 & 288 & $(550)$ & 0.158 & $(900)$ & 132 & $(19,180)$ & 0.67 & $(3,826)$ & 0.492 \\
\hline 11 & $4115-2$ & A333 Gr. 6 & 288 & $(550)$ & 0.158 & $(900)$ & 132 & $(19,180)$ & 0.67 & $(3,826)$ & 0.492 \\
\hline 12 & $4115-4$ & TP304 & 288 & (550) & 0.646 & $(3,687)$ & 242 & $(35,100)$ & 6.26 & $(35,730)$ & 0.982 \\
\hline 13 & $4115-5$ & TP304 & 288 & $(550)$ & 0.646 & $(3,687)$ & 242 & $(35,100)$ & 6.26 & $(35,730)$ & 0.982 \\
\hline 14 & $4115-7$ & TP304 & 288 & $(550)$ & 0.646 & $(3,687)$ & 242 & $(35,100)$ & 6.26 & $(35,730)$ & 0.982 \\
\hline 15 & $4115-8$ & TP304 & 288 & $(550)$ & 0.646 & $(3,687)$ & 242 & $(35,100)$ & 6.26 & $(35,730)$ & 0.982 \\
\hline 16 & $4115-9$ & TP304 & 288 & (550) & 0.646 & $(3,687)$ & 242 & $(35,100)$ & 6.26 & $(35,730)$ & 0.982 \\
\hline 17 & $4131-6$ & TP304 & 288 & $(550)$ & 0.646 & $(3,687)$ & 242 & $(35,100)$ & 6.26 & $(35,730)$ & 0.982 \\
\hline 18 & $4131-8$ & A333 Gr. 6 & 288 & $(550)$ & 0.158 & $(900)$ & 132 & $(19,180)$ & 0.67 & $(3,826)$ & 0.492 \\
\hline 19 & EPRI-13S & TP304 & 23 & (74) & 2.277 & $(13,000)$ & 896 & $(130,000)$ & 6.55 & $(37,430)$ & 0.502 \\
\hline 20 & EPRI-2S & TP304 & 23 & (74) & 1.769 & $(10,100)$ & 427 & $(62,000)$ & 2.74 & $(15,640)$ & 0.642 \\
\hline 21 & EPRI-3S & TP304 & 23 & (74) & 1.769 & $(10,100)$ & 427 & $(62,000)$ & 2.74 & $(15,640)$ & 0.642 \\
\hline 22 & EPRI-5S & TP304 & 23 & (74) & 1.769 & $(10,100)$ & 427 & $(62,000)$ & 2.74 & $(15,640)$ & 0.642 \\
\hline 23 & EPRI-6S & TP304 & 23 & (74) & 1.769 & $(10,100)$ & 427 & $(62,000)$ & 2.74 & $(15,640)$ & 0.642 \\
\hline 24 & EPRI-8S & TP304 & 23 & (74) & 1.769 & $(10,100)$ & 427 & $(62,000)$ & 2.74 & $(15,640)$ & 0.642 \\
\hline 25 & EPRI-9S & TP304 & 23 & (74) & 1.769 & $(10,100)$ & 427 & $(62,000)$ & 2.74 & $(15,640)$ & 0.642 \\
\hline 26 & EPRI-10S & TP304 & 23 & $(74)$ & 1.769 & $(10,100)$ & 427 & $(62,000)$ & 2.74 & $(15,640)$ & 0.642 \\
\hline 27 & 1.2.1.21 & TP304 & 288 & $(550)$ & 0.573 & $(3,270)$ & 439 & $(63,640)$ & 6.02 & $(34,353)$ & 0.809 \\
\hline 28 & 1.2.1.22 & TP304 & 288 & $(550)$ & 0.873 & $(4,985)$ & 289 & $(41,940)$ & 5.25 & $(29,990)$ & 0.854 \\
\hline
\end{tabular}

(a) $\mathrm{J}=\mathrm{J}_{\mathrm{i}}+\mathrm{C}_{1}\left[\frac{\Delta \mathrm{a}}{\Delta \mathrm{a}_{\mathrm{o}}}\right]^{\mathrm{m}}$ where $\Delta \mathrm{a}_{\mathrm{o}}=1$ inch if $\mathrm{J}$ and $\Delta \mathrm{a}$ are in in-lbs/in ${ }^{2}$ and inches, respectively, and $\Delta \mathrm{a}_{\mathrm{o}}=1 \mathrm{~m}$ if $\mathrm{J}$ and $\Delta \mathrm{a}$ are in $\mathrm{MJ} / \mathrm{m}^{2}$ and $\mathrm{m}$, respectively. 
Table 4.8 Comparison of NSC predictions with experimental data -- pure bending load cases

\begin{tabular}{|c|c|c|c|c|c|c|c|c|}
\hline \multirow{2}{*}{$\begin{array}{l}\text { Ref. } \\
\text { No. }\end{array}$} & \multirow{2}{*}{$\begin{array}{l}\text { Expt. } \\
\text { No. }\end{array}$} & \multicolumn{2}{|c|}{$\begin{array}{c}\text { Experimental } \\
\text { Maximum } \\
\text { Moment, }\end{array}$} & \multicolumn{2}{|c|}{$\begin{array}{c}\mathrm{M}_{\mathrm{nse}} \\
\text { Original }^{(a)} \text {, }\end{array}$} & \multicolumn{3}{|c|}{$\begin{array}{l}\text { Experiment Maximum Moment/ } \\
\text { Predicted NSC Moment, }\end{array}$} \\
\hline & & $k N-m$ & (in-kips) & $\mathrm{kN}-\mathrm{m}$ & (in-kips) & (Original) $^{(2)}$ & (Battelle) $^{(\mathbf{b})}$ & (Kurihara) $^{(c)}$ \\
\hline 1 & $4112-1$ & 230 & $(2,038)$ & 261 & $(2,311)$ & 0.88 & 1.01 & 1.07 \\
\hline 2 & $4112-2$ & 29.5 & (261.2) & 30.1 & (266.5) & 0.98 & 0.94 & 1.17 \\
\hline 3 & $4112-3$ & 59.6 & (527.3) & 51.0 & (451.4) & 1.17 & 1.02 & 1.41 \\
\hline 4 & $41 \cdot 12-4$ & 101 & (892.8) & 86.8 & (768.1) & 1.16 & 0.97 & 1.45 \\
\hline 5 & $4112-5$ & 38.0 & $(336.2)$ & 37.1 & (328.8) & 1.02 & 0.98 & 1.21 \\
\hline 6 & $4112-6$ & 80.1 & (708.6) & 84.1 & (744.8) & 0.95 & 0.82 & 1.18 \\
\hline 7 & $4112-7$ & 117 & $(1,039)$ & 105 & (933.3) & 1.11 & 0.93 & 1.31 \\
\hline 8 & $4112-8$ & 748 & $(6,623)$ & 826 & $(7,310)$ & 0.91 & 0.81 & 1.09 \\
\hline 9 & $4112-9$ & 366 & $(3,235)$ & 444 & $(3 ; 928)$ & 0.82 & 0.86 & 0.99 \\
\hline 10 & $4115-1$ & 221 & $(1,956)$ & 226 & $(2,003)$ & 0.98 & 0.87 & 1.30 \\
\hline 11 & $4115-2$ & 236 & $(2,073)$ & 231 & $(2,041)$ & 1.02 & 0.91 & 1.36 \\
\hline 12 & $4115-4$ & 71.4 & $(631.9)$ & 69.8 & (617.8) & 1.02 & 0.88 & 1.12 \\
\hline 13 & $4115-5$ & 65.0 & (575.3) & 65.7 & (581.1) & 0.99 & 0.85 & 1.19 \\
\hline 14 & $4115-7$ & 65.2 & (577.3) & 51.2 & (453.5) & 1.27 & 1.11 & 1.41 \\
\hline 15 & $4115-8$ & 60.3 & $(533.4)$ & 54.2 & $(479.9)$ & 1.11 & 0.97 & 1.23 \\
\hline 16 & $4115-9$ & 63.5 & $(561.8)$ & 50.6 & (447.9) & 1.25 & 1.09 & 1.39 \\
\hline 17 & $4131-6$ & 55.3 & (489.5) & 43.4 & (383.9) & 1.28 & 1.10 & 1.57 \\
\hline 18 & $4131-8$ & 195 & $(1,727)$ & 201 & $(1,782)$ & 0.97 & 0.89 & 1.21 \\
\hline 19 & EPRI-13S & 1260 & $(11,156)$ & 1204 & $(10,660)$ & 1.05 & 0.93 & 1.29 \\
\hline 20 & EPRI-2S & 41.1 & $(363.5)$ & 33.1 & (293.4) & 1.24 & 1.08 & 1.31 \\
\hline 21 & EPRI-3S & 33.0 & (292.1) & 26.1 & $(231.1)$ & 1.26 & 1.10 & 1.47 \\
\hline 22 & EPRI-5S & 37.7 & (333.9) & 35.6 & $(315.3)$ & 1.06 & 0.93 & 1.15 \\
\hline 23 & EPRI-6S & 33.6 & $(297.0)$ & 32.5 & (287.8) & 1.03 & 0.90 & 1.32 \\
\hline 24 & EPRI-8S & 37.5 & (331.7) & 31.6 & $(280.0)$ & 1.19 & 1.04 & 1.25 \\
\hline 25 & EPRI-9S & 30.3 & (267.9) & 20.7 & (183.5) & 1.46 & 1.28 & 1.62 \\
\hline 26 & EPRI-10S & 32.3 & $(286.0)$ & 27.4 & (242.8) & 1.18 & 1.03 & 1.35 \\
\hline 27 & 1.2.1.21 & 154 & $(1,365)$ & 115 & $(1020)$ & 1.34 & 1.12 & 1.56 \\
\hline \multirow[t]{3}{*}{28} & 1.2.1.22 & 44.3 & $(392.3)$ & 44.0 & (389.2) & 1.01 & 0.97 & 1.17 \\
\hline & & & & & Average & 1.10 & 0.98 & 1.29 \\
\hline & & & & & Std.Dev. & 0.15 & 0.11 & 0.15 \\
\hline
\end{tabular}

(a) Original NSC criterion, Equation 4.1. Also called the limit moment.

(b) Battelle's modification to NSC, see Section 4.2.5.

(c) Kurihara's modification to NSC, see Section 4.1.1.1. 
Table 4.9 Comparison of experimental crack initiation moments with analytical analyses predictions - pure bending load cases

\begin{tabular}{|c|c|c|c|c|c|c|c|c|c|c|}
\hline \multirow{2}{*}{$\begin{array}{l}\text { Ref. } \\
\text { No. }\end{array}$} & \multirow{2}{*}{$\begin{array}{c}\text { Expt. } \\
\text { No. }\end{array}$} & \multicolumn{2}{|c|}{$\begin{array}{l}\text { Experimental } \\
\text { Moment at } \\
\text { Initiation, }\end{array}$} & \multicolumn{7}{|c|}{ Experimental Initiation Moment/Predicted Moment, } \\
\hline & & kN-m & (in-kips) & SC.TNP1 & SC.TNP2 & SC.TKP1 & SC.TKP2 & SC.ENG1 & SC.ENG2 & R-6 \\
\hline 1 & $4112-1^{(2)}$ & 201 & $(1,782)$ & 0.77 & 1.00 & 1.34 & 1.18 & 0.92 & 1.08 & 0.98 \\
\hline 2 & $4112-2$ & 25.4 & $(225.0)$ & 0.65 & 0.81 & 1.02 & 0.87 & 0.76 & 0.88 & 0.86 \\
\hline 3 & $4112-3$ & 56.5 & $(500.3)$ & 1.13 & 1.42 & 1.92 & 1.65 & 1.40 & 1.62 & 1.36 \\
\hline 4 & $4112-4^{(b)}$ & 99.1 & (877.3) & 1.19 & 1.54 & 0.54 & 0.48 & 1.36 & 1.64 & 1.61 \\
\hline 5 & $4112-5$ & 24.1 & (213.1) & 0.51 & 0.65 & 0.78 & 0.71 & 0.60 & 0.71 & 0.77 \\
\hline 6 & $4112-6$ & 67.9 & $(601.1)$ & 0.87 & 1.13 & 1.30 & 1.17 & 1.12 & 1.33 & 1.18 \\
\hline 7 & $4112-7^{(b)}$ & 98.2 & $(869.3)$ & 0.84 & 1.06 & 0.49 & 0.45 & 1.02 & 1.18 & 1.37 \\
\hline 8 & $4112-8$ & 689 & $(6,103)$ & 1.00 & 1.28 & 1.57 & 1.35 & 1.33 & 1.51 & 1.42 \\
\hline 9 & $4112-9$ & 301 & $(2,661)$ & 0.76 & 0.98 & 1.22 & 1.06 & 0.96 & 1.11 & 1.02 \\
\hline 10 & $4115-1$ & 205 & $(1,815)$ & 1.00 & 1.31 & 1.36 & 1.22 & 1.23 & 1.58 & 1.34 \\
\hline 11 & $4115-2$ & 203 & $(1,793)$ & 0.96 & 1.26 & 1.34 & 1.20 & 1.19 & 1.54 & 1.29 \\
\hline 12 & $4115-4$ & $N A^{(c)}$ & NA & NA & NA & $\mathrm{NA}$ & NA & NA & NA & NA \\
\hline 13 & $4115-5$ & $\mathrm{NA}$ & NA & NA & NA & NA & NA & NA & NA & $\mathrm{NA}$ \\
\hline 14 & $4115-7$ & 60.6 & (536.2) & 1.18 & 1.49 & 2.05 & 1.77 & 1.65 & 1.80 & 1.50 \\
\hline 15 & $4115-8$ & 59.1 & (523.4) & 1.12 & 1.41 & 1.89 & 1.63 & 1.52 & 1.66 & 1.39 \\
\hline 16 & $4115-9$ & 55.9 & $(495.0)$ & 1.10 & 1.39 & 1.92 & 1.66 & 1.55 & 1.69 & 1.40 \\
\hline 17 & $4131-6$ & 54.4 & $(481.2)$ & 1.25 & 1.59 & 1.91 & 1.64 & 1.62 & 1.90 & 1.54 \\
\hline 18 & $4131-8$ & 181 & $(1,606)$ & 0.95 & 1.24 & 1.44 & 1.29 & 1.18 & 1.44 & 1.29 \\
\hline 19 & EPRI-13S & 970 & $(8,587)$ & 0.78 & 1.02 & 1.13 & 1.00 & 0.94 & 1.13 & 1.03 \\
\hline 20 & EPRI-2S & 40.7 & $(360.4)$ & 1.02 & 1.20 & 1.21 & 1.11 & 1.00 & 1.05 & 1.11 \\
\hline 21 & EPRY-3S & 32.1 & (283.9) & 0.96 & 1.25 & 1.42 & 1.27 & 1.12 & 1.29 & 1.19 \\
\hline 22 & EPRI-5S & 37.2 & (329.7) & 0.90 & 1.06 & 0.92 & 0.84 & 0.83 & 0.91 & 0.95 \\
\hline 23 & EPRI-6S & 32.4 & (286.8) & 0.84 & 1.09 & 0.93 & 0.84 & 0.90 & 1.14 & 1.02 \\
\hline 24 & EPRI-8S & 37.1 & (328.2) & 0.96 & 1.16 & 1.19 & 1.09 & 1.00 & 1.06 & 1.09 \\
\hline 25 & EPRI-9S & 29.8 & (264.1) & 1.01 & 1.31 & 1.58 & 1.41 & 1.36 & 1.50 & 1.38 \\
\hline 26 & EPRI-10S & 31.1 & (275.1) & 0.90 & 1.16 & 1.33 & 1.20 & 1.03 & 1.17 & 1.11 \\
\hline 27 & $1.2 .1 .21^{(\mathrm{b})}$ & 154 & $(1,362)$ & 1.42 & 1.75 & 0.59 & 0.52 & 1.43 & 1.65 & 1.81 \\
\hline \multirow[t]{3}{*}{28} & 1.2.1.22 & 36.8 & (325.3) & 0.70 & 0.84 & 0.77 & 0.67 & 0.69 & 0.79 & 0.84 \\
\hline & & & Average $^{(d)}$ & 0.93 & 1.18 & 1.37 & 1.21 & 1.14 & 1.32 & 1.23 \\
\hline & & & Std. Dev. (d) & 0.18 & 0.22 & 0.38 & 0.31 & 0.28 & 0.32 & 0.25 \\
\hline
\end{tabular}

(a) $\mathrm{R}_{\mathrm{i}} / t>20$.

(b) $\mathrm{R}_{\mathrm{i}} / \mathrm{t}<5$.

(c) NA - not available.

(d) The average and standard deviations for the SC.TNP and SC.TKP analyses are calculated for those experiments for which the $R_{\mathrm{i}} / t$ ratios are between 5 and 20 which is the region where $H$ - and $G_{N}$-functions are tabulated in the SC.TNP and SC.TKP analyses, respectively. 


\subsubsection{Predictions of the Bending Moment at Crack Initiation}

Seven of the methods listed in Section 4.4.1 can be used to predict the moments at which the cracks initiate in the pipe experiments. These include the two SC.TNP and the two SC.TKP methods, the two SC.ENG methods, and the R6 approach. The ratios of the moments at crack initiation to the values predicted using the various analysis methods are listed in Table 4.9. The average value of this ratio indicates that each of the methods, with the exception of the SC.TNP1 method, underpredicted the moments at crack initiation. Of these methods, the SC.TNP1 method was the most accurate with the lowest standard deviation, but slightly overpredicted initiation loads on the average. The SC.ENG1 method was the next most accurate method that underpredicts crack initiation loads on the average. The predictions using the R6 method, with its built in safety factors, was actually much closer to the experimental results than expected.

\subsubsection{Maximum Bending Moment Predictions}

In addition to the seven methods used to predict the moments at crack initiation, the ASME Section $\mathrm{XI}$ approaches as well as the DPZP method can be used to predict the maximum load-carrying capacity of the cracked pipes. The ratios of the experimental to the analytical predictions for the various analysis methods are presented in Table 4.10 along with the average values and standard deviations for all the methods. The ASME Section XI Appendix C method was used to analyze austenitic pipe experiments, while the Appendix $\mathrm{H}$ method was used for the ferritic pipe experiments.

As can be seen, the average results of all of the methods underpredicted the experimental maximum loads. As indicated by the average values, the two methods with the predictions closest to the experimental data are the SC.TNP1 method and the DPZP criterion with values of 1.02 and 1.18 , respectively. The improved J-estimation schemes SC.TNP2 and SC.TKP2, as well as the SC.ENG methods were found to underpredict the experimental data significantly. Reasons for this are discussed later. The ASME Appendix $C$ results for austenitic pipe (without safety factors) were relatively accurate, whereas the ASME Appendix $\mathrm{H}$ results for ferritic pipe significantly underpredicted the maximum loads. The ASME Code Case N-494-2 results for ferritic pipe were more accurate than the Appendix $H$ criteria.

\subsubsection{Load-Displacement Curves - Analysis and Experiments}

The load versus the pipe displacement at the load points for the two pure bending experiments conducted during this program (Experiments 1.2.1.21 and 1.2.1.22) are given in Figures 4.48 and 4.49 , respectively, along with the analytical predictions of the moment-rotation behavior. As seen, the elastic as well as the initial nonlinear portion of the plastic curve are predicted reasonably well by the estimation schemes. Beyond the "knee" in the load-displacement curves, all analysis methods predicted loads exceeding the experimental loads for a given displacement for Experiment 1.2.1.21 and predicted loads less than the experimental loads for a given displacement for Experiment 1.2.1.22. 


\begin{tabular}{|c|c|c|c|c|c|c|c|c|c|c|c|c|c|c|}
\hline \multirow{3}{*}{$\begin{array}{l}\text { Ref. } \\
\text { No. }\end{array}$} & \multirow{3}{*}{$\begin{array}{l}\text { Expt. } \\
\text { No. }\end{array}$} & \multirow{2}{*}{\multicolumn{2}{|c|}{$\begin{array}{c}\text { Experimental Maximum } \\
\text { Moment, }\end{array}$}} & \multicolumn{11}{|c|}{ Experimental Maximum Moment/Predlcted Maximum Moment, } \\
\hline & & & & \multirow[b]{2}{*}{ SC.TNP1 } & \multirow[b]{2}{*}{ SC.TNP2 } & \multirow[b]{2}{*}{ SC.TKPI } & \multirow[b]{2}{*}{ SC.TKP2 } & \multirow[b]{2}{*}{ SC.ENG1 } & \multirow[b]{2}{*}{ SC.ENG2 } & \multirow[b]{2}{*}{ R-6 } & \multirow{2}{*}{$\begin{array}{l}\text { Sec XI } \\
\text { App C }\end{array}$} & \multirow{2}{*}{$\begin{array}{l}\text { Sec XI } \\
\text { App H }\end{array}$} & \multirow{2}{*}{$\begin{array}{c}\text { Sec XI } \\
\text { Code Case } \\
\text { N-494-2. }\end{array}$} & \multirow[b]{2}{*}{ DPZP } \\
\hline & & kN-m & (in-kdps) & & & & & & & & & & & \\
\hline 1 & $4112-1^{(a)}$ & 230 & $(2,038)$ & 0.88 & 1.14 & 1.54 & 1.34 & 1.05 & 1.23 & 1.12 & 1.00 & N.A. ${ }^{(b)}$ & N.A. & 0.90 \\
\hline 2 & $4112-2$ & 29.5 & (261.2) & 0.75 & 0.94 & 1.18 & 1.01 & 0.89 & 1.02 & 0.99 & 0.87 & N.A. & N.A. & 1.02 \\
\hline 3 & $4112-3$ & 59.6 & $(527.3)$ & 1.19 & 1.49 & 2.02 & 1.74 & 1.48 & 1.71 & 1.43 & 1.06 & N.A. & N.A. & 1.26 \\
\hline 4 & $4112-4^{(c)}$ & 100.9 & (892.8) & 1.14 & 1.49 & 0.55 & 0.48 & 1.37 & 1.67 & 1.57 & 1.17 & N.A. & N.A & 1.31 \\
\hline 5 & $4112-5$ & 38.0 & $(336.2)$ & 0.80 & 1.03 & 1.23 & 1.13 & 0.95 & 1.12 & 1.22 & N.A. & 1.53 & 1.12 & 1.07 \\
\hline 6 & $4112-6$ & 80.1 & (708.6) & 1.02 & 1.33 & 1.54 & 1.37 & 1.32 & 1.57 & 1.39 & N.A. & 2.03 & 1.48 & 1.04 \\
\hline 7 & $4112-7(c)$ & 117 & $(1,039)$ & 1.00 & 1.27 & 0.58 & 0.54 & 1.22 & 1.42 & 1.64 & N.A. & 2.10 & 1.80 & 1.25 \\
\hline 8 & $4112-8$ & 748 & $(6,623)$ & 1.03 & 1.33 & 1.70 & 1.46 & 1.40 & 1.63 & 1.55 & N.A. & 1.85 & 1.58 & 1.01 \\
\hline 9 & $4112-9$ & 366 & $(3,235)$ & 0.91 & 1.18 & 1.48 & 1.28 & 1.17 & 1.34 & 1.24 & N.A. & 1.92 & 1.23 & 0.91 \\
\hline 10 & $4115-1$ & 221 & $(1,956)$ & 1.06 & 1.39 & 1.47 & 1.32 & 1.32 & 1.70 & 1.44 & N.A. & 1.79 & 1.41 & 1.04 \\
\hline 11 & $4115-2$ & 236 & $(2,073)$ & 1.10 & 1.44 & 1.55 & 1.39 & 1.37 & 1.78 & 1.50 & N.A. & 1.87 & 1.45 & 1.08 \\
\hline 12 & $4115-4$ & 71.4 & (631.9) & 1.10 & 1.33 & 1.39 & 1.22 & 1.21 & 1.30 & 1.23 & 0.93 & N.A. & N.A. & 1.11 \\
\hline 13 & $4115-5$ & 65.0 & (575.3) & 1.10 & 1.40 & 1.38 & 1.19 & 1.24 & 1.45 & 1.26 & 0.90 & N.A. & N.A. & 1.08 \\
\hline 14 & $4115-7$ & 65.0 & $(577.3)$ & 1.27 & 1.61 & 2.21 & 1.90 & 1.78 & 1.94 & 1.61 & 1.23 & N.A. & N.A. & 1.38 \\
\hline 15 & $4115-8$ & 60.3 & (533.4) & 1.14 & 1.44 & 1.92 & 1.66 & 1.55 & 1.69 & 1.42 & 1.08 & N.A. & N.A. & 1.20 \\
\hline 16 & $4115-9$ & 63.5 & $(561.8)$ & 1.24 & 1.57 & 2.18 & 1.88 & 1.75 & 1.92 & 1.58 & 1.21 & N.A. & N.A. & 1.36 \\
\hline 17 & 4131.6 & 55.3 & (489.5) & 1.27 & 1.62 & 1.95 & 1.67 & 1.64 & 1.93 & 1.57 & 1.16 & N.A. & N.A. & 1.39 \\
\hline 18 & $4131-8$ & 195 & $(1,727)$ & 1.02 & 1.33 & 1.54 & 1.38 & 1.27 & 1.55 & 1.39 & N.A. & 1.78 & 1.35 & 1.03 \\
\hline 19 & EPRI-13S & 1,260 & $(11,156)$ & 0.99 & 1.29 & 1.46 & 1.30 & 1.21 & 1.47 & 1.29 & 1.40 & N.A. & N.A. & 1.12 \\
\hline 20 & EPRI-2S & 41.1 & (363.5) & 1.03 & 1.21 & 1.22 & 1.12 & 1.01 & 1.06 & 1.12 & 1.41 & N.A. & N.A. & 1.33 \\
\hline 21 & EPRI-3S & 33.0 & $(292.1)$ & 1.00 & 1.29 & 1.46 & 1.31 & 1.16 & 1.33 & 1.23 & 1.44 & N.A. & N.A. & 1.36 \\
\hline 22 & EPRI-5S & 37.7 & (333.9) & 0.91 & 1.08 & 0.93 & 0.85 & 0.84 & 0.92 & 0.96 & 1.20 & N.A. & N.A. & 1.14 \\
\hline 23 & EPRI-6S & 33.6 & (297.0) & 0.87 & 1.12 & 0.97 & 0.87 & 0.93 & 1.19 & 1.06 & 1.18 & N.A. & N.A. & 1.11 \\
\hline 24 & EPRI-8S & 37.5 & (331.7) & 0.97 & 1.17 & 1.21 & 1.10 & 1.01 & 1.07 & 1.10 & 1.37 & N.A. & N.A. & 1.27 \\
\hline 25 & EPRI-OS & 30.3 & $(267.9)$ & 1.02 & 1.33 & 1.60 & 1.43 & 1.38 & 1.52 & 1.40 & 1.66 & N.A. & N.A. & 1.57 \\
\hline 26 & EPRI-10S & 32.3 & $(286.0)$ & 0.94 & 1.20 & 1.38 & 1.24 & 1.07 & 1.22 & 1.15 & 1.35 & N.A. & N.A. & 1.27 \\
\hline 27 & $1.2 .1 .21^{(\mathrm{c})}$ & 154 & $(1,365)$ & 1.24 & 1.62 & 0.54 & 0.47 & 1.37 & 1.64 & 1.70 & 1.30 & N.A. & N.A. & 1.50 \\
\hline \multirow[t]{3}{*}{28} & 1.2.1.22 & 44.3 & (392.3) & 0.82 & 0.99 & 0.90 & 0.78 & 0.81 & 0.93 & 0.99 & 0.87 & N.A. & N.A. & 1.02 \\
\hline & & & Average $^{(d)}$ & 1.02 & 1.30 & 1.49 & 1.32 & 1.24 & 1.44 & 1.33 & 1.19 & 1.87 & 1.43 & 1.18 \\
\hline & & & Std. Dev. ${ }^{(d)}$ & 0.14 & 0.18 & 0.36 & 0.29 & 0.25 & 0.30 & 0.21 & 0.21 & 0.16 & 0.20 & 0.17 \\
\hline
\end{tabular}

(a) $\mathrm{R}_{\mathrm{i}} / \mathrm{t}>20$.

(b) N.A. - Not applicable.

(c) $\mathrm{B}_{\mathrm{i}} / \mathrm{t}<5$.

(d) The average and standard deviations for the SC.TNP and SC.TKP analyses are calculated for those experiments for which the $R_{i} / t$ ratios are between 5 and 20 which is the region where the $H$ - and $G_{N}$-functions are tabulated in the SC.TNP and SC.TKP analyses, respectively. 
Table 4.11 List of surface-cracked-pipe experiments analyzed - combined bending and pressure load cases

\begin{tabular}{|c|c|c|c|c|c|c|c|c|c|c|c|c|}
\hline $\begin{array}{l}\text { Rcr. } .^{(a)} \\
\text { No. }\end{array}$ & $\begin{array}{l}\text { Expt. } \\
\text { No. }\end{array}$ & Material & \multicolumn{2}{|c|}{$\begin{array}{l}\text { Outcr Pipe } \\
\text { Diameter, }\end{array}$} & \multicolumn{2}{|c|}{$\begin{array}{l}\text { Pipe Wall } \\
\text { Thickness, }\end{array}$} & \multicolumn{2}{|c|}{$\begin{array}{l}\text { Pipe Intcrnal } \\
\text { Pressure, }\end{array}$} & \multicolumn{2}{|c|}{$\begin{array}{c}\text { Test } \\
\text { Temperature, } \\
\text { C }\end{array}$} & \multicolumn{2}{|c|}{$\begin{array}{l}\text { Surface Flaw } \\
\text { Dimensions, } \\
\theta / \pi \quad \mathrm{a} / \mathrm{t}\end{array}$} \\
\hline 29 & $4131-2$ & TP304 & 168 & $(6.627)$ & 13.4 & $(0.529)$ & 24.5 & $(3.550)$ & 288 & (550) & 0.521 & 0.709 \\
\hline 30 & $4131-4$ & A333 Gr. 6 & 273 & $(10.74)$ & 16.6 & $(0.654)$ & 18.3 & $(2,650)$ & 288 & (550) & 0.525 & 0.659 \\
\hline 31 & $4141-2$ & TP304 SAW & 167 & (6.582) & 14.8 & $(0.584)$ & 15.2 & $(2,200)$ & 288 & (550) & 0.500 & 0.642 \\
\hline 32 & $4141-4$ & TP304 SAW & 414 & (16.28) & 26.2 & (1.031) & 11.0 & $(1,600)$ & 288 & $(550)$ & 0.500 & 0.670 \\
\hline 33 & 4141.6 & TP304 SAW & 416 & $(16.39)$ & 26.4 & $(1.040)$ & 11.0 & $(1,600)$ & 288 & $(550)$ & 0.500 & 0.686 \\
\hline 34 & $4141-8$ & A106B SAW & 403 & $(15.87)$ & 25.4 & $(0.999)$ & 15.5 & $(2,250)$ & 288 & $(550)$ & 0.500 & 0.670 \\
\hline 39 & $4143-2$ & Aged CF8M & 325 & $(12.80)$ & 31.1 & $(1.225)$ & 15.5 & $(2,250)$ & 288 & $(550)$ & 0.500 & 0.653 \\
\hline 40 & $4143-1$ & Aged CF8M & 400 & $(15.73)$ & 26.4 & $(1.037)$ & 15.5 & $(2,250)$ & 288 & $(550)$ & 0.500 & 0.550 \\
\hline 41 & $4143-3$ & Aged CFBM Weld & 322 & $(12.66)$ & 29.6 & $(1.167)$ & 15.5 & $(2,250)$ & 288 & $(550)$ & 0.580 & 0.660 \\
\hline 42 & 1.1 .7 & A106 Gr. B & 168 & $(6.594)$ & 13.5 & $(0.531)$ & 15.5 & $(2.250)$ & 288 & (550) & 0.432 & 0.647 \\
\hline 43 & 1.1 .9 & A106 Gr. B & 167 & $(6.589)$ & 14.0 & $(0.552)$ & 15.5 & $(2,250)$ & 288 & $(550)$ & 0.419 & 0.720 \\
\hline 44 & $4.3-2$ & STS-49 & 765 & $(30.12)$ & 39.0 & $(1.535)$ & 9.10 & $(1,320)$ & 300 & (572) & 0.166 & 0.498 \\
\hline 45 & $1.2 .1 .20^{(\mathrm{b})}$ & TP304 & 406 & $(16.01)$ & 9.50 & $(0.374)$ & 1.55 & (225) & 93 & (200) & 0.250 & 0.476 \\
\hline 46 & $1.2 .3 .15^{(b)}$ & As16 Gr. 60 & 711 & $(28.0)$ & 22.7 & $(0.893)$ & 9.56 & $(1,387)$ & 288 & $(550)$ & 0.250 & 0.500 \\
\hline 47 & $1.2 .3 .16^{(b)}$ & TP316L SAW & 711 & $(28.0)$ & 30.2 & $(1.190)$ & 10.1 & $(1,470)$ & 288 & $(550)$ & 0.250 & 0.500 \\
\hline 48 & $1.2 .3 .17^{(b)}$ & A106 Gr. B SAW & 610 & $(24.0)$ & 42.7 & $(1.680)$ & 15.5 & $(2,250)$ & 288 & $(550)$ & 0.250 & 0.605 \\
\hline
\end{tabular}

(a) Experiments with Reference Numbers 35-38 involved weld overlay repairs and were excluded from the analyses in tlis table.

(b) Experinients conducted during this program. 


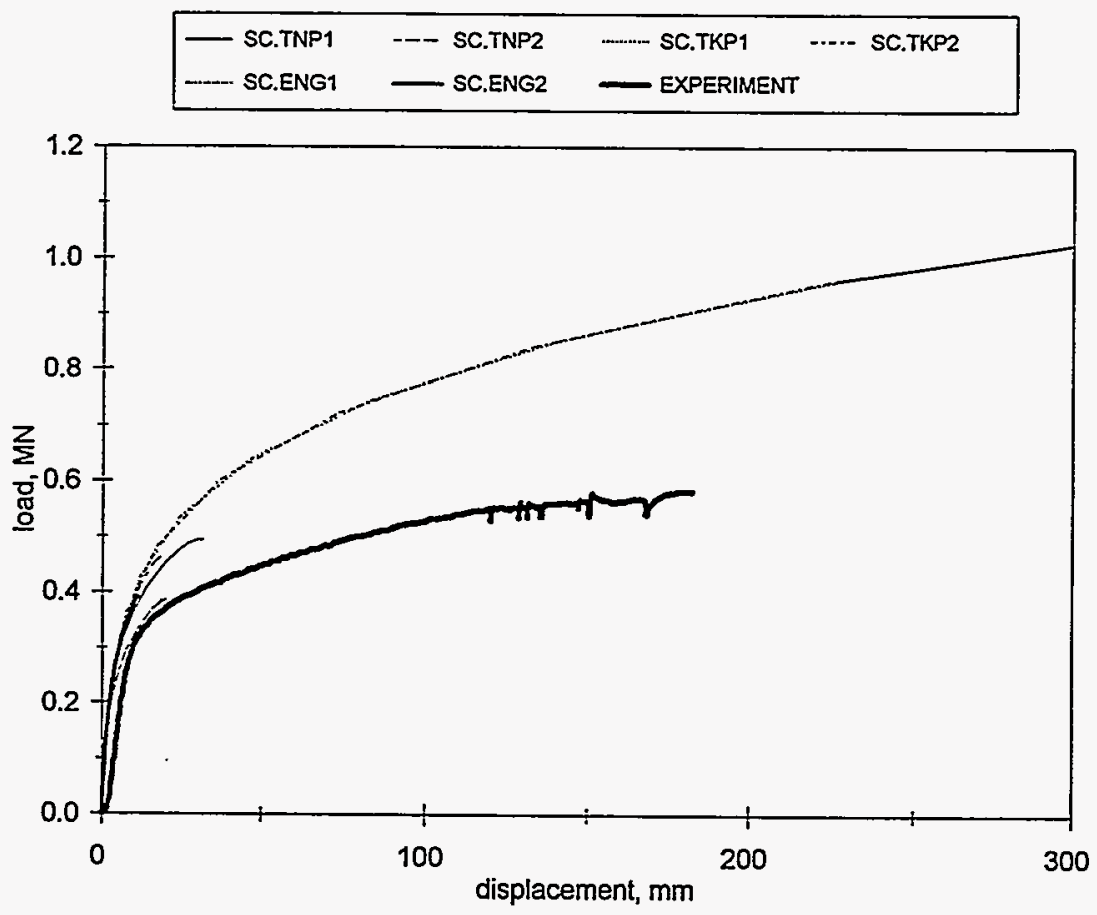

Figure 4.48 Load versus pipe displacement at the load point (excludes displacements from test machine compliance) for Experiment 1.2.1.21 - analytical predictions and experimental data

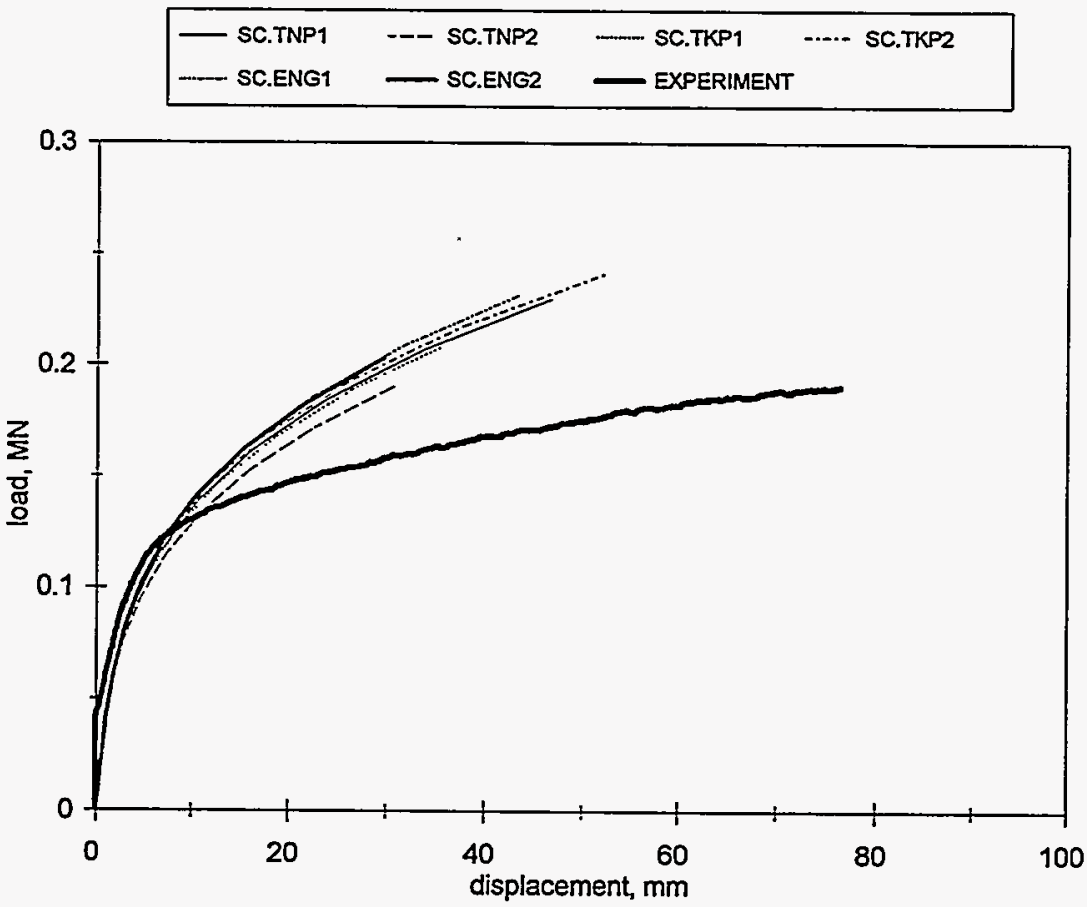

Figure 4.49 Load versus pipe displacement at the load point (excludes displacements from test machine compliance) for Experiment 1.2.1.22 - analytical predictions and experimental data 


\subsubsection{Analysis of Surface-Cracked-Pipe Experiments - Combined Bending and Tension Load Cases}

\subsubsection{List of Experiments Analyzed}

Sixteen full-scale pipe experiments, in which the pipes were subjected to combined pressure and bending loads, were analyzed using NRCPIPES, Version 2.0. The list of experiments with details about the pipe size, internal pressure, test temperature, and flaw geometry are detailed in Table 4.11. Four of the experiments, Reference Numbers 45 through 48 , were conducted during this program. The flaw length varied from 25 to 58 percent of the pipe circumference while the flaw depth varied from 47.6 to 72 percent of the pipe wall thickness.

The tensile properties for the pipes used in the experiments listed in Table 4.11 are given in Table 4.12. The tensile properties include the yield and ultimate strengths as well as the constants used to fit the tensile data to a Ramberg-Osgood model, which are used in the J-estimation schemes. The fracture resistance properties for the pipe materials in Table 4.11 are given in Table 4.13 and include the value of $J$ at crack initiation, $J_{i}$, the initial slope of the $J-R$ curve, $d J / d a$, as well as the curve-fit parameters used to fit the experimental data to a power-law function. The data provided in Tables 4.11 through 4.13 were obtained from the CIRCUMCK.WK1 database, Version 2.1b (Ref. 4.38).

\subsubsection{Predictions Using Limit-Load Approaches}

The experimental maximum moments for each of the combined pressure and bend pipe experiments are given in Table 4.14. The ratio of the maximum experimental stress (bending plus membrane due to internal pipe pressure) to the maximum predicted stress (bending plus membrane due to internal pipe pressure) for the three NSC criteria, i.e., the original, the Battelle, and the Kurihara modifications, are shown in Table 4.14. As for the cases involving pure bending loads, an average value for these ratios for the three methods and the standard deviation for each method were calculated.

On average, both the original and Battelle-modified Net-Section-Collapse analyses overpredicted the maximum experimental stresses, with the Battelle modification overpredicting the stresses by 15 percent on the average. The Kurihara modification underpredicted the maximum experimental stresses by 13 percent on average.

\subsubsection{Prediction of Bending Moment at Crack Initiation}

As for the cases involving pure bending, the seven methods listed in Section 4.4.1 were used to predict the moments and stresses at which the cracks initiated in the pipe experiments. These included the two SC.TNP and two SC.TKP methods, the two SC.ENG methods, and the R6 approach. In all cases, the $J_{D}-R$ curves were used to predict the experimental behavior. Since the amount of crack growth is small, both the $J_{D}-R$ and $J_{m}-R$ curves yield the same predictions. The ratios of the experimental stress at crack initiation (bending plus membrane due to internal pipe pressure) to the predicted initiation stress (bending plus membrane due to internal pipe pressure) for each experiment using the various analysis methods are listed in Table 4.15. 
Table 4.12 Tensile properties for pipe materials listed in Table 4.11

\begin{tabular}{|c|c|c|c|c|c|c|c|c|c|c|c|c|c|}
\hline \multirow{2}{*}{$\begin{array}{l}\text { Ref. } \\
\text { No. }\end{array}$} & \multirow{2}{*}{$\begin{array}{l}\text { Expt. } \\
\text { No. }\end{array}$} & \multirow[b]{2}{*}{ Material } & \multicolumn{2}{|c|}{$\begin{array}{l}\text { Yield }^{(a)} \\
\text { Strength, }\end{array}$} & \multicolumn{2}{|c|}{$\begin{array}{l}\text { Ultimate } \\
\text { Strength, }\end{array}$} & \multirow{2}{*}{$\begin{array}{l}\text { Percent } \\
\text { Elong. }\end{array}$} & \multirow{2}{*}{$\begin{array}{c}\text { Area } \\
\text { Reduct., } \\
\%\end{array}$} & \multicolumn{2}{|c|}{$\begin{array}{c}\text { Reference }^{(\mathrm{b})} \\
\text { Stress, }\end{array}$} & \multirow{2}{*}{$\begin{array}{c}\text { Reference } \\
\text { Strain }\end{array}$} & \multicolumn{2}{|c|}{$\begin{array}{l}\text { Ramberg- } \\
\text { Osgood } \\
\text { Constants, }\end{array}$} \\
\hline & & & MPa & ksi & $\mathrm{MPa}$ & ksi & & & MPa & ksi & & $\alpha$ & n \\
\hline 29 & $4131-2$ & TP304 & 139 & $(20.1)$ & 450 & $(65.2)$ & 53.8 & 71.4 & 139 & $(20.2)$ & 0.00076 & 11.23 & 3.57 \\
\hline 30 & $4131-4$ & A333 Gr. 6 & 239 & $(34.7)$ & 527 & $(76.5)$ & 27.3 & 60.0 & 239 & (34.7) & 0.00124 & 2.13 & 5.58 \\
\hline 31 & $4141-2$ & TP304 SAW & 139 & $(20.1)$ & 450 & $(65.2)$ & 53.8 & 71.4 & 139 & $(20.2)$ & 0.00076 & 11.23 & 3.57 \\
\hline 32 & $4141-4$ & TP304 SAW & 180 & (26.1) & 459 & $(66.5)$ & 46.4 & 74.5 & 174 & (25.3) & 0.00096 & 7.19 & 4.89 \\
\hline 33 & $4141-6$ & TP304 SAW & 180 & (26.1) & 459 & $(66.5)$ & 46.4 & 74.5 & 174 & $(25.3)$ & 0.00096 & 7.19 & 4.89 \\
\hline 34 & $4141-8$ & A106B SAW & 237 & (34.4) & 610 & $(88.5)$ & 24.0 & 41.4 & 240 & (34.8) & 0.00124 & 2.19 & 3.73 \\
\hline 39 & $4143-2$ & Aged CF8M & 173 & (25.1) & 501 & $(72.7)$ & N.A. ${ }^{(c)}$ & 46.7 & 173 & $(25.1)$ & 0.00097 & 14.35 & 2.60 \\
\hline 40 & $4143-1$ & Aged CF8M & 231 & $(33.5)$ & 610 & $(88.5)$ & 24.0 & 30.0 & 205 & $(29.8)$ & 0.00113 & 2.17 & 4.17 \\
\hline 41 & $4143-3$ & Aged CF8M & 173 & $(25.1)$ & 501 & $(72.7)$ & $\mathrm{NA}$ & 46.7 & 173 & (25.1) & 0.00097 & 14.35 & 2.60 \\
\hline 42 & $1.1-7$ & A106 Gr. B & 320 & $(46.4)$ & 621 & $(90.0)$ & 24.0 & 34.4 & 294 & $(42.6)$ & 0.00152 & 1.97 & 5.37 \\
\hline 43 & $1.1-9$ & A106 Gr. B & 320 & $(46.4)$ & 621 & $(90.0)$ & 24.0 & 34.4 & 294 & $(42.6)$ & 0.00152 & 1.97 & 5.37 \\
\hline 44 & $4.3-2$ & STS-49 & 244 & $(35.4)$ & 575 & $(83.4)$ & 31.0 & 74.8 & 244 & (35.4) & 0.00131 & 2.11 & 3.97 \\
\hline 45 & 1.2.1.20 & TP304 & 224 & (32.5) & 509 & $(73.8)$ & 62.5 & 80.5 & 223 & $(32.4)$ & 0.00108 & 5.01 & 4.95 \\
\hline 46 & 1.2 .3 .15 & A515 Gr. 60 & 231 & (33.5) & 544 & $(78.9)$ & 29.8 & 53.6 & 231 & (33.5) & 0.00119 & 1.38 & 5.64 \\
\hline 47 & 1.2 .3 .16 & TP316L SAW & 143 & (20.8) & 427 & $(62.0)$ & 38.4 & 70.8 & 143 & $(20.8)$ & 0.00081 & 9.46 & 3.28 \\
\hline 48 & 1.2.3.17 & A106B SAW & 234 & $(34.0)$ & 542 & $(78.6)$ & 27.5 & N.D. (d) & 220 & (31.9) & 0.00114 & 3.21 & 3.41 \\
\hline
\end{tabular}

(a) Average values from all specimens.

(b) Data from an individual tensile specimen were used to curve fit the tensile stress-strain curve data, hence the reference stress is the yield strength for that specimen and may differ from the average yield strength value in this table.

(c) N.A. - not applicable.

(d) N.D. - not determined. 
Table 4.13 Fracture resistance properties for pipe experiments listed in Table 4.1

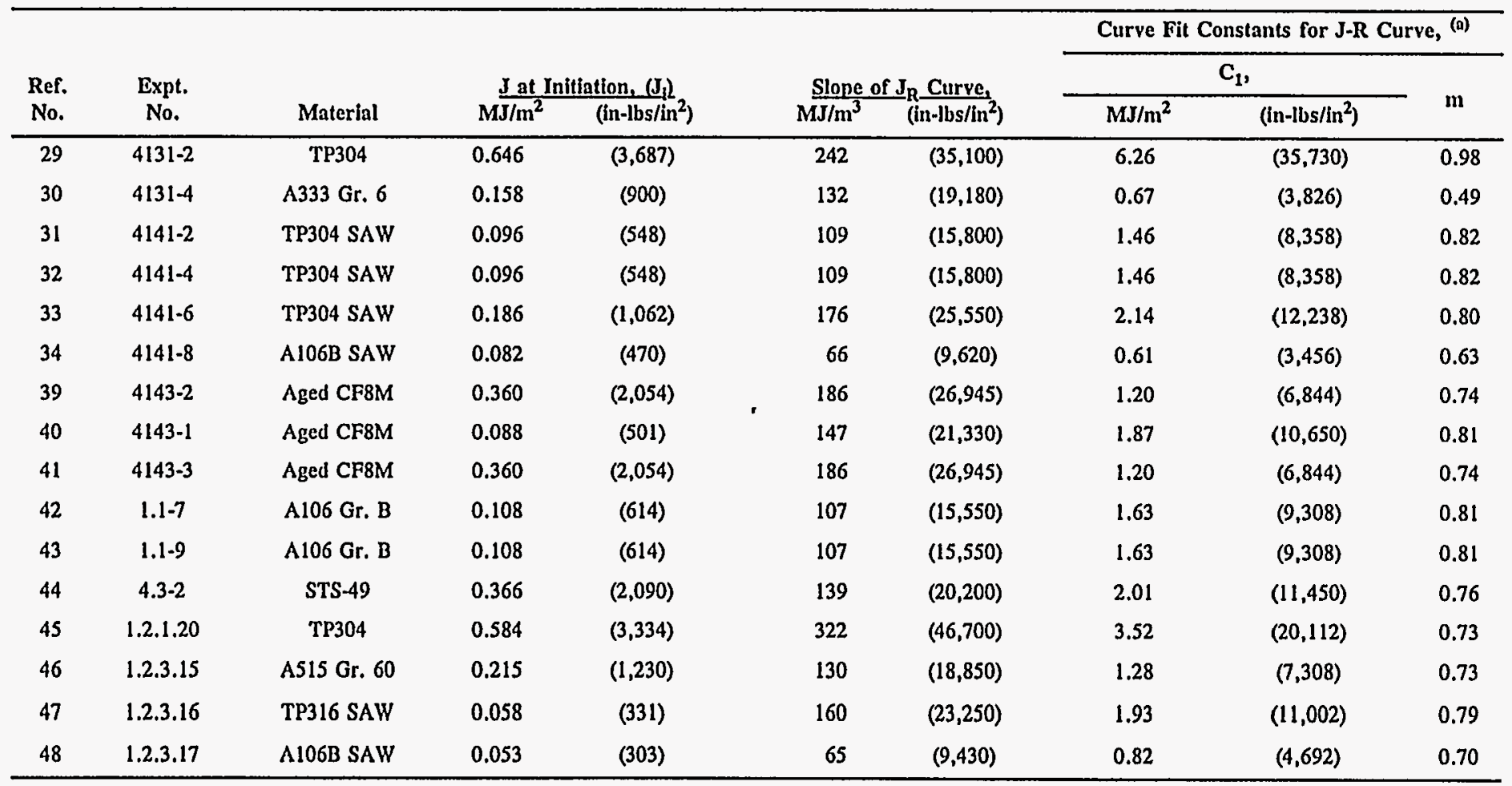

(a) $J=J_{1}+C_{1}\left[\frac{\Delta a}{\Delta a_{0}}\right]^{m}$ where $\Delta a_{0}$ is unity in the appropriate units. 
Table 4.14 Comparison of NSC predictions with experimental data - combined bending and pressure load cases

\begin{tabular}{|c|c|c|c|c|c|c|c|c|}
\hline \multirow{2}{*}{$\begin{array}{l}\text { Ref. } \\
\text { No. }\end{array}$} & \multirow{2}{*}{$\begin{array}{l}\text { Expt. } \\
\text { No. }\end{array}$} & \multicolumn{2}{|c|}{$\begin{array}{l}\text { Maximum } \\
\text { Moment, } \\
\end{array}$} & \multicolumn{2}{|c|}{$\mathbf{M}_{\mathrm{nsc}}$ Original $^{(a)}$, } & \multicolumn{3}{|c|}{$\begin{array}{c}\text { Experiment Maximum Stress/ } \\
\text { Predicted NSC Stress }^{(b)}\end{array}$} \\
\hline & & $\mathrm{kN}-\mathrm{m}$ & (in-kipss) & $\mathrm{kN}-\mathrm{m}$ & (in-kips) & (Original) $^{(2)}$ & (Battelle) $^{(\mathbf{C})}$ & (Kurihara) $^{(\mathrm{d})}$ \\
\hline 29 & $4131-2$ & 34.1 & $(301.9)$ & 25.8 & (228) & 1.19 & 1.10 & 1.68 \\
\hline 30 & $4131-4$ & 160 & $(1,416)$ & 155 & $(1,373)$ & 1.02 & 0.95 & 1.25 \\
\hline 31 & $4141-2$ & 41.1 & $(364.0)$ & 46.7 & (413) & 0.90 & 0.80 & 1.10 \\
\hline 32 & $4141-4$ & 502 & $(4,439)$ & 539 & $(4,766)$ & 0.94 & 0.86 & 1.16 \\
\hline 33 & $4141-6$ & 445 & $(3,942)$ & 530 & $(4,691)$ & 0.87 & 0.80 & 1.09 \\
\hline 34 & $4141-8$ & 595 & $(5,260)$ & 647 & $(5,730)$ & 0.93 & 0.86 & 1.15 \\
\hline 39 & $4143-2$ & 386 & $(3,414)$ & 426 & $(3,772)$ & 0.92 & 0.81 & 1.12 \\
\hline 40 & $4143-1$ & 672 & $(5,949)$ & 841 & $(7,447)$ & 0.83 & 0.75 & 0.94 \\
\hline 41 & $4143-3$ & 410 & $(3,625)$ & 354 & $(3,134)$ & 1.13 & 1.00 & 1.33 \\
\hline 42 & $1.1-7$ & 77.2 & (683.3) & 79.8 & $(706)$ & 0.97 & 0.86 & 1.21 \\
\hline 43 & $1.1-9$ & 61.6 & $(545.2)$ & 74.7 & (661) & 0.85 & 0.75 & 1.16 \\
\hline 44 & $4.3-2$ & 7201 & $(63,736)$ & 7056 & $(62,454)$ & 1.02 & 0.95 & 1.18 \\
\hline 45 & 1.2.1.20 & 356 & $(3,154)$ & 439 & $(3,885)$ & 0.82 & 0.95 & 0.93 \\
\hline 46 & 1.2.3.15 & 2189 & $(19,380)$ & 2975 & $(26,334)$ & 0.78 & 0.80 & 0.90 \\
\hline 47 & 1.2.3.16 & 2093 & $(18,533)$ & 2836 & $(25,097)$ & 0.79 & 0.76 & 0.92 \\
\hline \multirow[t]{3}{*}{48} & 1.2.3.17 & 2575 & $(22,790)$ & 3728 & $(32,992)$ & 0.73 & 0.66 & 0.93 \\
\hline & & & & & Average & 0.92 & 0.85 & 1.13 \\
\hline & & & & & Std. Dev. & 0.12 & 0.11 & 0.19 \\
\hline
\end{tabular}

(a) Original NSC criterion, Equation 4.1 (also called the limit moment).

(b) $\left(\sigma_{\mathrm{B}_{\mathrm{EXPT}}}+\sigma_{\mathrm{M}_{\mathrm{EXPT}}}\right) /\left(\sigma_{\mathrm{B}_{\mathrm{NSC}}}+\sigma_{\mathrm{M}_{\mathrm{EXPT}}}\right)$

(c) Battelle's modification to NSC, see Section 4.2.5.

(d) Kurihara's modification to NSC, see Section 4.1.1.1. 
Table 4.15 Comparison of experimental crack initiation moment with analytical predictions - combined bending and pressure load cases

\begin{tabular}{|c|c|c|c|c|c|c|c|c|c|c|}
\hline \multirow{2}{*}{$\begin{array}{l}\text { Ref. } \\
\text { No. }\end{array}$} & \multirow{2}{*}{$\begin{array}{c}\text { Expt. } \\
\text { No. }\end{array}$} & \multicolumn{2}{|c|}{$\begin{array}{c}\text { Experimental } \\
\text { Initiation Moment, }\end{array}$} & \multicolumn{7}{|c|}{ Experimental Initiation Stress/Predicted Maximum Stress ${ }^{(a)}$, } \\
\hline & & $\mathbf{k N}-\mathbf{m}$ & (in-kips) & SC.TNP1 & SC.TNP2 & SC.TKP1 & SC.TKP2 & SC.ENG1 & SC.ENG2 & R-6 \\
\hline 29 & $4131-2$ & 32.1 & (284.2) & 1.12 & 1.45 & 2.12 & 1.79 & 1.48 & 1.80 & (b) \\
\hline 30 & $4131-4$ & 142 & $(1,259)$ & 0.99 & 1.30 & 1.55 & 1.39 & 1.26 & 1.48 & 1.47 \\
\hline 31 & $4141-2$ & 39.9 & (352.8) & 1.39 & 1.74 & 2.03 & 1.76 & 1.70 & 1.95 & 1.68 \\
\hline 32 & $4141-4$ & 498 & $(4,406)$ & 1.41 & 1.84 & 2.17 & 1.92 & 1.78 & 2.12 & 1.63 \\
\hline $3 \hat{3}$ & $4141-6$ & 443 & $(3,917)$ & 1.16 & 1.52 & 1.82 & 1.61 & 1.47 & 1.77 & 1.43 \\
\hline 34 & $4141-8$ & 419 & $(3,745)$ & 0.99 & 1.27 & 1.52 & 1.31 & 1.33 & 1.53 & 1.34 \\
\hline 39 & $4143-2^{(c)}$ & 385 & $(3,409)$ & 1.35 & 1.55 & 1.66 & 1.40 & 1.68 & 1.89 & 1.55 \\
\hline 40 & $4143-1$ & 658 & $(5,824)$ & 1.16 & 1.44 & 1.52 & 1.34 & 1.37 & 1.50 & 1.50 \\
\hline 41 & $4143-3^{(c)}$ & 398 & $(3,518)$ & 1.52 & 1.76 & 2.16 & 1.80 & 2.01 & 2.22 & 1.87 \\
\hline 42 & $1.1-7$ & 75.3 & $(666.5)$ & 1.07 & 1.38 & 1.51 & 1.35 & 1.28 & 1.52 & 1.38 \\
\hline 43 & $1.1-9$ & 55.2 & $(488.6)$ & 0.85 & 1.11 & 1.31 & 1.18 & 1.08 & 1.38 & 1.14 \\
\hline 44 & $4.3-2$ & 6,907 & $(61,130)$ & 1.16 & 1.41 & 1.19 & 1.05 & 1.18 & 1.34 & 1.50 \\
\hline 45 & $1.2 .1 .20^{(d)}$ & 290 & $(2,568)$ & 0.66 & 0.82 & 0.85 & 0.76 & 0.64 & 0.73 & 0.72 \\
\hline 46 & 1.2 .3 .15 & N.A. ${ }^{(e)}$ & N.A. & N.A. & N.A. & N.A. & N.A. & N.A. & N.A. & N.A. \\
\hline 47 & 1.2 .3 .16 & 2,076 & $(18,380)$ & 1.58 & 1.84 & 1.72 & 1.52 & 1.62 & 1.79 & 1.55 \\
\hline \multirow[t]{3}{*}{48} & 1.2.3.17 & 2,364 & $(20,920)$ & 1.21 & 1.47 & 1.29 & 1.12 & 1.51 & 1.71 & 1.46 \\
\hline & & & Average ${ }^{(f)}$ & 1.18 & 1.48 & 1.64 & 1.45 & 1.42 & 1.65 & $1.44^{(g)}$ \\
\hline & & & Std. Dev. ${ }^{(I)}$ & 0.19 & 0.22 & 0.31 & 0.27 & 0.32 & 0.35 & $0.26^{(g)}$ \\
\hline
\end{tabular}

(a) $\left(\sigma_{\mathrm{B}_{\mathrm{EXPT}}}+\sigma_{\mathrm{M}_{\mathrm{EXTT}}}\right) /\left(\sigma_{\mathrm{B}_{\mathrm{PRED}}}+\sigma_{\mathrm{M}_{\mathrm{EXPT}}}\right)$

(b) For Experiment 4131-2, the R6 Option 1 analysis predicts failure due to intemal pipe pressure alone, so ratio was infinity.

(c) $\mathrm{R}_{\mathrm{i}} / \mathrm{t}<5$.

(d) $R_{i} / t>20$.

(e) N.A. - Not available.

(f) The average and standard deviations for the SC.TNP and SC.TKP analyses are calculated for those experiments for which the $R_{i} / t$ ratios are between 5 and 20 which is the region where the $\mathrm{H}$ - and $\mathrm{G}_{\mathrm{N}}$-functions are tabulated in the SC.TNP and SC.TKP analyses, respectively.

(g) Excluding Experiment 4131-2. Including Experiment 4131-2 result would increase the average and standard deviation significantly. 
Like the predictions for the pure bending case, the ratios shown for the combined load cases indicate that the methods on average underpredict the experimental data with the average values exceeding unity by a large margin in some cases. The most accurate of the methods was the SC.TNP1 method.

\subsubsection{Maximum Bending Moment Predictions}

As in the case for pure bending loads, six J-estimation schemes and the R6 Option 1 approach were used to predict the maximum moments and stresses for the pipe experiments. Additionally, other methods such as the ASME Section XI approaches as well as the DPZP method were used to predict the maximum load-carrying capacity of the pipe experiments but not crack initiation. These ratios of the maximum experimental stress (bending plus membrane due to internal pipe pressure) to the predicted maximum stress (bending plus membrane due to internal pipe pressure) for the experiments listed in Table 4.11 are given in Table 4.16. In addition, Table 4.16 presents the average values and standard deviations for the 16 combined pressure and bend experiments for each of the methods. The ASME Section XI Appendix C method was used to analyze the austenitic pipe experiments, while the Appendix $\mathrm{H}$ method was used to analyze the ferritic pipe experiments. As can be seen from Table 4.16, all methods underpredicted the experimental data. As indicated by the average values of these ratios, the SC.TNP1 and the DPZP methods are the most accurate methods.

\subsubsection{Load-Displacement Curves - Analysis and Experiments}

Curves of the load versus the pipe displacement at the load points for the four experiments conducted during this program are given in Figures 4.50 through 4.53 . The figures also show the predicted loaddisplacement curves from the six J-estimation scheme methods, i.e., SC.TNP1, SC.TNP2, SC.TKP1, SC.TKP2, SC.ENG1, and SC.ENG2.

For the Experiment Number 1.2.1.20 results shown in Figure 4.50, all analytical predictions follow the experimental data for the elastic and the initial plastic load values. Beyond the "knee" in the curve, the experimental loads fall below all of the analytical predictions. Surprisingly, the scatter between the various methods is very small.

For the Experiment 1.2.3.15 results shown in Figure 4.51, the analytical predictions are in excellent agreement with the data in following the load-displacement behavior. However, the loads predicted by the analyses for a given pipe displacement are lower than the experimental values.

For the Experiment 1.2.3.16 results shown in Figure 4.52, the experimental load value at zero pipe displacement is significantly greater than zero due to the dead-weight loads, but the initial slope of the load-displacement curve is captured closely by the SC.ENG2 method, as well as some of the other methods. The maximum load from the predictions falls below the experimental value for this experiment. 
Table 4.16 Comparison of experimental maximum moment with analytical predictions for combined bending and pressure load cases

\begin{tabular}{|c|c|c|c|c|c|c|c|c|c|c|c|c|c|c|}
\hline \multirow[b]{2}{*}{$\begin{array}{l}\text { Ref. } \\
\text { No. }\end{array}$} & \multirow[b]{2}{*}{$\begin{array}{c}\text { Expt. } \\
\text { No. }\end{array}$} & \multirow{2}{*}{\multicolumn{2}{|c|}{$\begin{array}{l}\text { Expt. Maximum } \\
\text { Moment, } \\
\text { kN-m (in-kips) }\end{array}$}} & \multicolumn{11}{|c|}{ Experimental Maximum Stress/Predicted Maximum Stress ${ }^{(a)}$, } \\
\hline & & & & SC.TNP1 & SC.TNP2 & SC.TKP1 & SC.TKP2 & SC.ENG1 & SC.ENG2 & R-6 & $\begin{array}{l}\text { Sec XI } \\
\text { App C }\end{array}$ & $\begin{array}{l}\text { Sec XI } \\
\text { App H }\end{array}$ & $\begin{array}{c}\text { Sec XI } \\
\text { Code Case } \\
\text { N-494-2 }\end{array}$ & DPZP \\
\hline 29 & $4131-2$ & 34.1 & $(301.9)$ & 1.17 & 1.51 & 2.20 & 1.87 & 1.54 & 1.87 & (b) & 1.18 & N.A. ${ }^{(c)}$ & N.A. & 1.24 \\
\hline 30 & $4131-4$ & 160 & $(1,416)$ & 1.07 & 1.41 & 1.69 & 1.51 & 1.37 & 1.61 & 1.60 & N.A. & 2.02 & 1.30 & 1.07 \\
\hline 31 & $4141-2$ & 41.1 & $(364.0)$ & 1.35 & 1.72 & 2.08 & 1.80 & 1.72 & 2.00 & 1.72 & 1.34 & N.A. & N.A. & 0.97 \\
\hline 32 & 4141.4 & 502 & $(4,439)$ & 1.33 & 1.76 & 2.15 & 1.90 & 1.73 & 2.10 & 1.64 & 1.47 & N.A. & N.A. & 1.02 \\
\hline 33 & $4141-6$ & 445 & $(3,942)$ & 1.12 & 1.47 & 1.82 & 1.61 & 1.45 & 1.78 & 1.44 & 1.36 & 2.47 & N.A. & 0.92 \\
\hline 34 & $4141-8$ & 595 & $(5,260)$ & 1.18 & 1.53 & 1.93 & 1.66 & 1.61 & 1.93 & 1.75 & N.A. & 1.11 & 1.63 & 1.15 \\
\hline 39 & $4143-2^{(d)}$ & 386 & $(3,414)$ & 1.31 & 1.52 & 1.67 & 1.40 & 1.68 & 1.89 & 1.55 & 0.98 & N.A. & N.A. & 0.99 \\
\hline 40 & 4143-1 & 672 & $(5,949)$ & 1.01 & 1.29 & 1.41 & 1.23 & 1.22 & 1.38 & 1.49 & 1.07 & N.A. & N.A. & 0.99 \\
\hline 41 & $4143-3^{(d)}$ & 410 & $(3,625)$ & 1.52 & 1.78 & 2.22 & 1.85 & 2.06 & 2.28 & 1.92 & 1.21 & N.A. & N.A. & 1.21 \\
\hline 42 & $1.1-7$ & 77.2 & (683.3) & 1.06 & 1.38 & 1.54 & 1.38 & 1.29 & 1.56 & 1.41 & N.A. & 2.15 & 1.46 & 1.05 \\
\hline 43 & $1.1-9$ & 61.6 & $(545.2)$ & 0.92 & 1.20 & 1.44 & 1.29 & 1.16 & 1.51 & 1.25 & N.A. & 1.89 & 1.26 & 0.92 \\
\hline 44 & $4.3-2$ & 7,201 & $(63,736)$ & 0.98 & 1.26 & 1.01 & 0.87 & 1.13 & 1.39 & 1.52 & N.A. & 2.68 & 1.68 & 1.08 \\
\hline 45 & $1.2 .1 .20^{(\mathrm{e})}$ & 356 & $(3,154)$ & 0.77 & 0.99 & 1.01 & 0.89 & 0.78 & 0.89 & 0.88 & 0.75 & N.A. & 0.97 & 0.84 \\
\hline 46 & 1.2 .3 .15 & 2,190 & $(19,380)$ & 0.85 & 1.08 & 0.90 & 0.81 & 0.90 & 1.04 & 1.21 & N.A. & 1.95 & N.A. & 0.84 \\
\hline 47 & 1.2 .3 .16 & 2,094 & $(18,533)$ & 1.02 & 1.28 & 1.16 & 0.99 & 1.21 & 1.43 & 1.45 & 1.33 & N.A. & N.A. & 1.00 \\
\hline \multirow[t]{3}{*}{48} & 1.2 .3 .17 & 2,575 & $(22,790)$ & 0.92 & 1.15 & 1.00 & 0.86 & 1.18 & 1.48 & 1.26 & N.A. & 1.83 & 1.43 & 1.12 \\
\hline & & & Average $^{(n)}$ & 1.10 & 1.41 & 1.38 & 1.21 & 1.39 & 1.65 & 1.43 & 1.16 & 2.14 & 1.42 & 1.05 \\
\hline & & & Std. Dev. ${ }^{(f)}$ & 0.15 & 0.20 & 0.52 & 0.45 & 0.30 & 0.34 & 0.40 & 0.19 & 0.29 & 0.18 & 0.13 \\
\hline
\end{tabular}

(a) $\left(\sigma_{\mathrm{B}_{\mathrm{EXPT}}}+\sigma_{\mathrm{M}_{\mathrm{EXPT}}}\right) /\left(\sigma_{\mathrm{B}_{\text {PRED }}}+\sigma_{\mathrm{M}_{\mathrm{PRED}}}\right)$

(b) For Experiment $4131-2$, the R6 analysis predicts failure due to internal pipe pressure alone.

(c) N.A. - Not applicable.

(d) $\mathrm{R}_{\mathrm{i}} / \mathrm{t}<5$.

(e) $R_{i} / t>20$.

(f) The average and standard deviations for the SC.TNP and SC.TKP analyses are calculated for those experiments for which the $R_{i} / t$ ratios are between 5 and 20 which is the region where the $H$ - and $G_{N}$-functions are tabulated in the SC.TNP and SC.TKP analyses, respectively. 


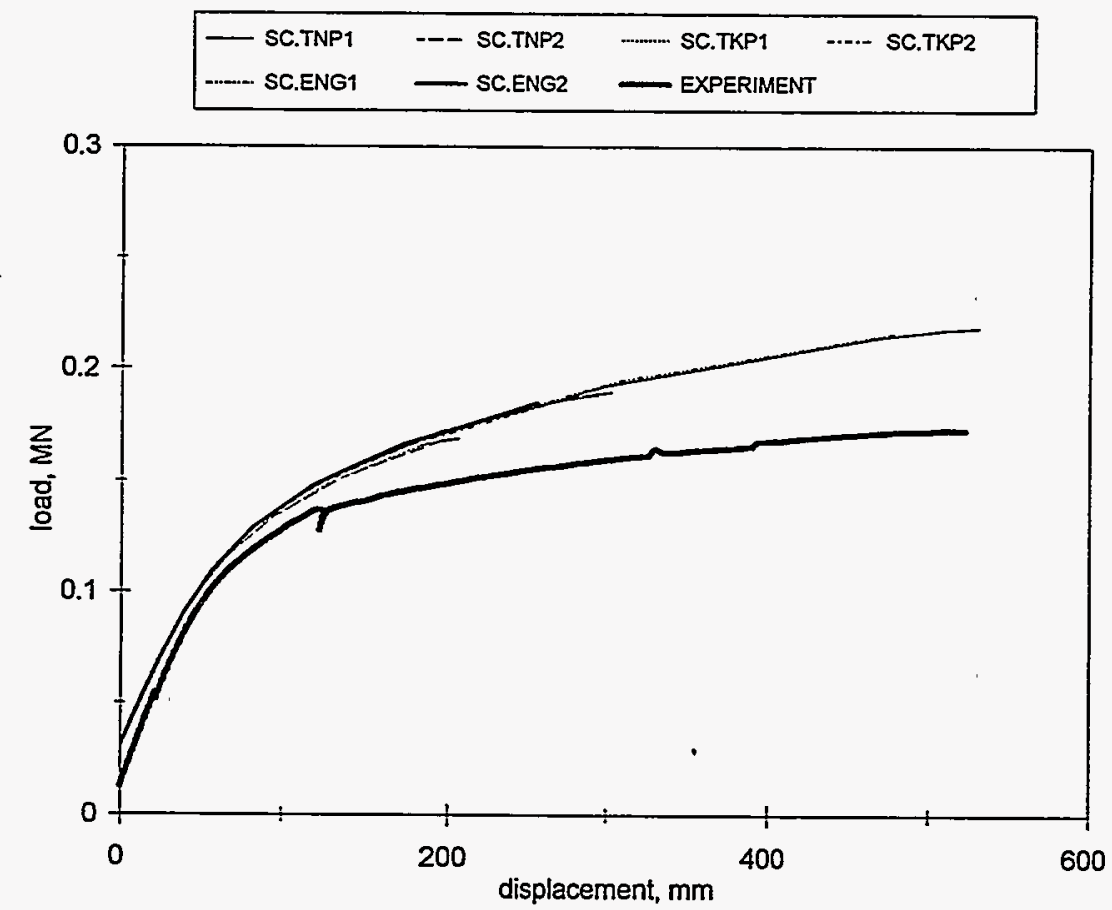

Figure 4.50 Comparison of experimental data with analytical prediction of load versus pipe. displacement at the load points for Experiment 1.2.1.20

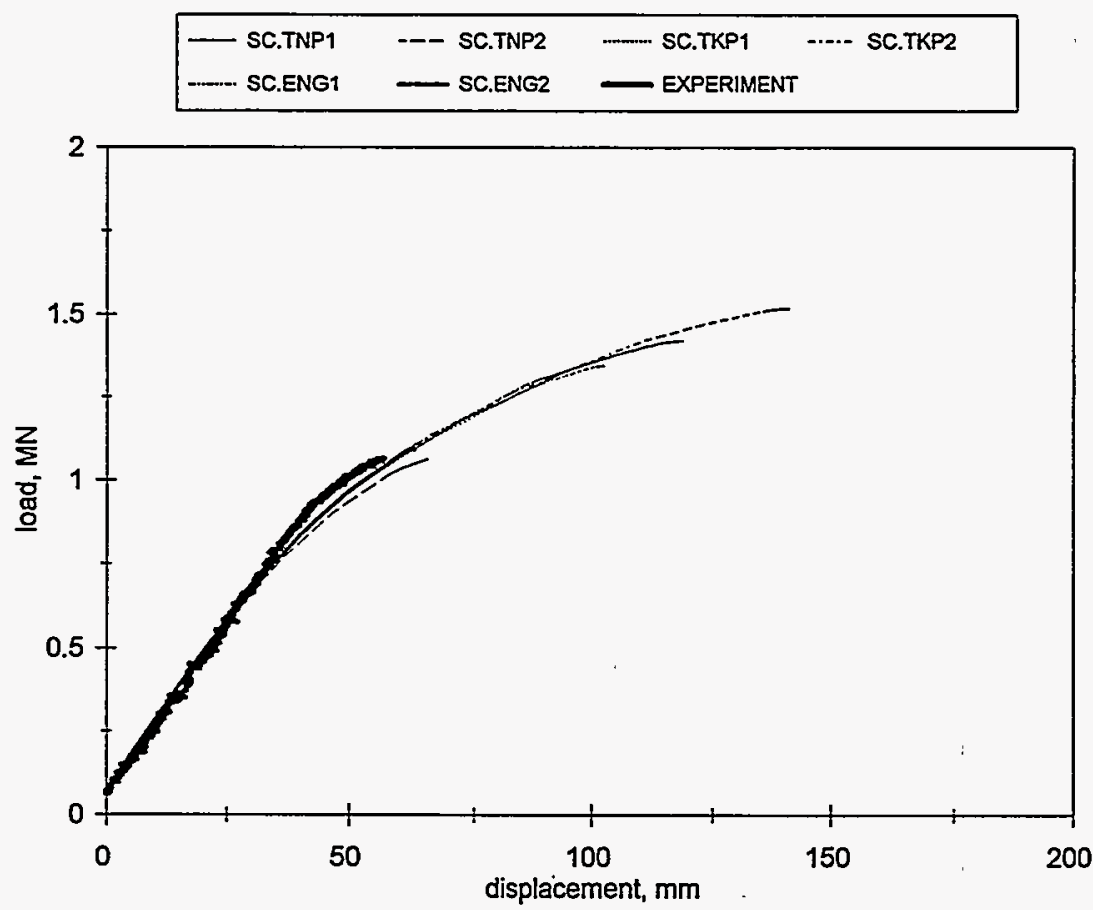

Figure 4.51 Comparison of experimental data with analytical prediction of load versus pipe displacement at the load points for Experiment 1.2.3.15 


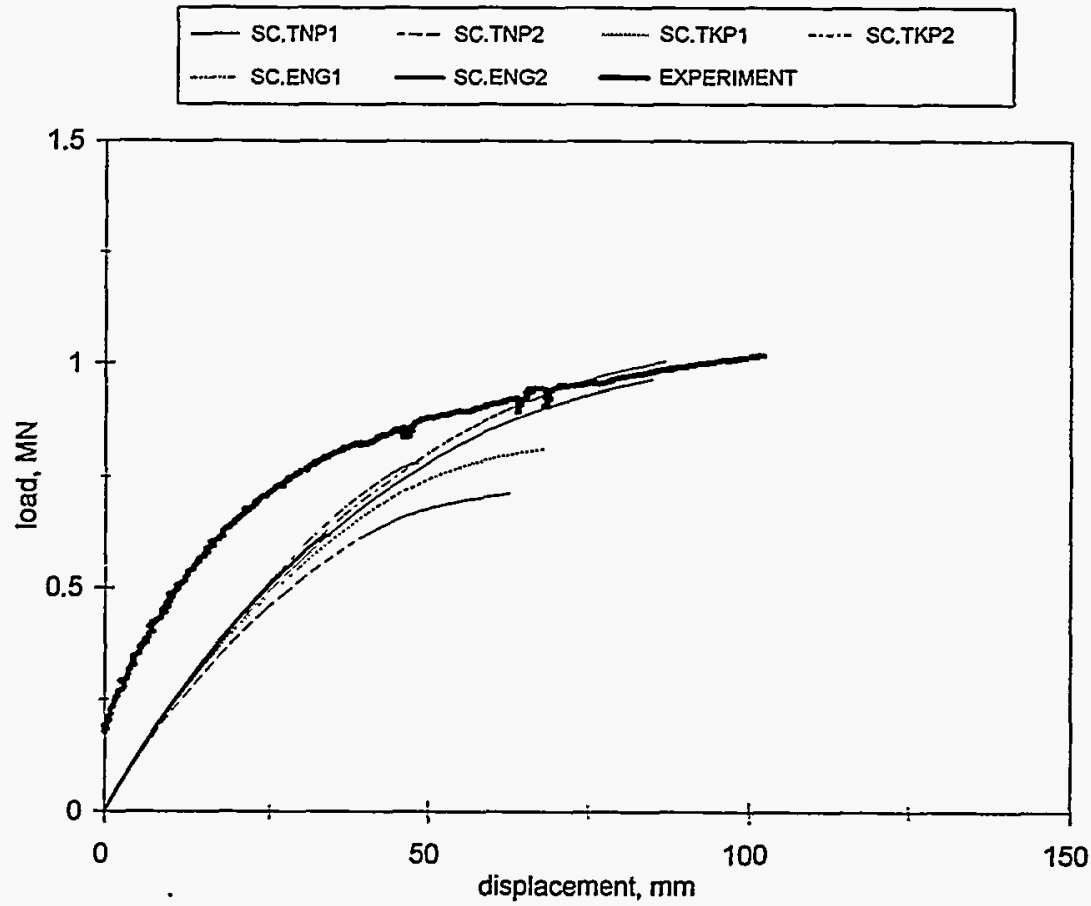

Figure 4.52 Comparison of experimental data with analytical prediction of load versus pipe displacement at the load points for Experiment 1.2.3.16

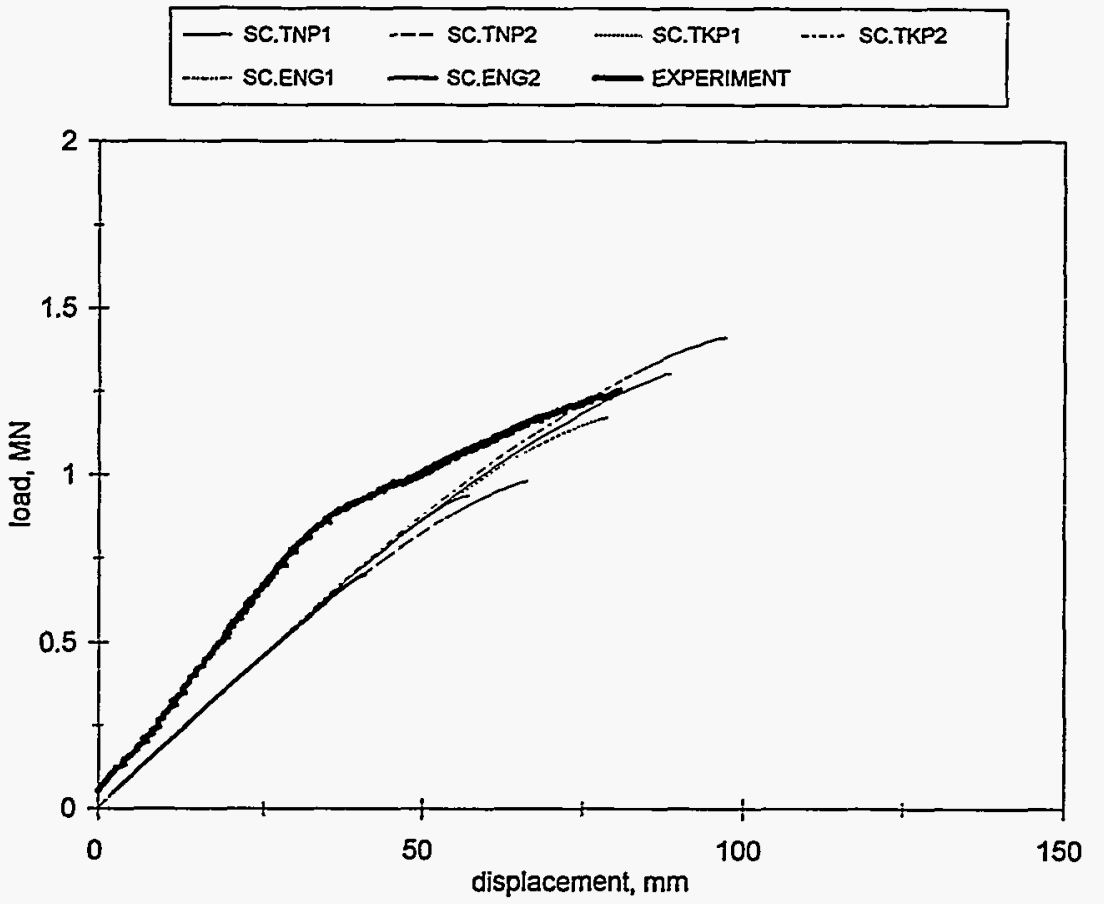

Figure 4.53 Comparison of experimental data with analytical prediction of load versus pipe displacement at the load points for Experiment 1.2.3.17 
Figure 4.53 shows the experimental and analytically predicted load-displacement curves for Experiment 1.2.3.17. Apart from the point of inflection in the experimental data (an anomaly), the initial elastic slope from the predictions is in good agreement with the experimental data. The maximum load values from the various analytical predictions are considerably higher than the experimental data.

\subsection{Discussion of Results}

Several observations made in Sections 4.4.2 and 4.4.3 in comparing the experimental data with analytical predictions warrant further discussion. These items are discussed in detail below.

\subsubsection{Limit-Load Approaches}

As noted above, the Original Net-Section-Collapse equation on average underpredicted the maximum experimental moments for the pure bending case. The Battelle modification to the Original NSC criterion agreed better with the experimental data, but on average resulted in a slight overprediction of the maximum experimental moments for the pure bending case, see Table 4.8. The empirical correction factor used in the Battelle modification was obtained by a linear fit of the experimental data to account for pipe ovalization effects. Thus, one would expect that the experimental maximum moment would be predicted better by this method than the original criterion. Using the Kurihara modification (Ref. 4.3) to the NSC criterion, which was developed for short, deep surface flaws to analyze all flaw sizes, yields results where the analysis significantly underpredicts the experimental data in certain situations. For the combined pressure and bending case, the original NSC criterion had the best agreement of the three methods with the experimental data as seen in Table 4.14. However, this method as seen by the average value did overpredict the experimental data. On average, the Battelle modification overpredicted the experimental data by 15 percent. This is probably because the effect of internal pressure is to increase the pipe resistance to ovalization, and hence the ovalization correction factor used may not be appropriate for combined loading. The Kurihara modification on average underpredicted the experimental stresses for the combined load case.

\subsubsection{Prediction of Moment at Crack Initiation}

A comparison of the predictions of crack initiation using the various analytical methods for several categories of loading and flaw lengths is given in Table 4.17. For each analysis method considered and for each load case and flaw geometry/location considered, Table 4.17 shows the mean values of the initiation stress ratios and the coefficient of variation, i.e., the standard deviation divided by the mean times 100 percent. As seen, for the pure bending cases the SC.TNP1, SC.TNP2, and SC.ENG1 methods are the most accurate when mean values of all the data are compared, although the SC.TNP1 method did overpredict the experimental data slightly on average. For the limited number of short surface-cracked pipe experiments, the SC.TNP2 and SC.ENG1 methods were found to be the most accurate methods considered. 
For the combined-load cases, all methods shown in Table 4.17 underpredicted the experimental values of the initiation stress significantly. This is also true for the case when only the short surface crack experiments are included in the analysis. The SC.TNP1 method resulted in the best predictions of the various methods.

When only pipe experiments involving surface cracks in welds under combined bending and tension loads are considered, all the methods again underpredicted the initiation stresses significantly. These findings indicate that for combined bending and pressure loading of pipes, some improvements are still needed in predicting initiation loads.

One important point to note however is that both the new as well as the improved J-estimation schemes predicted the value of the crack-driving force from finite element analyses much better as described in Sections 4.2 and 4.3. However, in predicting initiation loads, the improvements in predictions are not as significant. This discrepancy may be indicative of anisotropy and constraint differences when using the $\mathrm{L}-\mathrm{C}$ oriented $\mathrm{C}(\mathrm{T})$ specimen data.

\subsubsection{Prediction of Maximum Moment}

Table 4.18 shows the means and coefficients of variation of the maximum-load predictions using the various analysis methods. These results are separated into five categories by the type of loading as well as the flaw length and location. Comparison between the predictions using NRCPIPES Version $2.0 \mathrm{a}$ and the experimental data for maximum moment are discussed below for the two types of loading considered, pure bending and combined bending and tension.

For pure bending the following observations can be made:

- The method that gave the most accurate predictions of the maximum loads was the SC.TNP1 method where the mean experiment-to-predicted maximum load ratio was 1.02 and the standard deviation was also the lowest at 0.14 .

- The next most accurate methods were the Battelle DPZP method and the ASME austenitic pipe Appendix-C method (with safety factor of 1.0). The mean experiment-to-predicted maximum load ratios were 1.18 and 1.19 , respectively. The standard deviations were 0.17 and 0.21 , respectively.

- The method that underpredicted the maximum loads the most was the ASME Section XI ferritic pipe Appendix-H Z-factor approach with a mean experiment-to-predicted maximum load ratio of 1.87 and standard deviation of 0.16. The ASME Code Case N-494-2 analysis method for ferritic pipe was more accurate than the Appendix-H Z-factor method with a mean experiment-to-predicted maximum load ratio of 1.43 , the standard deviation was 0.20 .

- When only short ( $<25$ percent of the pipe circumference) flaw lengths are included in the statistical analysis, the SC.TNP2, SC.ENG1, and the Battelle-modified NSC methods resulted in the most accurate predictions of the maximum moments. 
The following observations pertain to cases involving combined pressure and bending:

- The method that gave the most accurate predictions of the maximum loads was the DPZP method where the mean experiment-to-predicted maximum load ratio was 1.05 and the standard deviation was also the lowest at 0.13 . This method was more accurate for combined loading than for pure bending.

- The next most accurate methods were the SC.TNP1 method and the ASME austenitic pipe Appendix $\mathrm{C}$ method (with safety factor of 1.0). The mean experiment-to-predicted maximum load ratios were 1.10 and 1.16 , respectively. The standard deviations were 0.15 and 0.19 , respectively. The SC.TNP1 method was slightly less accurate for combined loading, and the ASME Section XI Appendix C mean value was slightly better for combined loading.

- The method that underpredicted the maximum loads the most was the ASME Section XI ferritic pipe Appendix $\mathrm{H} \mathrm{Z}$ Z-factor approach with a mean experiment-to-predicted maximum load ratio of 2.14 and standard deviation of 0.29 , which was higher than for pure bending. The ASME Code Case N-494-2 analysis method for ferritic pipe was more accurate than the ASME Appendix $\mathrm{H} \mathrm{Z}$-factor analysis with a mean experiment-to-predicted maximum load ratio of 1.42 , the standard deviation was 0.18 , which was close to the same values as for pure bending.

- When only the five short-surface-cracked-pipe experiments were considered in the analysis, the SC.TKP1, SC.ENG1, and Appendix C methods agreed best with the experimental data.

It was somewhat disappointing to note in Table 4.18 that the new J-estimation schemes developed in this program to specifically address the problem of surface cracks in welds, SC.ENG1 and SC.ENG2, significantly underpredicted the experimental stresses for these seven weld experiments. The average ratios of the combined maximum experimental stress to the combined predicted stress (including the membrane stress due to internal pipe pressure) for the seven weld crack experiments were 1.44 and 1.75 for SC.ENG1 and SC.ENG2, respectively. This compares with the stress ratio for the original SC.TNP method (SC.TNP1) of 1.12. As previously noted, although the SC.TNP2, SC.TKP2, SC.ENG1, and SC.ENG2 methods agree well with the J values from finite element analyses, anisotropy and constraint effects from using the L-C oriented $C(T)$ specimen J-R curves could have resulted in these analyses underpredicting the maximum loads. 
Table 4.17 Mean and coefficient of variation of initiation load ratio predicted by various fracture analyses methods

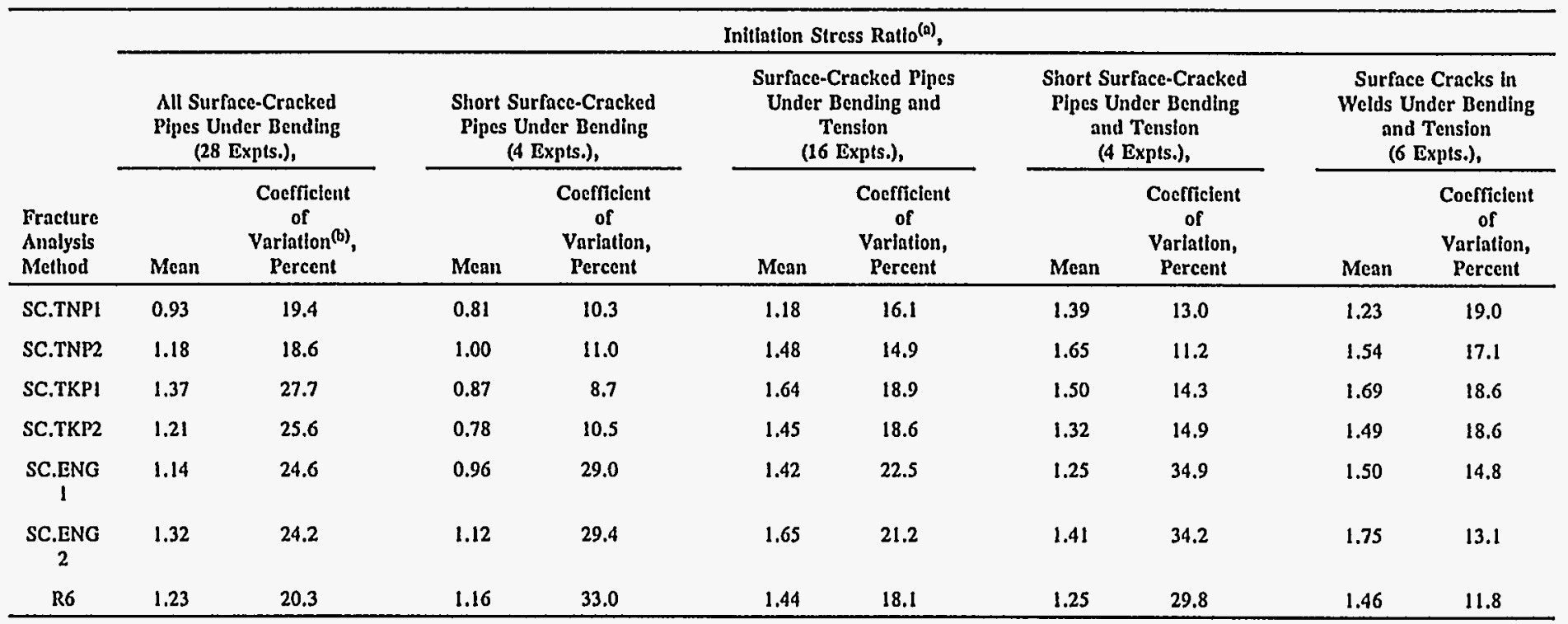

(a) Initiation stress ratio $=$ experimental initiation stress (bending plus membrance)/predicted initiation stress (bending plus membrane).

(b) Coefficient of variation (standard deviation/mean) $\times 100$. 
Table 4.18 Mean and coefficient of variation of maximum load ratio predicted by various fracture analyses methods

\begin{tabular}{|c|c|c|c|c|c|c|c|c|c|c|}
\hline \multirow[b]{3}{*}{$\begin{array}{l}\text { Fracture } \\
\text { Analysis } \\
\text { Method }\end{array}$} & \multicolumn{10}{|c|}{ Maxinum Stress Rntio ${ }^{(a)}$} \\
\hline & \multicolumn{2}{|c|}{$\begin{array}{c}\text { All Surface-Cracked } \\
\text { Pipes Under Bending } \\
\text { (28 Expts.), }\end{array}$} & \multicolumn{2}{|c|}{$\begin{array}{l}\text { Short Surface-Cracked } \\
\text { Pipes Under Bending } \\
\text { (4 Expts.), }\end{array}$} & \multicolumn{2}{|c|}{$\begin{array}{c}\text { Surface-Cracked } \\
\text { Pipes } \\
\text { Under Bendlug and } \\
\text { Tenslon } \\
\text { (16 Expts.), }\end{array}$} & \multicolumn{2}{|c|}{$\begin{array}{l}\text { Short Surface-Cracked } \\
\text { Pipes Under Bending } \\
\text { and Tension } \\
\text { (5 Expts.), }\end{array}$} & \multicolumn{2}{|c|}{$\begin{array}{l}\text { Surface Cracks in } \\
\text { Welds Under } \\
\text { Bending and Tension } \\
\text { (7 Expts.), }\end{array}$} \\
\hline & Mean & $\begin{array}{c}\text { Cocfficlent } \\
\text { of } \\
\text { Variation } \\
\text { Percent }\end{array}$ & Mean & $\begin{array}{l}\text { Cocfficient } \\
\text { of } \\
\text { Variation, } \\
\text { Percent }\end{array}$ & Mean & $\begin{array}{c}\text { Coefficient } \\
\text { of } \\
\text { Variation, } \\
\text { Percent }\end{array}$ & Mean & $\begin{array}{l}\text { Cocfficient } \\
\text { of } \\
\text { Variation, } \\
\text { Percent }\end{array}$ & Mean & $\begin{array}{c}\text { Coefficient } \\
\text { of } \\
\text { Varlation, } \\
\text { Percent }\end{array}$ \\
\hline SC.TNP1 & 1.02 & 13.7 & 0.87 & 4.4 & 1.10 & 13.6 & 0.93 & 7.5 & 1.12 & 14.9 \\
\hline SC.TNP2 & 1.30 & 13.8 & 1.06 & 5.4 & 1.41 & 14.2 & 1.17 & 7.0 & 1.44 & 15.6 \\
\hline SC.TKPI & 1.49 & 24.2 & 0.93 & 3.0 & 1.38 & 37.7 & 1.02 & 10.8 & 1.66 & 25.5 \\
\hline SC.TKP2 & 1.32 & 22.0 & 0.83 & 4.7 & 1.21 & 37.2 & 0.89 & 8.7 & 1.45 & 26.0 \\
\hline SC.ENGI & 1.24 & 20.2 & 0.99 & 22.6 & 1.39 & 21.6 & 1.02 & 18.2 & 1.44 & 16.3 \\
\hline SC.ENG2 & 1.43 & 20.8 & 1.17 & 25.1 & 1.65 & 20.6 & 1.21 & 20.8 & 1.75 & 14.6 \\
\hline R6 Opt. 1 & 1.33 & 15.8 & 1.18 & 25.8 & 1.43 & 28.0 & 1.12 & 17.1 & 1.50 & 12.8 \\
\hline Stc XI $A_{p p} C^{(c)}$ & 1.19 & 17.6 & 1.14 & 14.3 & 1.16 & 16.4 & 1.04 & 28.0 & 1.37 & 4.2 \\
\hline Sec XI App $H^{(d)}$ & 1.87 & 8.6 & N.A..$^{(t)}$ & N.A. & 2.14 & 13.6 & 1.89 & 3.1 & 2.06 & 14.0 \\
\hline$N-494-2^{(d)}$ & 1.43 & 14.0 & N.A. & N.A. & 1.42 & 12.6 & 1.43 & 17.9 & 1.43 & 14.6 \\
\hline DPZP & 1.18 & 14.4 & 1.19 & 15.4 & 1.05 & 12.4 & 0.95 & 12.4 & 1.01 & 8.3 \\
\hline NSC-Orig & 1.10 & 13.6 & 1.11 & 12.1 & 0.92 & 13.0 & 0.78 & 4.1 & 0.86 & 8.2 \\
\hline NSC-Battelle & 0.98 & 11.2 & 0.98 & 8.6 & 0.85 & 12.9 & 0.79 & 13.1 & 0.78 & 8.2 \\
\hline NSC-Kurihara & 1.29 & 11.6 & 1.30 & 12.6 & 1.13 & 16.8 & 0.92 & 1.3 & 1.07 & 9.0 \\
\hline
\end{tabular}

(a) Maximum load ratio $=$ experimental maximum load/predicted maximum load.

(b) Coefficient of variation $=$ (standard deviation/mean) $\times 100$,

(c) Austenitic pipe only.

(d) Ferritic pipe only.

(c) N.A. = Not applicable. 


\subsubsection{Sensitivity Analyses}

In this section the results from the comparisons of the maximum experimental results with the various analysis predictions will be discussed by examining the accuracy of the various methods; i.e., the ratio of the experimental moments, for the pure bending experiments, or stresses, for the combined pressure and bending experiments, to the predicted moments or stresses; for a set of six test parameters. The six test parameters considered are: the outside pipe diameter $\left(D_{0}\right)$, the mean pipe radius-to-pipe wall thickness ratio $\left(\mathrm{R}_{\mathrm{m}} / \mathrm{t}\right)$, the normalized crack length $(\theta / \pi)$, the normalized crack depth $(a / t)$, the strain-hardening exponent.(n), and the pipe pressure $(p)$.

\subsubsection{Effect of Outside Pipe Diameter}

Figure 4.54 is a plot of the maximum moment ratio (maximum experimental moment/maximum predicted moment) as a function of the outside pipe diameter for the SC.TNP1 and SC.TNP2 analyses for the pure bending experiments evaluated. As can be seen in Figure 4.54 the maximum moment ratio for these two analyses is essentially independent of the outside pipe diameter for the pure moment loading condition. A similar trend was seen for the other analysis methods considered, i.e., SC.TKP1 and SC.TKP2, SC.ENG1 and SC.ENG2, R6 Option 1, DPZP, ASME Appendices C and $\mathrm{H}$, and Code Case N-494-2. A similar finding was also observed for the combined pressure and bending experiments. For these experiments the maximum stress ratios (i.e., the ratio of the experimental bending stress plus membrane stress due to internal pipe pressure to the maximum predicted bending stress plus the membrane stress due to internal pipe pressure) was independent of outside pipe diameter for most of the analyses considered. The exceptions were the SC.TKP analyses (both SC.TKP1 and SC.TKP2) and the SC.ENG analyses (both SC.ENG1 and SC.ENG2). For these analyses, the trend is that the maximum stress ratio decreases slightly as the outside pipe diameter increases, see Figures 4.55 and 4.56 .

It is also of note from Figures 4.54 through 4.56 that the maximum moments and stress ratios for the SC.TNP2 and SC.ENG2 analyses are higher than the maximum moments and stress ratios for the SC.TNP1 and SC.ENG1 analyses, respectively, but the maximum stress ratios for the SC.TKP1 analysis are higher than the maximum stress ratios for the SC.TKP2 analysis.

\subsubsection{Effect of $R_{m} / t$}

For most of the analysis methods considered there was a slight dependence of the maximum moment ratio for the pure bending experiments on $R_{m} / t$. For most of the analyses, the maximum moment ratio decreased slightly as the $R_{m} / t$ ratio increased. This is probably attributed to the fact that the larger $R_{m} / t$ ratio pipes are more flexible and will have a tendency to ovalize and flatten more when subjected to a. bending load. Figure 4.57 shows the results for the SC.TNP1 and SC.TNP2 analyses. (This trend is fairly consistent with what was observed for the other analyses considered.) The exceptions are the two currently incorporated Section XI methods, Appendix C for austenitic piping and Appendix $\mathrm{H}$ for ferritic piping. For these two methods the maximum moment ratios are nearly independent of the $R_{m} / t$ ratio, see Figure 4.58. It is of note that the third ASME approach, i.e., Code Case $\mathrm{N}-494-2$, does show a dependence on the $\mathrm{R}_{\mathrm{m}} / \mathrm{t}$ ratio, see Figure 4.59. (The same trends hold true for the combined pressure and bend cases, as an example see Figure 4.60 for the SC.ENG1 and SC.ENG2 analyses.) 


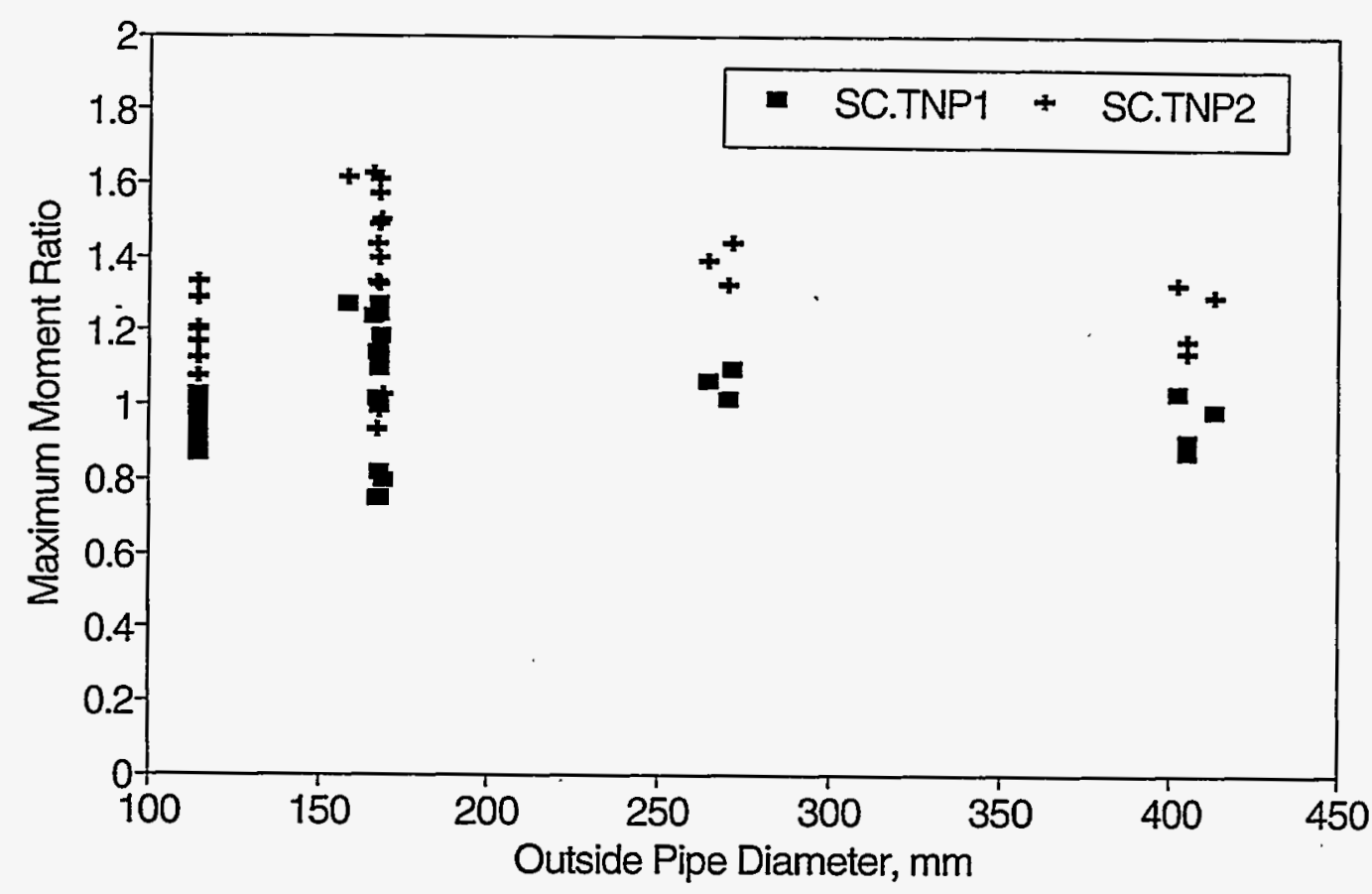

Figure 4.54. Plot of the maximum moment ratio (maximum experimental moment/maximum predicted moment) for the SC.TNP1 and SC.TNP2 analyses as a function of outside pipe diameter for the pure bending experiments

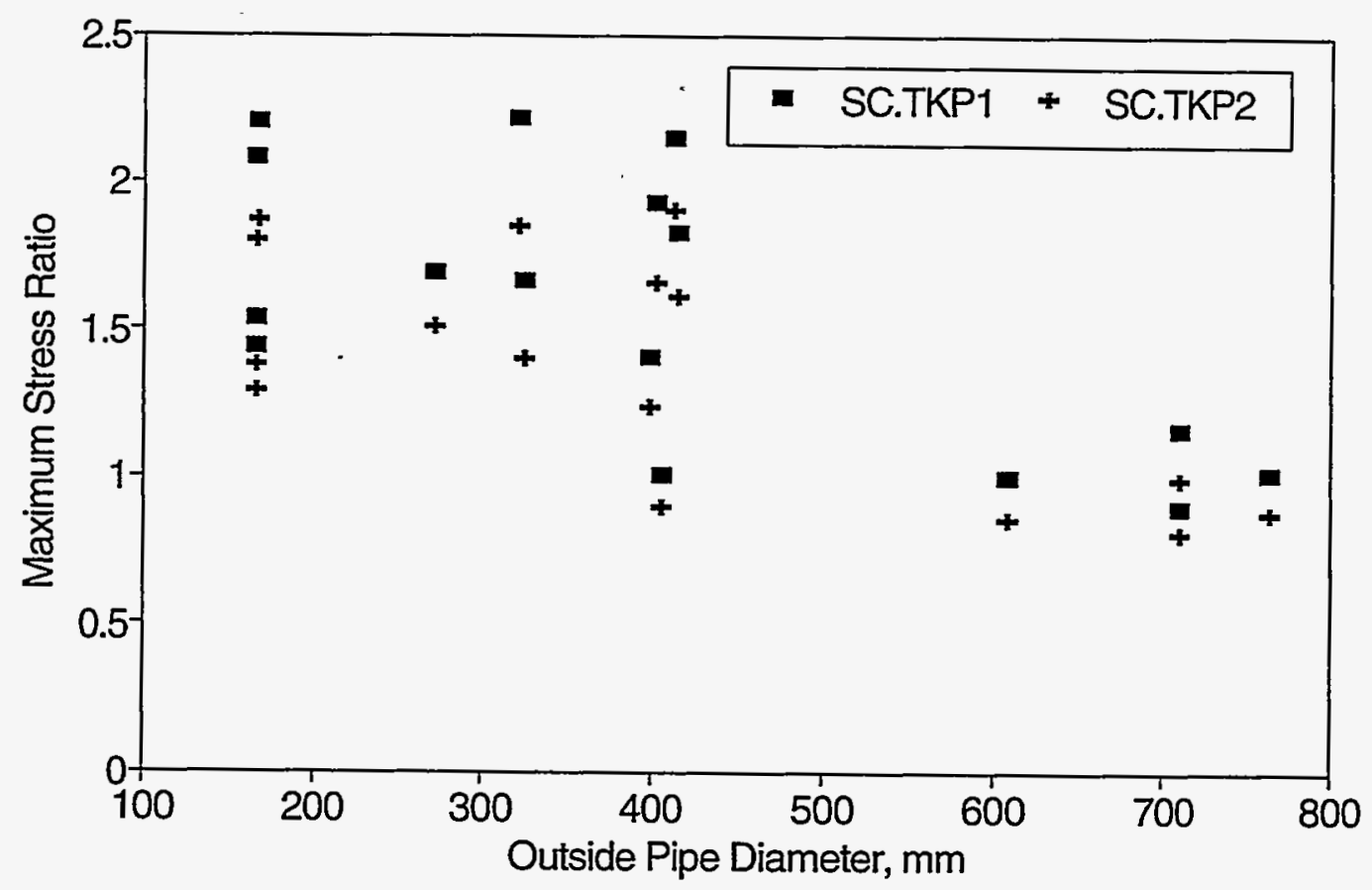

Figure 4.55 Plot of the maximum stress ratio (maximum experimental stress/maximum predicted stress) for the SC.TKP1 and SC.TKP2 analyses as a function of outside pipe diameter for the combined pressure and bend experiments 


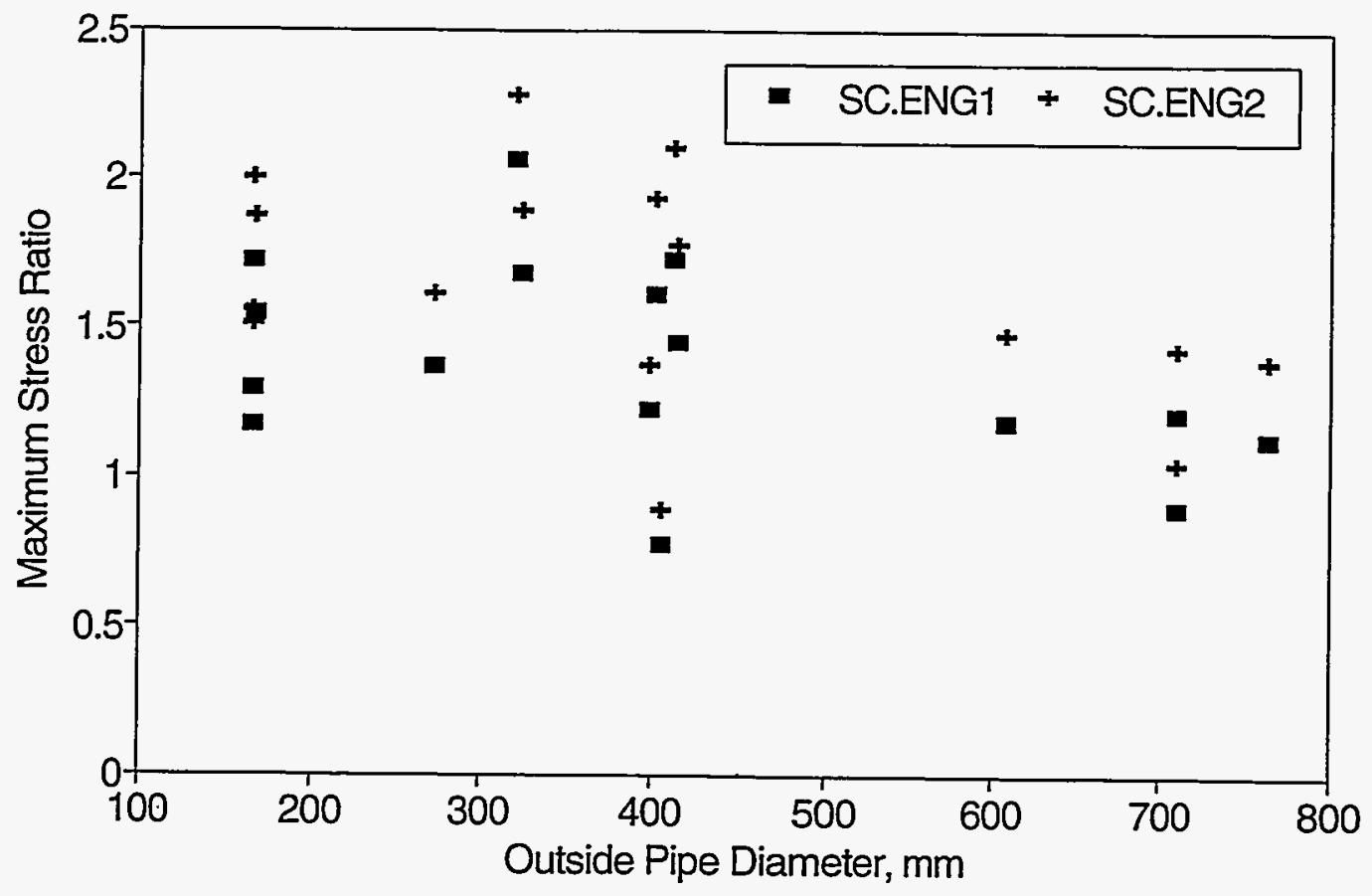

Figure 4.56 Plot of the maximum stress ratio (maximum experimental stress/maximum predicted stress) for the SC.ENG1 and SC.ENG2 analyses as a function of outside pipe diameter for the combined pressure and bend experiments

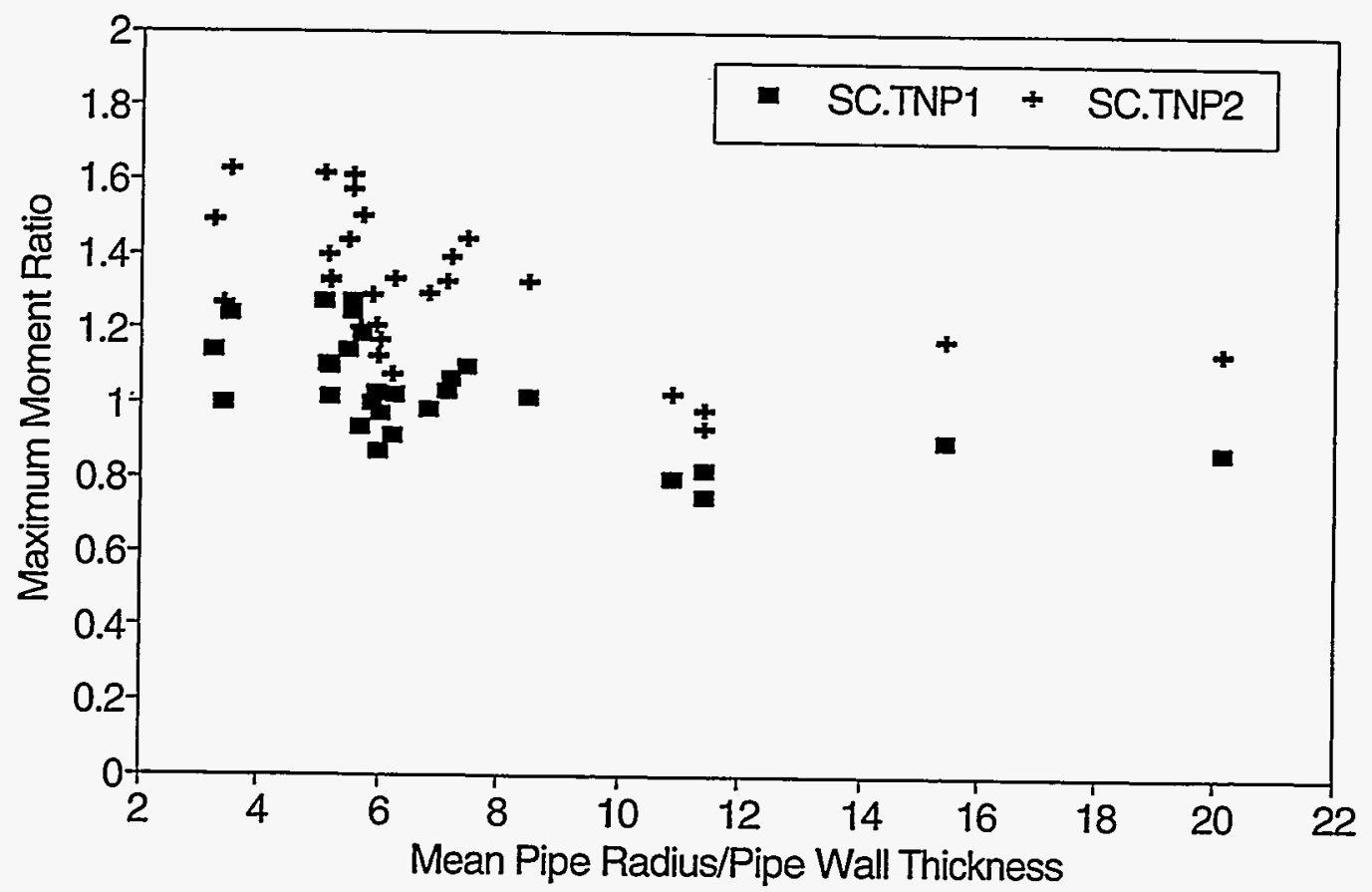

Figure 4.57 Plot of the maximum moment ratio (maximum experimental moment/maximum predicted moment) for the SC.TNP1 and SC.TNP2 analyses as a function of the mean pipe radius-to-pipe wall thickness ratio $\left(R_{m} / t\right)$ for the pure bending experiments 


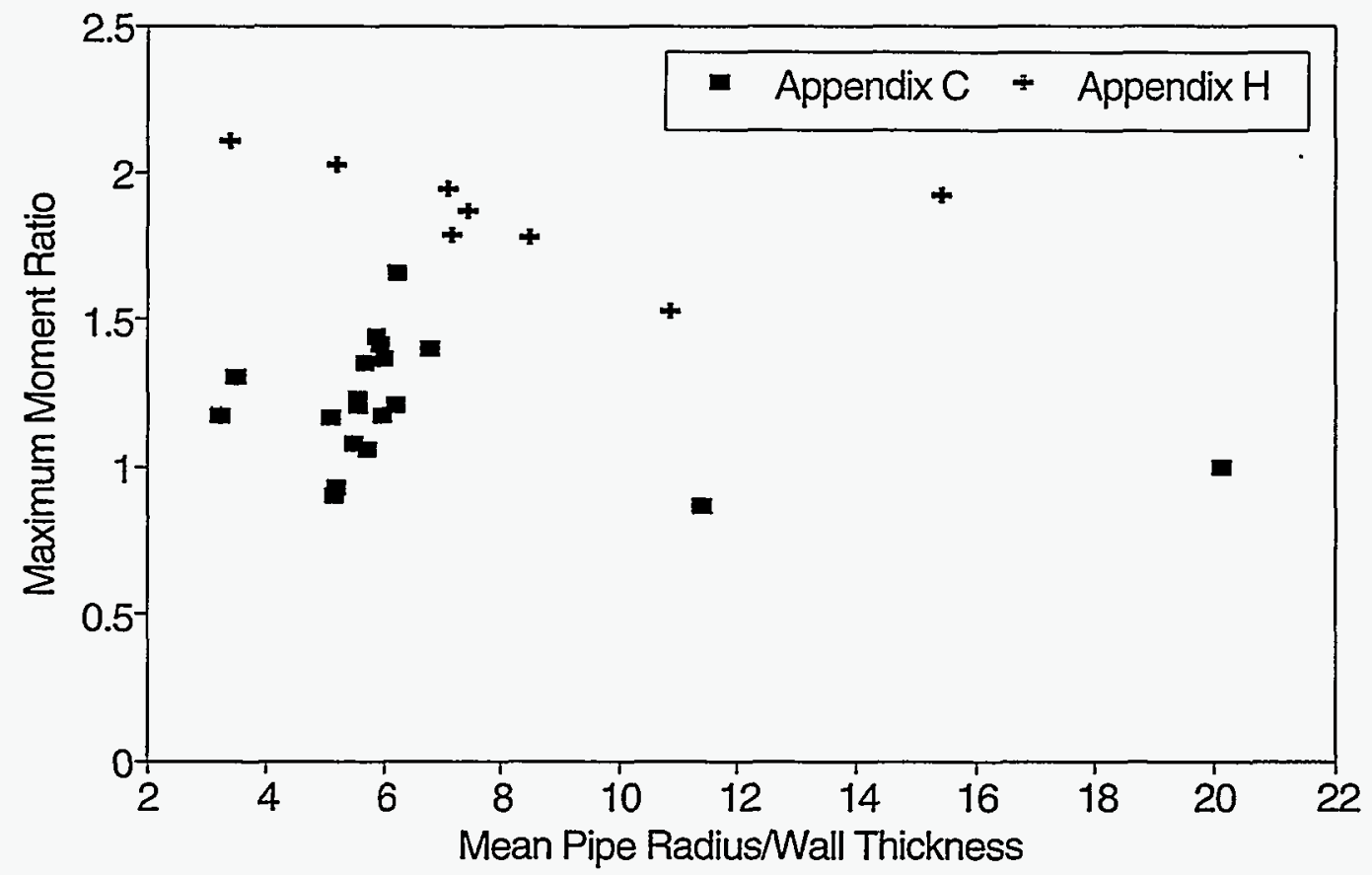

Figure 4.58 Plot of the maximum moment ratio (maximum experimental moment/maximum predicted moment) for the ASME Appendix $C$ and ASME Appendix $\mathrm{H}$ analyses as a function of the mean pipe radius-to-pipe wall thickness ratio $\left(R_{m} / t\right)$ for the pure bending experiments

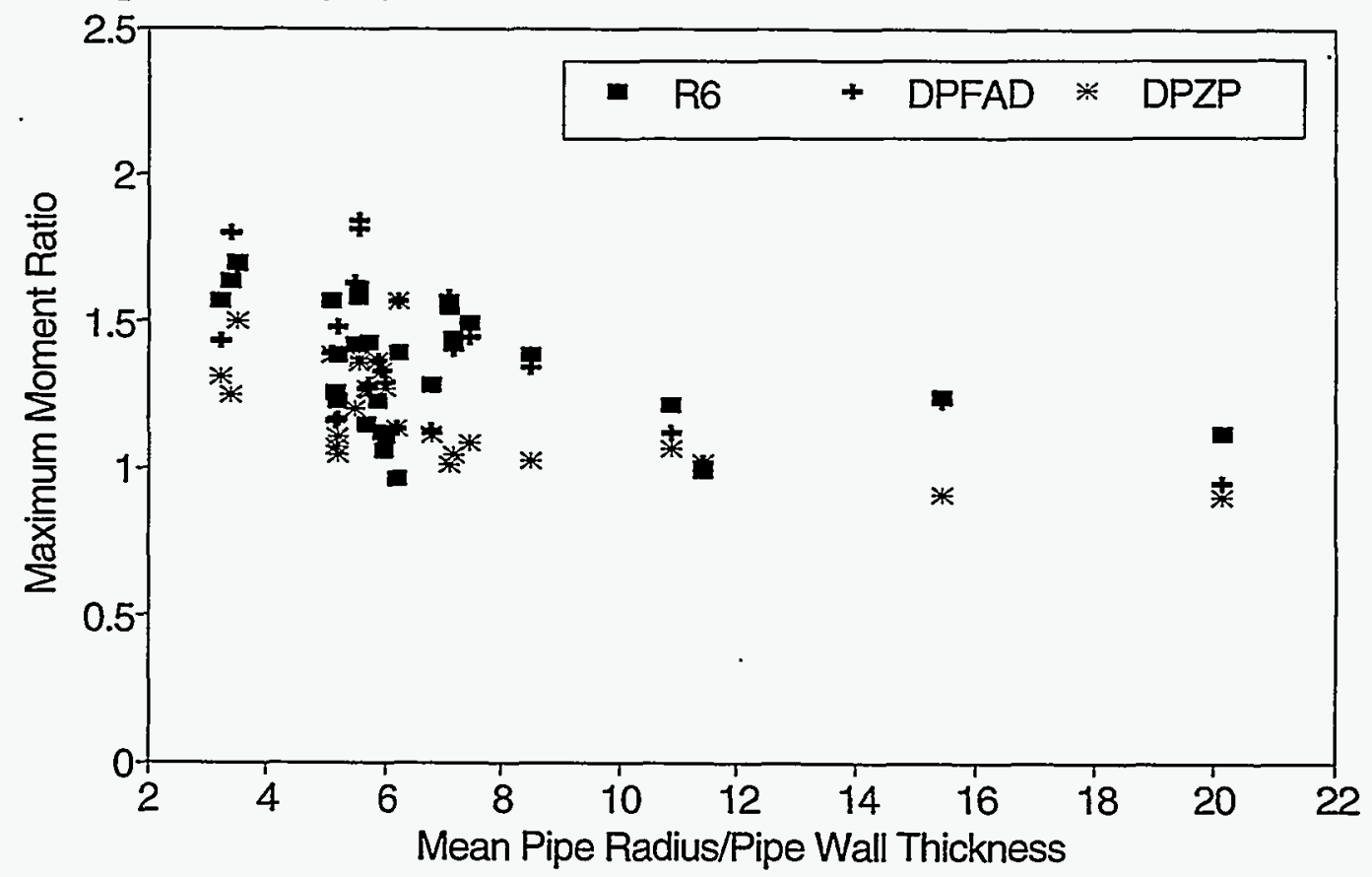

Figure 4.59 Plot of the maximum moment ratio (maximum experimental moment/maximum predicted moment) for the R6, Code Case N-494-2, and DPZP analyses as a function of the mean pipe radius-to-pipe wall thickness ratio $\left(R_{m} / t\right)$ for the pure bending experiments 


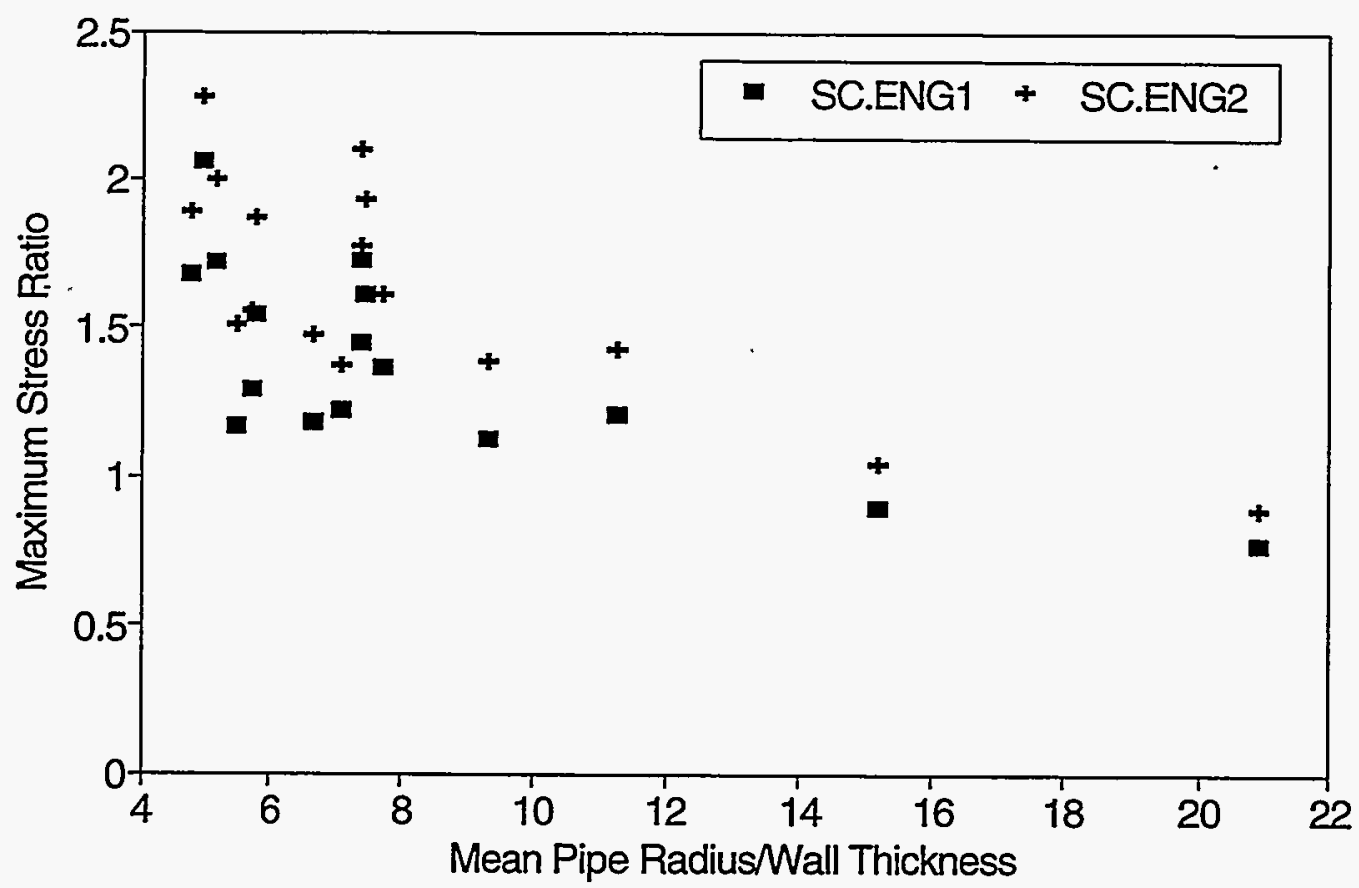

Figure 4.60 Plot of the maximum stress ratio (maximum experimental stress/maximum predicted stress) for the SC.ENG1 and SC.ENG2 analyses as a function of the mean pipe radius-to-pipe wall thickness ratio $\left(R_{m} / t\right)$ for the combined pressure and bend experiments

Of particular note is the effect of the $R_{m} / t$ ratio on the maximum moment ratio for the SC.TKP analyses. Figure 4.61 is a plot of the maximum moment ratio as a function of the $R_{m} / t$ ratio for the pure bending experiments for the SC.TKP1 and SC.TKP2 analyses. Of note from this plot are the three experiments $\left(4112-4,4112-7\right.$, and 1.2.1.21) for which the $R_{m} / t$ ratios are less than 4 . In each case the maximum experimental moments were only about half of the maximum predicted moments. The reason for this is that the $\bar{G}_{N}$ functions used in the SC.TKP analyses are tabulated only for $R_{i} / t$ values of 5,10 , and 20 . These $G_{N}$ functions are also extremely sensitive to the $R_{i} / t$ ratio, especially at the low end of the scale, i.e, at $\mathrm{R}_{\mathrm{i}} / \mathrm{t}$ values close to 5 . Small changes in $\mathrm{R}_{\mathrm{i}} / \mathrm{t}$ cause large changes in $G_{N}$, which results in large changes in the predictions. The algorithms embodied in the NRCPIPES code for the SC.TKP analyses use the $G_{N}$ values for $R_{i} / t$ values of 5 or 20 if the actual $R_{i} / t$ value is outside this range, which led to larger errors outside of this range. Figure 4.62 illustrates this point further. Figure 4.62 is a plot of the ratio of the predicted Net-Section-Collapse moment-to-the predicted SC.TKP1 moment as a function of $\mathrm{R}_{\mathrm{i}} / \mathrm{t}$ for a series of 6 -inch nominal diameter stainless steel pipes with different wall thicknesses. The material properties used in this analysis were those of the 6-inch nominal diameter, Schedule XXS, stainless steel pipe evaluated in Experiment $4112-4$ 


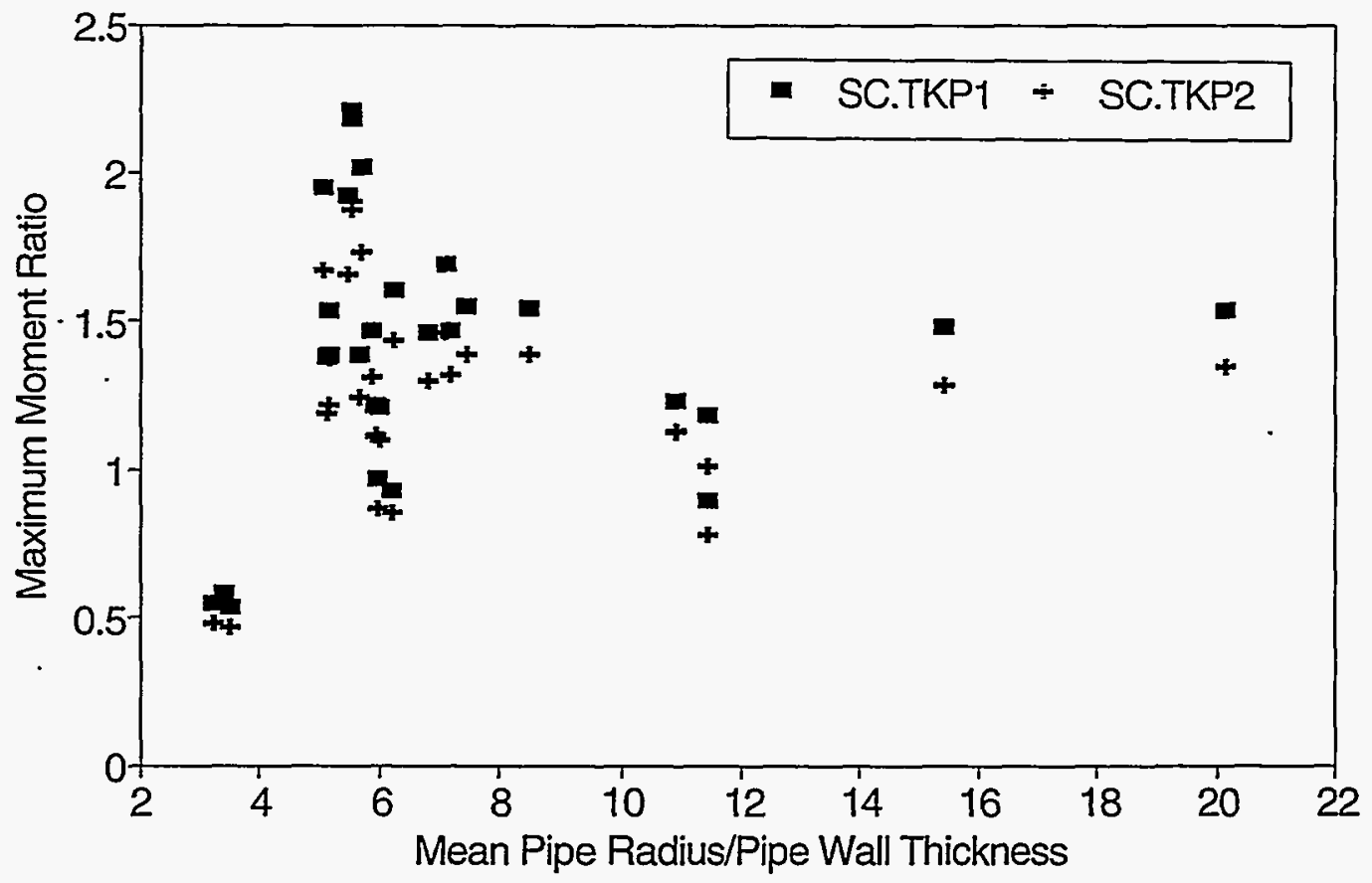

Figure 4.61 Plot of the maximum moment ratio (maximum experimental moment/maximum predicted moment) for the SC.TKP1 and SC.TKP2 analyses as a function of the mean pipe radius-to-pipe wall thickmess ratio $\left(R_{m} / t\right)$ for the pure bending experiments

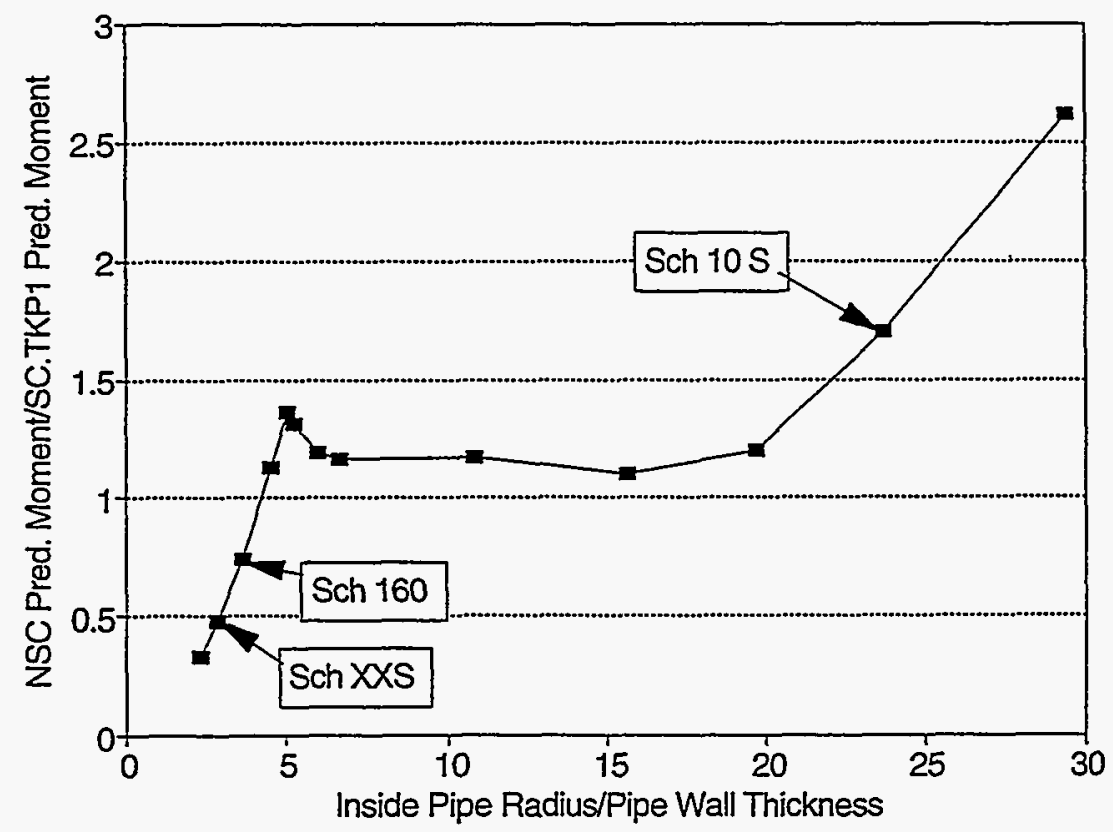

Figure 4.62 Plot of the ratio of the Net-Section-Collapse predicted moment to the SC.TKP1 predicted moment as a function of the inside pipe radius-to-pipe wall thickness ratio for the case of a 6-inch nominal diameter, stainless steel pipe with a crack 50 percent of the pipe wall thickness in depth and 50 percent of the pipe circumference in length 
from the Degraded Piping Program (Ref. 4.27) and Experiment 1.2.1.21 from this program. The crack evaluated in this analysis was a crack 50 percent of the pipe circumference in length and 50 percent of the pipe wall thickness in depth. By choosing this small diameter, high toughness pipe material for this analysis, fully-plastic conditions should exist such that the Net-Section-Collapse analysis should provide a very reasonable estimate of the actual failure moments. Consequently, the ratio of the Net-Section-Collapse predictions to the SC.TKP1 predictions should provide a reasonable evaluation of the accuracy of the SC.TKP1 analyses. From Figure 4.62 it can be seen that the SC.TKP1 analysis did a very reasonable job of following the trends for the Net-Section-Collapse moments when the $R_{i} / t$ ratios were between 5 and 20 , which is the regime for which the valid $G_{N}$ factors exist. However, outside this range in $\mathrm{R}_{\mathrm{j}} / \mathrm{t}$, the SC.TKP1 analysis begins to deviate significantly from the Net-Section-Collapse analysis, especially when the $\mathrm{R}_{\mathbf{i}} / \mathrm{t}$ ratio is less than $\mathbf{5}$. In those cases the SC.TKP1 analysis significantly overpredicts the Net-Section-Collapse moments, which are probably a reasonable approximation of the actual failure moments for this relatively small diameter, high toughness pipe. Consequently, these analyses (SC.TKP1 and SC.TKP2) in the NRCPIPES Code should not be used if the $\mathrm{R}_{\mathrm{i}} / \mathrm{t}$ ratio is outside the range of 5 to 20 . They should especially not be used for very thick wall pipe, with low $R_{\mathrm{i}} / t$ ratios, because in this regime the analyses can significantly overpredict the actual failure moments. Consequently, the perception that the SC.TKP (ThicK Pipe) analyses should be used in lieu of the SC.TNP (ThiN Pipe) analyses for thick-wall pipe calculations is not valid.

\subsubsection{Effect of Normalized Crack Length $(\theta / \pi)$}

For the pure bending experiments, the maximum moment ratio was independent of the normalized crack length $(\theta / \pi)$ for each of the analysis methods. As an example, Figure 4.63 shows the maximum moment ratio as a function of the normalized crack length for the SC.TNP1 and SC.TNP2 analyses. On the other hand, for the combined pressure and bend experiments, the maximum stress ratio does show a slight dependence on crack length for a number of the predictive analyses.

Figures 4.64 and 4.65 show the maximum stress ratios as a function of normalized crack length for the combined pressure and bend experiments for the SC.TNP1 and SC.TNP2 and SC.ENG1 and SC.ENG2 analyses, respectively. As can be seen from these figures, as the normalized crack length increases, the maximum stress ratio also increases.

\subsubsection{Effect of Normalized Crack Depth $(a / t)$}

For the pure bending experiments, the maximum moment ratios for the SC.ENG1 and SC.ENG2 methods show a slight dependence on the normalized crack depth $(\mathrm{a} / \mathrm{t})$, see Figure 4.66. The other analysis methods considered, i.e., SC.TNP1, SC.TNP2, SC.TKP1, SC.TKP2, R6 Option 1, DPZP, Code Case $\mathrm{N}-494-2$, and ASME Appendices $\mathrm{C}$ and $\mathrm{H}$ are essentially independent of crack depth for the pure bending case. However, such is not the case for the combined pressure and bend experiments. The maximum stress ratios for the SC.TNP, SC.TKP, SC.ENG, and R6 Option 1 analyses increased, and in some cases significantly increased, as the normalized crack depth (a/t) increased for the combined loading experiments. Figure 4.67 shows this trend for the SC.ENG1 and SC.ENG2 analyses. The maximum stress ratios for the DPZP, Code Case N-494-2, and ASME Appendices $\mathrm{C}$ and $\mathrm{H}$ analyses tended to be independent of crack depth. 


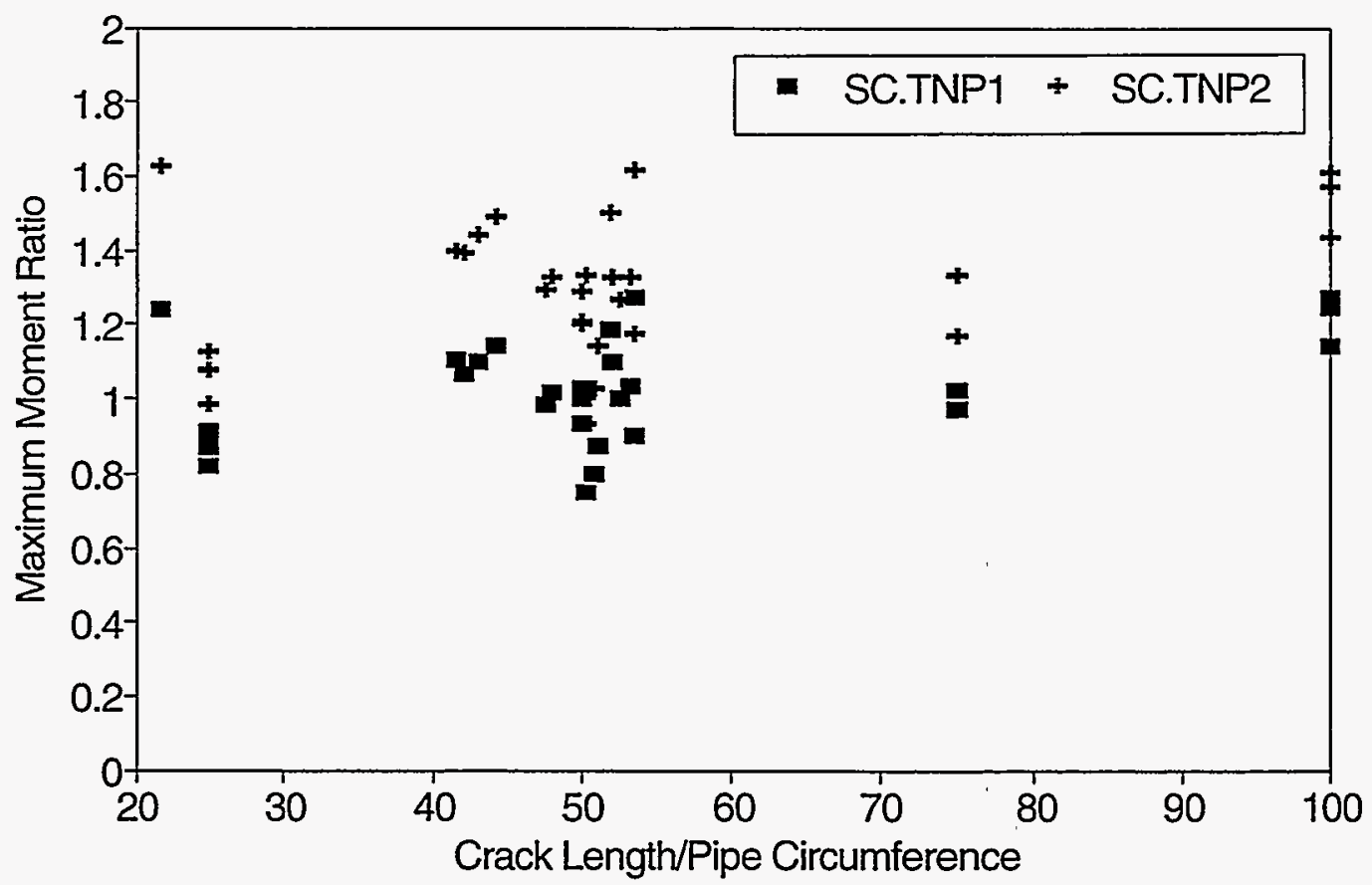

Figure 4.63 Plot of the maximum moment ratio (maximum experimental moment/maximum predicted moment) for the SC.TNP1 and SC.TNP2 analyses as a function of the crack length-to-pipe circumference ratio $(\theta / \pi)$ for the pure bending experiments

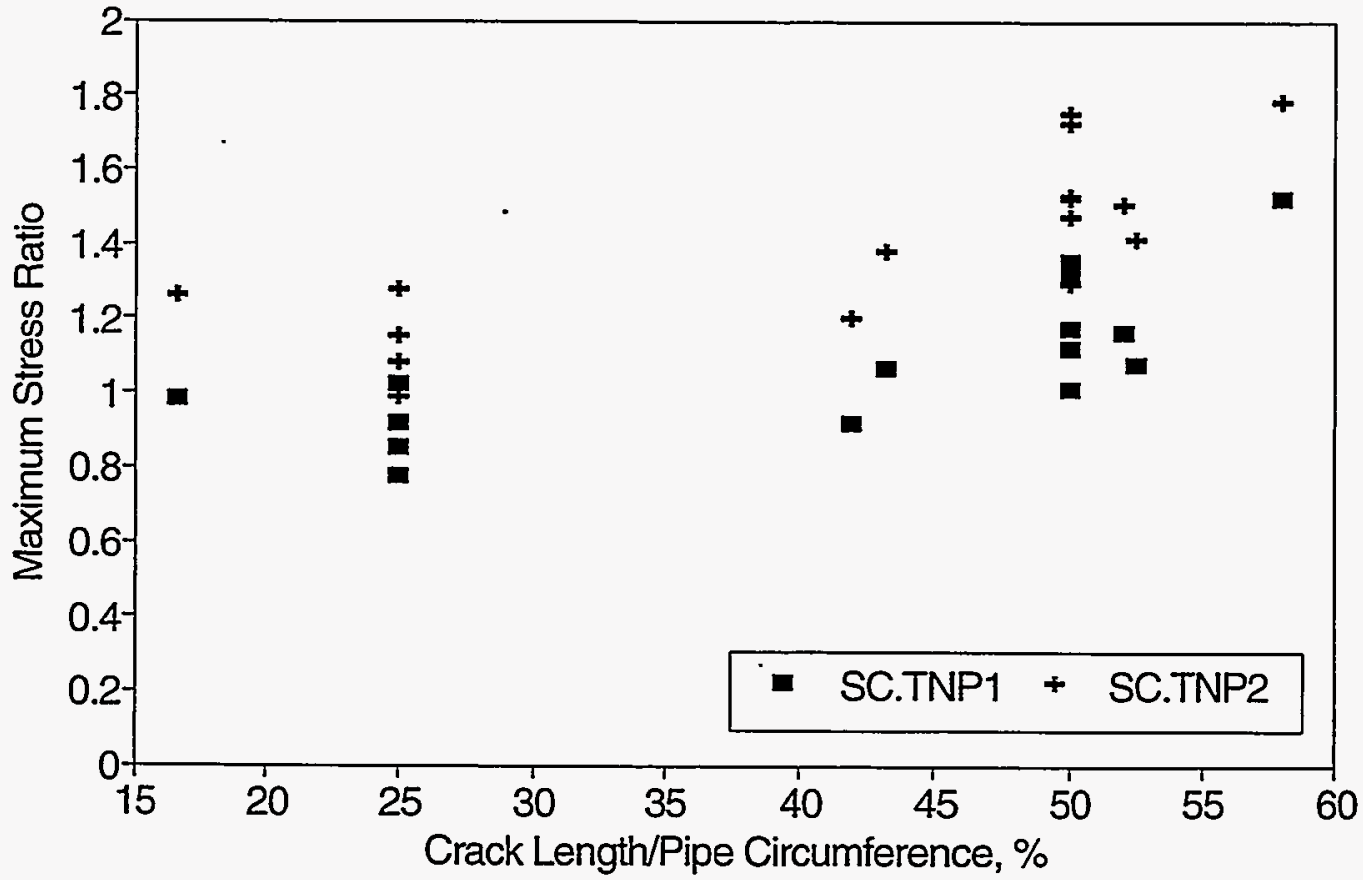

Figure 4.64 Plot of the maximum stress ratio (maximum experimental stress/maximum predicted stress) for the SC.TNP1 and SC.TNP2 analyses as a function of the crack length-to-pipe circumference ratio $(\theta / \pi)$ for the combined pressure and bend experiments 


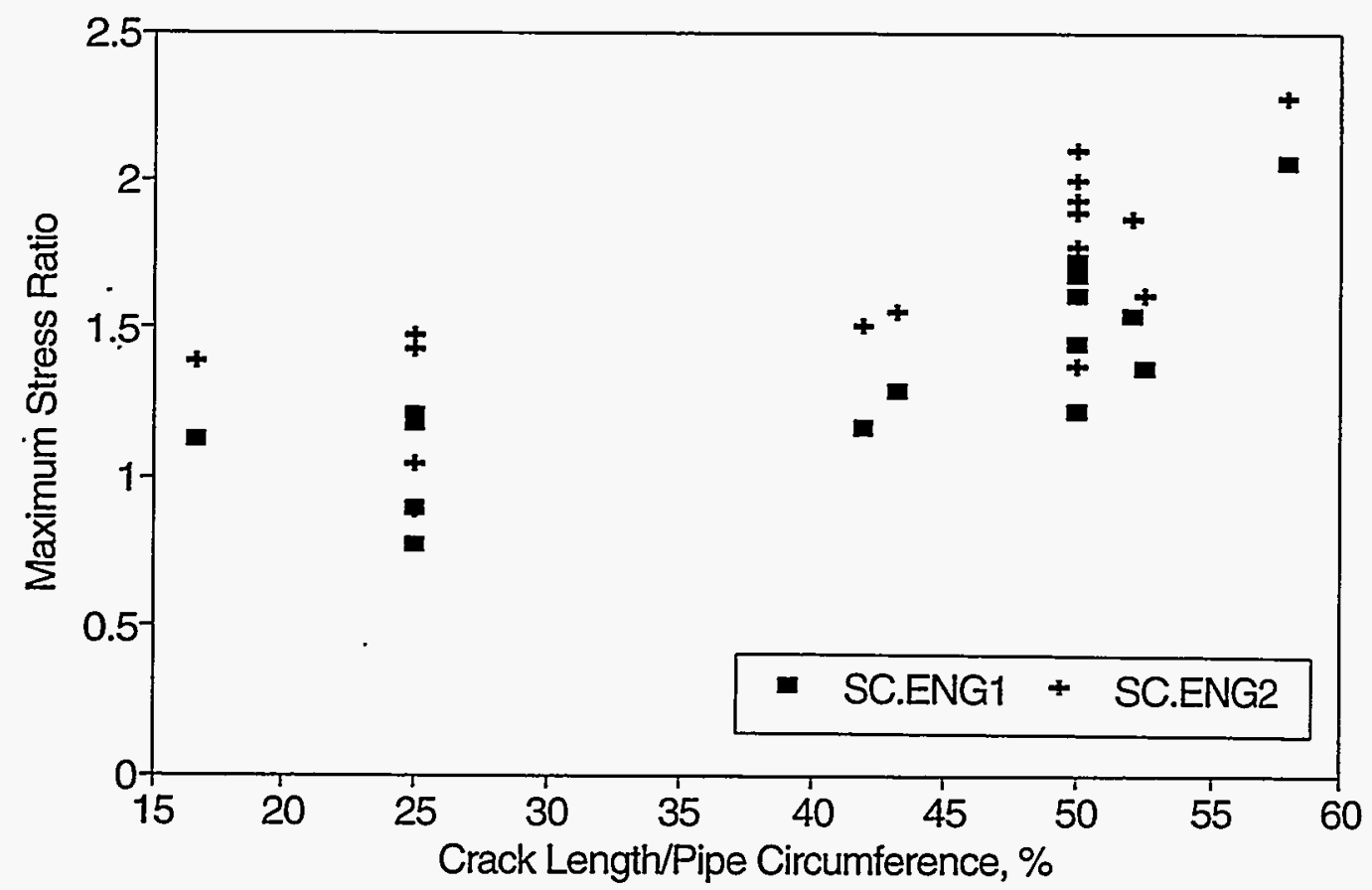

Figure 4.65 Plot of the maximum stress ratio (maximum experimental stress/maximum predicted stress) for the SC.ENG1 and SC.ENG2 analyses as a function of the crack length-to-pipe circumference ratio $(\theta / \pi)$ for the combined pressure and bend experiments

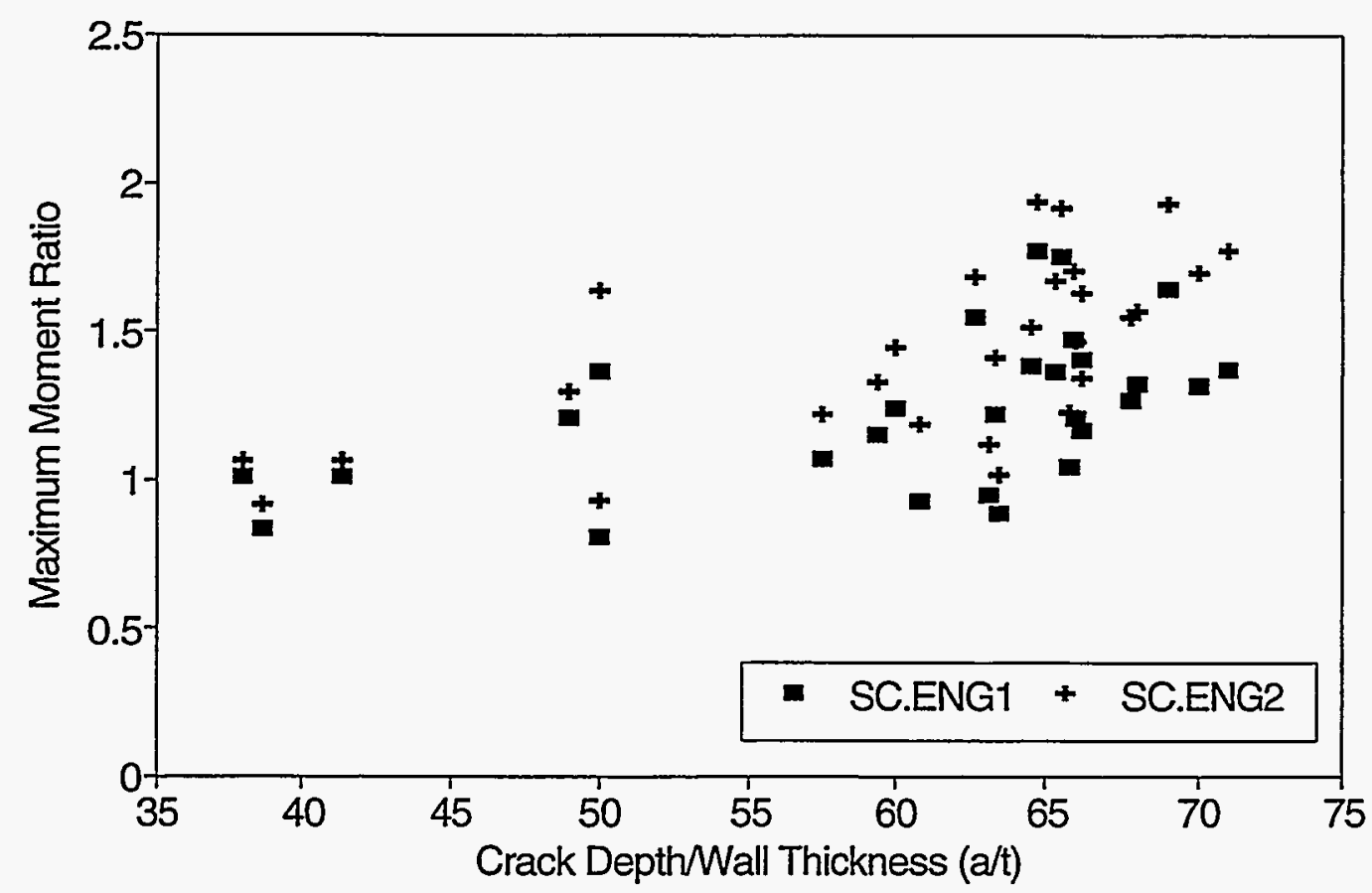

Figure 4.66 Plot of the maximum moment ratio (maximum experimental moment/maximum predicted moment) for the SC.ENG1 and SC.ENG2 analyses as a function of the crack depth-to-pipe wall thickness ratio $(a / t)$ for the pure bending experiments 


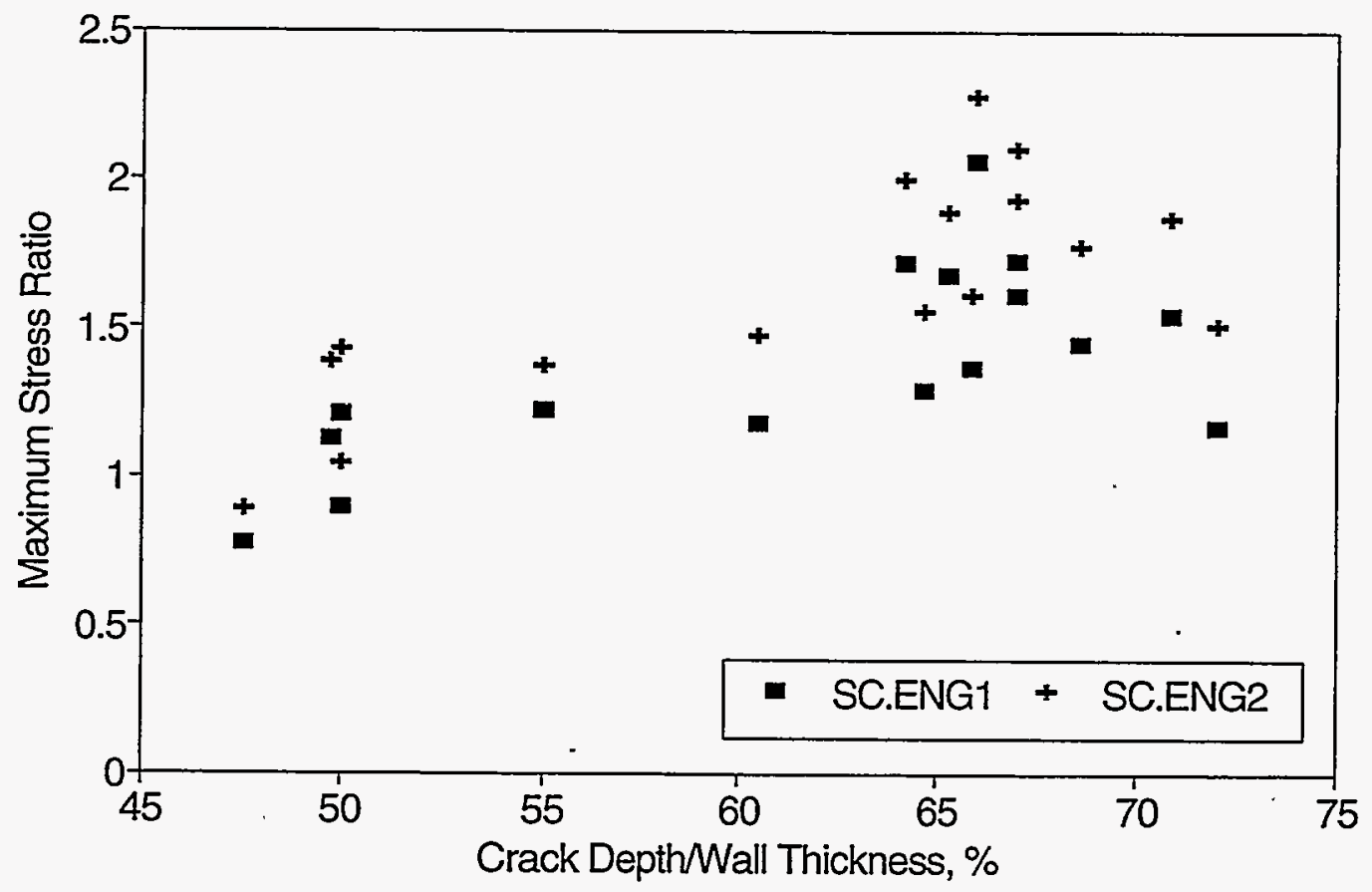

Figure 4.67 Plot of the maximum stress ratio (maximum experimental stress/maximum predicted stress) for the SC.ENG1 and SC.ENG2 analyses as a function of the crack depth-to-pipe wall thickness ratio (a/t) for the combined pressure and bend experiments

Figure 4.68 shows the results of a similar analysis as used in the development of Figure 4.62. Figure 4.68 is a plot of the ratio of the predicted Net-Section-Collapse stress plus the membrane stress due to internal pipe pressure to the predicted SC.ENG1 stress plus the membrane stress due to internal pipe pressure as a function of the normalized crack depth (a/t). The pipe used in this analysis is a 6-inch nominal diameter, Schedule 40 stainless steel pipe. The $R_{\mathrm{i}} / t$ ratio for this pipe is approximately 11 . The material properties assumed in this analysis were those of the 6-inch nominal diameter, Schedule XXS, stainless steel pipe evaluated in Experiments $4112-4$ and 1.2.1.21. This is the same material data used in the analysis that formed the basis for Figure 4.62. Both pure bending and combined pressure and bending load conditions were assumed in these analyses. For the combined pressure and bending load case, the internal pipe pressure was set at $6.895 \mathrm{MPa}(1,000 \mathrm{psi})$. 'The crack length assumed in this analysis was set at 50 percent of the pipe circumference. The crack depth was then varied from 10 to 90 percent of the pipe wall thickness to see the effect of a/t on the SC.ENG1 analysis method. By choosing this relatively small diameter, high toughness pipe material for this analysis, fully-plastic conditions should exist such that the Net-Section-Collapse analysis should provide a reasonable estimate of the actual failure stresses. Consequently, the ratio of the NetSection-Collapse predicted stress to the SC.ENG1 predicted stress should provide a reasonable evaluation of the accuracy of the SC.ENG1 analysis method. In examining Figures 4.67 and 4.68 , it can be seen that the shape of the curves in Figure 4.68 are similar to the trends in the actual data plotted in Figure 4.67, i.e., as the normalized crack depth (a/t) increases, the ratio of the failure

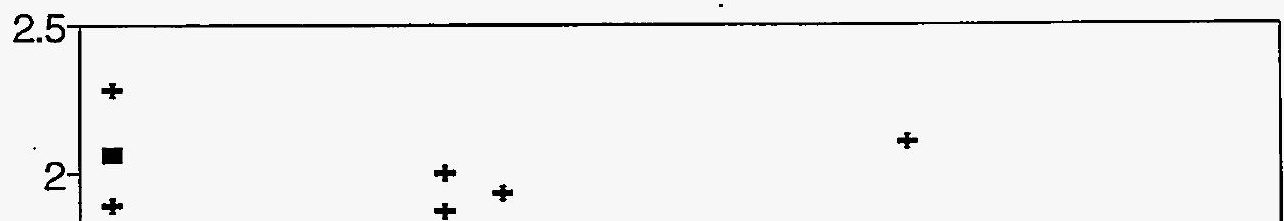




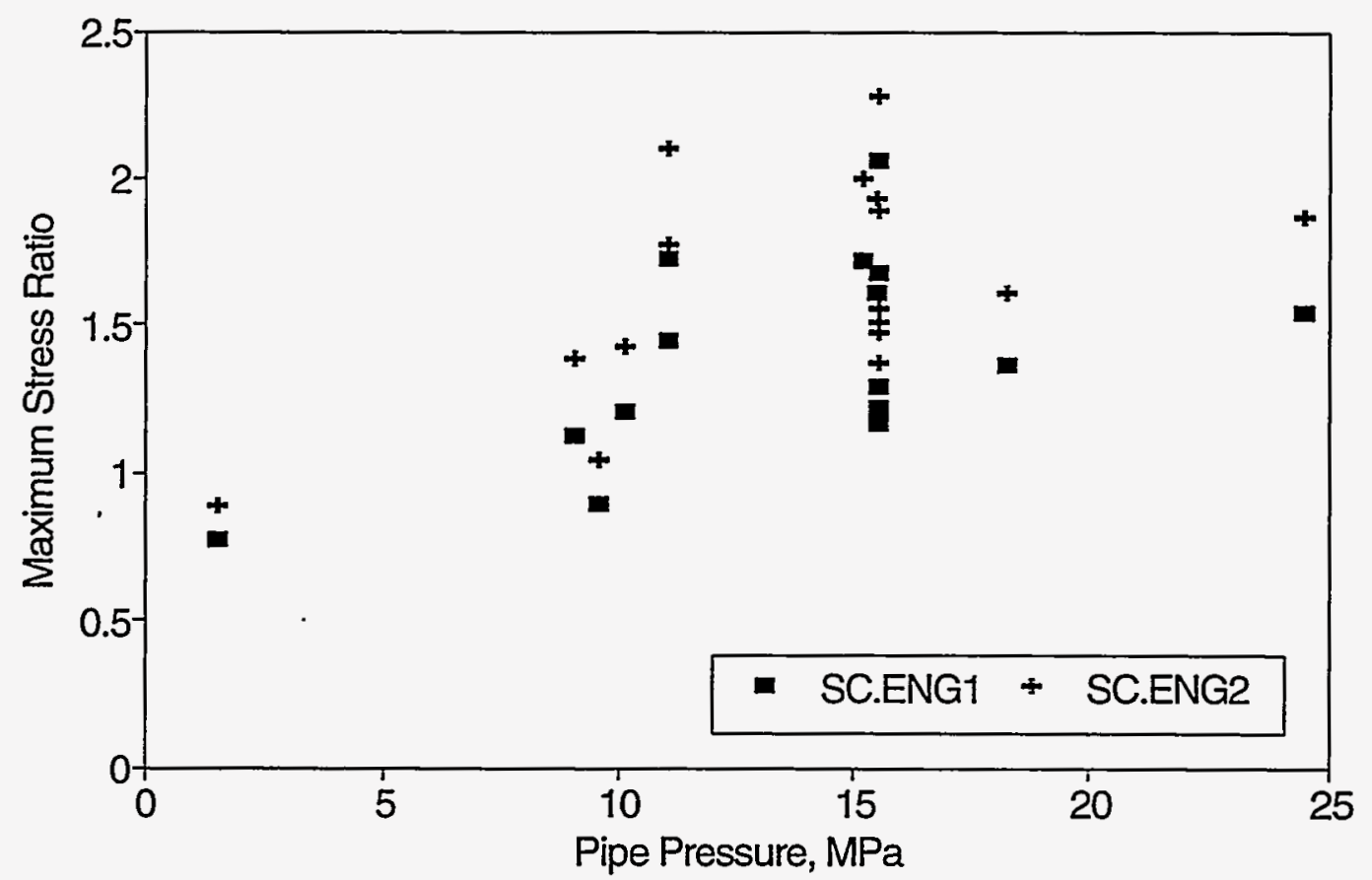

Figure 4.70 Plot of the maximum stress ratio (maximum experimental stress/maximum predicted stress) for the SC.ENG1 and SC.ENG2 analyses as a function of the internal pipe pressure for the combined pressure and bend experiments

specific parameters of concern to the analysis. Of the two SC.TNP analyses, the SC.TNP1 method will on average result in a more accurate prediction of load although the likelihood of overpredicting the actual failure stresses is higher using this method than it is in using the SC.TNP2 method.

Of all the analysis methods considered, the simple DPZP method seems to be the least dependent on the six test parameters considered in this exercise. It is also one of the more accurate methods, based on its average value of the maximum moment or stress ratio and its standard deviation.

\subsection{Effect of Anisotropy and Constraint on Toughness}

As shown earlier in this report, the SC.TKP2, SC.TNP2, SC.ENG1 and SC.ENG2 analyses were found to agree the best with $\mathrm{J}$ values from finite element analyses, but underpredicted the loads more than anticipated. This may be due to using the J-R curve data from L-C oriented $C(T)$ specimens. The L-C orientation corresponds to the crack growing as a circumferential through-wall crack around the pipe circumference, whereas the surface crack growth is in the radial or L-R orientation.

Furthermore, there may also be effects of constraint between the $C(T)$ specimen and a surface crack in a pipe that also differ. The effect of these parameters are discussed below in reference to the surface-cracked pipe predictions. 


\subsubsection{Anisotropy}

The effects of specimen orientation on the toughness of ferritic steels is well known. Typically the fracture toughness in the rolling direction is much lower than that in the direction transverse to the rolling. Furthermore, there is also evidence in the literature that the toughness through the thickness is much higher than the toughness of a crack growing as a through-thickness crack. Figure 4.71 is from WRC Bulletin 175 (Ref. 4.39), which shows that for an A106 Grade B pipe the toughness in the L-R orientation (corresponding to the circumferential surface crack growth direction, i.e., Specimen D in Figure 4.71) was about 2.7 times greater than the L-C orientation (direction corresponding to circumferential through-wall crack growth, i.e., Specimen C [in Figure 4.71]). This is about the same ratio as was found by Lereim (Ref. 4.40) for a high-strength low-alloy (HSLA) steel used for gas pipeline applications.

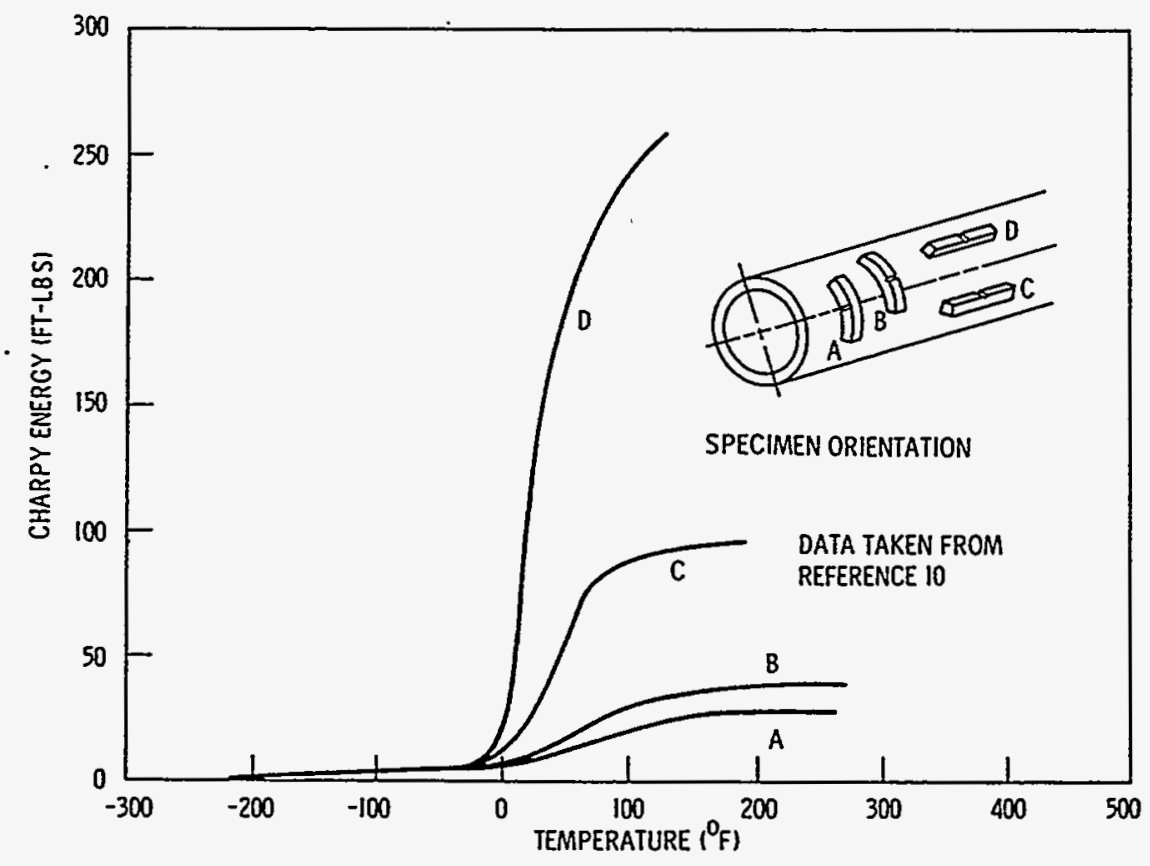

Figure 4.71 Toughness anisotropy of ASTM A 106B pipe (Note: Reprinted with permission) 
Additional data were developed at Battelle on a plate of A516 Grade 70 steel (Battelle material DP2F40). Table 4.19 gives the Charpy upper shelf values and $J_{i}$ values in the $L-C$ and $L-R$ orientations. The Charpy energy ratio for the specimen was greater than a factor of 2.51. (The Charpy L-R orientated specimen had 298 Joules ( $219 \mathrm{ft}-\mathrm{lb}$ ) of energy but did not break in half.)

The $\mathrm{J}_{\mathrm{i}}$ values were obtained from a $1 \mathrm{~T} \mathrm{C}(\mathrm{T})$ specimen in the $\mathrm{L}-\mathrm{C}$ orientation and a single-edge notched tension, SEN(T) specimen in the L-R orientation, Ref. 4.41. This SENT specimen had a width of $25.4 \mathrm{~mm}$ (1.0 inch) which was typical of many of the pipes tested in that program. Both the $C(T)$ and SEN(T) specimens had $a / w$ values of 0.5 . Thus the results from these tests will not only have anisotropy but constraint differences. The $\mathrm{J}_{\mathrm{i}}$ values from the two specimens had a ratio of 2.97 with the highest toughness in the L-R orientation.

In summary, these results showed that for ferritic base metals, the toughness can be from 2.5 to 3 times higher in the L-R orientation. Unfortunately, the L-R orientation toughness is seldom determined, even with Charpy specimens, so it was not possible to reanalyze the surface-cracked pipe experiments with such data. Furthermore, very little is known about the orientation effects in austenitic stainless steel, austenitic welds, or ferritic welds. Their toughness differences due to anisotropy in the L-R versus L-C orientation are expected to be different from the ferritic base metals.

To evaluate the effects of toughness anisotropy on a wrought stainless steel, a few Charpy tests were done on Pipe DP2-A8 material, which was a wrought TP304 stainless steel. The data are in Table 4.20. These data showed that there was essentially no difference in the toughness of wrought TP304 stainless steel related to the two orientations. This was expected since there are no inclusions in the TP304 stainless steel that are similar to the manganese-sulfide inclusions in ferritic steels. However, it should be noted that TP304 stainless steel wrought base metal has sufficient toughness that generally the failures are near limit load, and analyses with higher toughness values should not give higher failure loads.

\subsubsection{Constraint}

The topic of constraint effects on fracture is currently in an evolving phase. Much work is being done in the area to quantify effects that have been known to exist for decades. Two prevailing constraint parameters are the T-stress (Ref. 4.42) and J-Q parameter (Ref. 4.43). Reference 4.44 gives a good comparison of T-stress parameters from many specimen geometries, including a C(T) specimen and a circumferential surface crack in a pipe. These results show positive $T$ values for $C(T)$ specimens, indicative of high constraint conditions, and negative $T$ values for the circumferential surface crack in a cylinder, indicative of low constraint conditions. The low constraint condition means that the apparent toughness of the material in this geometry will be higher than in the $C(T)$ specimen. The qualitative effects of these differences in the T-stress values on toughness are not known for the materials of concern, and the relative magnitude of the effect of constraint to the anisotropy effects is not known. Nevertheless, the constraint aspects would contribute to the surfacecracked pipe toughness being higher than the $C(T)$ specimen values.

The higher toughness of the surface-cracked pipe is further substantiated by axial surface-cracked-pipe tests cited in Reference 4.45. In Reference 4.45, it was shown that the brittle-to-ductile transition 
Table 4.19 Toughness anisotropy data for an A516 Grade 70 Steel (Battelle Pipe DP2-F40)

$$
\begin{aligned}
& \text { (a) Chemistry } \\
& \text { Sulfur }=0.013 \text { percent } \\
& \text { Manganese }=1.080 \text { percent }
\end{aligned}
$$

(b) Charpy Upper Shelf Energy, Joules (ft-lb)

[Full-size specimens at $65.6 \mathrm{C}(150 \mathrm{~F})$ ]

\begin{tabular}{ccc}
\hline Orientation $^{(a)}$ & $\begin{array}{c}\text { Number of } \\
\text { Specimens }\end{array}$ & $\begin{array}{c}\text { Impact Energy, } \\
\text { Joules (ft-lb) }\end{array}$ \\
\hline T-L & 6 & $53.42(39.4)$ \\
T-S & 6 & $70.61(52.08)$ \\
L-T & 3 & $118.2(87.17)$ \\
L-S & 3 & $297.1(219.17)^{(b)}$ \\
\hline
\end{tabular}

(a) T- $\mathrm{L}$ orientation in plate is same as $\mathrm{C}-\mathrm{L}$ orientation in pipe. $S$ direction in plate is the same as the $R$ direction in pipe, i.e., $\mathrm{L}-\mathrm{S}=\mathrm{L}-\mathrm{R}$.

\begin{tabular}{|c|c|c|}
\hline Orientation & $\begin{array}{c}\text { Specimen } \\
\text { Type }_{(a)}\end{array}$ & $\begin{array}{c}\mathbf{J}_{\mathbf{i}}, \\
\mathrm{kJ} / \mathrm{m}^{2}\left(\mathbf{i n}-\mathbf{l b} / \mathbf{i n}^{2}\right)\end{array}$ \\
\hline $\mathrm{L}-\mathrm{T}$ & $1 \mathrm{~T} C(\mathrm{~T})$ & $235(1,345)$ \\
\hline L-S & SEN(T) & $700(4,000)$ \\
\hline
\end{tabular}

(b) Specimens did not break.

(c) $\mathrm{J}_{\mathrm{i}}$ values at $288 \mathrm{C}(550 \mathrm{~F})$

(d) Toughness Ratio

\begin{tabular}{cc}
\hline Test Method & $\begin{array}{c}\text { Toughness Ratio } \\
(\mathbf{L}-\mathrm{S}) /(\mathrm{L}-\mathrm{T})\end{array}$ \\
\hline Charpy & $>2.51$ \\
$\mathrm{~J}_{\mathrm{i}}$ & 2.97 \\
\hline
\end{tabular}


4.16 Zahoor, A., "Analysis of Part Through-Wall Crack in a Pipe Under Combined Tension and Bending," Journal of Engineering Materials \& Technology, Vol. 114, pp. 245-249, July 1992.

4.17 Brust, F. W., "Approximate Methods for Fracture Analyses of Through-Wall-Cracked Pipes," NUREG/CR-4853, February 1987.

4.18 Wilkowski, G. M. and others, "Short Cracks in Piping and Piping Welds," NUREG/CR-4599, Vol. 3, No. 2, February 1994.

4.19 Mesloh, R. E., Sorenson, J. E., and Atterbury, T. J., "Buckling Offshore Pipelines, " Gas Magazine, pp. 40-43, July 1973.

4.20 Johns, T. G., Mesloh, R. E., Winegardner, R., and Sorenson, J. E., "Inelastic Buckling of Pipelines Under Combined Loads," Seventh Offshore Technology Conference, Paper OTC 2209, Vol. 1, May 1975.

4.21 ABAQUS, User's Guide and Theoretical Manual, Version 5.3, Hibbitt, Karlsson, and Sorensen, Inc., Pawtucket, RI, 1993.

4.22 Yasuda, Y. and others, "Investigations on Ductile Fracture Behavior of 3-Inch-Diameter Type 304 Stainless Steel Pipe with a Circumferential Through-Wall Crack," JAERI-87-068, 1987.

4:23 "Technical Report on the Piping Reliability Proving Tests at the Japan Atomic Energy Research Institute," JAERI-M93-076, 1993.

4.24 Kassir, M. K. and others, "Analysis of Crack Initiation and Growth in the High Level Vibration Test at Tadotsu," NUREG/CR-6078, August 1993.

4.25 Wilkowski, G. M. and others, "Short Cracks in Piping and Piping Welds," NUREG/CR-4599, Vol. 1, No. 2, March 1992.

4.26 Shih, C. F. and Hutchinson, J. W., "Combined Loading of a Fully Plastic Ligament Ahead of an Edge Crack," Journal of Applied Mechanics, Vol. 53, pp. 271-280, June 1986.

4.27 Wilkowski, G. M. and others, "Degraded Piping Program - Phase II, Summary of Technical Results and Their Significance to Leak-Before-Break and In-Service Flaw Acceptance Criteria," March 1984 - January 1989, NUREG/CR-4082, Volume 8, March 1989.

4.28 Dowling, N. W., "Fatigue Crack Growth Rate Testing at High Stress Intensities," in Flaw Growth and Fracture, Proceedings of the Tenth National Symposium on Fracture Mechanics, ASTM STP 631, pp. 139-158, 1977.

4.29 Rahman, S., Brust, F., Nakagaki, M., and Gilles, P., "An Approximate Method for Estimating Energy Release Rates of Through-Wall-Cracked Pipe Weldments," in Fatigue, Fracture and Risk - 1991, ASME Special Publication PVP - Vol. 215, pp. 83-92, June 1991. 
4.30 Wilkowski, G. M., and others, "Degraded Piping Program -Phase II", Sixth Program Report, October 1986-September 1987, by Battelle Columbus Laboratories, NUREG/CR-4082, Vol. 6, April 1988.

4.31 Shimakawa, T., and Yagawa, G., "The Influences of Mesh Subdivision on Nonlinear Fracture Analyses for Surface-Cracked Structures, "International Journal of Pressure Vessels and Piping, Vol. 45, 1991.

4.32 Kanninen, M. F. and others, "Instability Predictions for Circumferentially Cracked Type 304 Stainless Steel Pipes Under Dynamic Loadings," EPRI Report NP-2347, April 1982.

4.33 Rahman, S. and Brust, F., "An Estimation Method for Evaluating Energy Release Rates of Circumferential Through-Wall Cracked Pipe Welds," Engineering Fracture Mechanics, Vol. 43, No. 3, pp. 417-430, 1992.

4.34 Rahman, S. and Brust, F., "Elastic-Plastic Fracture of Circumferential Through-Wall Cracked Pipe Welds Subject to Bending," Journal of Pressure Vessel Technology, Vol. 114, No. 4, pp. 410-416, November 1992.

4.35 Kumar, V. and German, M. D., "Elastic-Plastic Fracture Analysis of Through-Wall and Surface Flaws in Cylinders," EPRI Report NP-5596, January 1988.

4.36 Brickstad, B., "Numerical Analysis of IPIRG Cracked Pipe Experiments Subjected to Dynamic and Cyclic Loading," SA/FoU-Report 92/05, 1992.

4.37 Brust, F., Scott, P., Rahman, S., Ghadiali, N., Kilinski, T., Francini, R., Marschall, C., Muira, N., Krishnaswamy, P., and Wilkowski, G., "Assessment of Short Through-Wall Circumferential Cracks in Pipes - Experiments and Analyses," NUREG/CR-6235, April 1995.

4.38 Wilkowski, G. M. and others, "Short Cracks in Piping and Piping Welds," NUREG/CR-4599, Vol. 4, No. 1, April 1995.

4.39 "PVRC Recommendations on toughness Requirements for Ferritic Materials," WRC Bulletin 175, August 1972.

4.40 Lereim, J., and Embury, J. D., "Some Aspects of the Process Zone Associated with the Fracture of Notched Bars," What does Charpy Energy Really Tell Us?, published by ASM, ISBN 0-87170-027-1, 1978.

4.41 Wilkowski, G. M., Ahmad, J., Barnes, C. R., Broek, D., Brust, F., Guerrieri, D., Kiefner, J., Kramer, G., Landow, M., Marschall, C. W., Maxey, W., Nakagaki, M., Papaspyropoulos, V., Pasupathi, V., and Scott, P., "Degraded Piping Program - Phase II Semiannual Report, April 1985-September 1985," NUREG/CR-4082, BMI-2120, Vol. 3, March, 1986.

4.42 Hancock, J. W., Reuter, W. G., and Parks, D. M., "Constraint and Toughness Parameterized by T," Constraint Effects in Fracture, ASTM STP 1171, pp. 21-40, 1993. 
4.43 O’Dowd, N. P. and Shih, C. F., "Family of Crack-Tip Fields Characterized by A Triaxiality Parameter - I. Structure of Fields," J. of Mechanics and Physics of Solids, Vol. 39, No. 8, pp. 989-1015, 1991.

4.44 Sherry, A. H., France, C. C., and Glodthorpe, M. R., "Compendium of T-stress Solutions for Two and Three Dimensional Cracked Geometries," Fatigue and Fracture of Engineering Materials \& Structures, Vol. 18, No. 1, pp. 141-155, 1995.

4.45 Wilkowski, G. M., Barnes, C. R., Scott, P. M., and Ahmad, J., "Development of Analyses to Predict the Interaction of Fracture Toughness and Constraint Effects for Surface Cracked Pipe," American Gas Association project report on Project PR-3-407, April 1985.

4.46 Wilkowski, G., Rahman, S., and Mohan, R., "Low-Cycle Fatigue Crack Growth Considerations in Pipe Fracture Analyses," ASME PVP Vol. 280, June 1994, pp 281-298. 
, 


\subsection{APPLICATIONS OF RESULTS TO PIPE FLAW EVALUATION CRITERIA}

This section of the report discusses applications of the analysis procedures described and validated earlier in this report. The efforts discussed in this section include reviewing and validating the ASME Section XI pipe flaw evaluation criteria, noting some of the current limitations, and examining alternative approaches to evaluate ' $Z$ ' factors to improve their accuracy and simplify existing procedures.

\subsection{ASME Section XI Criteria}

\subsubsection{Background}

The ASME pipe flaw evaluation criteria for austenitic pipe are given in Article IWB-3640 Appendix C. Ferritic pipe flaw evaluations are given in Article IWB-3650 Appendix $\mathrm{H}$ and Code Case N-494-2. The IWB-3640 and IWB-3650 analysis procedures are simplified tables of the equations given in Appendices $\mathrm{C}$ and $\mathrm{H}$, respectively. Code Case $\mathrm{N}-494-2$ involves a different analysis procedure. These three procedures are summarized below. Further details are given in their technical basis documents (Refs. 5.1 to 5.3).

\subsubsection{The Austenitic Pipe EPFM Z-factor Approach}

The ASME flaw evaluation procedure for cracks in austenitic stainless steel base metal is essentially the same as the Net-Section-Collapse analysis procedure described in Section 4.2. The major differences between the two procedures are:

- The flow stress is defined as being equal to $3 \mathrm{~S}_{\mathrm{m}}$ in the $\mathrm{ASME}$ Code rather than the average of yield and ultimate strengths. For the analysis of cracks in welds, the base metal $S_{m}$ values are used in this procedure.

- For flux welds, such as SAW and SMAW, that have lower toughness values than those for base metals, the Z-factor is determined from EPFM considerations. TIG welds are considered to be as tough as the base metal and are analyzed by the limit-load equations. The Z-factor equations are:

$$
\begin{aligned}
& Z=1.30[1+0.010(N P S-4)] \text { for SAW } \\
& Z=1.15[1+0.013(N P S-4)] \text { for SMAW }
\end{aligned}
$$


where

NPS = nominal pipe size (diameter), inches.

These Z-factors resulted from the ratio of the limit-load solution to the EPFM analysis solution.

Reference 5.1 discusses the technical basis of the Z-factors. Basically, the Z-factors were calculated using the GE/EPRI J-estimation method (Ref. 5.4) for a circumferential through-wall-cracked pipe in bending. At that time, there were no solutions available for a finite length circumferential surface-cracked pipe in bending that could be used. To ensure the through-wall-cracked pipe solution was conservative, the Z-factors were evaluated as a function of crack angle. The largest Z-factor occurred at a crack angle of $\theta / \pi=0.3$. This through-wall-crack length was then used to calculate the Z-factors for surface-cracked pipe.

- For combined tension and bending, the Net-Section-Collapse analysis and the ASME Code use slightly different expressions to calculate the shift in the neutral axis (Equation 4-1), i.e., the $\beta$ term differs slightly as shown below.

For the ASME analysis,

$$
\beta=0.5\left(\pi-\theta \mathrm{a} / \mathrm{t}-\pi \mathrm{P}_{\mathrm{m}} / \sigma_{\mathrm{f}}\right)
$$

and for the Net-Section-Collapse analysis,

$$
\beta=0.5\left[\pi-\theta \mathrm{a} / \mathrm{t}-\pi \mathrm{R}_{\mathrm{i}}^{2} \mathrm{p} /\left(2 \mathrm{R}_{\mathrm{m}} \mathrm{t} \sigma_{\mathrm{f}}\right)\right]
$$

where

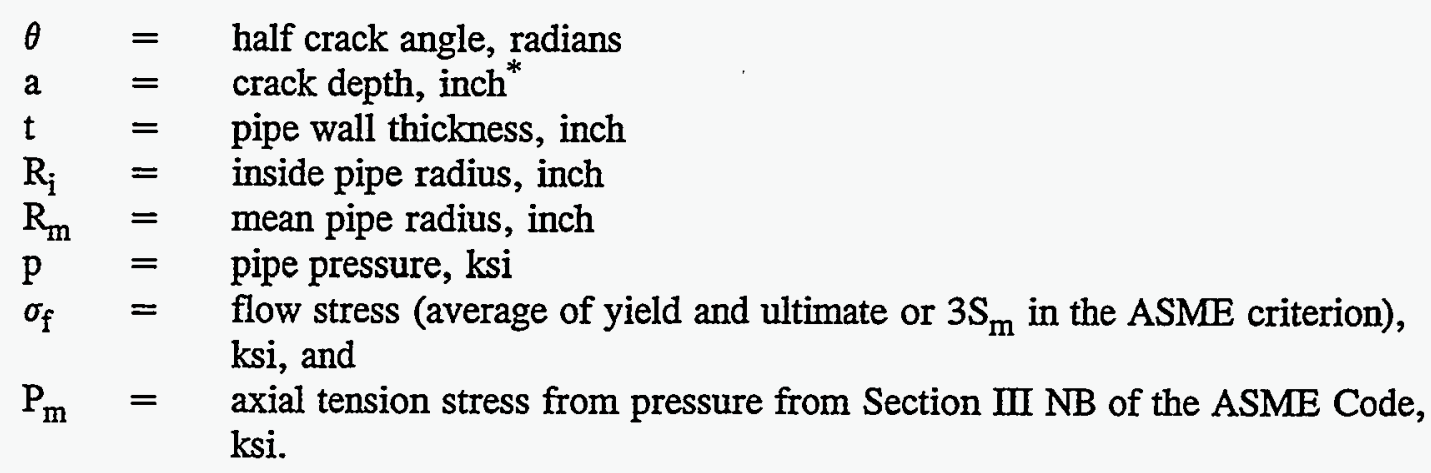

* Units shown here, and throughout this section when discussing the ASME Code criteria, are given in U.S. Customary units to be consistent with the ASME Code Section XI criteria. 


\subsubsection{The Ferritic Pipe EPFM Z-Factor Approach}

The ASME ferritic pipe flaw evaluation procedure is similar to the austenitic pipe evaluation criteria. However, the procedure is modified to account for failure stresses being below the Net-SectionCollapse stresses for a flaw in the base metal. The major differences between the ASME ferritic pipe flaw evaluation procedure and the Net-Section-Collapse analysis are:

- The flow stress used for ferritic pipe is $2.4 \mathrm{~S}_{\mathrm{m}}$ in the ASME Code.

- For combined tension and bending, the Net-Section-Collapse analysis and the ASME $\beta$ term differ slightly, as shown in Equations 5-2a and 5-2b.

- There is a screening criterion used to assess whether limit-load, elastic-plastic fracture, or linear-elastic fracture mechanics analyses should be used in the ASME procedure.

- There is a simple stress multiplier used for the elastic-plastic fracture analysis method to account for the lower failure stresses.

The stress multiplier, Z, used for a crack in the base metal (Material Category 1 for base metals and shielded-metal-arc welds, SMAW, in Reference 5.2) is

$$
Z=1.20[1+0.021(\mathrm{~A})(\mathrm{NPS}-4)]
$$

where
$A=\left[0.125\left(R_{m} / t\right)-0.25\right]^{0.25}$
for $5 \leq R_{m} / t \leq 10$, or
$A=\left[0.4\left(R_{m} / t\right)-3.0\right]^{0.25}$
for $10<R_{m} / t \leq 20$,

For a ferritic submerged-arc weld, SAW, Material Category 2 in the Appendix $H$, the Z-factor is defined by

$$
\mathrm{Z}=1.35[1+0.0184 \mathrm{~A}(\mathrm{NPS}-4)]
$$

The derivation of the Z-factors for the ferritic steels was similar in principle to the austenitic material $Z$-factor development. That is, a J Estimation scheme for a circumferential through-wall-cracked pipe under bending was used with a crack length of $\theta / \pi=0.3$. However, in this case the GE/EPRI J-estimation scheme was modified to try to obtain more accurate results. (In several studies the GE/EPRI estimation scheme was found to underpredict the experimental loads more than any of the other estimation schemes [Ref. 5.5]). 
The modification made to the GE/EPRI estimation scheme involves adding the exponent $[1 /(n+1)]$ to the $\alpha$ term as given in Equation 5-5.

$$
\mathrm{J}_{\mathrm{p}}=\alpha^{[1 /(\mathrm{n}+1)]} \sigma_{\mathrm{o}} \epsilon_{\mathrm{o}} \mathrm{c}(\mathrm{a} / \mathrm{b}) \mathrm{h}_{1}\left(\mathrm{M} / \mathrm{M}_{\mathrm{o}}\right)^{\mathrm{n}+1}
$$

This was an empirical modification and, as was noted in Reference 5.6, Equation 5-5 does not lead to a unique numerical solution because $\alpha$ is not independent of $\sigma_{0}$ in the normalized Ramberg-Osgood relation, i.e.,

$$
\alpha=\sigma_{\mathrm{o}}^{\mathrm{n}} /\left(\epsilon_{\mathrm{o}} \mathrm{F}^{\prime}\right)
$$

where $F^{\prime}$ is a constant and

$$
\mathrm{E}=\sigma_{\mathrm{o}} / \epsilon_{\mathrm{o}}
$$

In the original Ramberg-Osgood relation,

$$
\epsilon=\sigma / E+\sigma^{n} / F^{\prime}
$$

and in the normalized Ramberg-Osgood relation

$$
\epsilon / \epsilon_{\mathrm{o}}=\sigma / \sigma_{\mathrm{o}}+\alpha\left(\sigma / \sigma_{\mathrm{o}}\right)^{\mathrm{n}}
$$

The terms $\epsilon, \epsilon_{\mathrm{o}}, \sigma, \sigma_{0}, \alpha, \mathrm{n}$, and $\mathrm{E}$ were defined earlier in Section 4.

\subsubsection{The Code Case N-494-2 Approach}

The Code Case N-494-2 approach was initially developed from the deformation plasticity failure analysis diagram (DPFAD) approach of Bloom (Ref. 5.3). In this approach, a failure analysis curve similar to the one in the R6 analysis method (Ref. 5.7) is used. The failure analysis curve was developed using the GE/EPRI solution for a surface-cracked pipe under tension as a boundary value. Here the allowable stresses are calculated based on this curve and a simplified Z-factor is not used.

In this program, curve fits were developed through the ferritic pipe FAD curve points that were determined by Bloom. These curve fit equations and the tabular points are not in Code Case $\mathrm{N}-494-2$. Figure 5.1 shows the curve-fit equations and the tabular data points that are given in Table 5.1. The tabular values were obtained from Dr. Bloom through private communication.

\subsubsection{Validation of Z-factors}

During the course of this program, several activities were undertaken to assist the ASME Section XI Working Group on Pipe Flaw Evaluation. One activity was to try to reproduce the Z-factors calculated in the past, as one step of assisting the working group toward the eventual goal of consolidating the austenitic and ferritic pipe flaw evaluation criteria into one procedure. 


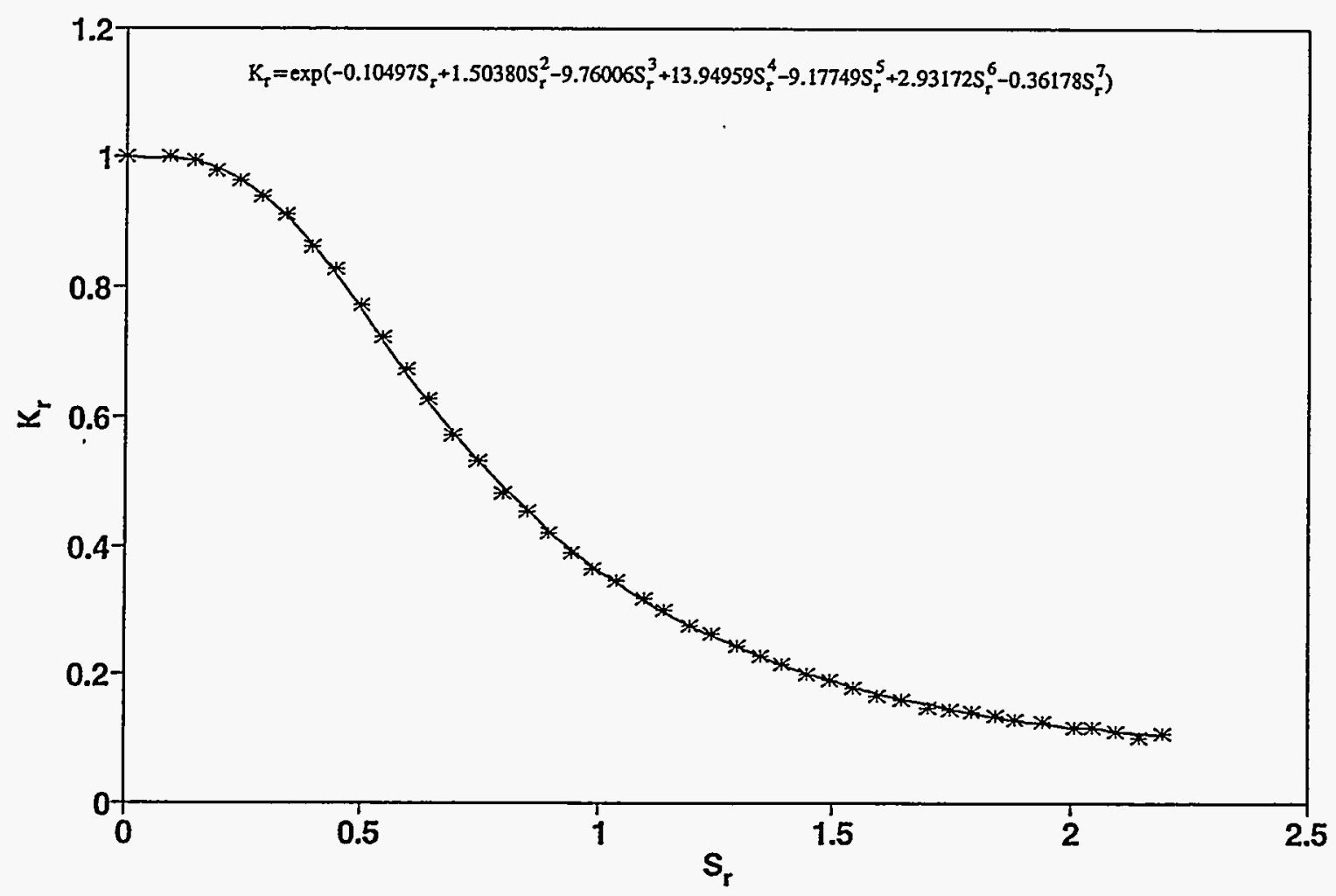

Figure 5.1 Ferritic pipe FAD curve from ASME Code Case N-494-2

\subsubsection{Validation of Austenitic Pipe Z-factors}

The first step in trying to reproduce the austenitic pipe Z-factors was to determine the traceability of all the material property input used in the J-estimation scheme analyses. The properties for both the SAW and SMAW Z-factors are given in the technical basis document (Ref. 5.1), but the precise 
Table 5.1 Code Case N-494-2 FAD curve tabular values ${ }^{(a)}$

\begin{tabular}{|c|c|c|c|}
\hline \multicolumn{4}{|c|}{ Ferritic Pipe } \\
\hline$S_{r}$ & $\mathrm{~K}_{\mathrm{r}}$ & $S_{r}$ & $\mathrm{~K}_{\mathrm{r}}$ \\
\hline 0.000 & 1.000 & 1.745 & 0.144 \\
\hline 0.094 & 0.998 & 1.793 & 0.141 \\
\hline 0.150 & 0.991 & 1.841 & 0.137 \\
\hline 0.195 & 0.975 & 1.886 & 0.129 \\
\hline 0.247 & 0.960 & 1.942 & 0.126 \\
\hline 0.295 & 0.936 & 2.010 & 0.118 \\
\hline 0.344 & 0.909 & 2.046 & 0.115 \\
\hline 0.396 & 0.862 & 2.098 & 0.111 \\
\hline 0.448 & 0.823 & 2.147 & 0.103 \\
\hline 0.501 & 0.768 & 2.195 & 0.108 \\
\hline 0.545 & 0.721 & & \\
\hline 0.598 & 0.670 & & \\
\hline 0.646 & 0.623 & & \\
\hline 0.695 & 0.572 & & \\
\hline 0.743 & 0.529 & & \\
\hline 0.796 & 0.482 & & \\
\hline 0.844 & 0.451 & & \\
\hline 0.892 & 0.419 & & \\
\hline 0.941 & 0.388 & & \\
\hline 0.985 & 0.365 & & \\
\hline 1.037 & 0.345 & & \\
\hline 1.094 & 0.318 & & \\
\hline 1.138 & 0.299 & & \\
\hline 1.194 & 0.275 & & \\
\hline 1.239 & 0.260 & & \\
\hline 1.295 & 0.244 & & \\
\hline 1.343 & 0.229 & & \\
\hline 1.391 & 0.217 & & \\
\hline 1.444 & 0.202 & & \\
\hline 1.492 & 0.190 & & \\
\hline 1.544 & 0.179 & & \\
\hline 1.592 & 0.167 & . & \\
\hline 1.645 & 0.160 & & \\
\hline 1.697 & 0.148 & & \\
\hline
\end{tabular}

(a) Values obtained from Dr. J. Bloom through private communication. 
source of these J-R curves and tensile test values was not given in that report. After reviewing the minutes of past ASME Task Group on Pipe Flaw Evaluation meetings, and talking to various committee members, the following items were determined:

- The Ramberg-Osgood equation parameters for the SAW analysis were not traceable. It appeared that the tensile test data used in the SAW analysis may have been from a room temperature test on TP304 stainless steel base metal from EPRI work at Westinghouse and subsequently published as an AWI report (Ref. 5.8). The stress-strain curves for stainless steel base metals are much higher at room temperature than at $288 \mathrm{C}(550 \mathrm{~F})$.

- The weld metal Ramberg-Osgood parameters were used in the SMAW Z-factor calculations. Typically the base metal and not the weld metal Ramberg-Osgood curve is used. The weld metal stress-strain curve is much higher than that for the base metal.

- The SAW J-R curve was actually from a SMAW. Perhaps there should be only one Z-factor curve for both SAW and SMAW evaluations.

Hence, with the more conservative GE/EPRI estimation scheme and the use of the higher RambergOsgood curves, there were compensating inaccuracies in the Z-factor development resulting in reasonably accurate Z-factors when compared with the quasi-static pipe tests in Reference 5.6.

Although the material property input could not be verified, the austenitic pipe SMAW Z-factors were recalculated. Figure 5.2 shows the J-R curve from Specimen 4SMAW-J2 for the SMAW from Reference 5.8 and a power-law fit through the data. For the SMAW case, the J-R curve was used with the rest of the technical basis document input, see Table 5.2. The original GE/EPRI J-estimation scheme for a pipe with a circumferential through-wall crack under pure bending was used to calculate the maximum moment. The crack length of $\theta / \pi=0.3$ was used as was done in the technical basis document. The Net-Section-Collapse moment was calculated for the same cases with the flow stress of $3 \mathrm{~S}_{\mathrm{m}}$ (351 $\mathrm{MPa}$ [50.85 ksi]) and the flow stress given in the technical basis document (382 $\mathrm{MPa}$ [55.4 ksi]). Figure 5.3 shows a comparison of the Appendix C SMAW Z-factor with Z-factors calculated from this effort. The two different calculated $\mathrm{Z}$-factor curves are due to the different flow stress definitions.

In Figure 5.3, it can be seen that the current Code Z-factors are higher than the calculated values for larger diameter pipe. The slope of the calculated $Z$ versus pipe diameter relationships did not agree with the Code SMAW Z-factor equation, and it was not affected by the flow stress value. Separate quality assurance checks were made to verify our analysis procedure.

In summary, from this evaluation, we could not trace the material property input data used in the technical basis document for the austenitic pipe flaw evaluation procedures, and using the technical basis document material property input, we did not get the same Z-factors reported in Reference 5.1. 


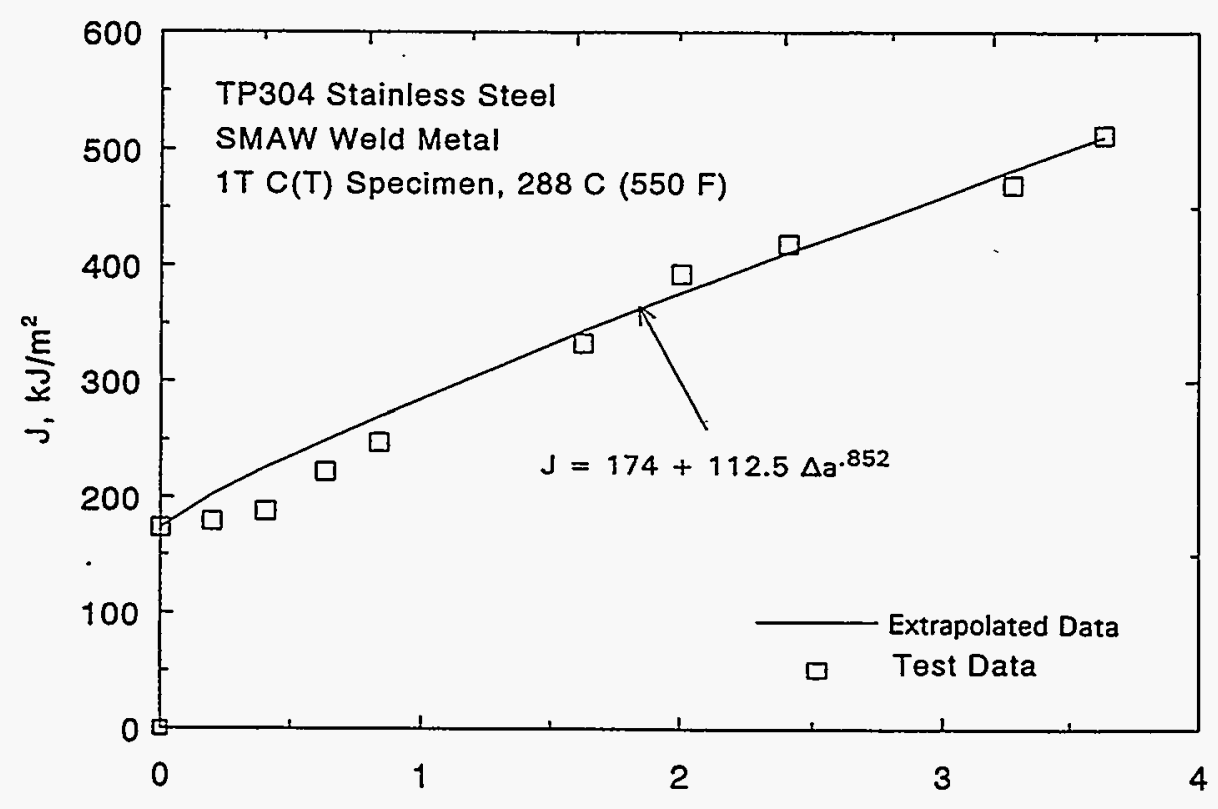

$\Delta \mathrm{a}, \mathrm{mm}$

Figure 5.2 Power-law extrapolated stainless steel weld $J_{D}-\mathbf{R}$ curve from Reference 5.8, Specimen 4SMAW-J2

Outer Pipe Diameter (OD), inch

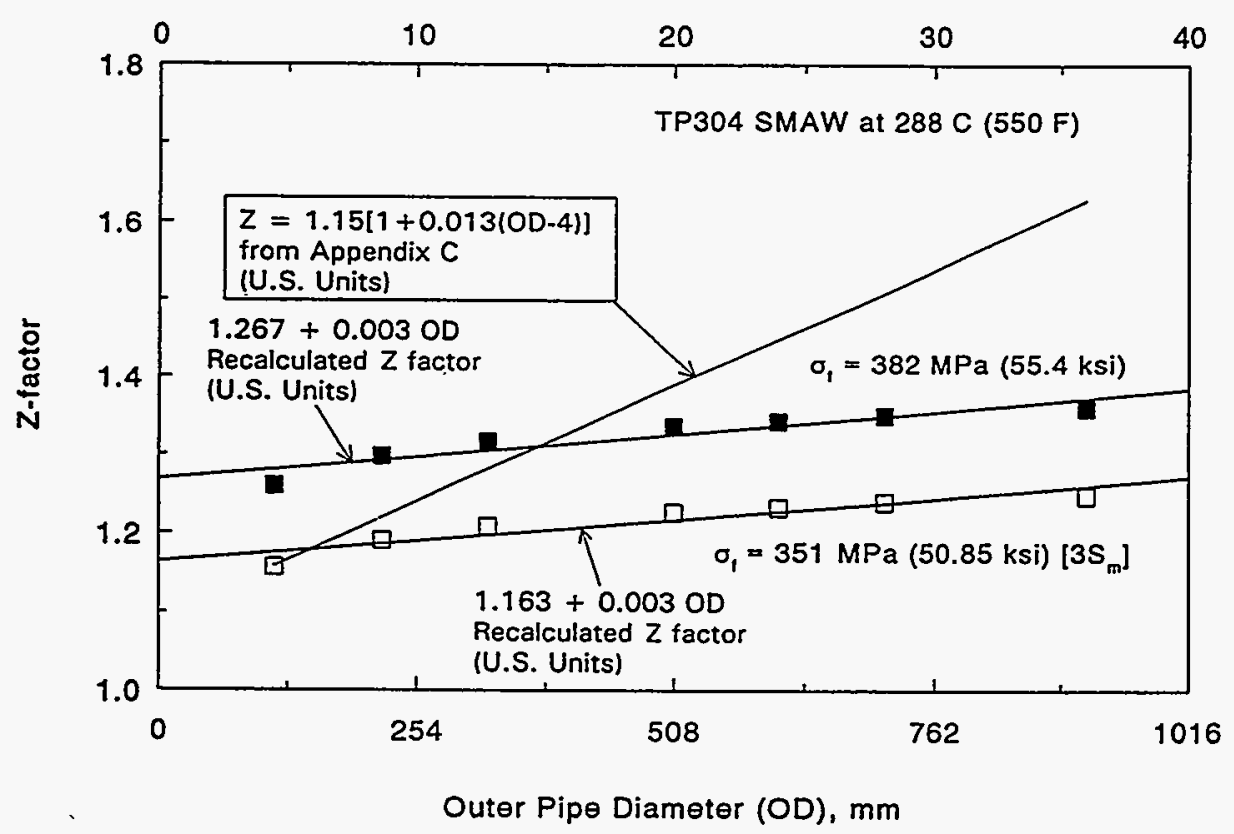

Figure 5.3 Comparison of Appendix C SMAW Z-factor with newly calculated values using technical basis document and power-law extrapolated $J_{D}-R$ curve, ASME Code equations in U.S. units 
Table 5.2 Material property values used in austenitic pipe technical basis document ${ }^{(a)}$

\begin{tabular}{lcc}
\hline & SAW & SMAW \\
\hline$\alpha$ & 11.0 & 9.0 \\
$\mathbf{n}$ & 6.9 & 9.8 \\
$\sigma_{0}$, MPA (ksi) & $232(33.7)$ & $341(49.4)$ \\
$\sigma_{\mathrm{f}}, \mathrm{MPA}(\mathrm{ksi})$ & $290(42.1)$ & $382(55.4)$ \\
$\mathrm{E}, \mathrm{GPA}(\mathrm{ksi})$ & $172(25,000)$ & $172(25,000)$ \\
$\mathrm{J}_{\mathrm{Ic}}, \mathrm{kJ} / \mathrm{m}^{2}\left(\mathrm{in}-\mathrm{lb} / \mathrm{in}^{2}\right)$ & $114(650)$ & $173(990)$ \\
\hline
\end{tabular}

(a) From page 2-12 of Reference 5.1.

\subsubsection{Validation of Ferritic Pipe Z-factors}

As with the austenitic pipe Z-factor validation, the first step in trying to reproduce the ferritic pipe $Z$-factors was to trace all the material property input used in the J-estimation scheme analyses. The properties for both the SAW and SMAW Z-factors are given in the technical basis document (Ref. 5.2). The ferritic pipe material property input was documented better in that report than the austenic properties in Reference 5.1. From a review of that document, past minutes from the task group meetings, and talking to various committee members, it was determined that most of the material property input were traceable; however, the $\mathrm{J} / \mathrm{T}$ plot from the $\mathrm{J}-\mathrm{R}$ curve could not be reproduced.

The input values are given in Table 5.3 for Material Categories 1 and 2. Material Category 1 represents base metals, non-flux welds, and SMAW welds. Material Category 2 represents SAW welds. The SAW J-R curve came from an NRC/Battelle C(T) specimen test, Specimen Number F40W2-54.

The Z-factors were recalculated using the technical basis material property input. One remaining question was to determine how the J-R curve was extrapolated. In this program and the Degraded Piping Program (Refs. 5.5 and 5.9), it was determined that a power-law extrapolation of the C(T) specimen $J_{D}-R$ curves could be used with conservative results. Another J-R curve extrapolation method involves plotting the J-R curve in J/T space, where

where

$$
T=\left(E / \sigma_{f}^{2}\right)(d J / d a)
$$

$$
\begin{array}{ll}
\mathrm{T} & =\text { Tearing modulus, } \\
\mathrm{E} & =\text { Elastic modulus, } \mathrm{ksi} \\
\sigma_{\mathrm{f}} & =\text { Flow stress, ksi, and } \\
\mathrm{dJ} / \mathrm{da} & =\text { Initial slope of J-R curve, ksi. }
\end{array}
$$


Table 5.3 Material property data input in Appendix $\mathbf{H}$ technical basis document ${ }^{(a)}$

\begin{tabular}{lll}
\hline & Material Category 1 & Material Category 2 \\
\hline$\alpha$ & 2.51 & 2.51 \\
$\mathrm{n}$ & 4.2 & 4.2 \\
$\sigma_{\mathrm{o}}=\sigma_{\mathrm{y}}, \mathrm{MPa}(\mathrm{ksi})$ & $187(27.1)$ & $187(27.1)$ \\
$\sigma_{\mathrm{u}}, \mathrm{MPa}(\mathrm{ksi})$ & $412(59.7)$ & $412(59.7)$ \\
$\sigma_{\mathrm{f}}, \mathrm{MPa}(\mathrm{ksi})$ & $299(43.4)=2.4 \mathrm{~S}_{\mathrm{m}}$ & $299(43.4)=2.4 \mathrm{~S}_{\mathrm{m}}$ \\
$\mathrm{E}, \mathrm{GPa}(\mathrm{ksi})$ & $179(26,000)$ & $179(26,000)$ \\
$\mathrm{J}_{\mathrm{Ic}}, \mathrm{kJ} / \mathrm{m}^{2}\left(\mathrm{in}-\mathrm{lb}_{\mathrm{in}}{ }^{2}\right)$ & $105(600)$ & $61(350)$ \\
\hline
\end{tabular}

(a) From Reference 5.2.

In this plot of the $J-R$ curve data in $J / T$ space, the $J / T$ curve was linearly extrapolated as a tangent to the curve at $T=50$ (Ref. 5.10). The $J-R$ and $J / T$ curves for the SAW metal are shown in Figure 5.4. Figure 5.5 shows the reconstructed $J-R$ curve from the $J / T$ extrapolation procedure.

Additional data existed on this same weld, including the $J_{M}-R$ curve from the same $1 T C(T)$ specimen (F40W2-54), and also J-R curves from 3T and 9.5T C(T) specimens, all having 25.4-mm (1-inch) thicknesses and from the same weldment (Ref. 5.9). The $J_{D}-R$ and $J_{M}-R$ curves are shown in Figure 5.6. Note that in this case the $J_{D}-R$ curves agree well among the different specimens, providing the crack growth is limited to 30-percent of the initial uncracked ligament (Ref. 5.9). However, the $J_{M}-R$ curve from the $1 \mathrm{~T}$ specimen is significantly steeper than the curves from the $3 \mathrm{~T}$ or $9.5 \mathrm{~T} \mathrm{C}(\mathrm{T})$ specimens. Figure 5.7 shows a comparison of all the different $J-R$ curves for this weld metal.

The different J-R curves in Figure 5.7 were used with the other material property input data from Table 5.3 for Material Category 2 (the SAW case). The modified Zahoor GE/EPRI method (Ref. 5.2) in the NRCPIPE Code (Version 2.0) ${ }^{*}$ was used to calculate the maximum loads for pipes with crack lengths of $\theta / \pi=0.3$ and $a R_{m} / t$ of 10 . The resulting Z-factors are compared with the ASME Appendix-H Z-factors in Figure 5.8. The newly calculated Z-factors with the $J / T$ extrapolation are higher than the Appendix-H equation values. The various $\mathrm{Z}$-factors calculated were in agreement at small values of pipe diameter as is expected since the failure load for these cases is close to limit load and was not very sensitive to pipe toughness. The power-law-extrapolated $J_{D}-R$ curve and $9.5 T$ specimen $J_{M}-R$ curve $Z$-factors are in very close agreement, but the $1 T C(T)$ specimen $J_{M}-R$ curve Z-factors are much lower since the J-R curve from this specimen is higher.

* See NUREG/CR-4599, Vol. 4, No. 1 for further information on the NRCPIPE Code. 


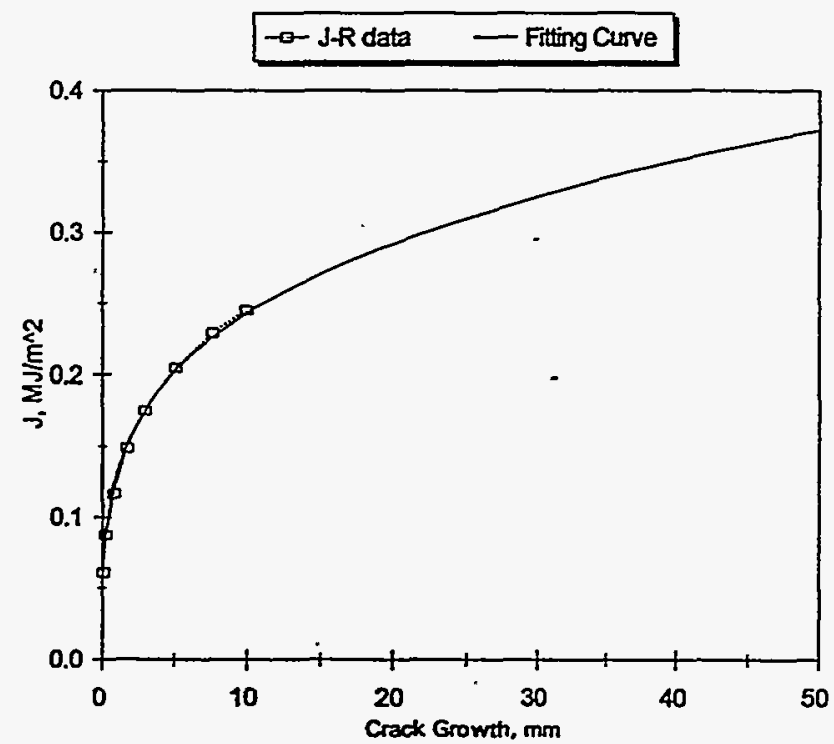

(a) J-R curve

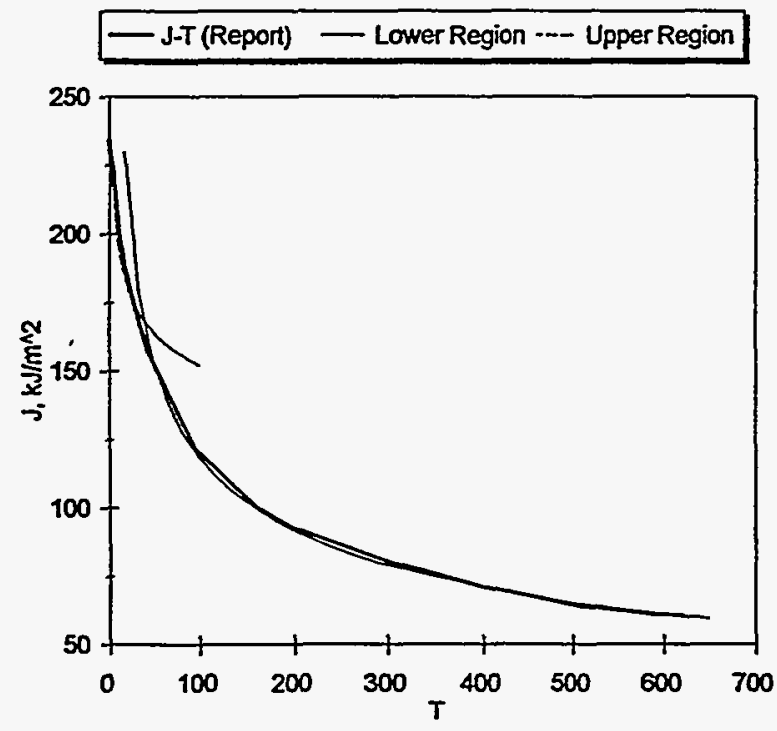

(b) $\mathbf{J} / \mathbf{T}$ curve

Figure 5.4 Material Category 2, carbon steel SAW toughness data (Specimen F40W2-54 from Battelle) 


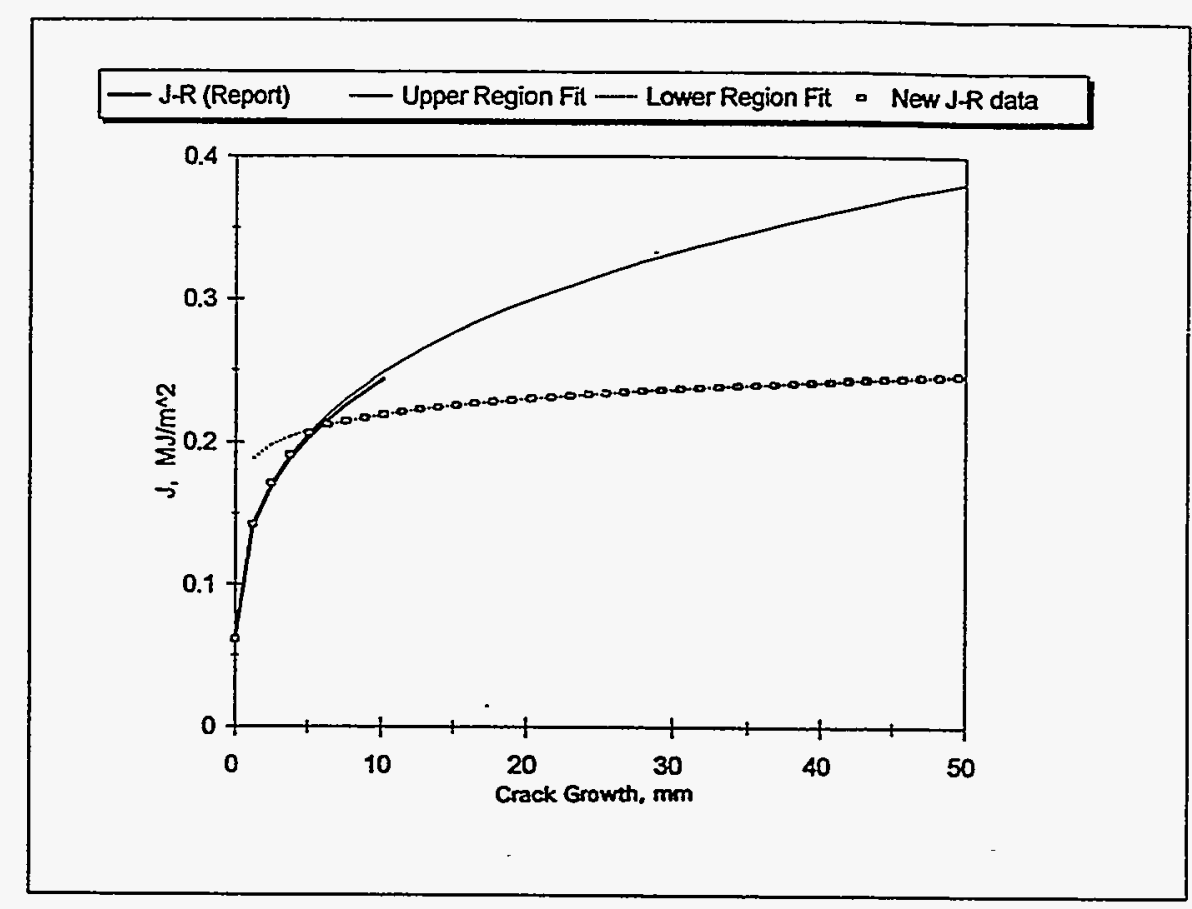

Figure 5.5 Reconstructed J-R curve from linear tangent extrapolation of $\mathrm{J} / \mathrm{T}$ curve in Figure 5.4

There are two basic problems evident in Figure 5.8. The first is that, as the pipe diameter becomes small, limit load should prevail and the Z-factor should become 1.0. This should occur for pipes around $114 \mathrm{~mm}$ (4.5 inches) in diameter. As seen in Figure 5.8, $\mathrm{Z}$ does not approach 1.0 even when the curves are extrapolated to a pipe diameter of zero. Second, there is a large sensitivity to the J-R curve used for the large diameter pipe cases. This sensitivity results from use of a through-wallcracked pipe analysis instead of a surface-cracked pipe analysis. Note that in Figure 5.7 there is very little difference in the J-R curves for crack growth up to $5.0 \mathrm{~mm}$ (0.2 inch). In Experiment 1.2.3.17 in this program, (see Section 3 on a 610 -mm (24-inch) diameter by $42.7-\mathrm{mm}$ (1.68-inch) thick pipe with a crack in a low toughness SAW), the crack growth at maximum load was about $3.0 \mathrm{~mm}(0.118$ inch). It is expected that $5.0 \mathrm{~mm}(0.2 \mathrm{inch})$ is about the amount of stable surface-crack growth that would realistically occur for pipes with thickness of up to $50 \mathrm{~mm}$ ( 2 inches). For pipes with an $\mathrm{R}_{\mathrm{m}} / \mathrm{t}$ of 10 , the corresponding outside pipe diameter would be $1.067 \mathrm{~m}$ ( 42 inches). Hence, with a surfacecracked pipe analysis there would be little difference between the Z-factors from the different J-R curves in Figure 5.7. Accordingly, some of the problems with the Z-factor approach in Reference 5.2 are due to the use of through-wall-cracked pipe analyses. 


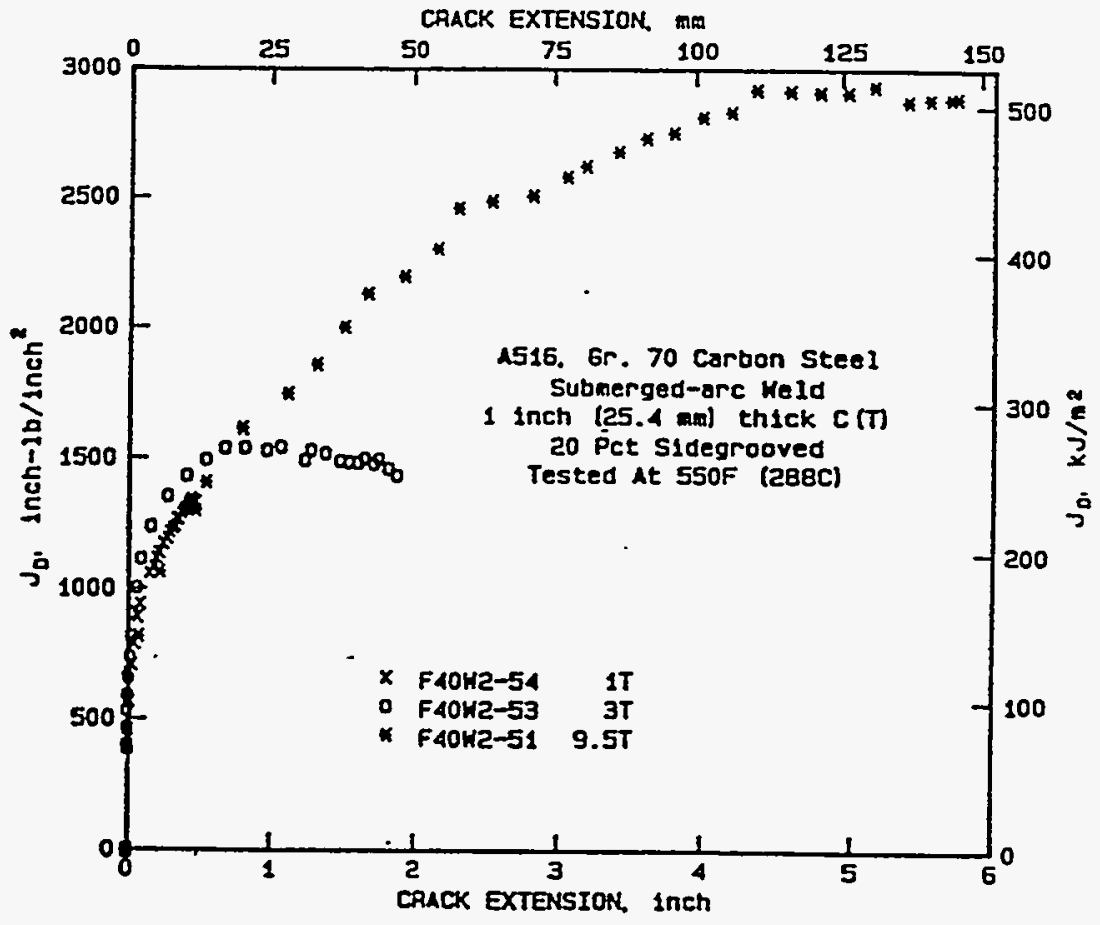

(a) $\mathbf{J}_{\mathbf{D}}-\mathbf{R}$ curves

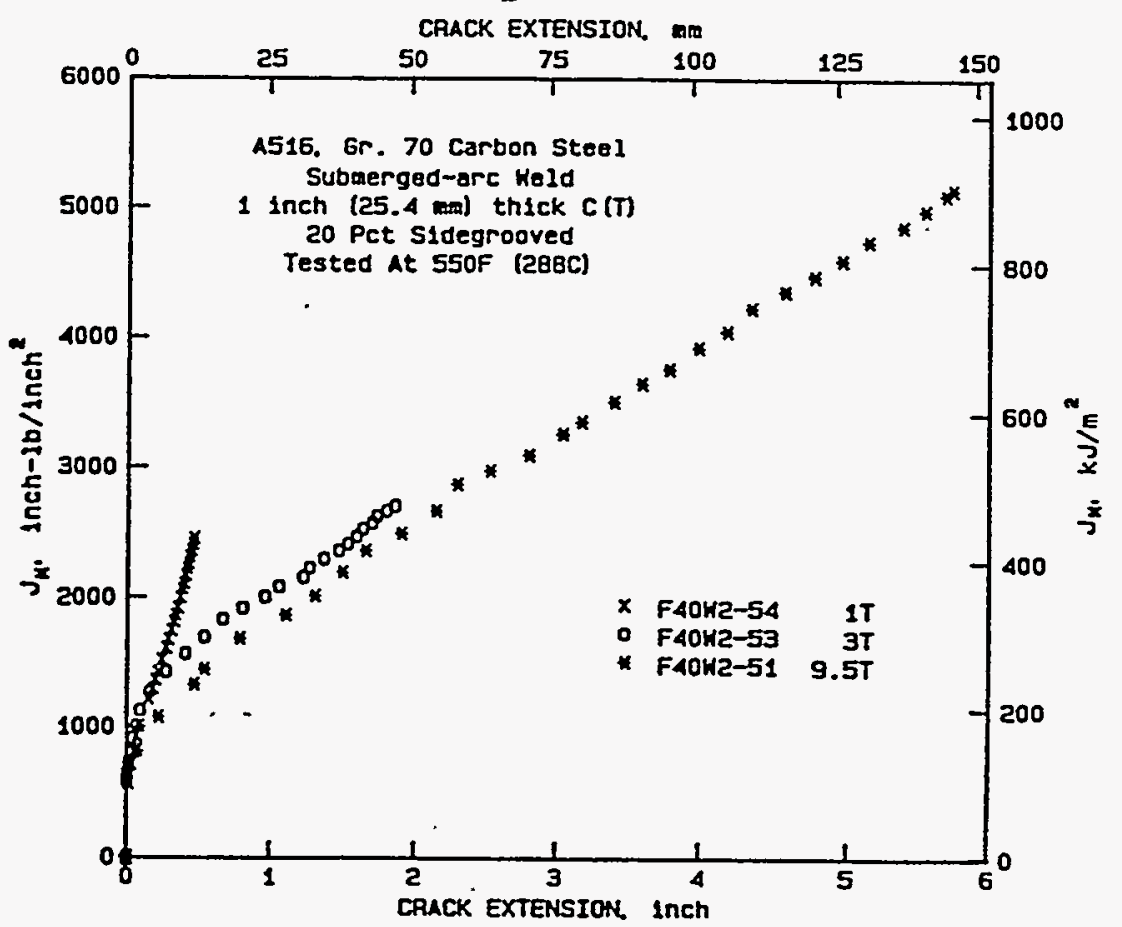

(b) $\mathbf{J}_{\mathrm{M}}-\mathbf{R}$ curves

Figure 5.6 1T, 3T, and 9.5T C(T) specimen J-R curves for ferritic submerged-arc weld compact specimens (DP2-F40W2), from Reference 5.5 


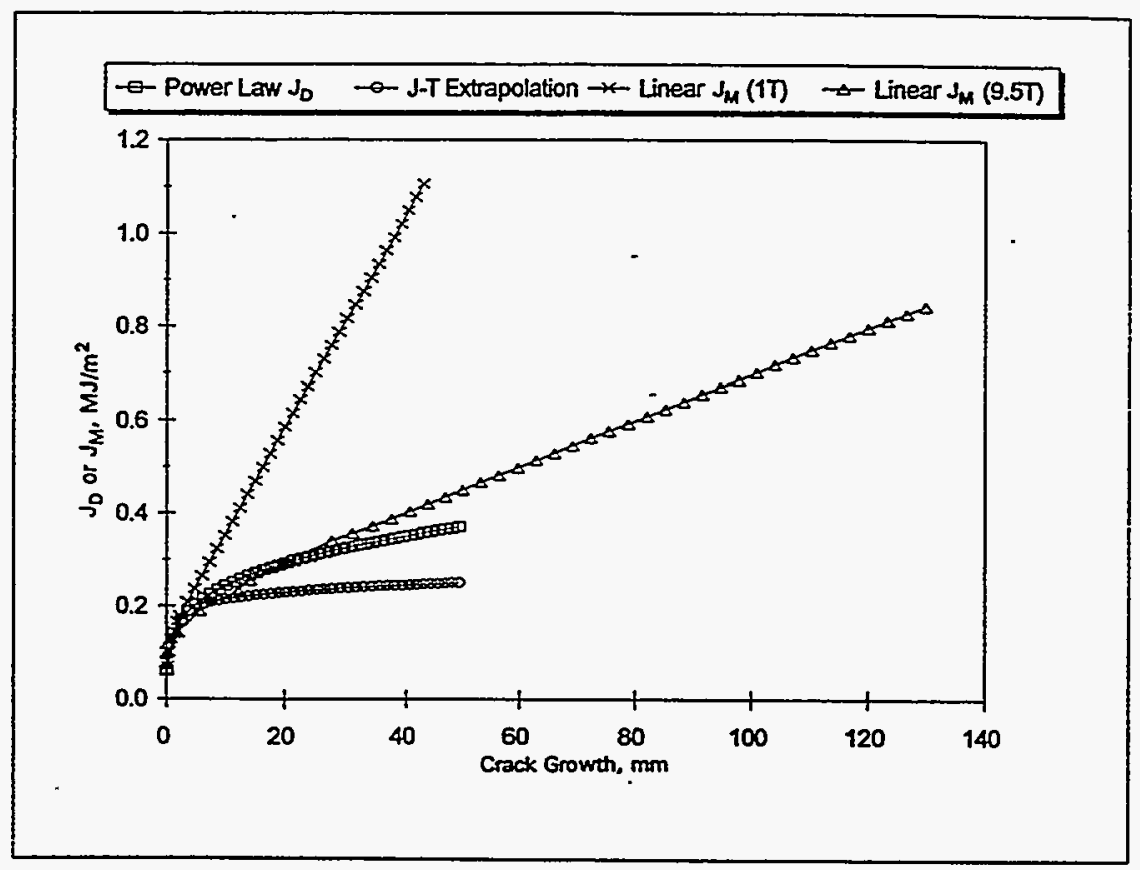

Figure 5.7 Comparison of various J-R curves for carbon steel SAW (ASME Section XI Appendix H Material Category 2)

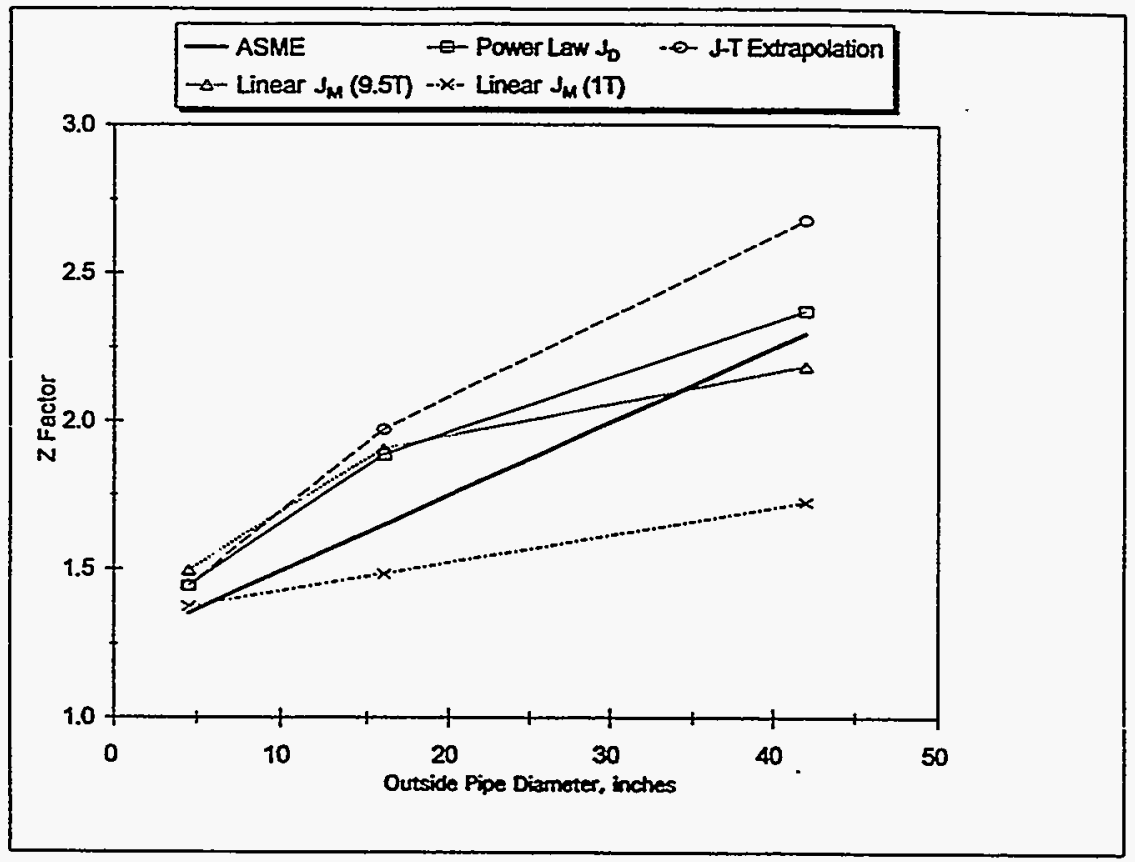

Figure 5.8 Comparison of ASME Section XI Appendix H SAW Z-factor equation with Z-factors using various $J-R$ curves in Figure 5.7, Zahoor modified GE/EPRI analysis, and technical basis document material property input 


\subsubsection{Calculation of Z-factors from other TWC J-Estimation Schemes}

It was also desirable to see if the Z-factors would change due to the choice of the through-wallcracked pipe J-estimation scheme. This question was assessed by using the $\alpha$-modified GE/EPRI method, the LBB.ENG3 method, and the original GE/EPRI method. The LBB.ENG3 method was developed in this program (Ref. 5.11) and was found to be the most accurate of the J-estimation schemes when compared with through-wall-cracked welded pipe experiments evaluated in Reference 5.5. The extrapolated J-R curve is used in these calculations so the input is the same as the Appendix $\mathrm{H}$ technical basis document. All other parameters are the same as in Table 5.3, which were also used in the technical basis document.

Figure 5.9 shows the comparison of the Z-factors calculated using various analyses with the ASME Section XI Appendix H Z-factor equation. None of these methods had a Z-factor of 1.0 for the small diameter pipe case. The Z-factors using the Zahoor-modified GE/EPRI method were only slightly lower than the original GE/EPRI method, and the LBB.ENG3 method was farther below the Zahoormodified GE/EPRI method. The LBB.ENG3 method gave the lowest values of the newly calculated $\mathrm{Z}$-factors, which were very close to the Appendix $\mathrm{H}$ values. The other analysis methods gave higher results than the Appendix $H$ values.

\subsubsection{Other Limitations with the Current ASME Pipe Flaw Evaluation Criteria}

Since the implementation of the current pipe flaw evaluation criteria into the ASME Code, user experience and additional technical developments suggest that several modifications are desired or needed. Possible improvements that could be made in future revisions to the Code are summarized below.

- There is a desire to combine the austenitic and ferritic pipe criteria and expand them to Class 2 and 3 piping. By redefining the flow stress in terms of the average of yield and ultimate strengths (rather than as a function of $S_{m}$ ), combining the austenitic and ferritic pipe criteria can be accomplished easily and extended to other classes of pipe.

- The Appendix $\mathrm{H}$ procedure has a step change in allowable stresses from limit load to EPFM analysis procedures and also from EPFM to LEFM procedures. A smooth transition between the different regions is desired. There were also some reported cases for the Appendix $\mathrm{H}$ ferritic piping criteria where the allowable stresses for EPFM are lower than those using LEFM analysis. This result should not occur and the Code should be modified.

- The IPIRG-1 pipe system experiments showed that if the stresses are below yield (large flaw sizes), then the thermal expansion $\left(\mathrm{P}_{\mathrm{e}}\right)$ stresses and seismic anchor motion (SAM) stresses contributed equally to fracture, even for flaws in TP304 stainless steel base metal (Ref. 5.12). Hence, for these stress levels, the secondary stresses should be incorporated with a full safety factor. 


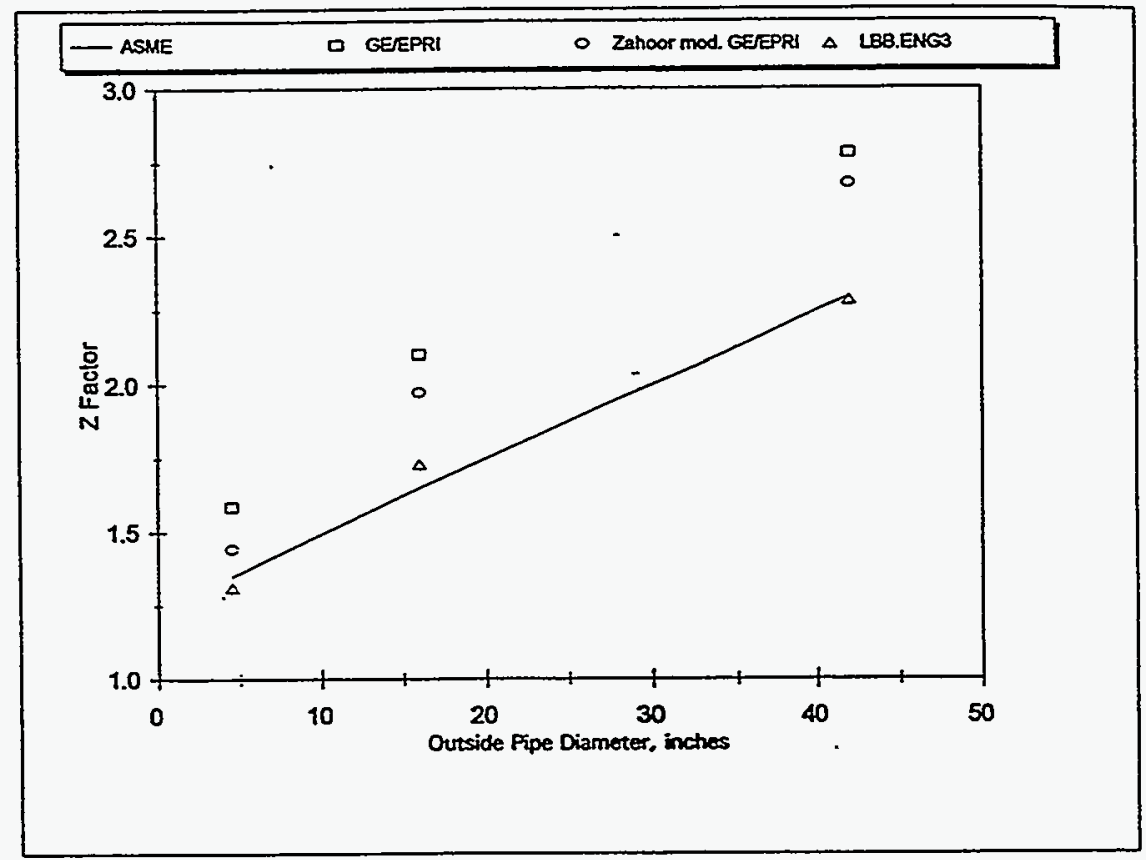

Figure 5.9 Comparison of Appendix $\mathrm{H}$ ferritic SAW Z-factor equation with Z-factors calculated with various TWC estimation schemes using technical basis properties and J/T extrapolated J-R curve

- If the stresses (calculated assuming elastic behavior) are above $S_{y}$ (the Code yield strength value), then a nonlinear correction will greatly increase the allowable flaw size and account for the fact that the $\mathrm{P}_{\mathrm{e}}$ and SAM stresses are displacement-controlled. This topic is discussed in NUREG/CR-4599 Vol. 4, No. 1, the 7th program report from this program.

- No aged cast stainless steel or bimetal weld criteria exist. A bimetallic weld experiment and analyses of that test were conducted as part of this program and are reported in NUREG/CR-6297. Criteria for these cases need to be developed.

- Seismic loading can:

(1) cause low cycle fatigue crack growth,

(2) reduce the J-R curve due to the cyclic loadings (Ref. 5.13), and

(3) increase the toughness of austenitic steels, but lower the toughness and strength of ferritic steels due to high loading rates.

- There may be constraint and anisotropy effects for surface-cracked pipe that give a higher effective toughness than considered in the current flaw evaluation criteria (Ref. 5.14). Currently the L-C oriented C(T) specimen data are used. This orientation is for the circumferential through-wall-crack growth direction. Such toughness anisotropy should be accounted for in the criteria. 
- The flaw evaluation criteria consider constant depth (rectangular shaped) surface flaws. Real cracks seldom have a constant depth. The development of an equivalent flaw length, as is done in ANSI Standard B31G for corrosion flaws in oil and gas pipelines, would be helpful.

- The Code Case $\mathrm{N}-494$ methods are limited to flaw lengths less than $\theta / \pi=0.5$, so the Appendix $\mathrm{C}$ or $\mathrm{H}$ methods must be used for long cracks.

- Both Appendix $\mathrm{H}$ and Code Case $\mathrm{N}-494-2$ use elastic F-functions for determining stress intensity factors. As stated in Reference 5.15, these functions are valid for $R_{m} / t$ of 5 to 10 , but are used in the Code for $R_{m} / t$ of 5 to 20 . Work in this report showed that there is considerable difference in the Code F-function and finite element results for a surfacecracked pipe with an $R_{m} / t$ of 20.3. Hence, the F-function in the Code should be corrected.

\subsection{Alternative Surface-Cracked Pipe Flaw Evaluation Criteria}

Two alternative pipe flaw evaluation criteria were also developed as part of this program. Each has its own advantages and limitations. The first method is a Charpy energy criterion based on the Dimensionless Plastic-Zone Parameter (DPZP) Analysis developed at Battelle (Ref. 5.16). The second approach was to use the finite-length surface-crack J-estimation schemes from this report and the Code Case $\mathrm{N}-494$ analysis method to assess the effects of surface-crack geometries on the $Z$-factors. Evaluation of finite-length flaws in the second approach is a desirable feature that the Charpy energy/DPZP method does not have. However, the Charpy energy/DPZP approach empirically accounts for toughness anisotropy and constraint effects and is relatively simple.

\subsubsection{Charpy Energy Based DPZP Criteria}

The first approach examined was a Charpy based criterion using the Dimensionless Plastic-Zone Parameter (DPZP) approach from the Degraded Piping Program (Refs. 5.5 and 5.16). This method, which was summarized in Section 4, has the following advantages:

(1) it is simple,

(2) it has a smooth transition from limit-load to EPFM,

(3) it is a semi-empirical fit through surface-cracked pipe data, and hence it inherently accounts for toughness anisotropy and constraint effects, and

(4) it uses Charpy data, which typically are the best data available from mill test reports.

One disadvantage of this method is that it may not be sensitive to small flaw sizes. This lack of sensitivity arises from basing the approach on existing surface-cracked pipe data that typically had large surface cracks all about the same size (i.e., $a / t=0.5$ to 0.7 and $\theta / \pi$ of 0.25 to 0.5 ). 
An ASME axial flaw criterion is presented in Appendix E. The rest of this report deals exclusively with circumferentially cracked piping.

\subsubsection{Circumferential Flaws}

The DPZP analysis (Refs. 5.5 and 5.16) was used to develop this alternative surface-cracked pipe flaw evaluation criterion. It uses available Charpy energy for any material to calculate what the Z-factor would be, rather than having to use the current Z-factors for the Code minimum toughness values for base or weld metals. Code minimum Charpy values could be defined if no data were available.

The DPZP analysis was reassessed by examining all the surface-cracked pipe data from the Degraded Piping Program and this program. The basic equation, as given in Section 4, is restated here as

$$
\sigma / \sigma_{\text {nsc }}=(2 / \pi)\left\{\arccos \left[\mathrm{e}^{-\mathrm{C}(\mathrm{DPZP})}\right]\right\}=\mathrm{Z}^{-1}
$$

where

$$
\mathrm{DPZP}=2 \mathrm{EJ}_{\mathrm{i}} /\left(\pi^{2} \mathrm{D} \sigma_{\mathrm{f}}^{2}\right)
$$

and

$\sigma \quad=$ predicted longitudinal failure stress, $\mathrm{ksi}$

$\sigma_{\text {nsc }}=$ Net-Section-Collapse analysis predicted failure stress, ksi

$\mathrm{E} \quad=$ elastic modulus, $\mathrm{ksi}$

$\mathrm{J}_{\mathrm{i}} \quad=\mathrm{J}$ at crack initiation, in-kips/in ${ }^{2}$

$\mathrm{D} \quad=$ nominal outside pipe diameter, inch

$\sigma_{\mathrm{f}} \quad=$ flow stress, $\mathrm{ksi}$

$\mathrm{C} \quad=$ an empirical constant.

The mean value of the flow stress was found to be 1.16 times the average of the yield and ultimate strengths, but a 95-percent reliability value (mean minus 1.96 times the standard deviation value) was found to give a flow stress equal to the average of the yield and ultimate strengths. Hence, the following equation is suggested

$$
\sigma_{\mathrm{f}}=\left(\sigma_{\mathrm{y}}+\sigma_{\mathrm{u}}\right) / 2 \quad \text { or } \quad\left(\mathrm{S}_{\mathrm{y}}+\mathrm{S}_{\mathrm{u}}\right) / 2
$$

where

$\sigma_{\mathrm{y}}=$ actual yield strength at operating temperature

$\sigma_{\mathrm{u}}=$ actual ultimate strength at operating temperature

$S_{y}=$ Code value of yield strength at operating temperature

$S_{u}=$ Code value of ultimate strength at operating temperature 
The DPZP C factor in the past was 21.8 for the best-fit curve through the surface-cracked-pipe data. This factor was reassessed using the expanded database, which included data from this program. Figure 5.10 shows that the value of $\mathrm{C}$ for the best fit of all data is 32 , and $\mathrm{C}=34$ if only ferritic pipe data are used. The difference between the curves using values of 32 or 34 is imperceptible in Figure 5.10; it is better seen in Figure 5.11, which reproduces Figure 5.10 using an expanded $x$-axis scale.

Also note that there are two 95-percent-confidence curves shown in Figures 5.10 and 5.11. One has a $C$ value of 8.9 while the other has a value of 3.0. The curve with a $C$ value of 8.9 used only data with the DPZP less than one, where EPFM is expected, while the curve with $C$ of 3.0 is biased by the data with DPZP values greater than one, where limit-load failure is expected. The $C=8.9$ value is the most appropriate for the 95-percent confidence curve in the EPFM range.

Next, an assessment was made to determine if the Charpy energy could be used in place of the $J_{i}$ value. It is well known that $\mathrm{J}_{\mathrm{i}}$ is proportional to the Charpy upper-shelf energy (Ref. 5.16). The proportional constant varies from 6 to 10 depending on the degree of conservatism desired. This proportional constant was determined empirically using the experimental pipe data and the DPZP analysis. Using the actual Charpy upper-shelf data and assuming $\mathrm{C}$ to be 34 , the Charpy energy constant was determined. This shows that

$$
\mathrm{J}_{\mathrm{i}}=7.5(\mathrm{CVP})
$$

where the units for $\mathrm{J}_{\mathrm{i}}$ are in-lb/in ${ }^{2}$ and the units for CVP are $\mathrm{ft}-\mathrm{lbs}$, and the 7.5 empirical constant accounts for the difference in units. This value of 7.5 is in good agreement with the 6 to 10 values found elsewhere in the literature.

The 95-percent confidence curve through the data set using the Charpy energy in the DPZP parameter gave a $\mathrm{C}$ value of 10 (see Figure 5.12).

Hence, Equations (5-11) and (5-12) can be rewritten in terms of Charpy energy data to solve for the Z-factor as shown below:

$$
\mathrm{Z}=\pi /\left\{2 \arccos \left[\mathrm{e}^{-\mathrm{C}\left(2 \mathrm{E} 7.5 \mathrm{CVP} / \pi^{2} \mathrm{D} \sigma_{\mathrm{f}}^{2}\right.}\right]\right\}
$$

or

$$
Z=\pi /\left\{2 \arccos \left[\mathrm{e}^{-1.52 \mathrm{C} \cdot \mathrm{E} \cdot \mathrm{CVP} /\left(\mathrm{D} \sigma_{\mathrm{f}}^{2}\right)}\right]\right\}
$$

where

$$
\begin{aligned}
& C=34 \text { for the best-fit curve, and } \\
& C=10 \text { for the } 95 \text {-percent-confidence curve. }
\end{aligned}
$$




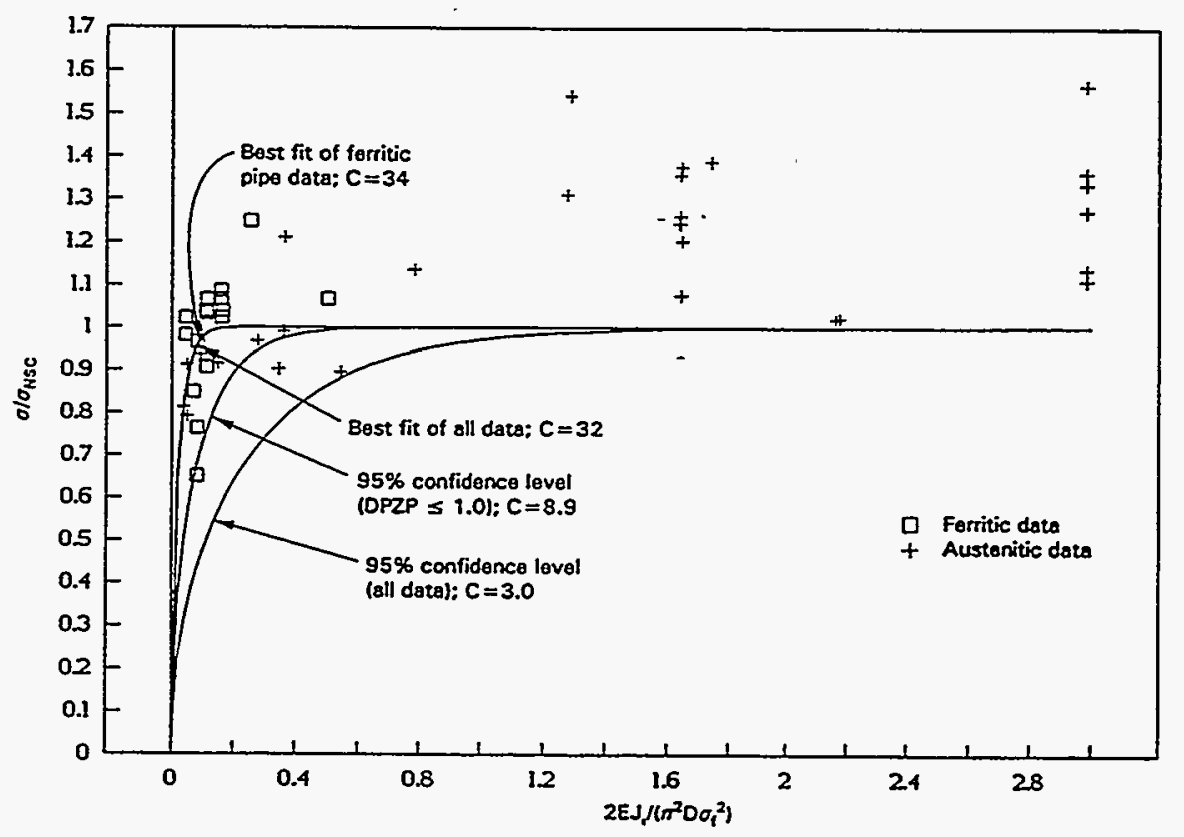

Figure 5.10 Redefining $\mathrm{C}$ factors in the DPZP analysis using all current surface-cracked pipe data

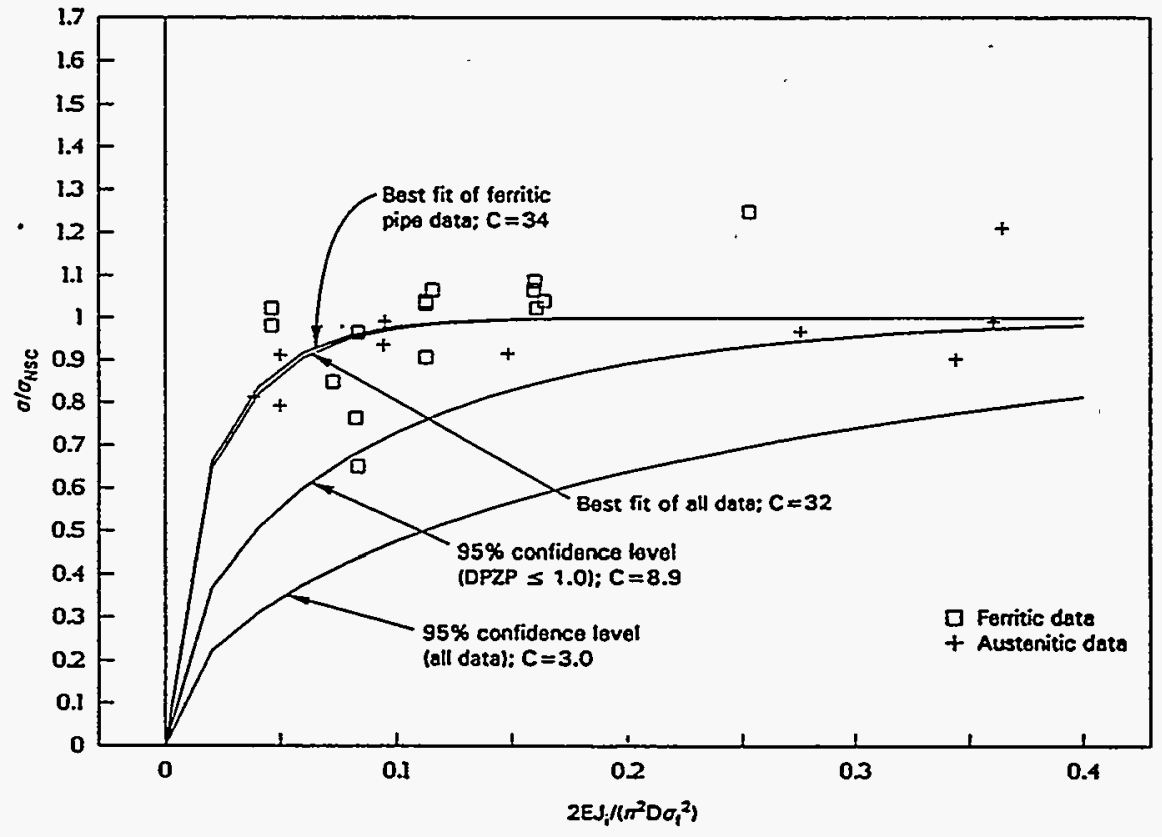

Figure 5.11 Redefining $C$ factors in the DPZP analysis using all current surfacecracked-pipe data (expanded scale of Figure 5.11) 


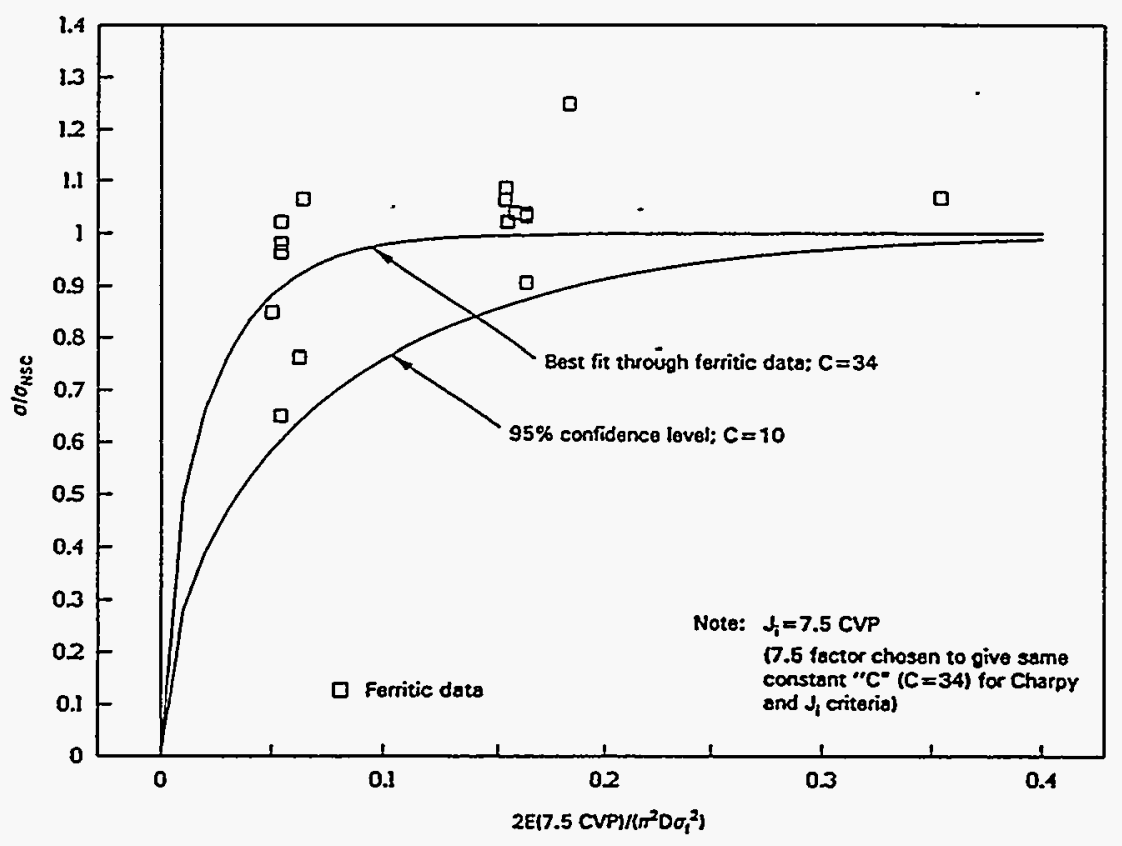

Figure 5.12 Fit of surface-cracked ferritic steel pipe data to define $J_{i}$ versus CVP constant and 95-percent confidence of $\mathrm{C}$ factor

The material properties used to develop the current ASME Z-factors in the ferritic and austenitic pipe criteria were used to calculate the DPZP-based Z-factors. These Z-factors were then compared with the Z-factors currently used in the Code.

For the ferritic pipe IWB-3650 Z-factors, there are two ASME Code Z-factor equations. One is for base metal and shielded-metal-arc welds with a lower bound $\mathrm{J}_{\mathrm{Ic}}$ of $105 \mathrm{~kJ} / \mathrm{m}^{2}\left(600 \mathrm{in}-\mathrm{lb} / \mathrm{in}^{2}\right)$. The other is for submerged-arc welds with a $J_{I c}$ of $61 \mathrm{~kJ} / \mathrm{m}^{2}\left(350 \mathrm{in}-1 \mathrm{~b} / \mathrm{in}^{2}\right)$. This criterion is limited to pipe larger than a nominal pipe diameter of $102 \mathrm{~mm}$ ( 4 inches).

Using a flow-stress definition for A106B pipe at $288 \mathrm{C}(550 \mathrm{~F})$ as the average of Code specified yield and ultimate strengths, i.e., $\left(S_{y}+S_{u}\right) / 2$, which is less than one percent different from the ASME flow stress of $2.4 \mathrm{~S}_{\mathrm{m}}$, the Z-factors by Equation 5-16 were calculated. These factors are shown in Figure 5.13 for both the best-fit and the 95-percent-confidence-level curves. The best-fit curves for the DPZP analysis Z-factors are significantly below the ASME Z-factor curves. The 95-percentconfidence curve for Material $1\left[\mathrm{~J}_{\mathrm{Ic}}=105 \mathrm{~kJ} / \mathrm{m}^{2}\left(600 \mathrm{in}-\mathrm{lb} / \mathrm{in}^{2}\right)\right]$ is below the ASME Z-factor curve. For Material 2, the ASME and DPZP 95-percent-confidence Z-factors are approximately the same, except for diameters less than $406 \mathrm{~mm}$ (16 inches), where the ASME curve is higher.

For the austenitic pipe, the calculated Z-factors shown in Figure 5.14 used the ASME Code definition of flow stress of $3 \mathrm{~S}_{\mathrm{m}}$, whereas Figure 5.15 shows the DPZP results using the average of the Codespecified yield and ultimate strengths of TP304 stainless steel at $288 \mathrm{C}(550 \mathrm{~F})$. For the ASME 
Pipe Diamoter, inches

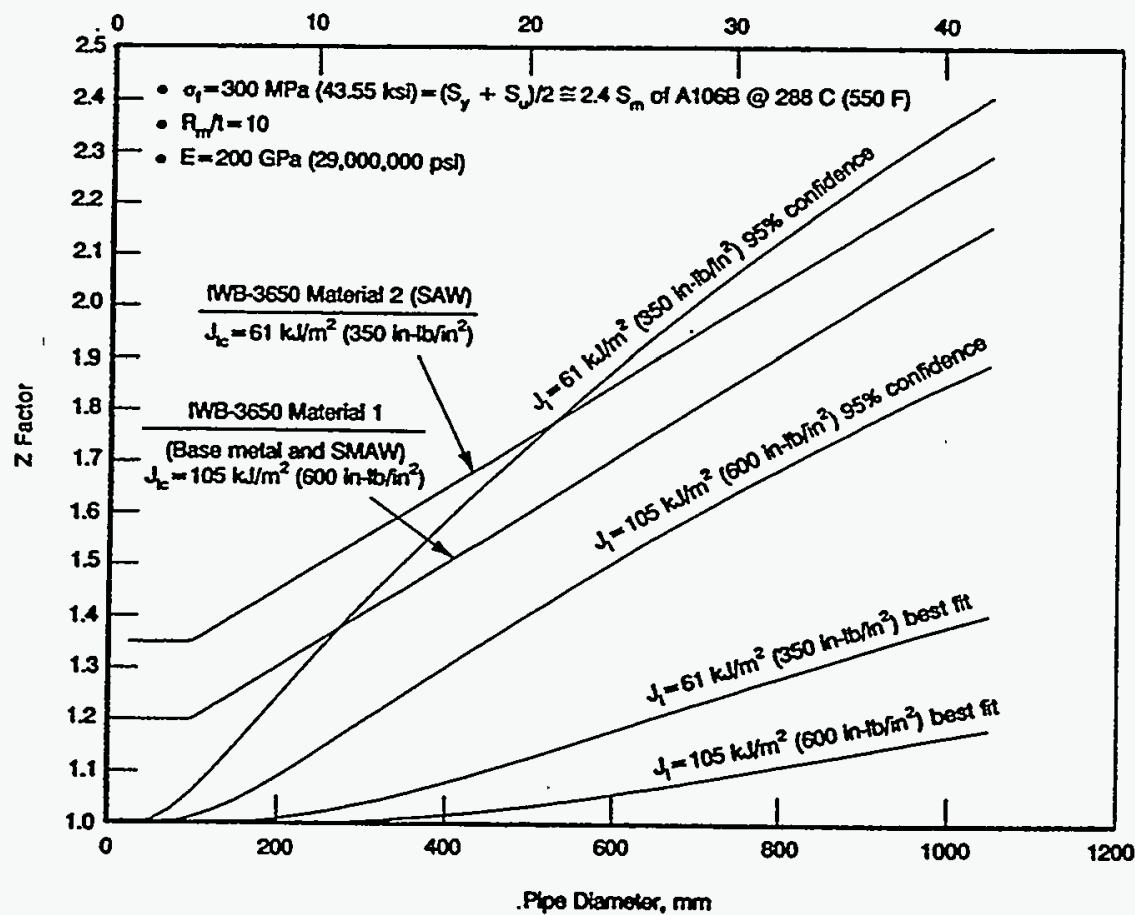

Figure 5.13 Comparison of Z-factors from DPZP analysis with ASME IWB-3650 analysis for ferritic steels

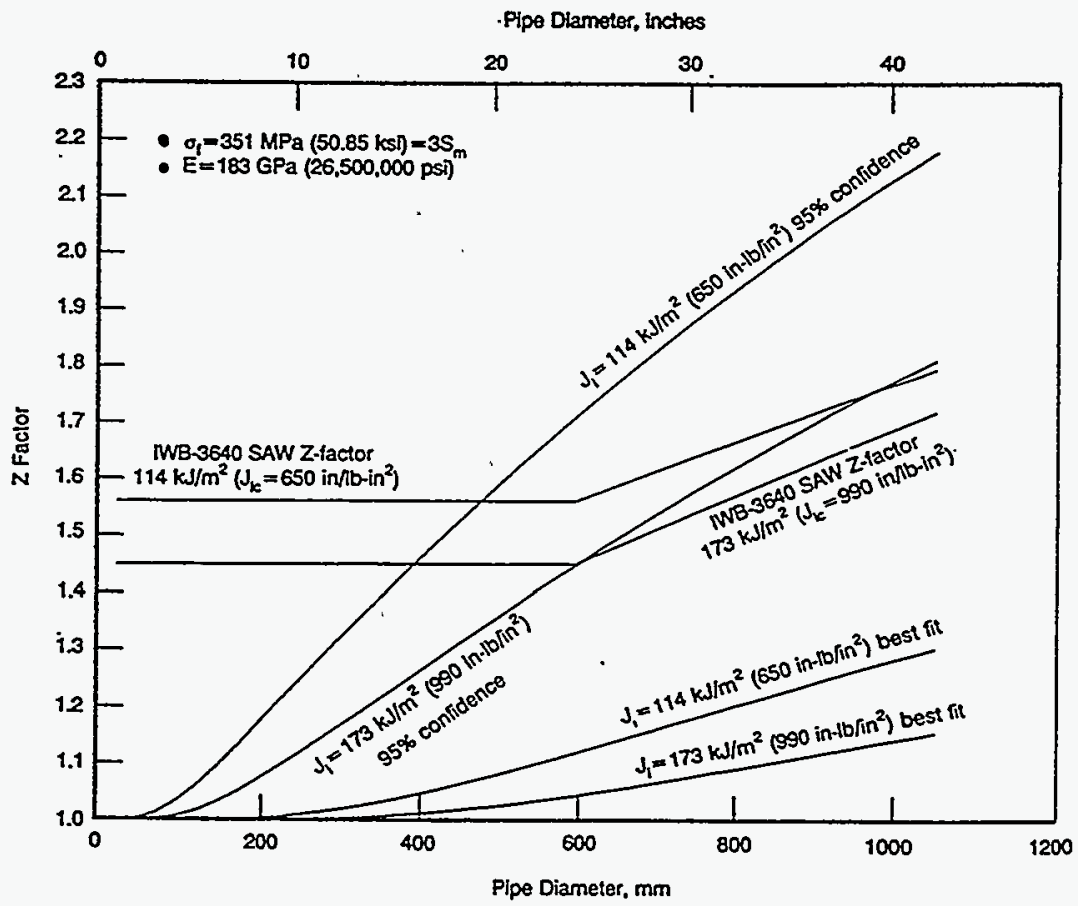

Figure 5.14 Comparison of Z-factors from DPZP analysis with ASME TWB-3640 analysis using $\sigma_{\mathrm{f}}=3 \mathrm{~S}_{\mathrm{m}}$ 


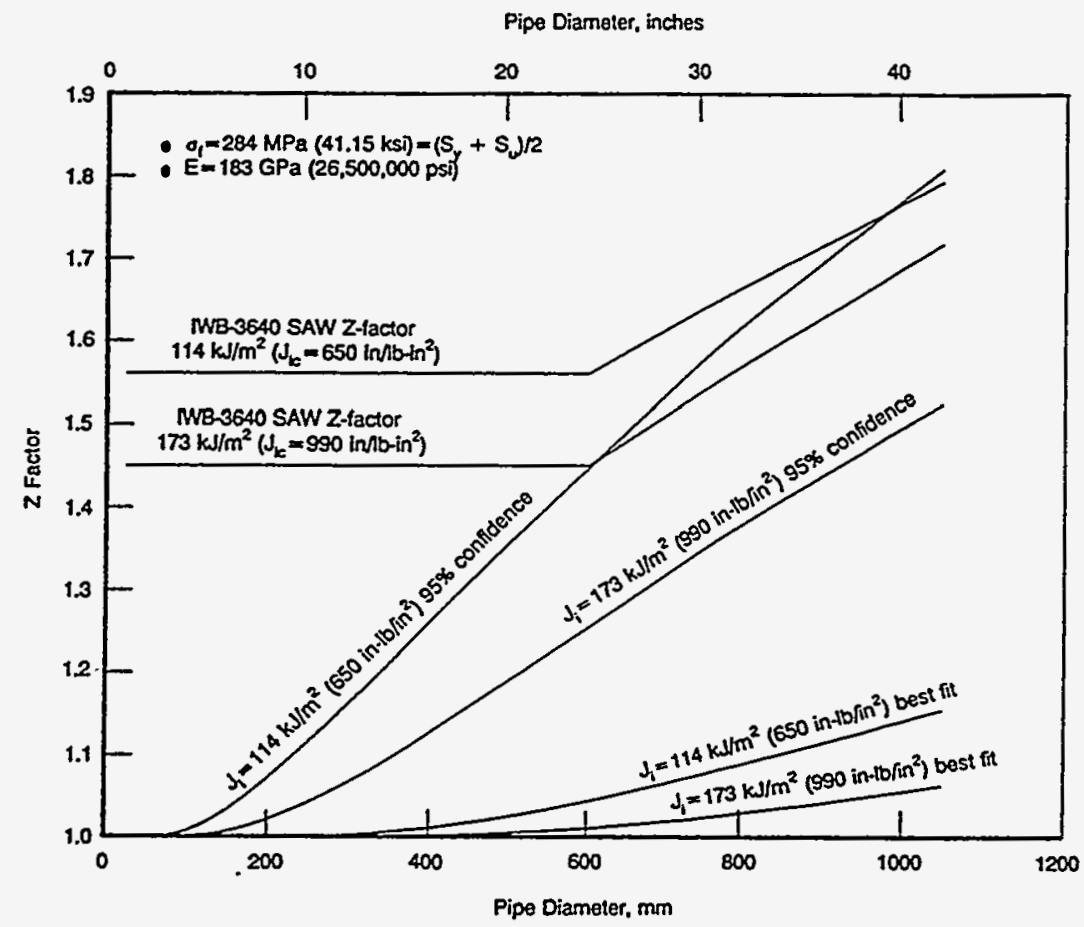

Figure 5.15 Comparison of Z-factors from DPZP analysis with ASME IWB-3640 analysis using $\sigma_{f}=\left(S_{y}+S_{u}\right) / 2$

austenitic criteria, if the pipe is smaller than 610-mm (24-inches) in diameter, then the ASME Z-factor for a $610-\mathrm{mm}$ (24-inch) diameter pipe is used.

In Figures 5.14 and 5.15, it can be seen that the DPZP best-fit curves are well below the ASME $Z$-factor curves. However, for the case where the flow stress is $3 S_{m}$ (Figure 5.15), the DPZP-based Z-factor curve, using the 95-percent confidence level, is higher than the ASME Z-factor curve, except for pipe having a diameter less than $457 \mathrm{~mm}$ (18 inches). The 95-percent-confidence DPZP-based Z-factor curve for the SMAW is approximately the same as the current ASME Z-factors for diameters larger than $610 \mathrm{~mm}$ (24 inches).

If the flow stress for stainless steel is changed to the average of the yield and ultimate strength, i.e., $\left(\mathrm{S}_{\mathrm{y}}+\mathrm{S}_{\mathrm{u}}\right) / 2$, then the curves in Figure 5.15 should be used. Here the 95-percent-confidence DPZPbased Z-factor curve for SAW is approximately the same as the ASME Z-factor curve for pipe diameters larger than $610 \mathrm{~mm}$ (24 inches). The 95-percent-confidence DPZP-based SMAW Z-factor curve is well below the ASME Z-factor curve, as shown in Figure 5.15.

Finally, the changes in the Z-factors with Charpy upper shelf energy are examined. Hence, the user is not required to use a single $\mathrm{Z}$-factor curve regardless of the actual toughness of the material.

Instead of the step change from limit-load to EPFM analysis procedure results in Appendices $C$ and $\mathrm{H}$, there is a smooth transition from limit load to EPFM analysis procedure results using this 


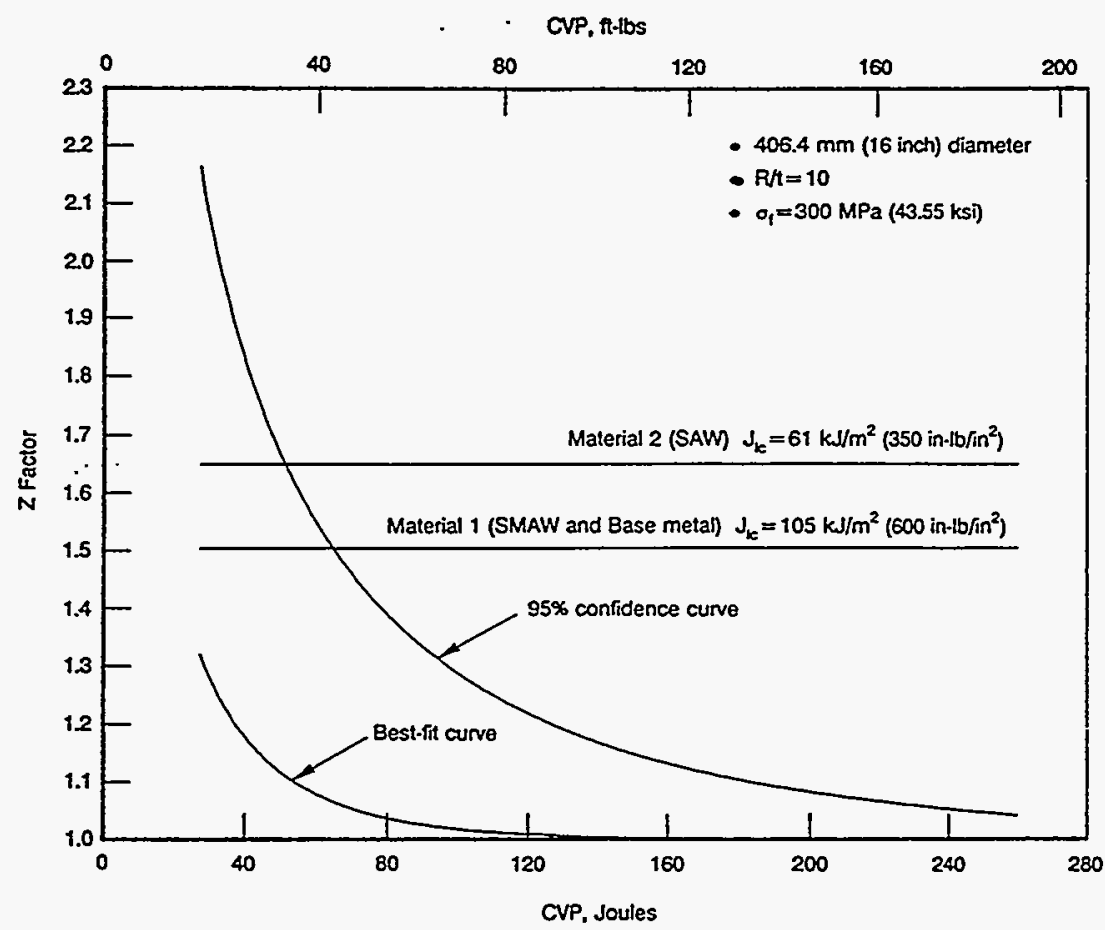

Figure 5.16 DPZP Z-factors as a function of Charpy energy for 406-mm (16-inch) diameter pipe and comparison with ASME IWB-3650 values

approach. This smooth transition is shown in Figure 5.16 where the DPZP-based Z-factor is calculated as a function of the Charpy energy for a 406-mm (16-inch) diameter A106 Grade B pipe at $288 \mathrm{C}(550 \mathrm{~F})$. The flow stress chosen was the average of the yield and ultimate strength, which was almost identical to $2.4 \mathrm{~S}_{\mathrm{m}}$ in this case. As can be seen in Figure 5.16, the ASME Z-factor curves are significantly higher than the 95-percent confidence DPZP curve when the L-C oriented full-size Charpy upper-shelf energy is greater than approximately 54 Joules (40 ft-lbs).

\subsubsection{Z-Factors From Finite-Length Surface-Cracked-Pipe J-estimation Schemes}

The second approach to calculate Z-factors was to use the finite-length surface-cracked pipe J-estimation schemes to assess the effects of surface-crack geometries on the Z-factors. The finitelength aspect of this analysis is an advantage that the Charpy energy/DPZP approach does not have. Two different analyses were used: the ASME Code Case N-494-2 and the SC.TNP1 analyses. These calculations were done only for the ferritic SAW case (Material Category 2).

\subsubsection{Comparison of Z-factors from ASME Section XI Appendix $\mathrm{H}$ with Z-factors calculated using Code Case N-494-2}

One way of developing independent Z-factors from a finite-length analysis method is to use the ASME Code Case N-494-2 procedures. This method was used for comparison to the ASME Section XI Appendix H ferritic pipe SAW (Material Category 2) Z-factors. 
The calculations used the Code Case N-494-2 analysis in the NRCPIPES Code (Version 2.0a). The inputs were the material property data from Table 5.3 with the J/T extrapolated J-R curve shown in Figure 5.5. Values of a/t varied from 0.1 to 0.75 and values of $\theta / \pi$ varied from 0 to 1.0 in the compilations. The Code Case does have a limitation that $\theta / \pi$ should be less than 0.5 , but calculations up to a value of 1.0 were made. These calculations were done for pipe with outside diameters of $114.3 \mathrm{~mm}$ (4.5 inch), $406.4 \mathrm{~mm}$ ( 16 inches), and $1.067 \mathrm{~m}$ (42 inches). The $R_{\mathrm{m}} / \mathrm{t}$ ratio was held constant at 10 , and the pipe was unpressurized in all these calculations. A safety factor of 1.0 was used in the analyses. The Z-factor is simply the limit-load moment divided by the Code Case allowable moment.

Figures 5.17 to 5.19 show the comparison of the ASME Appendix $\mathrm{H}$ values with the Z-factors from the Code-Case-analysis procedure. Each of these figures has three separate graphs. The first graph is the nominal bending stress (or limit stress) calculated using a Net-Section-Collapse analysis; the second graph is the Code-Case-calculated maximum bending stress; and the third graph is the Z-factor graph, which is simply the ratio of the Net-Section-Collapse analysis stress to the Code-Case-analysis stress.

Several observations can be made in these figures:

- If $\theta / \pi$ is greater than 0.5 , then the Z-factors start increasing. However, this is the invalid region of the Code-Case-analysis procedure and was shown for illustration purposes only.

- The Code Case Z-factors decrease with $\theta / \pi$ going from 0.1 to 0.5 and generally with a/t going from 0.75 to 0.1 . The exception is for the $a / t$ of 0.75 as $\theta / \pi$ becomes larger than 0.4 .

- For very small a/t values, the $\mathrm{Z}$-factors go to 1.0 as expected.

- The ASME Appendix $H$ values are greater than the Code Case Z-factor values except for deep cracks $(\mathrm{a} / \mathrm{t}>0.5)$ in small diameter pipe $(\leq 406-\mathrm{mm}$ [16-inch] diameter).

- As $\theta / \pi$ approaches zero, the Z-factors actually increase rather than approach a value of 1.0 as might be expected.

\subsubsection{Comparison of Z-factors from ASME Section XI Appendix H with Various Surface-Cracked Pipe J-estimation Schemes}

In Section 4 of this report, it was shown that the SC.TNP1 method was the most accurate of the finite length J-estimation schemes developed for predicting maximum load. This finding was determined by comparisons with pipe experiments from this program and the Degraded Piping program. Generally, these experiments had a/t values of 0.5 to 0.66 and $\theta / \pi$ values of 0.25 to 0.5 . 


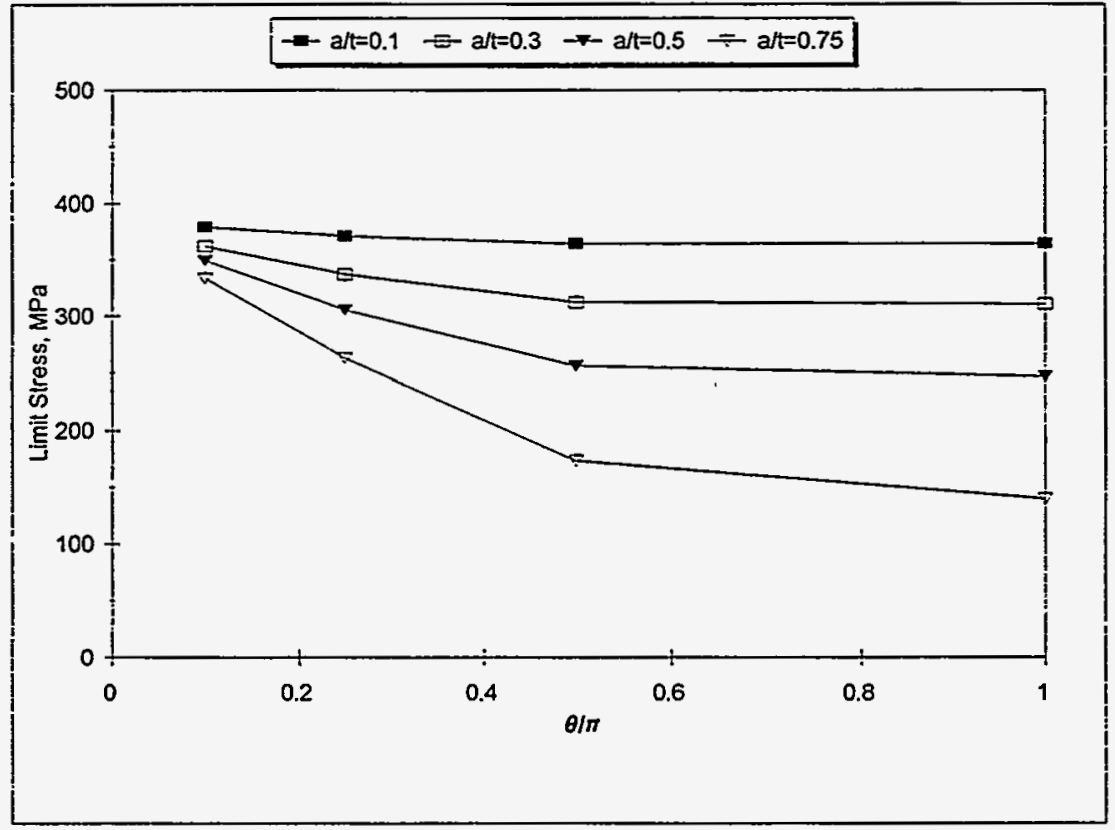

(a) Limit-load analysis maximum bending stress

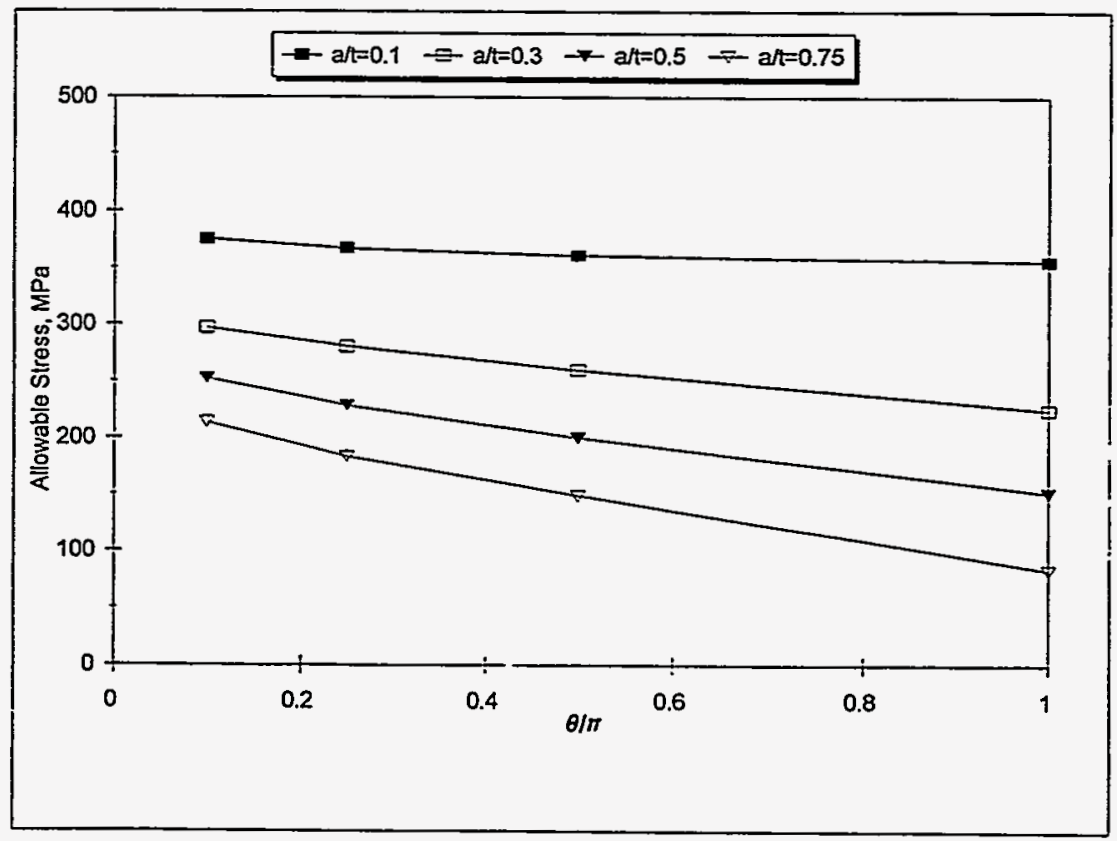

(b) Code-Case-calculated maximum bending stress

Figure 5.17 Code Case Z-factor analysis steps for 114.3-mm (4.5-inch) outside diameter pipe using $\mathrm{J} / \mathrm{T}$ extrapolated ferritic pipe SAW $\mathbf{J}-\mathrm{R}$ curve 


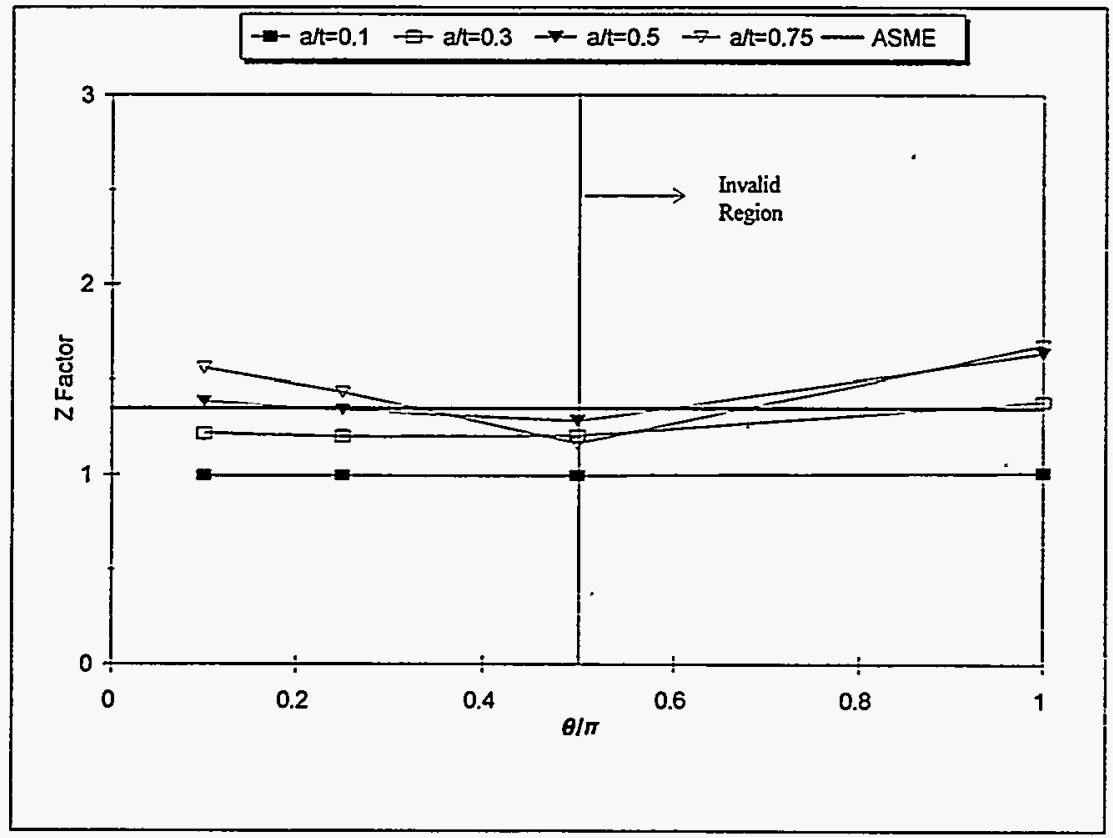

(c) Comparison of Z-factors from the Code Case analysis with the ASME Section XI Appendix $H$ value

Figure 5.17 (continued) 


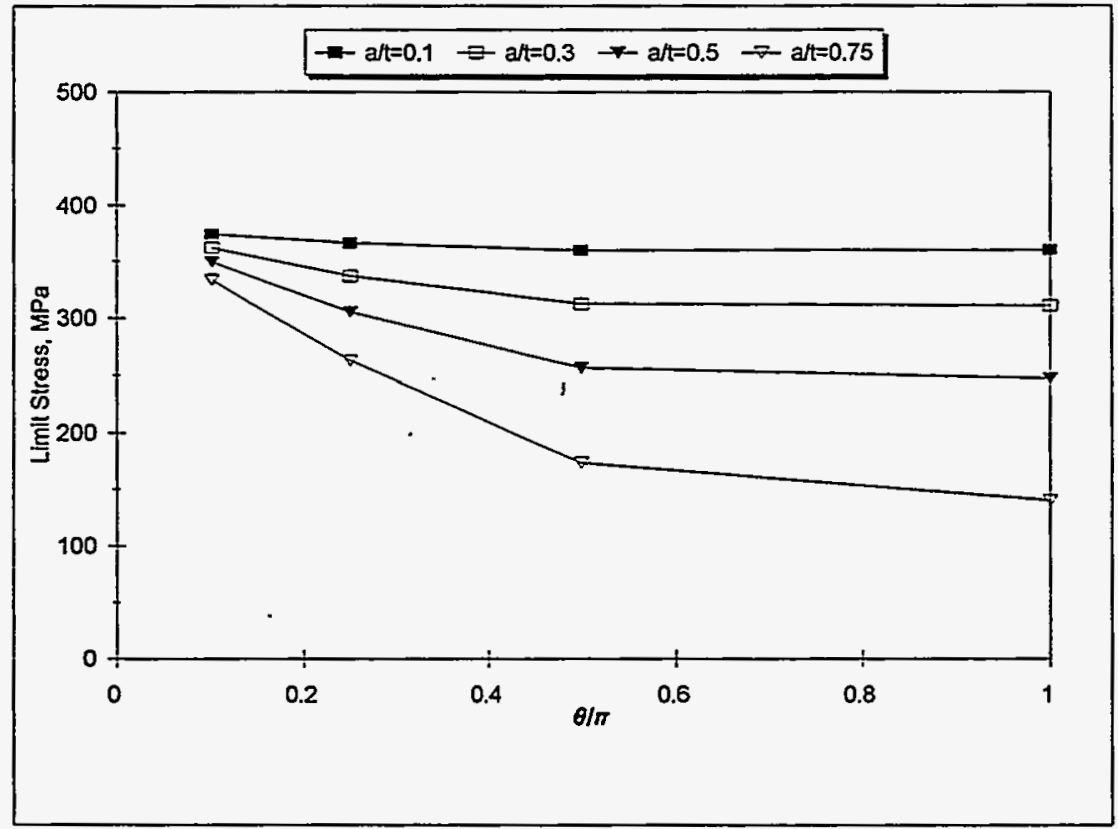

(a) Limit-load analysis maximum bending stress

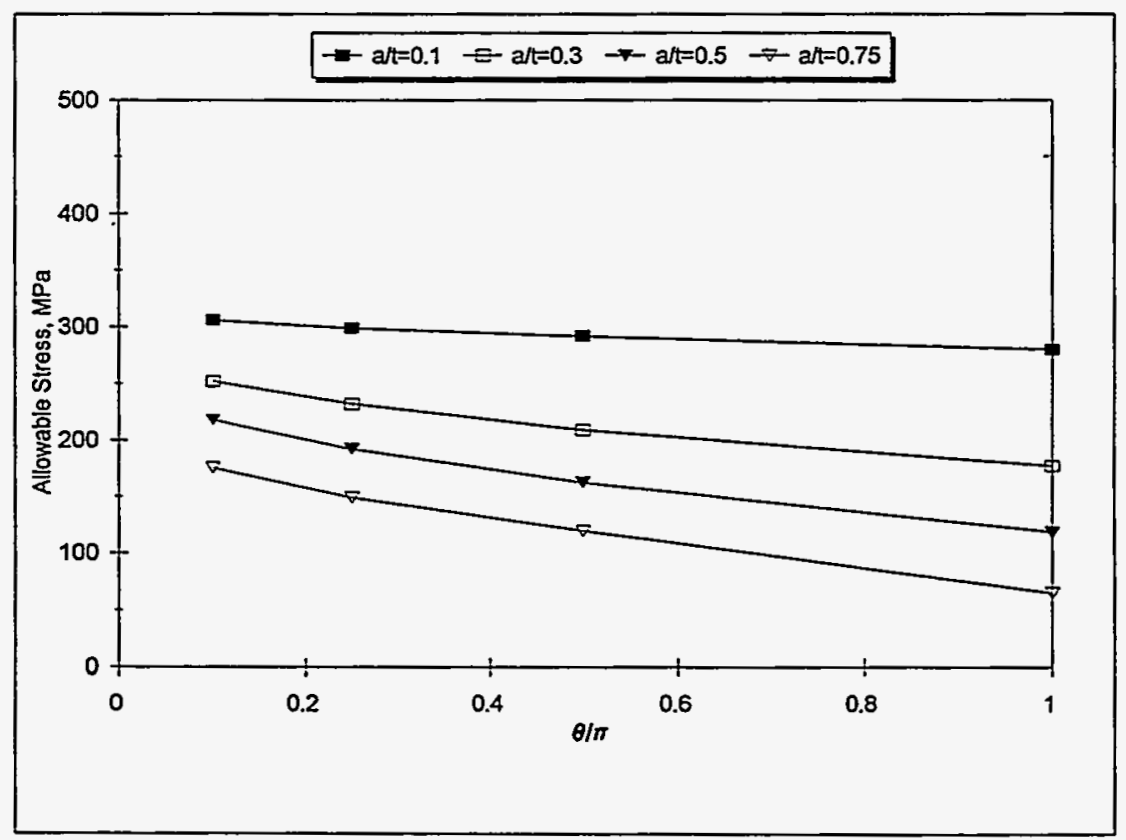

(b) Code Case calculated maximum bending stress

Figure 5.18 Code Case Z-factor analysis steps for 406.4-mm (16-inch) outside diameter pipe using J/T extrapolated ferritic pipe SAW J-R curve 


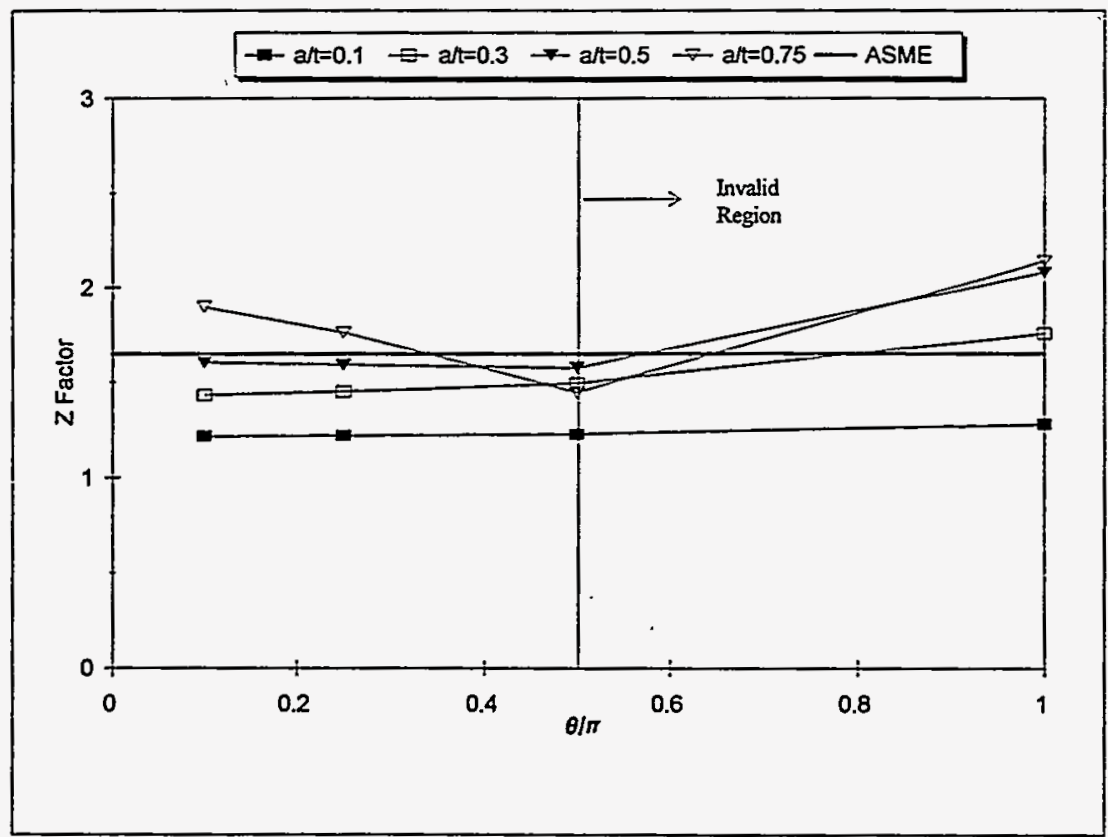

(c) Comparison of Z-factors from the Code Case analysis with the ASME Section XI Appendix $H$ value

Figure 5.18 (continued) 


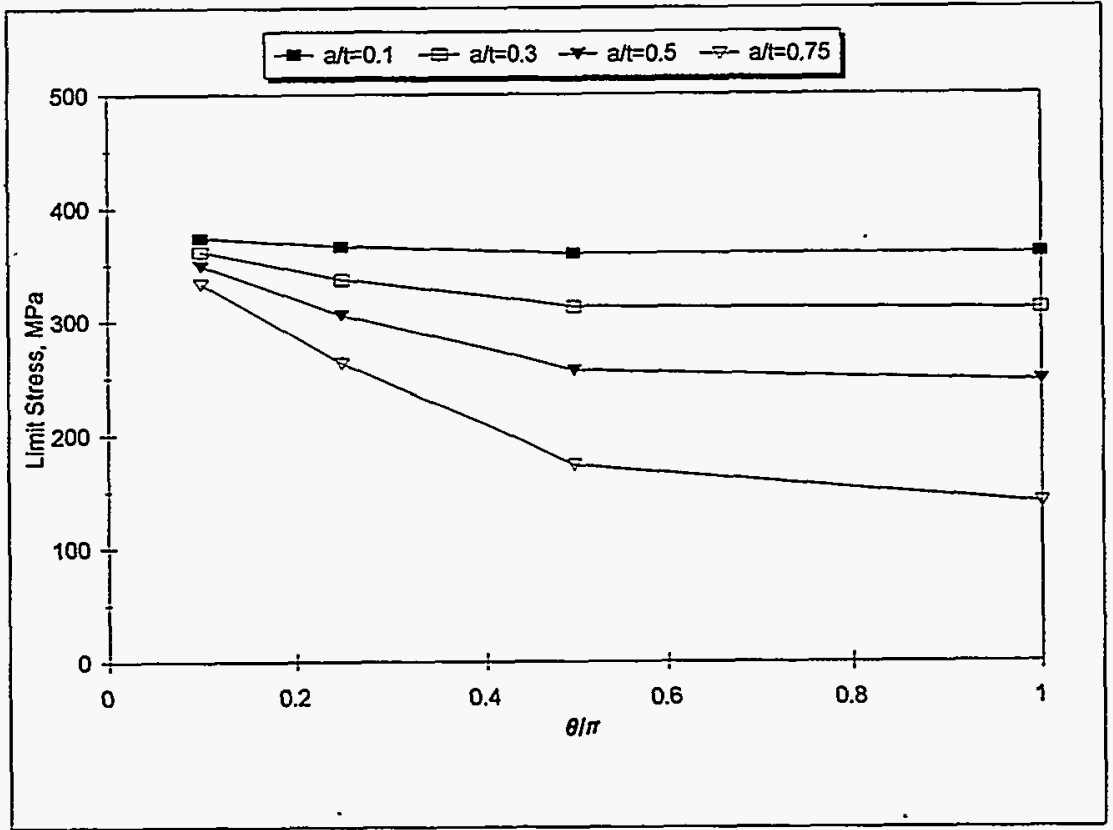

(a) Limit-load analysis maximum bending stress

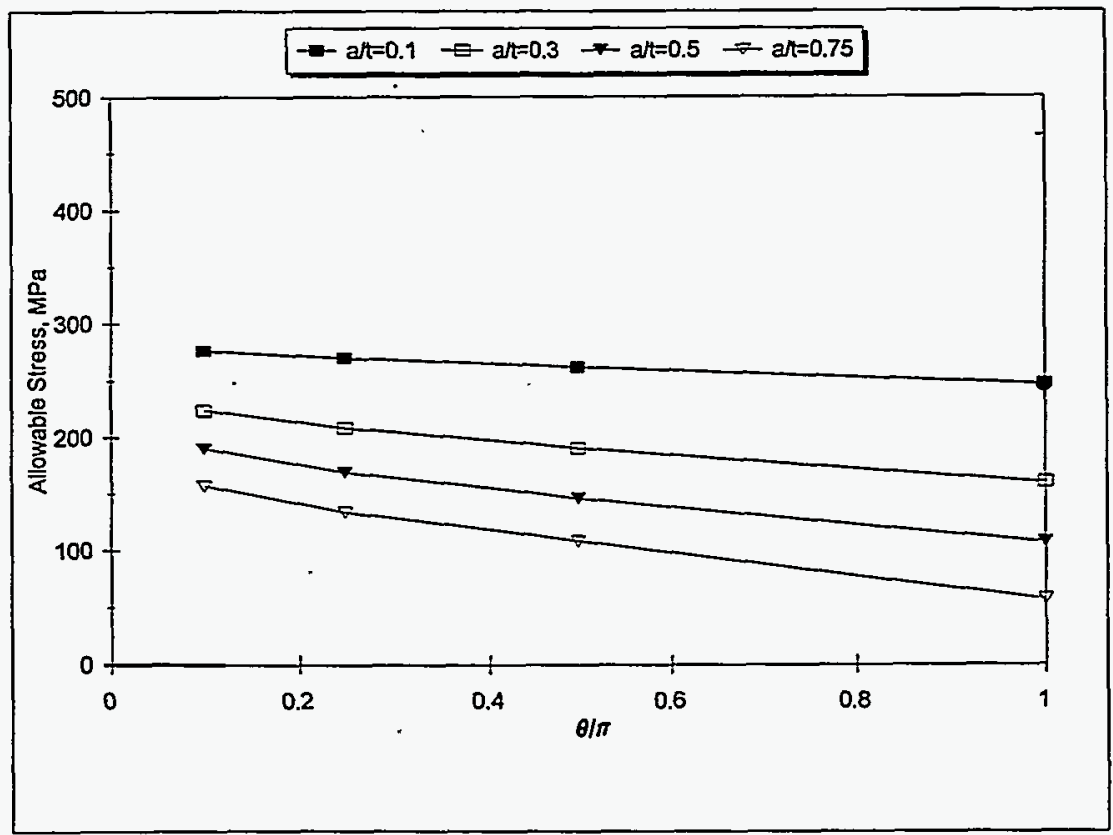

(b) Code Case calculated maximum bending stress

Figure 5.19 Code Case Z-factor analysis steps for 1.067-m (42-inch) outside diameter pipe using $J / T$ extrapolated ferritic pipe SAW J-R curve 


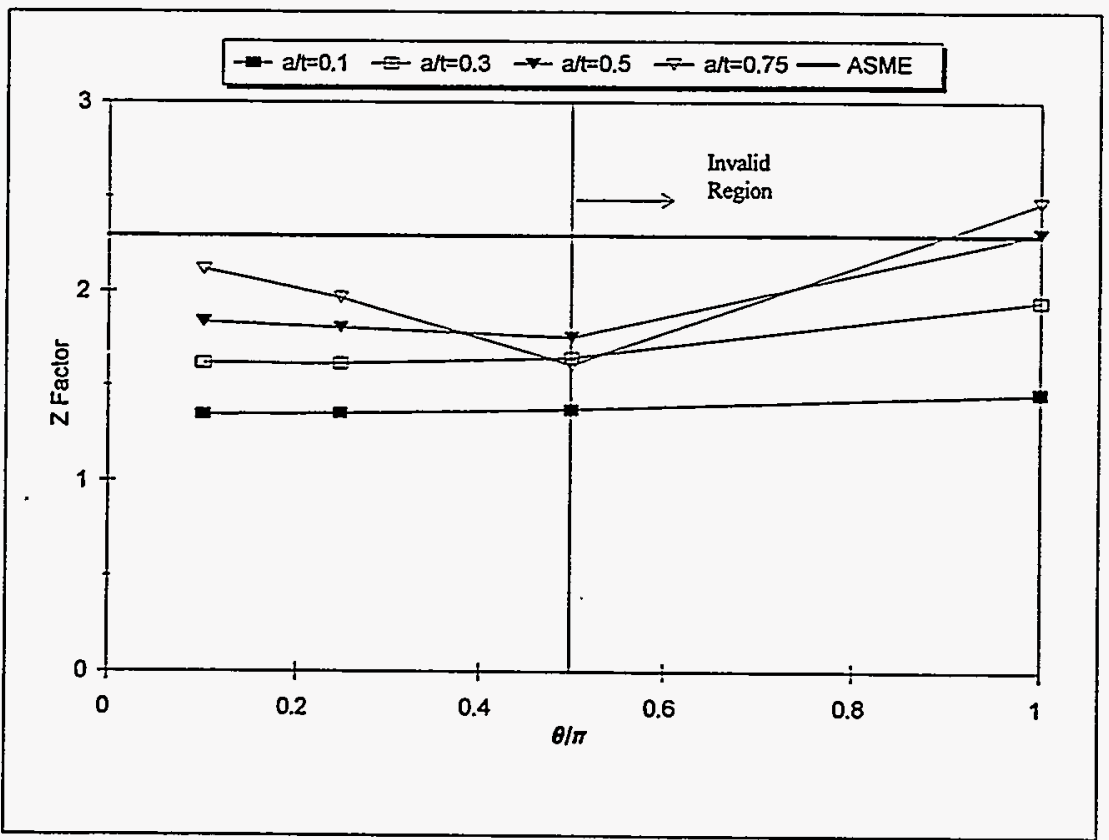

(c) Comparison of Z-factors from the Code Case analysis with the ASME Section XI Appendix $H$ value

Figure 5.19 (continued) 


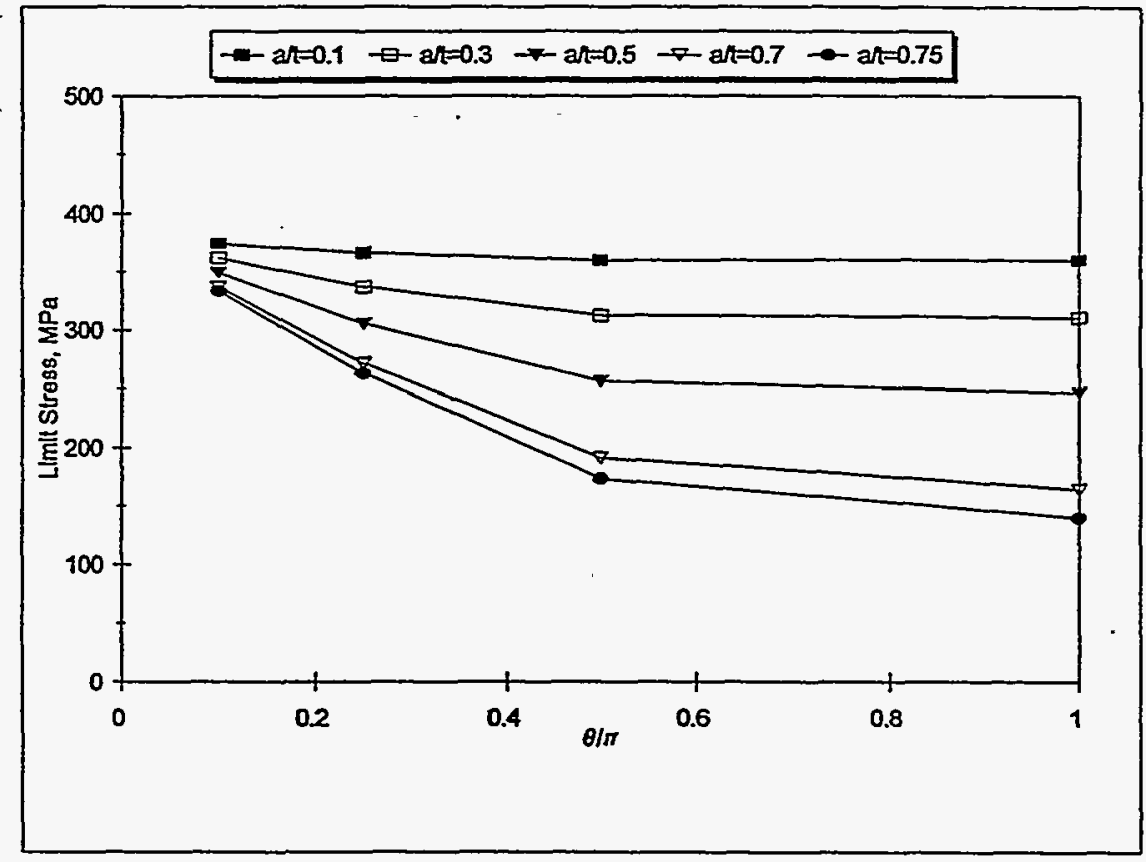

(a) Net-Section-Collapse analysis predicted moment

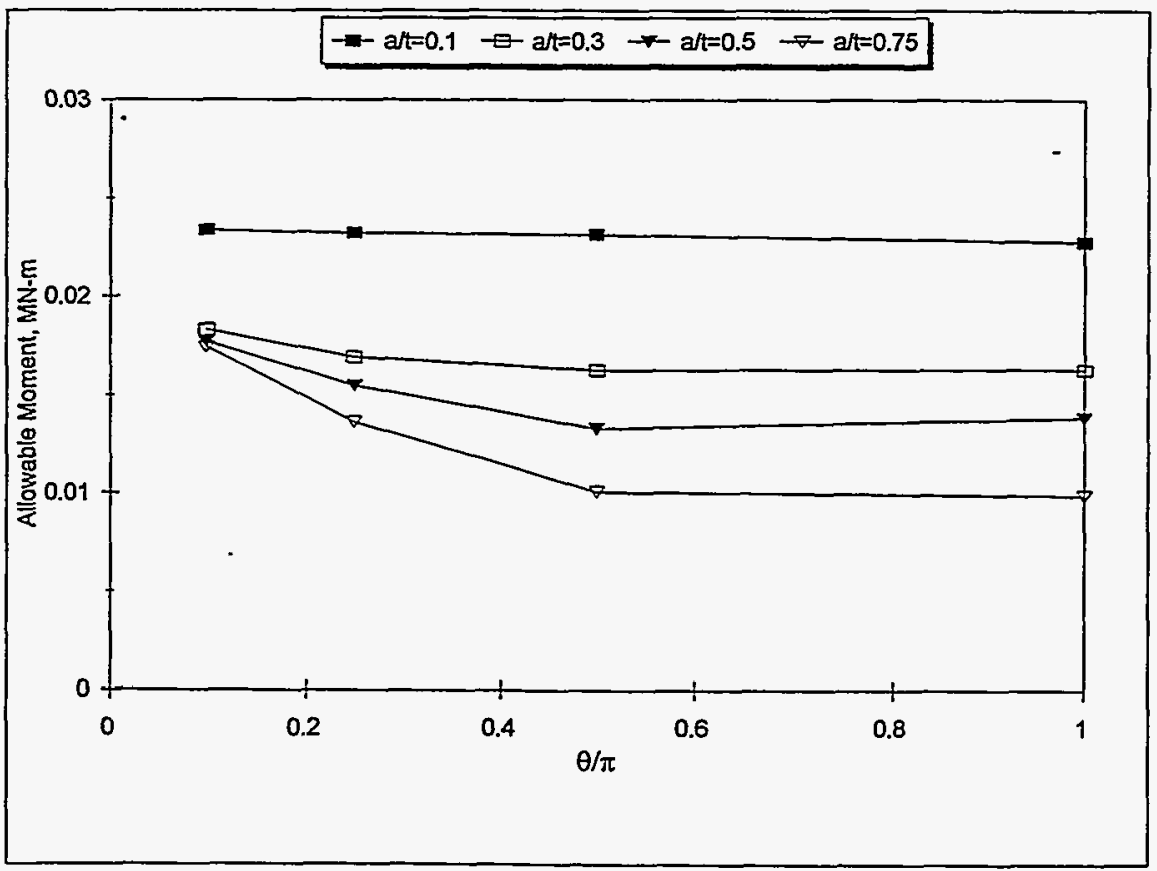

(b) SC.TNP1 calculated maximum moments with the $J / T$ extrapolated $J_{D}-R$ curve

Figure 5.20 SC.TNP1 Z-factor analysis steps for 114.3-mm (4.5-inch) outside diameter pipe using $\mathrm{J} / \mathrm{T}$ extrapolated ferritic pipe SAW J-R curve 


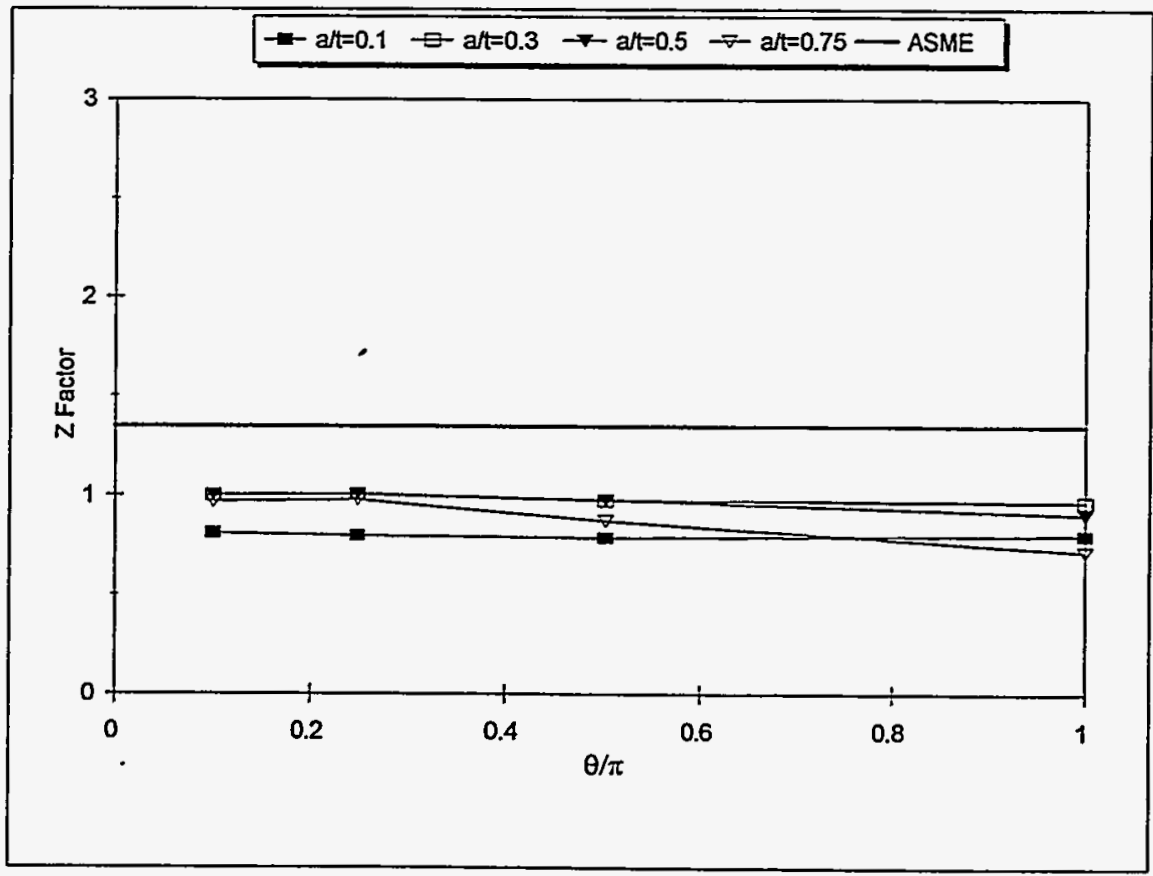

(c) Comparison of Z-factors from the SC.TNP1 analysis with the ASME Section XI Appendix $H$ value

Figure 5.20 (continued) 


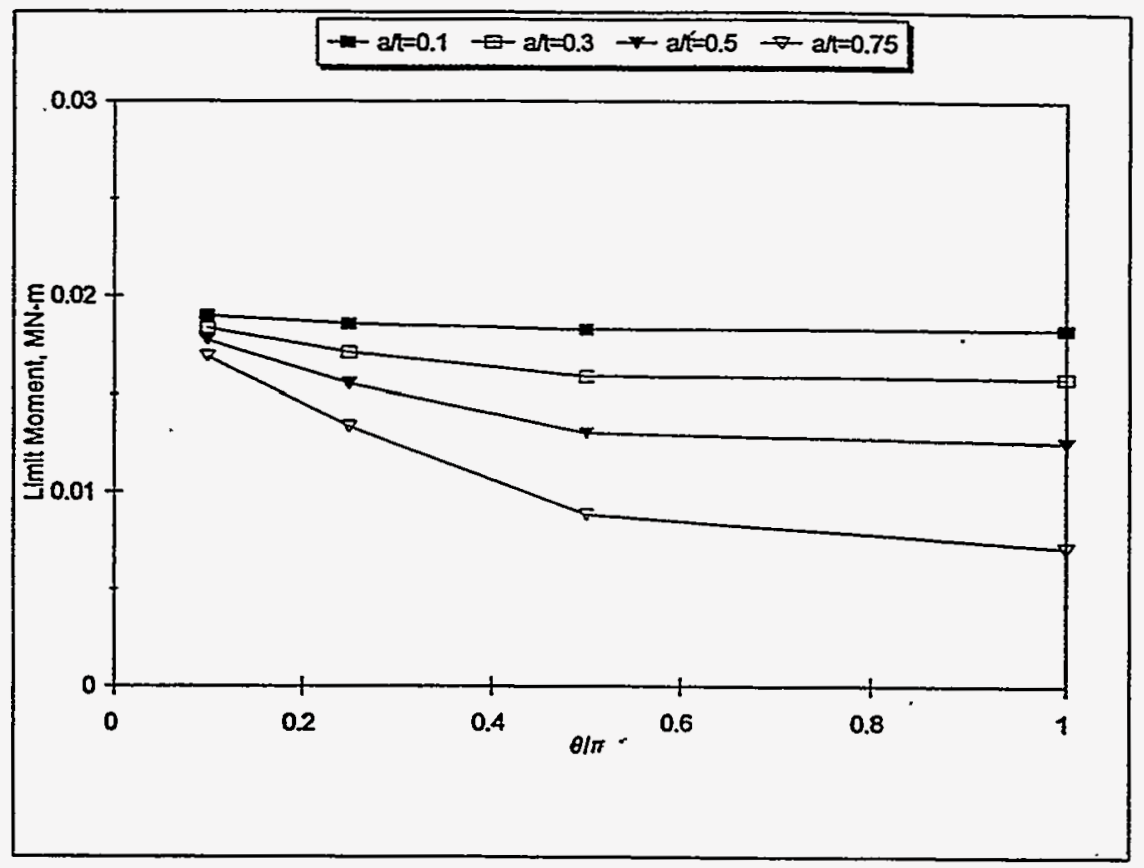

(a) Net-Section-Collapse analysis predicted moment

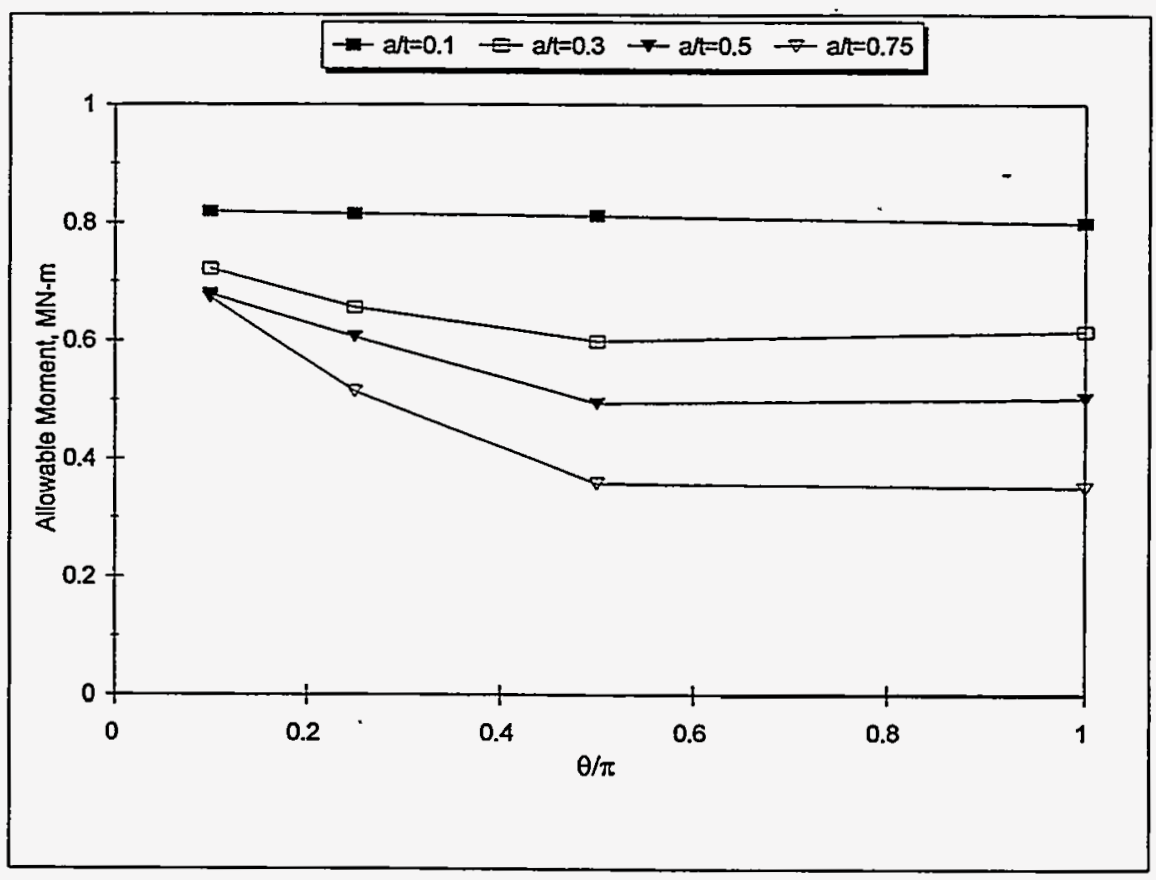

(b) SC.TNP1 calculated maximum moments with the $J / T$ extrapolated $J_{D}-R$ curve

Figure 5.21 SC.TNP1 Z-factor analysis steps for 406.4-mm (16-inch) outside diameter pipe using J/T extrapolated ferritic pipe SAW J-R curve 


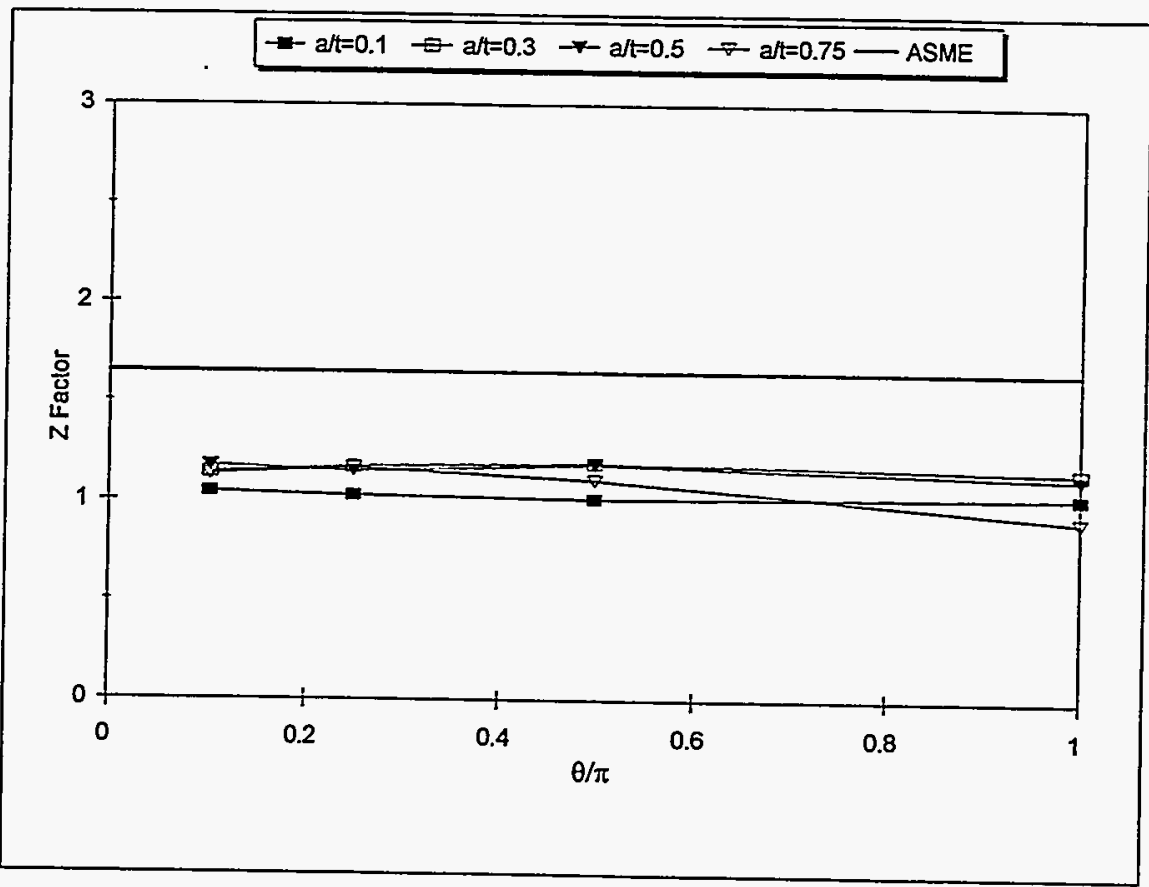

(c) Comparison of Z-factors from the SC.TNP1 analysis with the ASME Section XI Appendix $H$ value

Figure 5.21 (continued) 


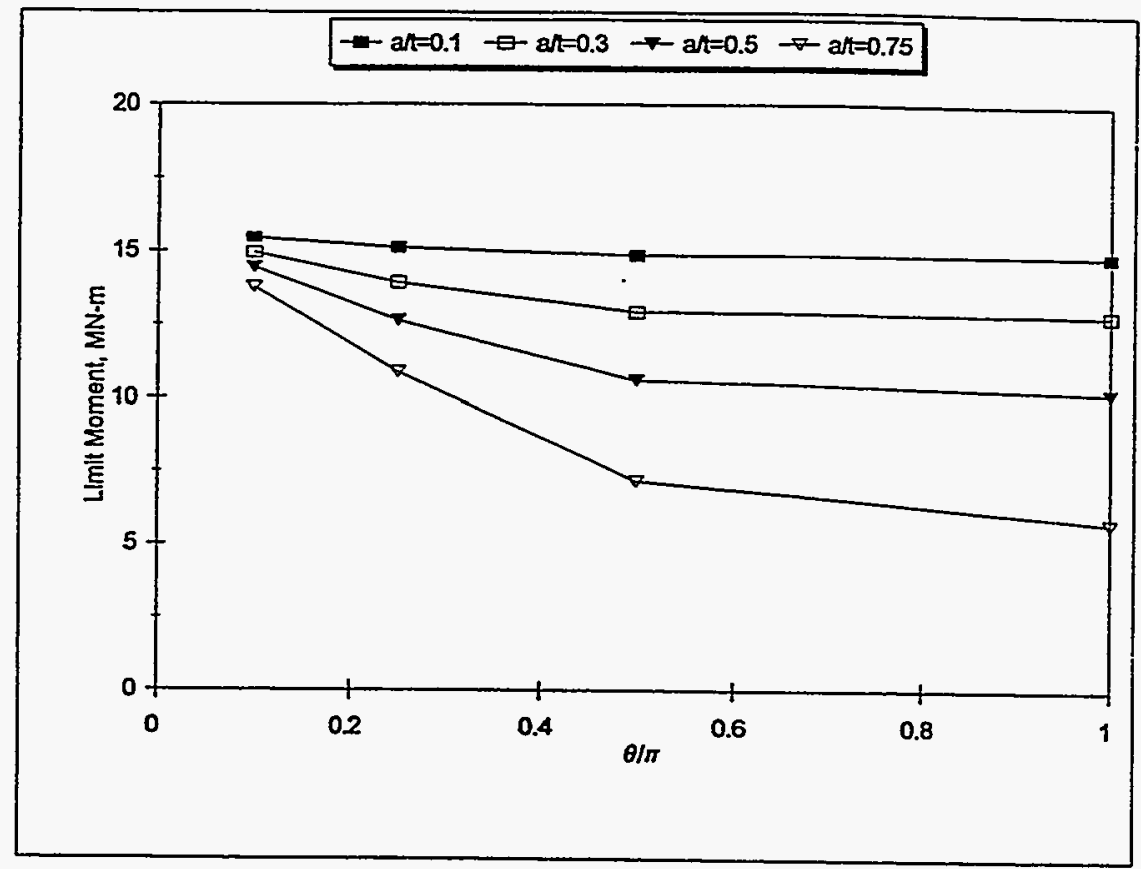

(a) Net-Section-Collapse analysis predicted moment

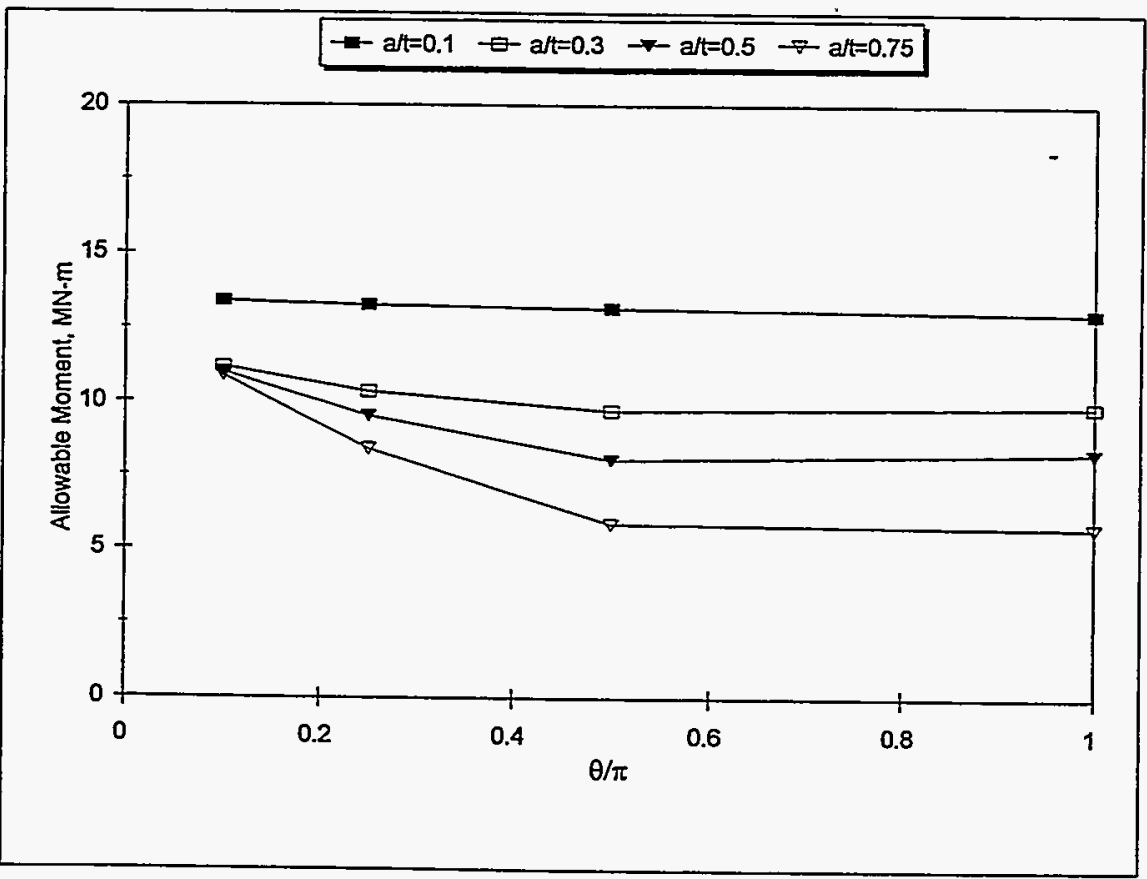

(b) SC.TNP1 calculated maximum moments with the $J / T$ extrapolated $J_{D}-R$ curve

Figure 5.22 SC.TNP1 Z-factor analysis steps for 1.067-m (42-inch) outside diameter pipe using J/T extrapolated ferritic pipe SAW J-R curve 


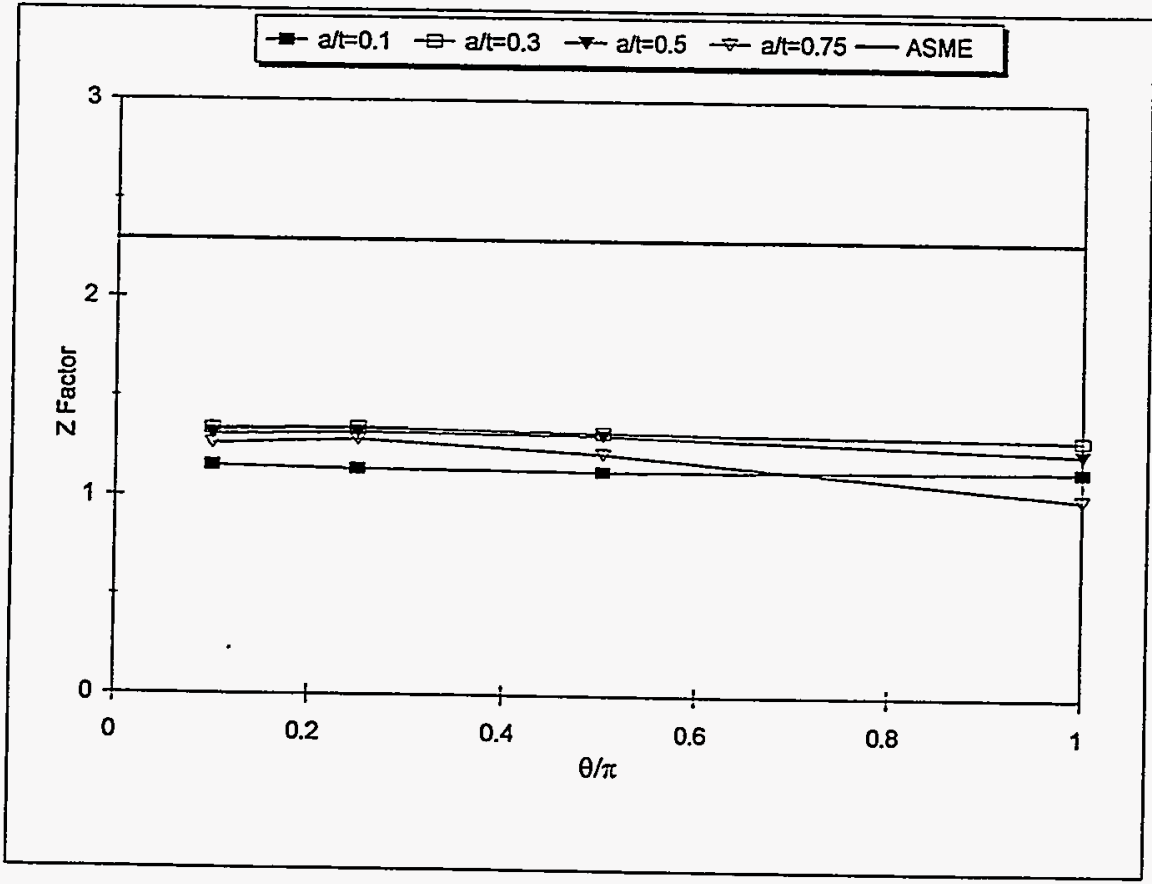

(c) Comparison of Z-factors from the SC.TNP1 analysis with the ASME Section XI Appendix $H$ value

Figure 5.22 (continued) 
To develop Z-factors using the SC.TNP1 analysis, exactly the same input values were used in these analyses as in determining the Code Case analyses Z-factors in the prior section. Figures 5.20 to 5.22 show the comparison of the ASME Appendix-H values with the Z-factors from the SC.TNP1 analysis procedure. Each of these figures also has three separate graphs. The Net-Section-Collapse solution was in terms of moment (or limit moment), but is the same result as in Figures 5.17(a), 5.18(a), and 5.19(a). The second graph in Figures 5.20 to 5.22 is the SC.TNP1 calculated maximum moments, and the third graph is the Z-factor graph, which is simply the ratio of the limit moment to the SC.TNP1 analysis predicted maximum moment.

During the program, it was found that a limit on a/t was needed for short crack depths in the SC.TNP1 analysis because the limit-load solutions used by Ahmad (Ref. 5.17), see Equation 5-17, were different from the limit-load solutions used in the Net-Section-Collapse analysis, see Equation 5-18.

$$
\begin{gathered}
\mathrm{M}_{\mathrm{o}}=4 \mathrm{R}_{\mathrm{m}}{ }^{2} \mathrm{t} \sigma_{\mathrm{o}}\{\cos [1-2(\mathrm{t}-\mathrm{a}) /(\mathrm{t} \sqrt{3})] \theta / 2-\{[1-2(\mathrm{t}-\mathrm{a}) /(\mathrm{t} \sqrt{3})] / 2\} \sin \theta\} \\
\mathrm{M}_{\mathrm{o}}=4 \mathrm{R}_{\mathrm{m}}{ }^{2} \mathrm{t} \sigma_{\mathrm{o}}\{\cos [1-(\mathrm{t}-\mathrm{a}) / \mathrm{t}] \theta / 2-[(1-(\mathrm{t}-\mathrm{a}) / \mathrm{t}) / 2 \mathrm{t}] \sin \theta\}
\end{gathered}
$$

The difference between the Ahmad limit-load solution and the Net-Section-Collapse solution tends to be negligible when the crack a/t values reach 0.5 to 0.66 (the values of most of the pipe tests), and hence was not noticed when making comparisons with pipe test results in the past. The trigonometric functions in Equation 5-17 are used throughout the SC.TNP1 solution.

The SC.TNP1 moment-versus-crack-length graphs show the limitation of this method for $\theta / \pi<0.1$ and $\mathrm{a} / \mathrm{t}<0.1$. The $\theta / \pi$ limitation is from lack of elastic $F$-function and $\mathrm{h}_{1}$-function solutions for such small crack lengths. The a/t limitation is from the Ahmad limit-load equation discussed above. Intuitively, one would think that for such small cracks, the failure should the approach the limit-load solution.

The results in Figures 5.20(c)-5.22(c) show similar, and more consistent, trends than the Code Case N-494-2 Z-factors. The important trends are:

- the Z-factors are constant for $0.1<\theta / \pi<1.0$ for a given $\mathrm{a} / \mathrm{t}$,

- the Z-factors are relatively constant for a/t from 0.3 to 0.75 ,

- the Z-factors for $\mathrm{a} / \mathrm{t}=0.1$ were near 1.0 , except for the $114.3-\mathrm{mm}$ (4.5-inch) diameter pipe where $\mathrm{Z}$ was below 1.0 (an erroneous prediction),

- as a simplification, it appears that the Z-factor could be linearly interpolated between $\mathrm{a} / \mathrm{t}=0.3$ and $\mathrm{a} / \mathrm{t}=0$, 


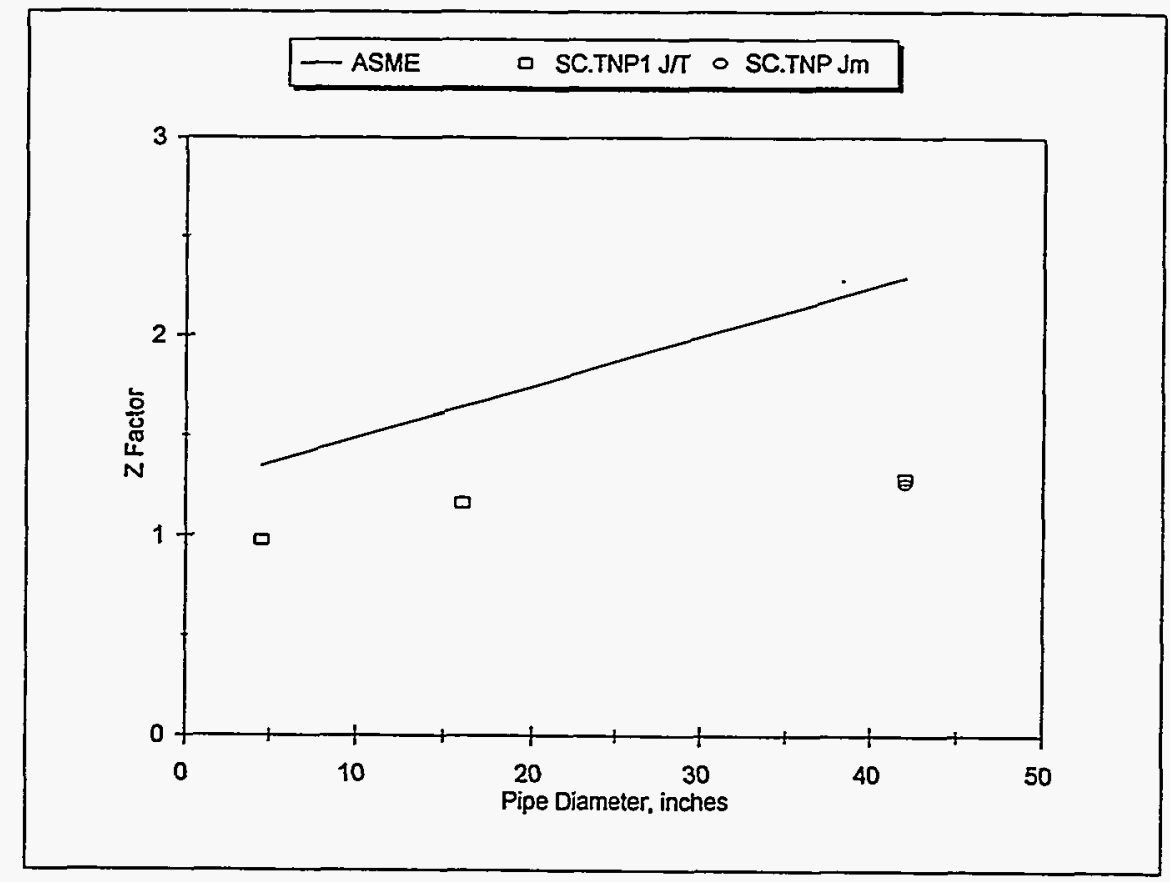

Figure 5.23 Comparison of the SC.TNP1 Z-factors with the ASME Appendix H equation $Z$-factor values versus pipe diameter using the $J / T$ extrapolated $J_{D}-R$ curve

- the Z-factors should go to 1.0 as $\theta / \pi$ approaches zero, but the analysis is not valid in this region. As a simplification, the Z-factor could be linearly interpolated between $\theta / \pi=0.1$ and $\theta / \pi=0$ (were $Z=1.0$ )

Using the SC.TNP1 Z-factor values from Figures 5.20(c) to 5.22(c), Figure 5.23 shows how the SC.TNP Z-factors compare with the Appendix- $H$ values as a function of pipe diameter. The peak $Z$ factor values were used in this graph. This comparison shows that the Appendix-H SAW Z-factors are much larger, by a considerable amount, especially for larger diameter pipes.

J-R Curve Sensitivity. To address the sensitivity of the calculated Z-factors due to the J-R curve used, an additional set of calculations was conducted. This involved using the 1T C(T) specimen $\mathrm{J}_{M}-\mathrm{R}$ curve, the highest $\mathrm{J}-\mathrm{R}$ curve in Figure 5.7. The $\mathrm{J} / \mathrm{T}$ extrapolated $\mathrm{J}_{\mathrm{D}}-\mathrm{R}$ curve used in the prior calculations was the lowest curve in Figure 5.7. The through-wall-cracked pipe Z-factor analyses in Section 5.1.2.3 showed large sensitivity to these two J-R curves, i.e., the Z-factors were 1.75 and 2.7 for the $1.067-\mathrm{m}$ (42-inch) diameter pipe case. This is a 54 percent difference. These calculations were done only for the large diameter pipe case where there should be the greatest sensitivity to the J-R curve used.

The results of the SC.TNP1 calculations with the $\mathrm{J}_{\mathrm{M}}-\mathrm{R}$ curve are shown in Figure 5.24. Figure 5.24(a) shows the SC.TNP1 calculated moments, and Figure 5.24(b) shows the calculated Zfactors. The limit moment stress is the same as in Figure 5.22(a). The peak Z-factor at a/t $=0.75$ and $\theta / \pi=0.25$ is also shown in Figure 5.23. Figure 5.25 shows the ratio of the J/T extrapolated 


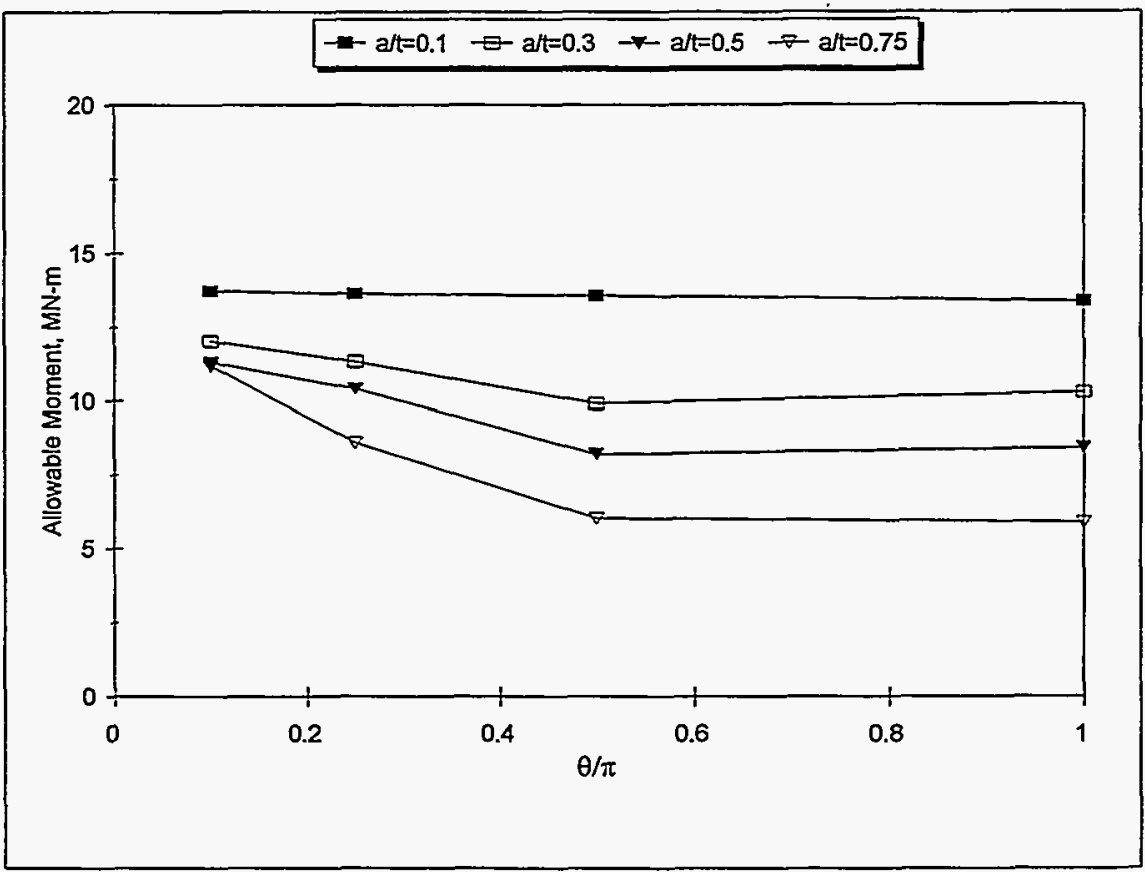

(a) SC.TNP1 calculated maximum moments

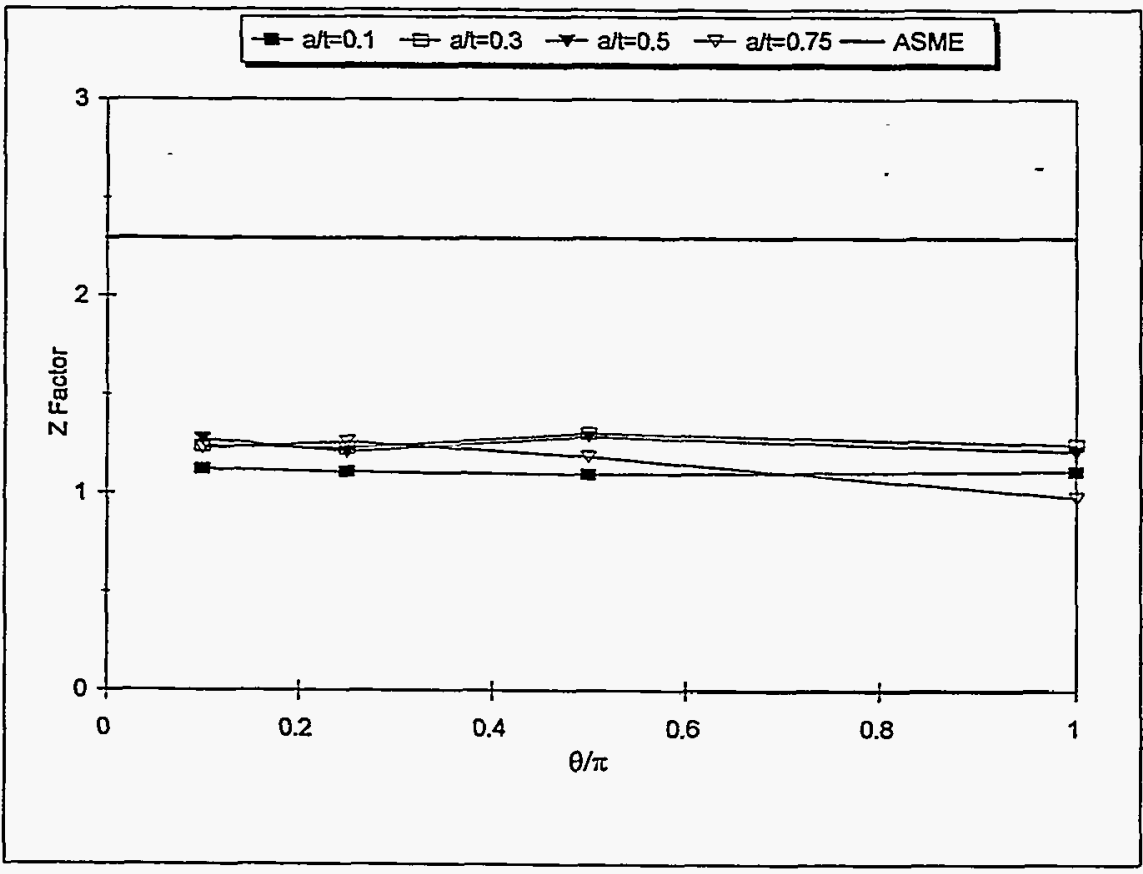

(b) Comparison of Z-factors from the SC.TNP1 analysis with the ASME Section XI Appendix H value

Figure 5.24 SC.TNP1 Z-factor analysis steps for 1.067-m (42-inch) outside diameter pipe (Using $1 T$ C(T) $J_{M}-\mathbf{R}$ curve from Figure 5.7) 


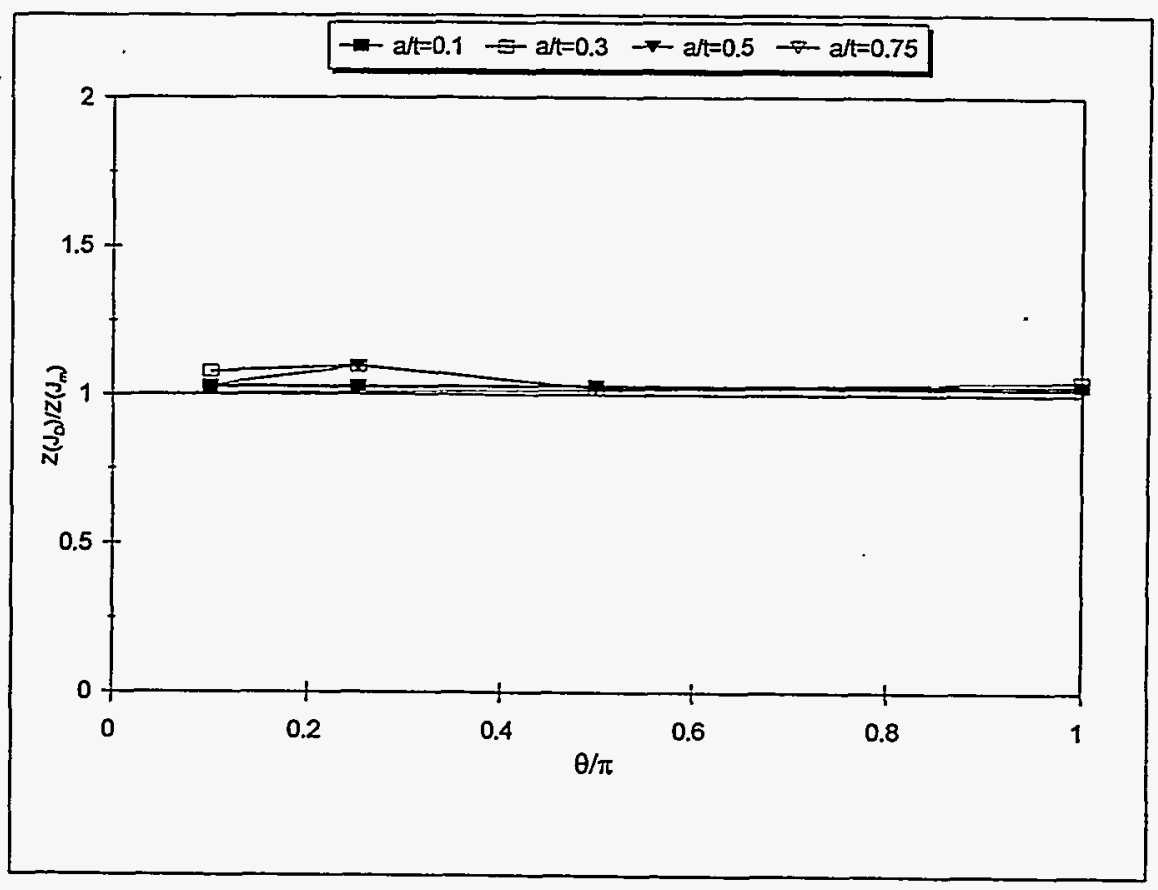

Figure 5.25 Ratio of SC.TNP1 Z-factors using $\mathrm{J} / \mathrm{T}$ extrapolated $\mathrm{J}_{\mathrm{D}}-\mathrm{R}$ curve to Z-factors using $J_{M}-R$ curve versus $\theta / \pi$

$\mathrm{J}_{\mathrm{D}}-\mathrm{R}$ curve Z-factors to the $\mathrm{J}_{\mathrm{M}}-\mathrm{R}$ curve $\mathrm{Z}$-factors versus $\theta / \pi$ for the various a/t values. It can be seen that the ratio of the $Z$-factors ranges from 1.1 to 1.0 . Hence, the sensitivity of the $Z$-factors using the surface-cracked pipe analysis for this case was reduced considerably from the TWC Z-factor analyses.

\subsection{Summary}

The results from the efforts described in this section showed that the ASME Section XI pipe flaw evaluation criteria could not be reproduced using the same input as the technical basis documents. For the austenitic pipe Z-factor case, even the material property input were not traceable.

. Z-factors were recalculated using several different methods, which are summarized below.

- The Z-factors calculated using various J-R curves with the Zahoor-modified GE/EPRI solution showed significant scatter. This scatter was found to be inherent in using a through-wall-cracked pipe analysis for a surface-cracked pipe problem.

- As the diameter decreased, Z-factors did not approach the value of 1 as expected, for various circumferential through-wall-cracked pipe J-estimation schemes.

- A Charpy energy-based criterion using the DPZP analysis was developed. This method allows for a smooth transition from limit-load to EPFM and inherently accounts for 
anisotropy and constraint effects, but does not account for flaw lengths. If the mean curve is used in the DPZP analysis, then the calculated Z-factors are well below the ASME $\mathrm{Z}$-factors. If the 95-percent-confidence curve is used, then the DPZP Z-factors are close to or below the ASME Z-factors in most cases.

- The Code Case N-494-2 analysis procedure was used to develop Z-factors for ferritic pipe SAW flaws. This procedure showed that in general the Appendix-H Z-factors were higher than the Code Case Z-factors, but the $a / t=0.75$ Code Case Z-factors were higher than the Appendix $H$ value. The Code Case $Z$-factors tend to increase with decreasing $\theta / \pi$, which is contrary to what was expected.

- The SC.TNP1 J-estimation scheme from this report was also used to develop Z-factors for ferritic pipe SAW flaws. This scheme showed that the SC.TNP1 Z-factors were constant for $\theta / \pi$ values from 0.1 to 1.0 and for $a / t$ values from 0.3 to 0.75 . For $a / t$ from 0.0 to 0.3 , it appears that the $Z$-factor could be linearly interpolated from the $a / t=0.3$ value to a $Z$ of 1.0 for $a / t-0.0$. Likewise for $\theta / \pi$ from 0.0 to 0.1 , it appears that the $Z$-factor could be linearly interpolated from the $\theta / \pi=0.1$ value to a $\mathrm{Z}$ of 1.0 at $\theta / \pi=0.0$.

An additional calculation using two significantly different J-R curves from the same material (i.e., a $J_{M}-R$ curve and $J / T$ extrapolated $J_{D}-R$ curve) and the SC.TNP1 analysis showed little difference in Z-factors for the most sensitive case. This contrasts with the through-wallcracked pipe Z-factors calculated using the same J-R curves, which showed a significant difference.

Z-factors were calculated for pipes with finite-length surface cracks using the SC.TNP1 procedure. These results could be extended to carbon steel base metal and stainless steel weld cases and combined with the Charpy energy criterion to take advantage of the desirable features of both approaches. Effects of $\mathrm{R}_{\mathrm{m}} / \mathrm{t}$ ratios need to be examined further.

The principle of extrapolating Z-factors for a/t less than 0.3 and $\theta / \pi$ less than 0.1 from the SC.TNP1 Z-factor analysis could be applied to the Charpy Energy/DPZP approach. There is some consistency between these approaches. For instance, the Charpy energy DPZP criterion showed very little difference in its Z-factor with surface flaws of $a / t=0.5$ and $\theta / \pi=0.25$ from this program and flaws of $a / t=0.66$ and $\theta / \pi=0.5$ from the Degraded Piping program. This result is consistent with the SC.TNP1 Z-factors.

A number of other considerations for improvements to the ASME pipe flaw evaluation criteria were also discussed. The more significant ones are summarized below:

- By redefining the flow stress as the average of the yield and ultimate strengths, rather than as a function of $S_{m}$, combined austenitic and ferritic pipe criteria and expansion to Class 2 and 3 piping can be easily accomplished.

- The contribution of $\mathrm{P}_{\mathrm{e}}$ and SAM stresses to fracture is equal to that of primary stresses, even for TP304 stainless steel base metal, when the total stresses are below the actual yield 
stress of the material. Hence, for these stress levels, the secondary stresses should be incorporated with a full safety factor.

If the calculated stresses assuming elastic behavior are above $S_{y}$, then a nonlinear correction will greatly increase the allowable flaw size and account for $P_{e}$ and SAM stresses being displacement-controlled. Methodology to do this needs to be developed. It will also be necessary to consider whether the inertial stresses are above yield. This aspect is especially important in light of the proposed design stress limits in ASME Section III.

- Seismic loading can:

(1) cause low cycle fatigue crack growth,

(2) reduce the J-R curve due to the cyclic loadings, and

(3) increase the toughness of austenitic steels, but may lower the toughness and strength of ferritic steels because of the higher loading rates.

These effects are not considered in the flaw evaluation criteria for Service Level B, C, or D service stresses.

- The flaw evaluation criteria consider constant depth (rectangular shaped) surface flaws.

Real cracks seldom have a constant depth. The development of an equivalent flaw length as is done in ANSI Standard B31G for the oil and gas industry would be helpful. 


\subsection{References}

5.1 "Evaluation of Flaws in Austenitic Steel Piping," (Technical basis document for ASME IWB3640 analysis procedure), prepared by Section XI Task Group for Piping Flaw Evaluation, EPRI Report NP-4690-SR, April 1986.

5.2 "Evaluation of Flaws in Ferritic Piping," EPRI Report NP-6045, prepared by Novetech Corporation, October 1988.

5.3 Bloom, J. M. and Malik, S. N., "A Procedure for the Assessment of Integrity of Structures Containing Defects,” EPRI Topical Report NP-2431, June 1982.

5.4 Kumar, V., et al., "An Engineering Approach for Elastic-Plastic Fracture Analysis," EPRI Report NP-1931, July 1981.

5.5 Wilkowski, G. M., and others, "Degraded Piping Program - Phase II," Summary of Technical Results and Their Significance to Leak-Before-Break and In-Service Flaw Acceptance Criteria, March 1984-January 1989, by Battelle Columbus Division, NUREG/CR4082, Vol. 8, March 1989.

5.6 Wilkowski, G. M., and others, "Analysis of Experiments on Stainless Steel Flux Welds," NUREG/CR-4878, April 1987.

5.7 Milne, I., Ainsworth, R. A., Dowling, A. R., and Stewart, A. T., “Assessment of the Integrity of Structures Containing Defects," R/H/R6-Rev. 3, Published by Central Electric Generating Board, England, May 1986.

5.8 Landes, J. D., and McCabe, D. E., "Elastic-Plastic Methodology to Establish R-Curves and Instability Criteria," Topical Report on Toughness Characterization of Austenitic Stainless Steel Pipe Weldments, AWI CP-86-003, February 1986.

5.9 Wilkowski, G. M., Marschall, C. W., and Landow, M., "Extrapolation of C(T) Specimen J-R Curves," in ASTM STP 1074, pp. 56-84, 1990.

5.10 "Evaluation of Potential for Pipe Breaks", prepared by NRC Pipe Break Task Group, Report NUREG-1061, Vol. 3, November 1984.

5.11 Rahman, S. and Brust, F. W., "An Approximate Method for Evaluating Energy Release Rates of Circumferential Through-Wall Cracked Pipe Welds," Engineering Fracture Mechanics, Vol. 43, No. 3, pp. 417-430, 1992.

5.12 Scott, P., Olson, R., and Wilkowski, G., “The IPIRG-1 Pipe System Fracture Tests Analytical Results," ASME PVP Vol. 280, pp. 153-165, June 1994. 
5.13 Wilkowski, G., Kramer, G., Vieth, P., Francini, R., and Scott, P., "The Effect of Cyclic Loading During Ductile Tearing on Circumferentially Cracked Pipe -- Analytical Results," ASME PVP Vol. 280, pp. 221-240, June 1994.

5.14 "PVRC Recommendations on Toughness Requirements for Ferritic Materials," WRC Bulletin 175, August 1972.

5.15 Zahoor, A., "Ductile Fracture Handbook, Volume 1, Circumferential Through-wall Cracks," EPRI Report Number NP-6301-D, June 1989.

5.16 Wilkowski, G. M. and Scott, P. M., “A Statistically Based Circumferentially Cracked Pipe Fracture Mechanics Analysis for Design or Code Implementation," Nuclear Engineering and Design, Vol. 111, pp. 173-187, 1989.

5.17 Scott, P. M., and Ahmad, J. A., "Experimental and Analytical Assessment of Circumferentially Surface-Cracked Pipes Under Bending,” NUREG/CR-4872, April 1972. 


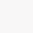

$\cdot$

$\checkmark$ 


\subsection{SUMMARY AND CONCLUSIONS}

The overall objective of this effort was to investigate the failure behavior of small and large diameter pipes with short, internal, surface cracks subjected to both pure bending and combined bending and pressure-induced tensile loads. Typically, the crack sizes for the pipe experiments were selected to be as short as possible, and yet large enough to avoid failure due to buckling.

The major accomplishments in this task are summarized below along with the impact of this work on the ASME Section XI - Flaw Evaluation Procedures.

\subsection{Material Characterization}

Six piping materials and two weld materials were characterized. The characterization procedures included chemical analysis, tensile tests, Charpy tests for the ferritic steels and the weld metals, and toughness tests to determine the $\mathrm{J}$-resistance curves.

The important findings in this effort were the following:

The high Mn-Mo carbon steel pipe submerged-arc weld evaluated in this program (DP2-F49W) was produced using a weld procedure employed in 90 percent of the $B \& W$ piping welds. Data on welds made by this weld procedure were not previously available. The B\&W $\mathrm{Mn}-\mathrm{Mo}-\mathrm{Ni}$ weld procedure, which was used to make the welds assessed in the Degraded Piping Program (Ref. 6.1) and the IPIRG-1 program (Ref. 6.2), was used for the other 10 percent of their carbon steel piping welds, as well as for some of their pressure vessel welds. For the $C(T)$ specimen tests at $22 \mathrm{C}(72 \mathrm{~F})$ on the high $\mathrm{Mn}$-Mo weld evaluated in this program, only a small amount of stable crack growth occurred prior to the specimens undergoing an unstable, cleavage fracture. At $288 \mathrm{C}(550 \mathrm{~F})$, the J-R curves from these two weld procedures were virtually identical.

The stainless steel ȘAW evaluated in this program was created using the same General Electric weld procedure used in the Degraded Piping Program (Ref. 6.3) and the IPIRG-1 Program (Ref. 6.2). There were significant differences in the weld metal yield strengths between the welds evaluated in this program, the Degraded Piping Program, and the IPIRG-1 Program. Although the $J_{I c}$ values differed considerably, the J-R curves for the three different welds were not significantly different. The stainless steel welds had a similar initiation toughness but higher J-R curves than the B\&W high Mn-Mo carbon steel weld.

Crack instabilities occurred in the side-grooved $C(T)$ specimens for the material evaluated in the 711-mm (28-inch) nominal diameter A515 Grade 60 carbon steel pipe experiment, but not in the non-side-grooved specimens. These crack instabilities also occurred in two throughwall-cracked pipe experiments conducted as part of this program (Ref. 6.4) and the Degraded Piping Program (Ref. 6.1). These instabilities were attributed to dynamic strain aging effects. However, materials that are susceptible to dynamic strain aging also typically exhibit serrations 
on their stress-strain curves. The stress-strain curves for this material exhibited no such serrations, which may be the result of differences in the effective strain rate between the tensile and the $\mathrm{C}(\mathrm{T})$ or cracked-pipe specimens.

Data from these material characterization efforts were incorporated into the NRC's PIFRAC (Ref. 6.5) database, which were valuable input to another report from this program entitled "Probabilistic Pipe Fracture Evaluations for Leak-Rate-Detection Applications," NUREG/CR-6004.

\subsection{Pipe Fracture Experiments}

Prior to this program, there were very few experimental data on short circumferential surface-cracked pipes under bending and combined loads especially for large diameter pipe for which elastic-plastic fracture is more likely to occur. Therefore, six short (25 percent of the pipe circumference) surfacecracked pipe experiments were conducted. These were:

- Two 152-mm (6-inch) nominal diameter and one 406-mm (16-inch) nominal diameter short surface-cracked stainless steel pipe experiments were conducted to investigate $R_{m} / t$ effects on the Net-Section-Collapse analysis method.

- The large diameter pipe experiments conducted were on one 711-mm (28-inch) nominal diameter carbon steel pipe experiment with a short surface crack in the base metal, one 711$\mathrm{mm}$ (28-inch) nominal diameter stainless steel pipe experiment with a short surface crack in a SAW, and one 610-mm (24-inch) nominal diameter carbon steel pipe experiment with a short surface crack in a SAW. These tests were conducted at $288 \mathrm{C}(550 \mathrm{~F})$ under combined pressure and bending loads to investigate the effect of large diameter pipe on the in-service flaw acceptance criteria embodied in Section XI of the ASME Code.

Data from all six of these experiments were included in the CIRCUMCK.WK1 database (Ref. 6.6). For each experiment, the applied loads, pipe displacements, crack growth history, crack-mouthopening displacements, pipe rotations, internal pressure, and pipe temperatures were recorded. These data were used to compare the experimental observations with analytical results.

Some of the key findings and observations from these experiments are summarized below.

During the 152-mm (6-inch) nominal diameter Schedule 40 stainless steel short surface-cracked pipe experiment (Experiment 1.2.1.22), the uncracked pipe buckled at a girth weld approximately $100 \mathrm{~mm}$ (4 inches) away from the crack plane. The surface crack initiated well after the buckle started, and a small instability occurred as the surface crack propagated through the pipe wall. The load at which buckling occurred agreed well with the predicted buckling loads from the pretest buckling analysis. Interestingly, fracture still occurred even though the crack initiated well after the buckle formed. Previously, it was believed that once buckling started, a fracture would not occur because the energy needed to extend the crack would be going toward extending the buckle, and not toward driving the crack. It is of note that the crack-mouth-opening displacement data showed that the surface crack was continually 
loaded during the buckling process even though the applied loads were decreasing during the buckling.

The extent of the pipe ovalization for the two larger diameter surface-cracked pipe experiments for which ovalization data were obtained, i.e., Experiments 1.2.3.15 and 1.2.3.17, was significantly less than the extent of the ovalization for the 406-mm (16-inch) nominal diameter Schedule 30 stainless steel pipe experiment conducted as part of this effort, i.e., Experiment 1.2.1.20. The explanations for this observation are that the pipe $\mathrm{R}_{\mathrm{m}} / \mathrm{t}$ ratios for the larger diameter pipe experiments were much lower than for the 406-mm (16-inch) diameter experiment, and the pressure level for the two larger diameter pipe experiments was much higher than it was for the 16-inch diameter pipe experiment. Both of these factors (lower $R_{m} / t$ ratios and higher internal pipe pressure) will tend to restrict the amount of pipe ovalization that takes place. The ovalization behavior observed, especially for Experiment 1.2.1.20 for which a significant amount of ovalization occurred, was consistent with trends that have been observed in the past where through-wall-cracked pipe increased in diameter in the vertical plane and surface-cracked pipe decreased in the vertical plane with increasing applied bending loads.

\subsection{Analysis of Surface-Cracked Pipe}

Analysis efforts in this task had four thrust areas: (i) improve existing analysis methods, (ii) develop new analysis procedures, (iii) validate analyses methods using experimental data and/or finite element results, and (iv) address some unresolved issues involving surface-cracked pipes. Significant advances were made in all four areas, especially since there has been very limited work done in developing surface-cracked pipe J-estimation-based schemes in the past. The key accomplishments in the four areas are summarized below:

- A simple empirical correction factor was developed for the Net-Section-Collapse Criterion to account for pipe ovalization under bending loads. This correction factor was found to be dependant on the pipe $R / t$ ratio and independent of the surface-crack length within the range of available data.

- Two improvements were made to the existing J-estimation schemes SC.TNP and SC.TKP (Ref. 6.7). In this report, the original SC.TNP and SC.TKP analyses from Reference 6.7 are referred to as SC.TNP1 and SC.TKP1, respectively. The first improvement involved developing GE-EPRI influence functions for deep surface cracks. The second improvement involved developing a correction based on comparisons to finite element results to the ' $L$ ' parameter used in these schemes to improve the predictions of J. These modified L-parameter schemes are called SC.TNP2 and SC.TKP2.

- A new J-estimation scheme (SC.ENG) independent of the other methods was developed. Two version of this method (SC.ENG1 and SC.ENG2) were derived based on either the original Net-Section-Collapse analysis limit-load equations or the Kurihara modification to the Net-Section-Collapse analysis equations. The predictions were verified against 
finite element results from this effort as well as those available in the literature. The predictions of $J$, the crack-driving force, using the SC.ENG methods were found to be much better than the SC.TNP1 or SC.TKP1 methods.

- $\quad$ Four previously unresolved issues were addressed.

- The discrepancy between finite element predictions and experimental data on stainless steel uncracked pipes under bending loads was resolved. It was found that full 3D brick elements are necessary to model the load deflection behavior of uncracked pipe beyond yielding.

- The level of mesh refinement required at the crack tip of a surface-cracked pipe that yields satisfactory finite element results was determined. Also, a comparison between $3 \mathrm{D}$ brick elements and the line-spring models indicated that the applied $\mathrm{J}$ can be calculated by the simpler line-spring approach with sufficient accuracy.

- New J-estimation schemes to handle external surface cracks under combined bending and internal pressure were developed. These estimation schemes were modifications of the SC.TNP1 and SC.TKP1 analyses. These analyses were delivered to Brookhaven National Laboratories for analyzing external flaws in piping that were subjected to fatigue loading.

- For deep surface-cracked pipe, influence functions for the GE/EPRI J-estimation scheme were developed using $3 \mathrm{D}$ finite element results.

- A new PC program NRCPIPES Version 2.0a to analyze the behavior of surface-cracked piping under bending and combined bending and tension loads was developed and released. At this writing, this is the only computer code available of its kind. The ASME Section XI procedures as well as the new and improved analysis methods were incorporated into this program.

- NRCPIPES was used to analyze past experiments as well as those from this program. Statistical comparisons between the predictions for maximum moment using various analyses and 28 pure bending and 16 combined pressure and bending surface-cracked pipe experiments from this and other programs showed the following.

For pure bending:

- The method that gave the most accurate predictions of the maximum loads was the SC.TNP1 method where the mean experiment-to-predicted maximum load ratio was 1.02 and the standard deviation was also the lowest at 0.14 .

- The next most accurate methods were the Battelle DPZP method and the ASME austenitic pipe Appendix-C method (with safety factor of 1.0). The mean experiment-to-predicted maximum load ratios were 1.18 and 1.19 , respectively. 
The standard deviations were 0.17 and 0.21 , respectively. For the DPZP method, the flow stress was defined as the average of the measured and ultimate strengths.

- $\quad$ The method that underpredicted the maximum loads the most was the ASME Section XI ferritic pipe Appendix-H Z-factor approach with a mean experimentto-predicted maximum load ratio of 1.87 and standard deviation of 0.16 . The ASME Code Case N-494-2 analysis method for ferritic pipe was more accurate than the Appendix-H Z-factor method with a mean experiment-to-predicted maximum load ratio of 1.43 . The standard deviation was 0.20 .

For combined pressure and bending:

- The method that gave the most accurate predictions of the maximum loads was the DPZP method where the mean experiment-to-predicted maximum load ratio was 1.05 and the standard deviation was also the lowest at 0.13 . Again, the average of the measured yield and ultimate strength was taken to be the flow stress for this analysis method. This method was more accurate for combined loading than for pure bending.

- The next most accurate methods were the SC.TNP1 method and the ASME austenitic pipe Appendix-C method (with safety factor of 1.0). The mean experiment-to-predicted maximum load ratios were 1.10 and 1.16 , respectively. The standard deviations were 0.15 and 0.19 , respectively. The SC.TNP1 method was slightly less accurate for combined loading, and the ASME Section XI Appendix-C mean value was slightly better for combined loading than it was for the pure bending case.

- The method that underpredicted the maximum loads the most was the ASME Section XI ferritic pipe Appendix-H Z-factor approach with a mean experimentto-predicted maximum load ratio of 2.14 and standard deviation of 0.29 , which was higher than for pure bending. The ASME Code Case N-494-2 analysis method for ferritic pipe was more accurate than the ASME Appendix-H Z-factor analysis with a mean experiment-to-predicted maximum load ratio of 1.42 . The standard deviation was 0.18 , which was close to the same value as for pure bending.

The SC.TNP2, SC.TKP2, and SC.ENG1 and SC.ENG2 analyses that had the best comparisons to $\mathrm{J}$ values from the FEM results had mean experiment-to-predicted maximum load ratios from 1.30 to 1.44 for pure bending and 1.21 to 1.66 for combined loading. The reason for this amount of underprediction of the loads while the $J$ values compare well with FEM analyses is suspected to be due to constraint and toughness anisotropy effects, especially for ferritic base metal pipe experiments. The toughness used in the analyses was the typically available $L-C$ oriented $C(T)$ specimen values, whereas the crack growth in a surface-cracked pipe is in the L-R direction. The L-R orientation toughness can be much higher in ferritic base metals. These methods should 
be better when used in low cycle fatigue crack growth calculations, as in Reference 6.8, than in the SC.TNP1 J-estimation scheme analysis.

\subsection{Application to ASME Section XI Flaw Evaluation Criteria}

These efforts included reviewing and validating the ASME Section XI pipe flaw evaluation criteria, noting some of the current limitations, and examining alternative approaches to evaluate $Z$-factors to improve their accuracy and simplify existing procedures. The results showed that the ASME Section $\mathrm{XI}$ pipe flaw evaluation criteria could not be reproduced using the same input as the technical basis documents in References 6.9 and 6.10. For the austenitic pipe Z-factor case (Ref. 6.9), even the material property input were not traceable.

Z-factors were recalculated using several different methods, which are summarized below.

\section{Z-factors from TWC Analyses}

- The ferritic pipe SAW Z-factors calculated using $J_{D}-R$ and $J_{M}-R$ curves with the Zahoormodified GE/EPRI solution showed significant differences. These differences were found to be inherent in using a through-wall-cracked pipe analysis for a surface-cracked pipe problem.

- For various circumferential through-wall-cracked pipe J-estimation schemes, as the diameter decreased the Z-factors did not approach the value of 1.0 as expected.

\section{Z-factors from Surface-Cracked Pipe Analyses}

- A Charpy energy-based criterion using the DPZP analysis was developed. This method allows for a smooth transition from limit-load to EPFM and inherently accounts for anisotropy and constraint effects, but does not account for flaw size effects. If the mean curve is used in the DPZP analysis, then the calculated Z-factors are well below the ASME ferritic Z-factors but close to the austenitic weld Z-factors.

- The Code Case N-494-2 analysis procedure was used to develop Z-factors for ferritic pipe SAW flaws. This procedure showed that in general the Appendix-H Z-factors were higher than the Code Case Z-factors, but the $a / t=0.75$ Code Case Z-factors were higher than the Appendix-H values. The Code Case Z-factors tend to increase with decreasing $\theta / \pi$, which is contrary to what was expected.

- The SC.TNP1 J-estimation scheme from this report was also used to develop Z-factors for ferritic pipe SAW flaws. The SC.TNP1 Z-factors were constant for $\theta / \pi$ values from 0.1 to 1.0 and for $\mathrm{a} / \mathrm{t}$ values from 0.3 to 0.75 . It is believed that the $\mathrm{Z}$-factors could be interpolated to $\mathrm{Z}=1.0$ at $\mathrm{a} / \mathrm{t}=0$ and $\theta / \pi=0$. 
An additional calculation using two significantly different $J-R$ curves from the same material (i.e., a $J_{M}-R$ curve and $J / T$ extrapolated $J_{D}-R$ curve) and the SC.TNP1 analysis showed little difference in $Z$-factors for the most sensitive case. This contrasts with the through-wall-cracked pipe Z-factors calculated using the same J-R curves which showed a significant difference.

New Z-factors were calculated for pipes with finite-length surface cracks using the SC.TNP1 procedure. These results could be extended to carbon steel base metal and stainless steel weld cases. They could also be combined with the Charpy Energy/DPZP criterion to take advantage of the desirable features of both approaches. The effects of $\mathrm{R} / \mathrm{t}$ ratio on the Z-factors using the SC.TNP1 analysis needs to be evaluated in the future.

The principle of extrapolating Z-factors for a/t less than 0.3 and $\theta / \pi$ less than 0.1 from the SC.TNP1 Z-factor analysis could be applied to the Charpy Energy/DPZP approach. The Charpy Energy/DPZP criterion showed very little difference in its Z-factor with surface flaws of $\mathrm{a} / \mathrm{t}=0.5$ and $\theta / \pi=0.25$ from this program and flaws of $a / t=0.66$ and $\theta / \pi=0.5$ from the Degraded Piping program. This result is consistent with the SC.TNP1 Z-factors. The SC.TNP1 and Charpy Energy/DPZP Z-factors were very close, which might be expected since they were the two most accurate analysis methods.

A number of other considerations for improvements to the ASME pipe flaw evaluation criteria were also discussed. The more significant ones are summarized below:

- By redefining the flow stress as the average of the yield and ultimate strengths, rather than as a function of $S_{m}$, combined austenitic and ferritic pipe criteria and expansion to Class 2 and 3 piping can be easily accomplished.

- The contribution of $\mathrm{P}_{\mathrm{e}}$ and SAM stresses to fracture is equal to that of primary stresses, even for TP304 stainless steel base metal, when the total stresses are below the actual yield of the material, Ref. 6.11. Hence, for these stress levels, the secondary stresses should be incorporated with a full safety factor.

If the stresses calculated assuming elastic behavior are above $S_{y}$, then a nonlinear correction will greatly increase the allowable flaw size and account for $\mathrm{P}_{\mathrm{e}}$ and $\mathrm{SAM}$ stresses being displacement-controlled, Ref. 6.6. Methodology to do this needs to be developed. It will also be necessary to consider whether the inertial stresses are above yield. This aspect is especially important in light of the proposed design stress limits in ASME Section III.

- Seismic loading can:

(1) cause low cycle fatigue crack growth (Ref. 6.8),

(2) reduce the J-R curve due to the cyclic loadings (Ref. 6.12), and

(3) increase the toughness of austenitic steels, but may lower the toughness and strength of ferritic steels because of the higher loading rates (Ref. 6.2). 
These effects are not considered in the flaw evaluation criteria for Service Level B, C, or $\mathrm{D}$ service stresses where quasi-static monotonic loaded specimen data are used in the development of the analyses. Hence, perhaps there should be different Z-factors (or toughness corrections) for Service Level A conditions than from Service Level B, C, and $\mathrm{D}$ conditions.

- The current ASME flaw evaluation criteria consider constant depth (rectangular shaped) surface flaws where the maximum depth of the flaw is assumed to exist for the entire length of the flaw. Real cracks seldom have a constant depth, and this approach could be quite penalizing. The development of an equivalent flaw length as is done in ANSI Standard B31G for the oil and gas industry would be useful.

\subsection{References}

6.1 Wilkowski, G. M., and others, "Degraded Piping Program - Phase II," Summary of Technical Results and Their Significance to Leak-Before-Break and In-Service Flaw Acceptance Criteria, March 1984-January 1989, by Battelle Columbus Division, NUREG/CR-4082, Vol. 8, March 1989.

6.2 Marschall, C. W., Landow, M., and Wilkowski, G. M., "Loading Rate Effects on Strength and Fracture Toughness of Pipe Steels Used in Task 1 of the IPIRG Program," NUREG/CR6098, October 1993.

6.3 Wilkowski, G. M., and others, "Analysis of Experiments on Stainless Steel Flux Welds," NUREG/CR-4878, April 1987.

6.4 Wilkowski, G. M., and others, "Short Cracks in Piping and Piping Welds," Semiannual Report, March 1990 to September 1990, NUREG/CR-4599, Vol. 1, No. 1, May 1991.

6.5 Hiser, A. L. and Callahan, G. M., "A User's Guide to the NRC's Piping Fracture Mechanics Database (PIFRAC)," NUREG/CR-4894, May 1987.

6.6 Wilkowski, G. M. and others, "Short Cracks in Piping and Piping Welds," Seventh Semiannual Report, NUREG/CR-4599, Vol. 4, No. 1, April 1995.

6.7 Scott, P. M., and Ahmad, J. A., "Experimental and Analytical Assessment of Circumferentially Surface-Cracked Pipes Under Bending," NUREG/CR-4872, April 1972.

6.8 Wilkowski, G., Rahman, S., and Mohan, R., "Low-Cycle Fatigue Crack Growth Considerations in Pipe Fracture Analyses," ASME PVP Vol. 280, pp 281-298, June 1994.

6.9 "Evaluation of Flaws in Austenitic Steel Piping," (Technical basis document for ASME IWB3640 analysis procedure), prepared by Section XI Task Group for Piping Flaw Evaluation, EPRI Report NP-4690-SR, April 1986. 
6.10 "Evaluation of Flaws in Ferritic Piping," EPRI Report NP-6045, prepared by Novetech Corporation, October 1988.

6.11 Scott, P., Olson, R., and Wilkowski, G., "The IPIRG-1 Pipe System Fracture Tests Analytical Results," ASME PVP Vol. 280, pp. 153-165, June 1994.

6.12 Wilkowski, G., Kramer, G., Vieth, P., Francini, R., and Scott, P., "The Effect of Cyclic Loading During Ductile Tearing on Circumferentially Cracked Pipe - Analytical Results," ASME PVP Vol. 280, pp. 221-240, June 1994. 


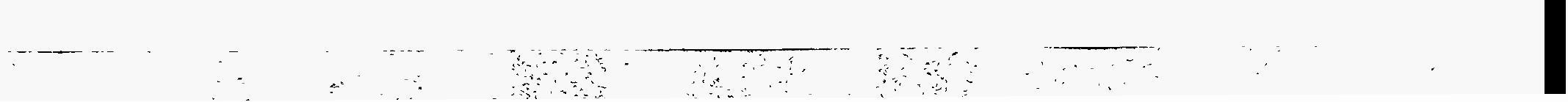




\section{APPENDIX A}

\section{J-ESTIMATION METHOD DEVELOPMENT FOR CIRCUMFERENTIALLY SURFACE-CRACKED PIPE UNDER COMBINED TENSION AND BENDING}

In this Appendix, we present the development of J-estimation formula, for combined tension and bending, based on the use of Ref. A:1 solutions for a 360-degree internal circumferential crack in a pipe under axial tension. The development is similar to that presented in Ref. A.2. However, there are subtle differences which are expected to lead to improved $J$ estimates. One of the $J$ formulas is for thin pipes ( $t \ll R_{m}$ ), and the other for the case where the pipe thickness cannot be considered small.

With reference to Figure A.1a,b,c, consider.a plane normal to the circumferential plane at $\gamma<\theta$, with dimensions $t \times 2 L$. Consider $L=(C)(t)$, with $C$ chosen so that at a distance $L$ from the crack plane, the pipe wall is subjected to the remote stress $\sigma_{\infty}$ caused by the applied bending moment, $M$. Assume that $\sigma_{\infty}$ can be replaced by a constant average stress through the pipe thickness. Then, for large $\theta$ and $\gamma \ll \theta$, Figure A.1 can be viewed as representing a plane from an axisymmetrically (360degree) surface-cracked pipe subjected to remote uniform tensile stress $\sigma$, or alternatively, an edgecracked panel subjected to uniform tension. Because the edge-cracked panel representation leads to an incorrect expression for the pipe's limit moment (Ref. A.3), the first representation is preferred.

Corresponding to $\sigma_{\infty}$, the remote strain in the pipe under combined tension and bending can be expressed using the simple-beam theory as

$$
\epsilon_{\infty}=\frac{ \pm\left(\mathrm{R}_{\mathrm{i}} \sin \rho_{\mathrm{n}}+\mathrm{R}_{\mathrm{m}} \cos \gamma\right) \phi}{2 \mathrm{~L}}+\frac{\delta}{2 \mathrm{~L}}
$$

where $\rho_{\mathrm{n}}$ represents the location of the intersection between neutral plane and the inside pipe surface as shown in Figure A.1(b). The positive and negative signs apply to the regions above and below the neutral plane, respectively. The remote displacement due to tension in " $\delta "$. For small $t / R_{m}$

$$
\mathrm{R}_{\mathrm{o}} \simeq \mathrm{R}_{\mathrm{i}} \simeq \mathrm{R}_{\mathrm{m}}
$$

where $R_{m}$ is the mean pipe radius. Therefore,

$$
\epsilon_{\infty}= \pm \frac{\mathrm{R}_{\mathrm{m}}}{2 \mathrm{~L}} \phi\left(\sin \rho_{\mathrm{n}}+\cos \gamma\right)+\frac{\delta}{2 \mathrm{~L}}
$$




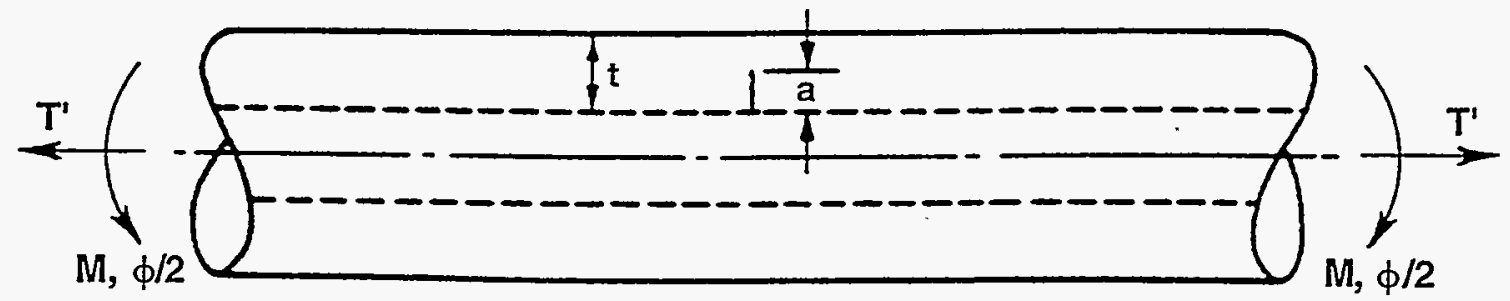

(a) Surface-cracked pipe under bending and tensile loading

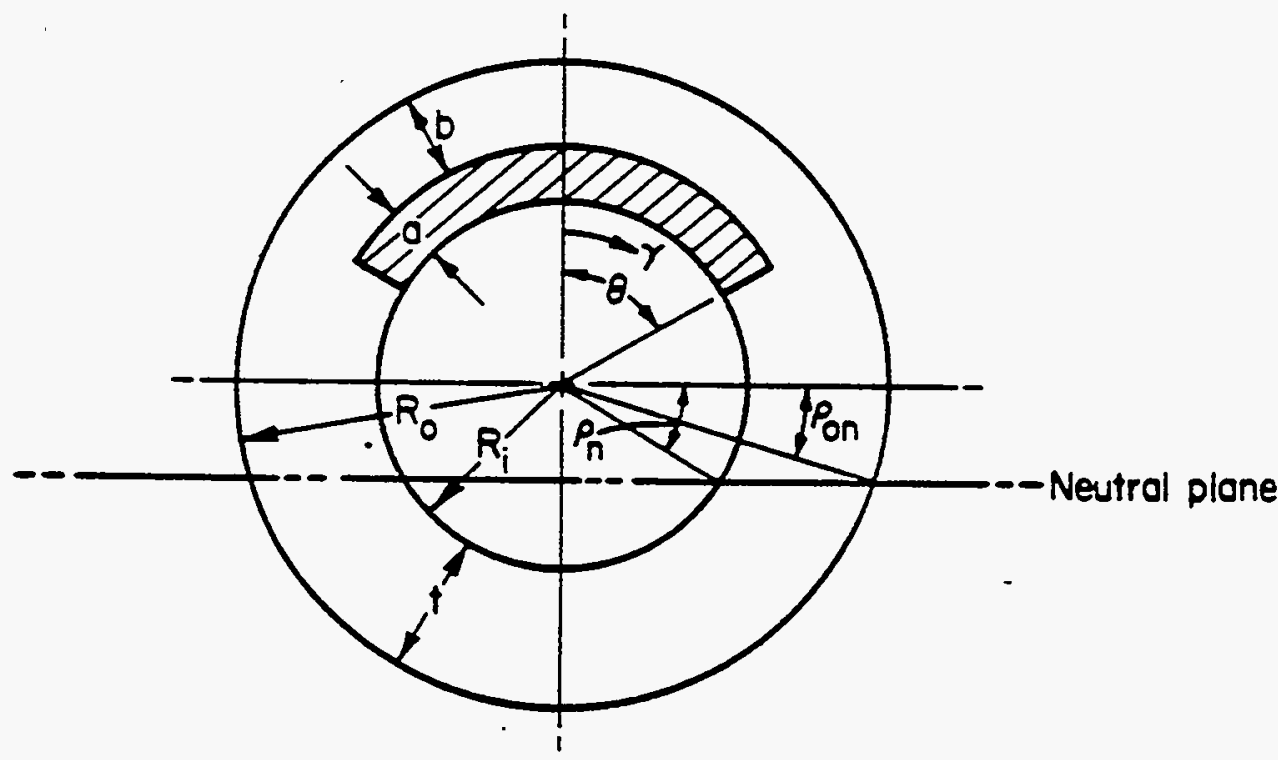

(b) Cross-section containing internal surface crack

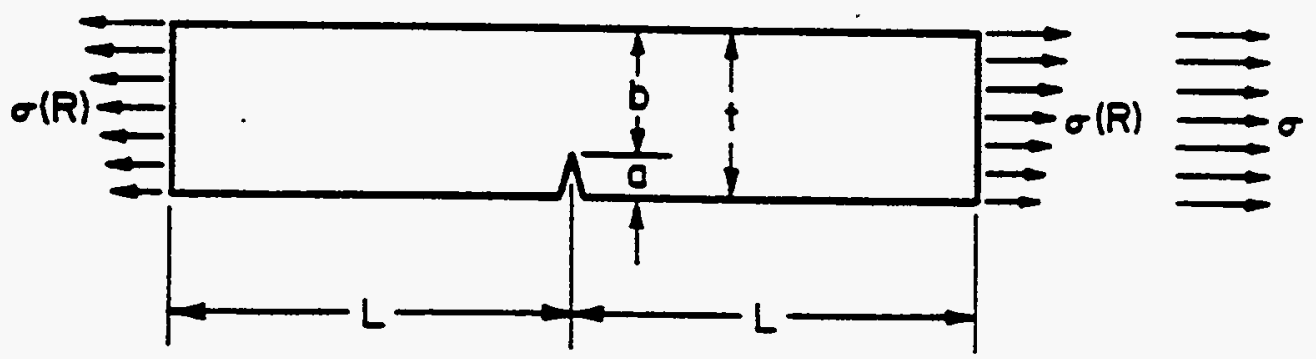

(c) Plane at $\gamma<\theta, \mathrm{L}=\mathbf{C t}$

Figure A.1 Geometry and loading of a pipe with an internal circumferential surface crack 
The average strain in the length $2 \mathrm{~L}$ can be expressed as

$$
\epsilon=\frac{\Delta}{2 \mathrm{~L}}
$$

where $\Delta$ is the total displacement of the geometry shown in Figure A.1(c). For $\gamma \leq \theta$, this is composed of displacement without the crack $\left(\Delta^{\mathrm{nc}}\right)$ and displacement caused by the crack $\left(\Delta^{\mathrm{C}}\right)$. That is,

$$
\Delta=\Delta^{\mathrm{nc}}+\Delta^{\mathrm{c}}
$$

Both $\Delta^{\mathrm{nc}}$ and $\Delta^{\mathrm{c}}$ include elastic $\left(\Delta_{\mathrm{e}}^{\mathrm{nc}}, \Delta_{\mathrm{e}}^{\mathrm{c}}\right)$ and plastic $\left(\Delta_{\mathrm{p}}^{\mathrm{nc}}, \Delta_{\mathrm{p}}^{\mathrm{c}}\right)$ contributions. That is,

$$
\Delta^{\mathrm{nc}}=\Delta_{\mathrm{e}}^{\mathrm{nc}}=\Delta_{\mathrm{p}}^{\mathrm{nc}}
$$

and

$$
\Delta^{\mathrm{c}}=\Delta_{\mathrm{e}}^{\mathrm{c}}+\Delta_{\mathrm{p}}^{\mathrm{c}}
$$

Therefore, the total displacement can be written as:

$$
\Delta=\Delta_{\mathrm{e}}+\Delta_{\mathrm{p}}
$$

where

$$
\Delta_{\mathrm{e}}=\Delta_{\mathrm{e}}^{\mathrm{nc}}+\Delta_{\mathrm{e}}^{\mathrm{c}}
$$

and

$$
\Delta_{\mathrm{p}}+\Delta_{\mathrm{p}}^{\mathrm{nc}}+\Delta_{\mathrm{p}}^{\mathrm{c}}
$$


Also.

$$
\Delta_{\mathrm{e}}^{\mathrm{nc}}=\frac{2 \mathrm{~L} \sigma}{\mathrm{E}^{\prime}}
$$

and

$$
\Delta_{\mathrm{e}}^{\mathrm{c}}=\frac{4 \sigma \mathrm{a}}{\mathrm{E}^{\prime}} \mathrm{V}_{2}\left(\mathrm{a} / \mathrm{t}, \mathrm{R}_{\mathrm{i}} / \mathrm{R}_{\mathrm{o}}\right)
$$

where $E^{\prime}=E\left(1-\nu^{2}\right), E$ is the Young's Modulus, $\nu$ is the Poisson's Ratio, and the function $V_{2}(a / t)$ can be found in Ref. A.1 for an axisymmetrically surface-cracked pipe in axial tension.

Assuming the material's stress versus plastic-strain behavior to be of the following form:

$$
\frac{\epsilon}{\epsilon_{\mathrm{o}}}=\alpha\left[\frac{\sigma}{\sigma_{\mathrm{o}}}\right]^{\mathrm{n}}
$$

where $\alpha, \epsilon_{0}, \sigma_{0}$, and $\mathrm{n}$ are material constants, one can write

$$
\Delta_{\mathrm{p}}^{\mathrm{nc}}=2 \alpha \epsilon_{\mathrm{o}} \mathrm{L}\left[\frac{\sigma}{\sigma_{\mathrm{o}}}\right]^{\mathrm{n}}
$$

Using the Reference A.1 solution for axisymmetrically cracked pipe in axial tension,

$$
\Delta_{\mathrm{p}}^{\mathrm{c}}=\alpha \epsilon_{\mathrm{o}} a \mathrm{~h}_{3}(\mathrm{a} / \mathrm{t}, \mathrm{n})\left[\frac{\mathrm{p}}{\mathrm{P}_{\mathrm{o}}}\right]^{\mathrm{n}}
$$

where $P$ is the applied load, $P_{0}$ is the limit load based on $\sigma_{0}$ as the yield stress, and values of function $\mathrm{h}_{3}(\mathrm{a} / \mathrm{t}, \mathrm{n})$ can be found in Ref. A.1. For remote, axially applied stress, $\sigma$, on an axisymmetrically cracked pipe, $P$ and a lower bound estimate for $P_{0}$ are given as:

$$
\mathrm{P}=\pi\left(\mathrm{R}_{\mathrm{o}}^{2}-\mathrm{R}_{\mathrm{i}}^{2}\right) \sigma=\mathrm{k} \sigma
$$


and

$$
\mathrm{P}_{\mathrm{o}}=\frac{2}{\sqrt{3}} \pi\left(\mathrm{R}_{\mathrm{o}}^{2}-\mathrm{R}_{\mathrm{c}}^{2}\right) \sigma_{\mathrm{o}}
$$

where

$$
R_{c}=R_{i}+a=R_{o}-b
$$

and

$$
k=\pi\left(R_{0}^{2}-R_{i}^{2}\right)
$$

Equating the strains of Eqs. A-3 and A-4 and using Eqs. A-5 through A-15, we get

$$
\frac{2 \mathrm{~L} \sigma}{\mathrm{E}^{\prime}}+\frac{4 \sigma \mathrm{a} \mathrm{V}_{2}}{\mathrm{E}^{\prime}}+2 \alpha \epsilon_{\mathrm{o}} \mathrm{L}\left(\frac{\sigma}{\sigma_{\mathrm{o}}}\right)^{\mathrm{n}}+\alpha \epsilon_{\mathrm{o}} a \mathrm{~h}_{3}\left(\frac{\mathrm{P}}{\mathrm{P}_{\mathrm{o}}}\right)^{\mathrm{n}}
$$

Ignoring elastic-displacement components (first two terms in Equation A-20) as being small compared with their plastic counterparts, we get

$$
\begin{aligned}
\sigma & =\sigma_{0}\left(\frac{1}{2 \mathrm{~L} \alpha \epsilon_{\mathrm{o}}}\right)^{1 / \mathrm{n}}\left( \pm \frac{\mathrm{Y}^{\prime} \phi+\delta}{\mathrm{Z}^{\prime}}\right)^{1 / \mathrm{n}} \\
& =\phi\left(\mathrm{R}_{\mathrm{i}} \sin \rho_{\mathrm{n}}+\mathrm{R} \cos \gamma\right)+\delta
\end{aligned}
$$

where

$$
\mathrm{Y}^{\prime}=\mathrm{R}_{\mathrm{i}} \sin \rho_{\mathrm{n}}+\mathrm{R} \cos \gamma
$$


J-Estimation Method Development for Circumferentially

Surface-Cracked Pipe Under Combined Tension and Bending

Appendix A

and

$$
\begin{array}{rlrl}
Z^{\prime}=1 & +\frac{a h_{3}}{2 L}\left(\frac{\sigma_{0} \mathrm{k}}{P_{\mathrm{o}}}\right)^{\mathrm{n}} & & \text { for } 0 \leq \gamma<\theta \\
=1 & \text { for } \theta \leq \gamma \leq \pi
\end{array}
$$

The angle $\rho_{\mathrm{n}}$ is found by using the axial force equilibrium condition. This is

$$
2 \int_{\mathrm{R}_{1}}^{\mathrm{R}_{\mathrm{o}}} \int_{0}^{\pi} \sigma \mathrm{R} \mathrm{dR} \mathrm{d} \gamma=\mathrm{T}^{\prime}
$$

where $\mathrm{T}^{\prime}$ is the axial force due to the internal pressure, "p" given by

$$
\mathrm{T}^{\prime}=\pi \mathrm{pR} \mathrm{R}_{\mathrm{c}}^{2}
$$

and

$$
\mathrm{R}_{\mathrm{l}}=\mathrm{R}_{\mathrm{i}}+\mathrm{a} \quad \text { for } \gamma \leq \theta
$$

and

$$
\mathrm{R}_{1}=\mathrm{R}_{\mathrm{i}} \quad \text { for } \theta<\gamma \leq \frac{\pi}{2}
$$

or

$$
2 \sigma_{\mathrm{o}}\left[\frac{1}{2 \mathrm{~L} \alpha \epsilon_{\mathrm{o}}}\right]^{1 / \mathrm{n}} \int_{\mathrm{R}_{1}}^{\mathrm{R}_{\mathrm{o}}} \int_{0}^{\pi}\left[\frac{ \pm \mathrm{Y}^{\prime} \phi+\delta}{\mathrm{Z}^{\prime}}\right]^{1 / \mathrm{n}} \mathrm{R} \mathrm{dR} \mathrm{d} \gamma=\mathrm{T}^{\prime}
$$

The moment equilibrium condition can be expressed as

$$
2 \int_{R_{1}}^{R_{0}} \int_{0}^{\pi} \sigma Y^{\prime} R d R d \gamma=M
$$


or

$$
2 \sigma_{\mathrm{o}}\left[\frac{1}{2 \mathrm{~L} \alpha \epsilon_{\mathrm{o}}}\right]^{1 / \mathrm{n}} \int_{\mathrm{R}_{\mathrm{l}}}^{\mathrm{R}_{\mathrm{o}}} \int_{\mathrm{o}}^{\pi}\left[\frac{ \pm \mathrm{Y}^{\prime} \phi+\delta}{\mathrm{Z}^{\prime}}\right]^{1 / \mathrm{n}} \mathrm{Y}^{\prime} \mathrm{R} \mathrm{dR} \mathrm{d} \gamma=\mathrm{M}+\mathrm{T}^{\prime} \mathrm{R}_{\mathrm{i}} \sin \rho_{\mathrm{n}}
$$

In the absence of $\mathrm{M}, \phi=0$, and Equation A-27 yields

$$
2 \sigma_{0}\left(\frac{1}{2 \mathrm{~L} \alpha \epsilon_{\mathrm{o}}}\right)^{1 / \mathrm{n}} \int_{\mathrm{R}_{1}}^{\mathrm{R}_{\mathrm{o}}} \int_{0}^{\pi}\left(\frac{\delta}{\mathrm{Z}^{\prime}}\right)^{1 / \mathrm{n}} \mathrm{R} \mathrm{dR} d \gamma=\mathrm{T}^{\prime}
$$

or

$$
\int_{\mathrm{R}_{1}}^{\mathrm{R}_{\mathrm{o}}} \int_{0}^{\theta} \frac{1}{\left[1+\frac{\mathrm{ah}}{2 \mathrm{~L}}\left[\frac{\sigma_{0} \mathrm{k}}{\mathrm{P}_{\mathrm{o}}}\right]^{\mathrm{n}}\right]^{1 / \mathrm{n}}} \mathrm{R} d \mathrm{R} d \gamma+\int_{\mathrm{R}_{\mathrm{i}}}^{\mathrm{R}_{\mathrm{o}}} \int_{\theta}^{\pi} \mathrm{R} d \mathrm{R} d \gamma=\frac{\mathrm{T}^{\prime}}{2 \sigma_{\mathrm{o}}}\left[\frac{2 \mathrm{~L} \alpha \epsilon_{\mathrm{o}}}{\delta}\right]^{1 / \mathrm{n}}
$$

or

$$
\frac{\theta\left(\mathrm{R}_{\mathrm{o}}^{2}-\mathrm{R}_{1}^{2}\right)}{\left[1+\frac{\mathrm{ah}}{2 \mathrm{~L}}\left[\frac{\sigma_{0} \mathrm{k}}{\mathrm{P}_{\mathrm{o}}}\right]^{\mathrm{n}}\right]^{1 / \mathrm{n}}}+(\pi-\theta)\left(\mathrm{R}_{\mathrm{o}}^{2}-\mathrm{R}_{\mathrm{i}}^{2}\right)=\frac{\mathrm{T}}{\sigma_{\mathrm{o}}}\left[\frac{2 \mathrm{~L} \alpha \epsilon_{\mathrm{o}}}{\delta}\right]^{1 / \mathrm{n}}
$$

Now " $\delta$ " can be written as

$$
\delta=\bar{\alpha}\left(\mathrm{T}^{\prime}\right)^{\mathrm{n}}
$$


where

$$
\bar{\alpha}=\frac{2 \mathrm{~L} \alpha \epsilon_{0}}{\sigma_{\mathrm{o}}^{\mathrm{n}}}\left[\frac{\theta\left(\mathrm{R}_{\mathrm{o}}^{2}-\mathrm{R}_{1}\right)^{2}}{\left[1+\frac{\mathrm{ah}}{2 \mathrm{~L}}\left[\frac{\sigma_{\mathrm{o}} \mathrm{k}}{\mathrm{P}_{\mathrm{o}}}\right]^{\mathrm{n}}\right]^{1 / \mathrm{n}}}+(\pi-\theta)\left(\mathrm{R}_{\mathrm{o}}^{2}-\mathrm{R}_{\mathrm{i}}^{2}\right)\right]^{-\mathrm{n}}
$$

Now, $\lambda$ is defined as the ratio of pressure to bending as

$$
\lambda=\frac{\text { Stress due to pressure, } \mathrm{p}}{\text { Maximum stress due to moment, } \mathrm{M}}
$$

that is

$$
\lambda=\frac{\mathrm{p} \pi \mathrm{R}_{\mathrm{i}}^{2}}{\mathrm{k}}\left[\frac{\mathrm{I}}{\mathrm{MR}_{\mathrm{o}}}\right]
$$

where, $I$ is the moment of inertia, given by

$$
I=\frac{k}{4}\left(R_{o}^{2}+R_{i}^{2}\right)
$$

Hence, $\lambda$ can now be stated as

$$
\lambda=\frac{\mathrm{p} \pi \mathrm{R}_{\mathrm{i}}^{2}\left(\mathrm{R}_{\mathrm{o}}^{2}+\mathrm{R}_{\mathrm{i}}^{2}\right)}{4 \mathrm{MR} \mathrm{R}_{\mathrm{o}}}
$$


or

$$
\lambda=\frac{\mathrm{T}^{\prime}}{\mathrm{M}}\left[\frac{\left(\mathrm{R}_{\mathrm{o}}^{2}+\mathrm{R}_{\mathrm{i}}^{2}\right)}{4 \mathrm{R}_{\mathrm{o}}}\right]
$$

where $T^{\prime}=p \pi R_{i}^{2}$.

For an internal surface crack, to account for crack face pressure, "p"

$$
\lambda=p\left(\frac{\pi \mathrm{R}_{\mathrm{i}}^{2}}{\mathrm{k}}+1\right) \frac{\mathrm{I}}{\mathrm{MR}_{\mathrm{o}}}
$$

or

$$
\lambda=p\left(\pi R_{i}^{2}+k\right) \frac{\left(R_{0}^{2}+R_{i}^{2}\right)}{4 M R_{o}}
$$

that is

$$
\lambda=\frac{\mathrm{T}^{\prime}}{\mathrm{M}}\left[\frac{\mathrm{R}_{\mathrm{o}}^{2}+\mathrm{R}_{\mathrm{i}}^{2}}{4 \mathrm{R}_{\mathrm{o}}}\right]
$$

where

$$
\mathrm{T}^{\prime}=\mathrm{p}\left(\pi \mathrm{R}_{\mathrm{i}}^{2}+\mathrm{k}\right)
$$


Now it is assumed that $T^{\prime}$ causes no rotation. Using Eqs. (A-27) and (A-33), for $\delta \neq 0$, we have

$$
2 \sigma_{\mathrm{o}}\left(\frac{\bar{\alpha}}{2 \mathrm{~L} \alpha \epsilon_{\mathrm{o}}}\right)^{1 / \mathrm{n}} \int_{\mathrm{R}_{1}}^{\mathrm{R}_{\mathrm{o}}} \int_{0}^{\pi}\left[\frac{\left( \pm \frac{\mathrm{Y}^{\prime} \phi}{\delta}+1\right)}{\mathrm{Z}^{\prime}}\right]^{1 / \mathrm{n}} \mathrm{R} \mathrm{dR} \mathrm{d} \gamma=1
$$

and using Equations (A-29) and (A-33)

$$
2 \sigma_{0}\left(\frac{\bar{\alpha}}{2 \mathrm{~L} \alpha \epsilon_{\mathrm{o}}}\right)^{1 / \mathrm{n}} \int_{\mathrm{R}_{1}}^{\mathrm{R}_{\mathrm{o}}} \int_{0}^{\pi}\left[\frac{\left( \pm \frac{\mathrm{Y}^{\prime} \phi}{\delta}+1\right)}{2}\right]^{1 / 2} \quad \mathrm{Y}^{\prime} \mathrm{R} \mathrm{dR} d \gamma=\frac{\mathrm{M}}{\mathrm{T}^{\prime}}+\mathrm{R}_{\mathrm{i}} \sin \rho_{\mathrm{n}}
$$

Now, define

$$
2 E_{n}=\int_{R_{1}}^{R_{0}} \int_{0}^{\pi}\left[\frac{\left( \pm \frac{Y^{\prime} \phi}{\delta}+1\right)}{Z^{\prime}}\right]^{1 / 2} Y^{\prime} R d R d \gamma
$$

Therefore

$$
\frac{\mathrm{M}}{\mathrm{T}^{\prime}}=4 \sigma_{\mathrm{o}} \mathrm{E}_{\mathrm{n}}\left[\frac{\bar{\alpha}}{2 \mathrm{~L} \alpha \epsilon_{\mathrm{o}}}\right]^{1 / \mathrm{n}}-\mathrm{R}_{\mathrm{i}} \sin \rho_{\mathrm{n}}
$$

and

$$
\sigma=\mathrm{T}^{\prime} \sigma_{\mathrm{o}}\left(\frac{\bar{\alpha}}{2 \mathrm{~L} \alpha \epsilon_{\mathrm{o}}}\right]^{1 / \mathrm{n}}\left[\frac{ \pm \frac{\mathrm{Y}^{\prime} \phi}{\delta}+1}{\mathrm{Z}^{\prime}}\right]^{1 / \mathrm{n}}
$$


Or, combining Equations (A-44) and (A-45)

$$
\sigma=\left[\frac{\mathrm{M}}{4 \sigma_{\mathrm{o}} \mathrm{E}_{\mathrm{n}}\left[\frac{\bar{\alpha}}{2 \mathrm{~L} \alpha \epsilon_{\mathrm{o}}}\right]^{1 / \mathrm{n}}-\mathrm{R}_{\mathrm{i}} \sin \rho_{\mathrm{n}}}\right] \sigma_{\mathrm{o}}\left[\frac{\bar{\alpha}}{2 \mathrm{~L} \alpha \epsilon_{\mathrm{o}}}\right]^{1 / \mathrm{n}}\left[\frac{ \pm \frac{\mathrm{Y} \phi}{\delta}+1}{\mathrm{Z}}\right]^{1 / \mathrm{n}}
$$

Using Equation (A-33), $\mathrm{Q}$ is defined as

$$
\mathrm{Q}\left(\mathrm{n}, \text { geometry) }=2 \sigma_{\mathrm{o}}\left[\frac{\bar{\alpha}}{2 \mathrm{~L} \alpha \epsilon_{\mathrm{o}}}\right]^{1 / \mathrm{n}}=\frac{2\left[1+\frac{\mathrm{ah}_{3}}{2 \mathrm{~L}}\left(\frac{\sigma_{0} \mathrm{k}}{\mathrm{P}_{\mathrm{o}}}\right)^{\mathrm{n}}\right]^{1 / \mathrm{n}}}{\theta\left(\mathrm{R}_{\mathrm{o}}^{2}-\mathrm{R}_{1}^{2}\right)+(\pi-\theta)\left(\mathrm{R}_{\mathrm{o}}^{2}-\mathrm{R}_{\mathrm{i}}^{2}\right)\left[1+\frac{\mathrm{ah}_{3}}{2 \mathrm{~L}}\left(\frac{\left.\sigma_{\mathrm{o}} \mathrm{k}^{\mathrm{n}}\right)^{1 / \mathrm{n}}}{\mathrm{P}_{\mathrm{o}}}\right.\right.}\right.
$$

Using Equation (A-47) in Equations (A-41) to (A-46), it can be shown that,

$$
Q \int_{R_{1}}^{R_{0}} \int_{0}^{\pi}\left[\frac{\left[ \pm \frac{Y^{\prime} \phi}{\delta}+1\right.}{Z^{\prime}}\right]^{1 / n} R d R d \gamma=1
$$

and

$$
\frac{\mathrm{M}}{\mathrm{T}^{\prime}}=2 \mathrm{E}_{\mathrm{n}} \mathrm{Q}-\mathrm{R}_{\mathrm{i}} \sin \rho_{\mathrm{n}}
$$

where

$$
2 \mathrm{E}_{\mathrm{n}}=\int_{\mathrm{R}_{1}}^{\mathrm{R}_{0}} \int_{0}^{\pi}\left[\frac{ \pm \frac{\mathrm{Y}^{\prime} \phi}{\delta}+1}{\mathrm{Z}^{\prime}}\right]^{1 / \mathrm{n}} \mathrm{Y}^{\prime} \mathrm{R} d \mathrm{R} d \gamma
$$


Also

$$
\sigma=\frac{T^{\prime} Q}{2}\left[\frac{ \pm \frac{Y^{\prime} \phi}{\delta}+1}{Z^{\prime}}\right]^{1 / n}
$$

which yields

$$
\sigma=\frac{\mathrm{M}}{4 \mathrm{E}_{\mathrm{n}}-\frac{2 \mathrm{R}_{\mathrm{i}} \sin \rho_{\mathrm{n}}}{\mathrm{Q}}}\left[\frac{ \pm \mathrm{Y}^{\prime} \frac{\phi}{\delta}+1}{2 \mathrm{Z}^{\prime}}\right]^{1 / \mathrm{n}} \text { for } \gamma \leq \theta
$$

Using the above derivation, the steps involved in calculating the plastic component of $\mathrm{J}$, that is $\mathrm{J}_{\mathrm{p}}$, and the moment-rotation behavior are described below. The steps in the computational algorithm are:

(1) Specify the geometry $\left(R_{0}, R_{i}, \theta, a\right)$ and material properties $\alpha, n, h_{3}$ for the pipe.

(2) Find Q using Equation A-47.

(3) Prescribe $\frac{\phi L}{\delta}$ the rotation on the pipe

(4) Solve Equation $\mathrm{A}-48$ for $\rho_{\mathrm{n}}$

(5) Use Equation $\mathrm{A}-50$ to find $\mathrm{E}_{\mathrm{n}}$

(6) Use Equation $A-49$ to find $\frac{M}{T}$ and $\lambda=\frac{T^{\prime}}{M}\left[\frac{R_{o}^{2}+R_{i}^{2}}{4 R_{o}}\right]$

The following quantities are therefore known at Step 6.

$$
\begin{array}{ll}
- & \left.\rho_{\mathrm{n}} \text { (geometry, } \lambda, \mathrm{n}\right), \\
- & \left.\mathrm{E}_{\mathrm{n}} \text { (geometry, } \lambda, \mathrm{n}\right), \\
- & \left.\mathrm{F}_{\mathrm{n}}=\frac{\phi}{\delta} \text { (geometry, } \lambda, \mathrm{n}\right)
\end{array}
$$

(7) For a given geometry, Ramberg-Osgood material properties and pressure "p" and moment " $M$ " find $\lambda$ using Equation A-39 for external surface cracks and Equation A-42 for internal cracks. 
(8) Determine $\mathrm{J}_{\mathrm{p}}$ using $\mathrm{J}_{\mathrm{p}}=\alpha \epsilon_{\mathrm{o}} \sigma_{\mathrm{o}}\left[1-\frac{\mathrm{a}}{\mathrm{t}}\right]$ a $\mathrm{h}_{1}\left[\frac{\sigma \mathrm{k}}{\mathrm{P}_{\mathrm{o}}}\right]^{\mathrm{n}+1}$ where $\sigma=\frac{M}{4 E_{\mathrm{n}}}\left[\frac{ \pm \mathrm{Y}^{\prime} \mathrm{F}_{\mathrm{n}}+1}{\mathrm{Z}^{\prime}}\right] \quad$ for $(\gamma \leq \theta)$

(9) Determine the displacement ( $\delta$ ) from Equation A-33.

(10) Determine the rotation $(\phi)=F_{n} \cdot \delta$ 
J-Estimation Method Development for Circumferentially

Surface-Cracked Pipe Under Combined Tension and Bending

Appendix A

\section{References}

A.1 Wilkowski, G. M., and others, "Degraded Piping Program - Phase II," Semiannual Report, October 1984 - March 1985, by Battelle Columbus Division, NUREG/CR-4082, Vol. 2, July 1985.

A.2 Wilkowski, G. M., and others, "Degraded Piping Program - Phase II," Semiannual Report, October 1985 - March 1986, by Battelle Columbus Division, NUREG/CR-4082, Vol. 4, September 1986.

A.3 Pan, J., "Estimation Of Energy Release Rates And Instability Analysis For Pipes With A Circumferential Surface Crack Subjected To Bending", ASME Paper No. 84-PVP-110, 1984. 


\section{APPENDIX B}

\section{PROGRAM - EXTCRK7}

PROGRAM TO CALCULATE GN FUNCTIONS (SC.TKP) THICK WALI SOLUTION PROGRAM TO CALCULATE GN FUNCTIONS (SC.TNP) THIN WALI SOLUTION

FOR EXTERNAL SURFACE CRACKS ONLY

COMBINED BENDING AND PRESSURE

SEARCH FOR NEUTRAL AXIS MODIFIED.

CALCULATE RHON UP TO PI/2 FOR CHANGING PHIOD

USE RHON $=$ PI/2 FOR ADDITIONAI PHIOD

COMPUTE ELASTIC AND PLASTIC J

IMPLICIT REAL*8 (A-H, O-Z)

REAL 8 LUSER

DIMENSION ROMA (20), THI (20)

DIMENSION A1 (50), A2 (50), A3 (50), A4 (50), A5 (50)

OPEN (UNIT $=2$, FILE =' EXTCRK7. OUT', STATUS =' UNKNOWN')

OPEN (UNIT $=5$, FILE $=$ ' CON' , STATUS $=$ ' UNNKNOWN')

OPEN (UNIT $=6$, FILE $=$ ' CON' ', STATUS $=$ ' UNKNNOWN')

WRITE $(6,49)$

49

FORMAT ( $1 X$,' Select the J-Estimation Method'/,

$\begin{array}{ll}+ & 1 \text {. Thin Wall Pipes }(t<<\mathrm{Ri}) \\ + & 2 \text {. Thick Wall Pipes }\end{array}$

$\operatorname{READ}(5, *)$ METHOD

IF (METHOD .NE. 1) METHOD $=2$

$\operatorname{WRITE}(6,50)$

50 FORMAT (1X,'Enter Pipe Outside Diameter (inches)', :,F13.5)

$\operatorname{READ}(5, *)$ POD

WRITE $(6,51)$

51 FORMAT (IX,'Enter Pipe wall Thickness (inches)')

$\operatorname{READ}(5, *) T$

NTYPE $=1$

IF (METHOD .EQ. 2) THEN

WRITE $(6,52)$

52

FORMAT (1X,'select the external crack defintion'/,

$+\quad 1$. Uniform depth (a and theta) $\% l$.

$+\quad 2$. Elliptical (a and theta) \%,"

$+\quad:$ 3. Elliptical $\left.(a \text { and } c)^{\prime}, / /, \prime, / /\right)$

READ $(5, *)$ NTYPE

END IF

IF (NTYPE .EQ. 1 .OR. NTYPE .EQ. 2) THEN

WRITE $(6,53)$

53 FORMAT (IX,'Enter the crack depth (a) ')

$\operatorname{READ}(5, \star) A$

WRITE $(6,54)$

54 FORMAT (1X,'Enter the crack angle (theta)')

$\operatorname{READ}(6, *)$ THETA

THETDEG $=$ THETA

END IF

IF (NTYPE .EQ. 3) THEN

WRITE $(6,53)$

$\operatorname{READ}(5, *) A$

WRITE $(6,55)$ 
55 FORMAT (1X, 'Enter the crack width (c) ')

$\operatorname{READ}(5, *) \mathrm{C}$

END IF

C

C MATERIAL CONSTANTS

C

WRITE $(6,56)$

56 FORMAT $(/ /, 1 \mathrm{x}$, 'The Pipe Material Constants ',//)

WRITE $(6,69)$

69 FORMAT (IX, 27HEnter Young's Modulus (psi) )

READ (5, *) YMOD

WRITE $(6,68)$

68

FORMAT (1X, 22HEnter Poisson's Ratio)

$\operatorname{READ}(5, *)$ POIS

IF (POIS .EQ. 0.0 ) POIS $=0.3$

$\mathrm{YMOD}=\mathrm{YMOD} /(1,-\mathrm{POIS} *$ POIS $)$

WRITE $(6,57)$

57 FORMAT (IX,'Enter SIGMA ZERO ')

READ (5, *) SIGMAO

WRITE $(5,58)$

58 FORMAT (IX,'Enter EPSILON ZERO ')

$\operatorname{READ}(5, *)$ EPSO

WRITE $(6,59)$

59 FORMAT (IX,'Enter Alpha ')

$\operatorname{READ}(5, *)$ ALPHA

WRITE $(6,60)$

60 FORMAT ( $1 \mathrm{x}$, 'Enter $\mathrm{n}$ ')

$\operatorname{READ}(5, *) \mathrm{EN}$

C

C

LOADING PRESSURE PLUS BENDING

WRITE $(6,61)$

61 FORMAT (//, IX, 'The Loading Parameters ',//)

65 CONTINUE

WRITE $(6,62)$

62 FORMAT ( $1 \mathrm{X}$, 'Enter Pressure (psi) ')

READ (5, *) PUSER

WRITE $(5,63)$

63 FORMAT ( $1 \mathrm{X}$, 'Enter Bending Moment (in-lb)')

READ (5, *) BMUSER

IF (PUSER .IE. 0.0 .AND. BMUSER .IE . 0.0 ) THEN

WRITE $(6,64)$

64 FORMAT (///,1X,'Both Pressure and Bending CANNOT be zero.',/, $+$

GO TO 65

END IF

SMPLFY $=1.0$

IF (PUSER .EQ. 0.0 ) THEN

SMPLFY $=0.0$

END IF

12

CONTINUE

$\mathrm{RO}=\mathrm{POD} / 2.0$

$\mathrm{RI}=\mathrm{RO}-\mathrm{T}$

RIOT $=\mathrm{RI} / \mathrm{T}$

TORI $=1.0 /$ RIOT

$P I=4.0 *(\operatorname{ATAN}(1.0))$

$\mathrm{PI} 2=\mathrm{PI} / 2.0$

$\mathrm{AOT}=\mathrm{A} / \mathrm{T}$

IF (METHOD . EQ . 2) THEN

$\mathrm{AK}=\mathrm{PI}$ * $(\mathrm{RO} * \mathrm{RO}-\mathrm{RI} * \mathrm{RI})$ 


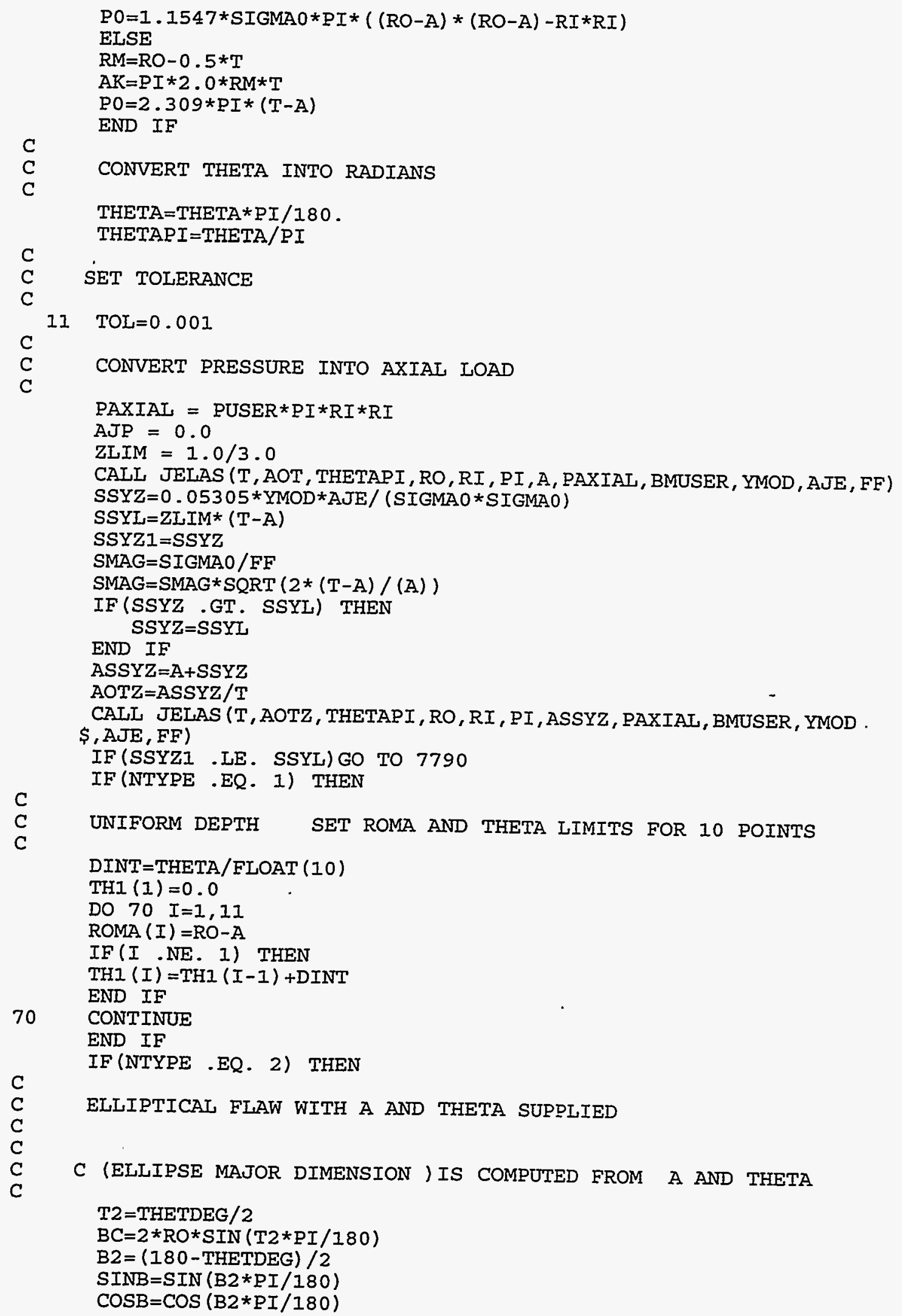




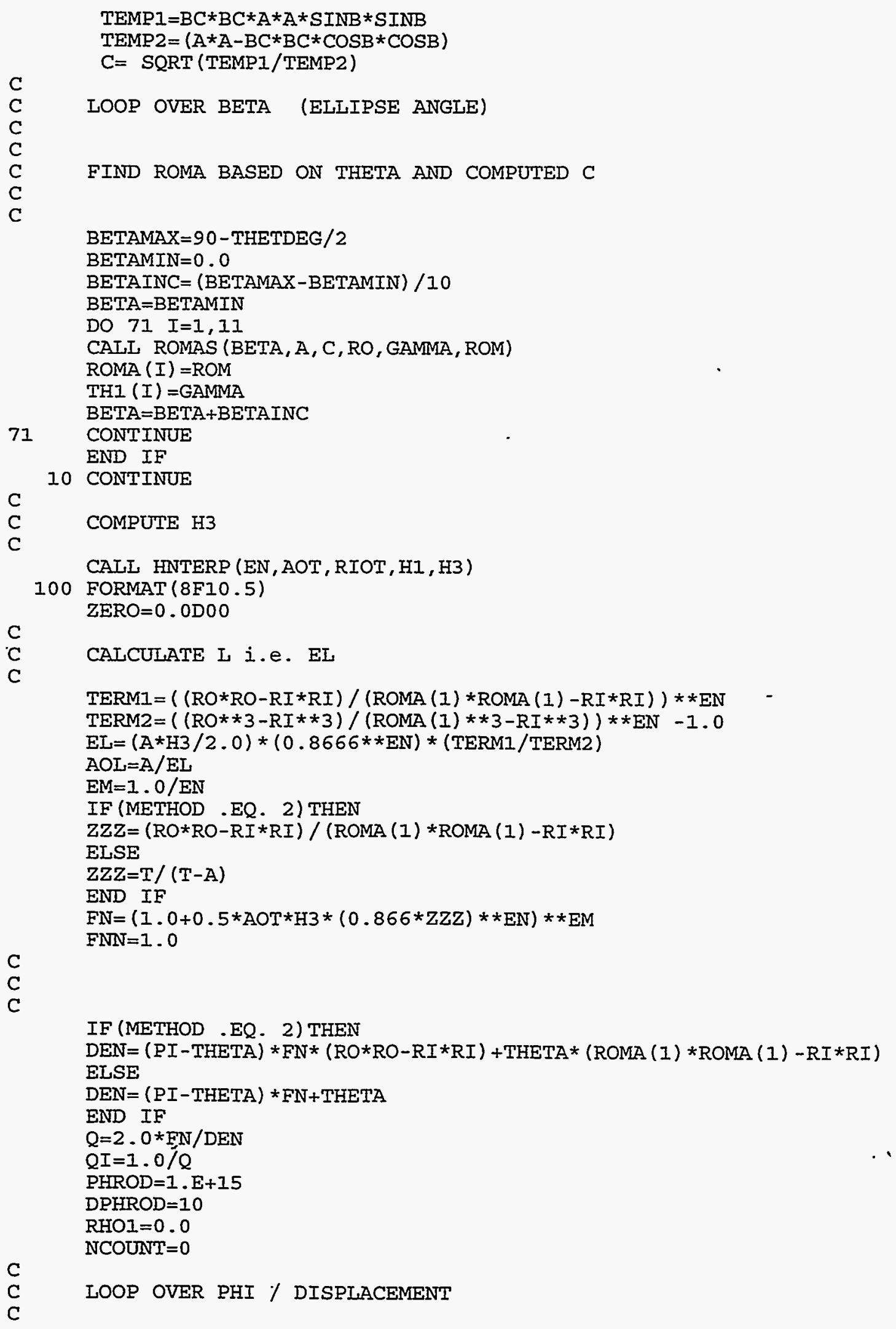


888 PHOD $=$ PHROD/RO

IF (SMPLFY .EQ . 0.0) PHOD $=1.0$

IF ( (THETA-PI2) . GT . RHO1) RHO1=THETA-PI2

$\mathrm{DRHO}=0.01$

$\mathrm{DINCR}=\mathrm{DRHO}$

TI=FINTGI (ZERO, TH1 , I , RHO1 , EN , RI , ROMA, RI , PHOD , RO , FN , SMPLFY , METHOD)

$\mathrm{T} 2=0.0$

IF (THETA. GE.PI2) GO TO 5

T2 =FINTG (THETA, PI2 , I , RHO1 , EN , RI , RO , RI , PHOD , RO , FNN , SMPLFY , METHOD)

$5 \mathrm{FL}=0$.

- IF (THETA.GT.PI2) FL=THETA-PI2

T3=FINTG (FI , RHO1 , 2, RHO1 , EN, RI , RO , RI , PHOD, RO, FNN, SMPLFY , METHOD)

T4 =FINTG (RHOI , PI2 , 3, RHOI, EN, RI , RO, RI , PHOD, RO, FNN, SMPLFY, METHOD)

$\mathrm{Y} 1=\mathrm{T} 1+\mathrm{T} 2+\mathrm{T} 3-\mathrm{T} 4-\mathrm{QI} * \mathrm{SMPLFY}$

$\mathrm{RHO}=\mathrm{RHO}+\mathrm{DRHO}$

$\mathrm{C}$
$\mathrm{C}$
$\mathrm{C}$

BISECTION METHOD

I TI=FINTGI (ZERO, THI , 1, RHOI , EN , RI , ROMA , RI , PHOD , RO, FN , SMPLFY, METHOD) $\mathrm{T} 2=0$.

IF (THETA.GE.PI2) GO TO 6

T2 =FINTG (THETA, PI2 1 1, RHOI , EN, RI , RO, RI , PHOD , RO, FNN, SMPLFY , METHOD)

$6 \mathrm{FL}=0.0$

IF (THETA. GT . PI2) FL=THETA-PI2

T3=FINTG (FI, RHOI , 2, RHOI, EN, RI , RO, RI , PHOD, RO, FNN, SMPLFY, METHOD)

T4 =FINTG (RHOI, PI2 , 3 , RHO1 , EN, RI , RO, RI , PHOD, RO, FNN , SMPLFY, METHOD)

$\mathrm{Y} 2=\mathrm{T} I+\mathrm{T} 2+\mathrm{T} 3-\mathrm{T} 4-\mathrm{QI} * \mathrm{SMPLFY}$

$\mathrm{Y} 1 \mathrm{Y} 2=\mathrm{Y} 1 * \mathrm{Y} 2$

IF (YIY2.GT. ZERO) GO TO 2

RATIO=ABS (DRHO/DINCR)

IF (RATIO. IE. TOL) GO TO 4

RHO1 $=$ RHO1 - DRHO

$\mathrm{DRHO}=\mathrm{DRHO} / 2.0$

GO TO 3

2 CONTINUE

$\mathrm{Y} 1=\mathrm{Y} 2$

3 RHO1=RHO1+DRHO

IF (RHOI . GE. PI2) THEN

$\mathrm{RHOI}=\mathrm{PI} 2$

GO TO 4

ELSE

GO TO I

END IF

4 CONTINUE

$T I=(0.5 / F N)$ *FINTGI (ZERO, THI , 5, RHOI, EN, RI, ROMA , RI , PHOD , RO , EN

\$, SMPLFY, METHOD)

$\mathrm{T} 2=0.0$

IF (THETA.GE.PI2) GO TO 7

T2 $=0.5 *$ FINTG (THETA, PI2, 5, RHOI, EN, RI, RO, RI, PHOD, RO, FNN

\$, SMPLFY, METHOD)

$7 \mathrm{FL}=0.0$

IF (THETA. GE.PI2) FL=THETA-PI2

T3=0 . 5 * FINTG (FI, RHOI , 6, RHO1, EN, RI , RO , RI , PHOD , RO , FNN

\$, SMPLFY, METHOD)

T4 =0 .5*FINTG (RHOI, PI2 , 7, RHO1, EN, RI, RO, RI, PHOD, RO, FNN

\$, SMPLFY, METHOD)

$\mathrm{GN}=\mathrm{T} 1+\mathrm{T} 2+\mathrm{T} 3-\mathrm{T} 4$

IF (METHOD .EQ. 2) THEN ELSE

EMOT $=2.0 * G N * Q-R O * \operatorname{SIN}(R H O I)$ 


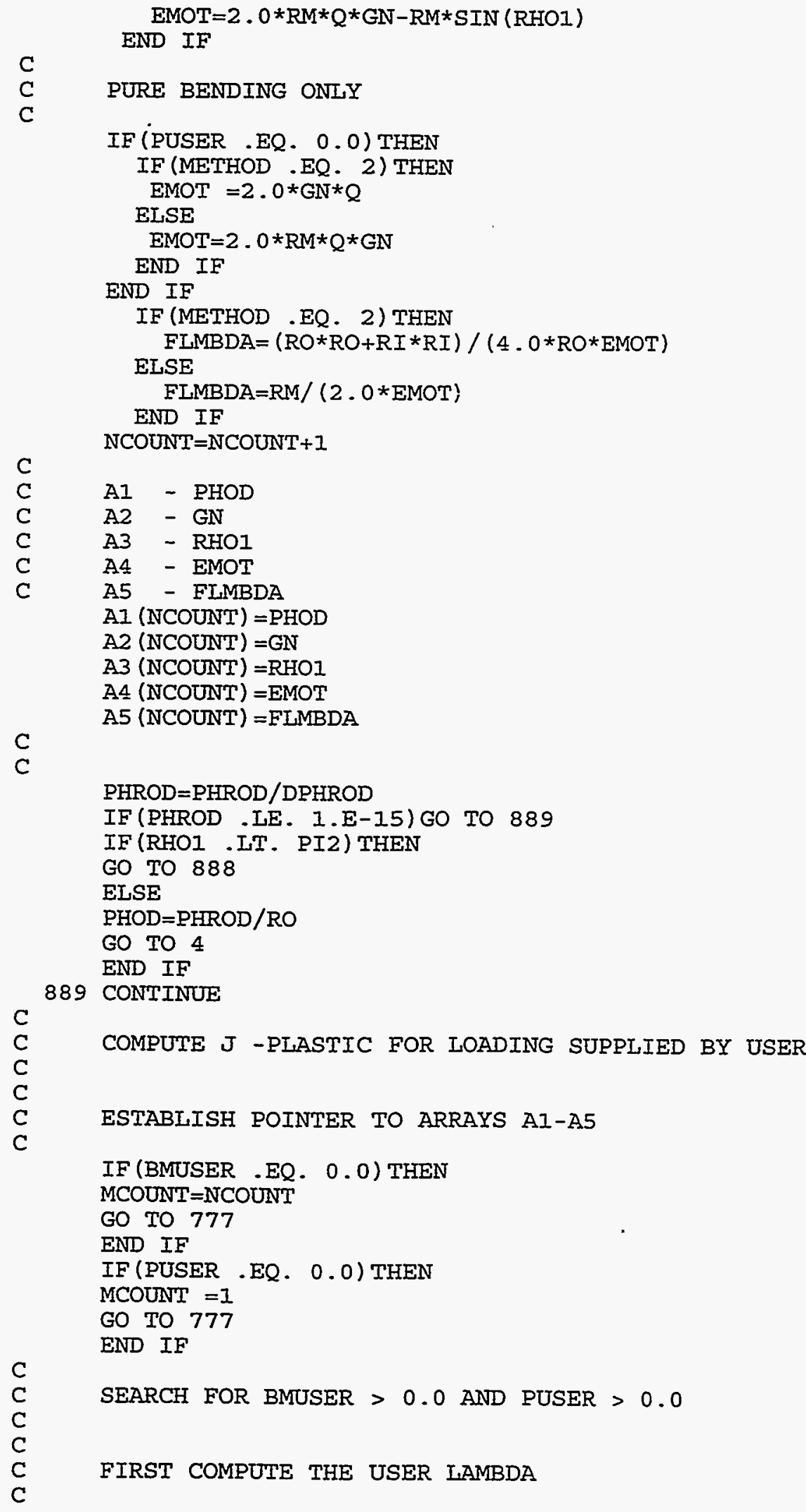




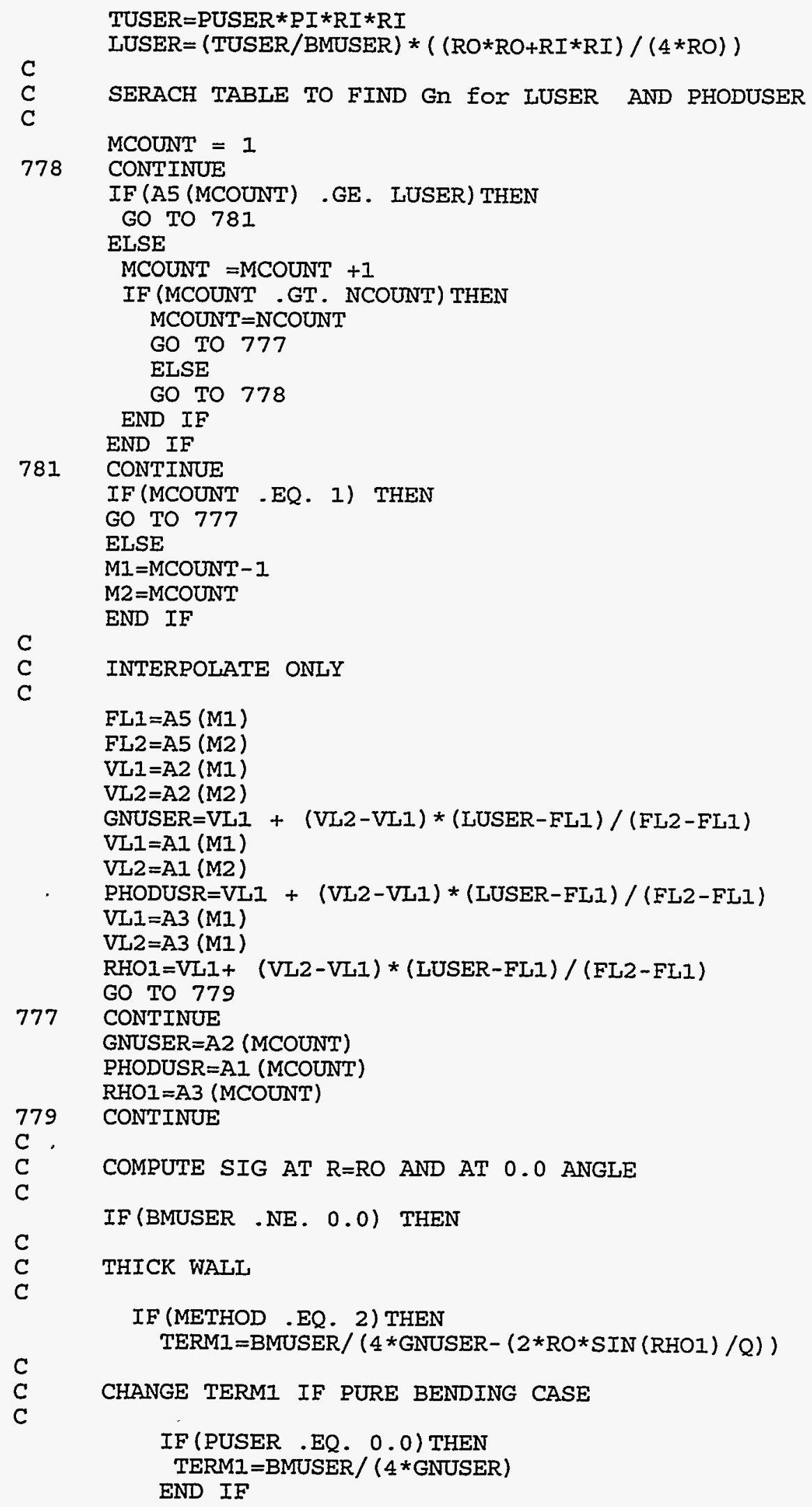




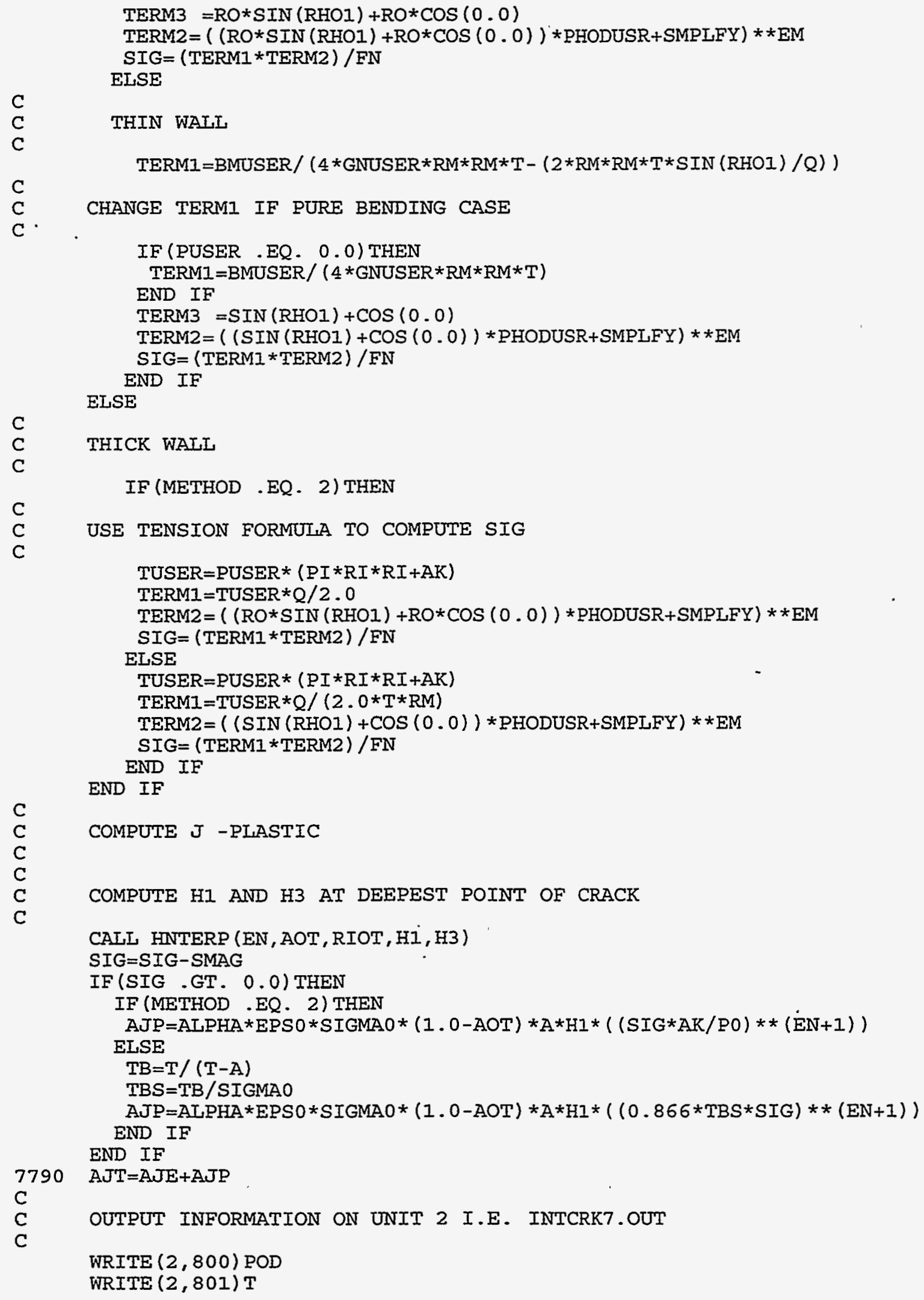


WRITE $(2,802) \mathrm{A}$

WRITE $(2,803)$ THETDEG

WRITE $(2,804)$ PUSER

WRITE $(2,805)$ BMUSER

800

801

802

803

804

805

880

C

$780 \quad$ FORMAT $(/ / /, 1 \mathrm{X}, ' \mathrm{~J}-$ FORMAT (5X,' Pipe Wall Thickness

FORMAT (5X,' Crack Depth

FORMAT (5X,' Crack Angle

FORMAT (5X,' Internal Pressure

FORMAT (5X, 'Bending Moment

WRITE $(2,880)$ AJE, AJP, AJT

FORMAT(///,5X,'J-Integral Estimate (Small Scale Yielding) (in-Ib/i $\$ n * * 2)-, E 15.5, /$,

$\$ \quad 5 X, ' J-I n t e g r a l$ Estimate (Plastic)

$\$ n * * 21-$, E15.5,/,

$\$ 5 X, ' J$-Integral Estimate (Total)

$\$ \mathrm{~N} * * 2)-(, \mathrm{E} 15.5)$

WRITE $(6,780)$ AJE, AJP, AJT

$\$$

$\$ n * * 2)-, E 15.5, /$,

$\$ 1 \mathrm{X}$, 'J-Integral Estimate (Total)

$\$ n * \star 2)-(, E I 5.5)$

$($ inches $)=, F 10.5)$

(inches) $=$, F10.5)

(inches) $=$ 'F $\mathrm{F} 10.5$ )

(degrees) $=$,F10.4)

$(p s i)=, F 10.4)$

$(i n-1 b)=, F 10.0)$

COMPUTE ROTATION AND DISPIAACEMENT

STOP 'END OF PROGRAM'

END

SUBROUTINE JELAS ( T, AOT , THETAPI, RO, RI, PI, A, PAXIAI, BMUSER

$\$, Y M O D, A J E, F F)$

IMPLICIT REAL*8 (A-H,O-Z)

$C$
$C$
$C$
$C$
$C$

COMPUTE ELASTIC J

EQUATIONS ARE FROM ASME Section XI IWB-3650 Analysis

TEMP $1=16.772 *(($ AOT*THETAPI $) * * 0.855)$

TEMP2 $=14.944 *((A O T *$ THETAPI $))$

FM $=1.10+A O T *(0.15241$ +TEMP1-TEMP2)

TEMP $1=5.0057 *(($ AOT $*$ THETAPI $) * * 0.565)$

TEMP2 $=2.8329 *($ AOT $*$ THETAPI $)$

$F B=1.10+A O T *(-0.09967+$ TEMPI -TEMP2 $)$

$R M=(R O+R I) / 2.0$

$A K I M=(P A X I A I /(2 * P I * R M * T)) *((P I * A) * * 0.5) * F M$

$F P S P=A K I M /((P I * A) * * 0.5)$

$\mathrm{AKIB}=(B M U S E R /(\mathrm{PI} * \mathrm{RM} * \mathrm{RM} * \mathrm{~T})) *((\mathrm{PI} * \mathrm{~A}) * * 0.5) * \mathrm{FB}$

$\mathrm{FBSB}=\mathrm{AKIB} /((\mathrm{PI} * \mathrm{~A}) * * 0.5)$

$A K I=A K I M+A K I B$

$A J E=(A K I * A K I) / Y M O D$

C
C

COMPUTE FF

IF (BMUSER .EQ. 0.0) THEN

RATIO $=1.0+($ FBSB $/$ FPSP $) * * 2$

$F F=S Q R T(F M * F M * R A T I O)$

ELSE

RATIO $=1.0+($ FPSP $/ F B S B) * * 2$

$F F=S Q R T(F B * F B * R A T I O)$ 


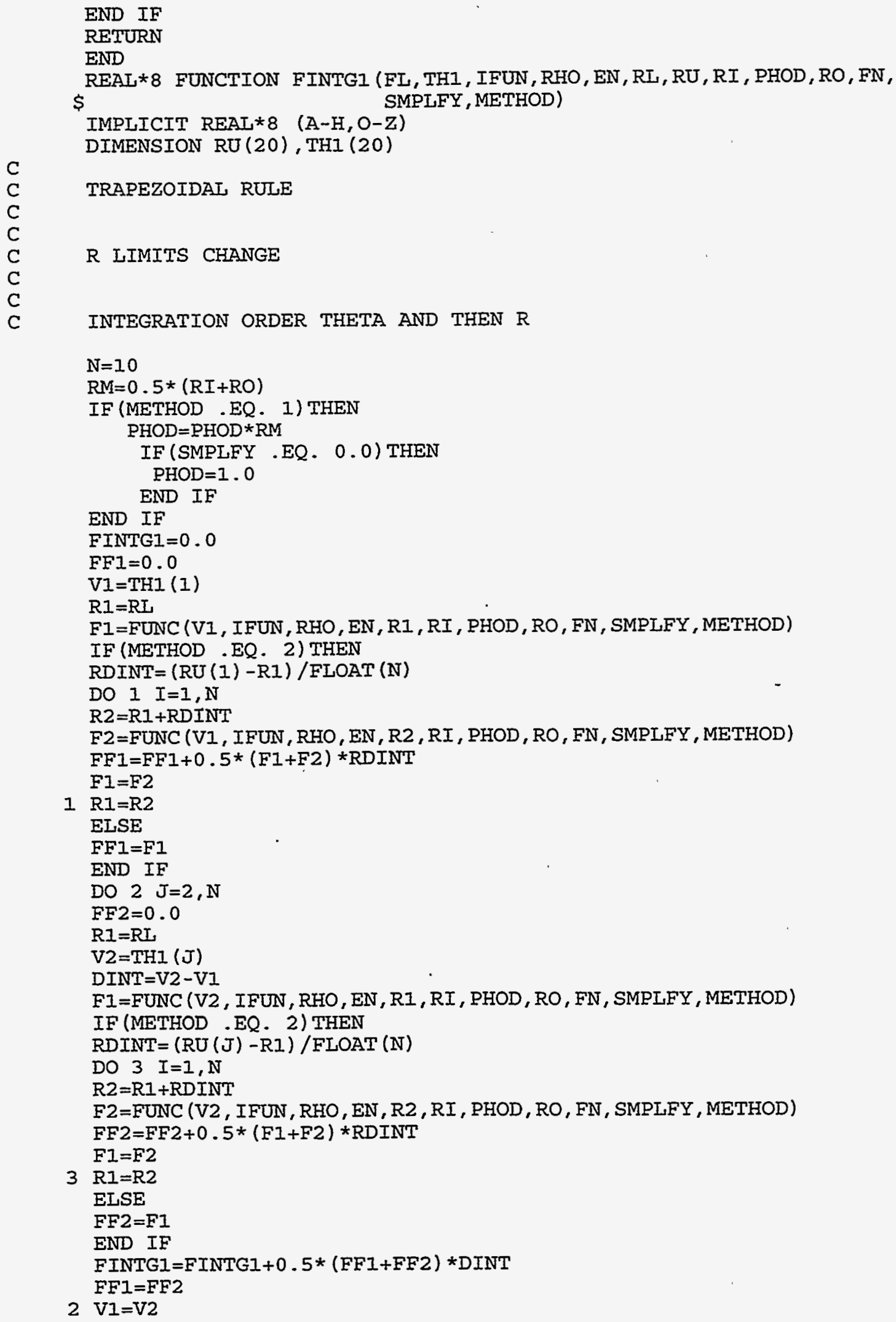

$1 \mathrm{R} 1=\mathrm{R} 2$

ELSE

$F F I=E 1$

END IF

DO $2 J=2, N$

$\mathrm{FF} 2=0.0$

$\mathrm{RI}=\mathrm{RI}$.

$\mathrm{V} 2=\mathrm{THI}(\mathrm{J})$

$\mathrm{DINT}=\mathrm{V} 2-\mathrm{V} 1$

FI=FUNC (V2, IFUN, RHO, EN , RI , RI , PHOD, RO , FN, SMPLFY, METHOD)

IF (METHOD . EQ. 2) THEN

$\operatorname{RDINT}=(\operatorname{RU}(\mathrm{J})-\mathrm{RI}) / \mathrm{FLOAT}(\mathrm{N})$

DO $3 I=1, N$

$\mathrm{R} 2=\mathrm{R} 1+\mathrm{RDINT}$

F2=FUNC (V2, IFUN , RHO , EN, R2 , RI, PHOD , RO, FN , SMPLFY , METHOD)

$F F 2=F F 2+0.5 *(F 1+F 2) * R D I N T$

$\mathrm{F} 1=\mathrm{F} 2$

$3 \mathrm{R} I=\mathrm{R} 2$

ELSE

$F F 2=F 1$

END IF

FINTG1 $=$ FINTG1 $1+0.5 *(F F 1+F F 2) * D I N T$

$\mathrm{FF} 1=\mathrm{FF} 2$

$2 \mathrm{~V} 1=\mathrm{V} 2$ 


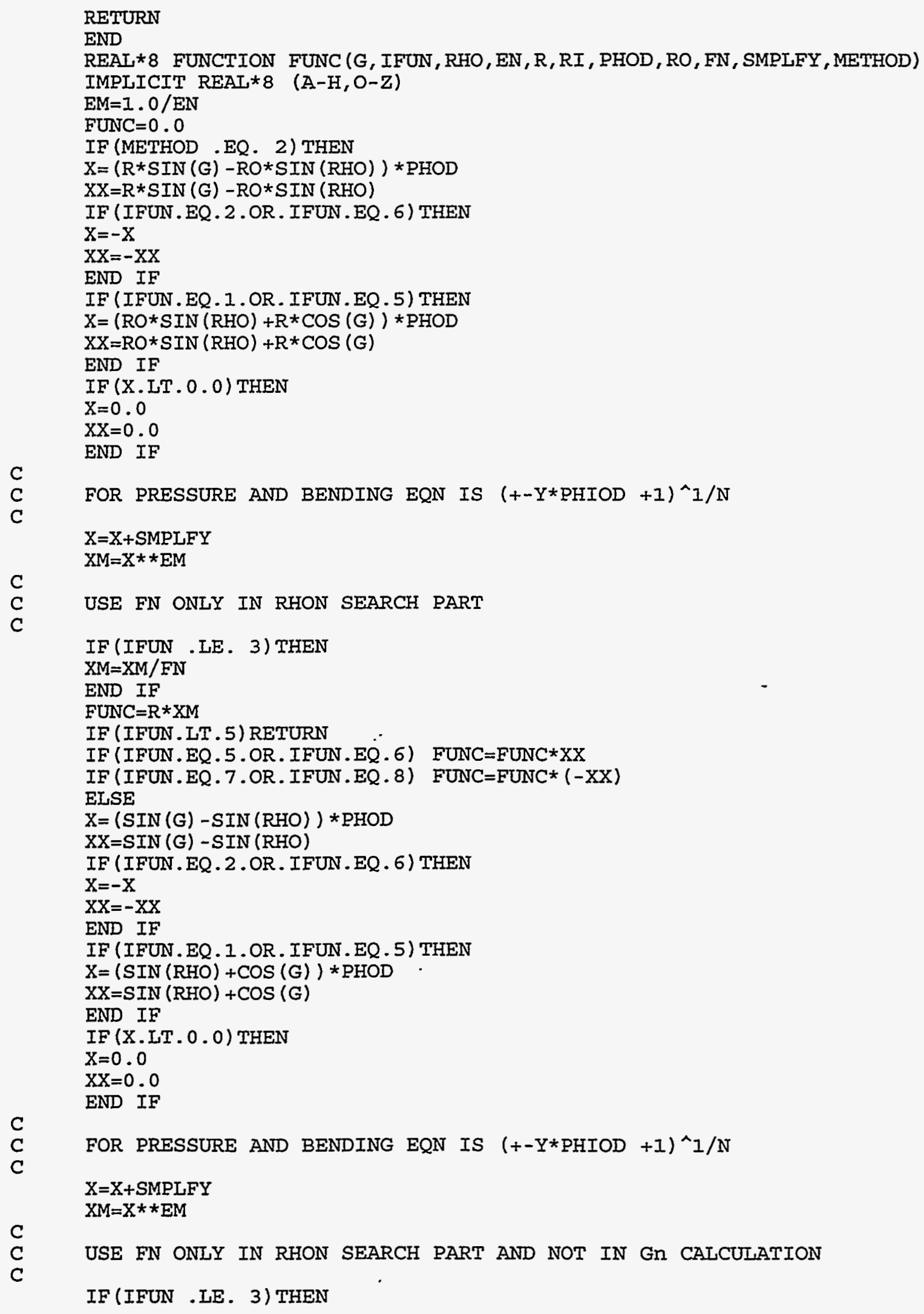




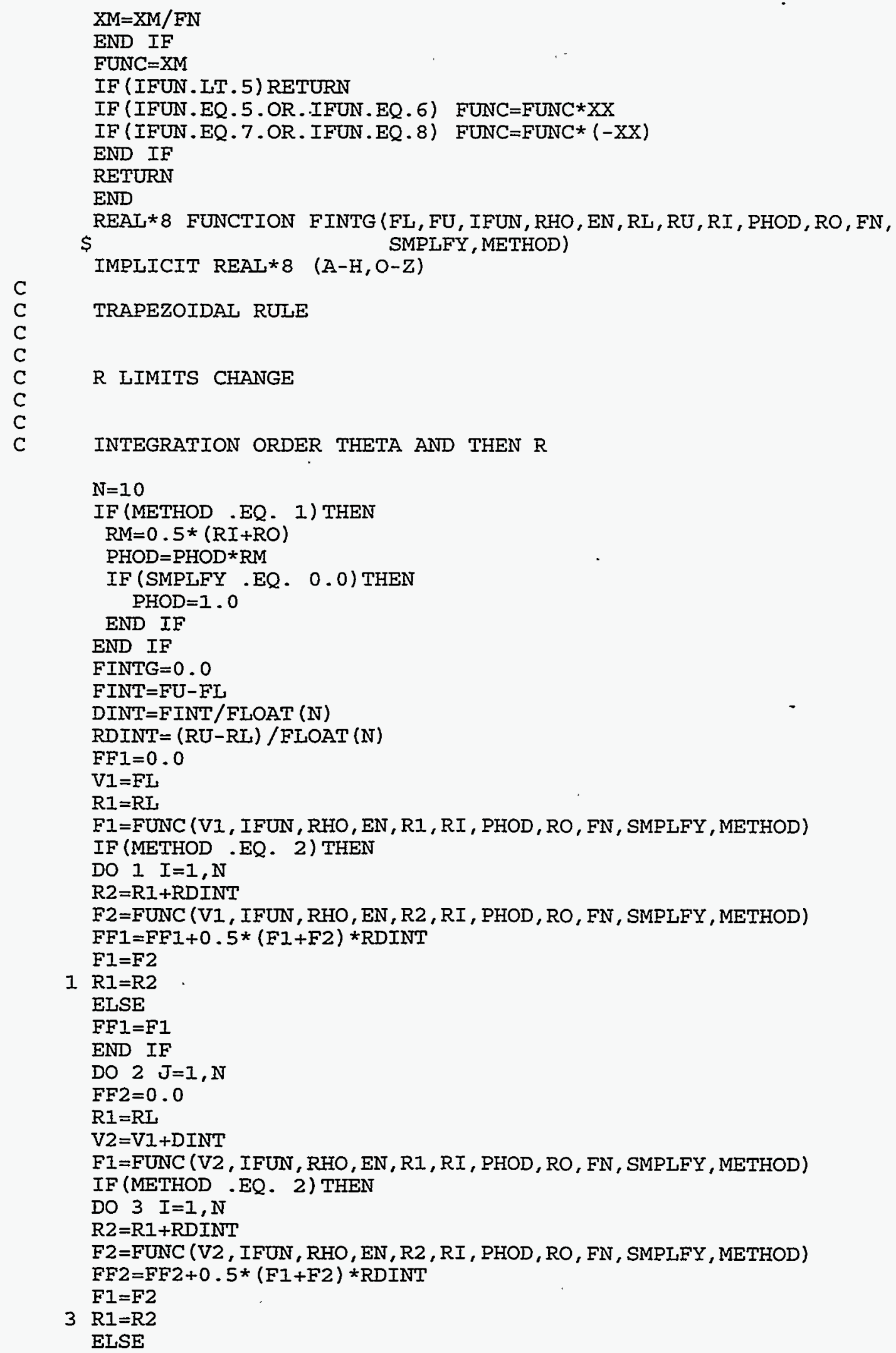




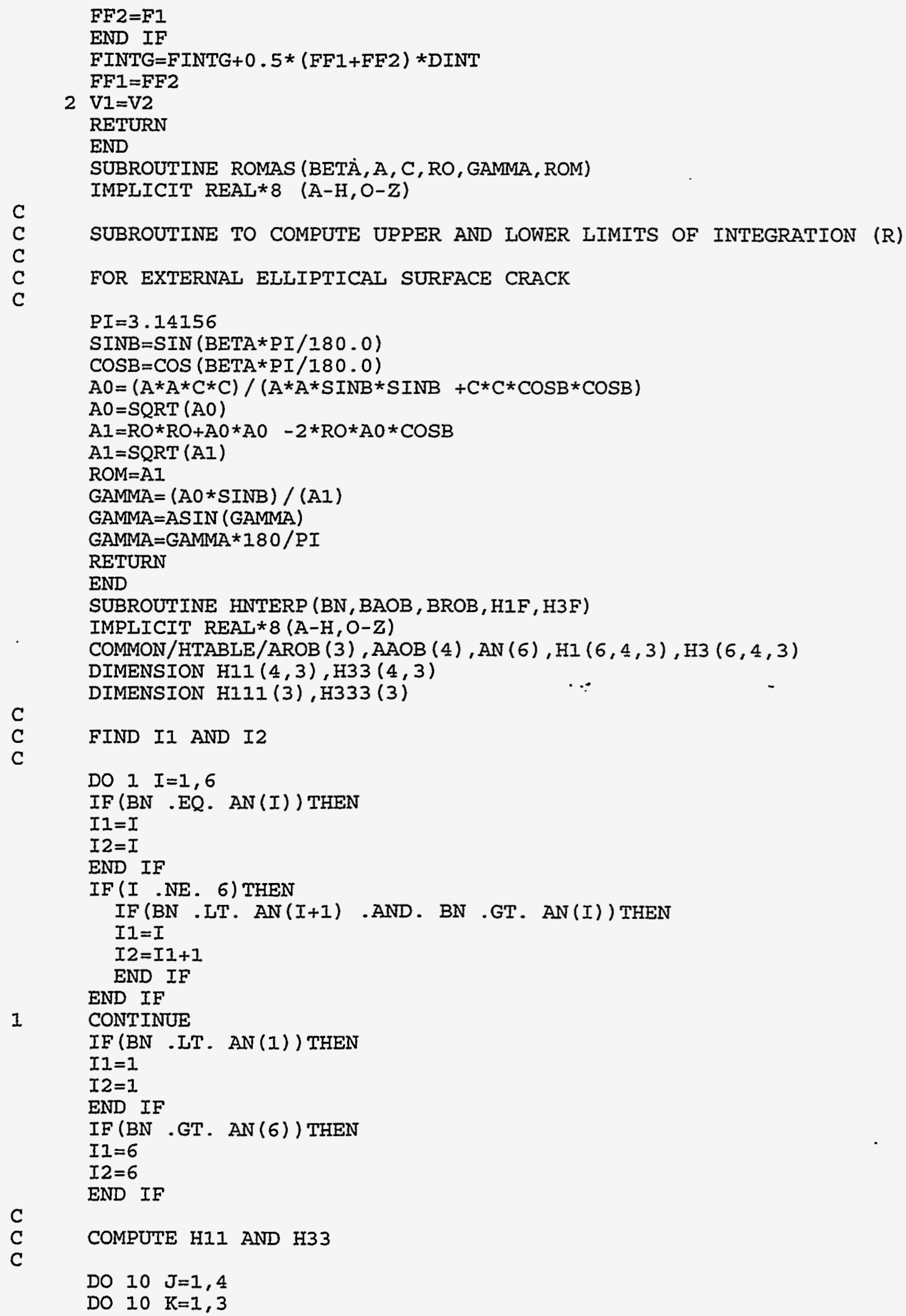




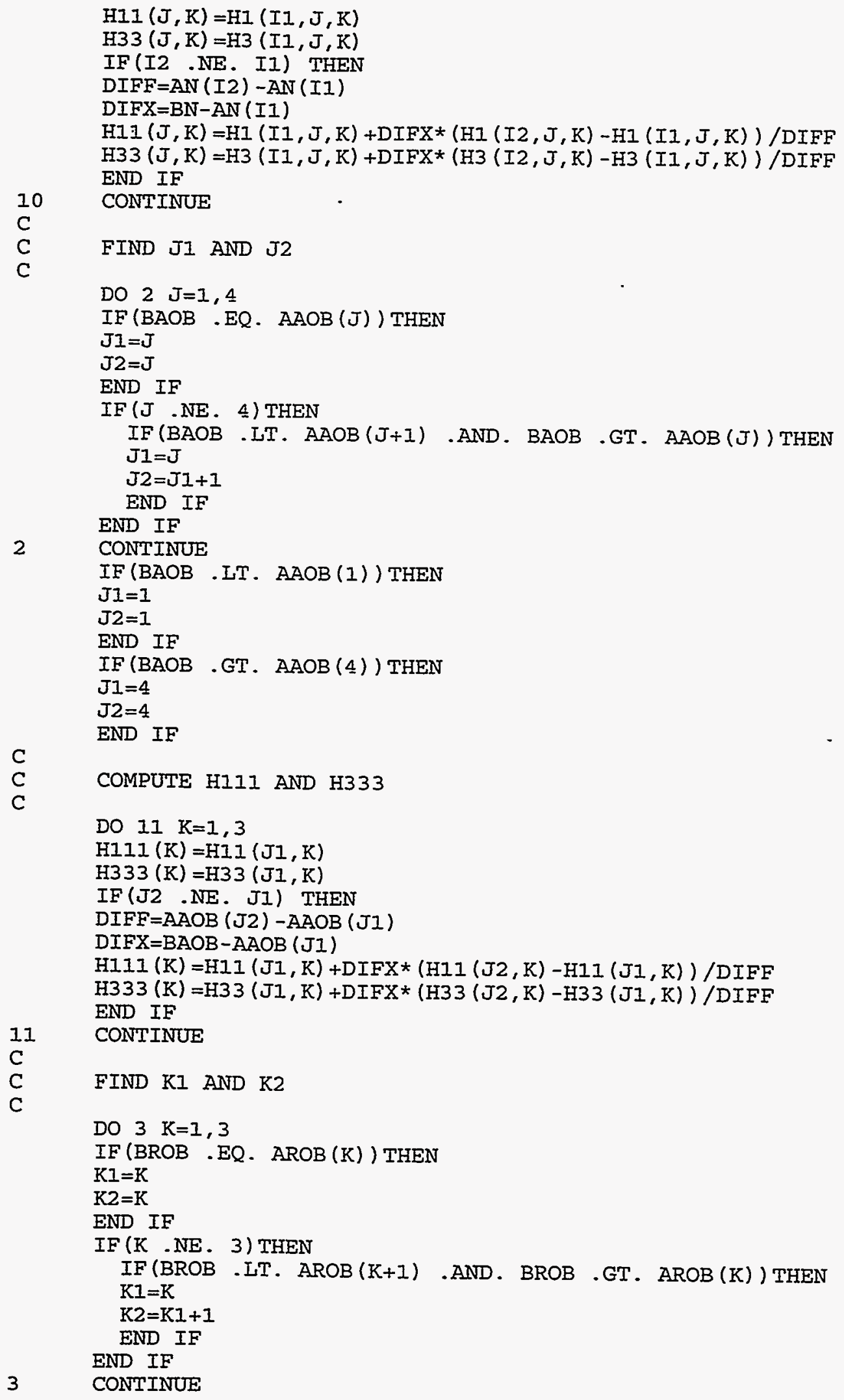




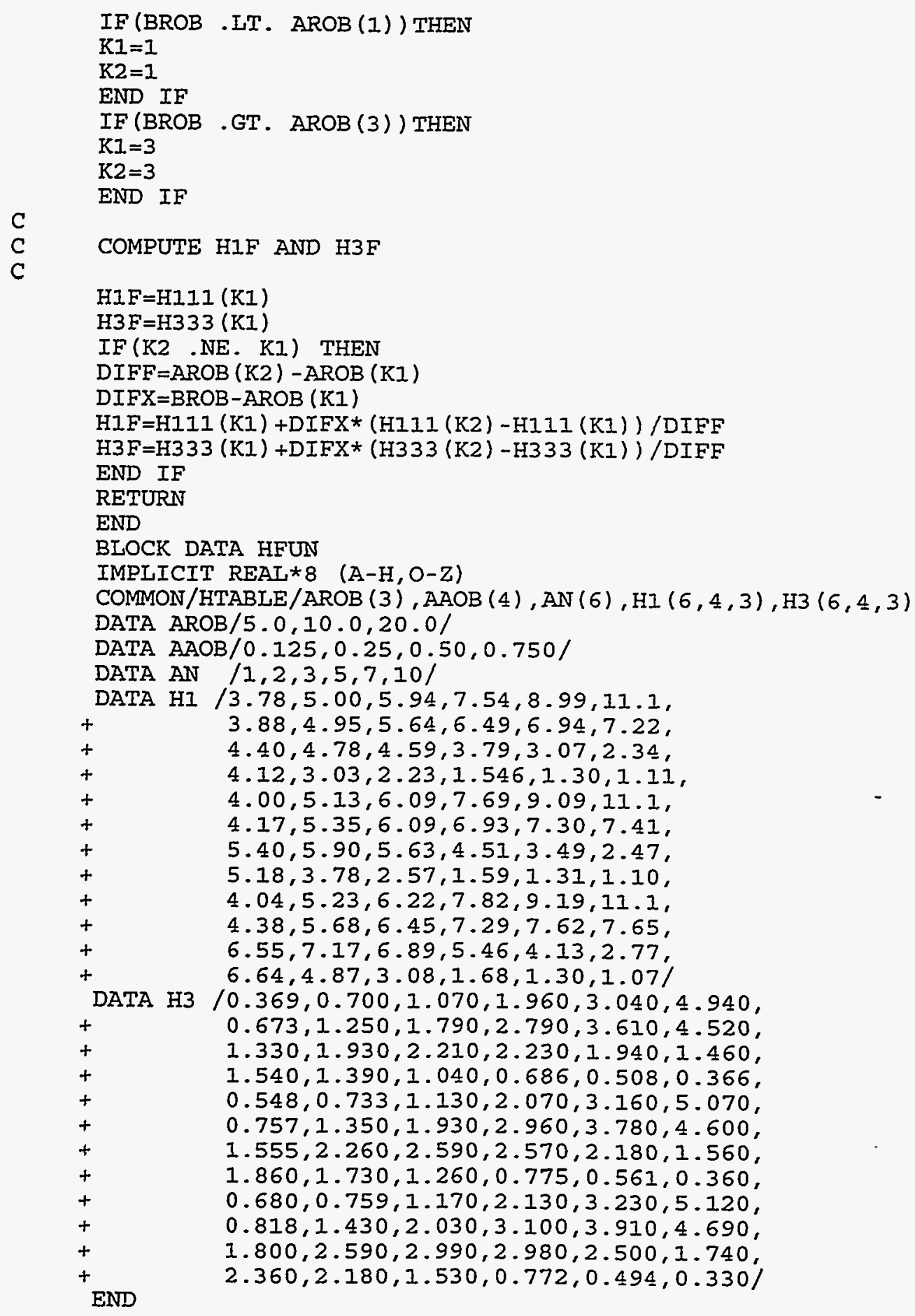




\section{APPENDIX B (continued)}

\section{PROGRAM - INTCRK7} PROGRAM TO CALCULATE Gn FUNCTIONS (SC.TKP) THICK WALI SOLUTION
PROGRAM TO CALCULATE Gn FUNCTIONS (SC.TNP) THIN WALI SOLUTION

FOR INTERNAI SURFACE CRACKS ONLY

COMBINED BENDING AND PRESSURE

SEARCH FOR NEUTRAL AXIS MODIFIED.

CALCULATE RHON UP TO PI/2 FOR CHANGING PHIOD

USE RHON=PI/2 FOR ADDITIONAL PHIOD

COMPUTE ELASTIC AND PLASTIC J

IMPLICIT REAI* $8 \quad(\mathrm{~A}-\mathrm{H}, \mathrm{O}-\mathrm{Z})$

REAI*8 IUSER

DIMENSION RIPA (20), TH1 (20)

DIMENSION A1 (50), A2 (50), A3 (50), A4 (50), A5 (50)

OPEN (UNIT=2, FILE=' INTCRK7. OUT' , STATUS=' UNKNOWN')

OPEN (UNIT =5, FILE $=$ ' CON' , STATUS =' UNKNOWN')

OPEN (UNIT $=6$, FILE $=$ ' CON' $^{\prime}$, STATUS $=$ ' UNKNOWN')

WRITE $(6,49)$

FORMAT (IX,' Select the J-Estimation Method'/,

$+\quad 1$. Thin Wall Pipes $(t<<R i)$ ' $/$,

$+$

' 2. Thick Wall Pipes

$\operatorname{READ}(5, *) M E T H O D$

IF (METHOD .NE. 1) METHOD $=2$

WRITE $(6,50)$

50 FORMAT (IX,'Enter Pipe Outside Diameter (inches)', :,F13.5)

$\operatorname{READ}(5, *)$ POD

WRITE $(6,51)$

51 FORMAT (IX,'Enter Pipe Wall Thickness (inches)')

$\operatorname{READ}(5, *) \mathrm{T}$

NTYPE $=1$

IF (METHOD .EQ. 2) THEN

WRITE $(6,52)$

52

FORMAT(1X,'select the internal crack defintion'/,

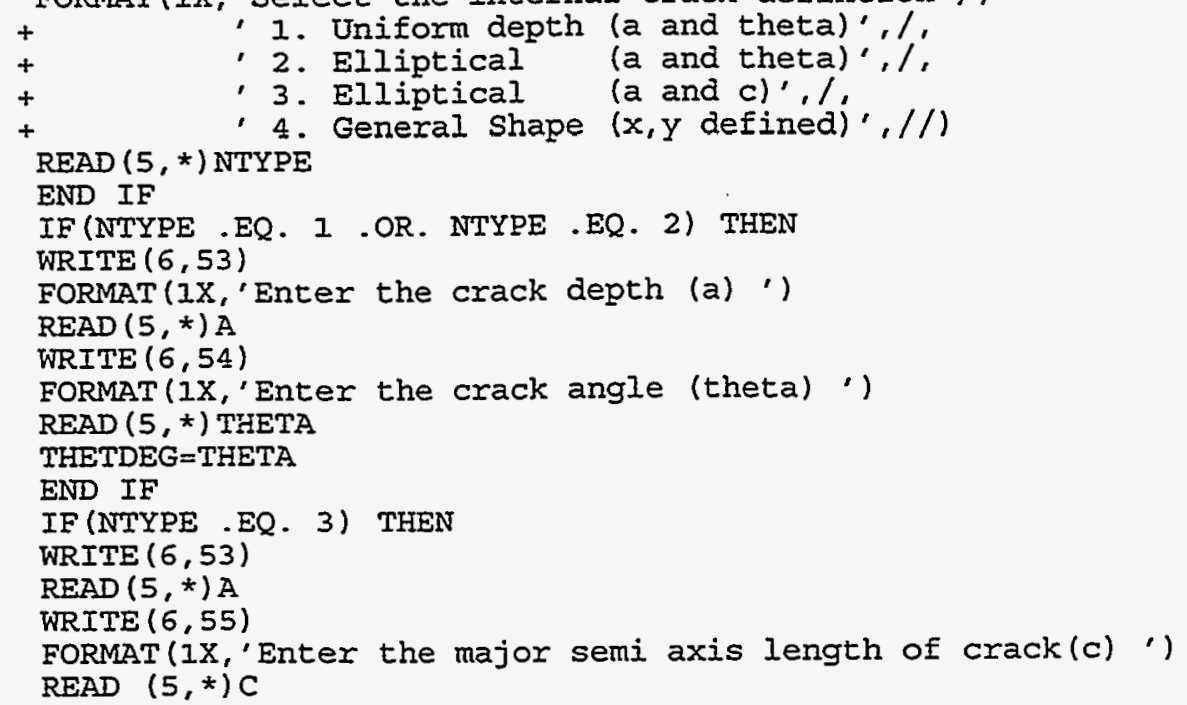


END IF

C MATERIAL CONSTANTS

WRITE $(6,56)$

56 FORMAT $(/ /, 1 \mathrm{X}$, 'The Pipe Material Constants ',//) WRITE $(6,69)$

69 FORMAT (1X,27HEnter Young's Modulus (psi)) $\operatorname{READ}(5, *)$ YMOD

WRITE $(6,68)$

68 FORMAT (IX, 22HEnter Poisson's Ratio)

\section{$\operatorname{READ}(5, *)$ POIS}

IF (POIS .EQ . 0.0) POIS $=0.3$

YMOD $=$ YMOD $/(1$. - POIS *POIS $)$

WRITE $(6,57)$

57 FORMAT( $1 \mathrm{X}$, 'Entex SIGMA ZERO (psi) ')

$\operatorname{READ}(5, *)$ SIGMAO

WRITE $(6,58)$

58 FORMAT ( $1 \mathrm{X}$,'Enter EPSILON ZERO')

$\operatorname{READ}(5, *)$ EPSO

WRITE $(6,59)$

59 FORMAT ( $1 \mathrm{X}$, 'Enter Alpha ')

$\operatorname{READ}(5, *)$ ALPHA

WRITE $(6,60)$

60 FORMAT (IX,'Enter n ')

$\operatorname{READ}(5, *)$ EN

C

C

C

WRITE $(6,61)$

61 FORMAT $(/ /, 1 \mathrm{X}$, 'The Loading Parameters ',//)

65 CONTINUE

WRITE $(6,62)$

62 FORMAT (1X,'Enter Pressure (psi) ')

$\operatorname{READ}(5, *)$ PUSER

WRITE $(6,63)$

63 FORMAT ( $1 \mathrm{X}$,'Enter Bending Moment (in-1b) ')

$\operatorname{READ}(5, *)$ BMUSER

IF (PUSER .IE. 0.0 .AND. BMUSER .LE. 0.0) THEN

WRITE $(6,64)$

64 FORMAT (///, 1X,'Both Pressure and Bending CANNOT be zero.',/.

$+\quad$ 'Please re-enter.', /)

GO TO 65

END IF

SMPLFY $=1.0$

IF (PUSER .EQ. 0.0 ) THEN

SMPLFY $=0.0$

CONTINUE

$\mathrm{RO}=\mathrm{POD} / 2.0$

$\mathrm{RI}=\mathrm{RO}-\mathrm{T}$

RIOT=RI/T

TORI $=T / R I$

TORI $=1.0 /$ TORI

$\mathrm{PI}=4.0 *(\operatorname{ATAN}(1.0))$

$\mathrm{PI} 2=\mathrm{PI} / 2.0$

$\mathrm{AOT}=\mathrm{A} / \mathrm{T}$

IF (METHOD .EQ. 2) THEN

$A K=P I *(R O * R O-R I * R I)$

$\mathrm{PO}=I .1547 *$ SIGMAO *PI* $(R O * \mathrm{RO}-(\mathrm{RI}+\mathrm{A}) *(\mathrm{RI}+\mathrm{A}))$ 


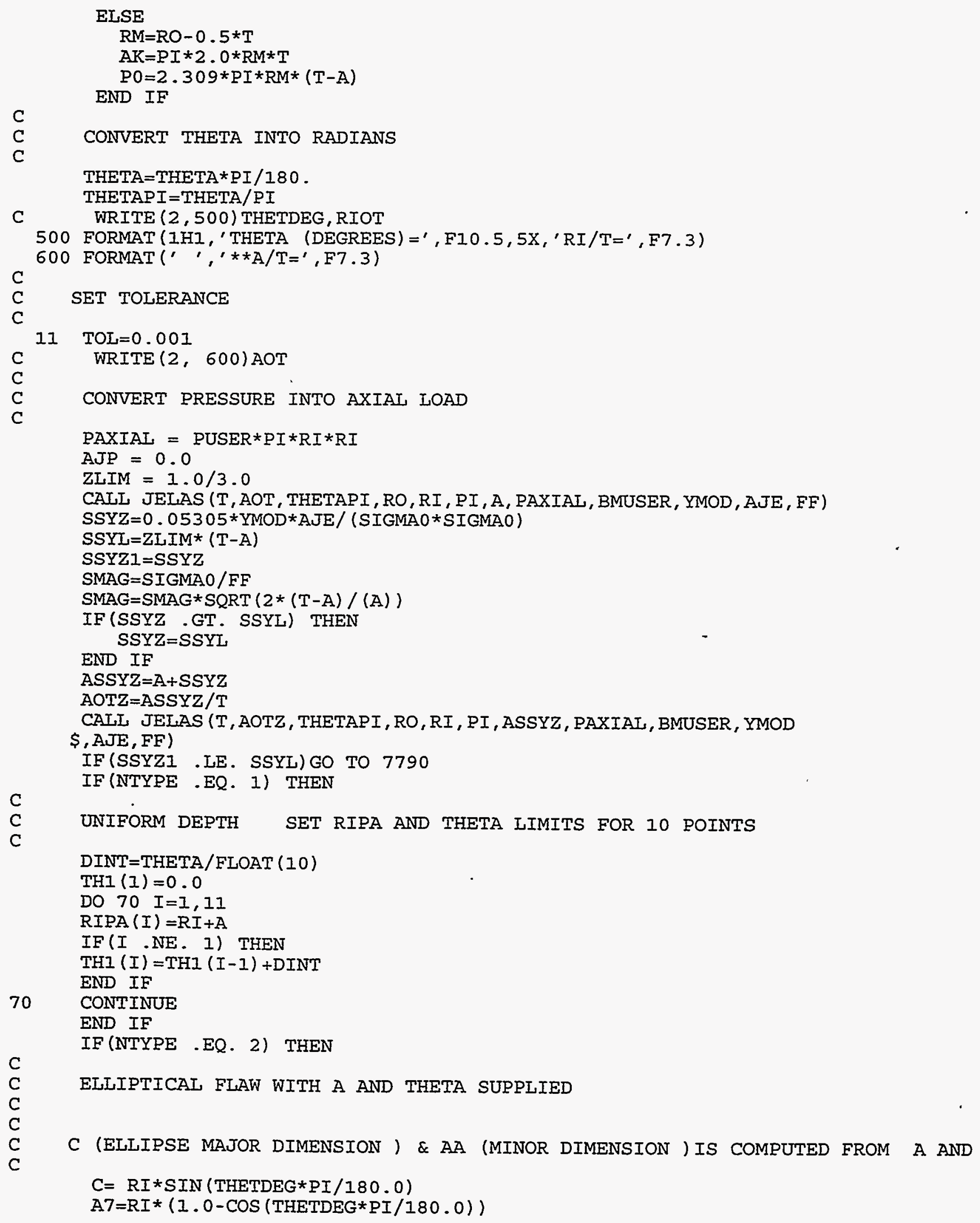




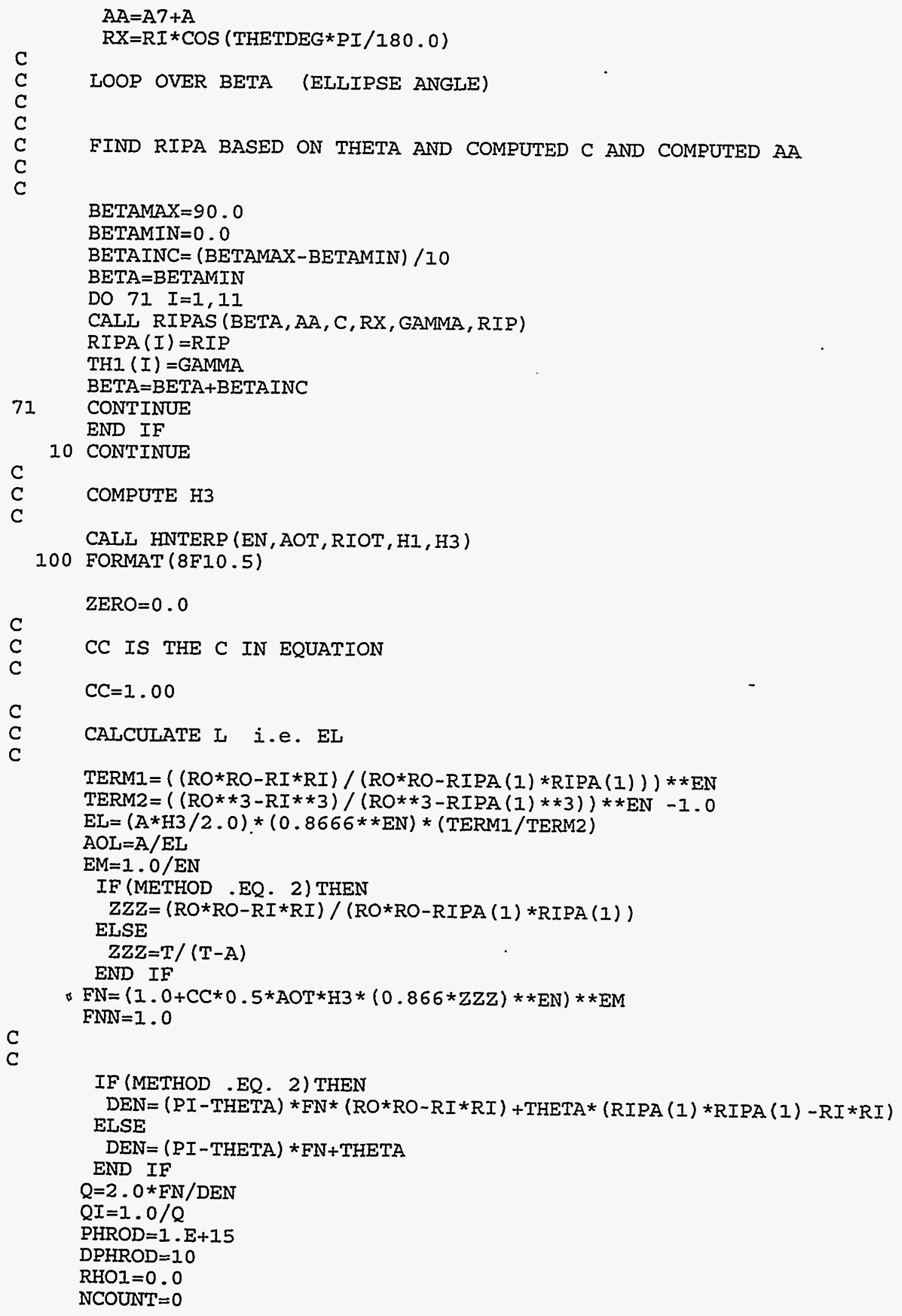




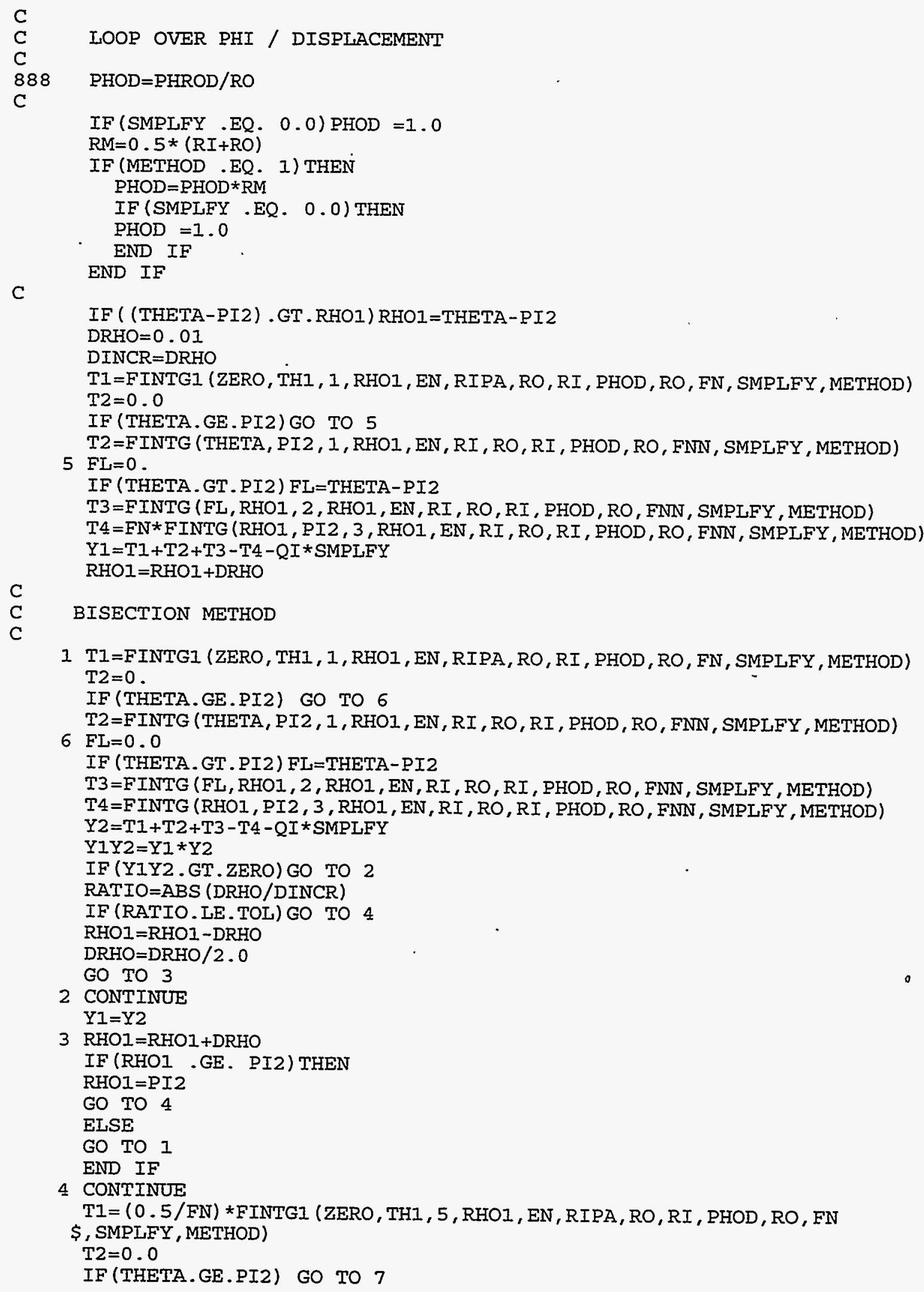


T2=0 . 5*FINTG (THETA, PI2, 5, RHOI, EN, RI, RO, RI , PHOD, RO, FNN $\$$, SMPLFY, METHOD)

$7 \mathrm{FI}=0.0$

IF (THETA. GE.PI2) FL=THETA-PI2

T3=0 .5*FINTG (FI, RHO1 , 6, RHO1, EN, RI, RO, RI , PHOD , RO , FNN $\$$, SMPLFY, METHOD)

T4 =0.5*FINTG (RHO1, PI2, 7, RHO1, EN, RI , RO , RI, PHOD , RO, FNN $\$$, SMPLEY, METHOD)

$\mathrm{GN}=\mathrm{T} 1+\mathrm{T} 2+\mathrm{T} 3-\mathrm{T} 4$

IF (METHOD .EQ. 2) THEN

ELSE

$E M O T=2.0 * \mathrm{GN} * Q-R O * \operatorname{SIN}(R H O I)$

$E M O T=2.0 * R M * Q * G N-R M * S I N(R H O 1)$

END IF

C

C

PURE BENDING ONLY

IF (PUSER .EQ . 0.0) THEN

IF (METHOD .EQ . 2) THEN

$E M O T=2.0 * G N * Q$

ELSE

$\mathrm{EMOT}=2.0 * \mathrm{RM} * \mathrm{Q} * \mathrm{GN}$

END IF

END IF

IF (METHOD .EQ. 2) THEN

FLMBDA $=(R O * R O+R I * R I) /(4.0 * R O * E M O T)$

ELSE

FLMBDA $=R M /(2.0 * E M O T)$

END IF

NCOUNT $=$ NCOUNT +1

$\mathrm{AI}(\mathrm{NCOUNT})=\mathrm{PHOD}$

A2 $($ NCOUNT $)=G N$

A. 3 (NCOUNT) $=$ RHOI

A4 (NCOUNT $)=$ EMOT

$A 5($ NCOUNT $)=$ FLMBDA

$\mathrm{C}$

C

C WRITE $(2,700)$ EN, PHROD, FLMBDA, H3, RHO1, GN

700 FORMAT (' ', 'N=', F5.2,'PHROD= ', EI0.5,',','FLMBDA=', E10.5,

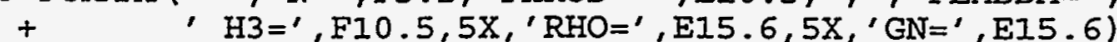

701 FORMAT (6E15.6)

$P H R O D=P H R O D / D P H R O D$

IF (SMPLFY .EQ. 0.0 ) GO TO 889

IF (PHROD . IE. 1.E-15) GO TO 889

IF (RHOI .LT. PI2) THEN

GO TO 888

ELSE

PHOD $=$ PHROD $/ \mathrm{RO}$

GO TO 4

END IF

C

889 CONTINUE

C

COMPUTE J -PLASTIC FOR LOADING SUPPIIED BY USER

ESTABLISH POINTER TO ARRAYS AI -A5

IF (BMUSER .EQ. 0.0$)$ THEN

MCOUNT $=$ NCOUNT 


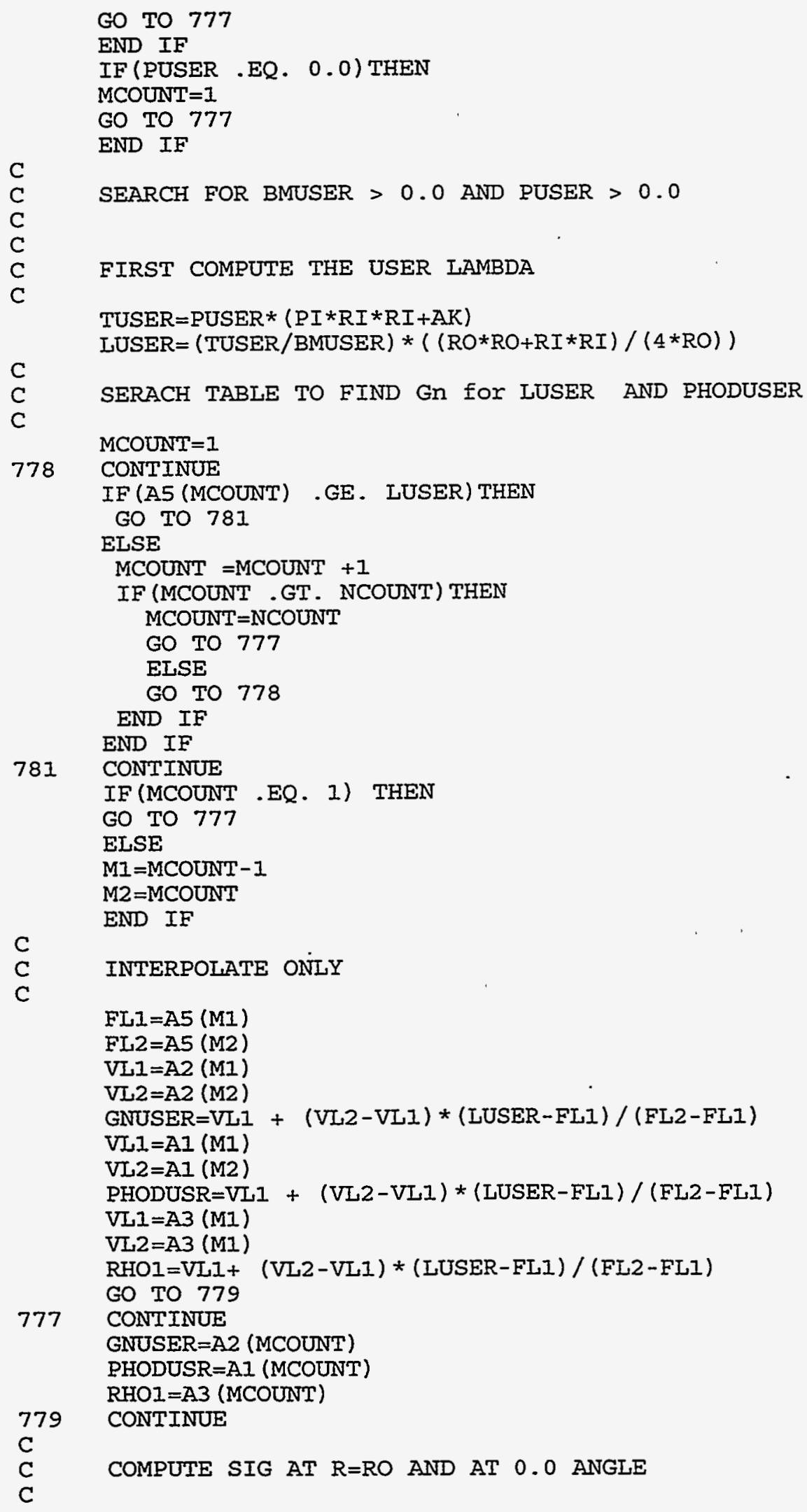




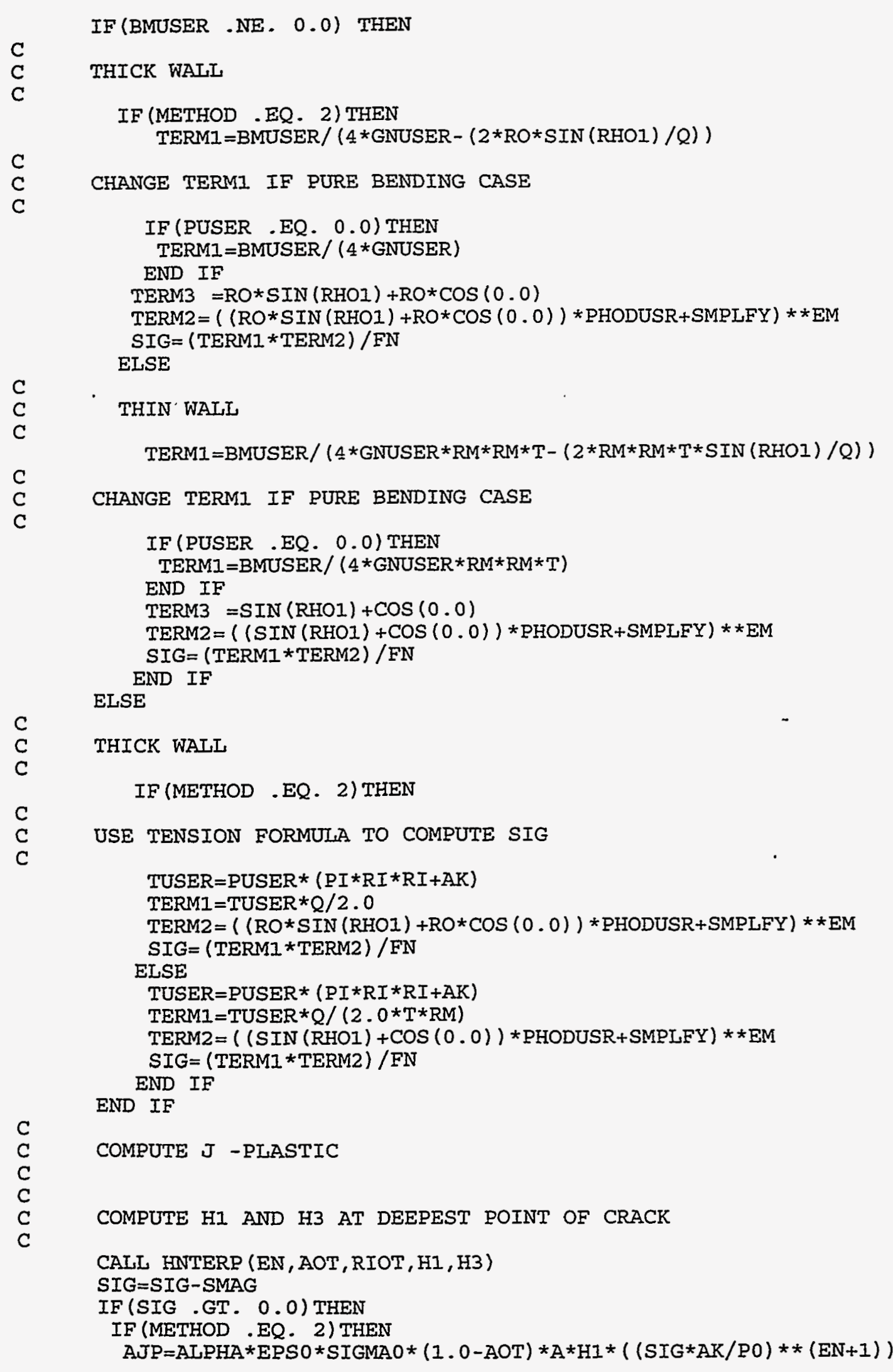




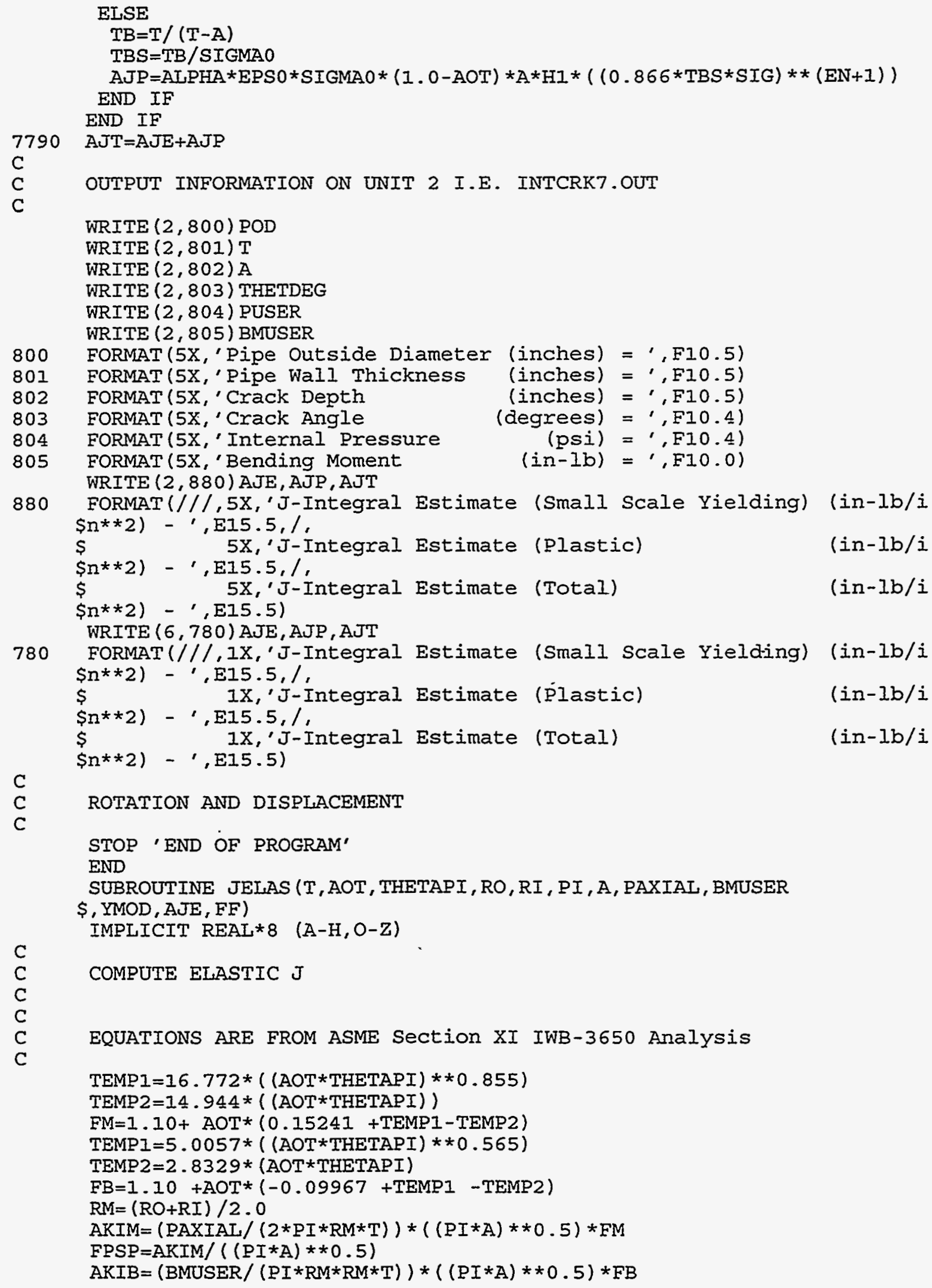




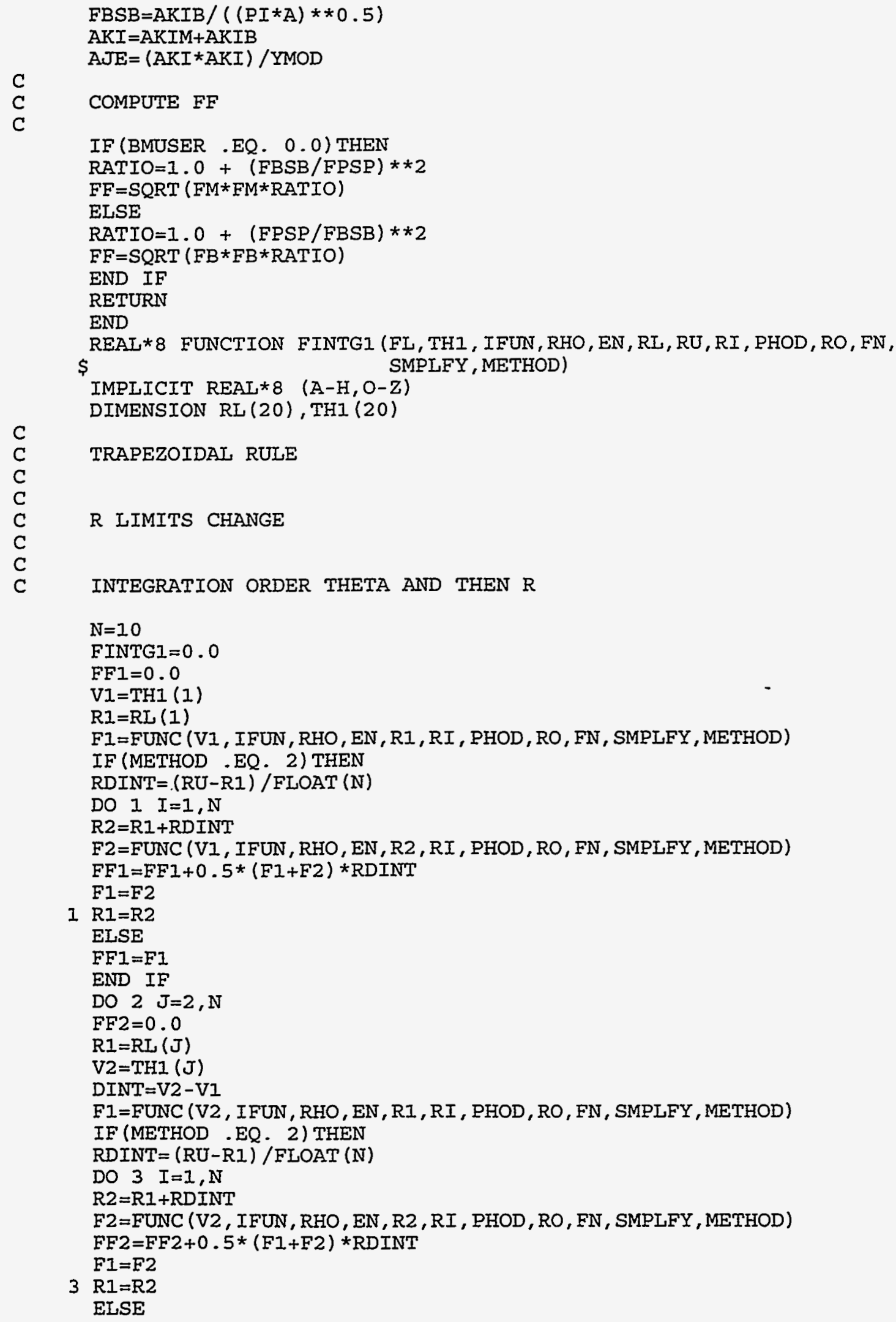




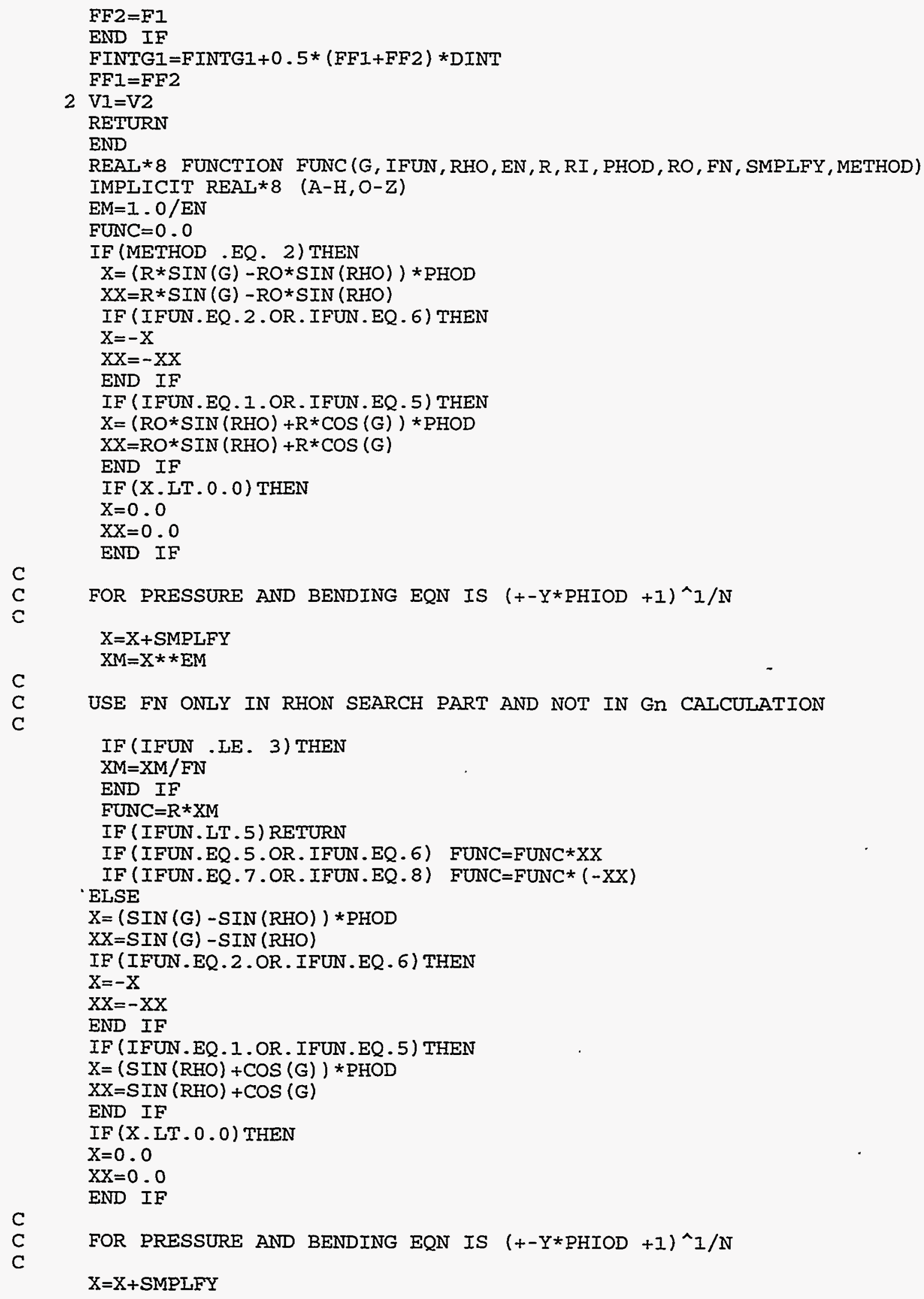




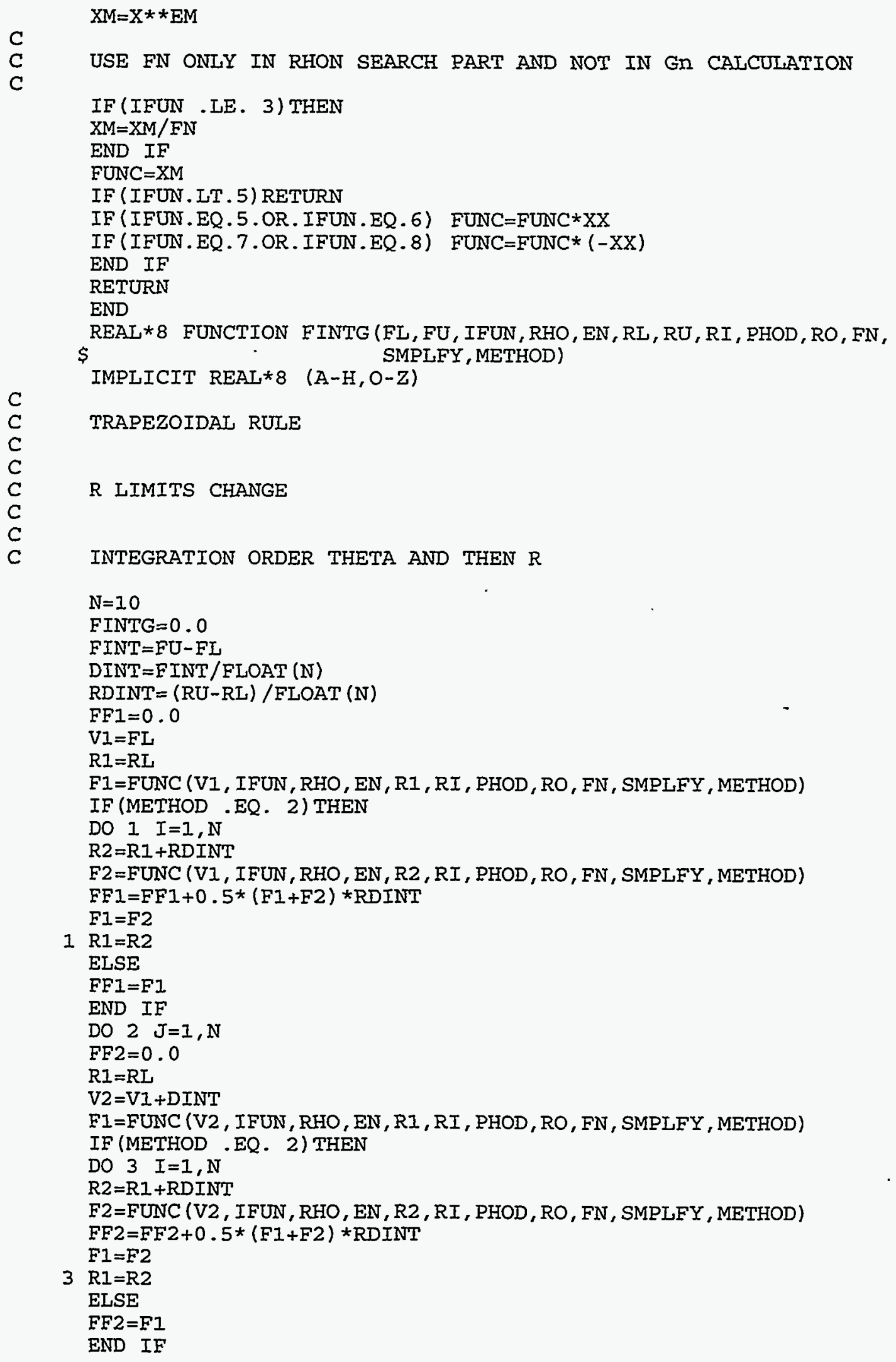




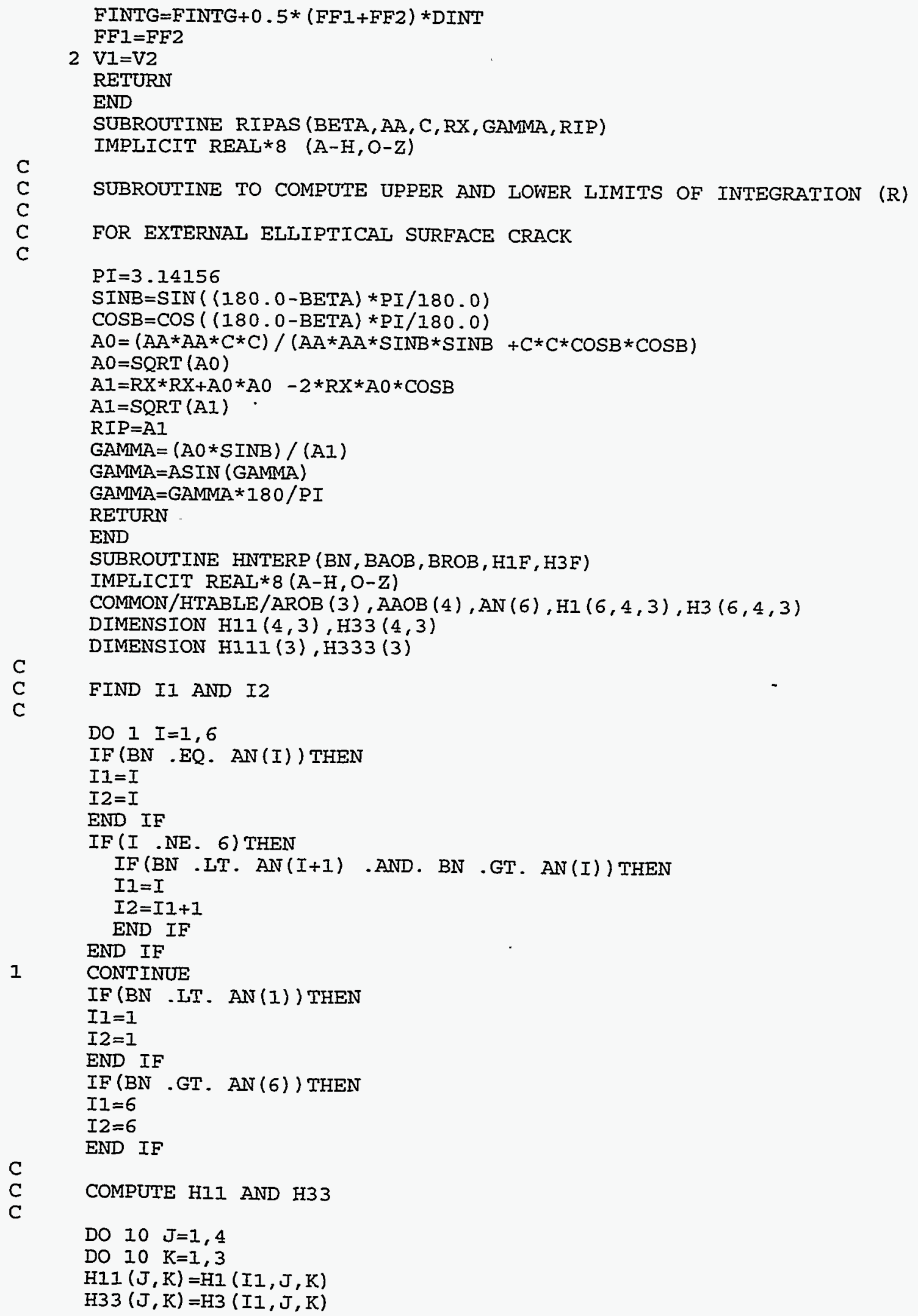




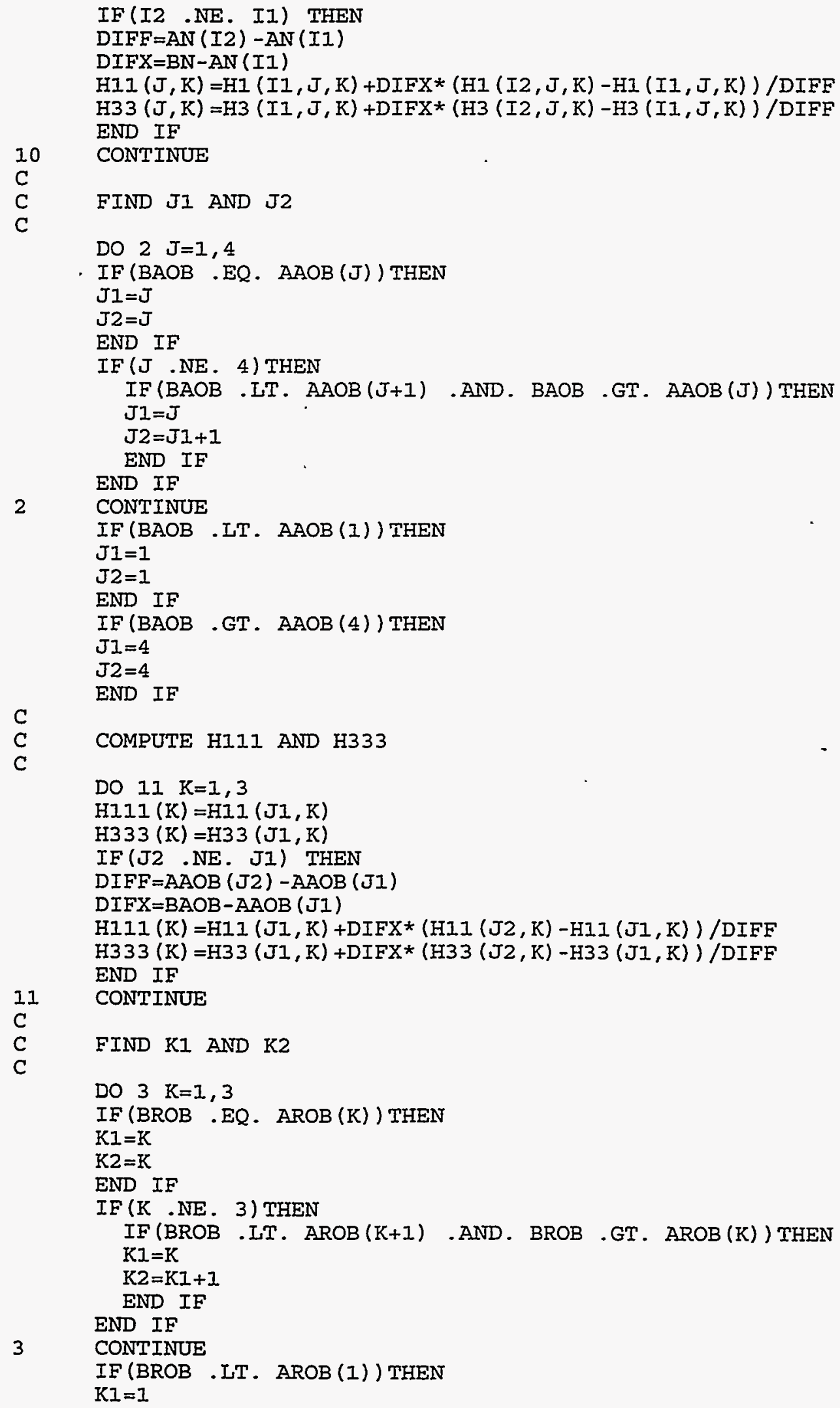




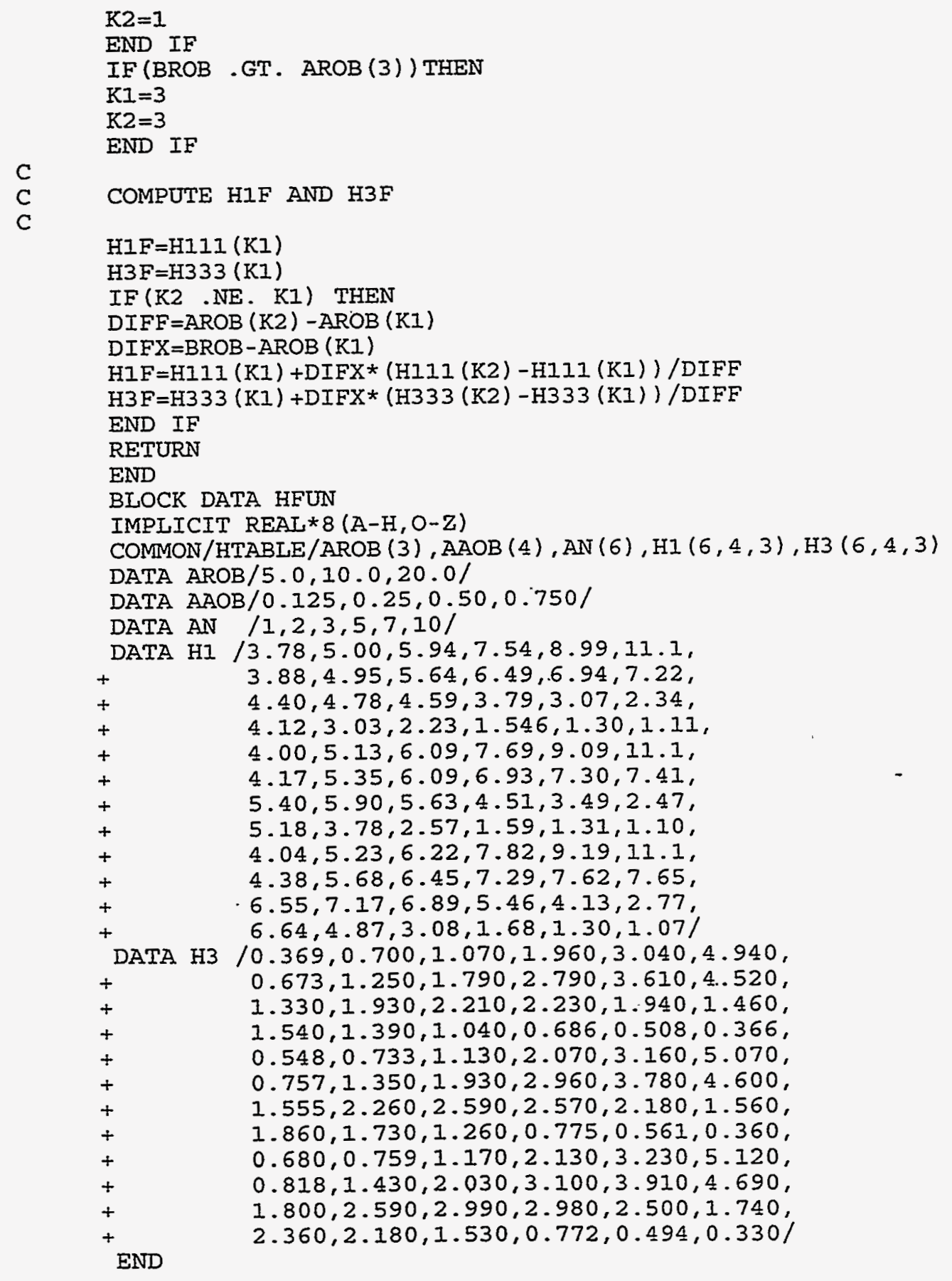




\section{APPENDIX C}

\section{THE FUNCTION $\mathrm{I}_{\mathrm{B}}(\mathrm{a} / \mathrm{t}, \theta / \pi)$}

According to the definition,

$$
\begin{aligned}
\mathrm{I}_{\mathrm{B}}(\mathrm{a} / \mathrm{t}, \theta / \pi) & =2 \theta\left(\mathrm{R}_{\mathrm{m}}-\mathrm{t} / 2\right) \int \mathrm{aF}_{\mathrm{B}}^{2}(\mathrm{a} / \mathrm{t}, \theta / \pi) \mathrm{da} \\
& +2 \theta \int \mathrm{a}^{2} \mathrm{~F}_{\mathrm{B}}^{2}(\mathrm{a} / \mathrm{t}, \theta / \pi) \mathrm{da} \\
& =2 \theta\left(\mathrm{R}_{\mathrm{m}}-\mathrm{t} / 2\right) \mathrm{I}_{\mathrm{B} 1}(\mathrm{a} / \mathrm{t}, \theta / \pi)+2 \theta \mathrm{I}_{\mathrm{B} 2}(\mathrm{a} / \mathrm{t}, \theta / \pi)
\end{aligned}
$$

where,

$$
\begin{aligned}
\mathrm{I}_{\mathrm{B} 1}(\mathrm{a} / \mathrm{t}, \theta / \pi) & =\mathrm{t}^{2}\left[0.605(\mathrm{a} / \mathrm{t})^{2}-0.07309(\mathrm{a} / \mathrm{t})^{3}+3.08909(\theta / \pi)^{0.565}(\mathrm{a} / \mathrm{t})^{3.565}\right. \\
& +\{0.002484-1.5581(\theta / \pi)\}(\mathrm{a} / \mathrm{t})^{4}-0.21859(\theta / \pi)^{0.565}(\mathrm{a} / \mathrm{t})^{4.565} \\
& +0.112944(\theta / \pi)(\mathrm{a} / \mathrm{t})^{5}+4.884412(\theta / \pi)^{1.13}(\mathrm{a} / \mathrm{t})^{5.13} \\
& \left.-5.09637(\theta / \pi)^{1.565}(\mathrm{a} / \mathrm{t})^{5.565}+1.33755(\theta / \pi)^{2}(\mathrm{a} / \mathrm{t})^{6}\right] \\
\mathrm{I}_{\mathrm{B} 2}(\mathrm{a} / \mathrm{t}, \theta / \pi)= & \mathrm{t}^{3}\left[0.40333(\mathrm{a} / \mathrm{t})^{3}-0.05482(\mathrm{a} / \mathrm{t})^{4}+2.4124(\theta / \pi)^{0.565}(\mathrm{a} / \mathrm{t})^{4.565}\right. \\
+ & \{0.001987-1.24648(\theta / \pi)\}(\mathrm{a} / \mathrm{t})^{5}-0.1793064(\theta / \pi)^{0.565}(\mathrm{a} / \mathrm{t})^{5.565} \\
+ & 0.09412(\theta / \pi)(\mathrm{a} / \mathrm{t})^{6}+4.08924(\theta / \pi)^{1.13}(\mathrm{a} / \mathrm{t})^{6.13} \\
& \left.-4.32008(\theta / \pi)^{1.565}(\mathrm{a} / \mathrm{t})^{6.565}+1.14697(\theta / \pi)^{2}(\mathrm{a} / \mathrm{t})^{7}\right]
\end{aligned}
$$




\section{APPENDIX D}

\section{GOVERNING DIFFERENTIAL EQUATIONS WITH POWER-LAW MODEL}

Using classical beam theory for small deformations, the governing differential equations for a pipe with power-law constitutive model (plastic part only) are (see Figure 4.41 for symbol definitions).

1. Segment $A B(\hat{a} / 2 \leq 2 c \leq L / 2)$

$$
\begin{gathered}
\frac{d^{2} y}{d x^{2}}=\frac{1}{R_{m}}\left[\frac{M}{M_{k}}\right]^{n} \\
\frac{d y}{d x}=\frac{1}{R_{m}}\left[\frac{M}{M_{k}}\right]^{n} x+C_{1}^{\prime} \\
y=\frac{1}{R_{m}}\left[\frac{M}{M_{k}}\right]^{\frac{n}{2}}+C_{1}^{\prime} x+C_{2}^{\prime}
\end{gathered}
$$

2. Segment $B C(0 \leq x \leq \hat{a} / 2)$

$$
\begin{gathered}
\frac{d^{2} y}{d x^{2}}=\frac{1}{R_{m}}\left[\frac{M}{M_{k}}\right]^{n}\left[\frac{t}{t_{e}}\right]^{n} \\
\frac{d y}{d x}=\frac{1}{R_{m}}\left[\frac{M}{M_{k}}\right]^{n}\left[\frac{t}{t_{e}}\right]^{n} x+C_{3}^{\prime}
\end{gathered}
$$




$$
y=\frac{1}{R_{m}}\left[\frac{M}{M_{k}}\right]^{n}\left[\frac{t}{t_{e}}\right]^{n} \frac{x^{2}}{2}+C_{3}^{\prime} x+C_{4}^{\prime}
$$

where

$$
\mathrm{M}_{\mathrm{k}}=\frac{4 \mathrm{KI} \hat{\mathrm{k}}}{\pi \mathrm{R}_{\mathrm{m}}}
$$

with

$$
\begin{gathered}
K=\frac{\sigma_{0}}{\left(\alpha \epsilon_{0}\right)^{1 / n}} \\
\hat{\mathrm{K}}=\frac{\sqrt{\pi}}{2} \frac{\Gamma\left(1+\frac{1}{2 \mathrm{n}}\right)}{\Gamma\left(\frac{3}{2}+\frac{1}{2 n}\right)}
\end{gathered}
$$

and

$$
\Gamma(u)=\int_{0}^{\infty} \xi^{u-1} \exp (-\xi) \mathrm{d} \xi
$$

is the gamma function and $I \simeq \pi R_{m}{ }^{3} t$ is the moment of inertia of an uncracked pipe cross section. Enforcing the appropriate boundary and compatibility conditions, the constants $C_{1}$ to $C_{4}$ can be determined as: 


$$
\begin{aligned}
& C_{1}^{\prime}=-\frac{1}{R_{m}}\left[\frac{M}{M_{k}}\right]^{n} \frac{\hat{a}}{2}\left[1-\left[\frac{t}{t_{e}}\right]^{n}\right] \\
& C_{2}^{\prime}=\frac{1}{R_{m}}\left[\frac{M}{M_{k}}\right]^{n}\left[-\frac{L^{2}}{8}+\frac{L a \hat{a}}{4}\left\{1-\left[\frac{t}{t_{e}}\right]^{n}\right\}\right] \\
& C_{4}^{\prime}=\frac{1}{R_{m}}\left[\frac{M}{M_{k}}\right]^{n}\left[-\frac{L^{2}}{8}+\frac{L a \hat{a}}{4}\left\{1-\left[\frac{t}{t_{e}}\right]^{n}\right\}-\frac{\hat{a}^{2}}{8}\right]
\end{aligned}
$$




\section{APPENDIX E}

\section{AXIAL FLAW CRITERIA}

An axial crack EPFM analysis using a Charpy energy approach was developed during this program and is reported here for completeness. The analysis method uses the semi-empirical axially-cracked failure-assessment equations developed by Maxey (Ref. E.1) to establish the allowable flaw depths for flawed piping meeting the EPFM criteria incorporated in Appendix $\mathrm{H}$. The allowable flaw depths for a given end-of-evaluation-period flaw length, $\ell_{f}$, for normal operating (including upset and test) or emergency and faulted conditions are determined using the following formula.

$$
\sigma_{\mathrm{h}}=\frac{2 \sigma_{\mathrm{f}} \arccos \left[\mathrm{e}^{-\mathrm{F}_{1}}\right]}{\pi(\mathrm{SF}) \mathrm{M}_{1}}
$$

where

$$
\begin{array}{lll}
\mathrm{M}_{1} & = & {\left[(\mathrm{t} / \mathrm{a})-\left(1 / \mathrm{M}_{2}\right)\right] /[(\mathrm{t} / \mathrm{a})-1]} \\
\mathrm{a} & = & \text { flaw depth, inch } \\
\mathrm{t} & = & \text { wall thickness, inch } \\
\sigma_{\mathrm{h}} & = & \text { allowable hoop stress, ksi } \\
\sigma_{\mathrm{f}} & = & \text { flow stress, } 2.4 \mathrm{~S}_{\mathrm{m}}, \mathrm{ksi} \\
\mathrm{F}_{1} & = & 12 \mathrm{E} \pi \mathrm{CVP} / 4000 \mathrm{a}_{\mathrm{c}} \ell \sigma_{\mathrm{f}}^{2} \\
\mathrm{CVP} & = & \text { Charpy upper-shelf energy, i.e., energy at } 100 \text { percent shear area, } \mathrm{ft}-\mathrm{lb} \\
\mathrm{A}_{\mathrm{c}} & = & \text { area of Charpy specimen, inch } \\
\mathrm{M}_{2} & = & {\left[1+\left(1.61 / 4 \mathrm{R}_{\mathrm{m}} \mathrm{t}\right) \ell^{2}\right]^{1 / 2}} \\
\mathrm{SF} & = & \text { safety factor } \\
& = & 3.0 \text { for normal operating (including upset and test) conditions } \\
\mathrm{E} & = & 1.5 \text { for emergency and faulted conditions } \\
\ell & = & \text { elastic modulus, ksi } \\
\mathrm{R}_{\mathrm{m}} & = & \text { metal axial crack length, inches }
\end{array}
$$

The limit of applicability of this equation is for $a / t \leq 0.75$ and $\ell<\ell_{\text {crit }}$.

The value of $\ell_{\text {crit }}$ is determined by the conditions for the stability of through-wall flaws and is used in place of $\ell$ in $\mathrm{M}_{2}$ when using Equation E-2. 


$$
\sigma_{\mathrm{h}}=\frac{2}{\pi} \frac{\sigma_{\mathrm{f}}}{\mathrm{M}_{2}} \arccos \left[\mathrm{e}^{-\mathrm{F}_{1}}\right]
$$

If the Charpy upper-shelf energy (100 percent shear area) data, CVP, are not available, there are two options. The first option is to use the Charpy energy data from the mill that is typically at room temperature or some other lower temperature, which would be conservative. The second option is to estimate the upper-shelf energy from available mill Charpy data using the following expression (Ref. E.2).

$$
\mathrm{CVP}=(100 \mathrm{CVN}) /(\mathrm{SA}+25)
$$

where

$$
\begin{array}{ll}
\mathrm{CVP}= & \text { Charpy V-notch upper-shelf energy, ft-lbs, } \\
\mathrm{CVN}= & \text { Charpy V-notch energy at any temperature, ft-lbs, and } \\
\mathrm{SA}= & \text { Shear area percent at the same temperature as the CVN energy. }
\end{array}
$$

Currently, in the ASME ferritic pipe flaw evaluation criteria in Appendix $\mathrm{H}$ of Section XI, EPFM analyses exist only in tabular form for materials with $\mathrm{J}_{\mathrm{Ic}}>105 \mathrm{~kJ} / \mathrm{m}^{2}\left(600 \mathrm{in}-\mathrm{lb} / \mathrm{in}^{2}\right)$ as given in Tables H-6410-1 and H-6410-2. For evaluation comparison purposes, the Charpy energy criterion was compared with selected critical values from Tables $\mathrm{H}-6410-1$ and $\mathrm{H}-6410-2$ and the experimental data of Maxey (Ref. E.1), see Figure E.1. Since the Table H-6410-1 and Table H-6410-2 values are for $\mathrm{J}_{\text {Ic }}$, an equivalent Charpy energy had to be calculated. From past Charpy versus $\mathrm{J}_{\text {Ic }}$ data, the mean and upper bound correlations are given by Equations E-4a and E-4b (Ref. E.2). These correlations were used to correlate the Charpy data to the $J_{\text {Ic }}$ data.

The mean fit to the data is given by

$$
\mathrm{J}_{\mathrm{Ic}}=10 \mathrm{CVP}
$$

and an upper bound fit to the data is given by

$$
\mathrm{J}_{\mathrm{Ic}}=20 \mathrm{CVP}
$$

where the units for $\mathrm{J}_{\mathrm{Ic}}$ are in-lb/in ${ }^{2}$ and the units for CVP are $\mathrm{ft}-\mathrm{lbs}$, and the empirical constants of 10 and 20 account for the difference in units.

Equation E-4b underestimates the CVP values from $\mathrm{J}_{\text {Ic }}$ data for a bounding evaluation during these comparisons.

The ranges of Charpy values for the selected stress ratios and flaw sizes chosen for analysis from Tables H-6410-1 and H-6410-2 are indicated by the bars connecting the open circle data points in Figure E.1. These calculations were made using a safety factor of 1.0 to facilitate the comparisons 
with the experimental data. The comparisons in Figure E.1 show that the method used to create the values in Tables $\mathrm{H}-6410-1$ and $\mathrm{H}-6410-2$ significantly underpredicted the experimental failure loads; furthermore, the stress ratio and flaw sizes chosen for analysis from Tables H-6410-1 and H-6410-2 should have been limit-load failures rather than EPFM failures.

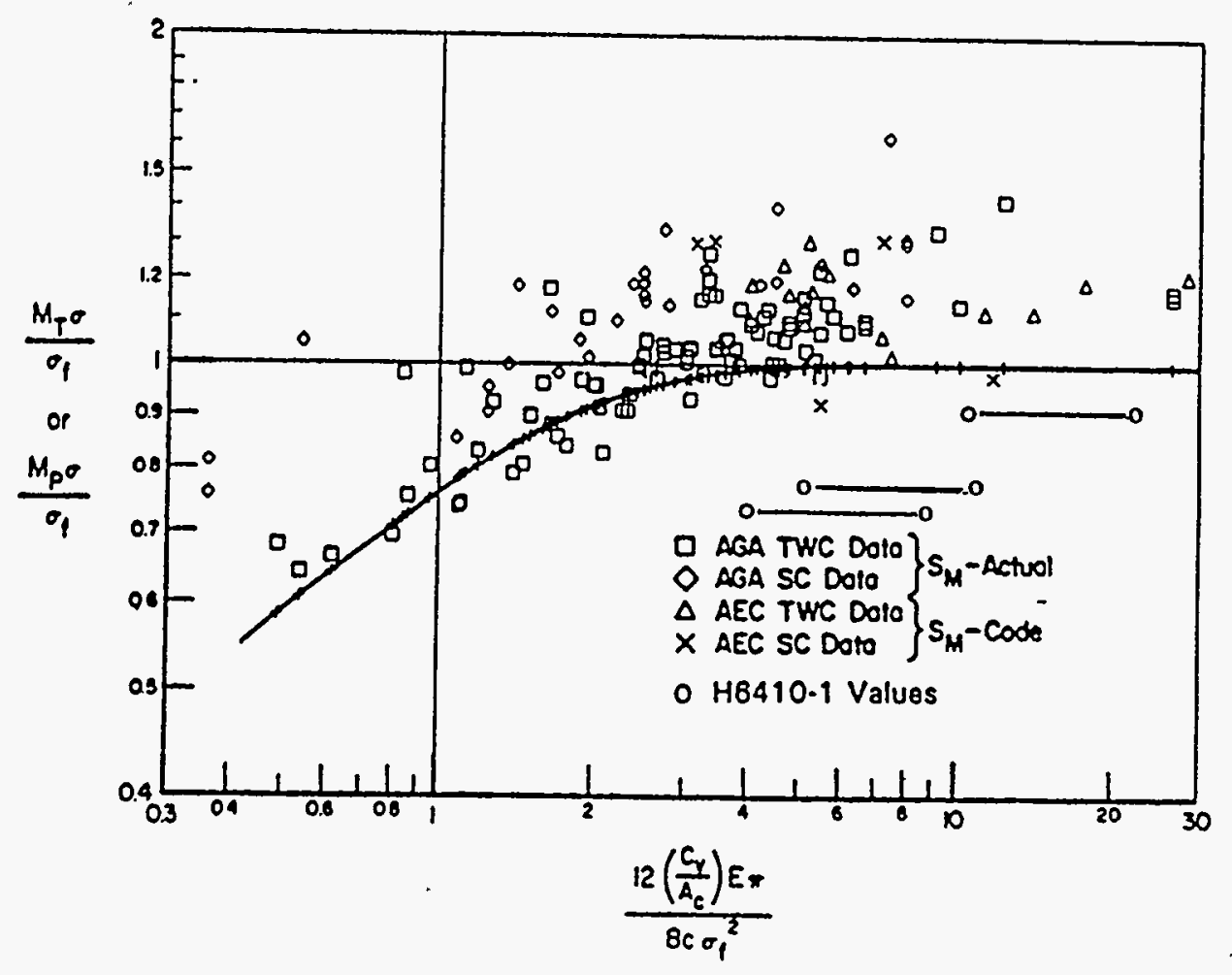

Figure E.1 Comparison of axial-cracked pipe burst data to Maxey analysis with $\sigma_{\mathrm{f}}=2.4 \mathrm{~S}_{\mathrm{m}}$ and ASME Table H-6410 values 


\section{References}

E.1 Kiefner, J. F., Maxey, W. A., Eiber, R. J. and Duffey, A. R., "Failure Stress Levels of Flaws in Pressurized Cylinders," Progress in Flaw Growth and Fracture Toughness Testing, ASTM STP 536, pp. 461-481, 1973.

E.2 Wilkowski, G. M. and Scott, P. M., "A Statistically Based Circumferentially Cracked Pipe Fracture Mechanics Analysis for Design or Code Implementation," Nuclear Engineering and Design, Vol. 111, pp. 173-187, 1989. 
(See instructions on the reverse)

NUREG/CR-6298

2. TITLE AND SUBTITLE

BMI-2183

Fracture Behavior of Short Circumferentially Surface-Cracked Pipe

3. DATE REPORT PUBLISHED November 1995

4. FIN OR GRANT NUMBER

B5702

5. AUTHOR(S)

P. Krishnaswamy, P. Scott, R. Mohan, S. Rahman, Y. H. Choi *

F. Brust, T. Kilinski, R. Francini, N. Ghadiali,

C. Marscha11, G. Wilkowski

6. TYPE OF REPORT

Technical

7. PERIOD COVERED (Inclusive Dates)

\section{$3 / 90-1 / 95$}

8. PERFORMING ORGANIZATION - NAME AND ADDRESS (If NRC, provide Division, Office or Region, U.S. Nuclear Regulatory Commission, and mailing address; if contractor, provide neme snd maillng address)

Battel le

505 King Avenue

Columbus, $\mathrm{OH} 43201-2693$
*Korea Institute of Nuclear Safety

P.0. Box 114, Yusung

Taejeon, Republic of Korea

9. SPONSORING ORGANIZATION - NAME AND ADDRESS IIf NRC, type "Same as above"; if contractor, provide NRC Division, Office or Region, U.S. Nuclear Regulatory COmmission, and malling addres)

Division of Engineering Technology

Office of Nuclear Research

U. S. Nuclear Regulatory Commission

Washington, D.C. 20555-0001

10. SUPPLEMENTARY NOTES

M. Mayfield, NRC Project Mañager

11. ABSTRACT (200 words or less)

This topical report summarizes the work performed for the Nuclear Regulatory Commission's (NRC) research program entitled "Short Cracks in Piping and Piping Welds" that specifically focuses on pipes with short, circumferential surface cracks. The following details are provided in this report: (i) material property determinations, (ii) pipe fracture experiments, (iii) development, modification and validation of fracture analysis methods, and (iv) impact of this work on the ASME Section XI Flaw Evaluation Procedures. The material properties developed and used in the analysis of the experiments are included in this report and have been implemented into the NRC's PIFRAC database. Six full-scale pipe experiments were conducted during this program. The analyses methods reported here fall into three categories (i) limit-load approaches, (ii) design criteria, and (iii) elastic-plastic fracture methods. These methods were evaluated by comparing the analytical predictions with experimental data. The results, using 44 pipe experiments from this and other programs, showed that the SC.TNP1 and DPZP analyses were the most accurate in predicting maximum load. New Z-factors were developed using these methods. These are being considered for updating the ASME Section XI criteria.

12. KEY WORDS/DESCR!PTORS (List words or phrases that will assist researchers in locating the report.)

Pipe, fracture, crack, circumferential surface cracks, J-integral, $J-R$ curve, ASME Section XI, fracture mechanics, fracture toughness welds, elastic-plastic fracture mechanics

Untimited

14. SECURITY CLASSIFICATION

TThis Page

Unclassified This Report

Unclassified

15. NUMBER OF PAGES 